Annual Report for the Ultra-Clean Fischer-Tropsch Fuels Production and Demonstration Project Agreement Number DE-FC26-01NT41099

Reporting Period: July 20, 2004 to July 20, 2005

Submitted by:

Steve Bergin, Integrated Concepts and Research Corporation

October 14, 2005 


\section{Table of Contents}

Submitting Organization.....................................................

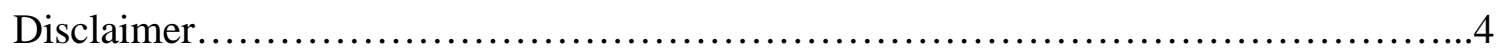

Abstract.................................................................

Appendix A: Report on Dynamometer Durability Testing.........................8

Appendix B: Report on Denali Fleet Demonstration............................. 30

Appendix C: Emissions Analysis of Bus Fleet Demonstrations......................... 34

Appendix D: Impact of SFP Fuel on Engine Performance.........................63

Appendix E: Economic Analysis.......................................... 134

Appendix F: Feasibility Study of SFPs for Rural Alaska..........................175

Appendix G: Report on Cold Weather Testing of Ultra-Clean Fuel....................322 


\section{Submitting Organization}

Integrated Concepts and Research Corporation

41150 Technology Park Drive, Suite 103

Sterling Heights, MI 48314

\section{Subcontractors}

Syntroleum Corporation

Suite 1100

1350 South Boulder Avenue

Tulsa, OK 74119

Tiax LLC

25 Acorn Park

Cambridge, MA 02140-2328

Denali National Park

PO Box 87

Denali Park, AK

99755

Washington Metropolitan Area Transit Authority

3433 Pennsy Drive

Landover, MD 20785

University of Alaska-Fairbanks

PO Box 757520

Fairbanks, AK 99775

West Virginia University

Department of Mechanical and Aerospace Engineering

PO Box 6106

Morgantown, WV 26506-6106

Massachusetts Institute of Technology

Building 31, Room 155

77 Massachusetts Avenue

Cambridge, MA 02139 
This report was prepared as an account of work sponsored by an agency of the United States Government. Neither the United States Government not any agency thereof, nor any of their employees, makes any warranty, express or implied, or assumes that its use would not infringe privately owned rights. Reference herein to any specific commercial product, process, or service by trade name, trademark, manufacturer, or otherwise does not necessarily constitute or imply its endorsement, recommendation, or favoring by the United States Government or any agency thereof. The views and opinions of authors expressed herein do not necessarily state or reflect those of the United States Government or any agency thereof. 


\title{
Report Structure
}

The Report Abstract provides summaries of the past year's activities relating to each of the main project objectives. Some of the objectives will be expanded on in greater detail further down in the report. The following objectives have their own addition sections in the report: Dynamometer Durability Testing, the Denali Bus Fleet Demonstration, Bus Fleet Demonstrations Emissions Analysis, Impact of SFP Fuel on Engine Performance, Emissions Analysis, Feasibility Study of SFPs for Rural Alaska, and Cold Weather Testing of Ultra Clean Fuel.

\begin{abstract}
Program Management

ICRC provided overall project organization and budget management for the project. Due to a delay in the availability of BP4 NETL funding, ICRC requested and was granted a 6-month no-cost extension of the project. As a result, project effort was scaled back somewhat during the summer to conserve financial resources until full NETL funding became available.

One of the initial technical concerns of the project was the potential for fuel-system wear in diesel engines attributable to the low inherent lubricity of ultra-clean Fischer-Tropsch (F-T) diesel fuel before being treated with a lubricity enhancing commercial additive package. A related initial assumption was that deposition at any point within the fuel system would be a non-issue with ultra-clean fuel. However, based upon the unexpected finding of diesel injector fouling in at least one test engine, ICRC believes that more time is needed to understand the situation adequately to finalize project reports and to give project partners whose engines were fleet-tested an accurate appraisal of the state of their post-test fuel systems. Therefore, a 6-month no-cost extension is currently being requested by ICRC in order to investigate the nozzle fouling issues that arose during dynamometer testing.
\end{abstract}

\section{SFP Construction and Fuel Production}

The plant produced all needed fuel on schedule.

Dynamometer Durability Tests

Testing has been completed on both the DDC Series 50 WMATA engine and the Caterpillar C-7 Denali National Park bus engine. Test data is currently being analyzed by ICRC and AVL. Emissions are being evaluated, and the fuel system components are being subjectively evaluated for wear. Preliminary results are provided in Appendix A.

\section{Cold Start Testing}

Cold start testing has been completed in both engines, and results are currently being evaluated by ICRC and AVL.

Fleet Testing at WMATA and Denali National Park

Fuel tests on buses at Denali National Park and the Washington Metropolitan Area have been completed. 
Exhaust Emissions Analysis

Emissions results form both bus fleet demonstrations showed that the F-T fuel provided decreases in emissions when compared to the fuel traditionally run in the buses. See Appendix $\mathrm{C}$ for more detail.

\section{SFP Fuel Assessment with Advanced Prototype Diesel Engines}

Daimler-Chrysler and Volkswagen originally planned to participate in this portion of the project by evaluating F-T fuel in their pre-production prototype new-technology diesel engines and emission control systems. Their participation was also expected to add some cost-share from the ICRC team to the project through the testing they would have provided. However, when the time for their participation came, both declined to participate, citing the need to devote all available resources to their efforts to develop emission-compliant systems for the 2007 model year that would operate satisfactorily on the 15-ppm sulfur diesel fuel that would be available in that timeframe, rather than F-T fuel with even lower emission potential. ICRC obtained similar data from buses belonging to project-partner WMATA. Furthermore, ICRC approached other diesel engine manufacturers including Ford, GM, Caterpillar, and Cummins, and emission control system manufacturers including Johnson-Matthey and Englehard. All of these companies declined participation in the project, citing reasons that were remarkably similar to those given by Daimler-Chrysler and Volkswagen.

\section{Impact of SFP Fuel on Engine Performance}

Modest NOx reductions were found, and 25-75\% particulates reductions resulted from using FT fuel over both $400 \mathrm{ppm}$ and $15 \mathrm{ppm}$ sulfur diesels fuels. Benefits arise not just from the fuel composition, but also from combustion characteristics and interactions with the engine technology as well. It is not believed that the effect of fuel sulfur on the observed PM emissions is as pronounced as was previously reported. The blend of FT fuel studied produced more than a proportional reduction in PM emissions. Overall, FT fuel gives greater freedom to engine designers when trying to optimize the engine/emission-control/fuel system in modern engines, since it provides the fuel properties as another flexible set of variables that affect the combustion and emission processes. Furthermore, the zero sulfur nature of the FT fuel allows for the use of additional and more aggressive exhaust aftertreatment devices, previously impossible due to the deleterious effects of fuel sulfur on the catalyst.

\section{Economic Analysis}

The final economic analysis has been completed. The study found that the lower energy efficiency and higher cost of producing F-T fuel compared to refining petroleum is balanced out by the greater energy security and environmental benefits provided by F-T fuel. The analysis is provided in Appendix E.

Feasibility Study of SFPs for Rural Alaska.

The study has been completed, and the main findings conclude that: F-T plants in Alaska will require government support, higher oil prices could make F-T plants more feasible; and the low-toxicity, and biodegradability of some F-T fuels is an advantage in pursuing their use. The study also concluded that the four best locations for a possible F-T plant are Healy, Beluga, Nikiski, and Bristol Bay. There are some risks associated with the potential project, which are discussed in Appendix F. 
Cold Weather Testing of Ultra-Clean Fuel

Arctic-grade F-T fuel was successfully run in several snowplows, loaders and related snow-removal vehicles at Denali National Park during the winter months of 2004 and 2005. See Appendix G for more detail.

Demonstration of Clean Diesel Fuels in Diesel Electric Generators in Alaska

The clean diesel fuel performed as expected, with no apparent negative impacts on the diesel engine.

Demonstration of Clean Diesel Fuels in Fuel Cells

A reformer/fuel cell system has been run successfully on F-T naphtha. 
47519 HALYARD DRIVE

PLYMOUTH, MI 48170-2438

PHONE: (734) 4149618

FAX: (734) 4149690

\section{APPENDIX A}

\section{Ultra Clean Transportation Fuels}




\section{Contents}

1. Introduction 3

2. Summary 4

$\begin{array}{lr}\text { 3. Durability } & 6\end{array}$

4. Emission Tests: WMATA, Denali, Syntroleum 10

$\begin{array}{ll}\text { 5. Observations } & 15\end{array}$

6. Appendix - Emission Data 16 


\section{Introduction}

AVL Powertrain Engineering Inc. (AVLPEI) performed the ICRC investigation regarding diesel engine performance as fueled with Syntroleum Corporation's S-2; a synthetic, high cetane, zero sulfur diesel fuel produced from natural gas using Fischer-Tropsch process. A 1500 hour durability segment using Syntroleum fuel was followed with emission testing on three fuels; Syntroleum, Washington Mass Transportation Authority (WMATA) low sulfur \#1 diesel and Denali "Jet A" fuels.

Two diesel engines were evaluated: a Detroit Diesel Corporation (DDC) Series 50 and a new 2004MY Caterpillar C7. All testing was conducted at AVL Mechanical Development and Validation Facility, Ann Arbor, Michigan between June 2004 and May 2005. 


\section{Summary}

\section{Durability}

The Durability investigation was to evaluate Syntroleum fuel injector wear and performance over a 1500 hour Chicago Transit Authority driving cycle equivalent.

- The DDC Series 50 performed 1500 hour Syntroleum durability without incident.

- The Caterpillar C7 performed 1500 hour Syntroleum fueled durability without incident. 


\section{Emissions}

The Emission investigation compared Syntroleum and Denali fuels to the WMATA fuel. WMATA fuel, a \#1 diesel fuel, is therefore defined as the 'reference' fuel.

For each engine, three AVL 8 Mode emission tests were performed on each of the three fuels. The weighted brake specific emissions were compared for each pollutant by averaging the three tests to a one value result. NOx and particulate matter (PM) were the pollutants of interest. For the DDC engine the Soot values are reported in place of PM.

Syntroleum NOx decreased 12\% (DDC) and 19\% (CAT) from the reference WMATA fuel. Syntroleum Soot decreased $29 \%$ (DDC only) from the reference WMATA fuel. Syntroleum PM decreased $42 \%$ (CAT only) from the reference WMATA fuel.

Other results are shown in tables below, Section 4 Emission Tests, and Appendix 1.

\begin{tabular}{|lcccccccc|}
\hline \multicolumn{7}{c|}{ DDC Series 50 } \\
Fuel Type & \multicolumn{7}{c|}{ Weighted Emission: gram/kilowatt-hour } & \% Delta from WMATA \\
& NOx & CO & THC & PM & Soot & NOx & Soot \\
WMATA & 8.64 & 0.27 & 0.11 & n/a & 0.017 & 0 & 0 \\
Denali & 7.78 & 0.28 & 0.17 & n/a & 0.019 & -10 & 15 \\
Syntroleum & 7.61 & 0.17 & 0.12 & n/a & 0.012 & -12 & -29 \\
\hline
\end{tabular}

\section{Caterpillar C7}

\begin{tabular}{lccccccc} 
Fuel Type & \multicolumn{9}{c}{ Weighted Emission: gram/kilowatt-hour } & \multicolumn{3}{c}{ Delta from WMATA } \\
& NOx & CO & THC & PM & Soot & NOx & PM \\
& & & & & & & \\
WMATA & 4.54 & 10.38 & 1.83 & 0.052 & n/a & 0 & 0 \\
Denali & 4.73 & 10.13 & 1.95 & 0.054 & n/a & 4 & 5 \\
Syntroleum & 3.67 & 9.28 & 1.26 & 0.030 & n/a & -19 & -42 \\
\hline
\end{tabular}




\section{Durability}

\subsection{Engine Configuration}

The Chicago Transit Authority (CTA) bus cycle test was written as an "Automatic" test using AVL PUMA Open data acquisition system. The engine was operated in "Speed/Alpha" mode: engine rpm controlled by the dynamometer and engine torque controlled by command of rack position. The five minute CTA cycle was repeated to accumulate 1500 engine hours. CTA representative traces for both engines are shown in

Figure 1.

\section{DDC Series 50}

Test Cell (TC) 13 was commissioned to run the DDC engine using an eddy current and AVL AFA 460kW ac regenerative dynamometer in series. The eddy current dyno applied a constant $500 \mathrm{Nm}$ of torque. The AFA dyno and EMCON controller absorbed the remaining load and controlled engine rpm to the target value.

The DDC engine had been previously used for cold start testing on Syntroleum fuel. New fuel injectors and a fuel delivery pump were installed prior to running the durability test on Syntroleum.

1500 hours of Syntroleum fueled CTA Cycle durability was accumulated from July thru September 2004.

Engine Specifics

Engine: 2000 MY DDC Series 50, 4 cylinder, 4 Stroke, Direct Injection, TCA

Calibration level: Remanufactured DDEC; Detroit Diesel $p / n 23519308$

Model: 6047MK2E

Rated Speed: $2100 \mathrm{rpm}$

Rated Power: $275 \mathrm{hp}$ with \#2 Diesel fuel (with Remanufactured DDEC above

Fuel Delivery System: The Series 50 utilized electronic unit injection (EUI). Fuel quantity and injection timing was electronically controlled by the DDEC engine control module. No emission aftertreatment device was used.

\section{Caterpillar C7}

A new 2004 CAT C7 was supplied by ICRC. Break-in was performed on an AVL AFA 450 $\mathrm{kW}$ dynamometer in TC 17.

1500 hours of Syntroleum fueled CTA Cycle durability was accumulated from September 2004 through February 2005.

\section{Engine Specifics}

Engine: 2004 MY Caterpillar C7, In-line 6 cylinder, 4 stroke, Direct Injection, TCA

Emission class: 2004 California, On-Highway, Medium Heavy Duty Diesel

Serial Number: KAL 44598

Calibration level: ECM Software 251-7442

Rated Speed: 2400 rpm 
Rated Power: 230 hp with \#2 Diesel fuel Engine Controls

The CAT C7 engine utilized HEUI fuel injection via electronically commanded hydraulically actuated unit injectors. Caterpillar's registered ACERT ${ }^{\circledR}$ technology adjusts engine air flow via valve actuation control. The emissions system is completed with addition of a diesel oxidation catalyst (DOC). 


\section{$\not \mathbf{A} \boldsymbol{V} \mathbf{L}$ powerraum

Figure 1: Chicago Transit Authority (CTA) Durability Cycles DDC Series 50: CTA Cycle

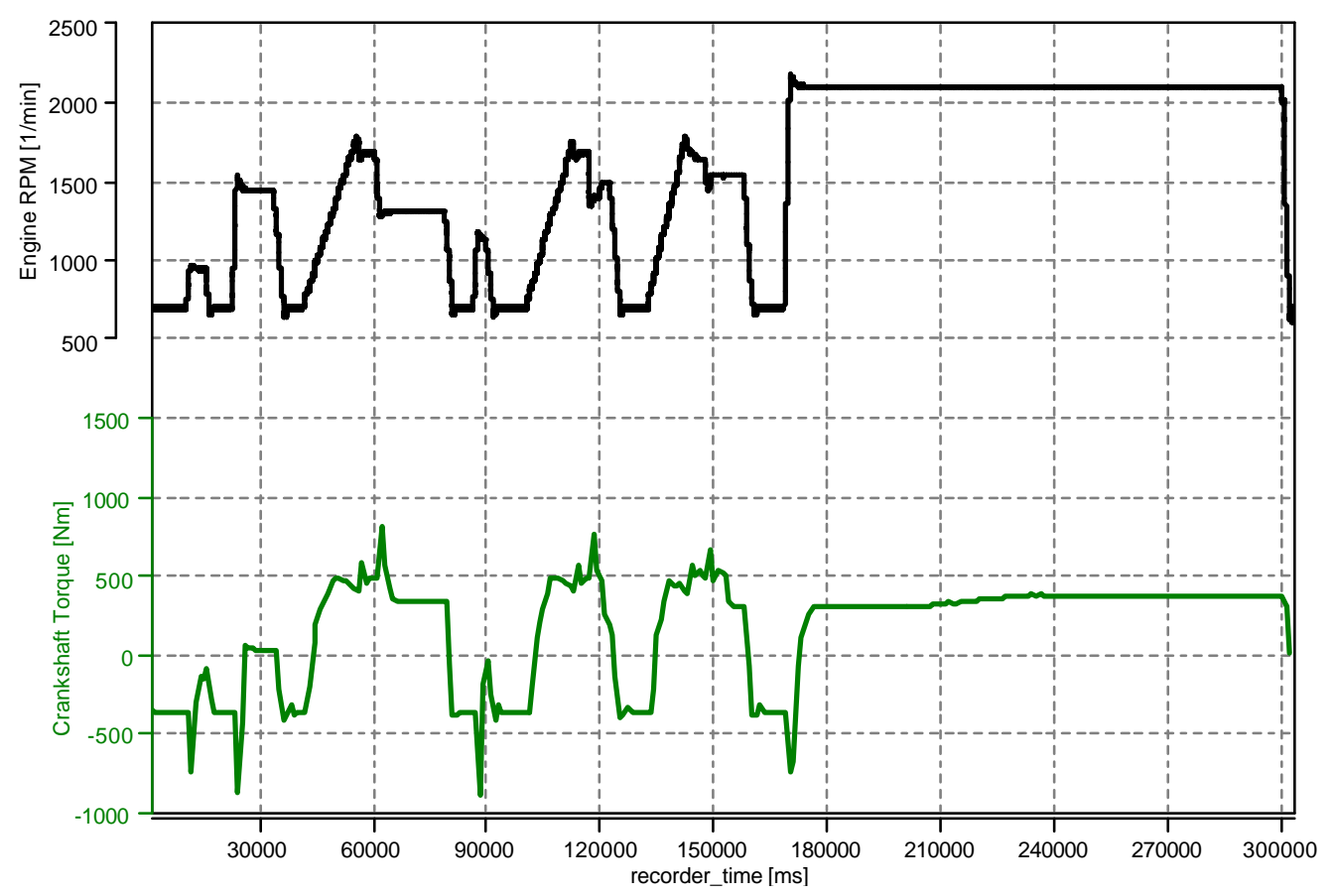

Caterpillar C7: CTA Cycle

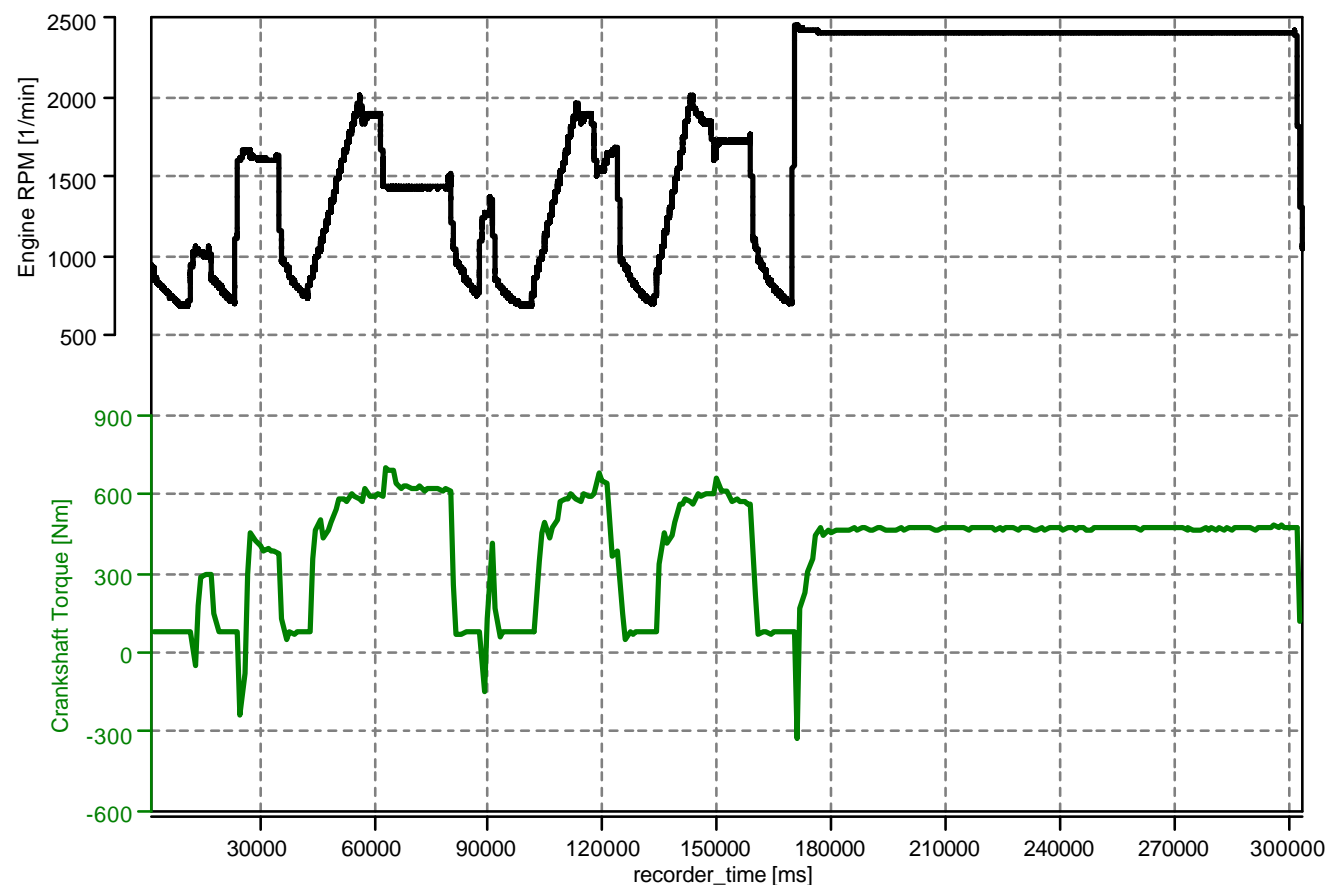




\subsection{Fuel Injector Inspection}

\section{DDC Series 50}

Fuel injectors were replaced at the start of Durability. Durability and Emission tests were performed on the same set of injectors. Fuel injectors were inspected following the emission tests on all three fuels; Syntroleum, Denali and WMATA.

Therefore, by definition, the Emission test data may have been affected by any nonuniform injector wear evolved during the Durability test.

\section{Caterpillar C7}

Durability and Emission tests were performed on different sets of fuel injectors. All fuel injectors were removed following the 1500 hour Durability, disassembled and inspected. Once disassembled the injectors cannot be re-assembled. A set of six new injectors were installed just prior to Emission tests and the engine processor re-flashed by a MichiganCAT dealer/distributor technician to accept the new injector idle trim code values.

Therefore, by definition, the Emission test data was not affected by any Durability induced injector wear. The Emission test installed injectors were not inspected following emission testing. 


\section{Emission Tests: WMATA, Denali, Syntroleum}

\section{AVL 8-Mode Emissions Test}

AVL 8 Mode emission tests were conducted with three different fuels: Syntroleum, Washington Mass Transportation Authority (WMATA), and Denali. The AVL 8-Mode test (Table 1) is an eight mode steady-state engine test procedure designed to correlate with exhaust emission results of the US FTP Heavy-Duty Transient Cycle. The AVL cycle was chosen as it allows eight individual steps for NOx analysis in addition to the summed modal values. The composite emission values are calculated by applying weight factors to each mode. The weighted mode results are summed to present one emission value over the entire test for each pollutant. NOx, CO and THC (total hydrocarbons) were measured over three runs on each of the three diesel fuels.

The sequential operating points are:

Table 1 AVL 8-Mode Emission Test Cycle-Weight Factors

\begin{tabular}{|c|c|c|c|c|c|}
\hline & Mode & $\% \mathrm{E}$ & & $\%$ Load & Weight factor ${ }^{\star \star}$ \\
\hline 1 & & 0 & 0 & & 35.00 \\
\hline 2 & & 11 & 25 & & 6.34 \\
\hline 3 & & 21 & 63 & & 2.91 \\
\hline 4 & & 32 & 84 & & 3.34 \\
\hline 5 & & 100 & 18 & & 8.40 \\
\hline 6 & & 95 & 40 & & 10.45 \\
\hline 7 & & 95 & 69 & & 10.21 \\
\hline 8 & & 89 & 95 & & 7.34 \\
\hline
\end{tabular}


Relative weights of particular modes are represented by the area of bubbles in Figure 2.

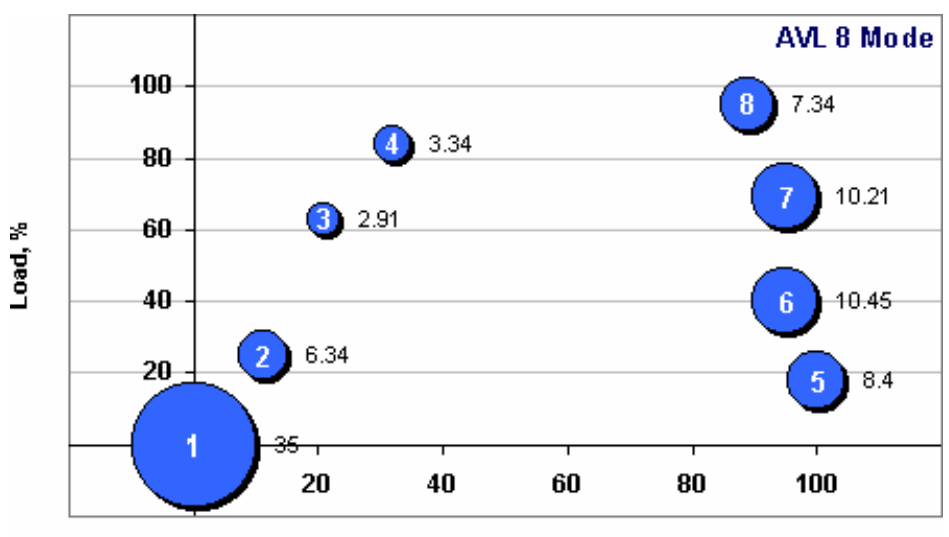

Speed, \%

Figure 2. AVL 8-Mode Emission Test Cycle-Visual Weight Factors

\section{DDC Series 50}

Just prior to AVL 8 Mode testing, the emissions bench, AVL 415S smoke meter and Lambda meter were connected. Engine mass flow was calculated using measured fuel rate, measured emissions based air/fuel ratio and raw emission analyzer values. (see Figure 3)

NOx mass emission output was corrected for ambient air humidity.

$\mathrm{CO}$ and $\mathrm{CO} 2$ raw emissions were converted from dry to wet based values to match with wet based values for THC and NOx.

Soot emissions were calculated based on measured AVL 415S Filter Smoke Number (FSN). Soot brake specific emissions in "g/kW-hr" were derived from a Motor Industry Research Association (MIRA) correlation that derives soot mass emission from the non-linear FSN value. The correlation calculates soot to a theoretical total pm mass emission; dry soot + an assumed soluble organic fraction as would be collected on conventional particulate filters. The brake specific soot values reported on the DDC engine may be compared among the three fuels as a general indicator of particulate mass emission. 
Overall Emission results are shown in Appendix 1

Averaged results of the three AVL 8 Mode tests per fuel are shown here:

\begin{tabular}{|lccccccccc|}
\hline \multicolumn{10}{c|}{ DDC Series 50} \\
Fuel Type & \multicolumn{10}{c|}{ Weighted Emission: gram $/$ kilowatt-hour } \\
& NOx & CO & THC & PM & Soot & NOx & \% Delta from WMATA \\
CO & THC & Soot \\
WMATA & 8.64 & 0.27 & 0.11 & n/a & 0.017 & 0 & 0 & 0 & 0 \\
Denali & 7.78 & 0.28 & 0.17 & n/a & 0.019 & -10 & 3 & 55 & 15 \\
Syntroleum & 7.61 & 0.17 & 0.12 & n/a & 0.012 & -12 & -38 & 4 & -29 \\
\hline
\end{tabular}

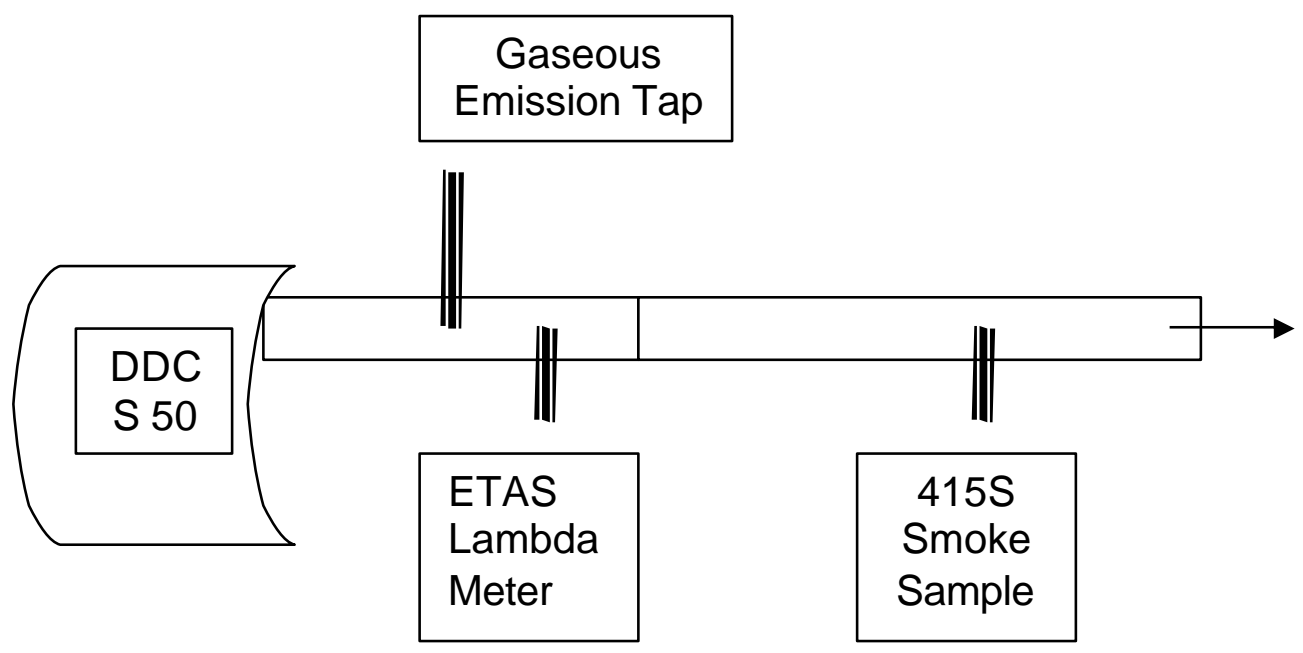

Figure 3. Exhaust System Layout - DDC Series 50 


\section{Caterpillar C7}

Just prior to AVL 8 Mode testing, the gaseous emissions sample taps, AVL 415S smoke meter, AVL 472 SPC and Merriam laminar air flow meter system were connected. Engine mass flow was calculated using measured air rate, measured fuel rate, and raw emission analyzer values. A carbon balance check verified emission based total carbon matched measured fuel mass carbon within $+/-3$ percent.

NOx mass emission output was corrected for ambient air humidity.

$\mathrm{CO}$ and $\mathrm{CO} 2$ raw emissions were converted from dry to wet based values to match with wet based values for THC and NOx.

The CAT C7 exhaust system also included a Diesel Oxidation Catalyst (DOC) installed between the turbocharger outlet and tailpipe (Figure 4). AVL 415S Smoke Meter and AVL 472 SPC pm filter samples were drawn downstream of the DOC. Therefore, smoke and pm emission data are considered "tailpipe" values and are representative of pollutants reaching ambient air.

Gaseous mass emissions of NOx, $\mathrm{CO}, \mathrm{CO} 2$ and THC were calculated based on the Pre$D O C$ emission tap location. The gaseous emissions reported directly compare the three fuels without the influence of DOC aftertreatment.

For the CAT C7 only, particulate matter (pm) mass emission was measured using an AVL Smart Sampler 472 SPC. The SPC uses a partial flow exhaust dilution technique to proportionally sample, dilute and time weight pm collection onto $47 \mathrm{~mm}$ high efficiency particulate filters. Proportional sampling controls the pm exhaust sample mass flow to be proportionally constant to engine exhaust system mass flow rate. SPC filter loading time values match the weight factors listed in Table 1. PM filters were stabilized and weighed pre and post test. The final pm data gives a one value, weighted, pm mass emission over each AVL 8 Mode test.

Overall Emission results are shown in Appendix 1

Averaged results of the three AVL 8 Mode tests per fuel are shown below:

\begin{tabular}{|lccccccccc|}
\hline \multicolumn{10}{c|}{ 2004 Caterpillar C7 } \\
Fuel Type & \multicolumn{10}{c|}{ Weighted Emission: gram/kilowatt-hour } \\
& NOx & CO & THC & PM & Soot & NOx & \% Delta from WMATA \\
& & & & & & & & THC & PM \\
WMATA & 4.54 & 10.38 & 1.83 & 0.052 & n/a & 0 & 0 & 0 & 0 \\
Denali & 4.73 & 10.13 & 1.95 & 0.054 & n/a & 4 & -2 & 7 & 5 \\
Syntroleum & 3.67 & 9.28 & 1.26 & 0.030 & n/a & -19 & -11 & -31 & -42 \\
\hline
\end{tabular}




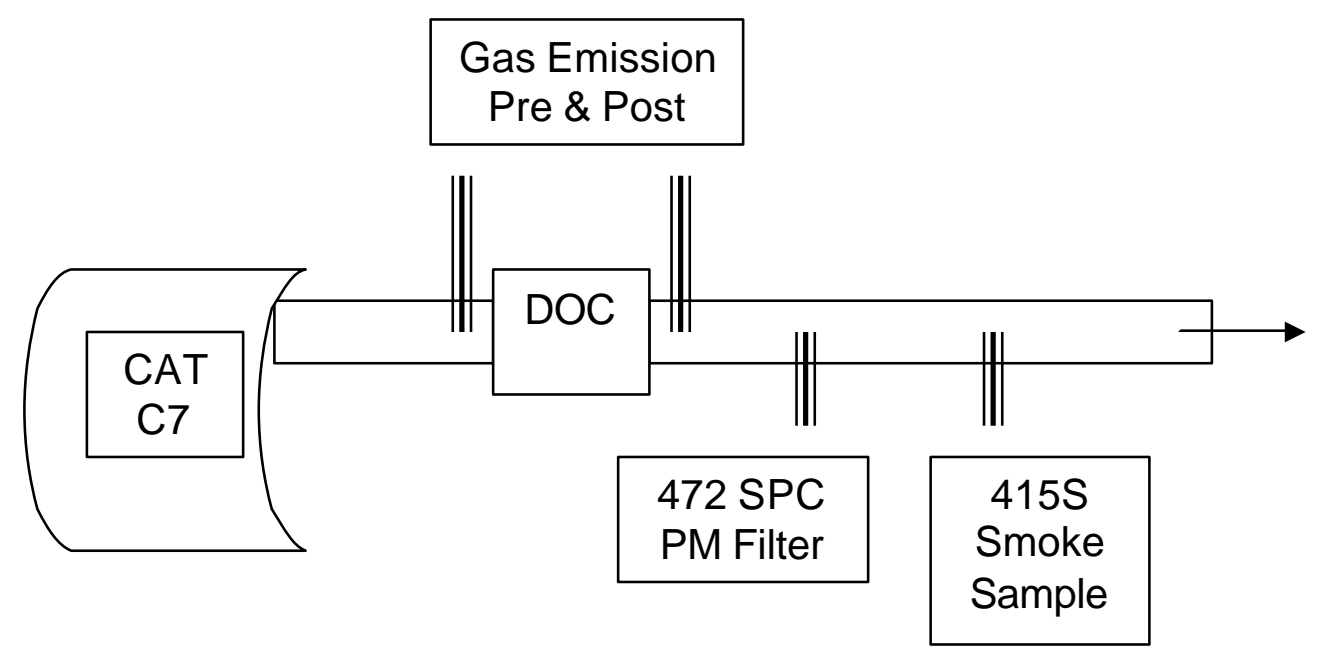

Figure 4. Exhaust System Layout - Caterpillar C7 Only 


\section{Observations}

\section{Durability}

Both engines exhibited a power loss when operated on Denali and Syntroleum fuels as compared to WMATA \#1 diesel "reference". The power loss is explained by the relative density differences between the three fuels. (Table 2) It was beyond the scope of the project to alter engine processor fuel delivery to account for fuel density differences. These diesel fuel systems control delivery of fuel volume and not fuel mass. Table 2 demonstrates how measured engine power decreases roughly in proportion to the decrease in fuel density.

Table 2: Effect of Measured Fuel Density on Brake Power (kilowatt)

\begin{tabular}{|l|c|c|c|}
\hline Fuel Type & $\begin{array}{c}\text { Fuel Density @ } \\
25 \text { deg. C } \\
\text { (grams/liter) }\end{array}$ & $\begin{array}{c}\text { DDC Series 50 } \\
\text { kW @ 1900 rpm }\end{array}$ & kW @ 2200 rpm \\
\hline WMATA & 830 & 189 & 156 \\
\hline Denali & 806 & 179 & 147 \\
\hline Syntroleum S-2 & 768 & 180 & 144 \\
\hline
\end{tabular}

Fuel injector wear and observations were discussed in Section 3 above.

\section{Emissions}

\section{DDC Series 50}

NOx specific weighted emissions are high in the $7 \mathrm{to} 9 \mathrm{~g} / \mathrm{kW}$-hr range for all fuels. Both $\mathrm{CO}$ and THC emissions are very low; CO around 0.25 and THC around $0.15 \mathrm{~g} / \mathrm{kW}-\mathrm{hr}$. Injection timing was not measured but advanced injection timing could explain the combination of high NOx mass emissions coupled with low THC and $\mathrm{CO}$ emissions.

PM emissions were not measured for the DDC engine as the AVL 472 SPC was not available. The Soot measurement is reported in place of PM.

\section{Caterpillar C7}

Soot emissions are not reported on the C7 engine. The FSN values from AVL $415 S$ smoke meter were too low to be reliable. The more accurate AVL 472 SPC pm weighed filter methodology is reported in place of soot values.

The reasons for high $\mathrm{CO}$ specific mass emissions are unknown. Modes 1 (idle) and 2 were significant $\mathrm{CO}$ contributors. 


\section{Appendix- Emission Data}

\section{Caterpillar C7}

Three AVL 8 Mode tests on each of three fuels are displayed. Specific emission units are in metric "grams / kilowatthour" and not in USA mixed unit standard "grams / horsepower-hour".

\section{DDC Series 50}

Three AVL 8 Mode tests on each of three fuels are displayed. Specific emission units are in metric "grams / kilowatthour" and not in USA mixed unit standard "grams / horsepower-hour". 


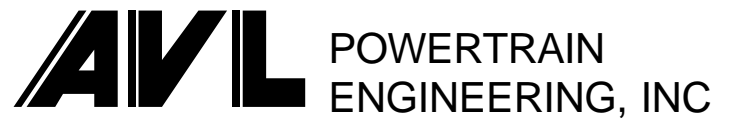

AVL 8 Mode: Average Weighted Brake Specific Emissions

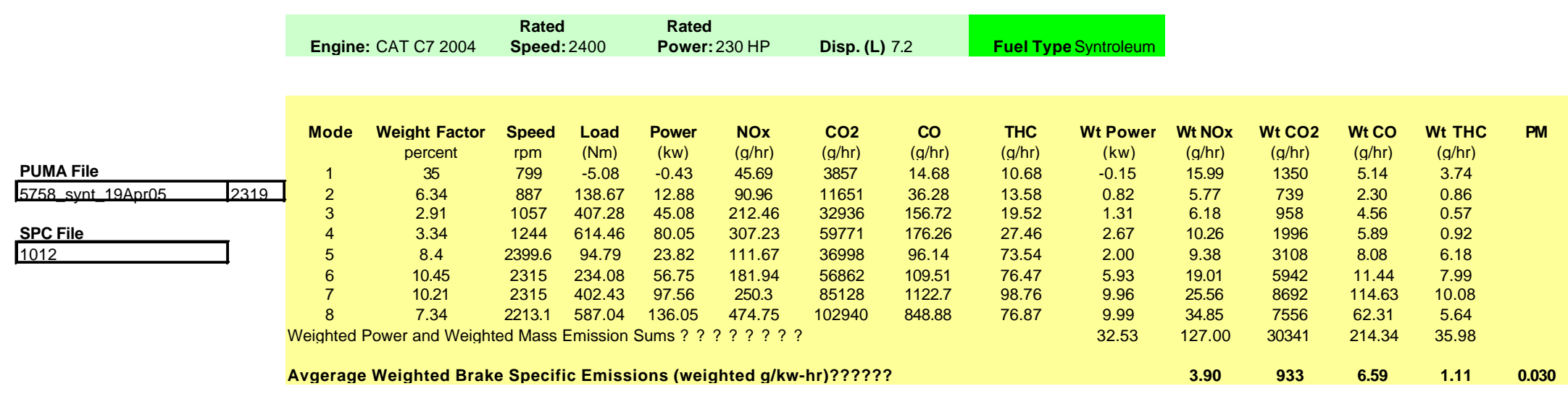

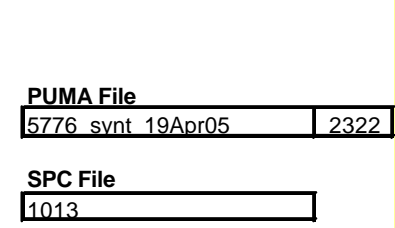

$\begin{array}{ccccccc}\text { Mode } & \begin{array}{c}\text { Weight Factor } \\ \text { percent }\end{array} & \begin{array}{c}\text { Speed } \\ \text { rpm }\end{array} & \begin{array}{c}\text { Load } \\ (\mathrm{Nm})\end{array} & \begin{array}{c}\text { Power } \\ (\mathrm{kw})\end{array} & \begin{array}{c}\text { NOx } \\ (\mathrm{g} / \mathrm{hr})\end{array} & \begin{array}{c}\mathrm{CO} 2 \\ (\mathrm{~g} / \mathrm{hr})\end{array} \\ 1 & 35 & 800.1 & -6.63 & -0.56 & 23.6 & 3861 \\ 2 & 6.34 & 887 & 138.49 & 12.86 & 75.27 & 11649 \\ 3 & 2.91 & 1057 & 408.31 & 45.19 & 214.78 & 33157 \\ 4 & 3.34 & 1244 & 612.92 & 79.85 & 313.92 & 59655 \\ 5 & 8.4 & 2400.2 & 100.17 & 25.18 & 113.78 & 37027 \\ 6 & 10.45 & 2315 & 232.76 & 56.43 & 183.01 & 56133 \\ 7 & 10.21 & 2314.9 & 402.12 & 97.48 & 255.04 & 85166 \\ 8 & 7.34 & 2213 & 586.74 & 135.98 & 466.52 & 102416\end{array}$

$\begin{array}{cc}\text { CO } & \text { THC } \\ (\mathrm{g} / \mathrm{hr}) & (\mathrm{g} / \mathrm{hr}) \\ 329.34 & 30.67 \\ 213.61 & 22.24 \\ 145.07 & 17.75 \\ 167.19 & 24.05 \\ 96.52 & 72.84 \\ 108.11 & 76.06 \\ 1119.6 & 95.81 \\ 849.89 & 77.42\end{array}$

Weighted Power and Weighted Mass Emission Sums ?? ? ? ? ? ?

Avgerage Weighted Brake Specific Emissions (weighted g/kw-hr)??????
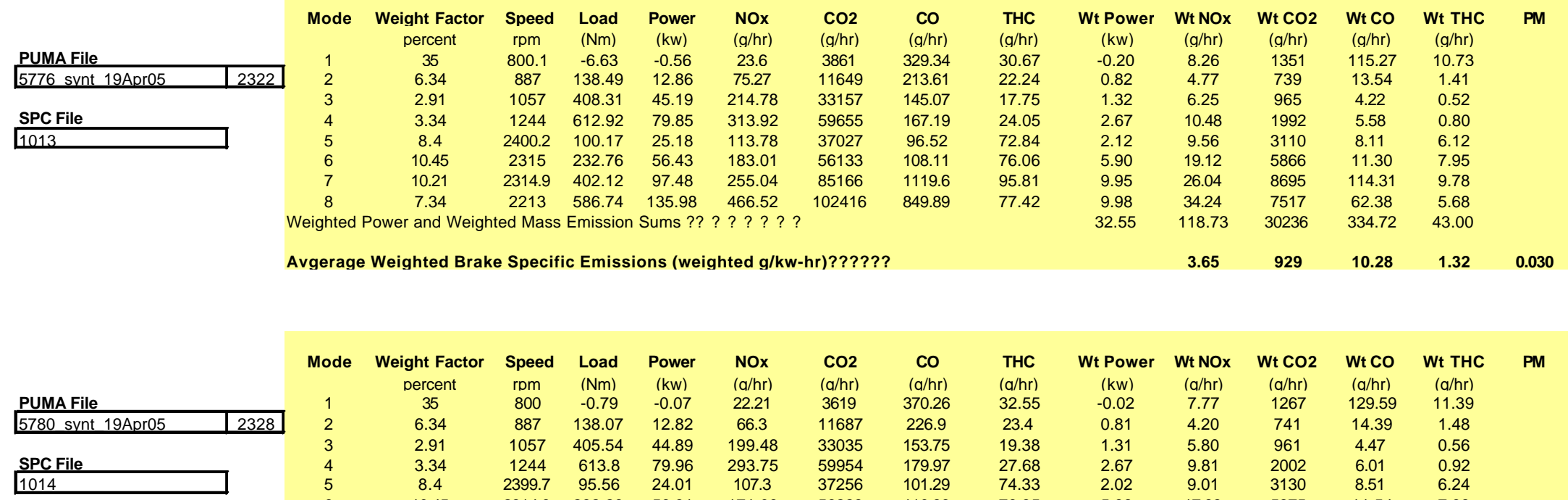

\begin{tabular}{|c|c|c|c|c|c|c|c|}
\hline Mode & $\begin{array}{l}\text { Weight Factor } \\
\text { percent }\end{array}$ & $\begin{array}{l}\text { Speed } \\
\text { rpm }\end{array}$ & $\begin{array}{l}\text { Load } \\
(\mathrm{Nm})\end{array}$ & $\begin{array}{c}\text { Power } \\
(\mathrm{kw})\end{array}$ & $\begin{array}{l}\text { NOx } \\
\text { (a/hr) }\end{array}$ & $\begin{array}{c}\mathrm{CO2} \\
(\mathrm{a} / \mathrm{hr})\end{array}$ & $\begin{array}{c}\mathrm{CO} \\
(\mathrm{a} / \mathrm{hr})\end{array}$ \\
\hline 1 & 35 & 800 & -0.79 & -0.07 & 22.21 & 3619 & 370.26 \\
\hline 2 & 6.34 & 887 & 138.07 & 12.82 & 66.3 & 11687 & 226.9 \\
\hline 3 & 2.91 & 1057 & 405.54 & 44.89 & 199.48 & 33035 & 153.75 \\
\hline 4 & 3.34 & 1244 & 613.8 & 79.96 & 293.75 & 59954 & 179.97 \\
\hline 5 & 8.4 & 2399.7 & 95.56 & 24.01 & 107.3 & 37256 & 101.29 \\
\hline 6 & 10.45 & 2314.9 & 232.29 & 56.31 & 171.09 & 56223 & 110.39 \\
\hline 7 & 10.21 & 2315.1 & 402.45 & 97.57 & 245.63 & 84632 & 1161.91 \\
\hline 8 & 7.34 & 2213 & 586.65 & 135.95 & 449.18 & 103196 & 872.24 \\
\hline
\end{tabular}

$\begin{array}{cc}\text { THC } & \text { W } \\ \text { (a/hr) } & \\ 32.55 & \\ 23.4 & \\ 19.38 & 0 . \\ 27.68 & \\ 74.33 & \\ 76.35 & 2 . \\ 97.8 & \\ 81 & \\ & \end{array}$

$\begin{array}{ccc}\begin{array}{c}\text { Wt Power } \\ \text { (kw) }\end{array} & \begin{array}{c}\text { Wt NOx } \\ (\mathrm{a} / \mathrm{hr})\end{array} \\ -0.02 & 7.77 \\ 0.81 & 4.20 \\ 1.31 & 5.80 \\ 2.67 & 9.81 \\ 2.02 & 9.01 \\ 5.88 & 17.88 \\ 9.96 & 25.08 \\ 9.98 & 32.97 \\ 32.61 & 112.53\end{array}$

\begin{tabular}{|c|c|c|c|}
\hline $\begin{array}{c}\text { Wt CO2 } \\
\text { (a/hr) } \\
1267\end{array}$ & $\begin{array}{c}\text { Wt CO } \\
\text { (a/hr) } \\
129.59\end{array}$ & $\begin{array}{c}\text { Wt THC } \\
\text { (a/hr) } \\
11.39\end{array}$ & PM \\
\hline 741 & 14.39 & 1.48 & \\
\hline 961 & 4.47 & 0.56 & \\
\hline 2002 & 6.01 & 0.92 & \\
\hline 3130 & 8.51 & 6.24 & \\
\hline 5875 & 11.54 & 7.98 & \\
\hline 8641 & 118.63 & 9.99 & \\
\hline 7575 & 64.02 & 5.95 & \\
\hline 30192 & 357.16 & 44.52 & \\
\hline 926 & 10.95 & 1.37 & 0.030 \\
\hline
\end{tabular}

Average Weighted Brake Specific Emissions for all 8Mode Tests Above (g/kw-hr) ? ? ?

3.67

929

$\begin{array}{lll}9.28 & 1.26 & 0.030\end{array}$

Report 


\section{$\boldsymbol{A} \boldsymbol{V} \boldsymbol{L}$ p poweraran \\ ENGINEERING, INC}

AVL 8 Mode: Average Weighted Brake Specific Emissions

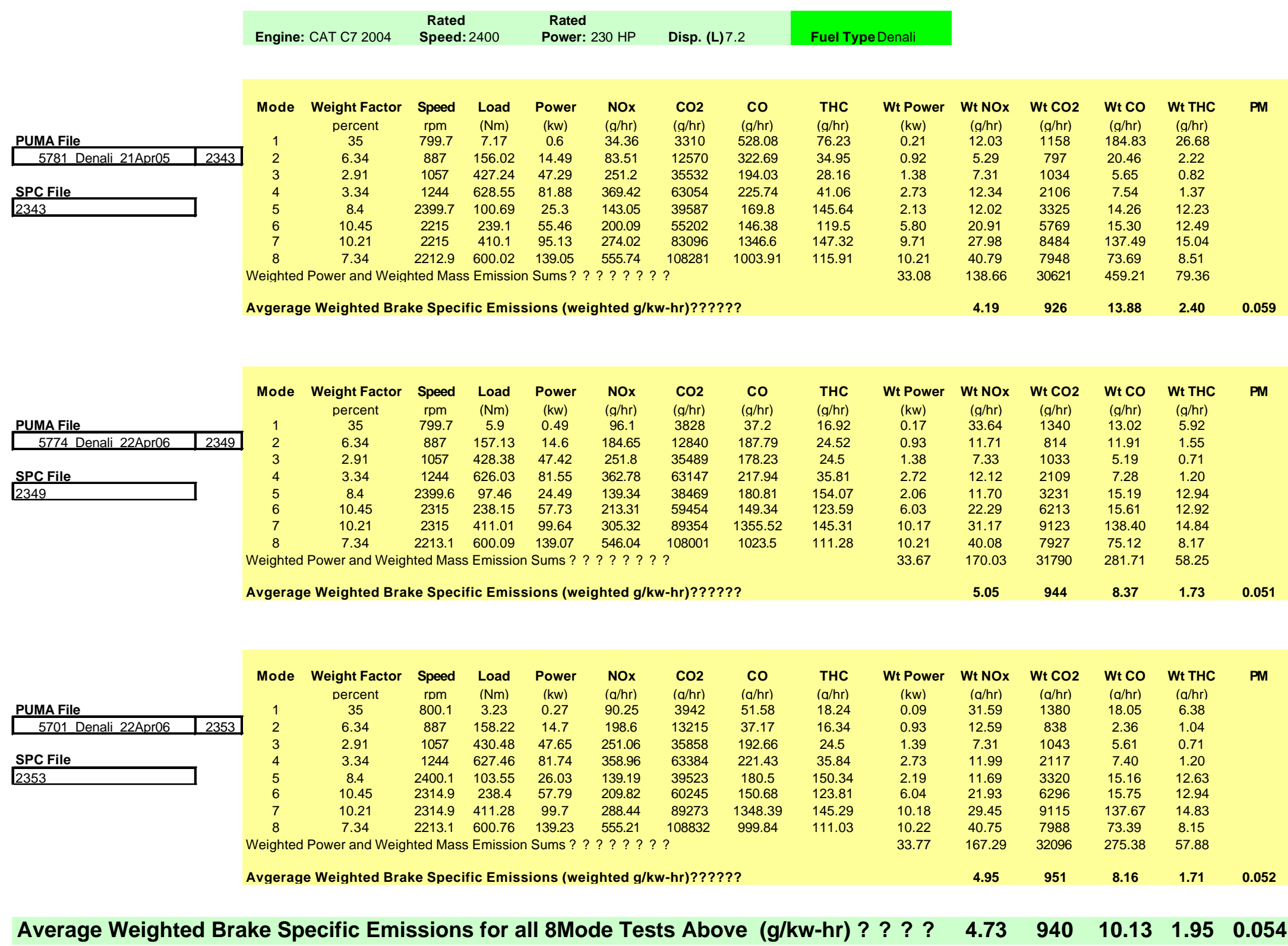




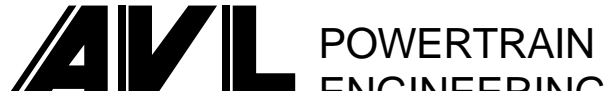 \\ ENGINEERING, INC}

AVL 8 Mode: Average Weighted Brake Specific Emissions

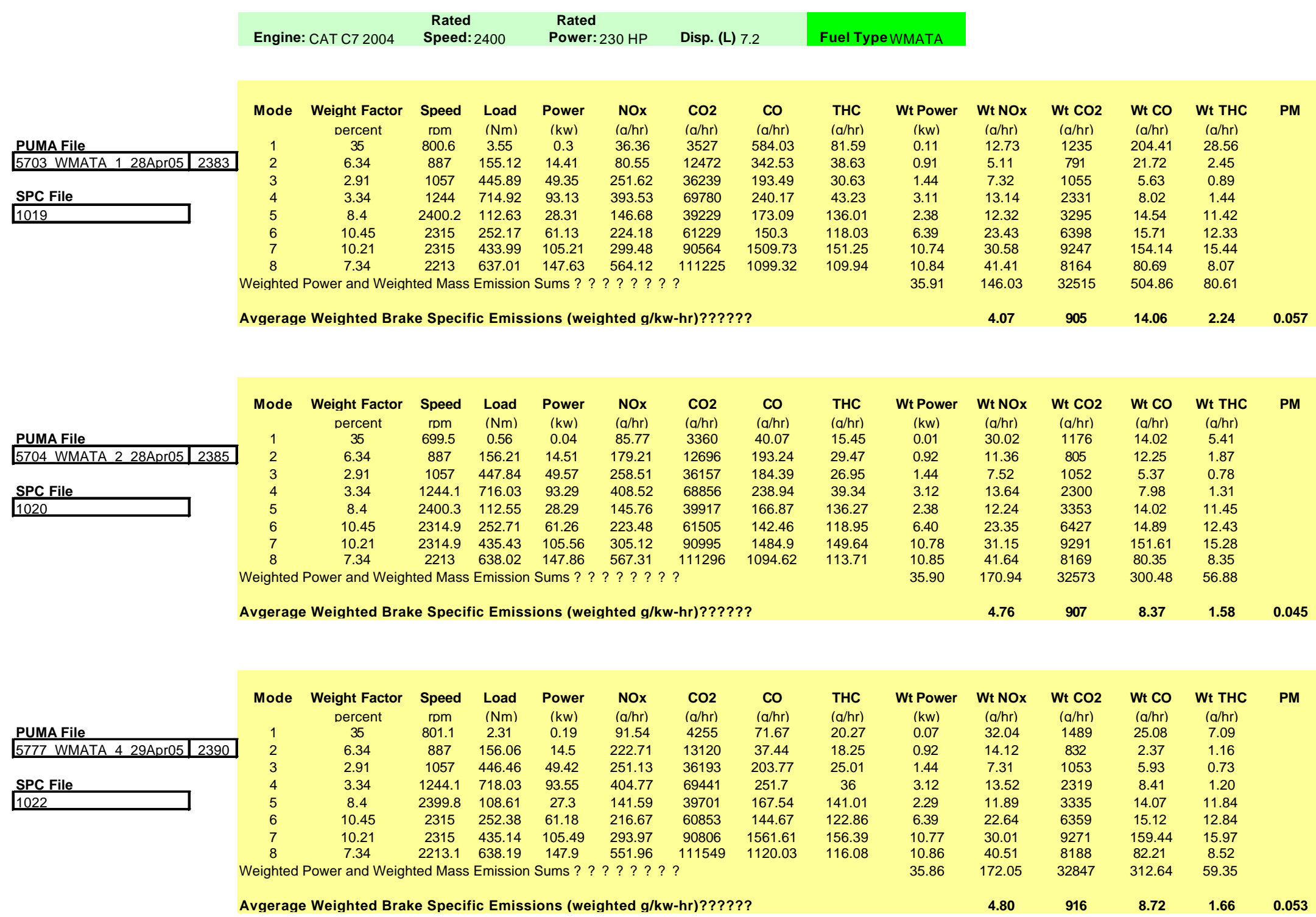




\section{$\boldsymbol{A} \boldsymbol{V} \boldsymbol{L} \mathbf{L}$ powertran \\ ENGINEERING, INC}

AVL 8 Mode: Average Weighted Brake Specific Emissions

\begin{tabular}{ccccc} 
Engine: DDC Series 50 & $\begin{array}{c}\text { Rated } \\
\text { Speed: } 2100\end{array}$ & $\begin{array}{c}\text { Rated } \\
\text { Power: } 320 \mathrm{HP}\end{array}$ & Disp. (L) 8.5 & Fuel Type Syntroleum \\
\hline
\end{tabular}

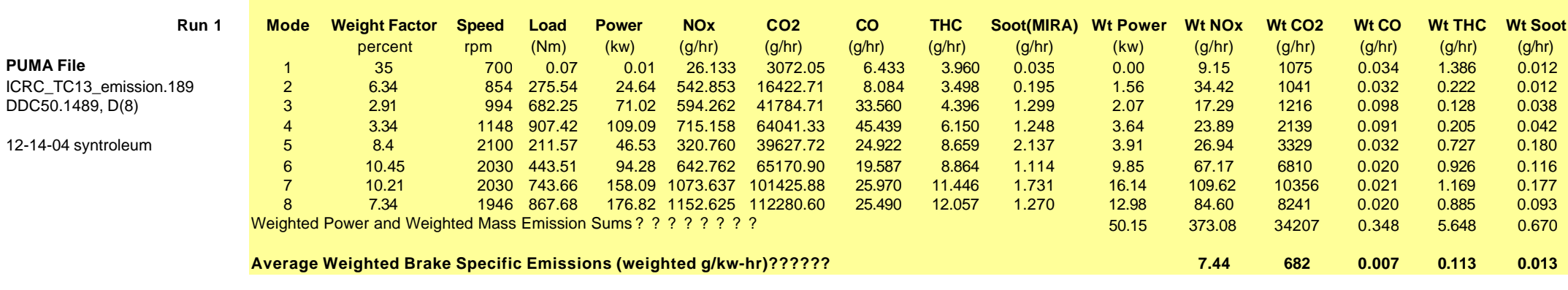

Run 2

\section{PUMA File}

ICRC TC13 emissions 189 DDC50 Syntroleum. 1499,D1(8) $12 / 15 / 2005$

$\begin{array}{cc}\text { Mode } & \begin{array}{c}\text { Weight Factor } \\ \text { percent }\end{array} \\ 1 & 35 \\ 2 & 6.34 \\ 3 & 2.91 \\ 4 & 3.34 \\ 5 & 8.4 \\ 6 & 10.45 \\ 7 & 10.21 \\ 8 & 7.34\end{array}$

\section{Speed Load Power}

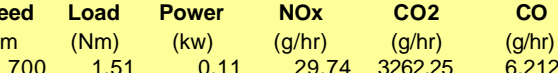

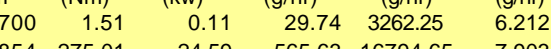
$\begin{array}{llllll}894 & 275.01 & 24.59 & 565.63 & 16794.65 & 7.903 \\ 994.74 & 71.07 & 603.22 & 42108.53 & 36.001\end{array}$ $\begin{array}{llllll}1148 & 906.54 & 108.98 & 766.59 & 64488.71 & 41.196\end{array}$ $\begin{array}{llllll}2100 & 189.22 & 41.61 & 339.53 & 40132.54 & 23.196\end{array}$ $\begin{array}{llllll}2030 & 443.5 & 94.28 & 674.96 & 65890.42 & 16.096\end{array}$ $\begin{array}{llllll}2030 & 743.44 & 158.04 & 1125.83 & 101878.26 & 23.538\end{array}$ Weighted Power and Weighted Mass Emission Sums ?? ? ? ? ?

Avgerage Weighted Brake Specific Emissions (weighted g/kw-hr)??????

\begin{tabular}{|c|c|c|c|c|c|c|}
\hline Soot(MIRA) & Wt Power & Wt NOx & Wt CO2 & Wt co & Wt THC & Wt Soot \\
\hline$(\mathrm{g} / \mathrm{hr})$ & $(\mathrm{kw})$ & $(\mathrm{g} / \mathrm{hr})$ & $(\mathrm{g} / \mathrm{hr})$ & $(\mathrm{g} / \mathrm{hr})$ & $(\mathrm{g} / \mathrm{hr})$ & (g/hr) \\
\hline 0.102 & 0.04 & & & & & \\
\hline 0.194 & 1.56 & 35.86 & 1065 & 0.501 & 0.224 & 0.012 \\
\hline 0.995 & 2.07 & & 1225 & & 0.131 & \\
\hline 0.940 & 3.64 & 25.60 & 2154 & 1.376 & 0.274 & 0.031 \\
\hline 1.674 & & 28. & & & 0.825 & \\
\hline 1.485 & 9.85 & 70.53 & 6886 & 1.682 & 1.027 & 0.155 \\
\hline 1.467 & 16.14 & 114.95 & 10402 & 2.403 & 1.346 & 0.150 \\
\hline \multirow{3}{*}{1.401} & 12.95 & 85.44 & 8261 & 1.717 & 0.942 & 0.055 \\
\hline & 49.74 & 388.87 & 34506 & 12.849 & 6.200 & 0.609 \\
\hline & & & 694 & 0.258 & 0.125 & \\
\hline
\end{tabular}

Run 3

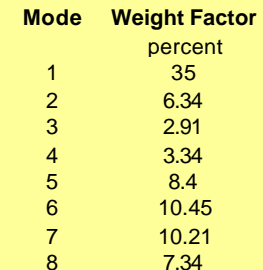

$\begin{array}{ccccc}\text { Speed } & \text { Load } & \text { Power } & \text { NOx } & \text { CO2 } \\ \text { rpm } & (\mathrm{Nm}) & (\mathrm{kw}) & (\mathrm{g} / \mathrm{hr}) & (\mathrm{g} / \mathrm{hr})\end{array}$

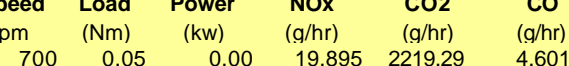
$\begin{array}{llllll}700 & 0.05 & 0.00 & 19.895 & 2219.29 & 4.601\end{array}$ $\begin{array}{rrrrrr}854 & 274.89 & 24.58 & 522.711 & 15617.30 & 7.120 \\ 994 & 681.21 & 70.91 & 597.619 & 41521.14 & 32.914\end{array}$ $\begin{array}{llrlll}1148 & 907.83 & 109.14 & 745.863 & 63507.20 & 41.755\end{array}$ $\begin{array}{lllllll}2100 & 202.39 & 44.51 & 319.395 & 38156.02 & 22.293\end{array}$ $\begin{array}{llll}94.39 & 663.912 & 64668.48 \quad 17.204\end{array}$ $\begin{array}{llllll}1930 & 743.79 & 158.12 & 1106.841 & 100272.73 & 22.180\end{array}$

Weighted Power and Weighted Mass Emission Sums ?? ? ? ? ? ?

Avgerage Weighted Brake Specific Emissions (weighted g/kw-hr)??????

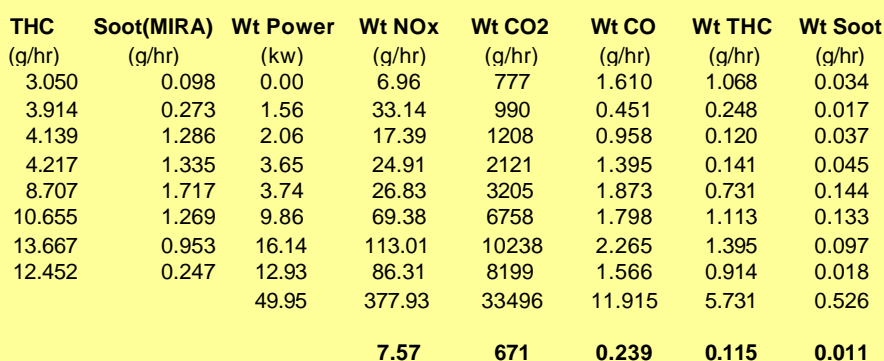

7.57

$671 \quad 0.239$ 0.011 


\section{$\boldsymbol{A} \boldsymbol{V} \boldsymbol{L}$ p powerraA \\ ENGINEERING, INC}

AVL 8 Mode: Average Weighted Brake Specific Emissions

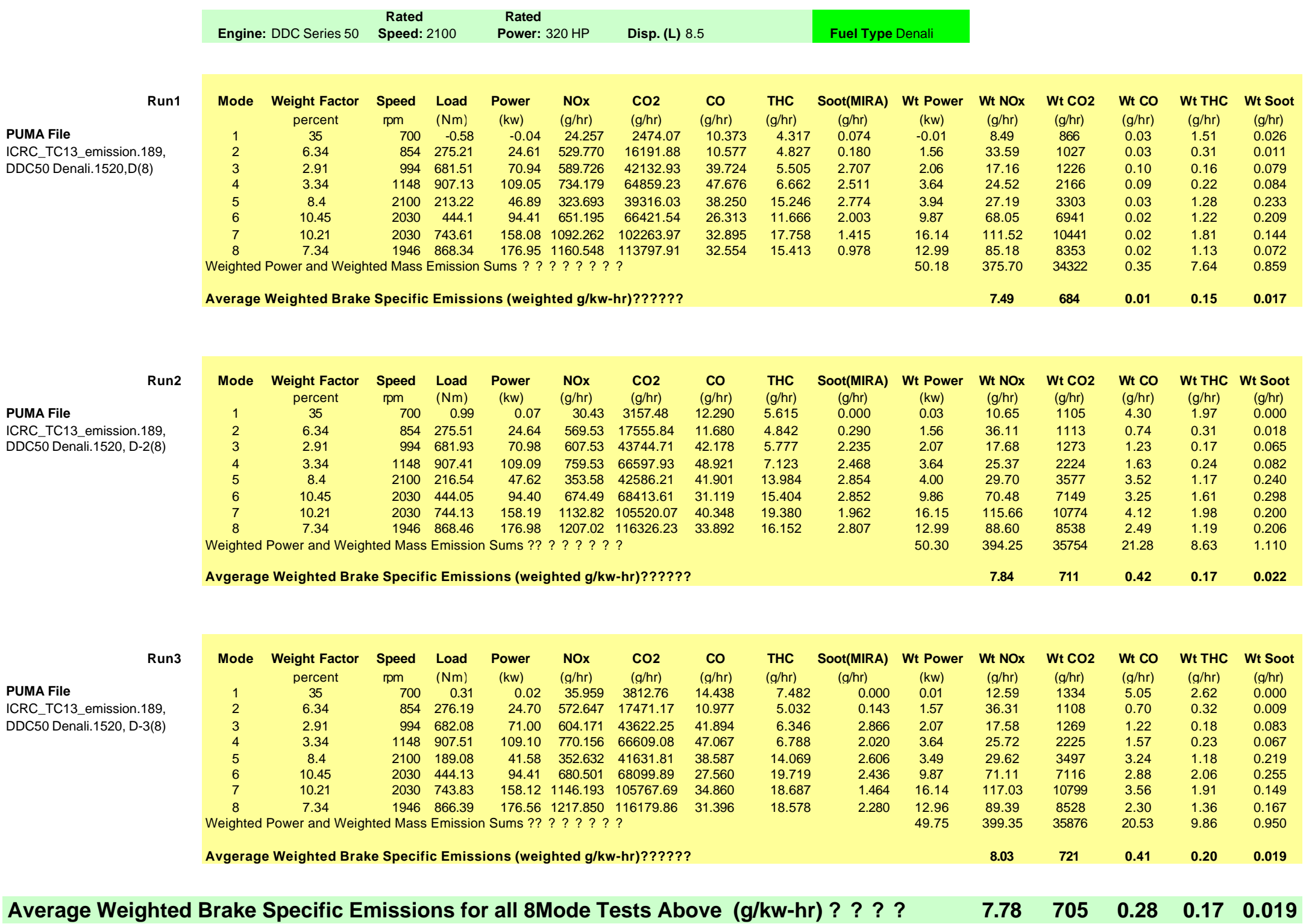




\section{$\mathbf{A} \boldsymbol{V} \mathbf{L}$ powerran \\ ENGINEERING, INC}

AVL 8 Mode: Average Weighted Brake Specific Emissions

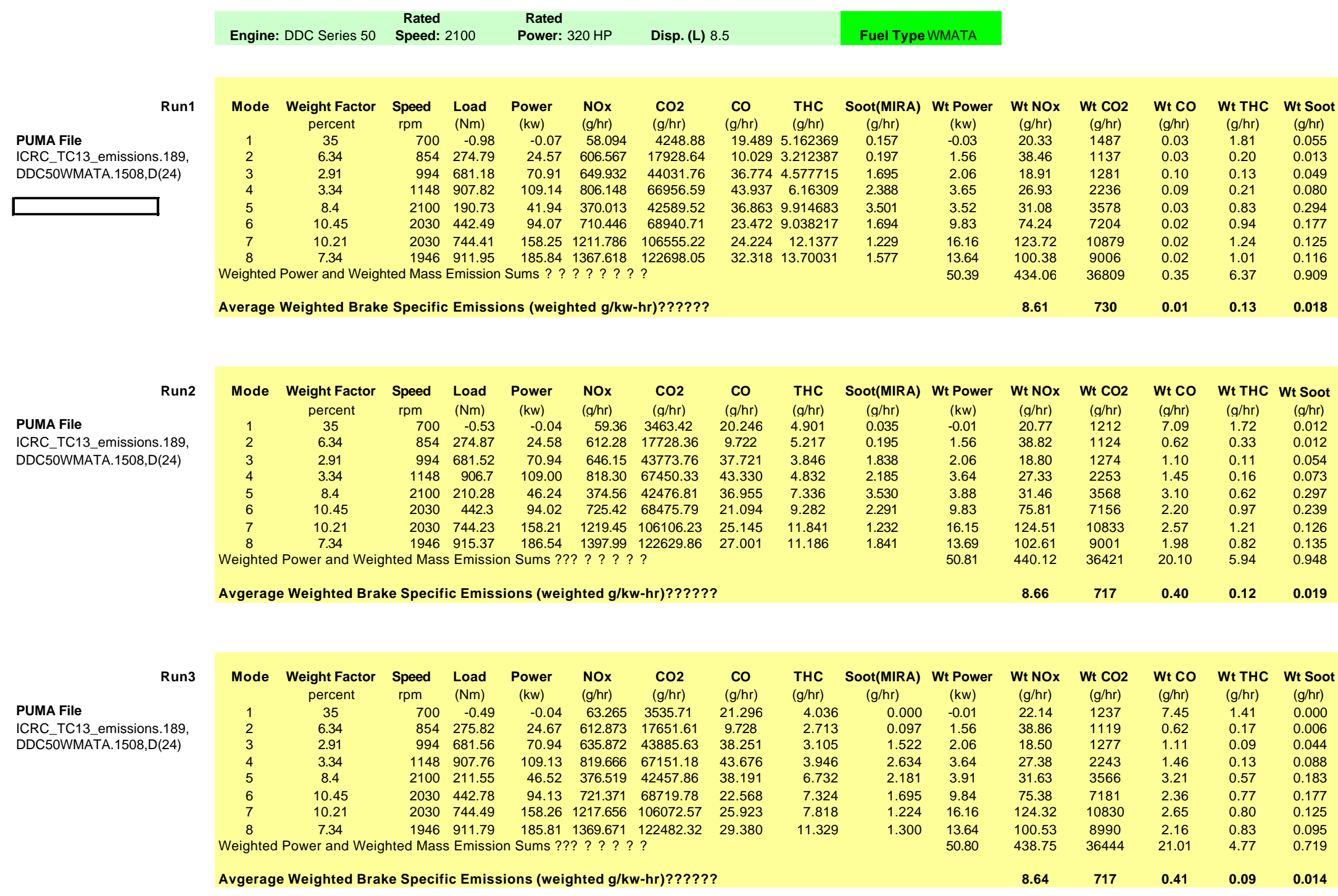

Average Weighted Brake Specific Emissions for all 8Mode Tests Above (g/kw-hr) ? ? ?

$8.64 \quad 722$

$\begin{array}{lll}0.27 & 0.11 & 0.017\end{array}$ 


\title{
APPENDIX B
}

\author{
Bus Fleet Testing Support at the Denali National Park \\ DOE Project: Ultra-Clean Transportation Fuels \\ FAS NO. DE-PS26-00NT40758
}

\section{F-T Fuel Demonstration Report and Fuel Consumption Analysis}

Sukumar Bandopadhyay, Ph.D., P.E. Professor of Mining Engineering Principal Investigator
Rajive Ganguli, Ph.D., P.E.

Associate Professor of Mining Engineering

Co-Principal Investigator

\section{College of Engineering and Mines \\ University of Alaska Fairbanks}

Introduction

The primary purposes of the overall program were:

1.) To demonstrate that Ultra-Clean Fischer-Tropsch (F-T) diesel fuel made from nonpetroleum domestic energy resources can be successfully substituted for conventional diesel fuel; and

2.) To document that diesel engine exhaust emissions can thereby be reduced,

for diesel buses operating in the pristine environment of one of the most beautiful and unspoiled places in the entire US, Denali National Park.

Exhaust emission results have been reported by the West Virginia University team that made the emission measurements. This particular analysis shows that the fuel economy of the buses was not reduced by substituting clean F-T diesel fuel for conventional No. 1 diesel fuel.

Two types of fuel economy data (miles per gallon or mpg) were available to the University of Alaska Fairbanks (see Appendix):

- CAT Electronic Technician records (ETR) that were collected by engine instrumentation

- Manual fuel usage logs

Additionally, the data included handwritten comments (not attached) from Doyon/Aramark, owner and operator of the Denali National Park buses, from drivers on overall bus performance. The drivers think that the "Synthetic fuel buses by far outweigh in performance and power.. those that run on diesel". Some other adjectives used in describing the S2 buses are "smoother", "quieter", "faster" and "more power".

The fuel economy analysis in this report did not use the manual fuel logs since some entries in every log (each bus had a separate log) did not contain the actual 
quantities of fuel that were filled. Instead, these entries simply indicated that the tank was completely filled.

A summary of the ETR is given in Table 1 below. No data was available for bus \#532. Buses 531, 532 and 536 used the regular fuel, designated R, which is No. 1 diesel fuel, while 533, 534 and 537 used the Syntroleum S2 fuel. Note that the ETR data reflected fuel consumption of periods prior to the tests as well. This is because all the buses had a few thousand miles from being driven up to Alaska from the lower 48. Therefore, Table 1 is an accurate indicator of the fuel consumption over the entire operating life of each bus, but it is not specific to during the summer fuelcomparison tests only.

Table 1: Overall Fuel Economy (OFE) and Driving Fuel Economy (DFE) data of the buses.

\begin{tabular}{|c|c|c|c|}
\hline Bus No & OFE (mpg) & DFE (mpg) & Fuel \\
\hline 531 & 5.41 & 5.44 & $\mathrm{R}$ \\
\hline 536 & 6.46 & 6.54 & $\mathrm{R}$ \\
\hline \multicolumn{3}{|c|}{532} & \multicolumn{2}{c|}{$\mathrm{R}$} \\
\hline 533 & 5.85 & 5.89 & $\mathrm{~S} 2$ \\
\hline 534 & 5.76 & 5.81 & $\mathrm{~S} 2$ \\
\hline 537 & 6.51 & 6.61 & $\mathrm{~S} 2$ \\
\hline
\end{tabular}

Table 2 lists the route pairings of the buses. For example, buses 531 and 533 were on the same route, covering a distance of 135 miles.

Table 2. Route pairings for the buses.

\begin{tabular}{|c|c|c|}
\hline R Fuel & S2-Fuel & Approx. miles for Route \\
\hline 531 & 533 & 135 \\
\hline 532 & 534 & 135 \\
\hline 536 & 537 & 200 \\
\hline
\end{tabular}

Analyses

A paired t-test was conducted on the buses (DFE data) with pairings as shown in Table 2. However, since there was no fuel economy data on 532, the t-test only had two pairs. The results (output from Excel ${ }^{\circledR}$ ) are given in Table 3 below.

Table 3. Paired two sample $t$ test for means of DFE

\begin{tabular}{|l|r|r|}
\hline \multicolumn{2}{|c|}{ Reg. Fuel } & \multicolumn{2}{c|}{ S2 Fuel } \\
\hline Mean & 5.99 & 6.25 \\
\hline Variance & 0.605 & 0.2592 \\
\hline Observations & 2 & 2 \\
\hline Pearson Correlation & 1 \\
\hline Hypothesized Mean Difference & 0 \\
\hline df & 1 \\
\hline $\mathrm{t}$ Stat & -1.36842 \\
\hline $\mathrm{P}(\mathrm{T}<=\mathrm{t})$ one-tail & 0.200879 \\
\hline $\mathrm{t}$ Critical one-tail & 6.313749 \\
\hline $\mathrm{P}(\mathrm{T}<=\mathrm{t})$ two-tail & 0.401758 \\
\hline
\end{tabular}




\begin{tabular}{|l|l|}
\hline $\mathrm{t}$ Critical two-tail & 12.70615 \\
\hline
\end{tabular}

From the test, it is apparent that there is no difference in the mean fuel consumption since the $t$ stat $(-1.37)$ is well below the critical two tail $t$ (12.7). It should be pointed out that when the sample size is small, it becomes very challenging to prove that two groups have different means since the $t$ critical is typically high. For the sake of a quick interpretation, t-critical can be thought of as the required distance (in terms of the standard deviations of the groups) between the means of the two groups. In this case (sample size 2), the two means have to be 12.7 standard deviations apart for them to be deemed different. As sample size increase, $t$ critical reduces.

The engine oil samples from the buses were subjected to spectrochemical analysis to obtain additional information on engine performance. The results are summarized in Table 4 below (see Appendix for raw data). Dusty roads are apparent from the high levels of $\mathrm{Si}$ in oil from most of the buses. Bus \#532 was also noted to have had excessive blowby since it was received.

Table 4. Oil analysis report

\begin{tabular}{|c|c|c|}
\hline Bus \# & Oil Analysis Report & Fuel Type \\
\hline 531 & High: $\mathrm{Si}$ & \multirow{2}{*}{ Regular } \\
& & \\
\hline 532 & High: $\mathrm{Si}, \mathrm{Cu}$ & \\
\hline 536 & OK & \multirow{2}{*}{ S2 } \\
\hline 533 & OK & \\
\cline { 1 - 2 } & & \\
\hline 534 & High: $\mathrm{Si}$ & \\
\hline
\end{tabular}

The oil analysis report does not provide any insight into the fuel consumption behavior of the buses.

Conclusion

The following can be concluded based on the above analyses.

- The fuel economy of the buses on the two different fuel types is statistically similar.

The lack of data on fuel economy is one reason for the similarity of the means. Note

that in the two bus pairs, S2 buses had better fuel economy than the buses on regular fuel.

- Oil analysis does not provide any insight into the fuel consumption of buses

Better overall performance of S2 buses (in comparison to regular diesel buses) is also indicated from the bus driver comments.

Recommendation

For the fuel consumption test results to be meaningful, it is strongly recommended that more tests be conducted. Increasing the sample size will allow differences in fuel consumption to be conclusively proven. Currently, despite both S2 pairs showing better mileage than regular buses, the two groups are statistically similar. Besides, better fuel economy data needs to be collected since the current data is for the total operating lives 
of the buses, not only for the summer tests. More accurate data could further highlight differences in fuel economy. 


\title{
APPENDIX C
}

\section{Ultra-Clean Transportation Fuels}

\author{
Annual Activities Report
}

August 2004 - August, 2005

DOE Award No: DE-FC26-01NT41099

Prepared by:

Dr. W. Scott Wayne, Ryan Barnett, Dr. Donald W. Lyons, Dr. Nigel N. Clark and Dr. Mridul Gautam National Research Center for Alternative Fuels Engines \& Emissions West Virginia University

PO BOX 6106

Morgantown, WV 26506-6106 


\section{EXECUTIVE SUMMARY}

The U.S. Department of Energy's National Energy Technology Laboratory (NETL) is the sponsor of an Ultra-Clean Fuels Production and Demonstration Program with Integrated Concepts and Research Corporation (ICRC) as the prime contractor and West Virginia University as a principal subcontractor. Under this demonstration program Syntroleum Corporation has built a small footprint plant to demonstrate Fischer-Tropsch (F-T) technology and produce ultra-clean diesel fuel from natural gas. The F-T fuel was demonstrated in a select number of urban transit buses operated by the Washington DC Metropolitan Transit Authority (WMATA) and in tour buses operated by Doyon/Aramark in Denali National Park, Alaska.

Exhaust emissions measurements were conducted on six 2000 model year transit buses equipped with 1999 model Detroit Diesel Corporation Series 50 engines and diesel oxidation catalysts at WMATA. Three buses were operated on Syntroleum S-2 gas-to-liquid fuel and three were operated on ultra-low sulfur type 1 petroleum derived diesel fuel. Emissions were measured shortly after the test buses were converted to Syntroleum S-2 fuel and then repeated 6 months later. Emissions measurements were also conducted on six 2004 model year Thomas buses equipped with 2004 model Caterpillar C7 ACERT engines and diesel oxidation catalysts at Denali National Park, Alaska. Three "test" buses were operated on Syntroleum S-2 fuel and three "control" buses were operated on low sulfur type 1 diesel fuel. Ultra-low sulfur fuel is not economically available in Alaska. The Denali Park buses were only tested on one occasion. All emissions changes are compared to the baseline petroleum diesel fuel typically used at each bus fleet.

Activities performed during the period from August 2004 to August 2005 and discussed in this report are phases 3 and 4 of the study. Phase 3, performed in August of 2004, consisted of testing three diesel-fueled control buses and three Syntroleum-fueled buses shortly after their conversion to the fuel. Phase 4, conducted 8 months later in April 2005, consisted of retesting the buses to evaluate the long term effects of the synthetic fuel on emissions and performance.

WMATA transit buses fueled with Syntroleum S-2 fuel demonstrated emissions reductions of between 16 and $22 \%$ for $\mathrm{NO}_{\mathrm{x}}$ and $35 \%$ for PM. HC and CO emissions from the WMATA buses were low for both fuels with no significant differences noted between the Syntroleum S-2 and ultra-low sulfur fuel given vehicle-to-vehicle variation. Emissions measurements were also conducted on a single WMATA transit bus equipped with an Engelhard DPX ${ }^{T M}$ passive catalyzed diesel particulate filter. Tests were conducted with the DPX installed and with the OEM oxidation catalyst installed. Installation of a catalyzed particulate filter in conjunction with the Syntroleum S-2 fuel reduced PM emissions to less than $0.01 \mathrm{~g} / \mathrm{mile}$. $\mathrm{HC}$ and $\mathrm{CO}$ emissions were also reduced to at or below ambient levels by the catalytic action of the DPX filter. During the emissions testing, fuel economy was computed from exhaust emissions data using a carbon balance. The Syntroleum S-2 fuel did not result in significant changes in fuel economy in either bus fleet.

Use of Syntroleum S-2 synthetic diesel fuel produced from natural gas resulted in reductions in $\mathrm{NO}_{\mathrm{x}}$ and PM emissions of transit buses equipped with DDC Series 50 engines operating in Washington DC. Although gas-to-liquid fuels, such as Syntroleum S-2 fuel, have the potential to produce modest reductions in regulated emissions, the near-zero sulfur content of these fuels may prove most beneficial by enabling advanced sulfur sensitive emission control devices on newer technology engines. 


\section{TABLE OF CONTENTS}

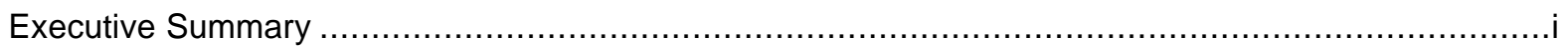

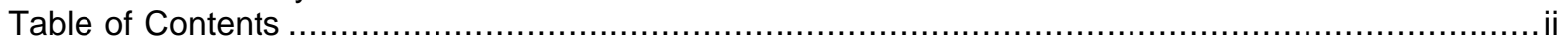

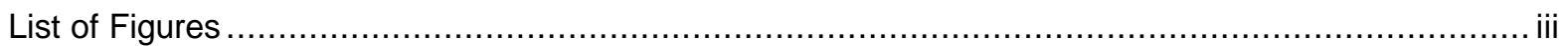

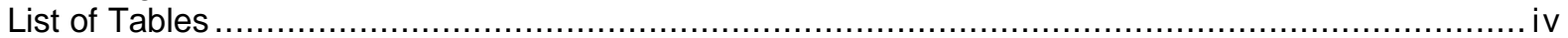

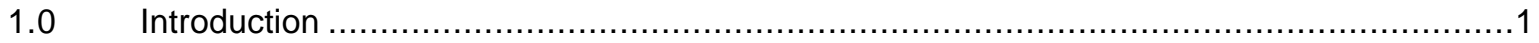

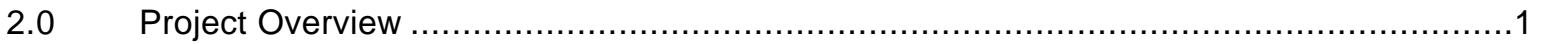

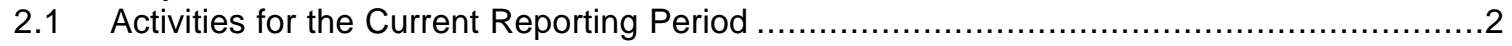

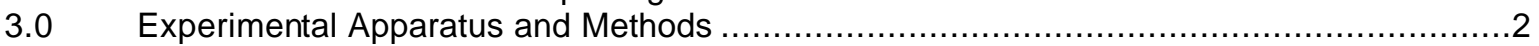

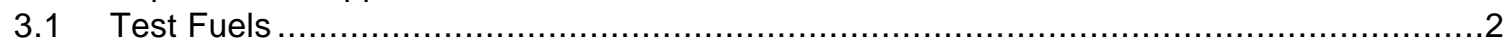

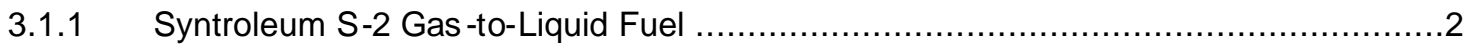

3.1.2 WMATA Ultra-Low Sulfur D1 Petroleum-Derived Diesel Fuel ............................

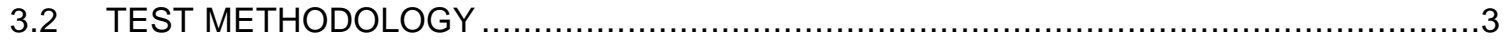

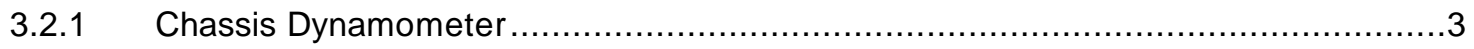

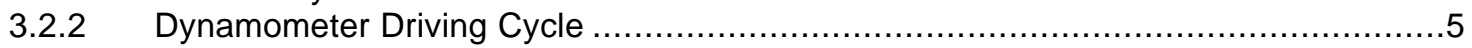

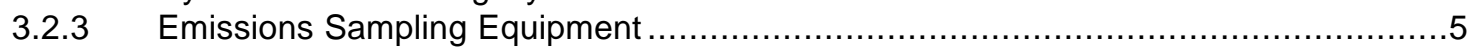

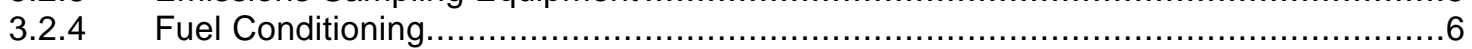

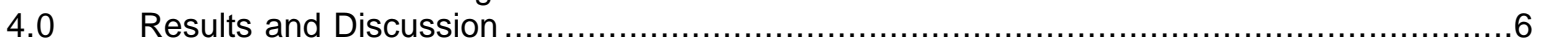

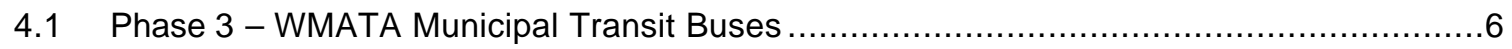

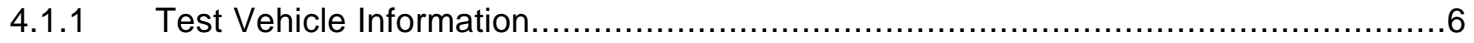

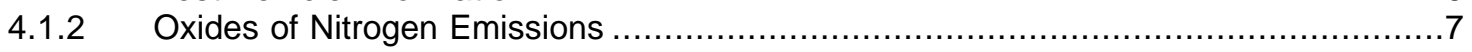

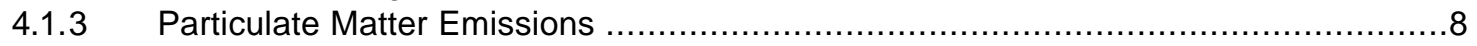

4.1.4 Hydrocarbon and Carbon Monoxide Emissions ...........................................

4.1.5 Carbon Dioxide and Fuel Economy Results ................................................. 10

4.1.6 Summary of Phase 3 Results .................................................................. 11

4.2 Phase 4 - 6-Month Retest of WMATA Municipal Transit Buses ................................. 12

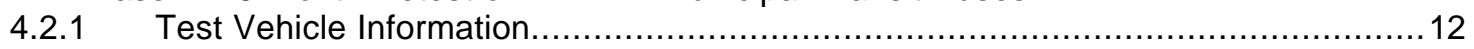

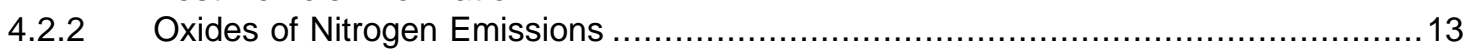

4.2.3 Particulate Matter Emissions ..................................................................... 14

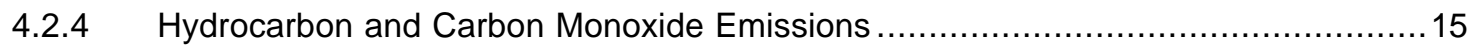

4.2.5 Carbon Dioxide and Fuel Economy Results .................................................. 16

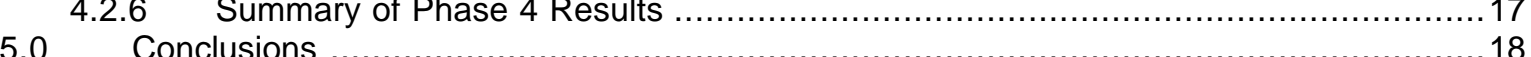

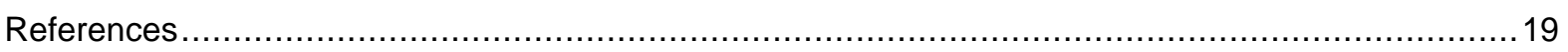

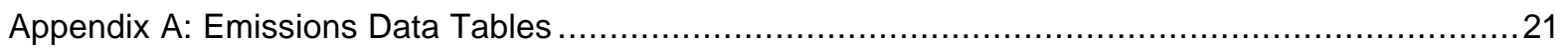




\section{LIST OF FIGURES}

Figure 1: The vehicle being tested is positioned on the dynamometer rollers..................................4

Figure 2: Hub adapters connect the vehicle's drive axle to the power absorber units. ..................... 4

Figure 3: WMATA Cycle target speed versus time schedule. .................................................. 5

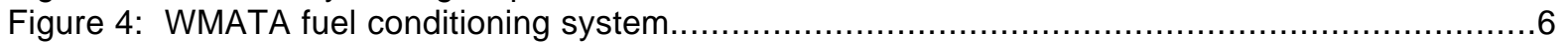

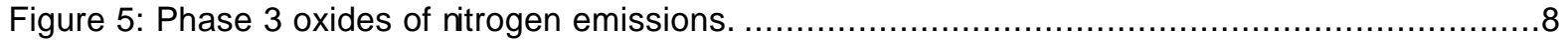

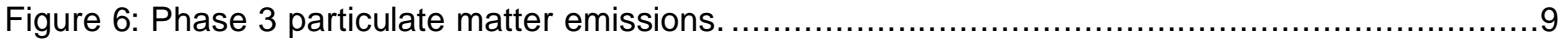

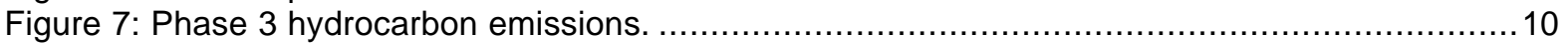

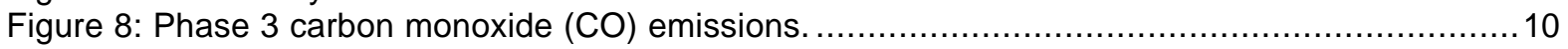

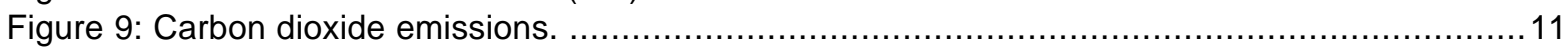

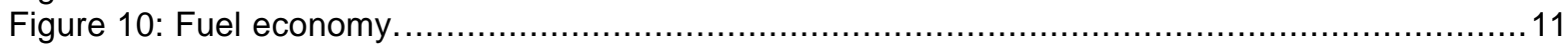

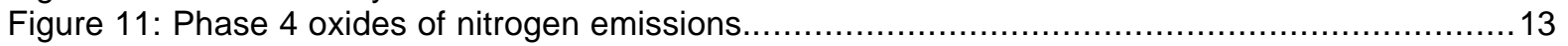

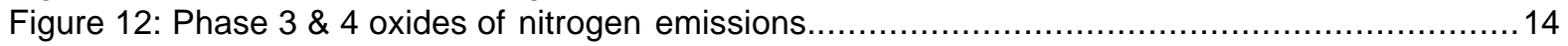

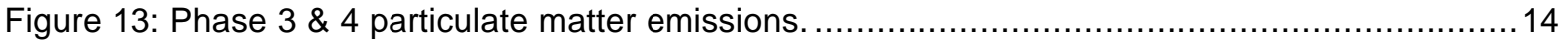

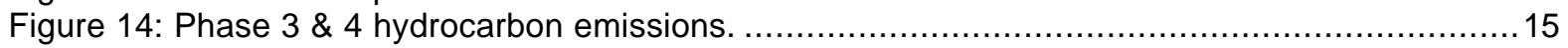

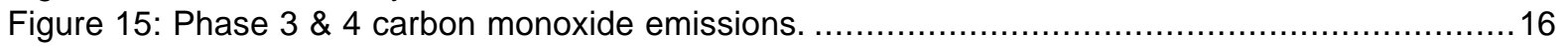

Figure 16: Phase 3 \& 4 carbon dioxide emissions. ......................................................... 17

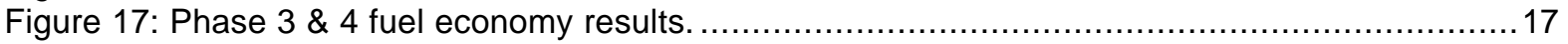




\section{LIST OF TABLES}

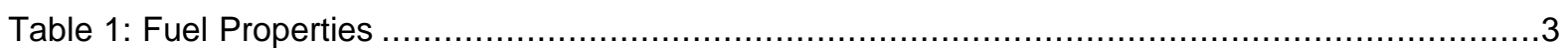

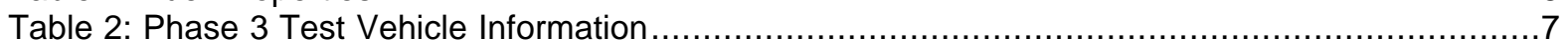

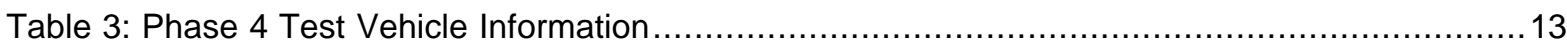




\subsection{INTRODUCTION}

The Fischer-Tropsch (F-T) process was invented in Germany in the 1920's and has been used in South Africa to produce gasoline and diesel fuel from coal for several decades. Recently, interest has grown in the production of GTL fuels. Two principal objectives underlie this interest; emissions reductions and energy security. The F-T process can allow liquid compression ignition fuels to be made from domestic energy sources such as coal, biomass, and natural gas, thereby reducing petroleum imports while simultaneously reducing harmful emissions. Through recent advances, F-T production facilities have become more economical as well as relatively portable. Production facilities can be positioned close to energy resources that might not otherwise be suitable for use because the gas is too far away from the end user. Alaska, for example, has a huge non-petroleum energy reserve, but much of it is in remote locations. In the near future, zero-sulfur, zero-aromatic, highcetane synthetic diesel fuel could be produced locally in Alaska, and at many other locations around the U.S. and the rest of the world using non-petroleum energy resources.

The U.S. Department of Energy's National Energy Technology Laboratory (NETL) was the sponsor of an Ultra-Clean Fuels Production and Demonstration Program with Integrated Concepts and Research Corporation (ICRC) as the prime contractor and West Virginia University as a principal subcontractor. The goal of the program was to pioneer a new generation of ultra-clean transportation fuels to significantly reduce tailpipe emissions from cars, trucks, and other heavy vehicles. Under this demonstration program Syntroleum Corporation has built a small footprint plant to demonstrate Fischer-Tropsch (F-T) technology and produce ultra-clean diesel fuel from natural gas. The fuel was produced in Tulsa Oklahoma at a gas-to-liquids demonstration facility built by the Syntroleum Corporation and Marathon Oil Company with funding, in part provided by U.S. DOE and NETL. The ultra-clean GTL fuel was manufactured using Syntroleum's proprietary gas-to-liquids technology called The Syntroleum Process ${ }^{\circledR}$.

The Syntroleum S-2 fuel was demonstrated in a select number of urban transit buses operated in revenue service by the Washington DC Metropolitan Transit Authority (WMATA) in Washington DC and in tour buses operated by Doyon/Aramark in Denali National Park, Alaska. Performance, exhaust emissions, and fuel economy of the buses operated on Syntroleum S-2 fuel were evaluated at each location and compared with identically equipped sister buses operated on petroleum-derived diesel fuels. Operational, maintenance, and fuel economy data were collected at each site by ICRC. The West Virginia University Center for Alternative Fuels, Engines and Emissions, as a subcontractor to ICRC, measured the exhaust emissions from three (3) test buses at WMATA and three (3) test buses at Denali National Park and compared the performance and emissions to that of three (3) identical technology "control" buses at each site that were fueled with each fleet's standard petroleum-derived diesel fuel.

\subsection{PROJECT OVERVIEW}

The overarching goal of the Ultra-Clean Transportation Fuels Production and Demonstration Program was to pioneer a new generation of gas-to-liquid fuels to significantly reduce tailpipe emissions from buses, trucks, and other heavy vehicles and to demonstrate this fuel in bus fleets operated in Washington DC and Denali Park, Alaska. The emissions testing component of the project was divided into four phases.

- In Phase 1, a single WMATA public transit bus was tested with and without a catalyzed diesel particulate filter to demonstrate the compatibility of Syntroleum S-2 fuel with catalyzed diesel particulate filters.

- In Phase 2, six tour buses equipped with 2004 model year Caterpillar C7 ACERT engines and diesel oxidation catalysts were tested in Denali National Park. Alaska; 3 buses fueled with Syntroleum S-2 fuel and 3 control buses fueled with the low sulfur Jet A diesel fuel utilized by Denali National Park.

- In Phase 3, six public transit buses equipped with 2000 model year DDC Series 50 engines and oxidation catalysts were tested in Washington DC; 3 buses fueled with Syntroleum S-2 fuel and 3 fueled with ultra-low sulfur type 1 diesel fuel. 
- In Phase 4 three out of the six WMATA buses were re-tested to evaluate the performance and emissions after the vehicles have been operating on Syntroleum S-2 fuel for a period of at least six months.

\subsection{Activities for the Current Reporting Period}

The activities performed by WVU for the current reporting period were Phases 3 and 4 of the project. In Phase 3, testing was performed on three WMATA transit buses shortly after their conversion to Syntroleum S-2 fuel. Three diesel-powered control buses were also tested for comparison purposes. In Phase 4, WVU returned to WMATA to retest the buses to determine any long term effects of the Syntroleum S-2 fuel on performance and emissions. As a result of bus-to-bus variability discovered in Phase 3, Phase 4 test buses were run on both fuel types back-to-back while emissions were measured. Approximately eight months elapsed between Phase 3 and Phase 4 to allow sufficient time for any effects to occur for the longevity evaluation.

\subsection{EXPERIMENTAL APPARATUS AND METHODS}

\subsection{Test Fuels}

Two different fuels were used in the course of completing this project. Syntroleum S-2 GTL fuel and ultra-low sulfur type 1 diesel fuel were tested in buses at Washington Metropolitan Transit Authority. An analysis was performed on both test fuels. Properties can be seen in Table 1.

\subsubsection{Syntroleum S-2 Gas-to-Liquid Fuel}

Syntroleum S-2 is a synthetic diesel fuel produced from natural gas with most of the positive benefits of petroleum based diesel fuel. Syntroleum S-2 is a paraffinic, high-cetane distillate fuel with extremely low levels of sulfur, olefins, metals, aromatics and alcohols. It is $99 \%+$ saturates (i.e. the fuel consists of hydrocarbon molecules that are saturated with hydrogen). Properties of the Syntroleum S-2 fuel determined by analysis of samples collected at WMATA are listed in Table 1.

In the United States, a minimum cetane number of 40 is specified for diesel fuels. The Syntroleum S2 fuel had a cetane number of 74 , due to its high paraffin content and near absence of aromatics. The higher the cetane number, the more readily the fuel will ignite and the shorter the ignition-delay period. Many of the leading aftertreatment technologies, including lean $\mathrm{NO}_{\mathrm{x}}$, catalyzed diesel particulate filters (DPF) and diesel oxidation catalysts cannot tolerate sulfur well. The Syntroleum Process $^{\circledR}$, removes all traces of sulfur from the natural gas feed stock during the feed preparation process, so Syntroleum S-2 fuel contains nearly zero sulfur. In newer technology engines, the near zero sulfur content of GTL fuel may prove most beneficial by enabling sulfur sensitive emission control devices.

\subsubsection{WMATA Ultra-Low Sulfur D1 Petroleum-Derived Diesel Fuel}

WMATA has recently switched to ultra-low sulfur No. 1 (ULSD1) diesel fuel as a means to reduce emissions and to enable the use of exhaust aftertreatment catalyzed particulate filters, which can virtually eliminate particulate (PM) emissions. WMATA's ULSD1 had a cetane number of 45 and an aromatic content of $21.6 \mathrm{wt} \%$ which is typical of petroleum-derived diesel fuels. The sulfur content was 18 ppm wt. Fuel density and heating values were typical of available diesel fuels. 
Table 1: Fuel Properties

\begin{tabular}{|c|c|c|c|c|}
\hline Property & Syntroleum S-2 & $\begin{array}{l}\text { WMATA Ultra- } \\
\text { Low Sulfur D1 }\end{array}$ & Units & Method \\
\hline Cetane Number & 73.6 & 45 & & ASTM D-613 \\
\hline API Gravity @ 60 deg F & 52.4 & & deg.API & ASTM D-4052 \\
\hline Density @ 60 deg F & 0.7687 & 0.8300 & $\mathrm{gm} / \mathrm{mL}$ & ASTM D-4052 \\
\hline Kinematic Viscosity @ 40 deg F & 1.705 & 1.773 & cSt & \multirow[t]{2}{*}{ ASTM D-445 } \\
\hline Kinematic Viscosity @ 100 deg F & 1.761 & & cSt & \\
\hline Flash Point , PMCC & 140 & 156 & $\operatorname{deg} F$ & ASTM D-93(A) \\
\hline Total Sulfur & 5 & 17.9 & ppm wt & ASTM D-5453 \\
\hline Aromatics & 1.1 & 19.7 & vol. \% & \multirow[t]{3}{*}{ ASTM D-1319 } \\
\hline Olefins & 0.3 & 1.1 & vol. \% & \\
\hline Saturates & 98.6 & 79.2 & vol. \% & \\
\hline Monoaromatics & 0.35 & 18.3 & wt\% & \multirow[t]{3}{*}{ ASTM D-5186 } \\
\hline Polynuclear Aromatic Hydrocarbons & $<0.1$ & 3.4 & $\mathrm{wt} \%$ & \\
\hline Total Aromatics & 0.35 & 21.6 & $w t \%$ & \\
\hline \multicolumn{5}{|c|}{ ASTM D-240 } \\
\hline Gross & 20460 & 19675 & $\mathrm{BTU} / \mathrm{lb}$ & \\
\hline Net & 19084 & 18447 & BTU/lb & \\
\hline Cloud Point & -14 & -46 & $\operatorname{deg} \mathrm{F}$ & ASTM D-2500 \\
\hline Pour Point & -30 & -48 & $\operatorname{deg} F$ & ASTM D-57 \\
\hline Carbon Content & 84.75 & 86.19 & wt\% & ASTM D-5291M \\
\hline Hydrogen Content & 15.19 & 13.46 & $w t \%$ & ASTM D-5291M \\
\hline Nitrogen Content & $<0.05$ & & $w t \%$ & ASTM D-5291M \\
\hline Oxygen Content & $<0.10$ & $<0.10$ & $w t \%$ & ASTM D-5291M \\
\hline \multicolumn{5}{|c|}{ ASTM D-86 } \\
\hline IBP & 321.0 & 354.4 & $\operatorname{deg} F$ & \\
\hline $5 \%$ Recovery & 370.2 & 391.7 & $\operatorname{deg} F$ & \\
\hline $10 \%$ Recovery & 380.3 & 397.0 & $\operatorname{deg} \mathrm{F}$ & \\
\hline $20 \%$ Recovery & 399.3 & 411.6 & $\operatorname{deg} \mathrm{F}$ & \\
\hline $30 \%$ Recovery & 422.5 & 421.1 & $\operatorname{deg} F$ & \\
\hline $40 \%$ Recovery & 446.1 & 430.0 & $\operatorname{deg} F$ & \\
\hline $50 \%$ Recovery & 471.3 & 438.6 & $\operatorname{deg} F$ & \\
\hline $60 \%$ Recovery & 494.9 & 447.9 & $\operatorname{deg} F$ & \\
\hline $70 \%$ Recovery & 521.2 & 458.5 & $\operatorname{deg} F$ & \\
\hline $80 \%$ Recovery & 550.8 & 471.4 & $\operatorname{deg} F$ & \\
\hline $90 \%$ Recovery & 588.5 & 489.2 & $\operatorname{deg} \mathrm{F}$ & \\
\hline $95 \%$ Recovery & 613.6 & 504.2 & $\operatorname{deg} F$ & \\
\hline FBP & 619.8 & 527.0 & $\operatorname{deg} F$ & \\
\hline Recovery & 97.1 & 99.1 & $\%$ & \\
\hline Residue & 1.8 & 0.5 & $\%$ & \\
\hline Loss & 1.1 & 0.5 & $\%$ & \\
\hline
\end{tabular}

\subsection{TEST METHODOLOGY}

\subsubsection{Chassis Dynamometer}

Chassis dynamometer testing is the most accurate and repeatable method of characterizing emissions from in-use heavy-duty vehicles and provides the most useful data for prediction of atmospheric emissions inventories, evaluation of clean-vehicle programs at transit agencies and truck fleets, and assessing the success of retrofit programs. Chassis dynamometer systems have been developed and used for many years and it has been demonstrated that they are reliable tools for studying vehicle emissions. The West Virginia University Transportable Heavy-Duty Vehicle Emissions Testing Laboratories were constructed to gather emissions data from in-use heavy-duty vehicles. Detailed information pertaining to the design and operation of the laboratories can be found in technical papers [20, 21, 22]. The dynamometer unit consisted of power absorbers and a set of selectable flywheels, which allowed simulation of tire rolling losses, aerodynamic drag and inertial load equivalent to a gross vehicle weight of up to 60,000 pounds. The vehicle to be tested was driven onto the chassis dynamometer and positioned on two sets of rollers (Figure 1). The outer wheel of the dual wheel set on each side of the vehicle was removed and replaced with hub adapters that couple the drive axle directly to the dynamometer units on each side of the vehicle ( Figure 2). Torque cells and speed transducers continuously measured drive axle torque and speed. Road load drag on the vehicle was mimicked partially by the irreversible (frictional) losses in the 
laboratory, and was adjusted to the correct value at each speed using eddy current power absorbers with closed-loop torque control. A human driver operated the vehicle according to a driving schedule.

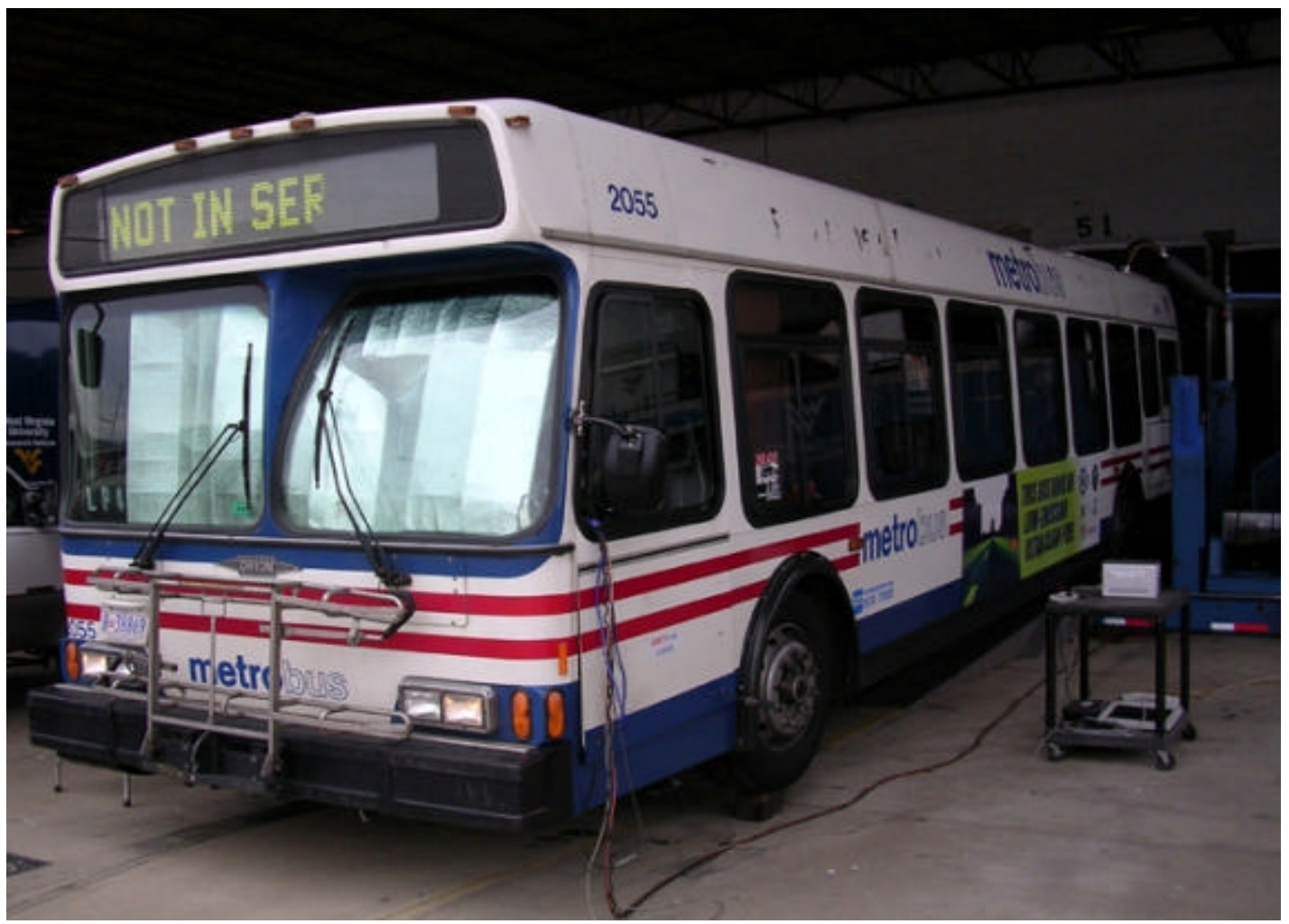

Figure 1: The vehicle being tested is positioned on the dynamometer rollers.

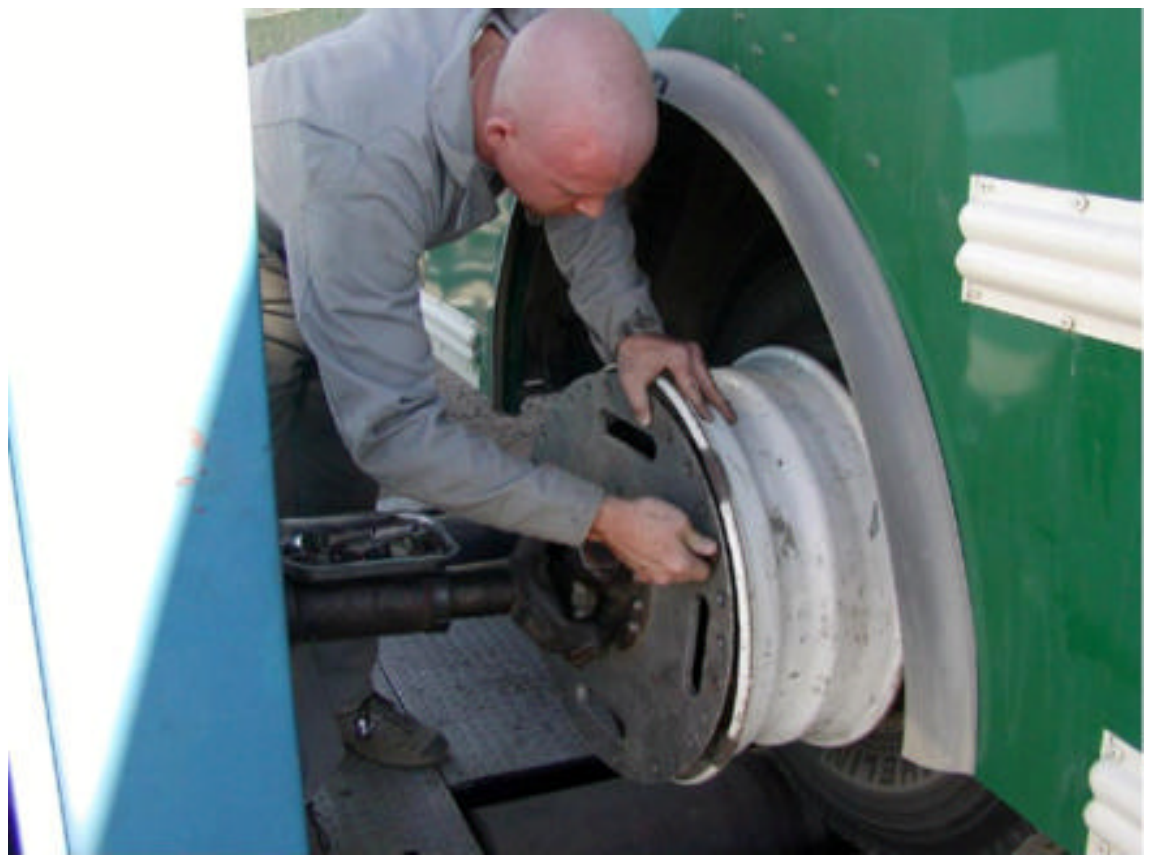

Figure 2: Hub adapters connect the vehicle's drive axle to the power absorber units. 


\subsubsection{Dynamometer Driving Cycle}

Emissions are known to be dependent on the duty cycle of the vehicle and thus the dynamometer test schedule used. The final two phases of the Ultra-Clean Transportation Project included emissions testing of urban transit buses in Washington DC. The Washington Metropolitan Transit Authority Cycle (WMATA) was selected as the dynamometer test schedule for the project. The WMATA Cycle was derived from vehicle speed data logged from transit buses during normal operation in Washington DC and surrounding areas. Vehicle activity data was logged from several WMATA transit buses during normal passenger service on multiple routes within the WMATA system. Vehicle speed data were recorded from a Global Positioning System. These data comprised a database of vehicle activity, which was analyzed to characterize the duty cycle of a typical WMATA transit bus. The WMATA Cycle is shown in Figure 3.

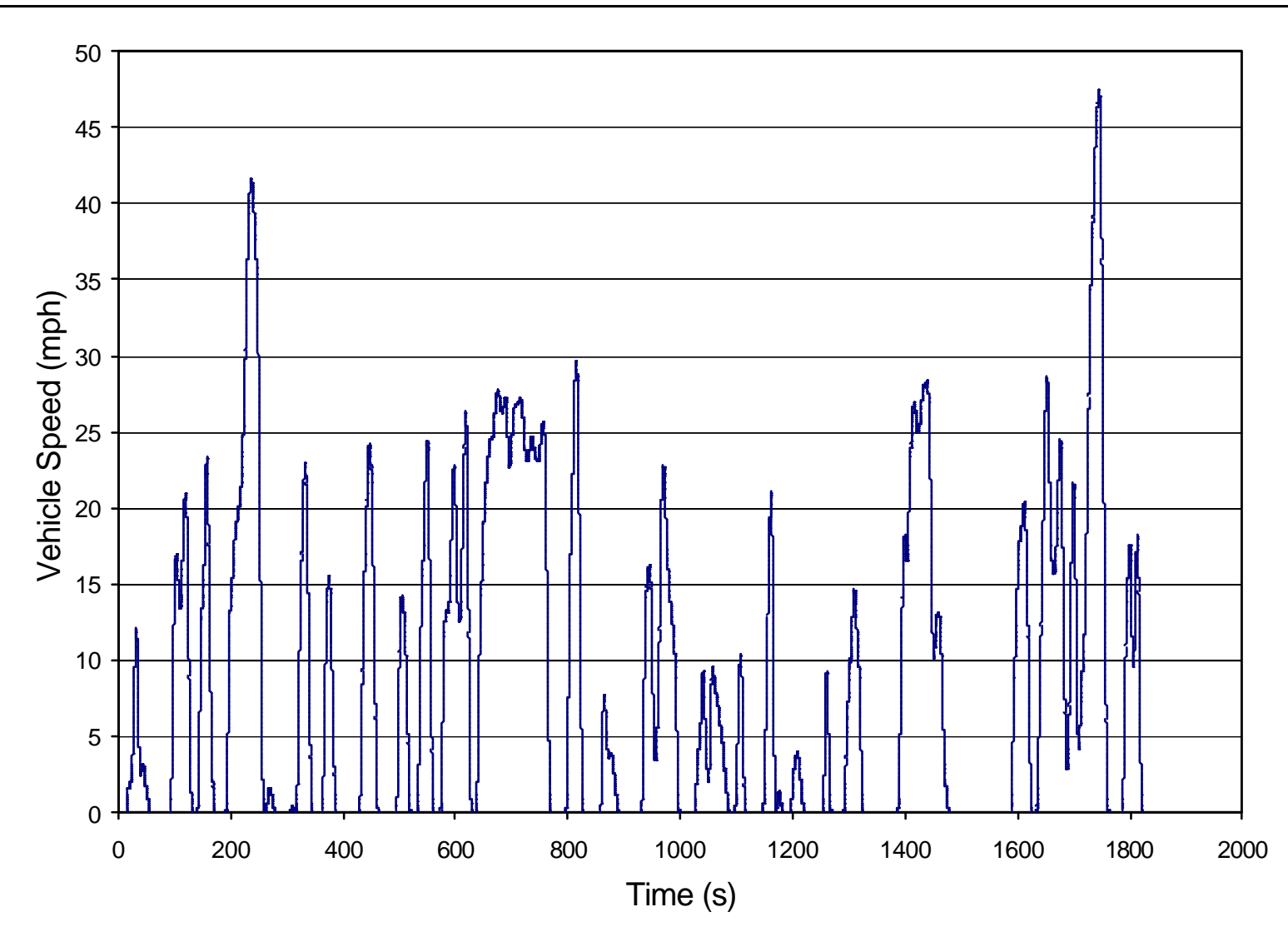

Figure 3: WMATA Cycle target speed versus time schedule.

\subsubsection{Emissions Sampling Equipment}

The emissions measurement system used a full-scale dilution tunnel measuring 18 inches $(45 \mathrm{~cm})$ in diameter and 20 feet $(6.1 \mathrm{~m})$ in length. The exhaust was mixed with HEPA filtered ambient air and the quantity of diluted exhaust was measured precisely by a critical flow venturi system (CVS). The diluted exhaust was analyzed using NDIR for carbon monoxide (CO) and carbon dioxide $\left(\mathrm{CO}_{2}\right)$, and using chemiluminescent detection for oxides of nitrogen $\left(\mathrm{NO}_{\mathrm{x}}\right)$. $\mathrm{NO}_{\mathrm{x}}$ emissions were corrected for standard humidity. Hydrocarbons (HC) were analyzed using flame ionization detection (FID). Simultaneous pre-tunnel bag samples were taken during each test to establish ambient background gas concentrations. The gaseous emissions measurements were performed in accordance with the CFR Title 40, Part 86 Subpart N (CFR40) [23] to the extent possible. A carbon balance using fuel properties and exhaust emissions data was used to determined fuel economy. Particulate matter 
(PM) was collected using 70-mm fluorocarbon coated glass fiber filter media and PM mass emissions were determined gravimetrically. Dilution tunnel background samples were collected for establishing particulate matter background levels. Even though the tunnel has HEPA filtered dilution air, PM backgrounds are essential because the dilution tunnel walls may shed particles that are re-entrained into the sample stream or outgas heavy hydrocarbons that condense onto the PM. Emissions were reported in distance-specific units (mass of pollutant emitted / unit distance traveled $-\mathrm{g} / \mathrm{mile}$ ).

\subsubsection{Fuel Conditioning}

When the test fuel was changed from the in-tank type, the fuel was drawn from 55 gallon steel drums. Circulation of the fuel through the hot engine could heat the comparatively smaller (compared to the fuel tank) volume of fuel in the drum enough to cause a drop in density. To avoid this, the fuel is conditioned with a liquid-to-air heat exchanger. This conditioing unit in its as-tested configuration is shown in Figure 4.

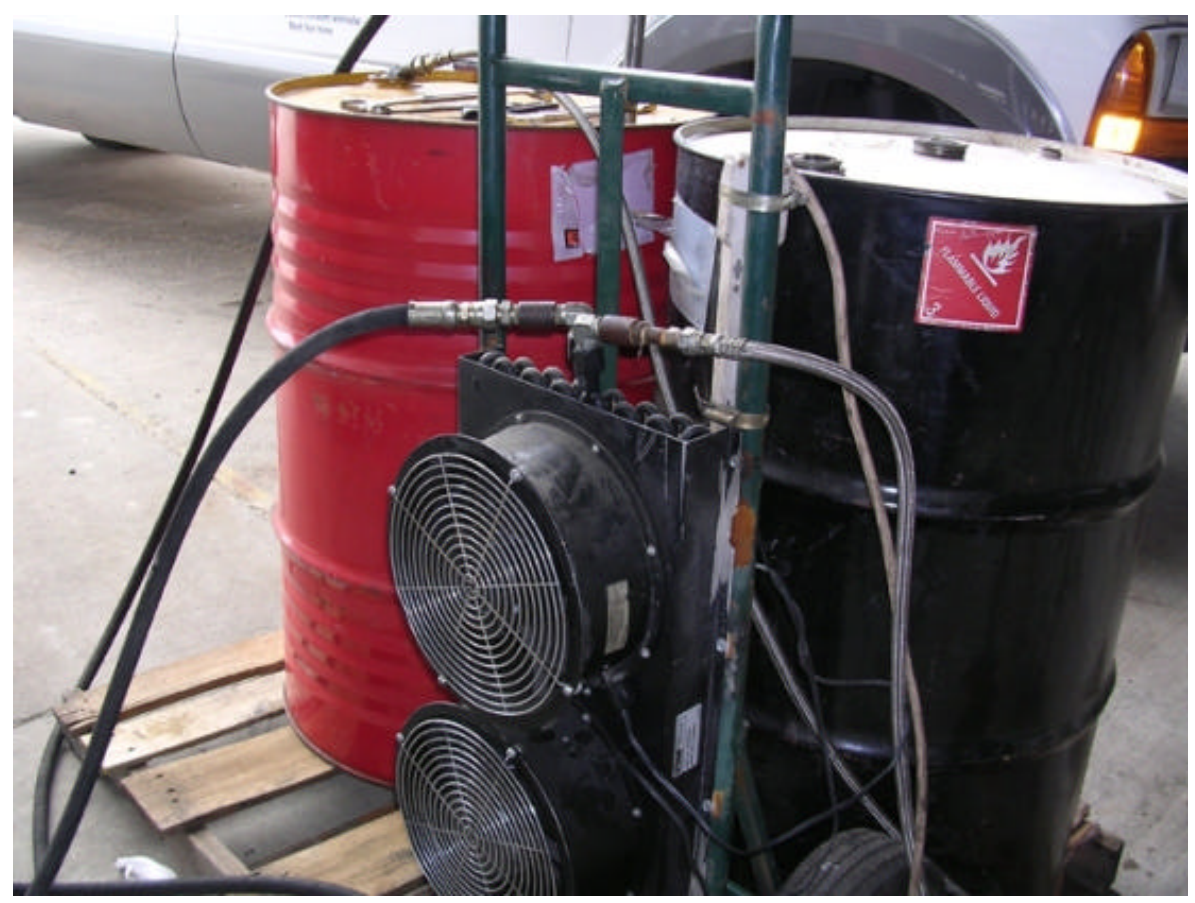

Figure 4: WMATA fuel conditioning system.

\subsection{RESULTS AND DISCUSSION}

The work performed for the conclusion of this project was divided into two phases. In phase 3, Six WMATA buses were tested in Washington DC on Syntroleum S-2 and ULSD fuels. In phase four, the final phase, three out of the six WMATA buses were re-tested to evaluate the performance and emissions after the vehicles had been operating on Syntroleum S-2 fuel for a period of at least six months. The results of the final two emissions measurement campaigns are discussed in following sections.

\subsection{Phase 3-WMATA Municipal Transit Buses}

In August 2004, the WVU Transportable Heavy-Duty Vehicle Emissions Laboratory returned to Washington DC to measure the emissions of six transit buses equipped with oxidation catalysts. Three buses fueled with Syntroleum S-2 fuel and three buses fueled with WMATA's conventional ultra-low sulfur (30 ppm S max.) were tested.

\subsubsection{Test Vehicle Information}

The test vehicles were 2000 model year Orion 40 -foot municipal transit buses each equipped with a 2000 model year Detroit Diesel Corporation (DDC) Series 50 diesel engines. The buses were owned 
by the WMATA and were operated in municipal transit service in the Washington D.C., Northern Virginia and Southern Maryland area. The transit buses had gross vehicle weight ratings of 42,540 lbs and an unloaded curb weight of $27,800 \mathrm{lbs}$. They could accommodate 39 seated passengers and 20 standing passengers. The bus emissions were characterized at a simulated weight of $33,300 \mathrm{lbs}$ representing approximately one-half of the maximum passenger capacity. The buses were equipped with original equipment (OEM) diesel oxidation catalysts (DOC). Table 2 summarizes the test vehicle information.

Table 2: Phase 3 Test Vehicle Information

\begin{tabular}{|c|c|c|c|c|}
\hline \multicolumn{5}{|c|}{ WMATA Transit Bus Specifications } \\
\hline Chassis & \multirow{2}{*}{\multicolumn{4}{|c|}{$\begin{array}{c}\text { MY } 2000 \text { Orion } \\
\text { MY 20009 Detroit Diesel Cornoration Series 50 }\end{array}$}} \\
\hline Engine Manufacturer/Model & & & & \\
\hline Engine Ratings & \multicolumn{4}{|c|}{$275 \mathrm{hp} @ 2100 \mathrm{rpm}$} \\
\hline After-treatment System & \multicolumn{4}{|c|}{ Diesel Oxidation Catalyst } \\
\hline Transmission Type & \multicolumn{4}{|c|}{ 4-speed Automatic } \\
\hline GVWR/Curb Weight & \multicolumn{4}{|c|}{$42,540 / 28,800 \mathrm{lb}$} \\
\hline Bus Number & VIN & $\begin{array}{l}\text { Engine Serial } \\
\text { Number }\end{array}$ & Odometer Reading & Fuel Type \\
\hline 2093 & 1VH6H2A25Y6600332 & $04 R 0032003$ & 181,688 & ULSD1 \\
\hline 2092 & 1VH6H2A23Y6600331 & 04R0032000 & 207,038 & ULSD1 \\
\hline 2094 & 1VH6H2A27Y6600333 & $04 \mathrm{R} 0032183$ & 194,125 & ULSD1 \\
\hline 2054 & 1VH6H2A28Y6600292 & 04R0031458 & 216,793 & SYNTRO \\
\hline 2056 & 1VH6H2A21Y6600294 & $04 \mathrm{R} 0031395$ & 197,420 & SYNTRO \\
\hline 2055 & 1VH6H2A2XY6600293 & 04R0031626 & 202,369 & SYNTRO \\
\hline
\end{tabular}

\subsubsection{Oxides of Nitrogen Emissions}

Measured $\mathrm{NO}_{x}$ emissions are plotted in Figure 5. Each bar represents the average of at least three separate repeat test runs and the error bars indicate the spread of the data by showing the maximum and minimum individual test results. Measured $\mathrm{NO}_{x}$ emissions, from the buses fueled with Syntroleum S-2 fuel were reduced by 22 percent compared to the control vehicles fueled with petroleum-derived ULSD1. The ratio of $\mathrm{NO}$ to $\mathrm{NO}_{x}$ emissions was determined using a dual $\mathrm{NO}_{x}$ analyzer method. The method employs two unique analyzers, one operated in the NOx mode, while the other analyzer operates in the NO mode. The technique and limitations have been previously described [9]. In Figure 5, the cross-hatched bar represents the NO fraction of the NOx emission. Oxides of nitrogen emission from a diesel engine's diesel oxidation catalyst may include $3 \%$ to $15 \%$ $\mathrm{NO}_{2}$ depending on engine design and operating conditions and are typically $3 \%$ to $5 \%$ averaged over a transient test cycle. The $\mathrm{NO}_{x}$ was generally comprised of $93 \%-97 \% \mathrm{NO}$ and the $\mathrm{NO} / \mathrm{NO}_{x}$ ratio was not generally affected by the fuel. 


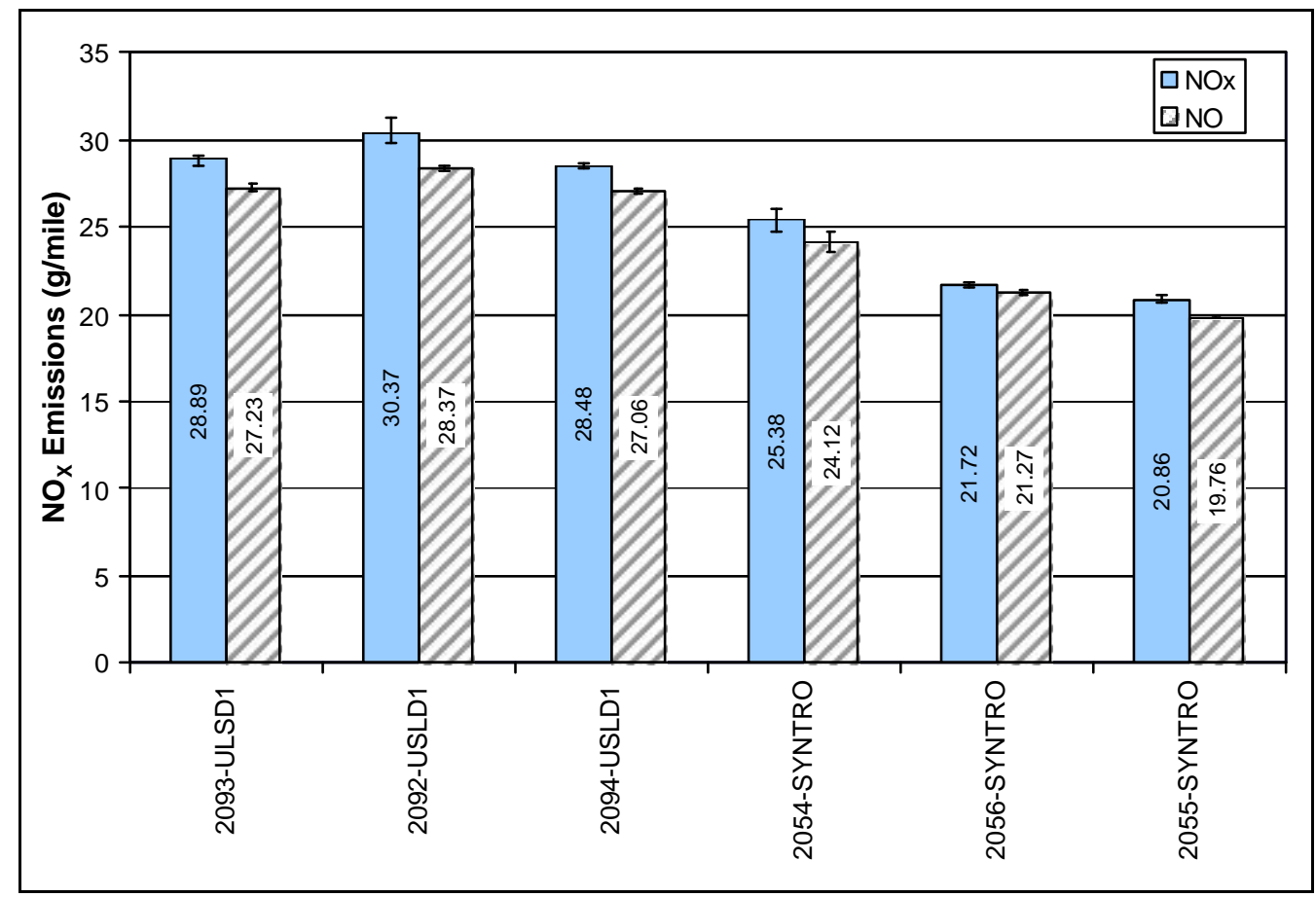

Figure 5: Phase 3 oxides of nitrogen emissions.

\subsubsection{Particulate Matter Emissions}

Particulate matter emissions are plotted in Figure 6. PM emissions exhibited considerable vehicle-tovehicle variation. PM emissions from the ULSD1 group ranged from 0.178 to $0.399 \mathrm{~g} / \mathrm{mile}$ with an average of $0.276 \mathrm{~g} / \mathrm{mile}$. The Syntroleum S-2 group ranged from 0.180 to $0.339 \mathrm{~g} / \mathrm{mile}$ with a group average of $0.287 \mathrm{~g} / \mathrm{mile}$. There was no statistically significant difference between the two groups. While the Syntroleum S-2 is lower in sulfur and aromatic content than the ultra-low sulfur conventional diesel fuel, these are both low-emissions fuels compared to conventional No. 1 diesel fuel which typically has a sulfur level of $\sim 400 \mathrm{ppm}$. It was recognized that it would be difficult to distinguish PM emissions differences between the two fuels considering vehicle-to-vehicle variations and the fact that the test vehicles were equipped with diesel oxidation catalysts.

It is also noted that the baseline fuel was a No. 1 diesel fuel which would be expected to have lower weight PM than a No.2 diesel fuel all else being equal. The Syntroleum S-2 fuel fell somewhere between No. 1 and No. 2 diesel fuel having a broader distillation range $\left(321^{\circ} \mathrm{F}-619^{\circ} \mathrm{F}\right)$ and higher final boiling point (FBP) than the ultra-low sulfur No. 1 fuel $\left(354^{\circ} \mathrm{F}-527^{\circ} \mathrm{F}\right)$. For comparison, a conventional Federal No. 2 diesel fuel recently used by WVU in another program had a distillation range of $359^{\circ} \mathrm{F}-$ $654^{\circ} \mathrm{F}$. All else being equal the Syntroleum S-2 fuel with a higher T90 and FBP would be expected to have slightly higher weight PM than the baseline No. 1 diesel fuel.

Fuel sulfur is converted to $\mathrm{SO}_{2}$ and sulfates which, along with bound water manifest themselves as $\mathrm{PM}$ emissions. There is generally a linear relationship between fuel sulfur consumption and the sulfate portion of PM emissions with a conversion rate of between 1 to 2 percent for engines without aftertreatment. The contribution of sulphates to the total particulate mass is only a few percent so that the reduction of PM through reduction of fuel sulfur content is limited. However, the high precious metal and platinum loading in passive catalyzed particulate filters such as the Engelhard DPX or Johnson-Matthey CRT substantially increase the formation of sulfates. It is important to note that the near zero sulfur content of Syntroleum S-2 GTL fuel may offer a marginal advantage over ultra-low sulfur petroleum-derived diesel for vehicles equipped with catalyzed particulate filters. 


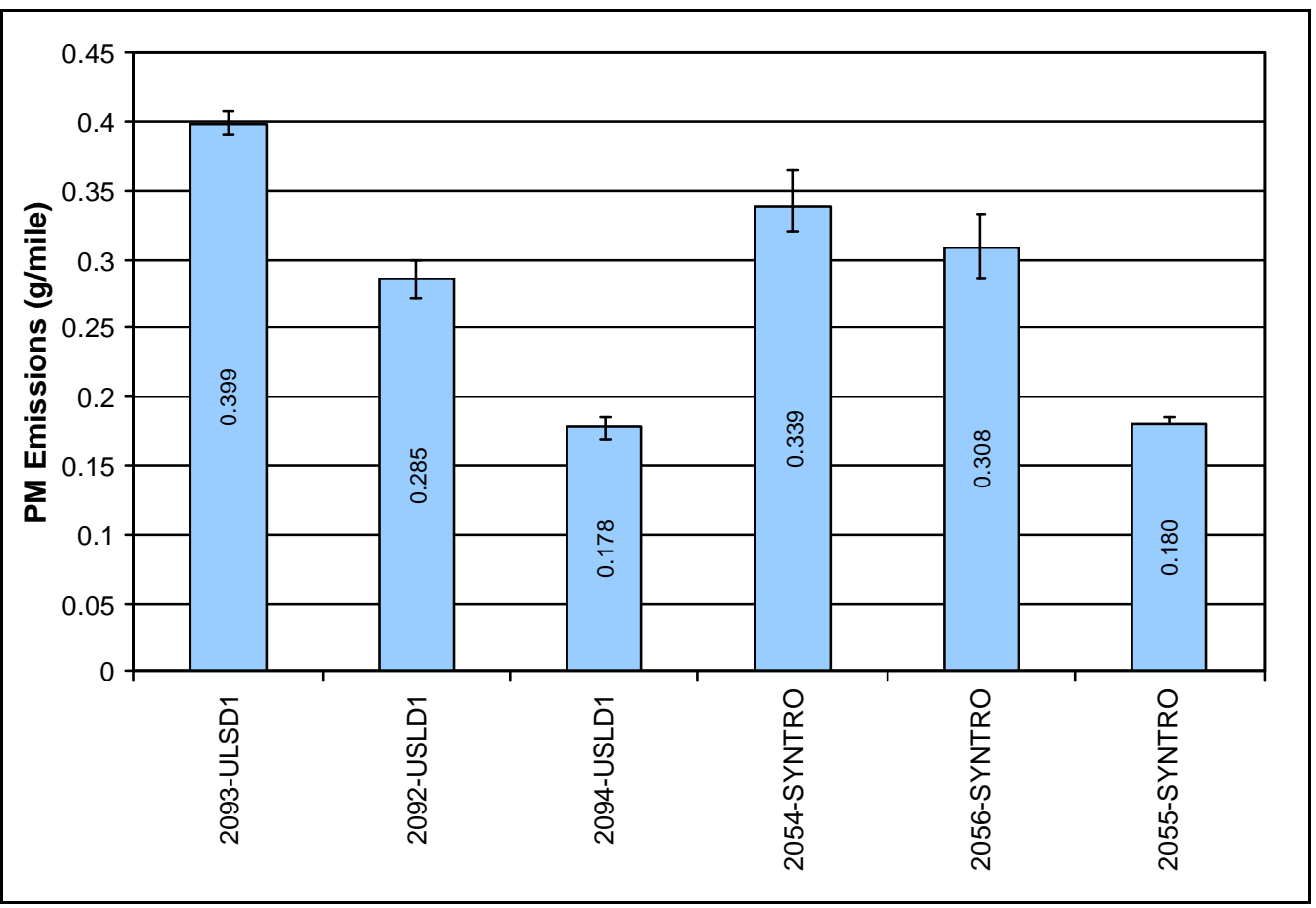

Figure 6: Phase 3 particulate matter emissions.

\subsubsection{Hydrocarbon and Carbon Monoxide Emissions}

Hydrocarbon results are plotted in Figure 7. Hydrocarbon levels from both groups of buses were very low as would generally be expected from vehicles equipped with oxidation catalysts. HC emissions from the ULSD1 fueled buses ranged from $0.02-0.23 \mathrm{~g} / \mathrm{mile}$ with a group average of $0.11 \mathrm{~g} / \mathrm{mile}$. The Syntroleum S-2 fueled buses produced HC emissions ranging from 0.06-0.24 g/mile with a group average of $0.15 \mathrm{~g} / \mathrm{mile}$. Given the data scatter there appeared to be no significant difference between the two fuels in terms of $\mathrm{HC}$ emissions. $\mathrm{HC}$ measurement at these extremely low levels was difficult because an ambient $\mathrm{HC}$ concentration which was near the engine-out levels, could have confounded the measurement.

Carbon monoxide emissions are shown in Figure 8. The ULSD1 fueled buses averaged $4.04 \mathrm{~g} / \mathrm{mile}$ CO over the WMATA test cycle while the Syntroleum S-2 fueled buses averaged $3.95 \mathrm{~g} / \mathrm{mile}$. The results exhibited some vehicle-to-vehicle variability in both groups. However, there appeared to be little difference in $\mathrm{CO}$ emissions between the two fuels. 


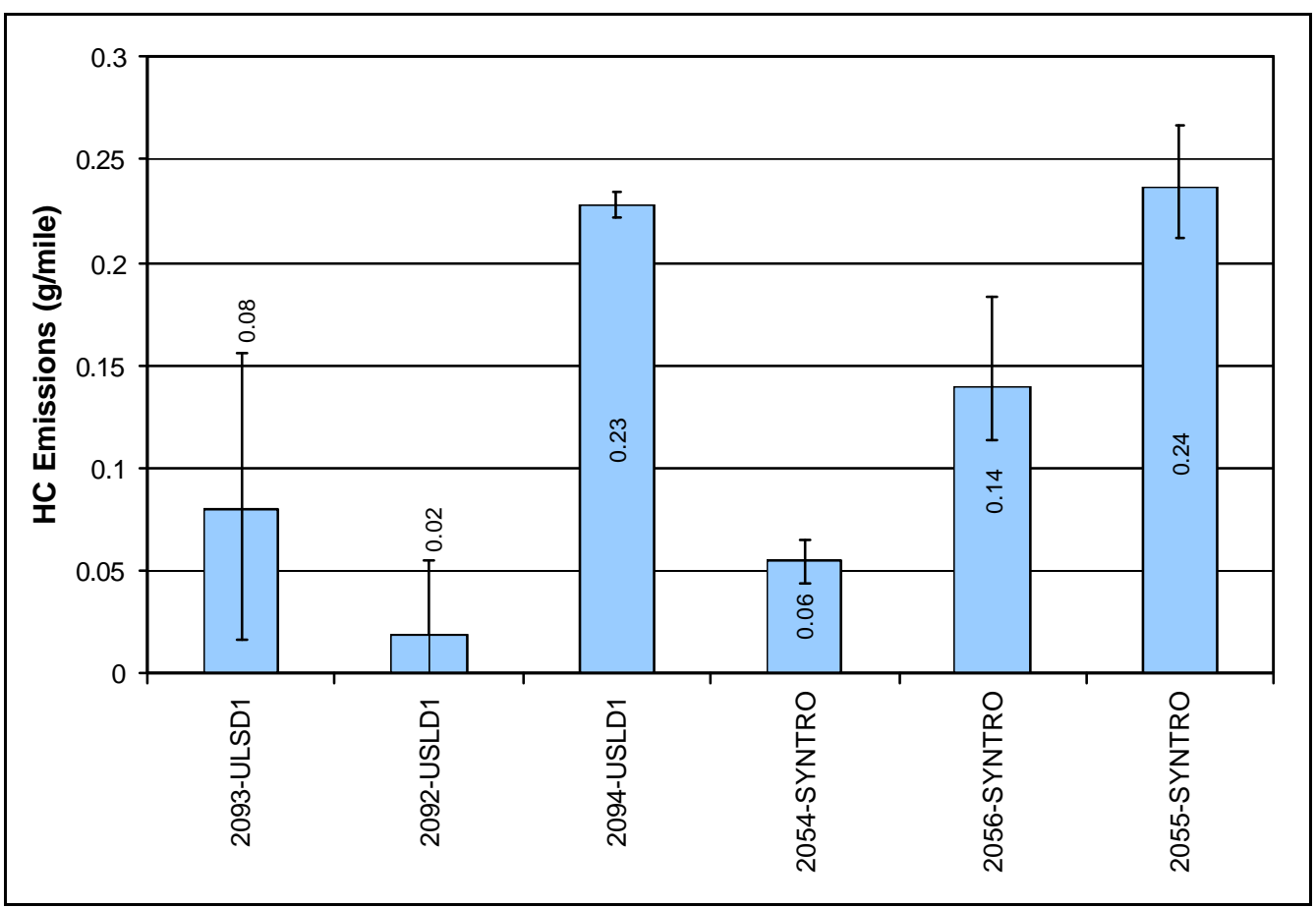

Figure 7: Phase 3 hydrocarbon emissions.

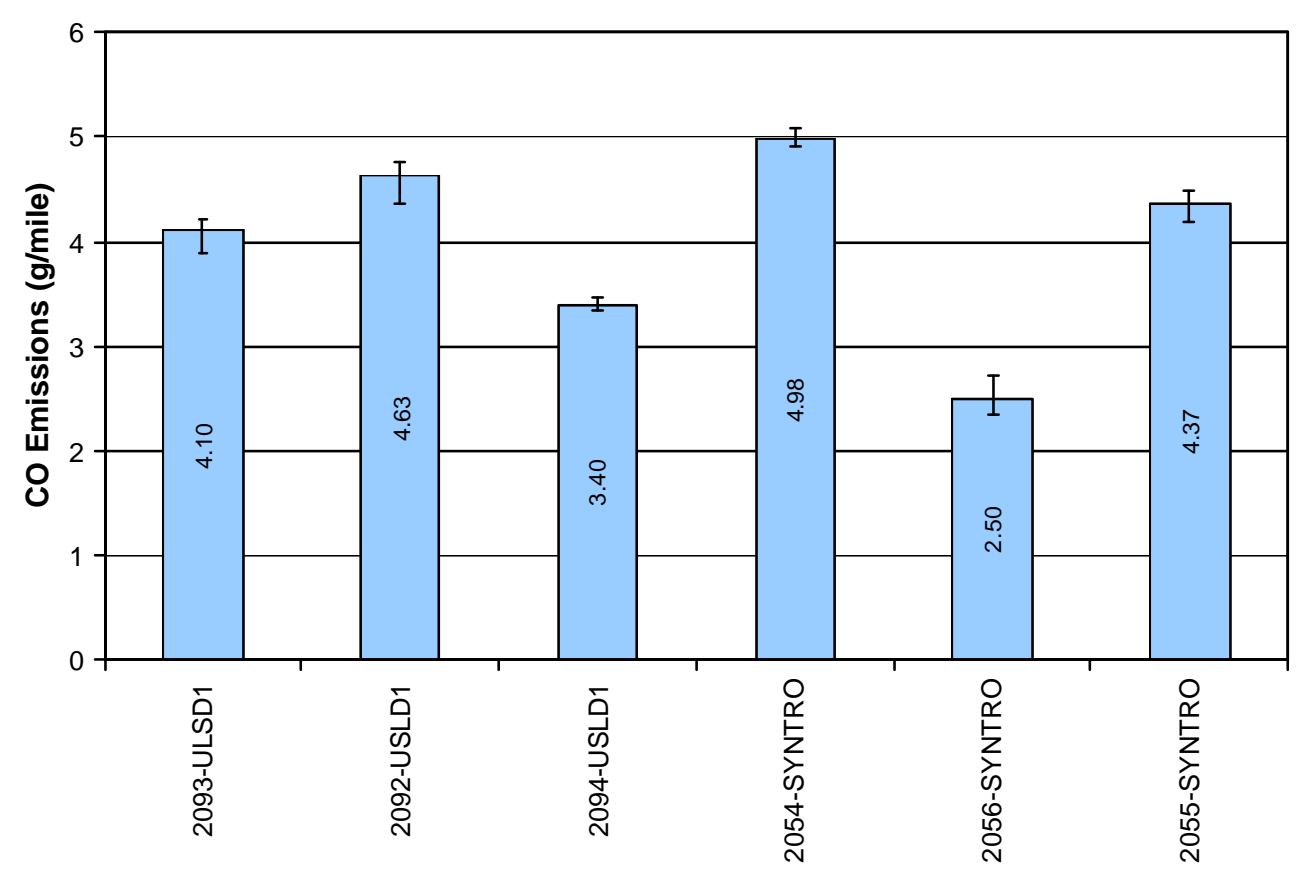

Figure 8: Phase 3 carbon monoxide (CO) emissions.

\subsubsection{Carbon Dioxide and Fuel Economy Results}

Carbon dioxide emissions are shown in Figure 9_and fuel economy results are shown in Figure 10. $\mathrm{CO}_{2}$ emissions from the USLD1 group averaged $2809 \mathrm{~g} / \mathrm{mile}$ ranging from 2612-2923. The Syntroleum S-2 fueled buses averaged $2736 \mathrm{~g} / \mathrm{mile}$ of $\mathrm{CO}_{2}$ ranging from 2612-2977 $\mathrm{g} / \mathrm{mile}$ representing a difference of less than $3 \%$ between the two groups. Fuel economy was also similar 
between the two fuels with the USLD1 group averaging 3.44 miles/gallon and the Syntroleum S-2 group averaging 3.38 miles/gallon.

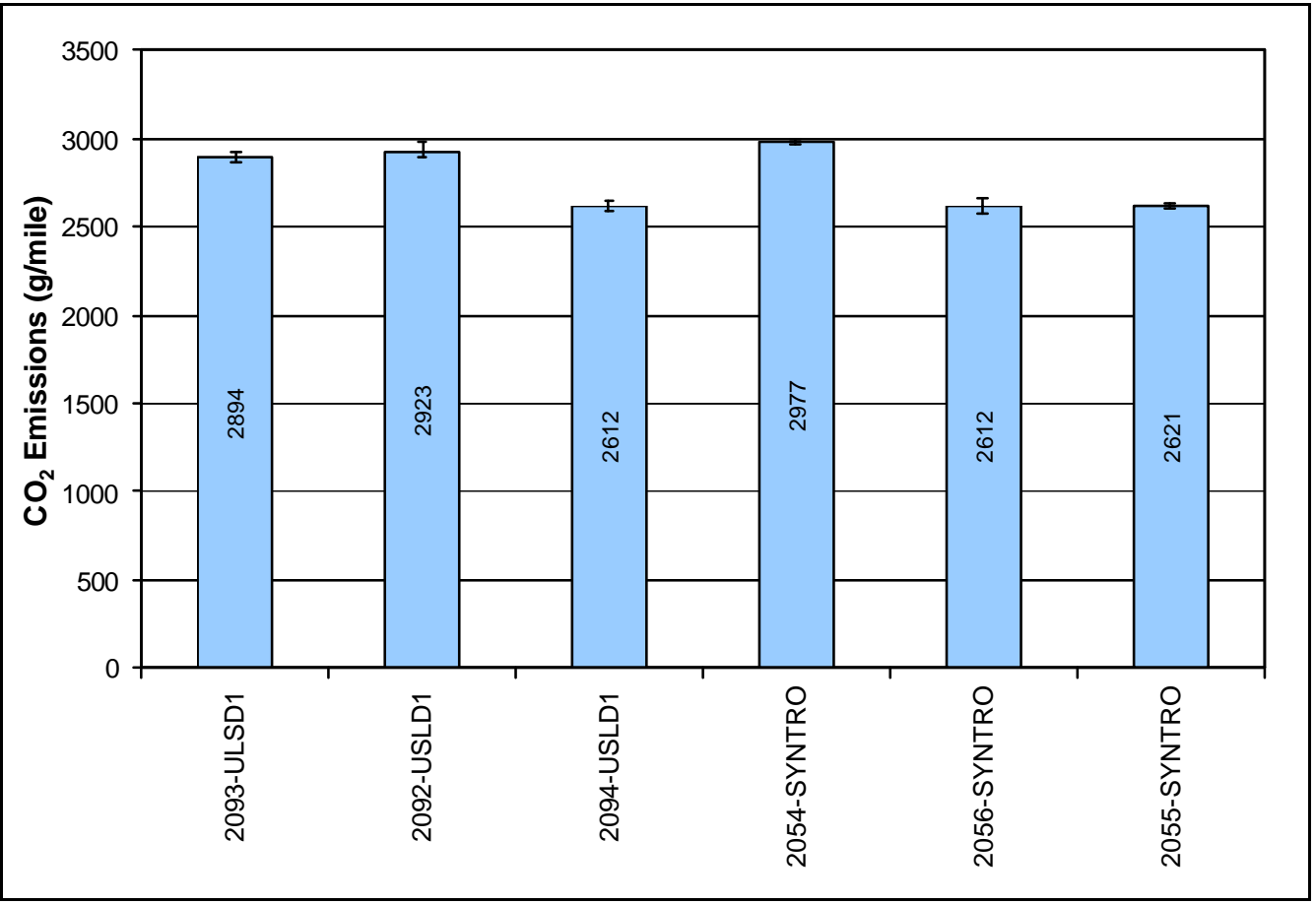

Figure 9: Carbon dioxide emissions.

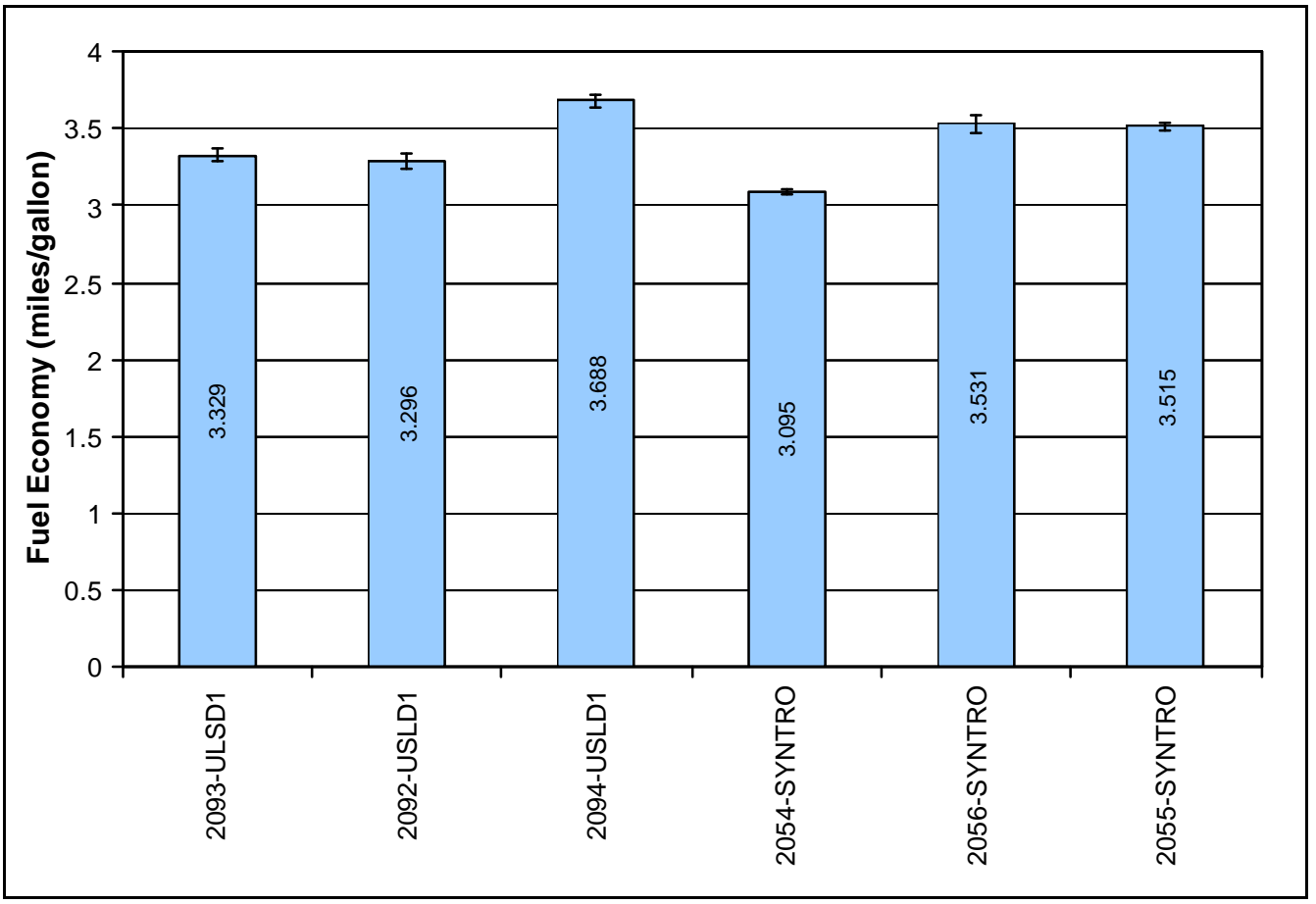

Figure 10: Fuel economy.

\subsubsection{Summary of Phase 3 Results}

Emissions tests were conducted on six 40-foot transit buses equipped with 2000 MY DDC Series 50 engines and diesel oxidation catalysts. Three buses were fueled with petroleum-derived ultra-low sulfur type 1 diesel fuel and three were fueled with Syntroleum S-2 fuel. 
- Measured $\mathrm{NO}_{x}$ emissions, from the buses fueled with Syntroleum S-2 fuel were reduced by 22 percent compared to the control vehicles fueled with petroleum-derived ultra-low sulfur type 1 diesel fuel due to the low aromatic content and high cetane number.

- No significant differences were observed between the two fuels in terms of PM, HC and CO emissions. This similarity may be due in part to the fact that both groups of buses were equipped with diesel oxidation catalysts and that any differences in engine-out emissions may have been obscured by the catalytic action of the oxidation catalysts.

- Carbon dioxide and fuel economy results were also very similar between the two fuels.

\subsection{Phase 4-6-Month Retest of WMATA Municipal Transit Buses}

The final phase of emissions testing re-examined the Syntroleum-fueled WMATA buses after they had been operating in normal revenue service on the S-2 fuel for at least 6-months. WVU conducted the follow-up testing at WMATA in April 2005. The approach to the second round of testing at WMATA differed somewhat from the testing conducted in August 2004 as explained below.

Determination of whether or not Fischer-Tropsch (F-T) fuel would be acceptable for operating bus fleets was one of the questions that the Ultra-Clean Fuels Project was intended to answer. Therefore, the use of three "control" buses running on conventional fuel during the bus fleet demonstrations of F-T fuel in three "test" buses in each fleet, provided a valuable reference in the event of any operating difficulties that could, potentially, have occurred with the then "new and unproven" F-T fuel. The approach to exhaust emission testing within the two bus-fleet demonstrations as spelled out in the original cooperative agreement between ICRC and NETL was to compare emissions from three F-T fueled buses to three similar "control" buses using their normal conventional fuel. This approach to emission measurements flowed rather naturally from the program's overall approach. The approach worked fairly well within the Denali National Park bus fleet, because all six buses were brand new and thus they exhibited relatively little bus-to-bus variation in emissions (within the two fuel-groups), allowing a reasonable comparison of the effects of the two fuels on emissions despite the additional variable of buses or engines.

However, in the WMATA fleet, the buses have been in year-round, heavy -use urban transit service for four to five years. The first-round emission test results at WMATA showed significant bus-to-bus variability within both groups (of 3 buses on each fuel) that may have obscured the fuel effects that are of primary interest. Therefore, for the second round of emission measurements at WMATA, ICRC and WVU determined that the comparison should be back-to-back emission tests on both F-T and conventional fuels in the three buses that have been operating on $\mathrm{F}-\mathrm{T}$ fuel for the past six months of the demonstration program, with no further emission testing of the 3 "control" buses.

\subsubsection{Test Vehicle Information}

The WMATA test buses have previously been described in Section 4.1.1. The intention was to re-test the three WMATA buses that had been operateing on the Syntroleum S-2 fuel (WMATA Bus Numbers 2054, 2055, 2056) on both the Syntroleum S-2 fuel and the ULSD1 fuel. However, Bus 2056 experienced a mechanical engine failure and could not be tested in Phase 4. Following consultation with ICRC, WVU tested Bus 2093 as a replacement for Bus 2056. Bus 2093 was one of the ULSD1 control buses tested in Phase 3. Table 3 summarizes the transit buses specifications. 
Table 3: Phase 4 Test Vehicle Information

\begin{tabular}{|c|c|c|c|}
\hline \multicolumn{4}{|c|}{ WMATA Transit Bus Specifications } \\
\hline Chassis & \multicolumn{3}{|c|}{ MY 2000 Orion } \\
\hline Engine Manufacturer/Model & \multicolumn{3}{|c|}{ MY 20009 Detroit Diesel Corporation Series 50} \\
\hline Engine Ratings & \multicolumn{3}{|c|}{ 275hp @ 2100rpm } \\
\hline After-treatment System & \multicolumn{3}{|c|}{ Diesel Oxidation Catalyst } \\
\hline Transmission Type & \multicolumn{3}{|c|}{ 4-speed Automatic } \\
\hline GVWR/Curb Weight & \multicolumn{3}{|c|}{$42,540 / 28,800 \mathrm{lb}$} \\
\hline Bus Number & VIN & Engine Serial Number & Odometer Reading \\
\hline 2054 & 1VH6H2A28Y6600292 & $04 \mathrm{R} 0031458$ & 252,652 \\
\hline 2055 & 1VH6H2A2XY6600293 & 04R0031626 & 236,676 \\
\hline 2093 & 1VH6H2A25Y6600332 & 04R0032003 & 216,937 \\
\hline
\end{tabular}

\subsubsection{Oxides of Nitrogen Emissions}

$\mathrm{NO}_{x}$ emissions results are plotted in Figure 11. In Phase 4, measured $\mathrm{NO}_{\mathrm{x}}$ emissions from Syntroleum S-2 fuel were reduced by 16 percent when compared to petroleum-derived ULSD1 fuel. The cross-hatched bar in Figure 11 represents the $\mathrm{NO}$ fraction of the $\mathrm{NO}_{x}$ emissions. On average, the $\mathrm{NO}_{x}$ emissions were comprised of 97 percent $\mathrm{NO}$. This agreed with typical $\mathrm{NO}$ fractions in $\mathrm{NO}_{\mathrm{x}}$ emissions for diesel oxidation equipped diesel vehicles, which are usually 93-97 percent NO. The ratio of $\mathrm{NO} / \mathrm{NO}_{x}$ was not affected by the fuel type.

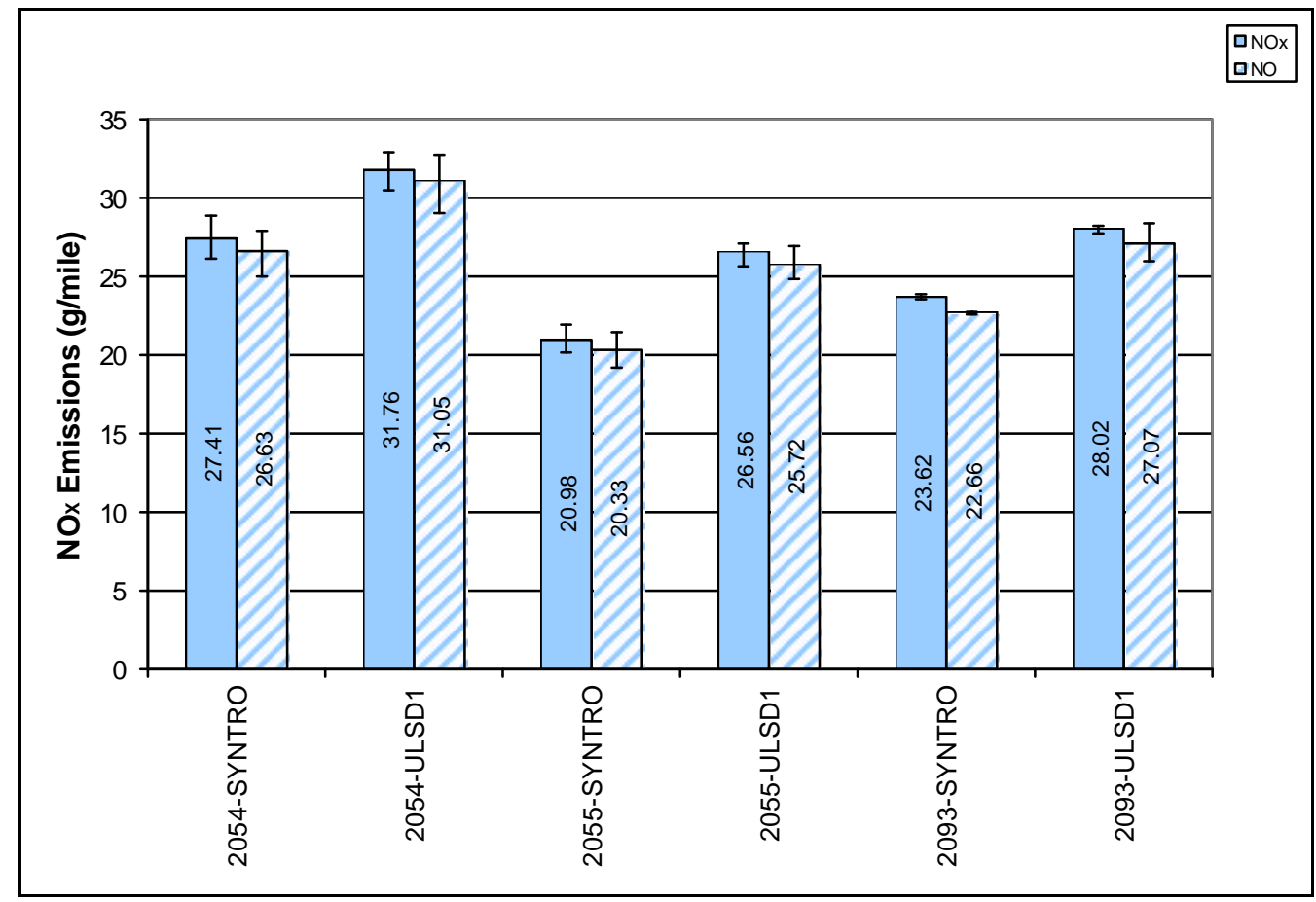

Figure 11: Phase 4 oxides of nitrogen emissions.

A comparison of measured $\mathrm{NO}_{x}$ emissions from Phase 3 and Phase 4 is shown in Figure 12. Bus number $2054 \mathrm{NO}_{x}$ emissions from Syntroleum S-2 fuel were increased by 7 percent after the 6-month period. NOx emissions from bus number 2055 fueled with Syntroleum S-2 fuel were increased as well, however the $\mathrm{NO}_{x}$ emissions difference was less than 1 percent. In Phase 3 bus numbers 2054 and 2055 were originally tested using Syntroleum S-2 fuel. In Phase 4 these two buses were tested with both ULSD1 and Syntroleum S-2 fuels. Bus number 2093 was chosen to replace bus number 2056 and it was tested with both fuels as well. ULSD1 fuel emissions from bus number 2093 were reduced by 3 percent when compared to the original results obtained in Phase 3 . In regard to the two fuels comparison, Syntroleum S-2 fuel $\mathrm{NO}_{x}$ emissions were reduced by about 17 percent compared to ULSD1 over the baseline fuel. 


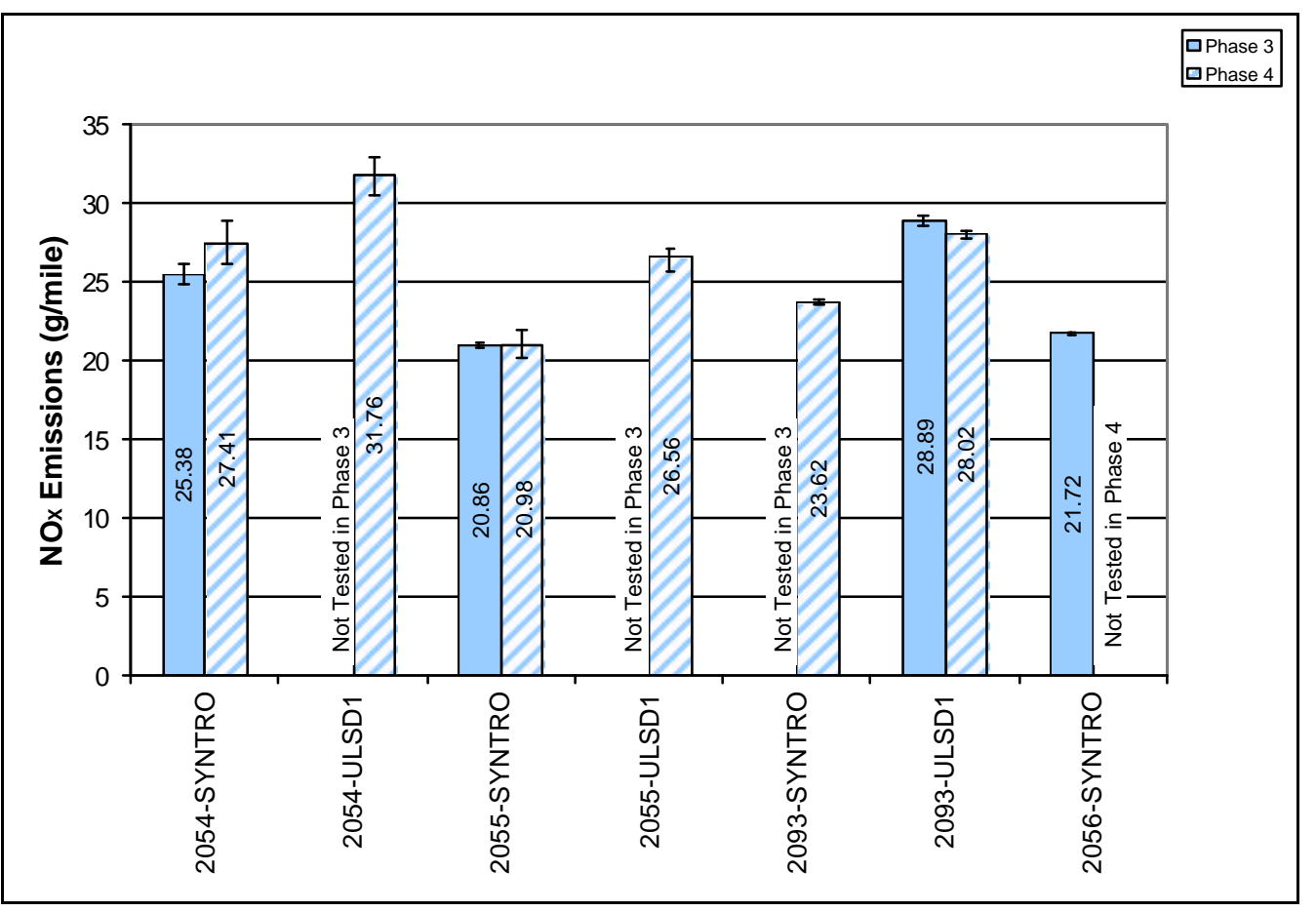

Figure 12: Phase $3 \& 4$ oxides of nitrogen emissions.

\subsubsection{Particulate Matter Emissions}

In Phase 4 the PM emissions levels produced by Syntroleum S-2 fuel were lower, on average, by 35 percent compared to ULSD1 fuel PM emissions. These results are represented by the cross-hatched bars in Figure 13. ULSD1 fuel PM emissions ranged from 0.188 to $0.334 \mathrm{~g} / \mathrm{mile}$ with an average of $0.245 \mathrm{~g} / \mathrm{mile}$. The Syntroleum S-2 fuel PM emissions ranged from 0.120 to $0.203 \mathrm{~g} / \mathrm{mile}$ with an average of $0.158 \mathrm{~g} / \mathrm{mile}$.

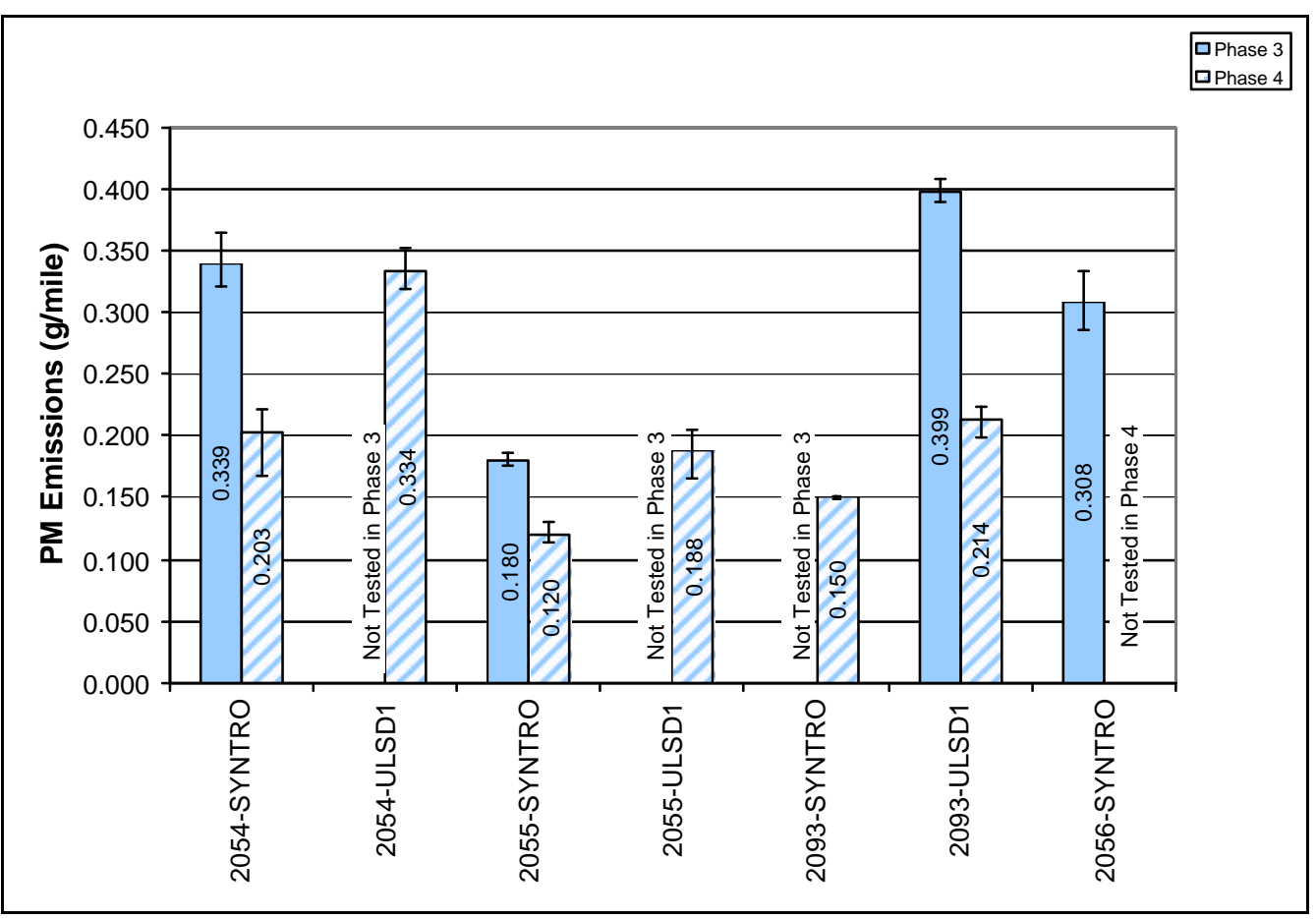

Figure 13: Phase $3 \& 4$ particulate matter emissions. 
PM emissions over Phases $3 \& 4$ exhibited considerable phase-to-phase variability. In Phase 3 bus number 2054 produced $0.339 \mathrm{~g} / \mathrm{mile}$ of $P M$ emissions compared to $0.203 \mathrm{~g} / \mathrm{mile}$ in Phase 4 when fueled with Syntroleum S-2 fuel. Bus 2093, fueled with ULSD1 also showed substantially lower PM emissions in Phase 4 than in Phase 3. Both Syntroleum S-2 fuel and ULSD1 fuel are both lowemissions fuels compared to conventional No.1 diesel fuel.

\subsubsection{Hydrocarbon and Carbon Monoxide Emissions}

Figure 14 shows the hydrocarbon emissions results. Phase $4 \mathrm{HC}$ emissions from Syntroleum S-2 fuel were reduced by 30 percent when compared to ULSD1 fuel emissions. The Syntroleum S-2 fuel $\mathrm{HC}$ emissions ranged from 0.25 to $0.3 \mathrm{~g} / \mathrm{mile}$ with an average of $0.28 \mathrm{~g} / \mathrm{mile}$. HC emissions produced from ULSD1 fuel ranged from 0.33 to $0.45 \mathrm{~g} / \mathrm{mile}$ with an average of $0.4 \mathrm{~g} / \mathrm{mile}$. Since each bus was tested with both fuels in subsequent order it was evident that Syntroleum S-2 fuel possessed an appreciative advantage over ULSD1 fuel.

Carbon monoxide emissions are plotted in Figure 15. In Phase 4 the $\mathrm{CO}$ emission from the Syntroleum S-2 fueled buses were reduced by 24 percent compared to emissions produced by ULSD1 fuel. The CO emissions produced by Syntroleum S-2 fuel ranged fom 2.46 to $3.85 \mathrm{~g} / \mathrm{mile}$ with an average of $2.99 \mathrm{~g} / \mathrm{mile}$. ULSD1 fuel produced CO emissions in the range of 2.95 to 5.22 $\mathrm{g} / \mathrm{mile}$ with an average of $3.94 \mathrm{~g} / \mathrm{mile}$. By combining the results of Phases 3 and 4 it was observed that the data exhibited vehicle-to-vehicle variation, however, there appeared to be no significant difference in $\mathrm{CO}$ emissions between the two fuels.

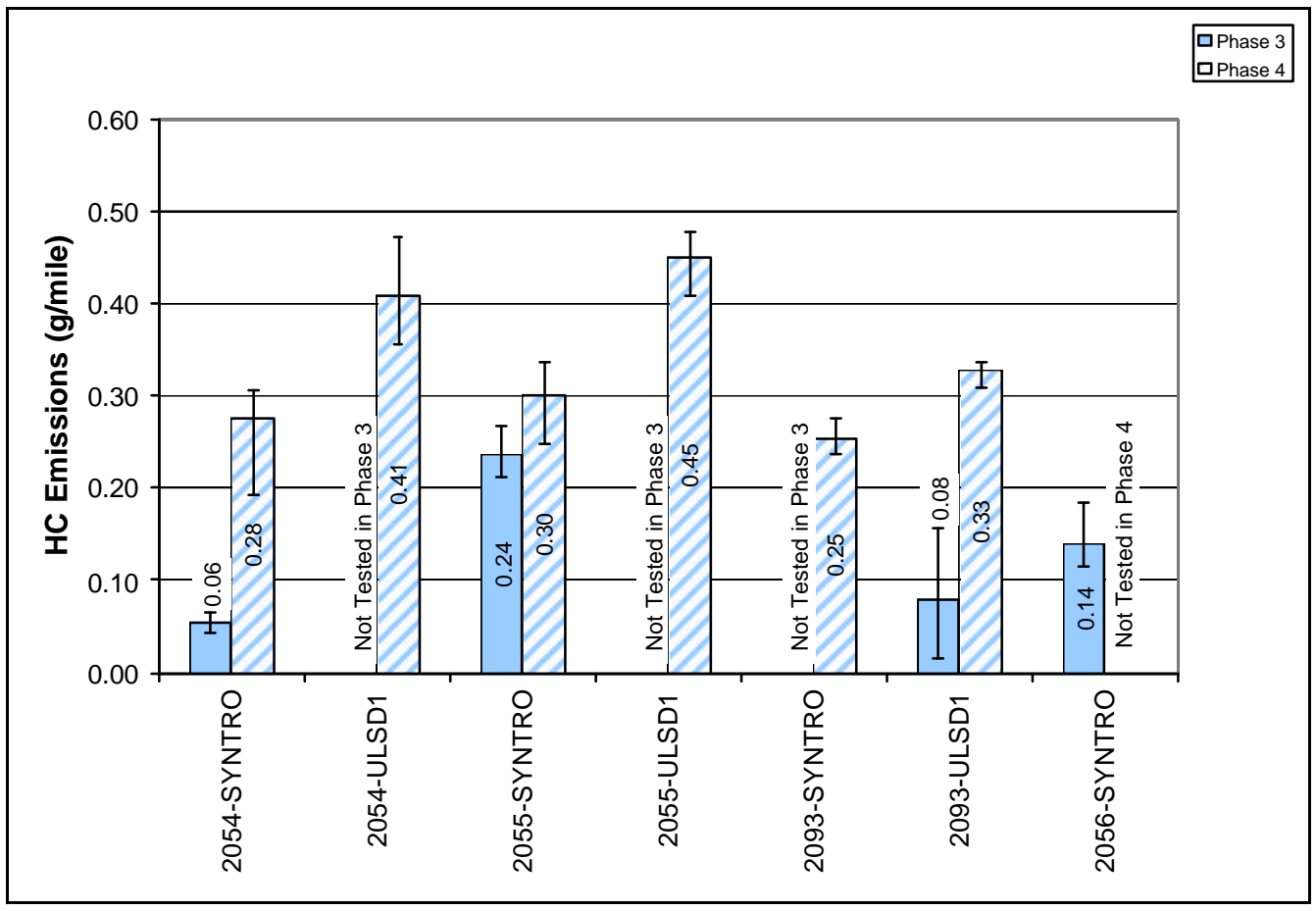

Figure 14: Phase $3 \& 4$ hydrocarbon emissions. 


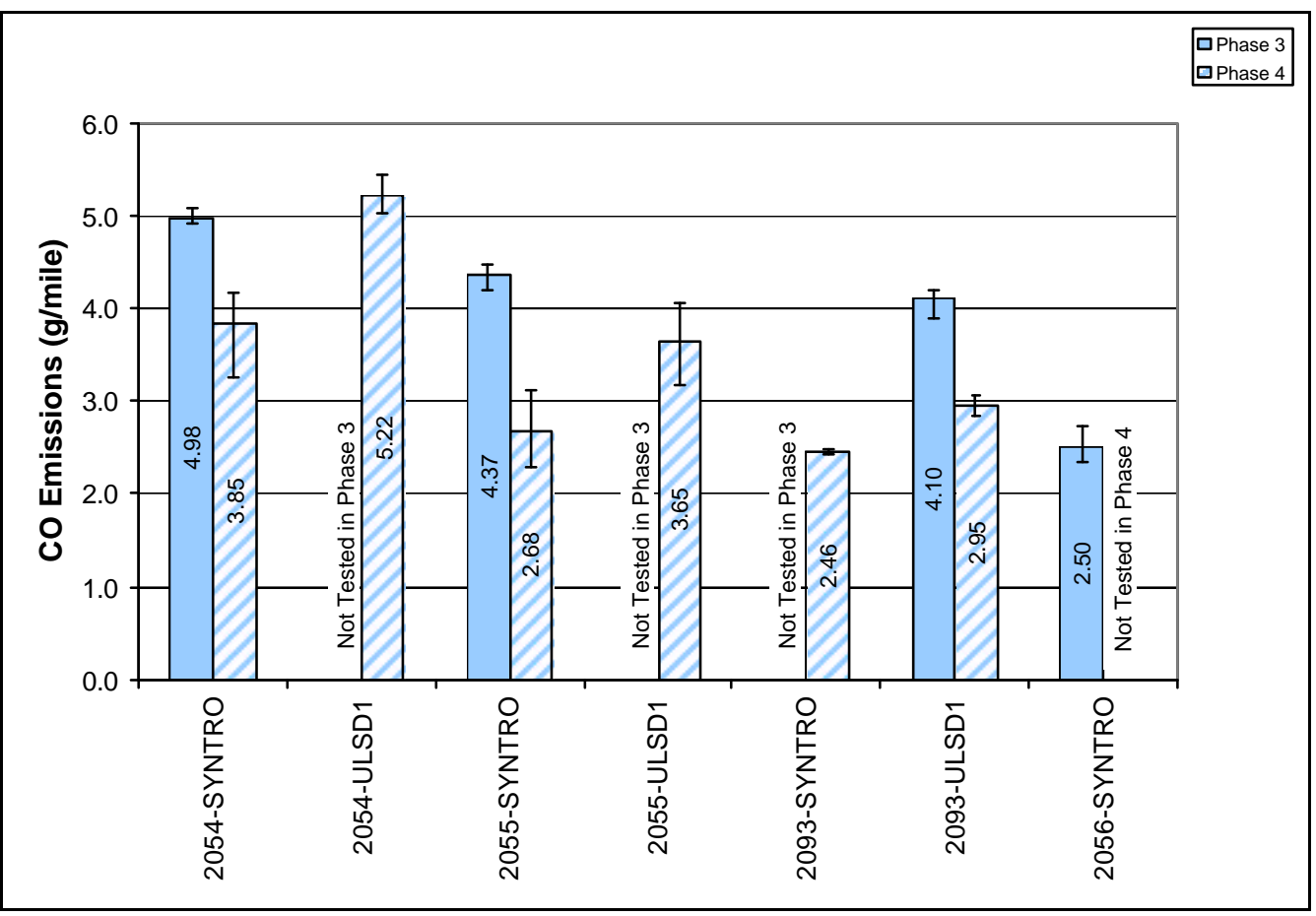

Figure 15: Phase 3 \& 4 carbon monoxide emissions.

\subsubsection{Carbon Dioxide and Fuel Economy Results}

Carbon dioxide emissions are plotted in Figure 16 and fuel economy results are shown in Figure 17. $\mathrm{CO}_{2}$ emissions from the Syntroleum S-2 fuel were reduced by about 4 percent compared to emissions produced by ULSD1 fuel. The range of $\mathrm{CO}_{2}$ emissions produced by Syntroleum S-2 fuel was 2591 to $3361 \mathrm{~g} / \mathrm{mile}$ with an average of $2887 \mathrm{~g} / \mathrm{mile}$. ULSD1 fuel $\mathrm{CO}_{2}$ emissions ranged from 2795 to $3439 \mathrm{~g} / \mathrm{mile}$ with an average of $3012 \mathrm{~g} / \mathrm{mile}$. The fuel economy was similar for both types of fuels with the Syntroleum S-2 fuel averaging $3.31 \mathrm{miles} / \mathrm{gallon}$ and the ULSD1 fuel averaging 3.27 miles/gallon representing a difference of about 1 percent. 


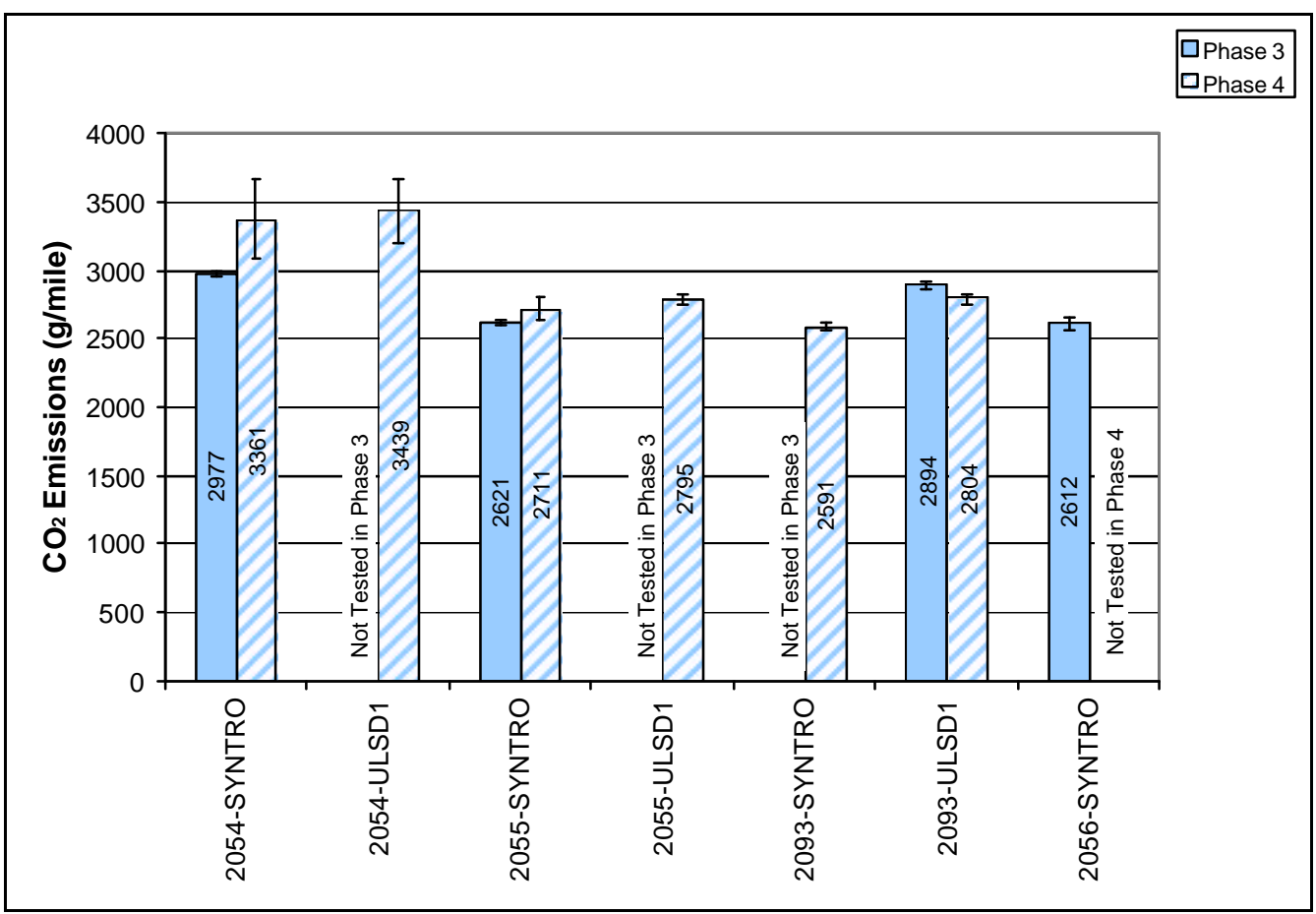

Figure 16: Phase 3 \& 4 carbon dioxide emissions.

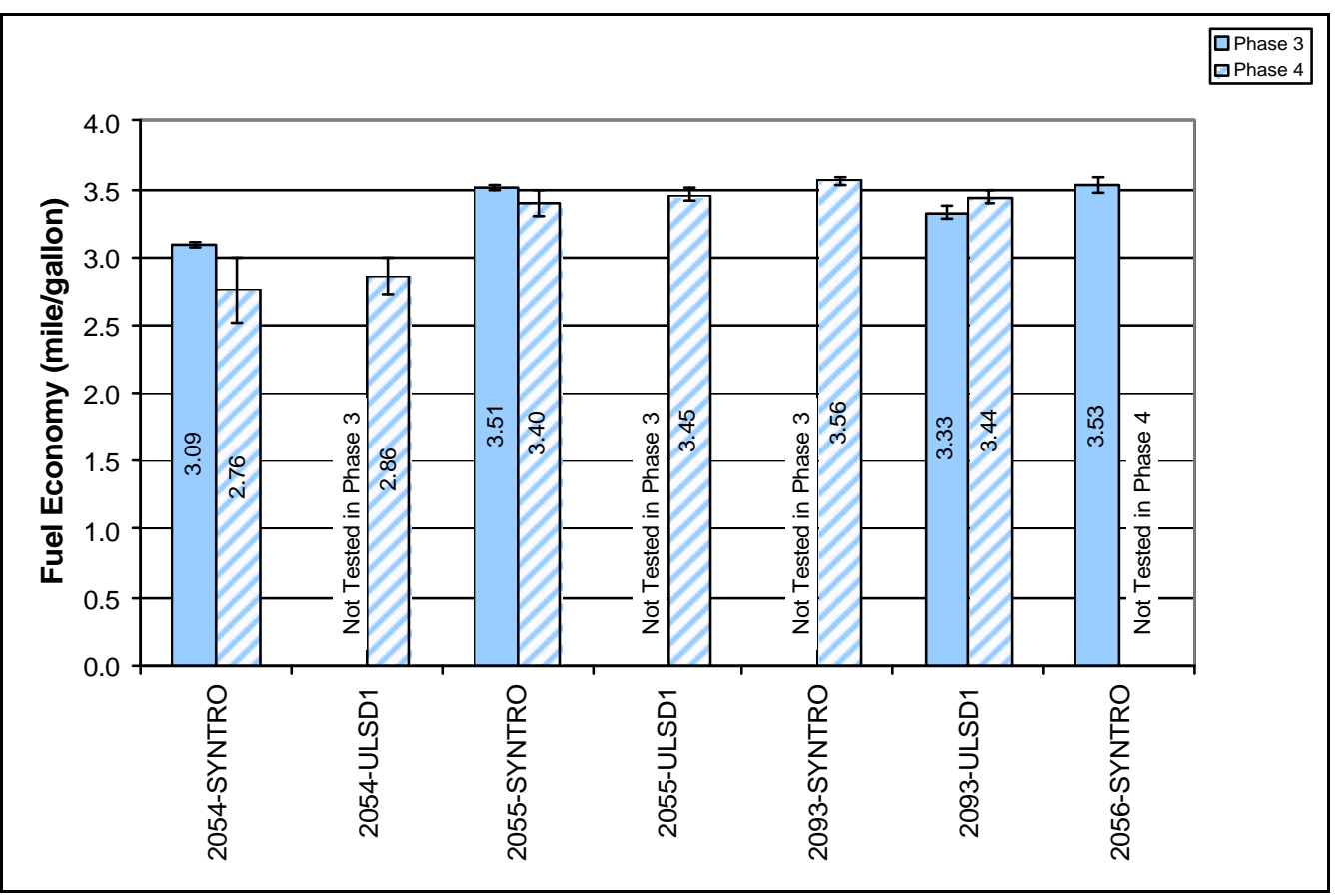

Figure 17: Phase 3 \& 4 fuel economy results.

\subsubsection{Summary of Phase 4 Results}

Three WMATA transit buses which were tested previously during phase 3 were retested after they had been operating in normal revenue service on the Syntroleum S-2 fuel for a period of 6 months. Each of the three buses was tested with both Syntroleum S-2 and ULSD1 fuels.

- $\mathrm{NO}_{x}$ emissions produced by the Syntroleum S-2 fuel were reduced by 16 percent compared to ULSD1 fuel due to the low aromatic content and high cetane number. 
- On average PM emissions when the buses were fueled with Syntroleum $S 2$ fuel were reduced by 35 percent compared to ULSD1 fuel.

- $\quad \mathrm{HC}$ and $\mathrm{CO}$ emissions were similarly reduced when the buses were fueled with Syntroleum S-2 fuel. HC emissions were reduced by 30 percent and CO emissions were reduced by 24 percent compared to ULSD1 fuel.

- Carbon dioxide and fuel economy results were very similar for both types of fuels.

\subsection{CONCLUSIONS}

The Ultra-Clean Fuels Production and Demonstration Program, sponsored by the U.S. Department of Energy's National Energy Technology Laboratory, was undertaken with the goal of pioneering a new generation of ultra-clean transportation fuels to significantly reduce tailpipe emissions from cars, trucks, and other heavy vehicles. Synthetic fuel was produced from natural gas at a small footprint plant by the Syntroleum Corporation and demonstrated in a select number of urban transit buses operated at Washington DC Metropolitan Transit Authority (WMATA) in Washington DC. Performance, exhaust emissions, and fuel economy of the buses operated on Syntroleum S-2 fuel were evaluated and compared with identically equipped sister buses operated on petroleum-derived diesel fuels. Follow up tests were also performed to test the long term performance of the fuel.

Results of two phases of emissions testing performed on the WMATA transit bus fleet showed reductions in $\mathrm{NO}_{x}$ emissions ranging from $16 \%$ to $22 \%$ for buses fueled with Syntroleum S-2 fuel compared to the ultra-low sulfur baseline fuel. These results are in agreement with published results from other studies of gas-to-liquid fuels.

In Phase 4 emissions testing at WMATA, PM reductions of approximately $35 \%$ was observed with the Syntroleum fuel compared to the ultra-low sulfur diesel fuel. The reduction in PM is likely due to a reduction in the soot portion of the PM as noted in previous GTL studies $[4,10]$. The buses tested in this program were all equipped with diesel oxidation catalysts. Although modest reductions in PM are possible through use of Syntroleum S-2 GTL fuel, the most beneficial attribute of Syntroleum fuel may arise by enabling the use of advanced sulfur sensitive aftertreatment systems, such as catalyzed diesel particulate filters, on newer technology engines.

Given vehicle-to-vehicle variability within the WMATA bus fleet, there appeared to be no substantial difference in $\mathrm{HC}$ and $\mathrm{CO}$ emissions between the Syntroleum S-2 and baseline ultra-low sulfur fuel. There also appeared to be no significant difference in the fuel economy of buses fueled with Syntroleum S-2 fuel and those fueled with petroleum derived diesel fuels. 


\section{REFERENCES}

1. CHOI, C., BOWER, G., REITZ, R., "Effects of Biodiesel Blended Fuels and Multiple Injections on D.I. Diesel Engines," SAE Technical Paper No. 970218, 1997.

2. NINE, R.D., CLARK, N.N., MACE, B.E., MORRISON, R.W., REMCHO, V.T., LOWE, P.C., McLAUGHLIN, L.W., "Use of Soy-Derived Fuel for Environmental Impact Reduction in Marine Engine Applications", Transactions of the American Society of Agricultural Engineers, Vol. 43, 2001, No. 6, pp. 1383-1391.

3. WANG, W.G., LYONS, D.W., CLARK, N.N., GAUTAM, M., "Emissions from Nine Heavy Duty Trucks Fueled by Diesel and Biodiesel without Engine Modification," Environmental Science \& Technology, Vol. 34, 2000, pp. 933-939.

4. SCHABERG, P., MYBURGH, I., BOTHA, J., ROETA, P., VILJOEN, C., KANCUART, L., STARR, M., "Diesel Exhaust Emissions Using Sasol Slurry Phase Distillate Process Fuels," SAE Technical Paper No. 972898, 1997.

5. CLARK, N.N., ATKINSON, C.M., THOMPSON, G.J., NINE, R.D., "Transient Emissions Comparisons of Alternative Compression Ignition Fuels," SAE Transactions, Jour. of Fuels \& Lubricants, Vol. 108, 1999, pp. 468-482.

6. CLARK, N.N., GAUTAM, M., LYONS, D.W., ATKINSON, C.M., XIE, W-W., NORTON, P., VERTIN, K., GOGUEN, S.P., EBERHARDT, J. "On-Road Use of Fischer-Tropsch Diesel Blends", SAE Technical Paper 1999-01-2251, 1999.

7. CHATERJEE, S., MCDONALD, C., CONWAY, R., WINDAWI, H., VERTIN, K., LETAVEC, C.A., CLARK, N.N., GAUTAM, M., "Emissions Reductions and Operational Experiences with Heavy Duty Diesel Fleet Vehicles Retrofitted with Catalytically Regenerated Particulate Filters in Southern California, SAE Technical Paper 2001-01-0512, 2000.

8. CLARK, N.N., GAUTAM, M., BOYCE, J., LYONS, D.W., VERTIN, K., LETAVEC, C.A., "Class 8 Trucks Operating on Ultra-Low Sulfur Diesel with Catalyzed Particle Filters: Regulated Emissions", SAE Technical Paper 2000-01-2815, 2000.

9. LeTAVEC, C., UIHLIEN, J., VERTIN, K., ChATTERJEE, S., HALLSTROM, K., WAYNE, W.S., CLARK, N.N., LYONS, D.W., CHANDLER, K., COBURN, T., "Year-long Evaluation of Trucks and Buses Equipped with Passive Diesel Particle Filters", SAE Transactions: Journal of Fuels \& Lubricants Vol. 111, 2002, pp. 242-266.

10. Alleman, T.L., EUDY, L., MiYASATO, M., OSHINUGA, A., AlLISON, S., CORCORAN, T., CHATTERJEE, S., JACOBS, T., CHERRILO, R.A., CLARK, R., VIRRELS, I., NINE, R., WAYNE, S., and LANSING, R., "Fuel Property, Emissions Test and Operability Results from a Fleet of Class 6 Vehicles Operating on Gas-To-Liquid Fuel and Catalyzed Diesel Particulate Filters," SAE Technical Paper 2004-01-2959, 2004.

11. "Syntroleum - Monetizing Stranded Gas," Syntroleum Corporation, 1350 South Boulder, Suite 1100, Tulsa OK 74119.

12. "S-2 Synthetic Diesel Fuel - Driving Clean-Fuel Innovation," Syntroleum Corporation, 1350 South Boulder, Suite 1100, Tulsa OK 74119, 2002.

13. MATHEAUS, A.C., NEELY, G.D., RYAN III, T.W., SOBOTOWSKI, R.A., WALL, J.C., HOBBS, C.H., PASSAVANT, G.W., BOND, T.J., "EPA HDEWG Program-Engine Test Results, SAE Technical Paper 2000-01-1858, 2000.

14. RYAN III, T.W., BUCKINGHAM, J., DODGE, L.G., OLIKARA, C., "The Effects of Fuel Properties on Emissions from a 2.5gm NO $\times$ Heavy -Duty Diesel Engine," SAE Technical Paper, 982491, 1998.

15. LEE, R., PEDLEY, J. and HOBBS, C., "Fuel Quality Impact on Heavy Duty Diesel Emissions: A Literature Review," SAE Technical Paper 982649, 1998. 
16. ALLEMAN, T.L., McCORMICK, R.L., "Fischer-Tropsch Diesel Fuel - Properties and Exhaust Emissions: A Literature Review," SAE Technical Paper 2003-01-0763, 2003.

17. MORGAN, P.M., VIJOEN, C.L. ROETS, P.N., SCHABERG, P.W., MYBURGH, I.S., BOTHA, J.J., DANCUART, L.P., "Some Comparative Chemical, Physical and Compatibility Properties of Sasol Slurry Phase Distillate Diesel Fuel," SAE Technical Paper 1999-01-1512, 1999.

18. NORTON, P., VERTIN, K., CLARK, N.N., LYONS, D.W., GAUTAM, M., GOGUEN, S., EBERHARDT, J., "Emissions from Busses with DDC 6V92 Engines Using Synthetic Diesel Fuel," SAE Technical Paper 1999-01-1512, 1999.

19. SIRMAN, M.B., OWENS, E.C., WHITNEY, K.A., "Emissions Comparison of Alternative Fuels in an Advanced Automotive Diesel Engine," SAE Technical Paper 2000-01-2048, 2000.

20. GAUTAM, M., CLARK, N., LYONS, D., LONG, Jr., T., HOWELL, A., LOTH, J., PALMER, G., and BATA, R., "Design Overview of a Heavy -Duty Mobile Vehicle Emissions Testing Laboratory." ASME DE-Vol. 40, Advanced Automotive Technologies, 1991.

21. WANG, W.G., PALMER, G.N., BATA, R.M., CLARK, N.N., GAUTAM, M., and LYONS, D.W., "Determination of Heavy-duty Vehicle Energy Consumption by a Chassis Dynamometer," SAE Transactions, Journal of Commercial Vehicles, Vol. 101, 1992, pp. 687-696.

22. CLARK, N.N., GAUTAM, M., BATA, R.M., LOTH, J., PALMER, G.M., WANG, W.G., and LYONS, D.W., "Design and Operation of a New Transportable Laboratory for Emissions Testing of Heavyduty Trucks and buses," International Jour. Of Vehicle Design (Heavy Vehicle Systems) 1995, Vol. 2, Nos. 3/4, pp. 285-299.

23. Code of Federal Regulations, Title 40, Part 86.1333, "Protection of Environment," US Government Printing Office, 2003 (http://www.epa.gov/epahome/cfr40.htm).

24. ALLANSSON, R., BLAKEMAN, P.G., COOPER B.J., HESS, H., SILCOCK. P.J., WALKER, A.P., "Optimizing the Low Temperature Performance and Regeneration Efficiency of the Continuously Regenerating Diesel Particulate Filter (CR-DPF) System," SAE Technical Paper 2002-01-0428, 2002. 
APPENDIX A: EMISSIONS DATA TABLES 
Table A- 1: Phase 3 Emissions Data

\begin{tabular}{|c|c|c|c|c|c|c|c|c|c|c|c|c|c|c|}
\hline $\begin{array}{c}\text { Vehicle } \\
\text { Configuration }\end{array}$ & $\begin{array}{c}\text { Exhaust } \\
\text { Aftertreatment }\end{array}$ & $\begin{array}{l}\text { Fuel } \\
\text { Type }\end{array}$ & $\begin{array}{l}\text { Vehicle } \\
\text { Number }\end{array}$ & Test ID & Run ID & $\mathrm{CO}$ & NOx & NO & $\mathrm{HC}$ & PM & $\mathrm{CO}_{2}$ & Miles & MPG & BTU/mile \\
\hline \multirow{25}{*}{$\begin{array}{c}2000 \text { MY DDC } \\
\text { Series } 50\end{array}$} & \multirow{25}{*}{ DOC } & \multirow{13}{*}{ ULSD1 } & \multirow{5}{*}{2093} & \multirow{4}{*}{4261} & & $\mathrm{~g} / \mathrm{mile}$ & $\mathrm{g} / \mathrm{mile}$ & $\mathrm{g} / \mathrm{mile}$ & $\mathrm{g} / \mathrm{mile}$ & $\mathrm{g} / \mathrm{mile}$ & $\mathrm{g} / \mathrm{mile}$ & & & \\
\hline & & & & & 2 & 3.90 & 29.10 & $\mathrm{~N} / \mathrm{A}$ & 0.16 & 0.407 & 2928 & 4.27 & 3.29 & 38873 \\
\hline & & & & & 3 & 4.20 & 29.04 & 27.47 & 0.02 & 0.390 & 2894 & 4.26 & 3.33 & 38421 \\
\hline & & & & & 4 & 4.20 & 28.53 & 26.99 & 0.07 & 0.399 & 2860 & 4.26 & 3.37 & 37969 \\
\hline & & & & \multicolumn{2}{|c|}{ Average } & 4.10 & 28.89 & 27.23 & 0.08 & 0.399 & 2894 & 4.26 & 3.33 & 38421 \\
\hline & & & \multirow{4}{*}{2092} & \multirow{3}{*}{4263.00} & 2 & 4.37 & 31.29 & $\mathrm{~N} / \mathrm{A}$ & 0.056 & 0.271 & 2887 & 4.20 & 3.34 & 38331 \\
\hline & & & & & 4 & 4.75 & 30.09 & 28.51 & 0 & 0.285 & 2977 & 4.21 & 3.24 & 39530 \\
\hline & & & & & 5 & 4.76 & 29.73 & 28.23 & 0 & 0.300 & 2905 & 4.21 & 3.31 & 38581 \\
\hline & & & & \multicolumn{2}{|c|}{ Average } & 4.63 & 30.37 & 28.37 & 0.056 & 0.285 & 2923 & 4.21 & 3.30 & 38814 \\
\hline & & & \multirow{4}{*}{2094} & \multirow{3}{*}{4276} & 2 & 3.34 & 28.67 & $\mathrm{~N} / \mathrm{A}$ & 0.23 & 0.168 & 2652 & 4.23 & 3.63 & 35212 \\
\hline & & & & & 3 & 3.38 & 28.46 & 27.21 & 0.23 & 0.182 & 2598 & 4.22 & 3.71 & 34486 \\
\hline & & & & & 4 & 3.48 & 28.30 & 26.91 & 0.22 & 0.185 & 2587 & 4.23 & 3.72 & 34345 \\
\hline & & & & \multicolumn{2}{|c|}{ Average } & 3.40 & 28.48 & 27.06 & 0.23 & 0.178 & 2612 & 4.23 & 3.69 & 34681 \\
\hline & & \multirow{12}{*}{ Syntroleum } & \multirow{4}{*}{2054} & \multirow{3}{*}{4267} & 2 & 4.94 & 25.35 & $\mathrm{~N} / \mathrm{A}$ & 0.04 & 0.321 & 2960 & 4.19 & 3.11 & 40119 \\
\hline & & & & & 3 & 5.07 & 26.03 & 24.72 & 0.06 & 0.332 & 2997 & 4.20 & 3.07 & 40617 \\
\hline & & & & & 4 & 4.92 & 24.76 & 23.51 & 0.07 & 0.364 & 2975 & 4.18 & 3.10 & 40323 \\
\hline & & & & \multicolumn{2}{|c|}{ Average } & 4.98 & 25.38 & 24.12 & 0.06 & 0.339 & 2977 & 4.19 & 3.09 & 40353 \\
\hline & & & \multirow{4}{*}{2055} & \multirow{3}{*}{4273} & 2 & 4.19 & 21.04 & $\mathrm{~N} / \mathrm{A}$ & 0.21 & 0.179 & 2635 & 4.24 & 3.50 & 35714 \\
\hline & & & & & 3 & 4.43 & 20.71 & 19.73 & 0.23 & 0.176 & 2608 & 4.29 & 3.53 & 35355 \\
\hline & & & & & 4 & 4.49 & 20.81 & 19.79 & 0.27 & 0.186 & 2620 & 4.25 & 3.52 & 35517 \\
\hline & & & & \multicolumn{2}{|c|}{ Average } & 4.37 & 20.86 & 19.76 & 0.24 & 0.180 & 2621 & 4.26 & 3.51 & 35528 \\
\hline & & & \multirow{4}{*}{2056} & \multirow{3}{*}{4270} & 3 & 2.73 & 21.82 & $\mathrm{~N} / \mathrm{A}$ & 0.12 & 0.333 & 2606 & 4.26 & 3.54 & 35287 \\
\hline & & & & & 4 & 2.35 & 21.81 & 21.39 & 0.18 & 0.306 & 2659 & 4.27 & 3.47 & 35994 \\
\hline & & & & & 5 & 2.43 & 21.53 & 21.15 & 0.11 & 0.286 & 2572 & 4.26 & 3.59 & 34823 \\
\hline & & & & \multicolumn{2}{|c|}{ Average } & 2.50 & 21.72 & 21.27 & 0.14 & 0.308 & 2612 & 4.26 & 3.53 & 35368 \\
\hline
\end{tabular}


Table A- 1: Phase 4 Emissions Data

\begin{tabular}{|c|c|c|c|c|c|c|c|c|c|c|c|c|c|c|}
\hline $\begin{array}{c}\text { Vehicle } \\
\text { Configuration }\end{array}$ & $\begin{array}{c}\text { Exhaust } \\
\text { Aftertreatment }\end{array}$ & $\begin{array}{l}\text { Fuel } \\
\text { Type }\end{array}$ & $\begin{array}{l}\text { Vehicle } \\
\text { Number }\end{array}$ & Test ID & Run ID & Co & NOx & NO & $\mathrm{HC}$ & PM & $\mathrm{CO}_{2}$ & Miles & MPG & BTU/mile \\
\hline \multirow{28}{*}{$\begin{array}{c}2000 \text { MY DDC } \\
\text { Series } 50\end{array}$} & \multirow{28}{*}{$\mathrm{DOC}$} & \multirow{9}{*}{ Syntroleum } & \multirow{17}{*}{2054} & \multirow{4}{*}{4472} & & $\mathrm{~g} / \mathrm{mile}$ & $\mathrm{g} / \mathrm{mile}$ & $\mathrm{g} / \mathrm{mile}$ & $\mathrm{g} / \mathrm{mile}$ & $\mathrm{g} / \mathrm{mile}$ & $\mathrm{g} / \mathrm{mile}$ & & & \\
\hline & & & & & 2 & 4.18 & 28.15 & $\mathrm{~N} / \mathrm{A}$ & 0.31 & 0.221 & 3668 & 4.20 & 2.51 & 49687 \\
\hline & & & & & 3 & 4.04 & 28.80 & 27.82 & 0.31 & 0.222 & 3573 & 4.21 & 2.58 & 48400 \\
\hline & & & & & 4 & 3.94 & 28.24 & 27.15 & 0.26 & 0.212 & 3558 & 4.22 & 2.59 & 48196 \\
\hline & & & & \multicolumn{2}{|c|}{ Average } & 4.05 & 28.40 & 27.48 & 0.29 & 0.219 & 3600 & 4.21 & 2.56 & 48761 \\
\hline & & & & \multirow{3}{*}{4510} & 2 & 3.26 & 26.66 & $\mathrm{~N} / \mathrm{A}$ & 0.19 & 0.167 & 3132 & 4.45 & 2.94 & 42417 \\
\hline & & & & & 3 & 3.69 & 26.56 & 25.58 & 0.29 & 0.187 & 3085 & 4.42 & 2.99 & 41794 \\
\hline & & & & & 4 & 3.99 & 26.05 & 24.89 & 0.30 & 0.209 & 3151 & 4.41 & 2.92 & 42695 \\
\hline & & & & \multicolumn{2}{|c|}{ Average } & 3.65 & 26.42 & 25.23 & 0.26 & 0.188 & 3123 & 4.43 & 2.95 & 42302 \\
\hline & & \multirow{8}{*}{ ULSD1 } & & \multirow{3}{*}{4473} & 2 & 5.18 & 32.76 & $\mathrm{~N} / \mathrm{A}$ & 0.41 & 0.332 & 3678 & 4.23 & 2.72 & 48457 \\
\hline & & & & & 3 & 5.30 & 32.41 & 31.01 & 0.47 & 0.319 & 3548 & 4.25 & 2.82 & 46755 \\
\hline & & & & & 4 & 5.44 & 32.96 & 31.24 & 0.35 & 0.342 & 3626 & 4.29 & 2.76 & 47769 \\
\hline & & & & \multicolumn{2}{|c|}{ Average } & 5.31 & 32.71 & 31.12 & 0.41 & 0.331 & 3617 & 4.26 & 2.76 & 47660 \\
\hline & & & & \multirow{3}{*}{4511} & 1 & 5.31 & 31.43 & $\mathrm{~N} / \mathrm{A}$ & 0.43 & 0.352 & 3287 & 4.34 & 2.93 & 43670 \\
\hline & & & & & 2 & 5.04 & 30.63 & $N / A$ & 0.41 & 0.329 & 3287 & 4.42 & 2.93 & 43665 \\
\hline & & & & & 3 & 5.02 & 30.39 & 29.06 & 0.39 & 0.327 & 3209 & 4.43 & 3.00 & 42622 \\
\hline & & & & \multicolumn{2}{|c|}{ Average } & 5.12 & 30.81 & 29.06 & 0.41 & 0.336 & 3261 & 4.40 & 2.95 & 43319 \\
\hline & & \multirow{8}{*}{ Syntroleum } & \multirow{11}{*}{2055} & \multirow{3}{*}{4476} & 2 & 3.13 & 21.35 & $\mathrm{~N} / \mathrm{A}$ & 0.25 & 0.127 & 2799 & 4.21 & 3.29 & 37906 \\
\hline & & & & & 3 & 2.76 & 20.43 & 19.38 & 0.30 & 0.122 & 2642 & 4.49 & 3.49 & 35778 \\
\hline & & & & & 4 & 3.00 & 20.17 & 19.08 & 0.32 & 0.130 & 2659 & 4.46 & 3.47 & 36016 \\
\hline & & & & \multicolumn{2}{|c|}{ Average } & 2.96 & 20.65 & 19.23 & 0.29 & 0.126 & 2700 & 4.39 & 3.42 & 36567 \\
\hline & & & & \multirow{3}{*}{4506} & 2 & 2.29 & 21.44 & $\mathrm{~N} / \mathrm{A}$ & 0.34 & 0.115 & 2744 & 4.40 & 3.36 & 37151 \\
\hline & & & & & 3 & 2.40 & 21.92 & 21.05 & 0.31 & 0.113 & 2755 & 4.40 & 3.35 & 37311 \\
\hline & & & & & 4 & 2.51 & 20.60 & 19.67 & 0.29 & 0.113 & 2670 & 4.51 & 3.45 & 36153 \\
\hline & & & & \multicolumn{2}{|c|}{ Average } & 2.40 & 21.32 & 20.36 & 0.31 & 0.114 & 2723 & 4.43 & 3.39 & 36872 \\
\hline & & \multirow{3}{*}{ ULSD1 } & & \multirow{3}{*}{4477} & 1 & 3.97 & 27.11 & $N / A$ & 0.45 & 0.201 & 2802 & 4.39 & 3.44 & 37222 \\
\hline & & & & & 2 & 3.90 & 26.90 & 25.45 & 0.41 & 0.201 & 2818 & 4.37 & 3.42 & 37421 \\
\hline & & & & & 3 & 4.05 & 26.79 & 25.42 & 0.48 & 0.204 & 2816 & 4.35 & 3.42 & 37401 \\
\hline
\end{tabular}


Table A- 4 Continued: Phase 4 Emissions Data

\begin{tabular}{|c|c|c|c|c|c|c|c|c|c|c|c|c|c|c|}
\hline $\begin{array}{c}\text { Vehicle } \\
\text { Configuration }\end{array}$ & $\begin{array}{c}\text { Exhaust } \\
\text { Aftertreatment }\end{array}$ & $\begin{array}{l}\text { Fuel } \\
\text { Type }\end{array}$ & $\begin{array}{l}\text { Vehicle } \\
\text { Number }\end{array}$ & Test ID & Run ID & $\mathrm{CO}$ & NOx & NO & $\mathrm{HC}$ & PM & $\mathrm{CO}_{2}$ & Miles & MPG & BTU/mile \\
\hline \multirow{17}{*}{$\begin{array}{c}2000 \text { MY DDC } \\
\text { Series } 50\end{array}$} & \multirow{17}{*}{ DOC } & \multirow{9}{*}{ ULSD1 } & \multirow{9}{*}{2055} & \multirow{4}{*}{4477} & & $\mathrm{~g} / \mathrm{mile}$ & $\mathrm{g} / \mathrm{mile}$ & $\mathrm{g} / \mathrm{mile}$ & $\mathrm{g} / \mathrm{mile}$ & $\mathrm{g} / \mathrm{mile}$ & $\mathrm{g} / \mathrm{mile}$ & & & \\
\hline & & & & & 1 & 3.97 & 27.11 & $\mathrm{~N} / \mathrm{A}$ & 0.45 & 0.201 & 2802 & 4.39 & 3.44 & 37222 \\
\hline & & & & & 2 & 3.90 & 26.90 & 25.45 & 0.41 & 0.201 & 2818 & 4.37 & 3.42 & 37421 \\
\hline & & & & & 3 & 4.05 & 26.79 & 25.42 & 0.48 & 0.204 & 2816 & 4.35 & 3.42 & 37401 \\
\hline & & & & \multicolumn{2}{|c|}{ Average } & 3.98 & 26.93 & 25.44 & 0.44 & 0.202 & 2812 & 4.37 & 3.42 & 37348 \\
\hline & & & & \multirow{3}{*}{4507} & 2 & 3.53 & 26.63 & $\mathrm{~N} / \mathrm{A}$ & 0.45 & 0.165 & 2821 & 4.43 & 3.41 & 37455 \\
\hline & & & & & 3 & 3.17 & 25.64 & 24.97 & 0.47 & 0.172 & 2746 & 4.42 & 3.51 & 36456 \\
\hline & & & & & 4 & 3.30 & 26.32 & 24.85 & 0.45 & 0.185 & 2765 & 4.48 & 3.48 & 36718 \\
\hline & & & & \multicolumn{2}{|c|}{ Average } & 3.33 & 26.20 & 24.91 & 0.46 & 0.174 & 2777 & 4.44 & 3.47 & 36876 \\
\hline & & \multirow{4}{*}{ Syntroleum } & \multirow{8}{*}{2093} & \multirow{3}{*}{4503} & 2 & 2.42 & 23.81 & 22.76 & 0.25 & 0.149 & 2616 & 4.53 & 3.52 & 35426 \\
\hline & & & & & 3 & 2.46 & 23.61 & 22.70 & 0.24 & 0.150 & 2589 & 4.51 & 3.56 & 35057 \\
\hline & & & & & 4 & 2.49 & 23.45 & 22.52 & 0.28 & 0.151 & 2568 & 4.53 & 3.59 & 34775 \\
\hline & & & & & & 2.46 & 23.62 & 22.66 & 0.25 & 0.150 & 2591 & 4.53 & 3.56 & 35086 \\
\hline & & \multirow{4}{*}{ ULSD1 } & & \multirow{3}{*}{4502} & 4 & 2.98 & 28.24 & $\mathrm{~N} / \mathrm{A}$ & 0.34 & 0.220 & 2836 & 4.47 & 3.40 & 37636 \\
\hline & & & & & 5 & 3.05 & 28.06 & 25.91 & 0.34 & 0.224 & 2816 & 4.47 & 3.42 & 37371 \\
\hline & & & & & 6 & 2.83 & 27.76 & 26.90 & 0.31 & 0.198 & 2760 & 4.53 & 3.49 & 36626 \\
\hline & & & & \multicolumn{2}{|c|}{ Average } & 2.95 & 28.02 & 26.40 & 0.33 & 0.214 & 2804 & 4.49 & 3.44 & 37211 \\
\hline
\end{tabular}




\title{
APPENDIX D
}

\section{ULTRA-CLEAN FUELS: FUEL, BLENDING, AND AFTERTREATMENT SYSTEM IMPACT ON GTL COMBUSTION AND EMISSIONS IN AN ADVANCED DI ENGINE}

\section{Annual Technical Progress Report}

\author{
Victor W. Wong, Alexander G. Sappok \\ Massachusetts Institute of Technology \\ Room 31-155, 77 Massachusetts Avenue \\ Cambridge, MA 02139
}




\title{
DISCLAIMER
}

This report was prepared as an account of work sponsored by an agency of the United States Government. Neither the United States Government nor any agency thereof, nor any or their employees, makes any warranty, express or implied, or assumes any legal liability or responsibility for the accuracy, completeness, or usefulness of any information, apparatus, product, or process disclosed, or represents that its use would not infringe privately owned rights. Reference herein to any specific commercial product, process, or service by trade name, trademark, manufacturer, or otherwise does not necessarily constitute or imply its endorsement, recommendation, or favoring by the United States Government or any agency thereof. The views and opinions of authors expressed herein do not necessarily state or reflect those of the United States Government or any agency thereof.

\begin{abstract}
This project aims at developing the fundamental knowledge base of how Syntroleum gas-toliquid (GTL) fuel, also referred to as Fischer-Tropsch (FT) fuel, affects the performance and emission characteristics of advanced engine systems. This project complements other production, testing, and assessment efforts in the overall Ultra-Clean Fuels Program. Specific tasks include performing engine experiments on a Cummins MY2002 ISB 5.9 liter 6 cylinder turbocharged after-cooled engine, employing cooled EGR and advanced electronic controls, to assess the manner in which the gas-to-liquid fuel impacts engine performance and emissions. In addition, this project also investigates the effects that FT fuel has on an exhaust aftertreatment system, specifically diesel particulate traps (DPT), and work in this area has already started.

Compared to regular diesel fuel over various steady-state conditions tested, the FT fuel reduces particulate emissions substantially (25-75\%), through sulfur and non-sulfur effects, but more significantly from a faster burn rate late in the combustion process. NOx emission reduction using the FT fuel ranges from 5-20\%, as FT fuel removes the sensitive dependence of PM production on EGR, allowing significant NOx reductions through the use of higher EGR rates before PM levels become unacceptably high. Therefore, EGR and injection timings can be utilized more effectively with the FT fuel in controlling both particulates and NOx. A blend of $25 \%$ (by volume) FT fuel with $75 \% 400$ ppm sulfur fuel demonstrated that the $25 \%$ FT fuel in the blend produced about $50 \%$ of the particulate reduction of using neat FT fuel, thus showing a more than proportional benefit of using blends. Chemical analysis of the PM confirmed these results and showed a more than proportional benefit of the blend in reducing SOL and SOF. Furthermore, a detailed combustion analysis of the fuels over a wide range of engine operating conditions attempted to shed further insight into this phenomenon. A particulate trap system utilizing catalyzed and un-catalyzed cordierite honeycomb substrates has been designed, fabricated, instrumented, and installed in the existing engine set up. Initial testing on a smaller prototype trap has already been completed. Overall, FT fuel gives greater freedom to engine designers when trying to optimize the engine/emission-control/fuel system in modern engines, since it provides the fuel properties as another flexible set of variables that affect the combustion and emission processes. Furthermore, additional benefits can be realized through the use of more aggressive aftertreatment systems due to the zero sulfur nature of the FT fuel.
\end{abstract}




\section{TABLE OF CONTENTS}

TITLE PAGE

DISCLAIMER

ABSTRACT

TABLE OF CONTENTS

LIST OF FIGURES

LIST OF TABLES

EXECUTIVE SUMMARY

1.0 SCOPE OF WORK FOR THIS REPORTING PERIOD 10

2.0 CUMMULATIVE ACCOMPLISHMENTS 10

3.0 LITERATURE SURVEY

$\begin{array}{lll}3.1 & \text { Fuel Effects } & 12\end{array}$

$\begin{array}{ll}3.1 .1 & \text { Cetane Number } \\ 3.1 .2 & 12\end{array}$

3.1.2 Sulfur 13

3.1.3 Density 13

3.1.4 Aromatics 13

3.1.5 Back-End Volatility 13

3.2 Combustion Characteristics 14

3.3 Engine Technology 14

3.4 Aftertreatment Systems 15

3.4.1 Diesel Particulate Traps 15

4.0 REPORT ORGANIZATION AND DISCUSSION OF RESULTS 16

5.0 EXPERIMENTAL SET-UP

5.1 Engine 16

$\begin{array}{lll}5.2 & \text { Engine Control Software } & 17\end{array}$

5.3 Dynamometer Setup and Dynamometer Controller 17

5.4 Data Acquisition System 18

5.4.1 High Sampling Rate Measurements 19

5.4.2 Pressure Transducer Calibration and Encoder Phasing 19

5.5 Fueling System 20

5.6 Intake Air Measurement and Preparation 20

5.7 Gaseous Emissions Analyzers 21

5.8 Mini-Dilution Tunnel 22

5.9 Gravimetric Particulate Matter Sampling System 23

6.0 EXPERIMENTAL FUELS

6.1 Number 2 Diesel Fuel 24

6.1.1 Low Sulfur Diesel Fuel 24

6.1.2 Ultra Low Sulfur Diesel Fuel 26

6.1.3 No. 2 Diesel Combustion Equation 27

6.2 Fischer-Tropsch Fuel 27

6.2.1 Syntroleum FT Diesel 27

6.2.2 Syntroleum FT Diesel Combustion Equation 30

$6.3 \quad$ Fuel Blends 30

6.3.1 25\% FT / 75\% Low Sulfur Diesel Blend 30

$6.4 \quad$ Fuel Analysis 30

7.0 EXPERIMENTAL TEST MATRIX AND PROCEDURE 33

7.1 Engine Operation 33

7.1.1 Experimental Test Matrix 33

7.1.2 Expanded Test Matrix 34

7.2 Particulate Matter Sampling Conditions 35

$\begin{array}{ll}\text { 7.2.1 Dilute Exhaust Sampling } & 35\end{array}$ 
7.2.2 Raw Exhaust Sampling 36

7.3 Engine Operation During Experiments 36

$\begin{array}{ll}\text { 7.3.1 } & \text { Fuel Change Procedure } \\ 7.3 .2 & \end{array}$

7.3.2 Oil Change Procedure 37

7.4 Data Processing and Reduction $\quad 38$

$\begin{array}{lll}7.5 & \text { Heat Release Analysis } & 39\end{array}$

7.5.1 In-Cylinder Pressure Signal Data Processing 39

8.0 EXPERIMENTAL RESULTS

$\begin{array}{lll}8.1 & \text { Emissions Characteristics } & 40\end{array}$

8.1.1 Particulate Emissions $\quad 40$

8.1.2 NOx Emissions 41

8.1.3 Hydrocarbon Emissions 42

8.2 Particulate Analysis $\quad 42$

8.2.1 PM Constituent Distribution 43

8.2.2 Non-soluble Fraction and Soot 44

8.2.3 Soluble Organic Fraction 45

8.2.4 Sulfates 45

8.3 Combustion Characteristics 48

$\begin{array}{lll}\text { 8.3.1 Ignition Delay } & 48\end{array}$

8.3.2 Burn Duration 49

8.3.3 Maximum In-Cylinder Pressure and Location 51

8.3.4 Pressure Trace and Heat Release Curves 53

8.3.5 Pilot-Injection Maximum Heat Release Rates and Location 54

8.3.6 Main-Injection Maximum Heat Release Rates and Location 55

8.3.7 Post-Injection Maximum Heat Release Rates and Location 56

9.0 DISCUSSION 57

9.1 Fuel Effects $\quad 57$

$\begin{array}{lll}9.2 & \text { Combustion Characteristics } & 58\end{array}$

$\begin{array}{lll}9.3 & \text { Engine Technology } & 58\end{array}$

10.0 EXHAUST AFTERTREATMENT SYSTEM

$10.1 \quad$ Major Accomplishments to Date 60

10.1.1 Subtask (a): Design, Fabricate, and Install Particulate Trap 61

10.1.2 Subtask (b): Fully Instrument Filter 62

10.1.3 Subtask (c): Evaluate PM Characteristics 64

$10.2 \quad$ Current Work $\quad 64$

10.2.1 Subtask (d): Trap testing and Evaluation of Fuel Effects 65

11.0 CONCLUSIONS

12.0 ACKNOWLEDGEMENT

13.0 REFERNECES

14.0 ADDITIONAL REFERENCES NOT CITED 71 


\section{LIST OF FIGURES}

$\begin{array}{lll}\text { Figure 5.1 } & \text { Emission sampling system schematic } & 21\end{array}$

Figure 6.1 Distillation curves for each of the three fuels tested 31

$\begin{array}{lll}\text { Figure 6.2 } & \text { GC results for 400 PPM low sulfur diesel } & 32\end{array}$

Figure 6.3 GC results for 15 PPM ultra-low sulfur diesel $\quad 32$

$\begin{array}{lll}\text { Figure 8.1 } & \text { Specific particulate emissions } & 40\end{array}$

$\begin{array}{lll}\text { Figure 8.2 } & \text { Specific NOx emissions } & 41\end{array}$

$\begin{array}{lll}\text { Figure 8.3 } & \text { Average measured exhaust temperature } & 41\end{array}$

$\begin{array}{lll}\text { Figure 8.4 Specific hydro-carbon emissions } & 42\end{array}$

Figure 8.5 Distribution of particulate constituents over the three operating conditions 43

$\begin{array}{lll}\text { Figure 8.6 Comparison of solid non soluble fraction } & 44\end{array}$

Figure 8.7 Comparison of soluble organic fractions 45

Figure 8.8 Comparison of sulfate contribution to TPM 46

Figure 8.9 Comparison of lube oil and fuel contribution to PM sulfate 46

$\begin{array}{lll}\text { Figure 8.10 } & \text { Ignition delay } & 48\end{array}$

$\begin{array}{lll}\text { Figure } 8.11 & \text { Start of injection to } 99 \% \text { burn duration } & 49\end{array}$

$\begin{array}{lll}\text { Figure } 8.12 & 50 \%-90 \% \text { burn duration } & 49\end{array}$

\begin{tabular}{ll} 
Figure 8.13 & Location of $50 \%$ heat release \\
\hline
\end{tabular}

$\begin{array}{lll}\text { Figure } 8.14 & 10 \%-50 \% \text { burn duration } & 50\end{array}$

$\begin{array}{lll}\text { Figure 8.15 } & \text { Tail-end burn duration } & 51\end{array}$

Figure 8.16 Maximum in-cylinder pressure after start of injection 52

Figure 8.17 Location of maximum in cylinder pressure after start of injection $\quad 52$

$\begin{array}{lll}\text { Figure 8.18 } & \text { Pressure trace for severely retarded timing } & 53\end{array}$

$\begin{array}{lll}\text { Figure 8.19 } & \text { Heat release curves, severely retarded timing } & 53\end{array}$

$\begin{array}{lll}\text { Figure 8.20 Pilot injection maximum heat release rate } & 54\end{array}$

$\begin{array}{lll}\text { Figure 8.21 } & \text { Location of pilot injection maximum heat release } & 54\end{array}$

Figure 8.22 Main injection maximum heat release rate $\quad 55$

Figure 8.23 Location of main injection maximum heat release $\quad 55$

Figure 8.24 Post injection maximum heat release rate $\quad 56$

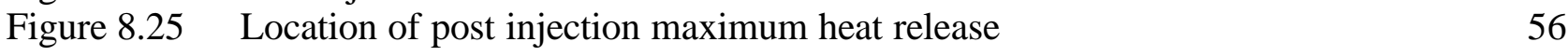

$\begin{array}{lll}\text { Figure 10.1 } & \text { Prototype trap installed in ISB exhaust system } & 61\end{array}$

$\begin{array}{lll}\text { Figure 10.2 } & \text { Schematic of full flow parallel particulate trap system } & 62\end{array}$

Figure 10.3 Thermo couple locations and orientation within trap substrate 63

$\begin{array}{lll}\text { Figure 10.4 Pressure and emission tap locations } & 63\end{array}$

$\begin{array}{lll}\text { Figure 10.5 Schematic of test bed and exhaust sampling systems } & 64\end{array}$

Figure 10.6 Schematic of full-flow trap on test bed 65 


\section{LIST OF TABLES}

$\begin{array}{lll}\text { Table 5.1 Pre-production ISB } 300 \text { engine details } & 17\end{array}$

Table 6.1 Manufacturers specifications for the low sulfur diesel 25

Table 6.2 Manufacturers specifications for the ultra-low sulfur diesel 26

$\begin{array}{lll}\text { Table 6.3 } & \text { ASTM D975 requirements for diesel fuel oils } & 28\end{array}$

Table 6.4 S-2 fuel properties for the two batches of synthetic diesel testing 29

Table 6.5 Fuel properties comparison determined from Syntroleum analysis $\quad 31$

$\begin{array}{lll}\text { Table 7.1 } & \text { Initial test matrix } & 34\end{array}$

$\begin{array}{lll}\text { Table 7.2 } & \text { Expanded test matrix to evaluate combustion characteristics } & 34\end{array}$ 


\title{
FUEL, BLENDING, AND AFTERTREATMENT SYSTEM IMPACT ON GTL COMBUSTION AND EMISSIONS IN AN ADVANCED DI ENGINE
}

\author{
Annual Technical Progress Report \\ Reporting Period: September 1, 2004 - August 31, 2005 \\ (Third Year)
}

\author{
by \\ Sloan Automotive Laboratory \\ Massachusetts Institute of Technology \\ EXECUTIVE SUMMARY
}

This subcontract at MIT complements other production, testing, and assessment efforts in the overall Ultra-Clean Fuels Program by exploring how advanced engine and emission control systems may benefit from the use of Syntroleum gas-to-liquid fuel.

Specific tasks in this subcontract project include:

(1) To assess how gas-to-liquid fuels impact engine performance and emissions, directly and in blends; to evaluate tradeoffs among fuel properties and blending ratios; to evaluate engine modifications in further improving engine emissions; and to determine combustion and emission characteristics.

(2) To explore opportunities of injection strategy control and exhaust-gas-recirculation (EGR) in pushing limits of NOx/particulates reduction using Syntroleum Fischer Tropsch (FT) fuels produced from small footprint plant (SFP). The engine will be modified for various injection control and EGR systems. Since particulates are expected to be substantially lower with the GTL fuel, limits of NOx reduction via EGR and injection variables will be explored using the specific fuels.

(3) To evaluate exhaust aftertreatment systems performance and design tradeoffs available using gasto-liquid fuels. Optimize the fuel/engine/emission-control system.

If future resources become available, fundamental models and experiments to verify the effects of fuel characteristics on diesel processes most critical to effective engine performance and low emissions will also be developed. These advanced models will focus on fuel chemical composition effects.

Goals for this reporting period, the third year, were to (i) confirm the more than proportional benefits of using the FT/LSD blend observed in the previous reporting period, (ii) develop a better understanding of the fundamental processes influencing the fuel effects on engine out emissions by conducting detailed combustion and particulate chemical analyses, and (iii) continue investigating interactive effects of different fuel properties and an exhaust aftertreatment system. Tasks (1) and (2), except for the fuel blends and detailed characterizations, have essentially been covered in the past two years as previously reported. Work on Task (3) was initiated in the past reporting period as well. The differences in the measured combustion characteristics, PM chemical composition, and fuel properties were compared to the emissions variations between the fuels studied, and an explanation for the 
observed emissions behavior of the fuels was developed. The goals in this period have thus been accomplished, and work on the aftertreatment system, a particulate trap, is continuing.

The experiments were performed on a Cummins model year 2002 ISB 300, 5.9 liter, 6cylinder, turbocharged, heavy-duty direct injection diesel engine, rated at $224 \mathrm{~kW}$ (300 hp) at 2500 RPM. The engine has an active cooled EGR system with advanced electronic controls, heavily retarded injection timings, and employs a multiple fuel injection strategy. In-cylinder pressure measurements were used to calculate key thermal indicators representative of combustion variations. Results from the combustion analysis, obtained for a much expanded test matrix, confirm results presented in previous reporting periods and also provide further insight into key combustion differences between the fuels. Emissions characteristics also showed the same trends as those measured previously. Combustion rates and emission formation mechanisms were studied earlier using an analytical model based on heat release rates and published conceptual models of diesel combustion.

Specifically, compared to regular diesel, FT fuel reduces particulate emission substantially $(25-75 \%)$. We concluded in the first year that most of this reduction came from sulfur in the 400 ppm sulfur diesel fuel, as the reduction was consistent with the expected sulfates contribution from the high sulfur fuel. However, the data from the second year using $15 \mathrm{ppm}$ sulfur fuel also produced similar particulate reductions. In the current reporting period, Syntroluem carried out detailed chemical analysis of the fuels, and a number of particulate samples were sent to the emissionschemistry laboratory of a major engine manufacturer for analysis as well. The results of these tests provide increasing evidence for the contribution of a significant non-sulfur effect on the overall reduction in PM emissions.

The results of the combustion analysis provided further evidence for combustion derived PM reduction pathways. The reduced ignition delay due to the higher cetane number of the FT fuel, combined with the FT fuel's lower density reduces the amount of fuel consumed in the pre-mix burn phase and thus reduces the amount of PM generated as well. Furthermore, the faster burn rate of the FT fuel during the latter part of combustion also leads to increased particulate oxidation in the cylinder further reducing PM output. It was also shown in the previous reporting period that the faster burn rate of the FT fuel as compared to the diesel at retarded injection timings did not produce the particulates increase that normally accompanied retarded injection timings for NOx control using the regular diesel fuel. Therefore, late injection timings can be utilized more effectively with the FT fuel in controlling both particulates and NOx.

Also, conventional diesel fuel normally produces more particulates as EGR increases. Results show that FT fuel removes the sensitive dependence of PM production on EGR rate, allowing significant NOx reductions through the use of higher EGR rates before PM levels become unacceptably high. Current results are consistent with earlier findings that NOx decreases by up to $20 \%$ with the FT fuel. It is possible that further optimization of the engine to take advantage of the large particulates reduction can reduce NOx even further.

The issue of fuel blending was investigated to verify whether the benefits of FT fuel are proportional to its content in the fuel blend, as previously reported. A blend of $25 \%$ (by volume) FT fuel with $75 \% 400 \mathrm{ppm}$ sulfur fuel was studied. The particulates data show that the $25 \%$ FT fuel in the blend produced about half of the particulate reduction of using neat FT fuel. This non-linear benefit is consistent with independent results reported elsewhere. In addition, the results of the detailed chemical analysis performed at the emissions-chemistry laboratory of a major engine 
manufacturer demonstrated more than proportional reductions, in the range of $40 \%$ to $60 \%$, in nonsoluble soot and soluble organics for the blend when compared to the reductions observed for the neat FT fuel alone. These results confirm the observed trends in the reduction in PM emissions for the blend.

Results of the work completed during the current reporting period related to the emissions and combustion characteristics of FT diesel and conventional diesel fuels were accepted for publication and will be presented at the ASME Internal Combustion Engine Division 2005 Fall Technical Conference in Ottawa, Canada.

We are currently continuing our investigation of the impact of using the FT fuel on emission control via exhaust aftertreatment. A prototype diesel particulate rap system has already been evaluated. Based on the results of the tests with the prototype trap, a full-flow parallel trap unit was designed, fabricated, instrumented, and installed on the test bed. The trap consists of two parallel cordierite units of $19.05 \mathrm{~cm}$ (7.5") in diameter and $30.5 \mathrm{~cm}$ (12.0") in length. The experiments will address differences in trap regeneration characteristics, if any, of using FT fuel and opportunities made available, such as enhanced catalytic reactions in a sulfur-free exhaust stream. The final report will focus on this area.

In summary, we observed modest NOx reductions but $25-75 \%$ particulates reductions from using FT fuel over both $400 \mathrm{ppm}$ and $15 \mathrm{ppm}$ sulfur diesels fuels. Benefits arise not just from the fuel composition, but also from combustion characteristics and interactions with the engine technology as well. It is not believed that the effect of fuel sulfur on the observed PM emissions is as pronounced as was previously reported. The blend of FT fuel studied produced a more than a proportional reduction in PM emissions. Exhaust aftertreatment tests are continuing. Overall, FT fuel gives greater freedom to engine designers when trying to optimize the engine/emissioncontrol/fuel system in modern engines, since it provides the fuel properties as another flexible set of variables that affect the combustion and emission processes. Furthermore, the zero sulfur nature of the FT fuel allows for the use of additional and more aggressive exhaust aftertreatment devices, previously impossible due to the deleterious effects of fuel sulfur on the catalyst. 


\title{
FUEL, BLENDING, AND AFTERTREATMENT SYSTEM IMPACT ON GTL
} COMBUSTION AND EMISSIONS IN AN ADVANCED DI ENGINE

\author{
Annual Technical Progress Report \\ (September 1, 2004 - August 31, 2005) \\ ICRC: DOE Prime Contract No. DE-FC26-01NT41099 \\ MIT: ICRC Subcontract No. 3044-SUB-02
}

\subsection{SCOPE OF WORK FOR THIS REPORTING PERIOD}

The role of MIT in the project team is to complement other production, testing, and assessment efforts in the overall Ultra-Clean Fuels Program by exploring how advanced engine and emission control systems may benefit from the use of Syntroleum gas-to-liquid fuel.

Specific project tasks are:

(1) To assess how gas-to-liquid fuels impact engine performance and emissions, directly and in blends; to evaluate tradeoffs among fuel properties and blending ratios; to evaluate engine modifications in further improving engine emissions; and to determine combustion and emission characteristics.

(2) To explore opportunitie s of injection strategy control and exhaust-gas-recirculation (EGR) in pushing limits of NOx/particulates reduction using Syntroleum Fischer Tropsch (FT) fuels produced from small footprint plant (SFP). The engine will be modified for various injection control and EGR systems. Since particulates are expected to be substantially lower with the GTL fuel, limits of NOx reduction via EGR and injection variables will be explored using the specific fuels.

(3) To evaluate exhaust aftertreatment systems performance and design tradeoffs available using gas-to-liquid fuels. Optimize the fuel/engine/emission-control system.

If future resources become available, fundamental models and experiments to verify the effects of fuel characteristics on diesel processes most critical to effective engine performance and low emissions will also be developed. These advanced models will focus on fuel chemical composition effects.

Goals for this reporting period, the third and final year, were to (i) confirm the more than proportional benefits of using the FT/LSD blend observed in the previous reporting period, (ii) develop a better understanding of the fundamental processes influencing the fuel effects on engine out emissions by conducting detailed combustion and particulate chemical analyses, and (iii) continue investigating interactive effects of different fuel properties and an exhaust aftertreatment system. Tasks (1) and (2), except for the fuel blends and detailed characterizations, have essentially been covered in the past two years as previously reported. Work on Task (3) was initiated in the past reporting period as well. The differences in the measured combustion characteristics, PM chemical composition, and fuel properties were compared to the emissions variations between the fuels studied, and an explanation for the observed emissions behavior of the fuels was developed. The goals in this period have thus been accomplished, and work on the aftertreatment system, a particulate trap, is continuing. 


\subsection{CUMULATIVE ACCOMPLISHMENTS}

We have measured and correlated the NOx and particulate emissions trends with the combustion characteristics for a modern diesel engine (Cummins MY 2002 ISB 5.9 liters). Different injection timing strategies as well as EGR rates were explored. Initial results using limited quantities of the FT fuel and 400 ppm sulfur fuel showed NOx reductions of 6-13\% and particulate reductions with the FT fuel up to $75 \%$ compared to the $400 \mathrm{ppm}$ sulfur diesel fuel.

Subsequent tests expanded the test matrix. We explored substantial changes in fuel injection timings and EGR rates from the standard factory settings and included $15 \mathrm{ppm}$ and $400 \mathrm{ppm}$ sulfur diesel fuel, as well as FT/diesel blends (25\% FT/75\% 400ppm and $15 \mathrm{ppm}$ diesel by volume). While NOx reductions were still limited to $20 \%$ or less, the bulk of the data showed particulate reductions between $25-50 \%$. Particulate reductions of up to $75 \%$ by FT fuel compared to the standard diesel were observed at extremely retarded timing and light load conditions, primarily due to the increase of particulates of the regular diesel fuel at those extreme conditions.

Comparison with the ultra low sulfur fuel indicates that the particulate reduction benefit of FT fuel originates beyond the zero sulfur content of the FT fuel. In fact, the analyses suggest that the FT fuel maintains its combustion rates, even as injection timings are severely retarded and EGR rates heavily increased to reducing NOx. This is in contrast to conventional diesel fuel, where these conditions result in an increase in particulates.

Detailed chemical analyses of the particulate composition confirmed the results obtained in previous tests. Furthermore, the analyses provided conclusive evidence for the contribution of significant non-sulfur effects to the observed emissions trends. In fact, fuel sulfur may actually have very little influence on the observed differences in PM emissions for the fuels studied. The combustion analysis, carried out over a much larger range of engine operating conditions than in previous reporting periods, provided additional insight into the combustion characteristics and differences in observed emissions trends.

Samples of each of the test fuels were also sent to Syntroleum for analysis, as not all of the relevant fuel property data was provided by the fuel manufacturers. The results of the Syntroleum study include detailed distillation maps and gas chromatograms (GC) profiles, and provided additional information to explain the combustion and emissions behavior of the fuels.

Results of the work completed during the current reporting period, related to the emissions and combustion characteristics of FT diesel and conventional diesel fuels were accepted for publication and will be presented at the ASME Internal Combustion Engine Division 2005 Fall Technical Conference in Ottawa, Canada.

Hence, we have shown that FT fuel offers additional flexibility to the engine designer in optimizing the combined fuel/engine/emission-control system.

We are currently continuing our investigation of the impact of using the FT fuel on emission control via exhaust aftertreatment. A prototype diesel particulate trap system has already been evaluated. Based on the results of the tests with the prototype trap, a full-flow parallel trap unit was designed, fabricated, instrumented, and installed on the test bed. The 
trap consists of two parallel cordierite units of 7.5" in diameter and 12.0" in length. The experiments will address differences in trap regeneration characteristics, if any, of using FT

fuel and opportunities made available, such as enhanced catalytic reactions in a sulfur-free exhaust stream. The final report will focus on this area.

\subsection{LITERATURE SURVEY}

The emissions characteristics of FT fuels are well documented in the literature, and the results of a number of studies [1-10] on FT fuels have been presented in the previous two reporting periods. The current work in this program distinguishes from previous studies in two respects: The current study is done on a modern advance engine that has incorporated much of the latest engine technology and control strategies (Model year 2002 heavy-duty engine). Secondly, the author is unaware of any studies to date in which the combustion and emissions characteristics of neat FT fuels and blends have been carried out on an engine employing a multiple injection strategy. Furthermore, very little data exists on the effects of FT fuels on the performance and operating characteristics of exhaust aftertreatment systems, namely diesel particulate traps.

Despite the numerous studies of FT fuels and their effects on engine out emissions, the underlying mechanisms responsible for the observed emissions behavior are still not well understood. It is widely accepted that a number of factors contribute to the emissions behavior of the fuel, the most important of which are: chemical and physical properties, combustion characteristics, and engine technology. Furthermore, much work remains in the area of aftertreatment systems to fully exploit the positive characteristics of FT fuels.

\subsection{Fuel Effects}

The intercorreltations between fuel properties makes investigation into the effect of a specific property on emissions quite difficult. Relatively few studies have succeeded in adequately decoupling the change in a specific fuel property from changes in additional properties in the test fuel. Furthermore, it is nearly impossible to link changes in emissions to a particular fuel property when a number of properties are varied simultaneously [11]. The literature review compiled by Lee et al. focused solely on those studies where the intercorrelations between the fuel properties were decoupled, allowing for direct comparison between changes in a specific fuel property and engine-out emissions. In this review, the following fuel properties were identified as having a significant effect on diesel emissions: cetane number, fuel sulfur, density, and aromatics.

\subsubsection{Cetane Number}

Cetane number is the measure of a fuel's tendency to auto-ignite, with higher cetane number fuels exhibiting a shorter ignition delay. Recent studies have shown some benefit to reduced NOx emissions as cetane number was increased, however the impact of cetane number on particulates tends to be much less pronounced and engine specific. The reduced ignition delay with higher cetane number fuels leads to a reduction in pre-mixed combustion and a more gradual temperature rise in the cylinder, thus slowing the rate of NOx formation $[12]$. 


\subsubsection{Sulfur}

One of the most widely investigated diesel fuel parameters, the conversion of fuel sulfur to sulfate following the combustion process contributes to particulate exhaust emissions. Previous studies have shown that the amount of sulfur converted to PM is at least $1-2 \%$ of the fuel sulfur content irrespective of the total fuel sulfur level or engine type [13]. In addition to contributing to particulate emissions, fuel sulfur has also been linked to catalyst poisoning, limiting the use of exhaust aftertreatment systems with diesel engines.

Furthermore, the production of sulfuric acid from fuel sulfur has detrimental effects on the durability of EGR systems as well [14]. Aside from influencing particulate emissions and its detrimental impact on specific engine subsystems, fuel sulfur is not known to have any effect on regulated gaseous engine-out emissions [11].

\subsubsection{Density}

A number of studies have linked fuel density to particulate emissions. It has been shown that reducing fuel density can lead to a significant reduction in particulate emissions in older technology engines; however the effect is substantially reduced in newer technology engines with advanced injection strategies and improved mixing. In addition to reducing particulates, less dense fuels tend to reduce NOx emissions as well. On the other hand, emissions of $\mathrm{CO}$ and HC's may increase as the fuel density is reduced. Aside from emissions, density also directly affects an engine's power output, with less dense fuels leading to reduced power output, all other factors remaining constant $[15,11]$.

\subsubsection{Aromatics}

Much of the data regarding the impact of aromatics on emissions in the past presented conflicting results and failed to decouple the effect of the aromatics from density, cetane number, and T90. Despite this fact, it is widely agreed that total aromatics do not contribute significantly to $\mathrm{HC}, \mathrm{CO}$, or PM emissions, and only slightly affect NOx emissions. On the other hand, poly-aromatics (PAH) can have a substantial impact on particulate emissions and a smaller effect on NOx and CO emissions. However, similar to density, the effect of polyaromatics on emissions is seen to decrease with newer technology engines $[11,16]$.

\subsubsection{Back-End Volatility}

While the effect of back-end volatility, T90/T95, on emissions is generally considered minor and heavily dependent on the composition of the back end, this property can have a small effect on engine-out gaseous emissions. A number of studies have shown that reducing back-end volatility can lead to a slight increase in $\mathrm{HC}$ and $\mathrm{CO}$ emissions along with a decrease in NOx emissions. As mentioned above, T90/T95 has not been shown to have a noticeable effect on PM emissions [11, 17]. 


\subsection{Combustion Characteristics}

Although the effects of FT fuel on engine out emission have been well documented in the literature, there are very few published reports on the combustion characteristics of FT fuel. Furthermore, the author is not aware of any analysis of the combustion behavior of neat FT fuel or FT blends in a modern diesel engine employing a multiple fuel injection strategy and heavily retarded injection timing in addition to a number of other advanced engine subsystems.

Atkinson et al. presented perhaps the first detailed combustion analysis of FT fuel in a direct injection diesel engine. In this study, a Navistar T444E (7.3liter, V8) diesel engine was outfitted with two in-cylinder pressure transducers and subjected to twelve steady-state operating conditions. Over the entire test range, it was found that the higher cetane number of the FT fuel yielded a reduced ignition delay, and thus, reduced fuel evaporation before ignition. Furthermore, the FT fuel exhibited a slightly longer combustion duration and more uniform heat release rate than the baseline diesel. However, the total time from the start of injection to the end of combustion for each fuel was approximately equivalent. FT fuel was observed to reduce nearly all regulated emissions over the entire engine operating range, with the exception of hydrocarbons at some test conditions. It was also noted that FT fuel reduced the exhaust gas temperature, thus reducing NOx emissions. During the course of the Atkinson study the engine was operated completely stock, with no engine control parameters altered to compensate for the differences in the combustion characteristics of the two fuels [18].

Following the Atkinson study, McMillan and Gautam investigated the combustion and emission characteristics of FT and a federal low-sulfur diesel fuel in a Ricardo single-cylinder four-stroke DI research engine outfitted for in-cylinder pressure measurements. The engine was run at several steady-state operating conditions and timing was varied for each fuel at these conditions as well. McMillan and Gautam cited the higher cetane number and lower density of the FT fuel as primarily responsible for the observed differences in the combustion characteristics. They also observed similar overall burn durations and peak pressures for the two fuels; however the FT did exhibit a slightly shorter 50\% to $90 \%$ mass fraction burn duration [19]. Consistent with the Atkinson study, nearly all regulated exhaust emissions were reduced with the FT fuel, and the higher cetane number of the FT contributed to its shorter ignition delay.

\subsection{Engine Technology}

While the fuel properties and combustion characteristics have a significant effect on exhaust emissions, the relative importance of each specific effect can change depending on the type of engine and its operating characteristics. Numerous studies have indicated that the relative impact of fuel properties on emissions decreases with modern technology engines. In addition, Mann et al. noted that fuel effects on engine calibration significantly influenced the observed emissions effects. In this study, seven diesel fuels were tested in a modern electronically controlled direct-injection diesel engine and significant changes in engine calibration settings (most notably EGR rate and injection timing) were observed [20]. More recently, the effects of multiple injections and injection pressure have also demonstrated a significant effect on engine-out emissions and heat release rate [21, 22]. 


\subsection{Aftertreatment Systems}

Increasingly stringent emissions regulations aimed at drastically reducing exhaust emissions from diesel engines are some of the most important factors driving diesel engine development in the United States and Europe today. This new legislation is motivated by growing concern over the contribution of diesel engines to the overall atmospheric emissions inventory, coupled with increasing evidence demonstrating the adverse health effects posed by diesel particulate (PM) emissions [23]. The new regulations imposed by the United States Environmental Protection Agency (EPA) will decrease the allowable emissions limits for diesel engines by an order of magnitude between 2002 and 2007. In order to meet these strict requirements, engine manufacturers are finding it more and more difficult to meet emission levels through in-cylinder optimization. As a result, exhaust aftertreatment systems present additional means for meeting these requirements.

\subsubsection{Diesel Particulate Traps}

Few published reports exist in the open literature examining the effects of synthetic fuels, namely FT diesel, on particulate trap performance and regeneration. While the FT fuel alone demonstrates significant potential in reducing particulate emissions, the potential for further particulate reduction when the fuel is used in conjunction with advanced trap systems is even greater.

May et al. explored the emissions reduction potential of using FT fuels in a 2000 PowerStroke 7.3L V8 engine calibrated to conform to US 1998 emissions limits and equipped with an exhaust aftertreatment system. The aftertreatment system consisted of a DeNOX catalyst, a secondary fuel system, auxiliary exhaust cooler, and diesel particulate trap. In this study the DPT was located directly behind the DeNOx catalyst. Two FT fuels and a baseline $19 \mathrm{ppm}$ standard No. 2 diesel were evaluated, and the engine was run at select steady state operating conditions from both the light- and heavy-duty FTP cycle. Initial results showed light-duty

emissions within Tier 2 bin 8 standards and heavy-duty emissions approaching the 2007 limits for the FT fuel used in conjunction with the aftertreatment system. The fuel consumption penalty incurred ranged from an increase of $1.7 \%$ in the light-duty case to $5.6 \%$ in the heavyduty case. Transient effects were not examined in this study, nor was the DPT regenerated on line. Furthermore, significant improvements are expected for more sophisticated engines employing a 4 valve/cylinder design with central injector, higher injection pressures, and a variable geome try turbo-charger as the engine under study was of a 2 valve/cylinder design and only equipped with a standard wastegated turbocharger [8].

More recently Frank et al. investigated the effects of fuel type and emissions control systems on regulated gaseous emissions from heavy-duty diesel engines. A number of US and Canadian government agencies participated in this joint project along with numerous emission control and aftertreatment systems manufacturers. The study evaluated the gaseous emissions from a heavy-duty diesel engine using ten different test fuels, including FT diesel, as well as four aftertreatment configurations: engine out (no aftertreatment), diesel oxidation catalyst (DOC), continuously regenerating diesel particulate filter (CRDPF), and exhaust gas recirculation with CRDPF (EGR-DPF). The study found that the use of more aggressive 
aftertreatment devices had a much more pronounced effect on emissions than any of the nonstandard fuels, including blends. Aside from the PNOx fuel, the Fischer-Tropsch fuel tested consistently yielded the lowest NOx levels of any fuel regardless of the aftertreatment device. Furthermore, the FT fuel yielded the lowest PM emissions of all the fuels studied. However, interestingly, the authors noted that the removal of fuel sulfur did not appear to affect engineout PM emissions, but did reduce PM emissions when lower sulfur fuels were used in conjunction with a DOC [24].

Additional contributions to the literature have also been made in the area of exhaust emissions characterization with engines using FT and other low-sulfur diesel fuels in conjunction with exhaust aftertreatment systems. Thompson et al. investigated the fuel effects on regulated emissions from advanced diesel engines and vehicles. In this study a number of conventional fuels were compared with Swedish Class 1 and FT diesel in two advanced lightduty diesel vehicles and three heavy-duty diesel engines, spanning the Euro-3 to Euro-5 certification range. Significant reductions in particulate emissions were realized with a combination of low-sulfur fuels and DPFs [25]. Lev-On et al. performed a detailed chemical speciation of the exhaust emissions from trucks and buses fueled with low-sulfur diesels and FT diesel. The study examined the chemical characterization of the exhaust emissions using test fuels with and without aftertreatment systems (DPF) for a number of truck and bus fleets. The detailed exhaust speciation included emissions profiles for TPM, $\mathrm{PM}_{10}, \mathrm{PM}_{2.5}$, inorganic ions, elements, VOC's, ethane, olefins, BTEX, and benzene, among others, and the reader is referred to the published report [26] for further details.

Despite the apparent progress made in this area, specifically in the characterization of the fuel effects on engine out emissions with and without exhaust aftertreatment systems, much work still remains. Future work in this project area will focus on FT fuel effects on particulate trap loading and regeneration characteristics, a topic not adequately addressed in the current literature.

\subsection{REPORT ORGANIZATION AND DISCUSSION OF RESULTS}

Following a summary of the Experimental Set-Up in Section 5, the Fuels Tested in Section 6, and the Test Matrices and Procedures in Section 7, the Results of the effects of FT fuel versus conventional diesels, as well as blends will be presented in Section 8. Section 9 presents a Discussion along with plausible explanations for the observed results, Section 10 summarizes the progress to date on the study of the impact of FT fuel use on the Exhaust Aftertreatment Systems, and Section 11 summarizes the major Conclusions for this reporting period.

\subsection{EXPERIMENTAL SET-UP}

\subsection{Engine}

Cummins supplied a close-to-production development engine based on the model year 2002 (MY02) ISB 300. The ISB 300 is a turbocharged, 6-cylinder, 5.9-liter direct injection diesel engine. The engine is rated at $224 \mathrm{~kW}(300 \mathrm{hp})$ at $2500 \mathrm{RPM}$ and $890 \mathrm{~N}-\mathrm{m}(660 \mathrm{lb}-\mathrm{ft})$ torque at 1600 RPM. In order to meet 2002 EPA standards, the engine has advanced 
subsystems like a Bosch common-rail fuel injection system, Holset variable geometry turbocharger, and a cooled-EGR system. In addition to these subsystems, the engine also employs a multiple fuel injection strategy to further optimize the combustion process. To control these devices, the ISB 300 has an electronic control module (ECM) (version CM 850) that has been calibrated to meet emissions when operating with an EPA No. 2 diesel fuel. Table 5.1 contains further detailed information of engine specifications and geometry.

\begin{tabular}{|l|c|}
\hline Model & Cummins ISB 300 \\
\hline Number Of Cylinders & 6 \\
\hline Combustion System & Direct Injection \\
\hline Aspiration & Turbocharged \\
\hline Stroked (Displaced) Volume [liters] & 5.9 \\
\hline Bore [mm] & 102 \\
\hline Stroke [mm] & 120 \\
\hline Connecting Rod Length [mm] & 192 \\
\hline Crank Radius [mm] & 60 \\
\hline Compression Ratio & 17.2 \\
\hline Valve Timing & IVO $=9.5^{\circ}$ bTDC $\mid \mathrm{IVC}=23.5^{\circ}$ aBDC \\
\cline { 2 - 2 } & EVO $=142.0^{\circ} \mathrm{aTDC} \mid \mathrm{EVC}=18.0^{\circ}$ aTDC \\
\hline Injection Nozzle & O.D. $=158 \mu \mathrm{m}, \mathrm{L}=1.00 \mathrm{~mm}$ \\
\cline { 2 - 2 } & $8 \mathrm{Sac}-$ less $(\mathrm{VCO})$ Nozzles Per Injector \\
\hline
\end{tabular}

Table 5.1 Pre-production ISB 300 engine details

\subsection{Engine Control Software}

The pre-production ISB 300 engine came equipped with an unlocked ECM, allowing for engine calibration changes and realtime monitoring and modification of engine parameters. To communicate and link to the engine's ECM, Cummins provided their inhouse software, CalTerm (Calibration Terminal) version 7.63. Once the engine was installed, the stock 300-horsepower calibration, based on No. 2 diesel and provided by Cummins was uploaded into the ECM. This was done to ensure the engine would run on the 2002 EPAemission-certified performance maps.

While CalTerm allows for the monitoring and modification of hundreds of engine parameters, unlike the previous reporting period, no parameters were modified during the tests carried out in the current reporting period. Despite this fact, CalTerm was used to monitor and log a number a number of engine control parameters of interest such as charge flow, pilot injection quantity and timing, post injection quantity and timing, EGR fraction, boost pressure, and common-rail accumulator pressure, among others. Furthermore, CalTerm proved invaluable as a diagnostic tool aiding in the diagnosis of occasional engine problems by providing real-time logging and display of fault codes as well.

\subsection{Dynamometer Setup and Dynamometer Controller}

A Digalog AE 250 eddy current dynamometer, able to absorb up to $250 \mathrm{~kW}$, was used to load the engine. A Maywood Instruments U4000, $500 \mathrm{~kg}$ load cell measures torque by resisting the rotation of the outer casing. A differential pressure switch on the cooling-water 
outlet protects the dynamometer from failing if the cooling water supply happens to shut off.

Connecting the engine to the dynamometer is a drive shaft assembly made with two Spicer 1710 Series flange yokes attached to a $10.16 \mathrm{~cm}$ (4”) O.D. tube. The flange yokes are rated to withstand up to $1220 \mathrm{~N}-\mathrm{m}$ at steady state or spikes of up to $6500 \mathrm{~N}-\mathrm{m}$. The driveshaft is installed at about an $8^{\circ}$ to relieve stresses in the flange yokes as they rotate.

A Digalog Model 1022A-STD dynamometer controller was used to control engine speed while reading out the load from the Maywood Instruments load cell. The PID settings in the dynamometer controller were also adjusted to reduce load fluctuations when the commanded throttle setting changes. Before any tests were run, the controller and dynamometer were calibrated at two points, the $50 \%$ and $100 \%$ loads of the engine.

\subsection{Data Acquisition System}

A full complement of National Instruments data acquisition (DAQ) hardware and software was used to measure and record various temperatures, pressures, and flows. The heart of the system is the high-speed DAQ board, a National Instruments PCI-6024E. This board can read up to 200,000 samples per second. The high-speed DAQ board is limited to 16 single-ended channels (signals with a common ground) or 8 differential channels (signals with separate grounds). In order to get around this limitation, an SCXI-1000 multiplexing chassis was also used. The SCXI-1000 chassis can house up to 4 special modules containing various signal amplification, isolation, and noise suppression circuitry. The multiplexing chassis works by quickly scanning, one after another, all the channels of each module installed streaming the data into one differential channel of the DAQ board.

A special 32-channel module for thermocouples (SCXI-1102B) containing a fixed low-pass filter of $200 \mathrm{~Hz}$ was installed into the multiplexing chassis. The SCXI-1102B allows for gain and filter settings to be programmed on a per-channel basis. Most slow-speed signals were connected to this module. Attached to the SCXI-1102B is a TBX-1303 terminal block. The TBX-1303 provides a convenient location for the sensors to wire into while also containing a cold-junction-compensation sensor to provide a reference voltage to correctly scale any thermocouples plugged into the terminal block. A general 32-channel module (SCXI-1100) was used for mixed measurements. This module has user-selectable low-pass filter settings $(4 \mathrm{~Hz}, 10 \mathrm{kHz}$, and no filter) that apply to all channels. Since high-speed cylinder measurements (see Section 5.4.1) were recorded through this module along with various slow-speed signals, the $10 \mathrm{kHz}$ filter setting was used to provide some noise filtering while preventing the possibility of introducing phase errors into the high-speed signals due to poor low-pass filter response. Another TBX-1303 terminal block is attached to the SCXI1100 module to facilitate sensor wiring.

In addition to the two modules mentioned above, an additional 32-channel SCXI1102B module was also installed in the multiplexing chassis to accommodate the additional thermocouples and pressure transducers used to instrument the particulate traps. This module also contains a fixed $200 \mathrm{~Hz}$ low-pass filter, and was connected to a TBX-1303 terminal block equipped with cold-junction-compensation sensors to correctly scale the thermocouple

signals. 


\subsubsection{Crank-Angle-Resolved (High Sampling Rate) Measurements}

High-speed measurements taken during the experiments consisted of in-cylinder pressure, intake manifold pressure, and engine-position-indexing signals. Since in-cylinder pressures in a diesel engine can rise very rapidly after the auto-ignition event, a highresolution crank-angle encoder was installed onto the tone wheel to act as an external clock to the DAQ system. An 1800-pulse-per-revolution BEI encoder provides a $0.2^{\circ}$ resolution for the high-speed data. The BEI encoder also has another channel that gives out one digital pulse per revolution. This once-per-revolution signal was used to trigger the high-speed DAQ measurements, ensuring the data recording started at the same point of an engine revolution, although not always on the same stroke. This removed the need to superimpose a reference signal to the cylinder pressure data.

The pre-production ISB 300 engine installed at MIT was actually used at Cummins to perform development work on the engine currently available on the market. When the engine was shipped to MIT, an AVL QC33C heavy-duty pressure transducer was already installed in cylinder number 6 (cylinder closest to flywheel). The QC33C is a quartz, piezo-electric pressure transducer that is actively liquid-cooled to reduce the effects of thermal shock. A Bernard Model 2500SS MIG welder cooler is plumbed into the pressure transducer and circulates and cools a 50:50 mixture of distilled water and ethylene glycol. The transducer's small current output is converted to a voltage using a Kistler Model 5010B charge amplifier. The charge amplifier's output is fed into the DAQ system.

Since piezo-electric pressure transducers only measure changes in pressure, a method of referencing the pressure is required. The intake manifold pressures recorded along with the in-cylinder pressure provide a value to peg the cylinder pressure. The in-cylinder pressure signal is usually averaged around BDC and then scaled to equal the intake manifold pressure.

In order to provide precise fueling, the engine's ECM not only must know where the pistons are in relation to TDC, it also needs to differentiate which aspect of the four-stroke cycle each piston is going through. To provide engine-position data, the engine has Halleffect sensors on both the camshaft and tone wheel. The tone wheel is a $60(-1)$ design, originally containing 60 equally spaced teeth with one removed to provide a point of reference. The signal from the tone-wheel sensor was also fed into the DAQ system to check the phasing of the in-cylinder pressure signal.

\subsubsection{Pressure Transducer Calibration and Encoder Phasing}

In order to obtain meaningful results from the high-speed in-cylinder pressure measurements, correct phasing of the pressure signal is of utmost importance. Two methods were used to correctly adjust the phasing of the start of the high-speed data recording with respect to TDC. The first method used as a first approximation to set the proper phasing was to adjust the encoder so that the reference signal on the crankshaft tone wheel (the location after the missing tooth where the signal transitions from high to low) occurs $60.0^{\circ} \mathrm{bTDC}$. Once the encoder was set at this approximate position, the peak pressure was determined from a motoring pressure trace and $0.4^{\circ}$ were added due to heat transfer and blow-by effects. This is the procedure recommended by Cummins, and results in a more precise determination of 
TDC. In order to obtain the motoring pressure trace for TDC determination, the engine parameter FSI_x_ExtCylMask_c was set to 001F (hexadecimal representation of cylinder 6) in order to cut fueling to the cylinder so that motoring pressure traces could be recorded. The motoring traces were thus recorded and fine adjustments to the encoder made until proper phasing of the signal was achieved. As a final check for correct phasing, the log-pressure versus log-volume curves were plotted for the motoring pressure traces to verify that the compression and expansion lines did not cross [27].

\subsection{Fueling System}

As in the last reporting period, the current system used to determine fuel flow rates consists of an Ohaus Scout II Pro balance and a four-liter beaker containing some quantity of fuel. The balance was connected to the serial port of the data acquisition computer and continuously polled to display the updated fuel mass every second. Because only approximately one gallon of fuel could be contained in the beaker, fuel flow data was only taken when gaseous emissions and slow speed data were recorded. The counter flow heat exchangers installed for the previous system were retained, though they were superfluous as the new system measures the mass flow directly without the need to correct for temperature. To control the fuel supply and return, two three-way ball valves were installed to select either the beaker or tank as fuel source, and likewise for return. The beaker was generally refilled by selecting the tank as a source and the beaker for the return.

In order to prevent cross contamination of sulfur and aromatics between the two fuels used in the experiments, two 81.4-liter (22-gallon) ATL Inc. SP122B racing fuel cells were installed on the engine test bed. Two bulkhead connections near the engine allow switching between the individual fuel tanks. Another bulkhead allows for fuel to bypass the return system in order to drain the entire system or purge standing fuel in various fuel galleries in the engine when changing fuels. The entire fuel system uses Teflon lines since diesel fuel is a strong solvent, while stainless-steel over-braids over the Teflon protect them from physical wear and tear.

\subsection{Intake Air Measurement and Preparation}

An Eldridge Products, Inc. Series 8732 thermal mass flow meter measures airflow into the turbocharger's compressor inlet. The inline-style flow meter consists of a sensing element installed into a flow section. The flow section has a laminar flow element to ensure fully developed flow by the time the air reaches the sensing element. The sensing element uses two RTDs (resistance temperature detector) to measure airflow. One RTD measures the temperature of the incoming air stream. The second RTD is forced through self-heating to maintain a constant temperature above the incoming gas. The sensing element's signal processor takes both the required current to heat the second sensor and the initial temperature read by the first RTD to calculate the mass of air flowing through the flow section. A K\&N paper filter fitted upstream of the thermal mass flow meter filters the ambient air in the test cell before it flows into the engine.

After being compressed by the turbocharger, the pressurized air leaving the turbocharger is extremely hot. To reduce peak pressures in the engine, the compressed air is 
cooled once it leaves the compressor. A Spearco Universal Air/Liquid Intercooler was used to cool the fresh charge leaving the turbocharger. The amount of charge-air cooling is controlled by a gate valve on the liquid side of the charge-air cooler that controls the flow of water through the core of the charge-air cooler. Connections between the engine and aftercooler are made with $7.54 \mathrm{~cm}$ (3”) I.D. silicone rubber hose, capable of withstanding temperatures up to $450 \mathrm{~K}$.

\subsection{Gaseous Emissions Analyzers}

A gas analyzer system was designed and fabricated at the Sloan Automotive Laboratory. This system is capable of measuring exhaust gas concentrations in both the raw exhaust stream and dilution tunnel, as well as in the intake manifold to determine the EGR fraction. In this study, all gaseous emissions comparisons were based on measurements sampled from the raw exhaust using heated sample lines and filters to prevent any water from condensing out of the exhaust stream.

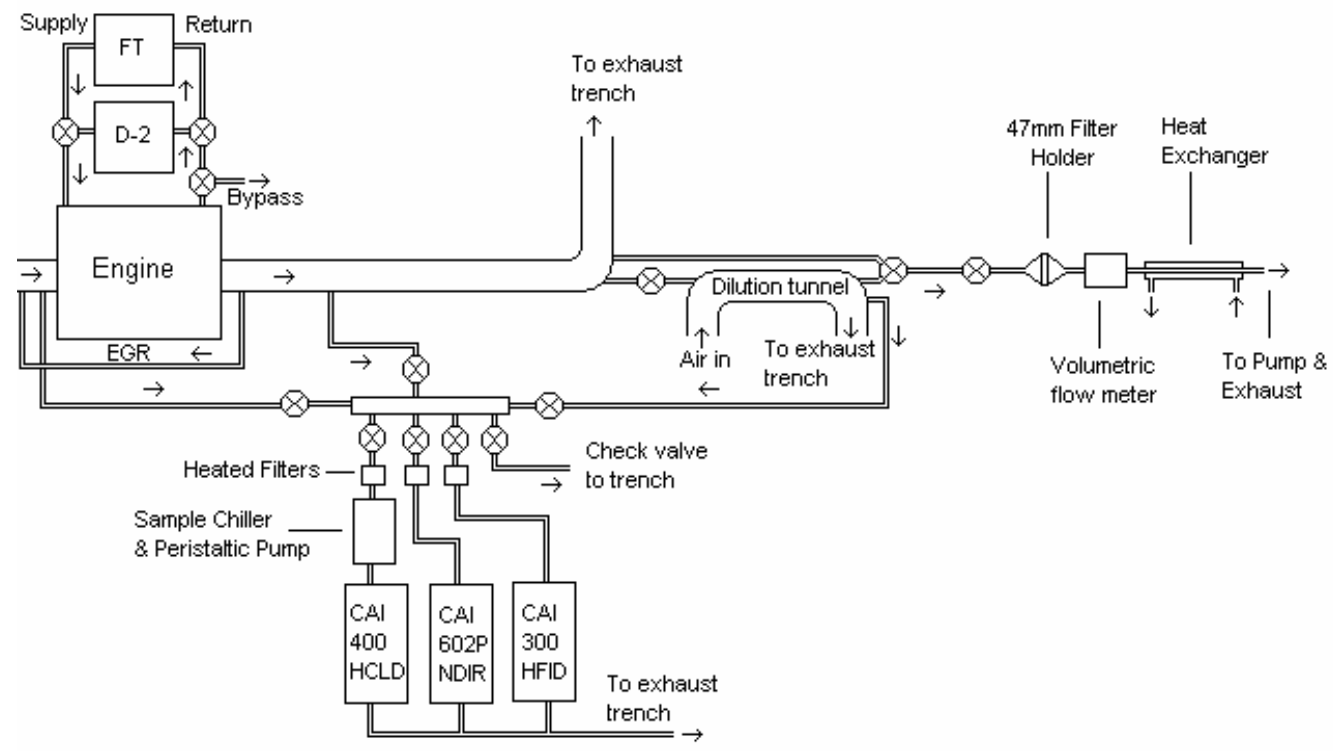

Figure 5.1 Emission sampling system schematic

Figure 5.1 shows a schematic of the emission sampling system and general experimental set-up. A full suite of California Analytical Instruments (CAI) emissions analyzers comprised the heart of the gaseous emissions sampling system, and enabled measurement of $\mathrm{HC}, \mathrm{NO} / \mathrm{NOx}, \mathrm{CO}_{2}, \mathrm{CO}$, and $\mathrm{O}_{2}$.

Hydrocarbon emissions were measured using a CAI Model 300-HFID. The Model 300-HFID was calibrated with 300 PPM propane $\left(\mathrm{C}_{3} \mathrm{H}_{8}\right)$, resulting in an effective range of 0 900 PPM of $\mathrm{C}_{1}$. During experiments, the Model 300-HFID was left on the $0-30$ PPM range since HC emissions from the ISB 300 are fairly low. The 300 HFID is a flame ionization detector, and as such a flame ionizes the sample stream and electrodes in the instrument measure the particles. The flame in the Model 300-HFID is fueled by HC-free air and a fuel mixture of $40 \%$ hydrogen and $60 \%$ helium. 
A California Analytical Instruments Model 400 HCLD Heated chemiluminescence $\mathrm{NO}_{\mathrm{x}}$ analyzer was used to measure $\mathrm{NO} / \mathrm{NO}_{\mathrm{x}}$ concentrations in the raw exhaust. For engineout $\mathrm{NO}_{\mathrm{x}}$, a sample point about 10 pipe diameters away from the nearest elbow was used, ensuring fully developed flow at the sample point. To calibrate the Model 400, a calibration gas of $296 \mathrm{PPM}$ of $\mathrm{NO}_{\mathrm{x}}$ and zero gas of high-grade compressed air was used to create a linear voltage output between the two concentrations. This output of the NOx analyzer is fed into the DAQ system, and the voltage read is converted back to a PPM concentration and recorded.

A recently installed CAI 602P Non-Dispersive Infrared (NDIR) analyzer replaced the Horiba MEXA $554 \mathrm{JU}$ for $\mathrm{CO}_{2}$ measurements. In addition to $\mathrm{CO}_{2}$, the NDIR analyzer is also capable of measuring $\mathrm{CO}$ and $\mathrm{O}_{2}$ content in the sample gas. $\mathrm{CO}_{2}$ measurements were taken from three sample streams: raw exhaust, intake air, and dilution tunnel air. These figures were used to do consistency checks of the fuel and air flow measurements and to calculate EGR and dilution ratios. For intake- mixture $\mathrm{CO}_{2}$ (for EGR fraction calculations), a sample point $0.1016 \mathrm{~m}$ (4") downstream from the closest elbow (0.3048 m (12") from EGR valve) was installed. The intake sample point was installed in the middle of the intake air heater, the heating elements within the flow stream acting as guide vanes, helping to distribute the flow uniformly. For dilution ratio measurements, a sample point was installed about $0.762 \mathrm{~m}$ (30") away from the transfer tube, again ensuring fully developed flow at the sampling point.

All of the above-mentioned gaseous emissions analyzers were mounted in a newly fabricated analyzer rack. In addition to the analyzers, the rack houses a number of sample preparation and conditioning systems as well. The samples for all of the CAI instruments were carried from their respective sample points on the engine/exhaust system to the analyzer rack via heated sample lines. The lines connected directly to individual Universal Analyzers Model 270S heated stack filters that employ 2 micron ceramic filter elements to remove any large particulate matter that can also clog sample and capillary tubes within the gas analyzers. A series of heated stainless steel lines connected the heated filters to a manifold and corresponding bulkhead mounted on the front panel of the analyzer rack. The bulkhead contains a series of valves, which control zero and span gas flow, as well as enable selection of the various sample points.

As the $\mathrm{HC}$ and NOx measurements are carried out wet, the sample gasses for these analyzers are routed directly from the bulkhead, via heated lines to the sample port of the analyzers. On the other hand, since the $\mathrm{CO}_{2}, \mathrm{CO}$, and $\mathrm{O}_{2}$ emissions must be measured dry to avoid interference between any moisture in the exhaust stream and the optical measurement systems in the analyzer, the sample stream is first passed through a Universal Analyzers single stage sample chiller to cool the sample to $3.5^{\circ} \mathrm{C}$ and remove any water vapor present in the sample stream. Furthermore, a secondary moisture sensor/filter assembly provides an additional check before the dry gas stream is routed into the NDIR analyzer.

\subsection{Mini-Dilution Tunnel}

The EPA defines particulate matter as all solid matter and condensable species that can be collected on a paper filter from a diluted exhaust sample held at no higher than $52^{\circ} \mathrm{C}$ [28]. The EPA defines particulate matter in such a way since it forces the sampling system to employ some form of a dilution tunnel that helps simulate particle transformations (i.e. 
agglomeration, adsorption, and nucleation) that would normally occur outside of the laboratory. Dilution tunnels can be designed to condition the entire exhaust flow or can be arranged in such a way as to only take and dilute a small sample of the exhaust.

The mini dilution tunnel used with the experimental setup is based on the dilution of a fraction of the exhaust stream. The dilution tunnel is predominantly made of $75.4 \mathrm{~cm}$ (3") O.D. stainless steel 304 tubing. The exhaust gas sample is transferred, due to a positive pressure differential, through a $1.88 \mathrm{~cm}(3 / 4$ ") O.D. tube with a high-temperature resistant ball valve in place to regulate exhaust gas flow. The transfer tube introduces raw exhaust into the dilution tunnel $0.762 \mathrm{~m}$ (30") away from the sample point, allowing the dilution air and raw exhaust to mix and become fully developed before being sampled. The pressure in the dilution tunnel is held below atmospheric conditions by connecting the exit of the dilution tunnel to the intake of a Spencer Model 1001-1/2SS blower. As air is drawn through the minidilution tunnel, the pressure drops due to losses within the tubing. A Solberg FS-31P-250 air filter holder with a HEPA filter element is installed at the inlet of the dilution tunnel system, providing an additional pressure drop within the tunnel. The dilution ratio is measured by comparing the $\mathrm{CO}_{2}$ readings in the tunnel to the $\mathrm{CO}_{2}$ readings in the raw exhaust. Additional checks of the dilution ratio can also be made by monitoring both raw and dilute NO/NOx readings as well.

\subsection{Gravimetric Particulate Matter Sampling System}

The gravimetric particulate matter sampling system used to sample raw and dilute gas samples employs a Pall Corporation stainless steel $47 \mathrm{~mm}$ filter holder that housed Pall Corporation Pallflex ${ }^{\circledR}$ Fiberfilm glass filters (Model T60A20-47 MM). Made with borosilicate glass fibers and a moisture-resistant fluorocarbon (TFE) coating, the Pallflex Model T60A20 brand of filters resist moisture uptake and prevent moisture-gas reactions, eliminating the need for lengthy drying times when using normal hygroscopic glass fiber filters. As such, the EPA recommends the Model T60A20 brand of filters for use in gravimetric filter measurements [29]. The Model T60A20 filters can also withstand very high temperatures, up to $315.5^{\circ} \mathrm{C}$, making them ideal for raw exhaust gas sampling as well.

To measure sample flow through the filter, an Omega FVL-1611 volumetric flow meter was installed downstream of the filter/filter holder assembly. The Omega FVL-1611 sensor body houses differential pressure transducers, a thermocouple, and a laminar flow element that the flow computer uses to measure flow rates up to 250 SLPM. The flow computer output is fed into the National Instruments DAQ system, so flow rates over time can be recorded and averaged. This helps account for the variation in flow rates as the filter paper is loaded. A Gast Model 0823 rotary vane vacuum pump was used to draw the raw or dilute sample through the sampling lines, filter paper, and mass flow meter. To prevent condensation of particles on the walls with raw exhaust samples, the stainless steel lines from the raw exhaust sample point were insulated with silicon-rubber based tubing insulation. Also, a rope heater was installed from the sample point to a position $1.524 \mathrm{~m}$ ( 5 feet) downstream.

In order to verify compliance with EPA dilute particulate sampling procedures, thermocouples were installed at locations slightly in front of the $47 \mathrm{~mm}$ filter holders. The temperature readings were also fed into the National Instruments data acquisition system. 


\subsection{EXPERIMENTAL FUELS}

The three neat fuels investigated in this reporting period were a low sulfur diesel (400 ppm), ultra-low sulfur diesel (15 ppm), and a Fischer-Tropsch synthetic diesel produced from natural gas. A blend of 25\% FT and 75\% low sulfur diesel by volume was used as well.

\subsection{Number 2 Diesel Fuel}

The No. 2 diesel fuels used to create a performance and emission baseline were supplied by Fleetline, distributed by Dennis K. Burke Inc. The two fuels differed primarily in sulfur content, with one containing $400 \mathrm{ppm}$ sulfur by volume and the other containing 15 ppm sulfur by volume. Based on the product information brochure, these fuels are formulated with anti-oxidants to reduce volatility and prevent fuel degradation, inhibitors to fight gum and deposit formations in the fuel system, viscosity improvers for fuel injector lubrication and correct spray pattern, and additives for low-temperature operation.

\subsubsection{Low Sulfur Diesel Fuel}

Initial work on this project used Fleetline's "Low Sulfur Diesel Fuel" (LSD). Although this diesel fuel has a fuel-sulfur content of 400 PPM (see Table 6.1), it still meets the EPA Low-Sulfur Fuel requirement ( $<500$ PPM). Also, since it meets the ASTM D 975 specifications for No. 2 diesel fuel, it should contain a high aromatic content, although no more than $35 \%$ as required by law (see Table 6.2). As this is a typical worst-case fuel currently allowed and available to on-road heavy-duty diesel engines, it was used to provide a good baseline to compare the improvements seen when running with FT fuel.

The typical value for the lower heating value of the low sulfur fuel was not listed in the product literature provided by Fleetline. In order to compare the lower heating values of three different fuels used in the experiments, the lower heating value for a typical EPA No. 2 diesel fuel given by Syntroleum's S-2 brochure was used [30]. The value reported in the brochure is: $\mathrm{Q}_{\mathrm{LHV}, \mathrm{No} .2}=129,400 \mathrm{Btu} / \mathrm{gal}$. Converting this to SI units on a mass basis requires the density of the fuel. Table 6.1 lists the API (American Petroleum Institute) gravity obtained using the ASTM D 287 method. The ASTM D 287 method lists API gravity at $16^{\circ} \mathrm{C}$ as:

Equation 6.1

$$
\text { API @ } 16^{\circ} \mathrm{C}=\frac{141.5}{\text { s.g. @ } 16^{\circ} \mathrm{C}}-131.5
$$

Using the above equation and the fuel's API gravity of 37, we get a fuel density of $\rho_{\mathrm{No.2}}=840 \mathrm{~kg} / \mathrm{m}^{3}$. Finally, converting the lower heating value appropriately leads to a lower heating value of $\mathrm{Q}_{\mathrm{LHV}, \mathrm{No.2}}=42.9 \mathrm{MJ} / \mathrm{kg}$. This checks closely to data about general light diesel fuels listed as $\mathrm{Q}_{\mathrm{LHV}, \mathrm{No} .2}=43.2 \mathrm{MJ} / \mathrm{kg}$ in [31]. Additional data provided by Fleetline for the low sulfur diesel is listed below in table 6.1. 


\section{PREMIUM LOW-SULFUR DIESEL FUEL}

\begin{tabular}{|c|c|c|c|}
\hline TEST DESCRIPTION & $\begin{array}{l}\text { ASTM } \\
\text { METHOD }\end{array}$ & $\begin{array}{l}\text { ASTM NO. 2-D } \\
\text { STANDARD (D 975) }\end{array}$ & $\begin{array}{l}\text { TYPICAL } \\
\text { ANALYSIS }\end{array}$ \\
\hline Cetane Number & D 976 & $40 \mathrm{~min}$. & 47 \\
\hline API Gravity at $16^{\circ} \mathrm{C}\left(60^{\circ} \mathrm{F}\right)$ & D 287 & $30 \mathrm{~min}$. & 37 \\
\hline Pour Point, ${ }^{\circ} \mathrm{C}\left({ }^{\circ} \mathrm{F}\right)$ & D 97 & $-7(20) \max$. & $-11(12)^{*}$ \\
\hline Cloud Point, ${ }^{\circ} \mathrm{C}\left({ }^{\circ} \mathrm{F}\right)$ & D 2500 & - & $-10(14)^{*}$ \\
\hline Flash Point (Pensky-Martens), ${ }^{\circ} \mathrm{C}\left({ }^{\circ} \mathrm{F}\right.$ & D 93 & 52 (125) min. & $66(151)$ \\
\hline BTU/Gallon (gross) & -- & -- & 139,200 \\
\hline Sulfur, Weight $\%$ & D 1552 & $0.05 \max$ & 0.04 \\
\hline $\begin{array}{l}\text { Viscosity, Saybolt, } \\
\text { SUS at } 38^{\circ} \mathrm{C}\left(100^{\circ} \mathrm{F}\right)\end{array}$ & D 2161 & $32.6-40.1$ & 34.5 \\
\hline $\begin{array}{l}\text { Viscosity, Kinematic, } \\
\text { cSt at } 40^{\circ} \mathrm{C}\left(104^{\circ} \mathrm{F}\right)\end{array}$ & D 445 & $1.9-4.1$ & 2.52 \\
\hline $\begin{array}{c}\text { Copper Strip Corrosion, } \\
3 \text { Hrs. @ } 50^{\circ} \mathrm{C}\left(122^{\circ} \mathrm{F}\right)\end{array}$ & D 130 & $3 \max$ & 1 \\
\hline $\begin{array}{l}\text { Distillation (Evap.), }{ }^{\circ} \mathrm{C}\left({ }^{\circ} \mathrm{F}\right) \\
10 \% \text { Recovered } \\
50 \% \text { Recovered } \\
90 \% \text { Recovered } \\
\text { End Point } \\
\text { Recovery \% } \\
\text { Residue \% } \\
\text { Loss \% }\end{array}$ & D 86 & $\begin{aligned} & - \\
- & - \\
282-338 & (540-640) \\
& - \\
- & - \\
-- & -\end{aligned}$ & $\begin{array}{c}206(402) \\
260(500) \\
335(635) \\
353(667) \\
98.0 \\
1.5 \\
0.5\end{array}$ \\
\hline $\begin{array}{l}\text { Carbon Residue, Ramsbottom } \\
\text { (10\% Bottoms, Weight \%) }\end{array}$ & D 524 & $0.35 \max$. & 0.05 \\
\hline Water and Sediment, Vol. \% & D 1796 & $0.05 \max$. & 0.001 \\
\hline Ash, Weight $\%$ & D 482 & $0.01 \max$. & $<0.001$ \\
\hline Color (Visual) & - & - & Clear to Amber \\
\hline \multicolumn{4}{|c|}{ Date Approved: 3/15/00 (Specification valid only if dated) } \\
\hline \multirow[t]{2}{*}{$\begin{array}{l}\text { * Adjusted with additives and kerosene } \\
\text { blending for winter operation. }\end{array}$} & ues only. Minor & \multicolumn{2}{|c|}{$\begin{array}{l}\text { Note: Other additives may be added } \\
\text { to enhance lubricity when needed. }\end{array}$} \\
\hline & DENNIS K & \multicolumn{2}{|c|}{$\begin{array}{l}\text { We can also custom blend fuel to meet } \\
\text { customer's specifications. }\end{array}$} \\
\hline
\end{tabular}

284 EASTERN AVE. • CHELSEA, MASS. 02150 - PHONE: 1-800-289-2875 - FAX: (617) 884.7638 • WEBSITE: WWW.BURKEOIL.COM

Table 6.1 Manufacturer's specifications for the low sulfur diesel used in the experiments 


\subsubsection{Ultra-Low Sulfur Diesel Fuel}

To provide a more realistic baseline for comparison with the FT fuel, baseline tests were also performed with Fleetline's "Ultra-Low Sulfur Diesel Fuel," (ULSD) which meets the 2006 standard of 15 PPM sulfur by volume. The fuel properties provided by Fleetline for the ultra- low sulfur diesel are listed in table 6.2 below.

\section{FLEETLHE \\ PRODUCT SPECIFICATIONS}

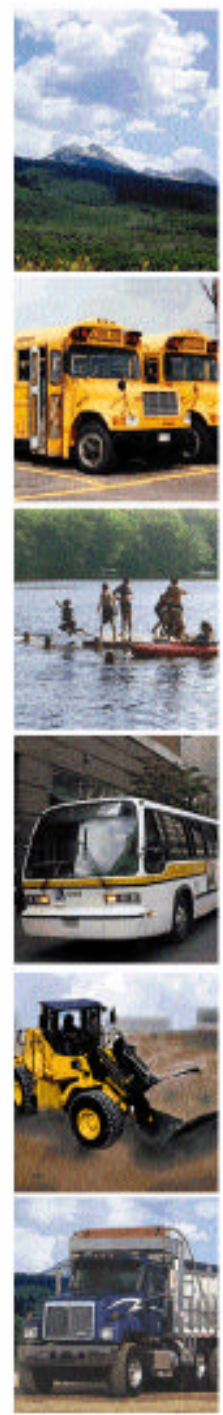

Note: Premium Additive Package includes oetare improvers, lubncity enhancers and detergents.

\section{ULTRA LOW SULFUR DIESEL}

\begin{tabular}{|c|c|c|c|}
\hline TEST DESCRIPTION & $\begin{array}{c}\text { ASTM } \\
\text { METHOD }\end{array}$ & $\begin{array}{l}\text { ASTM NO. 2-D } \\
\text { STANDARD (D 975) }\end{array}$ & $\begin{array}{l}\text { TYPICAL } \\
\text { ANALYSIS }\end{array}$ \\
\hline Cetane Index (Calculated) & D 976 & $40 \mathrm{~min}$. & 42.7 \\
\hline Cetane Number & D 613 & $40 \mathrm{~min}$. & 50 \\
\hline API Gravity at $16^{\circ} \mathrm{C}\left(60^{\circ} \mathrm{F}\right)$ & D 4053 & $30 \mathrm{~min}$. & 40.3 \\
\hline Density, lbs./gallon & Table 8 & - & 6.858 \\
\hline Pour Point, ${ }^{\circ} \mathrm{C}\left({ }^{\circ} \mathrm{F}\right)$ & D 97 & $-6(20) \max$ & $-30(-22)$ \\
\hline Cloud Point, ${ }^{\circ} \mathrm{C}\left({ }^{\circ} \mathrm{F}\right)$ & D 2500 & - & $-30\langle-22\}$ \\
\hline Flash Point (Pensky-Martens), ${ }^{\circ} \mathrm{C}\left({ }^{\circ} \mathrm{F}\right)$ & D $93 \mathrm{~A}$ & 52 (125) min. & $63(146)$ \\
\hline Heat of Combustion, BTU/gallon & D 240 & - & 135,514 \\
\hline Viscosity, Saybolt, SUS at $38^{\circ} \mathrm{C}\left(100^{\circ} \mathrm{F}\right)$ & D 2161 & $32.6-40.1$ & 31.47 \\
\hline Viscosity, Kinematic, cSt at $40^{\circ} \mathrm{C}\left(104^{\circ} \mathrm{F}\right)$ & D 445 & $1.9-4.1$ & 1.67 \\
\hline Sulfur, parts per million & D 5453 & $30 \max$. & 15 \\
\hline Nitrogen, parts per million & D 5762 & - & 5 \\
\hline Corrosion, Copper Strip & D 130 & 1 max. & 1 \\
\hline Alkali or Mineral Acids & D 974 & - & neutral \\
\hline Distillation (Evap.), ${ }^{\circ} \mathrm{C}\left({ }^{\circ} \mathrm{F}\right)$ & D 86 & & \\
\hline $10 \%$ Recovered & & - & $199(390)$ \\
\hline $50 \%$ Recovered & & - & $218(425)$ \\
\hline $90 \%$ Recovered & & $282-338(540-640)$ & $248(478)$ \\
\hline End Point & & - & $269(517)$ \\
\hline Recovery $\%$ & & - & 98.0 \\
\hline Residue $\%$ & & - & 1.4 \\
\hline Loss $\%$ & & - & 0.6 \\
\hline Carbon Residue, Wt. $\%$ (10\% Bottoms) & D 524 & 0.35 max. & 0.15 \\
\hline Water and Sediment, Vol. $\%$ & D 1796 & $0.05 \max$ & 0,00 \\
\hline Ash, Weight $\%$ & D 482 & $0,01 \max$ & 0.00 \\
\hline Color (Visual) & D 1500 & (Clear to Amber) & $<0.5$ \\
\hline \multicolumn{4}{|c|}{ Date Approved: $2 / 15 / 04$ (Specification valid only if dated) } \\
\hline
\end{tabular}

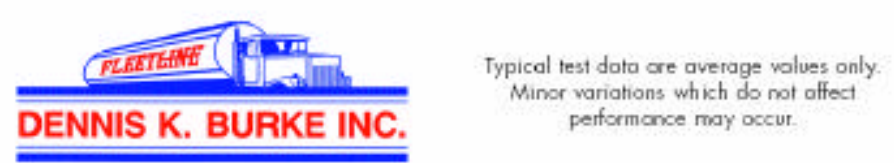

284 EASTERN AVE. - CHELSEA, MASS, 02150 - PHONE: 1.800289-2875 - FAX: $1617 \mid$ 884.7638 - WEBSITE: WWW BURKEOIL COM

Table 6.2 Manufacturer's specifications for the ultra-low sulfur diesel used in experiments 
The purpose of using this fuel is twofold: first, to allow for evaluation of fuel sulfur effect on emissions and, second, to compare FT fuel to a fuel that will be widely available in the future.

The lower heating value of the No. 2 diesel fuel is not listed in the table provided by Fleetline. In order to compare the lower heating value of the No. 2 diesel fuel to the Syntroleum Fischer-Tropsch fuel used in the experiments, the lower heating value for an EPA No. 2 diesel fuel given by Syntroleum's S-2 brochure was, once again, used [30]. The value reported in the brochure is: $\mathrm{Q}_{\mathrm{LHV}, \mathrm{No} .2}=129,400 \mathrm{Btu} / \mathrm{gal}$. Converting this value to SI units, and taking into account the measured fuel density of $845 \mathrm{~kg} / \mathrm{m}^{3}$, yields $\mathrm{Q}_{\mathrm{LHV}}, \mathrm{No} .2=42.7$ $\mathrm{MJ} / \mathrm{kg}$ [32]. This also checks closely to data about general light diesel fuels listed as $\mathrm{Q}_{\mathrm{LHV}, \text { No.2 }}$ $=43.2 \mathrm{MJ} / \mathrm{kg}$ in $[31]$.

\subsubsection{No. 2 Diesel Combustion Equation}

In order to make combustion-characteristic comparisons between No. 2 diesel and Syntroleum S-2 FT diesel, a simplified chemical composition of $\mathrm{CH}_{1.8}$ and molecular weight of $170 \mathrm{~g} / \mathrm{mol}$ [31] was used in order to write the ideal combustion equation (using the simplified chemical composition) for No. 2 diesel as follows:

Equation $6.2 \quad 12.3 \mathrm{CH}_{1.8}+\frac{17.835}{\phi}\left(\mathrm{O}_{2}+3.773 \mathrm{~N}_{2}\right) \rightarrow 12.3 \mathrm{CO}_{2}+11.07 \mathrm{H}_{2} 0+17.835\left(\frac{1}{\phi}-1\right) \mathrm{O}_{2}+\frac{67.29}{\phi} N_{2}$

Using Equation 6.2, the air/fuel ratio of No. 2 diesel fuel is 14.50:1. This equation was used in the analysis of both the 400 PPM and 15 PPM fuel

\subsection{Fischer-Tropsch Diesel}

The trend toward cleaner fuels for reduced emissions and improved compatibility with aftertreatment devices has led to renewed interest in Fischer-Tropsch fuels in recent years. Developed in the 1920's by Franz Fischer and Hans Tropsch, the FT process can be used to produce hydrocarbon fuels from a wide range of carbonaceous materials. This process consists of four major steps. The first step is the production of synthesis gas ( $\mathrm{CO}$ and $\mathrm{H} 2)$ from the feedstock, typically natural gas, coal, or biomass. This step is followed by the purification of the synthesis gas, since the FT process relies heavily on the use of catalysts, and any sulfur in the synthesis gas can poison the catalysts, thus reducing fuel production. The third step is the FT catalysis process in which the synthesis gas is converted to heavy, straight chain liquid hydrocarbons and waxes. The final step in the process consists of refining the heavy hydrocarbons by means of hydrocracking, isomerization, fractionation, and distillation to produce the desired fuel [15].

\subsubsection{Syntroleum FT Diesel Combustion Equation}

The Syntroleum Corporation provided the Fischer-Tropsch fuel (Syntroleum S-2) used in the experiments. Syntroleum S-2 is synthesized using the Syntroleum Process ${ }^{\mathrm{TM}}$, which consists of a special auto-thermal-reformer (ATR) that produces synthesis gas from natural gas and untreated air. This reduces the overall production costs, making S-2 fuel economically marketable. 
Due to the zero-sulfur content (not listed in preliminary specifications, but found in Syntroleum's detailed S-2 synthetic diesel prospectus [30]) of the S-2 fuel, the lubricity properties of the fuel are low, increasing the likelihood of wear and tear in the fuel injection system. To pass lubricity tests, 300 ppm of a lubricity additive from Lubrizol was added to the fuel before shipping to MIT. The Lubrizol additive should not affect the combustion characteristics of the S-2 fuel. Lubricity additives contain polar groups that attract to metal forming a thin surface film on the injector surfaces that are subject to wear [30].

Like many other FT diesel fuels available, the S-2 fuel has a combination of advantageous properties. The S-2 fuel has a very high cetane index $(\mathrm{CNI}=74.4)$, zero aromatic content, and zero olefin content. In addition, it has a viscosity similar to that of No. 2 diesel, eliminating the need for any modifications to the fuel injection system to properly handle the fuel. The ASTM requirements for typical diesel fuel oils are given in table 6.3 below. Furthermore, FT diesel is completely miscible with conventional diesel making it an ideal candidate as both a blending agent with and eventual replacement for conventional petroleum-based diesel fuels.

\begin{tabular}{|c|c|c|c|c|c|c|}
\hline Property & $\begin{array}{c}\text { Test } \\
\text { Method* }\end{array}$ & $\begin{array}{l}\text { Low Sulfur } \\
\text { No. 1-D }\end{array}$ & No. 1-D & $\begin{array}{l}\text { Low Sulfur } \\
\text { No.2-D }\end{array}$ & No. 2-D & No. 4-D \\
\hline Flash point, ${ }^{\circ} \mathrm{C}, \mathrm{min}$ & D 93 & 38 & 38 & 52 & 52 & 55 \\
\hline $\begin{array}{l}\text { Water and sediment, } \\
\% \text { vol, max }\end{array}$ & $\begin{array}{l}\text { D } 2709 \\
\text { D } 1796\end{array}$ & 0.05 & 0.05 & 0.05 & 0.05 & 0.50 \\
\hline $\begin{array}{l}\text { Distillation temperature, }{ }^{\circ} \mathrm{C} \text {, } \\
90 \% \text { vol recovered } \\
\min \\
\max \end{array}$ & D 86 & 288 & 288 & $\begin{array}{l}282 \\
338\end{array}$ & $\begin{array}{l}282 \\
338\end{array}$ & \\
\hline $\begin{array}{l}\text { Kinematic viscosity, } 40^{\circ} \mathrm{C}, \mathrm{cSt} \\
\min \\
\max \end{array}$ & D 445 & $\begin{array}{l}1.3 \\
2.4\end{array}$ & $\begin{array}{l}1.3 \\
2.4\end{array}$ & $\begin{array}{l}1.9 \\
4.1\end{array}$ & $\begin{array}{l}1.9 \\
4.1\end{array}$ & $\begin{array}{c}5.5 \\
24.0\end{array}$ \\
\hline Ash, $\%$ mass, max & D 482 & 0.01 & 0.01 & 0.01 & 0.01 & 0.1 \\
\hline Sulfur, $\%$ mass, max & D 2622 & 0.05 & 0.50 & 0.05 & 0.50 & 2.00 \\
\hline $\begin{array}{l}\text { Copper strip corrosion, } \\
3 \mathrm{hr} \text { at } 50^{\circ} \mathrm{C} \text {, max rating }\end{array}$ & D 130 & No. 3 & No. 3 & No. 3 & No. 3 & \\
\hline Cetane number, min & D 613 & 40 & 40 & 40 & 40 & 30 \\
\hline $\begin{array}{l}\text { One of the following: } \\
\text { 1) Cetane index, min } \\
\text { 2) Aromaticity, } \% \text { vol, max }\end{array}$ & $\begin{array}{l}\text { D } 976 \\
\text { D } 1319\end{array}$ & $\begin{array}{l}40 \\
35\end{array}$ & & $\begin{array}{l}40 \\
35\end{array}$ & & \\
\hline $\begin{array}{l}\text { Ramsbottom carbon residue } \\
\text { on } 10 \% \text { distillation residue, }\end{array}$ & D 524 & 0.15 & 0.15 & 0.35 & 0.35 & \\
\hline
\end{tabular}

\section{Table 6.3 ASTM D 975 requirements for diesel fuel oils}

Additional fuel properties provided by Syntroleum for the two batches of FT fuel used during this study are presented on the in tables 6.4 and 6.5. The lower heating value of Syntroleum S-2 was calculated using information from Syntroleum Corporation's product brochure and values listed in table 6.4. The product brochure lists a lower heating value of $\mathrm{Q}_{\mathrm{LHV}, \mathrm{S}-2}=121,500 \mathrm{Btu} / \mathrm{gal}$. Converting this to a mass basis with the S-2 density listed as $\mathrm{r}_{\mathrm{S}-2}$ $=775 \mathrm{~kg} / \mathrm{m}^{3}$ results in a value of $\mathrm{Q}_{\mathrm{LHV}, \mathrm{S}-2}=43.7 \mathrm{MJ} / \mathrm{kg}$. 


\begin{tabular}{|c|c|c|c|c|}
\hline \multicolumn{2}{|c|}{$\begin{array}{l}\text { SYN S-2 } \\
\text { SYNTHETIC DIESEL FUEL }\end{array}$} & \multicolumn{3}{|c|}{$\begin{array}{l}\text { Grade S2-Summer Climate diesel fuel with Cloud } \\
\text { Point between }-20^{\circ} \mathrm{C} \text { and }-29^{\circ} \mathrm{C}\end{array}$} \\
\hline $\begin{array}{l}\text { SYNTHETIC DIESEL FUEL } \\
\text { BATCH } 5 \text { LOT } 1\end{array}$ & SUMMER GRADE & 150 Container : & $124015-1$ & \\
\hline PHYSICAL PROPERTIES & TEST METHOD & UNITS & S-2 \$2 SPECIFICAIION & ACTUAL \\
\hline Flash Point min & D93 & $-C(-F)$ & $52(125)$ & $58\langle 1389$ \\
\hline Distitation, $10 \%$ Vo. Recevered & Des & ${ }^{\circ} \mathrm{C}$ & Repori & 194 \\
\hline Disfilation, 50\% Vol Fecovered & D86 & ${ }^{4} \mathrm{C}$ & Report & 243 \\
\hline Distillation, $90 \%$ Vol Recovered & D88 & C & 282.338 & 307 \\
\hline Kinematic Viscosity \& $40^{\circ} \mathrm{C}$ & ASTM D.445 & cSt & 1.92 .5 & 20 \\
\hline Ash & ASTM D-482 & $\$$ mass & $\infty .01$ & $\infty .001$ \\
\hline Cloud Point MirdMax & 05771 & C(F) & -20 to $-29^{\circ} \mathrm{C}$ & 25 \\
\hline Conductivity & ASTM D-2624 & ps & $250-450$ & 278 \\
\hline Density ef $15^{\circ} \mathrm{C}$ & ASTM D.4052 & $\mathrm{kgh}$ & $0.76-0.70$ & 0.77 \\
\hline API & ASTM D.40S12 & 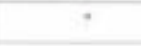 & $49-64$ & 52.2 \\
\hline Appearance & Visual & & Clear \& Bright & Clear \& Bright \\
\hline Sullur & ASTM D 4045 & pFen & $<1$ & \\
\hline Cetano Niamber & ASTMD-613 & & $>70$ & \\
\hline Copper Strip Cocrosion & 0130 & & No 1 & \\
\hline Water and Setimentn & ASTM D-2709 & $3 / 4$ vol & $<005$ & \\
\hline Ramshotion Carbon & D624 & * mass & $e 0.1$ & \\
\hline Aromates Cortent": & AstM D 527n:-93 & Mol $\%_{11}$ & $<0.1$ & \\
\hline Or Cetane index & D978 ar D473? & & $>70$ & \\
\hline Lubcialy, HFRRgesinc & ASTM D6079 & Mctens & 300.460 & \\
\hline
\end{tabular}

\section{S-2
SYN
SYNTETIC DIESEL FUEL}

Grade S2 - Summer Climate diesel fuel with Cloud Point between $-20^{\circ} \mathrm{C}$ and $-29^{\circ} \mathrm{C}$

\begin{tabular}{|c|c|c|c|c|}
\hline \multicolumn{2}{|c|}{ SYNTHETIC DIESEL FUEL OIL-SUMMER GRADE } & \multicolumn{3}{|c|}{150 Contaher Plumber: $124260-0$} \\
\hline PHYSICAL PROPERTIES & TEST METUSD & & & \\
\hline Fiseth Point, min & & & & \\
\hline Distillation. 10\% Va. Racovered & & & & \\
\hline Dietilstion, $50 \%$ Vol Recovered & & & Raport & 156 \\
\hline & D.6 & ${ }^{\circ C}$ & Fiapont & 250 \\
\hline Distilation, $90 \%$ Vol Racovered & De6 & ${ }^{\circ} \mathrm{C}$ & $202-330$ & 306 \\
\hline Kinematic Mscosily a $40^{\circ} \mathrm{C}$ & ASTM D-445 & cSt & $1.00-2.5$ & 2.2 \\
\hline Aah, max & ASTM D-482 & \% mass & $<0.01$ & $<0.0001$ \\
\hline Cloud Point & D5771 & ${ }^{\circ} \mathrm{C}$ & -20 to $-29^{7} \mathrm{C}$ & -24 \\
\hline Conduativity & ASTM D-2624 & ps & $250-460$ & 303 \\
\hline Densily & ASTM D-4052 & $\mathrm{kg} \Omega$ & $0.76-0.78$ & 0.77 \\
\hline API & ASTM D.4062 & $\cdot$ & 49554 & 81.5 \\
\hline Appearance & Msual & & Clear \& Bright & Clear 8 Brigh \\
\hline Sutfur: & ASTMD 4045 & perm & $<1$ & \\
\hline Cotane Number & ASTM0.613 & & -70 & \\
\hline Copper Strip Cocrosian & 0.130 & & No: 1 & \\
\hline Woter and Seciments & ASTM D-2709 & \% vol & $<0.05$ & \\
\hline Ramsbatton Catoon & 0524 & Wmase & $<0.1$ & \\
\hline Aramatics Conteitit & ASTMO $6292-83$ & molso & $<01$ & \\
\hline Or Cesencinder & Dare a $0+737$ & & $\infty 70$ & \\
\hline Ltaricty, H+RRED $60^{\circ} \mathrm{C}$ & ASTM DEO79 & Macrons & 300460 & \\
\hline
\end{tabular}




\subsubsection{Syntroleum FT Diesel Combustion Equation}

Correspondence with Syntroleum provided further S-2 properties necessary to carry out the detailed combustion calculations. The molecular weight of the FT fuel is $205 \mathrm{~g} / \mathrm{mol}$ with a chemical composition of $84.9 \%$ carbon and $15.1 \%$ hydrogen, with no other impurities detectable (i.e. oxygen and nitrogen). This composition gives a reduced chemical C:H ratio of $\mathrm{CH}_{2.12}$ for the S-2 diesel fuel. Using this simplified composition, the ideal combustion formula for Syntroleum S-2 is:

Equation $6.3 \quad 14.49 \mathrm{CH}_{2.12}+\frac{22.17}{\phi}\left(\mathrm{O}_{2}+3.773 \mathrm{~N}_{2}\right) \rightarrow 14.49 \mathrm{CO}_{2}+15.36 \mathrm{H}_{2} 0+22.17\left(\frac{1}{\phi}-1\right) \mathrm{O}_{2}+\frac{83.65}{\phi} N_{2}$

Using the above equation nets an air/fuel ratio of 14.95:1 for Syntroleum S-2 diesel.

\subsection{Fuel Blends}

To examine how varying fuel properties contribute to emissions reductions, fuel blends were studied. This allowed assessment of the effect of fuel sulfur level on particulate emissions. A blend of $25 \%$ FT diesel and $75 \%$ low sulfur diesel was used in order to realize the greatest benefit of using the FT fuel as a blending agent.

\subsubsection{5\% FT - 75\% Low Sulfur Diesel Blend}

This blend was studied to determine whether or not the major advantages of FT fuel could be realized if it is only a portion of the engine's fuel. Other studies have found that the effect on emissions of FT/D-2 blends is not linear with respect to the portion of FT in the blend; rather that most of the benefit can be had with less than $50 \%$ FT in the blend. Given our setup, it was convenient to choose a 3:1 by volume LSD to FT fuel ratio. Derived from the above figures for standard and FT fuel, the following properties were used in the analysis. Converting $25 \%$ by volume FT fuel to a mass basis yields a fuel density of $824 \mathrm{~kg} / \mathrm{m}^{3}$ and $23.5 \%$ FT fuel by mass. Based on a $25 \%$ molar fraction of FT, the simplified composition of the blend is $\mathrm{CH}_{1.9}$, and the lower heating value was calculated to be $43.1 \mathrm{MJ} / \mathrm{kg}$. Assuming complete combustion, the ideal combustion equation is:

Equation $6.4 \quad 12.88 \mathrm{CH}_{1.9}+\frac{19.0}{\phi}\left(\mathrm{O}_{2}+3.773 \mathrm{~N}_{2}\right) \rightarrow 12.88 \mathrm{CO}_{2}+12.24 \mathrm{H}_{2} 0+19.0\left(\frac{1}{\phi}-1\right) \mathrm{O}_{2}+\frac{71.69}{\phi} N_{2}$

From equation 6.4, the stoichiometric air-fuel ratio for the blend is $14.61: 1$

\subsection{Fuels Analysis}

In order to verify the fuel properties provided by the manufacturers, a sample of each fuel tested was sent to Syntroleum for analysis. The results match the data provided by Fleetline reasonably well, however the values provided by Fleetline are only the results of typical values computed from an average of a number of samples, and minor variations are to be expected. A specific comparison of the fuel properties analyzed by Syntroleum is presented in Table 6.5 below. 


\begin{tabular}{|c|c|c|c|}
\hline & $\begin{array}{l}\text { Fleetline Fuel LSD } \\
\quad(400 \mathrm{ppm})\end{array}$ & $\begin{array}{l}\text { Fleetline Fuel } \\
\text { ULSD (15ppm) }\end{array}$ & Syntroleum S-2 \\
\hline Flash point, ${ }^{\circ} \mathrm{F}$ & 130 & 139 & 142 \\
\hline Viscosity @40 $\mathrm{C} \mathrm{C}$ & 2.777 & 2.288 & 2.2 \\
\hline Cloud Point. ${ }^{\circ} \mathrm{C}$ & -13 & -24 & -25 \\
\hline Freezing Point. ${ }^{\circ} \mathrm{C}$ & -10.5 & -18.5 & -- \\
\hline Density, $15^{\circ} \mathrm{C}$ & 0.851 & 0.82 & 0.7701 \\
\hline $\mathrm{Sp} \mathrm{Gr}, 15^{\circ} \mathrm{C}$ & 0.855 & 0.824 & 0.775 \\
\hline $\mathrm{API}, 60^{\circ} \mathrm{F}$ & 33.95 & 40.16 & 51.06 \\
\hline \multicolumn{4}{|l|}{ Distillation Data } \\
\hline D2887,IBP ํ F & 225 & 254 & 246 \\
\hline $\mathrm{D} 2887,5 \%$ & 335 & 321 & 330 \\
\hline $\mathrm{D} 2887,10 \%$ & 369 & 343 & 357 \\
\hline D2887.20\% & 409 & 368 & 400 \\
\hline D2887.30\% & 442 & 389 & 435 \\
\hline D2887.40\% & 473 & 410 & 467 \\
\hline D2887,50\% & 502 & 428 & 498 \\
\hline D2887,60\% & 534 & 449 & 528 \\
\hline D2887,70\% & 576 & 467 & 561 \\
\hline D2887,80\% & 622 & 491 & 594 \\
\hline D2887.90\% & 673 & 517 & 640 \\
\hline D2887.95\% & 703 & 540 & 675 \\
\hline D2887,FBP & 758 & 652 & 741 \\
\hline
\end{tabular}

Table 6.5 Fuel properties comparison as determined from analysis carried out by Syntroleum

Of specific interest to this study is the distillation data presented in the chart comparing the distillation curves for the three different fuels in figure 6.1 below. It is quite clear from the chart that the distillation curve for the FT fuel is very similar to that of the low sulfur (400 ppm) diesel. Furthermore, the ultra- low sulfur diesel (15 ppm) contains a significantly greater amount of the lower boiling point (higher volatility) fraction, especially near the back end.

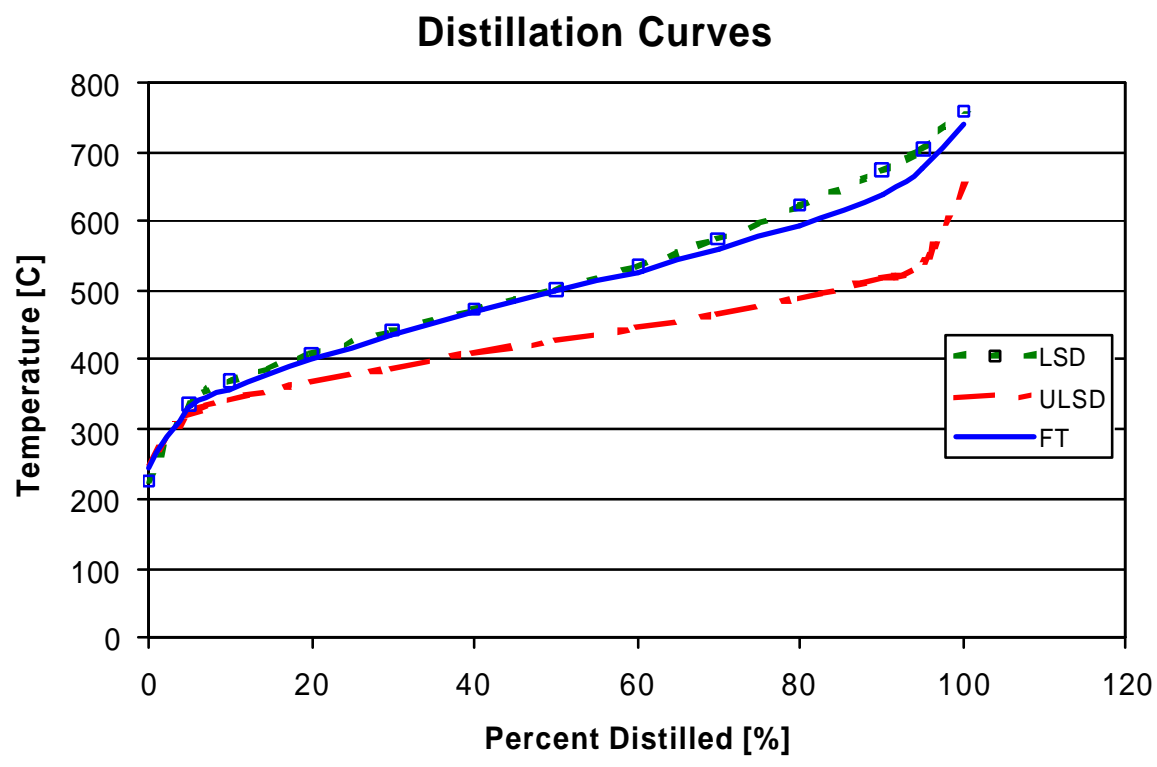

Figure 6.1 Distillation curves for each of the three fuels tested 
In addition to verifying the distillation curves, Syntroleum also analyzed the fuel samples using gas chromatography. The gas chromatograms present the results of their analysis and are presented figures 6.2 and 6.3 below.

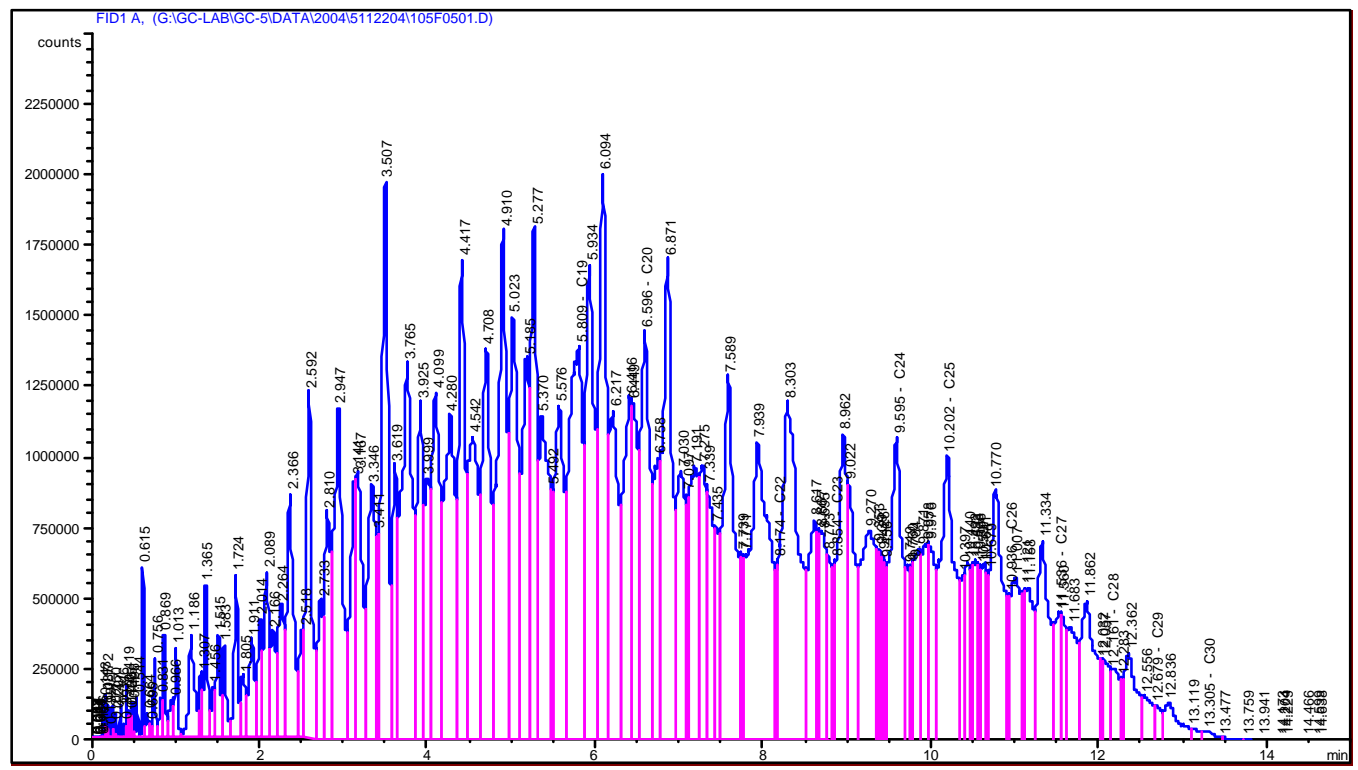

Figure 6.2 GC results for $400 \mathrm{ppm}$ low sulfur diesel

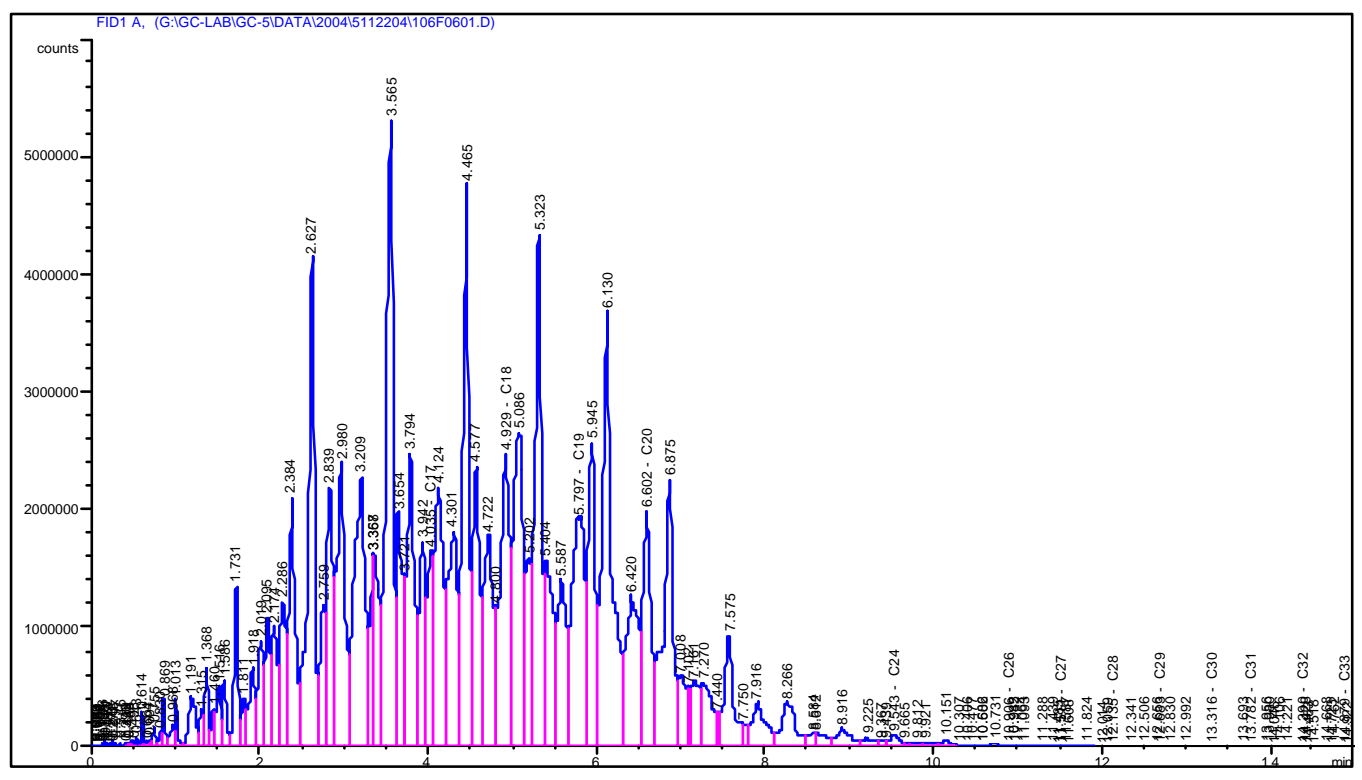

Figure 6.3 GC results for $15 \mathrm{ppm}$ ultra-low sulfur diesel

If the final gas chromatograms for Syntroleum's S-2 fuel evaluated in this study becomes available, a comparison of all of the fuels based on their GC traces will be very informative. The GC trace for the S-2 fuel is not available at the time of this writing. 


\subsection{EXPERIMENTAL TEST MATRIX AND PROCEDURE}

\subsection{Engine Operation}

In the present study, the stock 300 horsepower calibration provided by Cummins was uploaded into the ECM and no additional modifications to any control parameters were made. In some cases it was, however, necessary to override the stock control settings during engine warm- up, as the engine would shift from the stock control algorithm to a condensation protection algorithm. Cummins monitors intake manifold temperature, intake manifold pressure, airflow, EGR flow, and a number of other parameters to infer if water may be condensing in the intake manifold or EGR system. When the engine is first started and the intake manifold temperature is excessively cold as the charge air cooler is still warming up, oftentimes the engine control algorithm would switch to the condensation protection mode. As a result, the EGR valve closed completely to prevent excessive corrosion of the aluminum components, and the engine switched to a completely different set of operating tables. However, since the engine was operated in a controlled laboratory environment, this was often not the case. To expedite engine warm- up, the condensation protection algorithm was oftentimes manually overridden to return the engine to the stock control settings. The testing was carried out using the stock calibration to provide the worst-case scenario for a modern engine that switches to FT fuel without properly calibrating the ECM to account for the change in fuel properties.

\subsubsection{Experimental Test Matrix}

As part of engine development, Cummins uses the European Stationary Cycle (ESC) outlined by the Euro-III directive that came into effect in October 2000 [33]. A subset of the Euro-III test modes is listed in Table 7.1. In general, high average load factors and very high exhaust gas temperatures, simulating actual on-road driving conditions quite well, characterize the ESC test. The engine speeds A, B, and C are defined by the following: 1) the high speed RPM, $\mathrm{RPM}_{\text {high }}$, is defined by calculating the highest engine speed (above the rated speed) where $70 \%$ of the declared maximum net power occurs, 2) the low speed RPM, $\mathrm{RPM}_{\text {low }}$, is defined by calculating the lowest engine speed (below the rated speed) where $50 \%$ of the declared maximum net power occurs, 3 ) the following formulas are then used to calculated each mode speed:

Equation 7.1

$$
\begin{aligned}
& A=R P M_{\text {low }}+0.25^{*}\left(R P M_{\text {high }}-R P M_{\text {low }}\right) \\
& B=R P M_{\text {low }}+0.50 *\left(R P M_{\text {high }}-R P M_{\text {low }}\right) \\
& C=R P M_{\text {low }}+0.75 *\left(R P M_{\text {high }}-R P M_{\text {low }}\right)
\end{aligned}
$$

Using the above equations with the torque and power curves of the test engine gives the following values for the above mode speeds: $\mathrm{A}=1682 \mathrm{RPM}, \mathrm{B}=2013 \mathrm{RPM}$, and $\mathrm{C}=2345$ RPM. Table 7.1 below shows the original test matrix from the previous reporting period, which formed the basis for the initial tests carried out at the start of this reporting period. 


\begin{tabular}{|c|r|r|r|}
\hline Mode & Speed & Load & BMEP \\
\hline & [RPM] & [N-m] & [kPa] \\
\hline A25 & 1682 & 224 & 477 \\
\hline A50 & 1682 & 470 & 1001 \\
\hline B50 & 2013 & 447 & 952 \\
\hline \multicolumn{4}{|c|}{${ }^{*}$ A50 is actually 53\% load } \\
\hline
\end{tabular}

\section{Table 7.1 Initial test matrix}

The test matrix shown above represents the three steady state speed and load points that were used to evaluate the fuel effects on engine-out emissions. The A50 test point at 53\% load was retained from the previous two reporting periods to allow for direct comparison of the results. The initial test matrix was chosen for the following two reasons: first, to verify the initial results observed in the last reporting period for the fuel blends and, second, to reduce dilute particulate collection times, as the test points represent operating conditions producing a relatively large amount of particulate emissions.

\subsubsection{Expanded Test Matrix}

Following the initial round of testing, the test matrix was expanded to 10 steady-state speed-load points for each fuel to represent a larger portion of the engine's operating range. Similar to the initial test matrix, the expanded test matrix is comprised of a subset of the Euro III 13-mode test cycle. The specific operating conditions are listed in Table 7.2.

\begin{tabular}{|l|r|r|r|}
\hline Mode & Speed & Load & BMEP \\
\hline & [RPM] & [N-m] & [kPa] \\
\hline Z25 & 1200 & 180 & 383 \\
\hline A25 & 1682 & 224 & 477 \\
\hline A50 & 1682 & 470 & 1001 \\
\hline A75 & 1682 & 671 & 1429 \\
\hline B25 & 2013 & 223 & 475 \\
\hline B50 & 2013 & 447 & 952 \\
\hline B75 & 2013 & 669 & 1425 \\
\hline C25 & 2345 & 217 & 462 \\
\hline C50 & 2345 & 433 & 922 \\
\hline C75 & 2345 & 650 & 1384 \\
\hline \multicolumn{4}{|c|}{${ }^{*}$ A50 is actually 53\% load } \\
\hline
\end{tabular}

\section{Table 7.2 Expanded test matrix to evaluate combustion characteristics}

Due to the lengthy sampling times necessary to collect a significant amount of dilute particulates for gravimetric analysis, combined with the fact that diesel particulate emissions are fairly well documented in the literature $[15,34,35]$ and the precious two reporting periods, exhaust emission measurements were not continued with the expanded test matrix, and the focus of the study was shifted to a detailed combustion analysis. 
This test matrix was designed to complement the data previously collected in several ways. As can be seen in Tables 7.1 and 7.2, there is significant overlap in the A25, A50, and B50 conditions. The purpose of this is two-fold: to provide an opportunity to correlate results of the combustion analysis with previous emissions data and to allow a direct comparison of the $400 \mathrm{ppm}$ and $15 \mathrm{ppm}$ sulfur fuel to the FT fuel. This expanded test matrix extends the scope of the work to cover a full range of engine operating conditions, and encompasses relatively high speed and load test conditions not covered in the last two reporting periods.

Data sets recorded in experiments and presented here adhere to a prescribed naming convention that indicates fuel used and engine operating parameters. A two to four letter prefix indicates the type of fuel for the data set. FT, BL, LSD, and ULSD represent FischerTropsch, FT/400 ppm blend, low sulfur diesel (400 ppm), and ultra-low sulfur diesel (15 ppm) respectively. Following the fuel specification, the general operating condition is indicated by the letter corresponding to the speed and two digits representing the percent load for that speed, as outlined in table 7.2. Unlike the previous reporting period, all other engine control parameters such as EGR rate and injection timing were maintained at their respective stock settings and no changes to the stock engine calibration were made.

\subsection{Particulate Matter Sampling Conditions}

Unlike prior work reported, this study did not continue sampling raw particulates, and all particulates collected were sampled from the exhaust stream after passing through the mini-dilution tunnel. Although the sampling times required to collect a comparable amount of dilute particulates are approximately 6 times longer when compared with the raw sampling method, only dilute particulates were sampled during the current reporting period in order to reduce the error and uncertainty inherent to the raw sampling method.

Before each test, the Pallflex filter papers were placed in individual plastic petri dishes and allowed to condition for at least 56 hours in accordance with protocol recommended by the EPA [29]. All filter preparation, conditioning, and settling were done in an airconditioned room where the temperature was between the EPA mandated range of $68^{\circ}-86^{\circ}$ and relative humidity of $30 \%-70 \%$. However, it was found that daily variation in room conditions had a substantial effect on filter mass, in some cases on the order of the entire particulate mass sampled. To correct for this, a set of "control" filters were kept in the sample room at all times so that a correction could be calculated based on the variation of the control filters in the period between filter weighing.

\subsubsection{Dilute Exhaust Sampling}

Dilution ratios were generally kept between 7 and 12, and verified by measuring the $\mathrm{CO}_{2}$ concentration in both the raw and dilute exhaust stream. Additional checks of the dilution ratio were made by measuring the dilute and raw NOx concentrations as well. The goal was to dilute the exhaust just enough to reduce the sample temperature below the mandated $52{ }^{\circ} \mathrm{C}$, and not too much more. This helped to keep sample times reasonable. With the Gast rotary vane pump installed, sample times were typically around 30 minutes to collect at least $2 \mathrm{mg}$ of sample. It was observed that filters sitting idle in the climate controlled conditioning room could vary in weight by $\pm 0.5 \mathrm{mg}$. Even though measures were taken to 
correct for this, the best way to improve data quality was to collect as much sample as possible.

As mentioned in the previous section, new filter papers were allowed to condition in a climate controlled room for at least 56 hours prior to use. After the conditioning period, four PM samples were taken consecutively in order to collect a large enough sample to calculate a meaningful average. After the filter papers were loaded, they were again allowed to sit for at least 56 hours in the climate controlled room in order to dry the paper and settle the particulates.

\subsubsection{Raw Exhaust Sampling}

While some raw particulate samples were collected in the previous reporting period due to time constraints, it typically shows lower PM output than dilute sampling and was not continued for the current reporting period. Since the raw exhaust is sampled hot and undiluted, the driving forces for nucleation and adsorption of condensable gas species are severely reduced, thus significantly reducing the extractable fraction. Therefore, the raw PM emission levels are much less than a comparable sampling run with a dilute sample for the same operating point.

Generally, the dilute sampling produced more consistent results, and was the only sampling method that ensured the sample stream was cooled to below $52{ }^{\circ} \mathrm{C}$ in accordance with the EPA particulate sampling guidelines. Despite this fact, the dilute sampling method still leaves much room for improvement. Of primary concern is the filter conditioning preand post- weighing.

\subsection{Engine Operation during Experiments}

Before beginning each round of experiments, the CAI Models 300-HFID, 400 HCLD, and 602P NDIR gas analyzers were calibrated with zero and span gases covering the instrument's expected operating range. All analyzers were allowed to warm up for approximately one hour prior to calibration. After the instrumentation was properly calibrated, the engine was then started and allowed to idle for a few minutes as the National Instruments and CalTerm software programs were started and the dynamometer idle torque offset settled. After all the computers and gas analyzers were ready for use, the ECM settings were left in stock form while the voltage output from the Watlow controller was slowly increased until the appropriate load condition was reached. The engine was run at the predetermined test condition until normal operating oil and coolant temperatures were reached before initial testing was initiated. This time also allowed the filter holders and sampling apparatus to reach operating temperature. As mentioned in section 7.1, the condensation protection control algorithm was occasionally overridden to expedite the warm- up process; however all engine control parameters were returned to their stock settings before any measurements were taken.

Once the engine reached a steady-state condition, a 60-second scan of all slow-speed engine data including fuel flow was taken. After this, two 30-second scans of the gas analyzers were run and $\mathrm{CO}_{2}$ data was manually recorded in a lab book. During these runs, the 
engine's fuel was drawn from the fuel beaker instead of the tank, which provided fuel flow figures for the conditions. Once the emissions scans had finished, the first filter sample was begun. During the particulate sampling, the data acquisition system recorded the flow through the filter for calculation of actual engine out data. Between the four particulate samples, another round of emissions data was taken and the particulate sampling process repeated. All in all, four particulate samples were taken in between five sets of emissions and fuel consumption data. Finally, after all particulate samples were taken at a particular test condition, a final scan of all data was taken, along with a 100-cylce high-speed scan to record in-cylinder pressure data. The 100-cycle scan was taken at the end of all tests (approximately 2.5 hours after the first slow speed scan) since this ensured ample time for all operating parameters to reach a steady state.

It should be noted that the particulate and emissions measurements were not continued for the expanded test matrix. During these tests only the 60-second scan of all slow-speed engine data, including fuel flow, was taken. Following the slow-speed data, the 100-cycle high speed in-cylinder pressure measurements were taken. This process (alternating slowand high-speed scans) was repeated four times for each test condition in order to collect enough data to calculate meaningful averages for each test condition.

\subsubsection{Fuel Change Procedure}

Fuel changes were initiated following the completion of a full round of testing for each fuel under investigation. Testing began with the FT fuel (zero sulfur content) and subsequent fuel tests were carried out in the order of increasing fuel sulfur content. The fuels were tested in this order for the purpose of reducing the potential for residual fuel sulfur in the fuel system leftover from a high sulfur fuel to contaminate the ultra-low sulfur and FT fuels.

In order to minimize cross-contamination of the FT and standard No. 2 diesel fuels, the engine is equipped with two separate ATL fuel cells. Despite this fact, a number of additional precautions were taken when switching from one fuel to another. First, the supply and return valves on the bulkhead controlling fuel routing were switched to the desired fuel source. In addition, the bypass valve was opened and the engine's electronic fuel lift pump was run to purge any remaining fuel from the supply-side of the system. At this point, the engine's fuel filter was removed and replaced to prevent any cross-contamination of fuel sulfur. In order to purge any remaining fuel from the return side of the system, the lift pump was again run with the return line disconnected from its respective tank, and all fuel routed to a waste fuel container. As a further precaution, the return line was left connected to the waste fuel container for the first few minutes of engine operation with the new fuel to fully eliminate the possibility of any cross-contamination.

\subsubsection{Oil Change Procedure}

All engine tests for the current reporting period were carried out using a standard 15W-40 heavy-duty diesel oil as recommended by Cummins. Routine oil and filter changes were carried out at the manufacturer's prescribed maintenance intervals. Furthermore, new and used oil samples were collected and sent to the emissions-chemistry laboratory of a major engine manufacturer for analysis. 


\subsection{Data Processing and Reduction}

The emission data reported by Cummins is given on a wet basis. The values recorded by the CAI Models 300-HFID and 400 HCLD are already on a wet basis, while the Model 602P NDIR reports data on a dry basis due to the sample chiller and water separator upstream. Therefore, to convert everything to a wet basis to compare to the ESC data, the water content of the intake and exhaust had to be estimated. The following equation was used to estimate the mole fraction of species in an intake mixture with EGR. The unburned mixture per mole of $\mathrm{O}_{2}$ is:

Equation $7.7\left(1-x_{b}\right)\left[\frac{4}{M_{f}}(1+2 \varepsilon) \phi\left(C H_{y}\right)_{\alpha}+O_{2}+\psi_{-} N_{2}\right]+x_{b}\left(n_{\mathrm{CO}_{2}}+n_{\mathrm{H}_{2} \mathrm{O}}+n_{\mathrm{CO}}+n_{\mathrm{H}_{2}}+n_{\mathrm{N}_{2}}\right)$

where $\mathrm{x}_{\mathrm{b}}$ is the burned gas fraction (equal to the EGR rate in the case of no residuals), $\mathrm{M}_{f}$ is the molecular weight of the fuel, $\mathrm{y}$ is the molar $\mathrm{H} / \mathrm{C}$ ratio of the fuel, $\varepsilon$ is $4 /(4+\mathrm{y}), \phi$ is the fuel/air equivalence ratio, $\mathrm{n}_{i}$ is the mole fraction of species $i$ per mole of $\mathrm{O}_{2}$ reactant, $\alpha$ is the coefficient to multiply the molecular weight of the simplified chemical composition to equal $\mathrm{M}_{f}$, and $\psi$ is the molar N/O ratio (3.773 for air). The mole fractions of each species are obtained by dividing by the total number of moles of unburned mixture [31].

Equation 7.8

$$
n_{u}=\left(1-x_{b}\right)\left[\frac{4(1+2 \varepsilon) \phi}{M_{f}}+1+\psi\right]+x_{b} n_{b}
$$

where $n_{b}$, the total number of moles of burned mixture is given by the following equation for a lean mixture [31]:

Equation 7.9

$$
n_{b}=(1-\varepsilon) \phi+1+\psi
$$

An assumption made in the above equations is that the residual gas fraction is negligible since the engine is turbocharged. Therefore, $\mathrm{x}_{\mathrm{b}}$ is initially equal to the EGR fraction determined from the dry-basis $\mathrm{CO}_{2}$ ratio from scans in the intake manifold and exhaust system. After calculating the corrected water vapor mole fraction in the intake, and estimating the water vapor mole fraction from the ideal combustion of the above reactants, the dry-basis $\mathrm{CO}_{2}$ readings can be corrected to a wet basis, and the actual EGR fraction can be determined. The above equations are iterated with the newly determined EGR fraction until a steady-state value is found.

The PM sample flow rate data recorded from the Omega FVL-1611 volumetric flow meter was averaged during the PM sampling period. Any offsets during filter loading were recorded and appropriately applied to get a properly scaled and averaged sample flow rate across the filter. The sample flow rate across the filter was then used to compute the actual particulate emissions from the engine normalized in units of power and time $(\mathrm{g} / \mathrm{hp}-\mathrm{hr})$ to allow for direct comparison over a range of operating conditions. 


\subsection{Heat Release Analysis}

The major thermodynamic indicators used in this study to quantify the specific aspects of the combustion process were calculated via a simple single-zone heat release analysis. The analysis is based on the First Law of Thermodynamics and assumes a single zone of uniform products in a closed system between intake valve closing (IVC) and exhaust valve opening (EVO). The gas properties in the cylinder are calculated using the ideal gas relationships and the gas constant for air. Due to the nature of this simple single zone model, heat loss through crevice effects and non-uniformities within the cylinder, the model can only produce approximate results. The following form of the First Law forms the basis of the model:

Equation 7.10

$$
d U_{\text {internal }}=\delta Q_{\text {chemical }}-\delta Q_{H T}-\delta W
$$

where $\delta \mathrm{Q}_{\text {chemical }}$ is the calculated energy of the fuel, $\delta \mathrm{Q}_{\mathrm{HT}}$ is the energy lost through heat transfer and $\delta \mathrm{W}$ is the work term. In order to apply the First Law directly to in-cylinder pressure data, the following form is used:

Equation 7.11

$$
\frac{\delta Q_{\text {chemical }}}{d \theta}=\frac{1}{\gamma-1} V \frac{d P}{d \theta}+\frac{\gamma}{\gamma-1} P \frac{d V}{d \theta}+\frac{\delta Q_{H T}}{d \theta}
$$

where $\mathrm{V}$ is the cylinder volume, $\mathrm{P}$ is the cylinder pressure, and $\gamma$ is the ratio of specific heats. The differential forms of some of the terms are written on a crank-angle basis, since pressure and volume data are recorded referenced to a signal from the crank-angle encoder. The heat transfer term was determined from a Nusselt-Reynolds number correlation analogous to that used for steady turbulent pipe flow. See Reference [36] for further information on the heat transfer model for its implementation in the heat-release analysis code.

\subsubsection{In-Cylinder Pressure Signal and Data Processing}

The pressure signal from the crank angle encoder was first processed via a $10 \mathrm{kHz}$ hardware filter in the National Instruments SCXI data acquisition module. The $10 \mathrm{kHz}$ filter setting was used to provide some noise filtering while preventing the possibility of introducing phase errors into the high-speed signals due to poor low-pass filter response.

In addition to the hardware filtering, a simple software filter was created in MatLab to further process the data prior to carrying out the heat release and combustion analysis. This code essentially employs a Discrete Fourier Transform to convert between the time and frequency domains and computes and filters the signal at and above the Nyquist frequency to eliminate the problem of alias frequencies. The filtered output from the MatLab code was then input into the FORTRAN heat release program to calculate the various thermodynamic indicators of interest. 


\subsection{EXPERIMENTAL RESULTS}

\subsection{Emissions Characteristics}

Due to the overall-lean operation of diesel engines, and the advanced subsystems and combustion strategy of the Cummins ISB, carbon monoxide (CO) levels are fairly low. The compression of only air during the compression stroke eliminates several major sources of unburned hydrocarbons (UHC) common in pre-mixed engines, thus UHC emissions from diesels are usually within acceptable levels. Therefore, the following discussion focuses primarily on oxides of nitrogen $\left(\mathrm{NO}_{\mathrm{x}}\right)$ and particular matter $(\mathrm{PM})$ emission behavior in the experiments.

\subsubsection{Particulate Emissions}

The particulate matter that exits the engine is based on two competing processes, the extent of particulate formation and oxidation. The specific particulate emissions rates for the three initial test conditions under investigation are shown in figure 8.1 below.

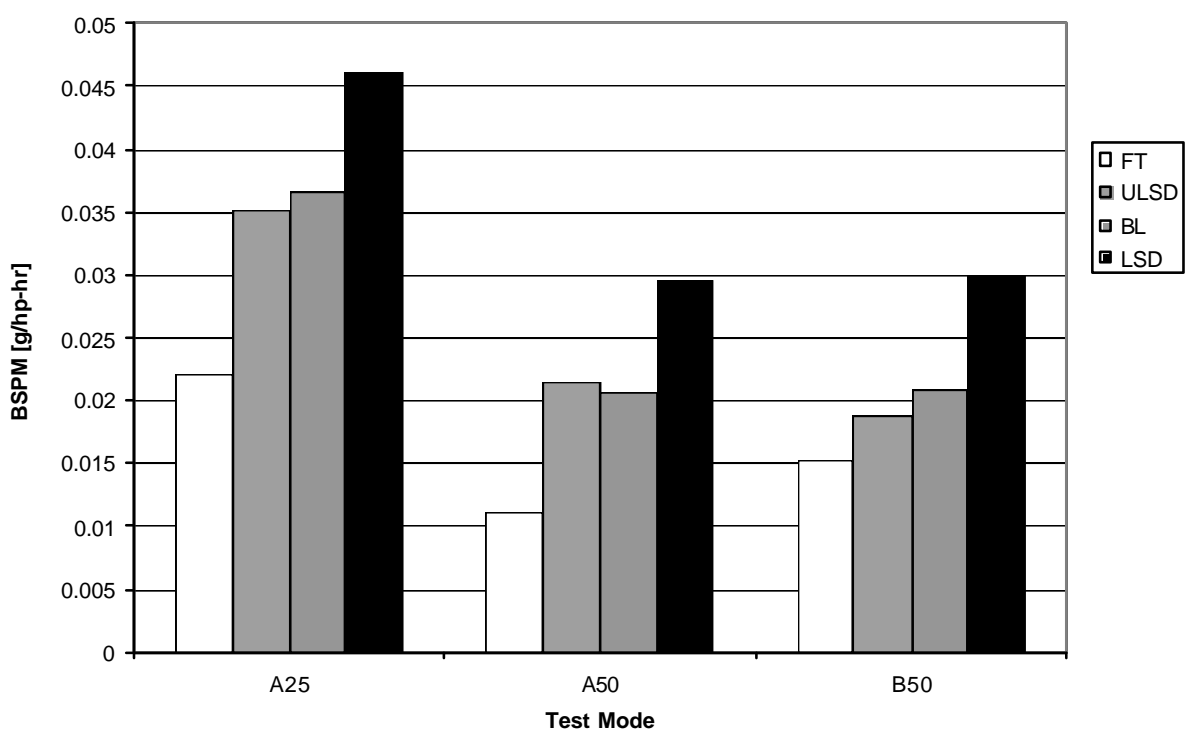

Figure 8.1 Specific particulate emissions

Both the FT fuel and the blends reduced regulated emissions for each test condition. The fuel effects were most pronounced in regards to particulate emissions, where the FT fuel alone reduced particulate emissions by $54 \%$ on average as compared to the baseline fuel over all three test conditions. The blend performed nearly as well as the ultra-low sulfur diesel in reducing particulate emissions, with both fuels reducing particulates by an average of $28 \%$ compared to the baseline fuel. The fact that the blend produced approximately half the particulate reduction of using neat FT fuel alone suggests a more than proportional benefit of using the blend. 


\subsubsection{NOx Emissions}

It is well understood that the principal factor driving $\mathrm{NO}_{\mathrm{x}}$ formation is in-cylinder temperature during combustion. The extended Zeldovich mechanism is very sensitive to temperature and $\mathrm{NO}_{\mathrm{x}}$ control techniques typically attempt to lower peak cylinder temperatures. Based on this fact and data presented in the previous two reporting periods, it is not surprising that the fuel effect on NOx emissions is much less pronounced. The greatest reduction in NOx emissions was observed with the FT fuel, which reduced NOx by approximately $12 \%$ as compared to the low sulfur diesel. The blend and ultra-low sulfur diesel reduced NOx emissions only slightly, on the order of $2 \%$ and $4 \%$ respectively. The specific NOx emissions rates for the three initial test conditions are depicted in figure 8.2.

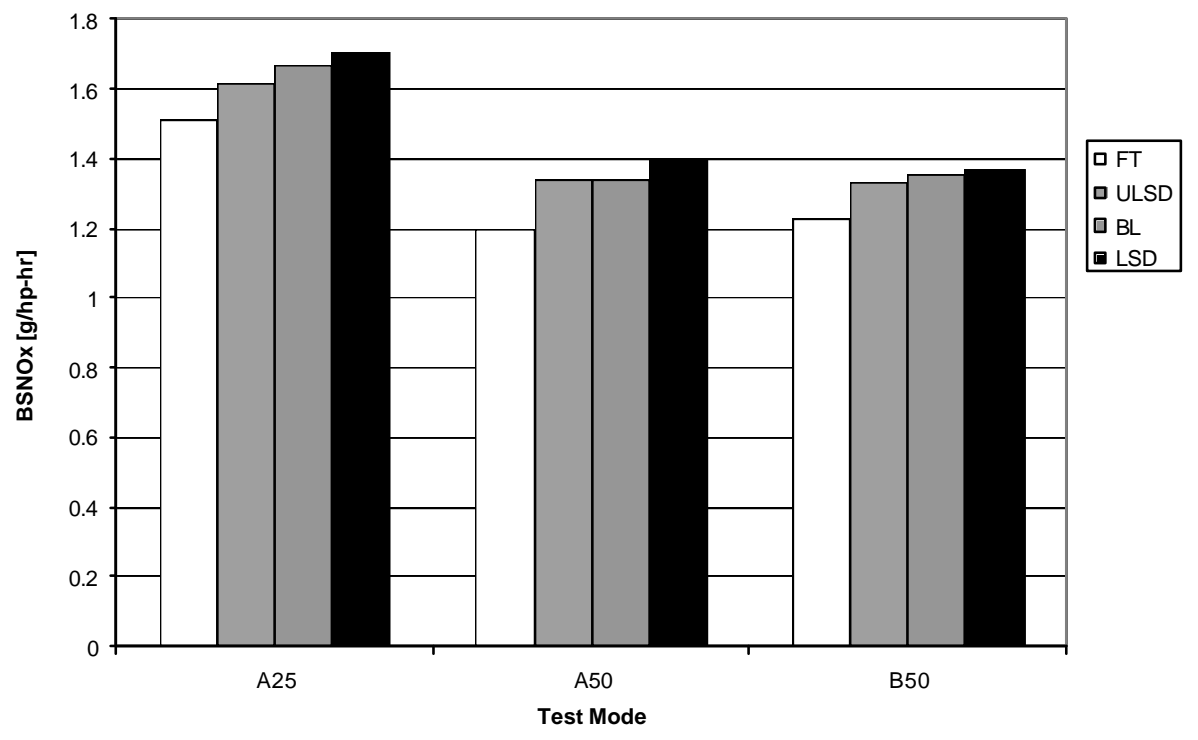

Figure 8.2 Specific NOx emissions

The average exhaust temperatures measured from thermocouples located just outside each exhaust port are plotted in figure 8.3.

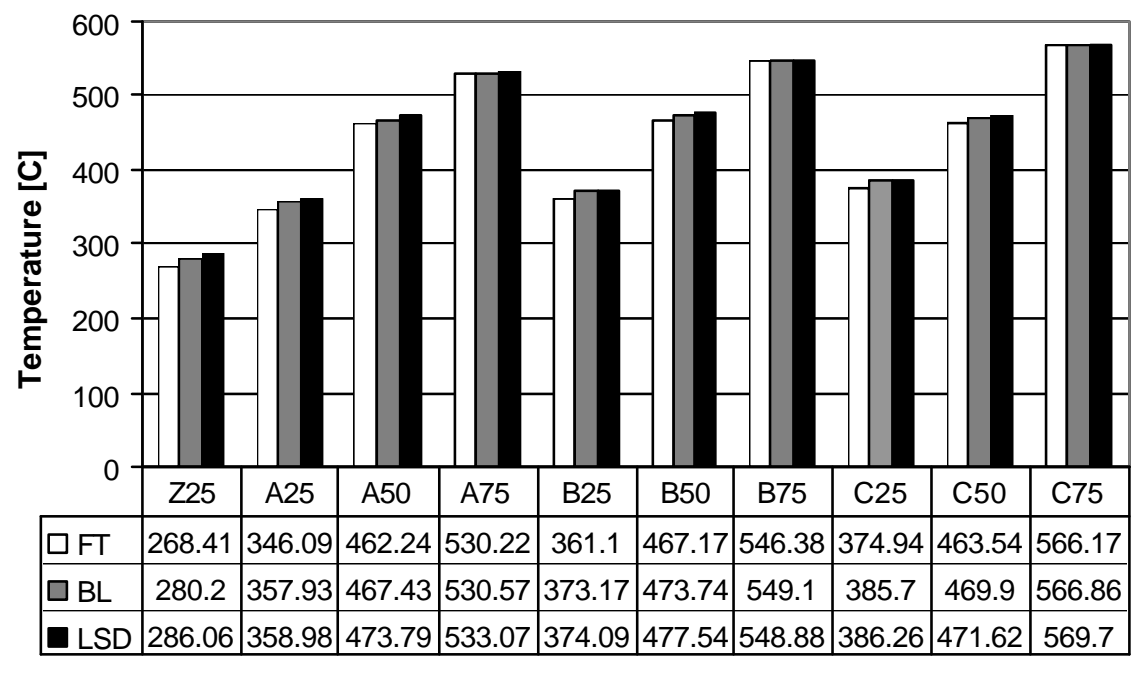

Test Mode

Figure 8.3 Average measured exhaust temperature 
The FT fuel exhibited a slightly lower exhaust temperature for each test condition, with values ranging from a maximum temperature reduction of $17.6^{\circ} \mathrm{C}$ to a minimum reduction of $2.5^{\circ} \mathrm{C}$. The blend exhibited only a slight decrease in exhaust temperature relative to that of the baseline fuel.

The effect of the FT fuel and blend on reducing the measured exhaust and corresponding cylinder temperatures is most likely the primary factor contributing to the reduction in NOx emissions. This observation confirms the temperature sensitivity of the extended Zeldovich mechanism as primarily responsible for the majority of the NOx formation in the power cylinder.

\subsubsection{Hydrocarbon Emissions}

As can be seen from figure 8.4, the effect of the fuels on hydrocarbon emissions was variable, with the FT and blend yielding approximately the same reduction in HC emissions and the ULSD increasing hydrocarbon emissions by nearly $15 \%$ on average when compared with the baseline LSD.

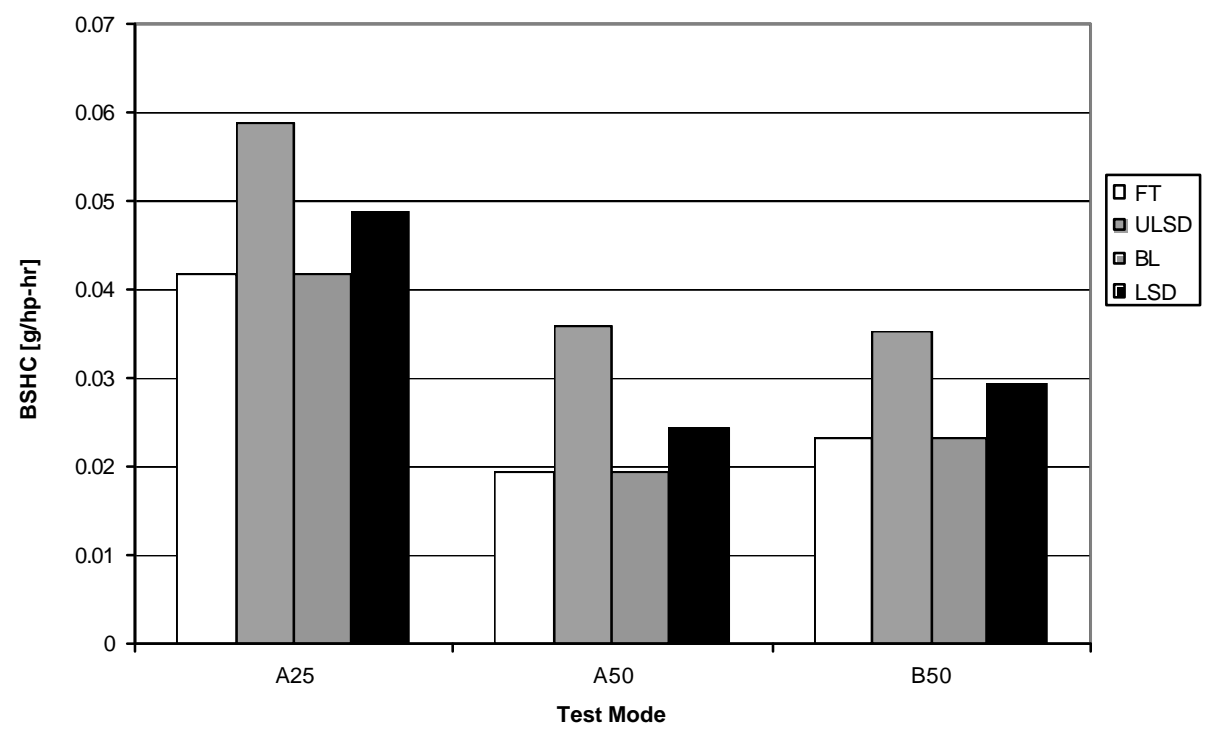

Figure 8.4 Specific hydrocarbon emissions

Hydrocarbon emissions are the product of a number of factors related to fuel properties, cylinder geometry, combustion characteristics, and a multitude of additional factors. It is, therefore, quite difficult to attribute the observed differences in $\mathrm{HC}$ emissions to any one specific factor. While a number of fuel property interactions maybe responsible for the trend, the most likely cause may be due to the higher volatility of the ULSD as depicted by the distillation curves shown in figure 6.1 .

\subsection{Particulate Analysis}

In order to determine more precisely the effect of various fuels on particulate composition, all particulate samples were sent to the emissions-chemistry laboratory of a major engine manufacturer for detailed analysis. Prior to analysis, all samples were 
conditioned and reweighed in a strictly controlled environment at the engine manufacturer's chemistry lab to confirm the particulate mass values, determined at the Sloan Automotive Lab at MIT. Following the conditioning and weighing the samples were analyzed to determine the contribution of sulfates (SO4), nitrates (NO3), and soluble organic fraction (SOF) to the total particulate mass (TPM). As nitrates are not of primary interest, and since the nitrate levels were extremely low, their contribution to the TPM is neglected in the following sections. Once total SOF and SO4 are known, and neglecting the contribution of the nitrates, the SOL (non-soluble or soot) was calculated from the total particulate mass as follows:

Equation 8.1

$$
\mathrm{TPM}=\mathrm{SOL}+\mathrm{SOF}+\mathrm{SO} 4
$$

The SOL is important as it consists of the basic solid particles formed during combustion [34]. The following sections present the results of the detailed PM analysis.

\subsubsection{PM Constituent Distribution}

An overview of the results of the particulate analysis carried out by the chemistry lab of a major engine manufacturer for each of the three test conditions is presented in figure 8.5. Of particular interest is the apparently small contribution of sulfate to the total particulate mass, which ranged from a minimum of $0.64 \%$ to a maximum of $3.05 \%$ of the TPM.

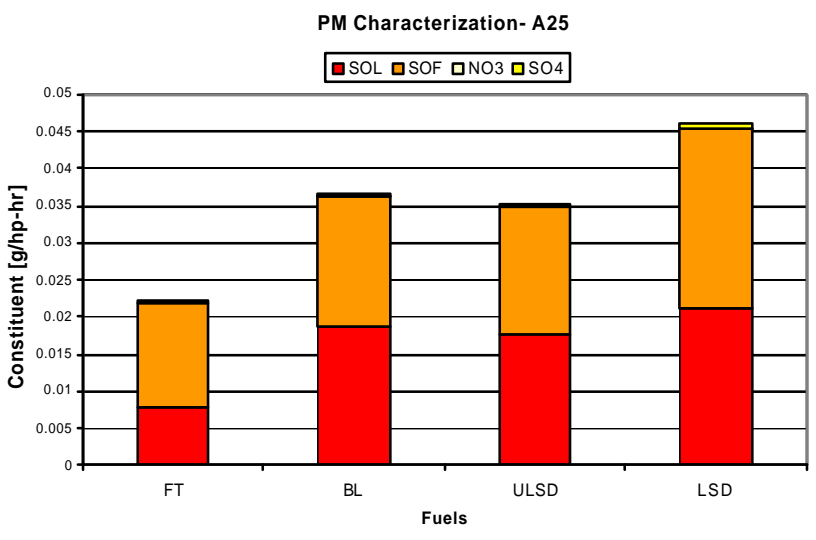

(a) 1682 RPM, 474 kPa BMEP

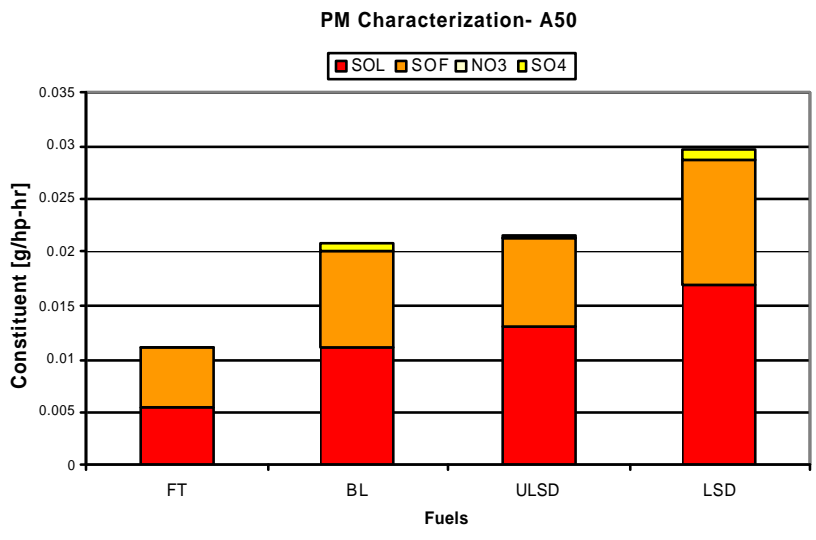

(b) 1682 RPM, 1000 BMEP

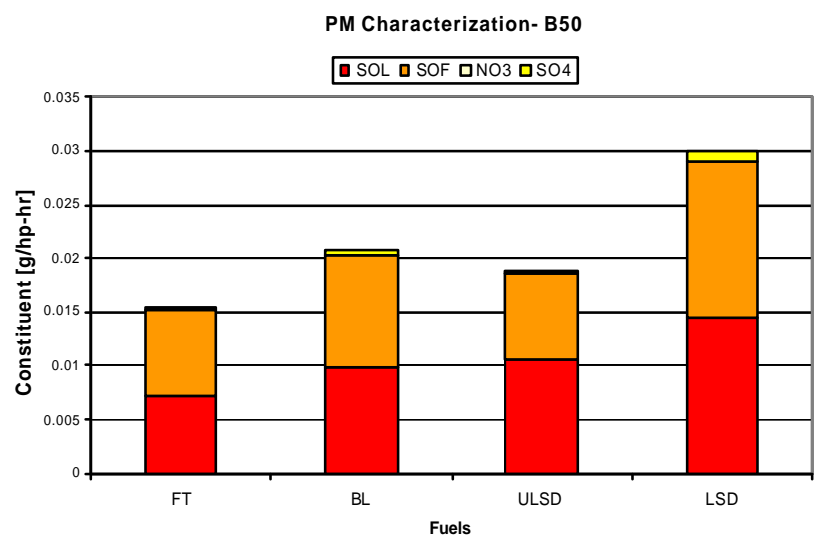

(c) 2011 RPM, 947 BMEP 
Figure 8.5 Distribution of particulate constituents over the three operating conditions

A simple calculation of the fuel sulfur to sulfate conversion rate, based on the known fuel sulfur content and fuel consumption rate, yielded a range from a low of $0.22 \%$ for the FT/LSD blend to a high of $1.94 \%$ for the ULSD. Furthermore, the sulfur to sulfate conversion rates of the blend and low sulfur diesel comprised the low end of the range $(0.22 \%$ to $0.43 \%$ ) while the ultra-low sulfur diesel made up the high end $(0.52 \%$ to $1.94 \%)$. These values are suspect as previous studies have shown that the amount of fuel sulfur converted to PM is at least 1-2\% of the fuel sulfur content irrespective of the total fuel sulfur level or engine type [13]. Despite this discrepancy, the relative trends observed in the data still hold considerable merit.

The fuel sulfur to sulfate conversion rates were observed to vary directly with load, however the trends differed for each of the fuels tested. The fuel sulfur to sulfate conversion rates for both the blend and low sulfur diesel tended to increase with increasing load, while the conversion rates for the ultra-low sulfur diesel exhibited the opposite behavior.

In general, the contribution of the SOF to the total particulate mass decreased with increasing load, while SOL and SO4 increased. This trend is consistent with other published reports in the literature [37].

\subsubsection{Non-soluble Fraction and Soot}

The SOL contribution to the total particulate mass ranged from $43.7 \%$ for the FT fuel to $54.4 \%$ for the ULSD. A comparison of the solid fraction for each of the fuels over all of the test conditions is shown in figure 8.6.

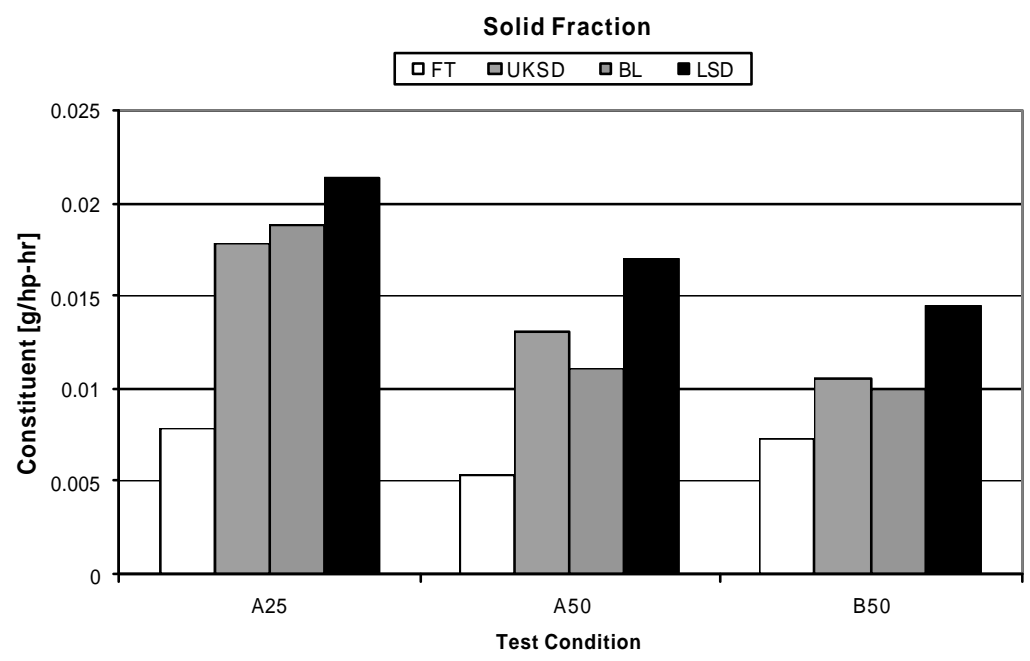

Figure 8.6 Comparison of solid non-soluble fraction

On average, over all of the test conditions, the FT fuel reduced SOL by $60.6 \%$, the ULSD reduced SOL by $22.1 \%$, and the blend reduced SOL by $26.16 \%$ as compared to the baseline low-sulfur diesel. Estimates based on the simplified chemical composition of the fuels, molecular weight, and carbon content provided by the manufacturers give a lower carbon content of $9.8 \%$ by weight for the FT fuel as compared to the LSD. As demonstrated in the figure above, the blend yielded a more than proportional reduction in SOL by approximately $43.0 \%$ as compared to the reduction obtained with the FT fuel alone. 


\subsubsection{Soluble Organic Fraction}

The soluble organic fraction was determined via supercritical fluid extraction using $\mathrm{CO}_{2}$ as the working fluid. This method is believed to produce more consistent results than those achieved by performing the soxhlet extraction using dichloromethane. The trends observed in the SOF are very similar to those presented in the previous section for the SOL. The SOF contribution to the total particulate mass ranged from $41.8 \%$ for the ULSD to $55.7 \%$ for the FT fuel. While the FT fuel yielded proportionally the greatest contribution of SOF to the TPM, it still produced an average reduction in SOF of $46.0 \%$ as compared to the baseline LSD. The blend and ULSD both yielded average reductions in SOF of $26.2 \%$ and $34.2 \%$, respectively, over the baseline fuel.

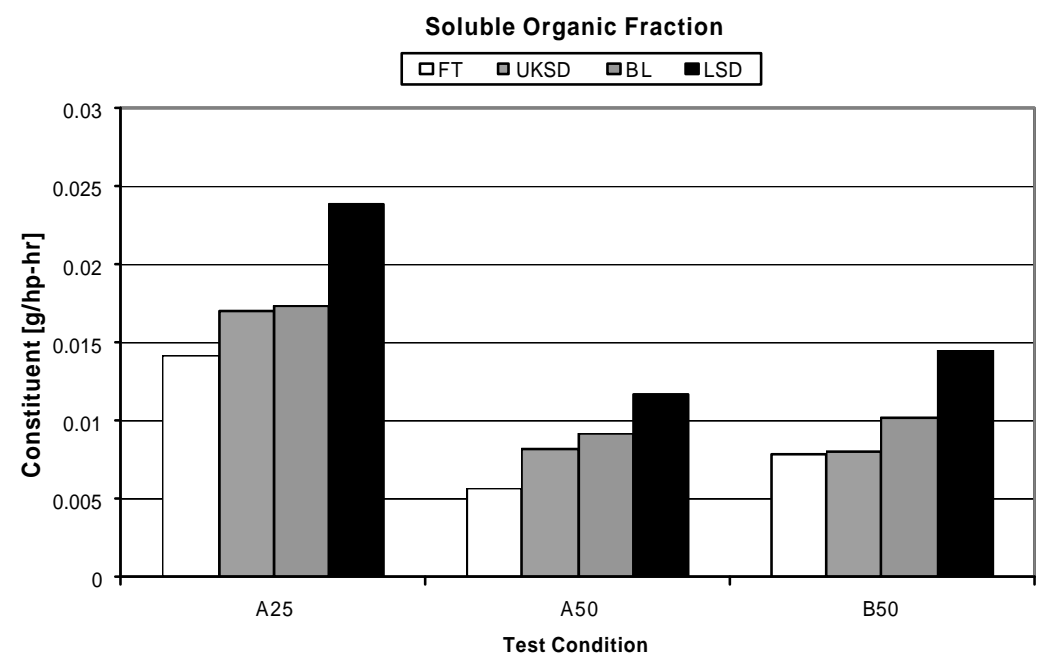

Figure 8.7 Comparison of soluble organic fraction

As demonstrated in figure 8.7, the blend yielded a more than proportional reduction in SOF by approximately $56.9 \%$ when compared with the reduction obtained using the FT fuel alone.

\subsubsection{Sulfates}

The sulfate contribution to the TPM was determined via ion chromatography. As discussed in section 8.2.1, the low absolute magnitudes of the SO4 values (between $0.22 \%$ and $3.05 \%$ of the TPM) are suspect, as they do not correlate well to the accepted fuel sulfur to sulfate conversion rates presented in the literature. Nonetheless, the relative trends are still quite valid. As was expected, the FT fuel and ULSD contributed least to the SO4, as these fuels contained little to no sulfur. The blend and LSD on the other hand, contained considerably more sulfur, 305.9 ppm and 400 ppm sulfur by weight respectively. 


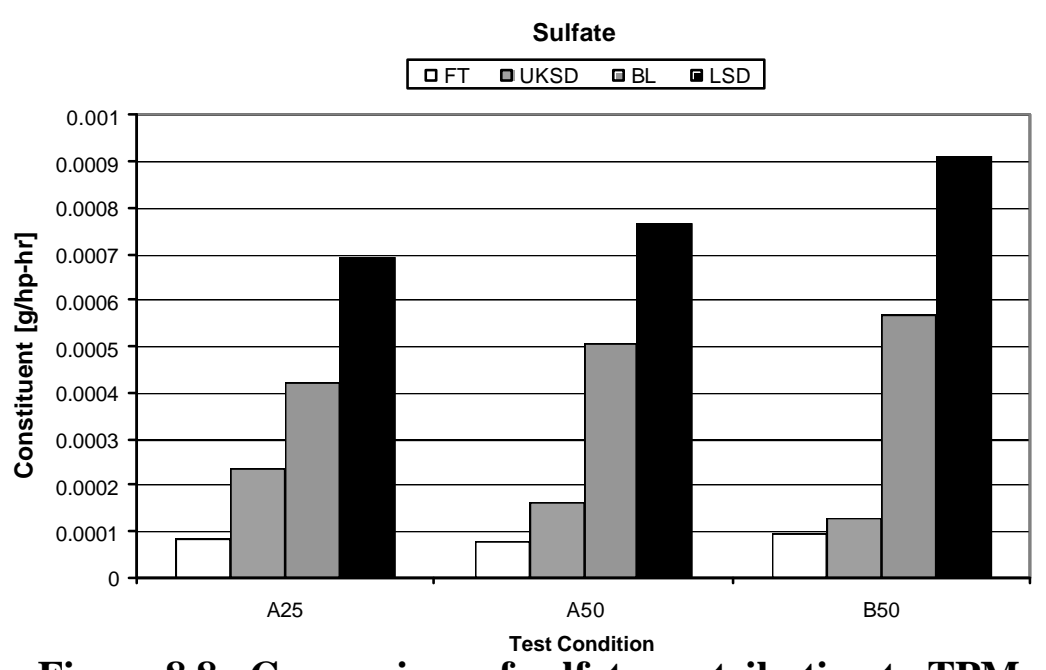

On average, the FT fuel reduced SO 4 by $89.1 \%$, the ULSD reduced SO 4 by $76.9 \%$, and the blend reduced SO 4 by $37.0 \%$ as compared to the baseline low-sulfur diesel. As demonstrated in figure 8.8, the blend yielded a more than proportional reduction in $\mathrm{SO} 4$ by approximately $41.5 \%$ as compared to the reduction obtained with the FT fuel alone. Despite these significant reductions in SO4, the impact to the overall particulate mass was nearly negligible due to the small contribution of the SO4 to the TPM.

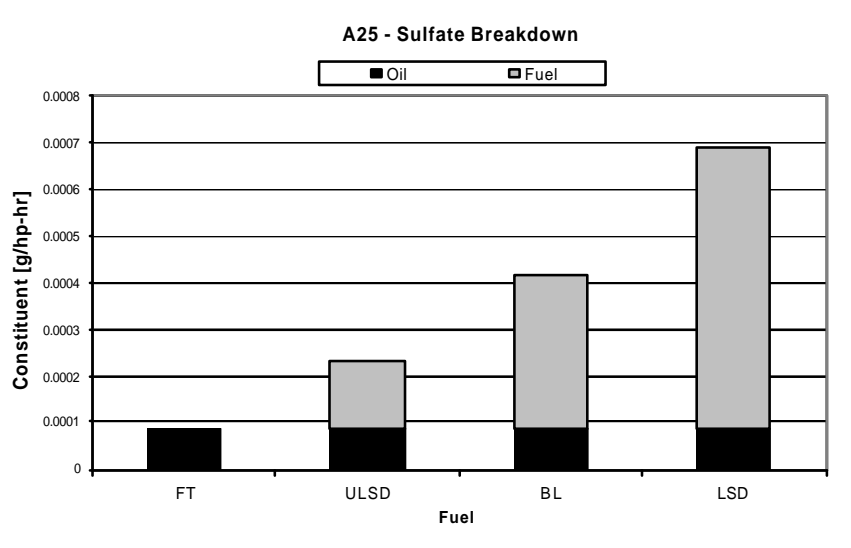

(a) 1682 RPM, 474 BMEP

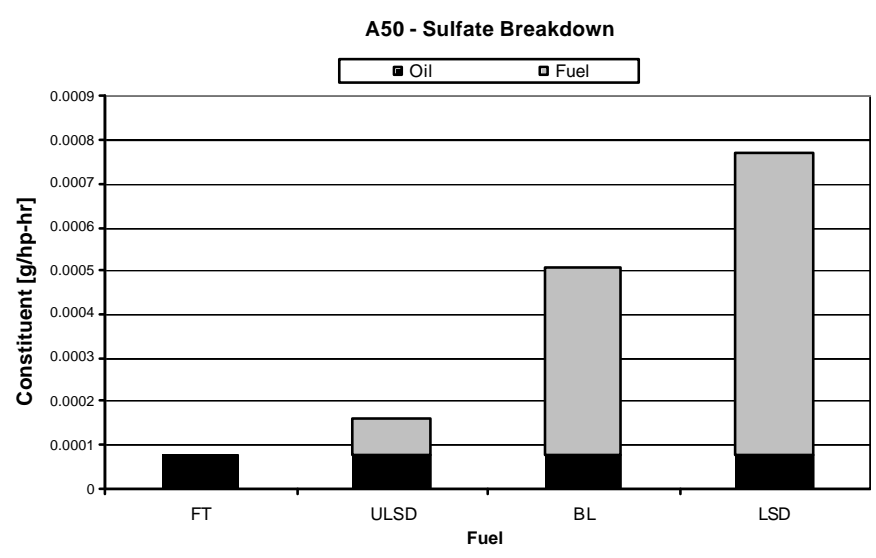

(b) 1682 RPM, 1000 BMEP

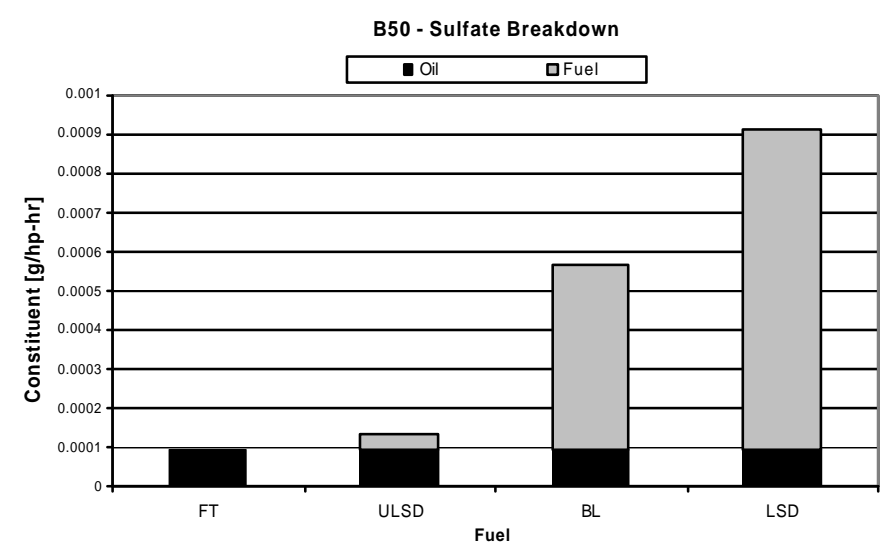

(c) 2011 RPM, 947 BMEP 
The contribution of sulfur in the engine lube oil is depicted in figure 8.9 for each of the three test conditions. The zero sulfur nature of the FT fuel allowed for simple and straightforward determination of the lube oil contribution, as any SO4 in the PM must be attributed to the lube oil.

Although the absolute magnitude of lube oil derived SO4 increased with increased engine speed and load, a result of the associated increase in lube oil consumption, the relative lube oil contribution to the total SO4 declined as the increase in oil consumption was negated by the significantly larger increase in fuel consumption. On average the lube oil contributed to between $13.9 \%$ and $24.9 \%$ of the SO4 determined from the LSD PM emissions, between $63.3 \%$ and $74.3 \%$ of the SO4 determined from the ULSD PM emissions, and between $17.9 \%$ and $35.7 \%$ of the SO4 determined from the PM emissions observed from the blend. 


\subsection{Combustion Characteristics}

For the sake of clarity, the combustion data for the ultra-low sulfur fuel was not included in the figures comparing the combustion characteristics. It should be noted, however, that the ULSD exhibited very similar combustion characteristics to the standard low sulfur baseline fuel. Thus, the following discussion is focused on comparing the combustion characteristics of the neat FT fuel, low sulfur diesel, and blend of FT/LSD.

\subsubsection{Ignition Delay}

Figure 8.10 compares the ignition delay of the three fuels. The FT fuel yielded a shorter ignition delay over the range of operating conditions, with the blend exhibiting an ignition delay between that of the FT and LSD.

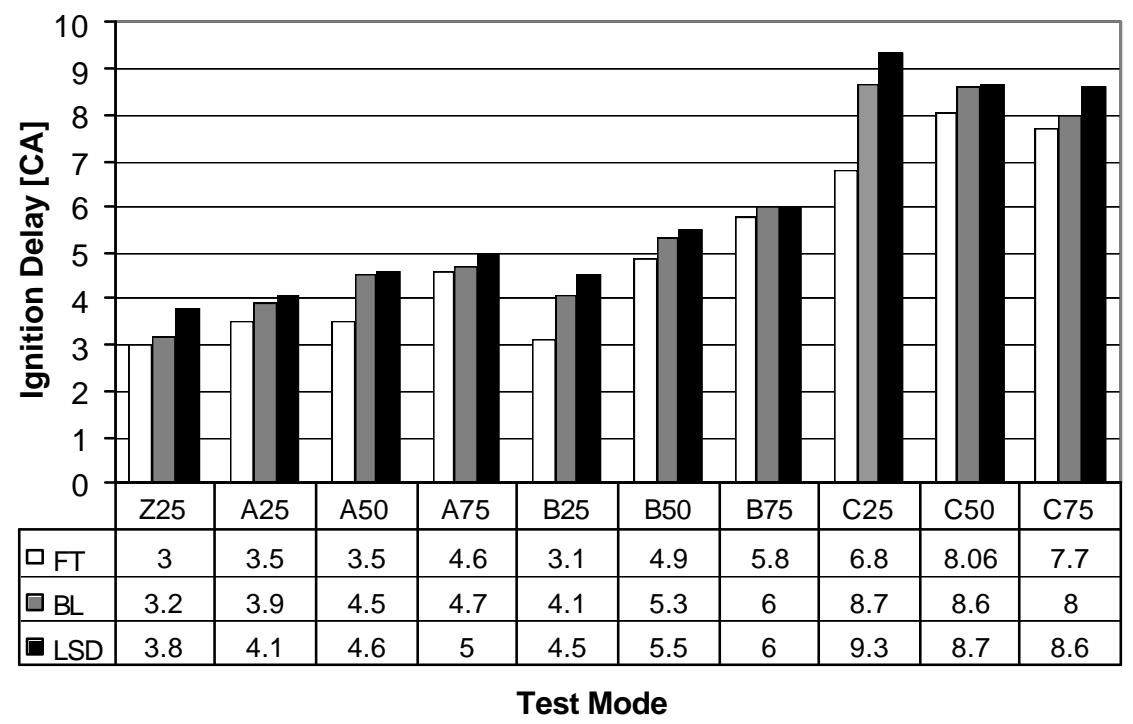

Figure 8.10 Ignition delay

The decreased ignition delay for the FT and blend results in less fuel injected during the premixed combustion phase, yielding a more uniform and less rapid temperature rise within the cylinder. This is evidenced by the significantly lower heat release rate in the pilot injection (see figure 8.19), however the heat release profile of the main injection seemed little affected by the reduced ignition delay. 


\subsubsection{Burn Duration}

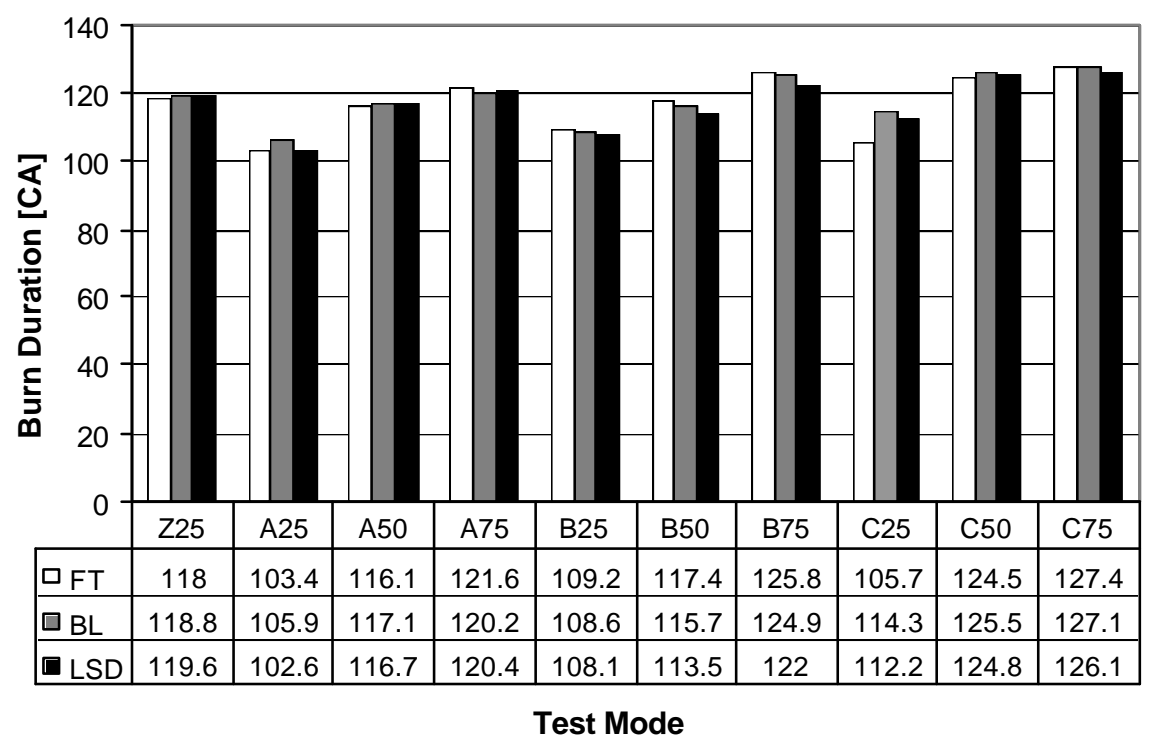

Figure 8.11 Start of injection to $99 \%$ burn duration

Figure 8.11 depicts the total time from the start of injection (SOI) to the end of combustion (EOC), which is nearly the same for both fuels. Despite the reduced ignition delay of the FT fuel and blend, the fact that the time from SOI to EOC varied little with the three fuels is attributed to the lower density of the FT fuel which results in more fuel injected per cycle (longer injection duration), as well as the slightly longer tale-end burn observed in the FT fuel and blend.

The FT fuel and the blend also exhibited reduced $50 \%$ to $90 \%$ burn durations, indicating a faster burn rate for the FT fuel during the latter part of the combustion process as shown in figure 8.12. On average, the FT fuel reduced the diffusion burn duration by approximately $7.4 \%$, with values ranging from a maximum reduction of $20.2 \%$ to a slight increase of $1.4 \%$ as compared to the low sulfur diesel.

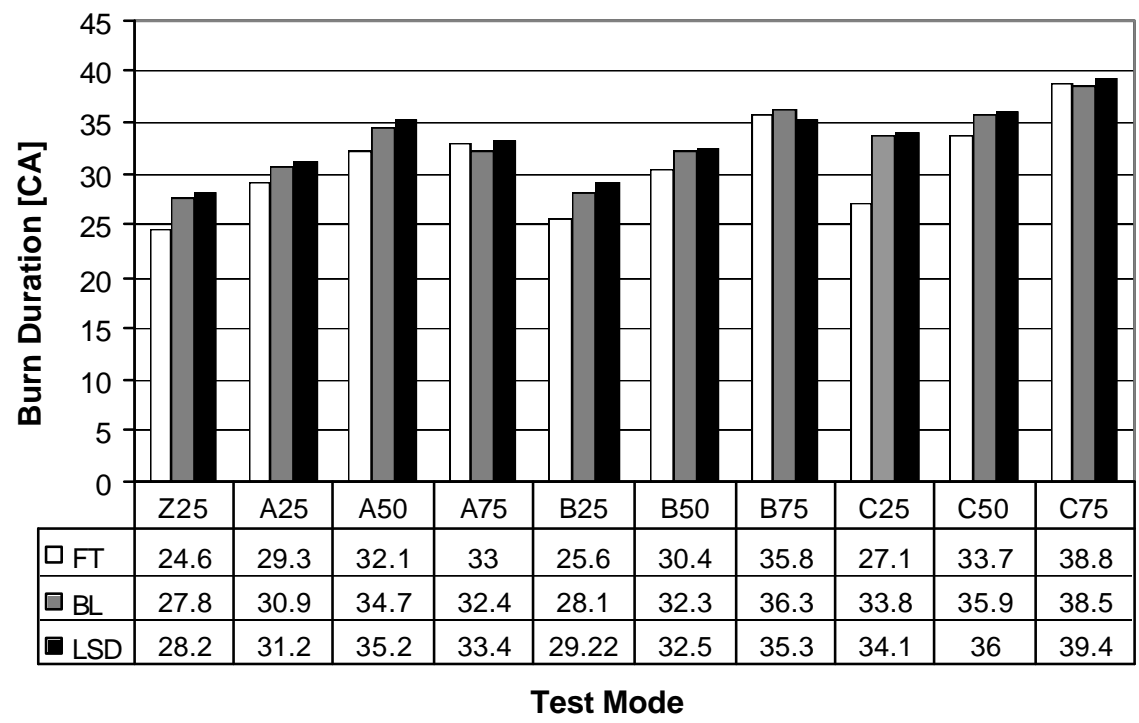

Figure $8.1250 \%$ to $90 \%$ burn duration 
In addition to exhibiting a faster burn rate during the diffusion burn, the location of the $50 \%$ heat release occurring slightly earlier for both fuels as shown in Figure 8.13. This observation is attributed primarily to the reduced ignition delay of the FT fuel and blend, essentially initiating the combustion process earlier and thus liberating more energy faster than the baseline fuel.

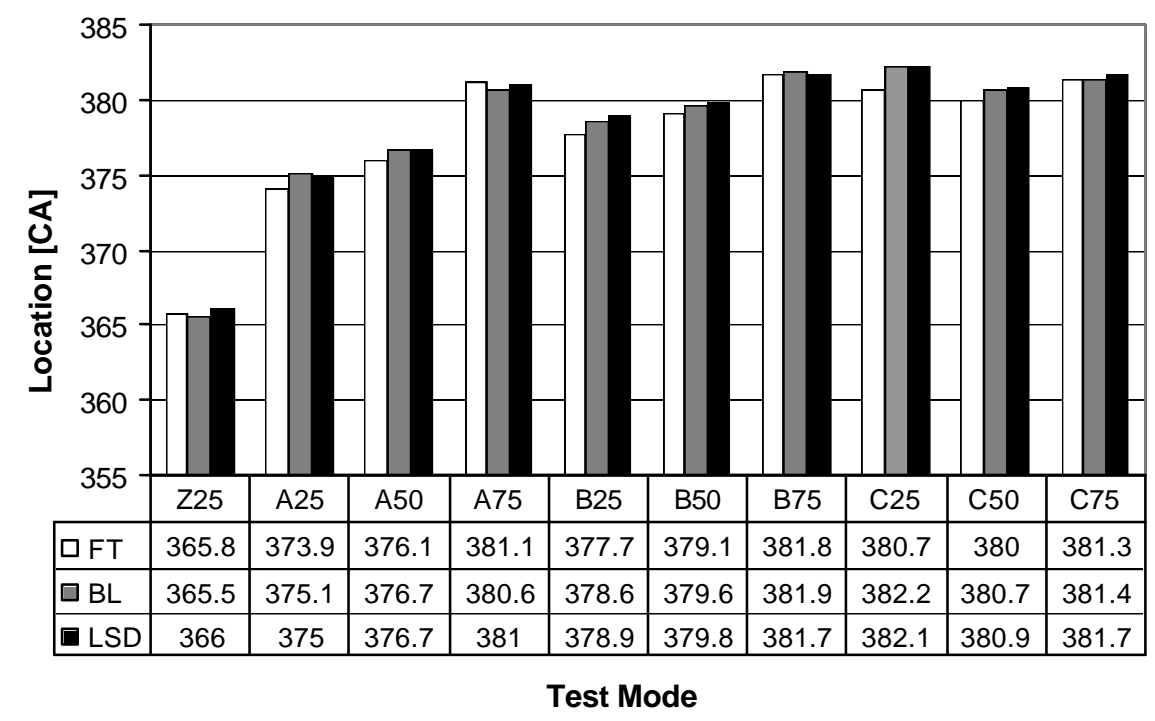

Figure 8.13 Location of $50 \%$ heat release

Figure 8.14 shows the initial $10 \%$ to $50 \%$ burn duration, which did not vary significantly for the three fuels. The reduced ignition delay for the FT fuel and blend, combined with the lower density of the FT fuel which reduces the amount of fuel injected for a given time interval, may lead to a reduction in the amount of fuel burned during the premixed burn phase and thus contribute significantly to the observed reduction in PM emissions.

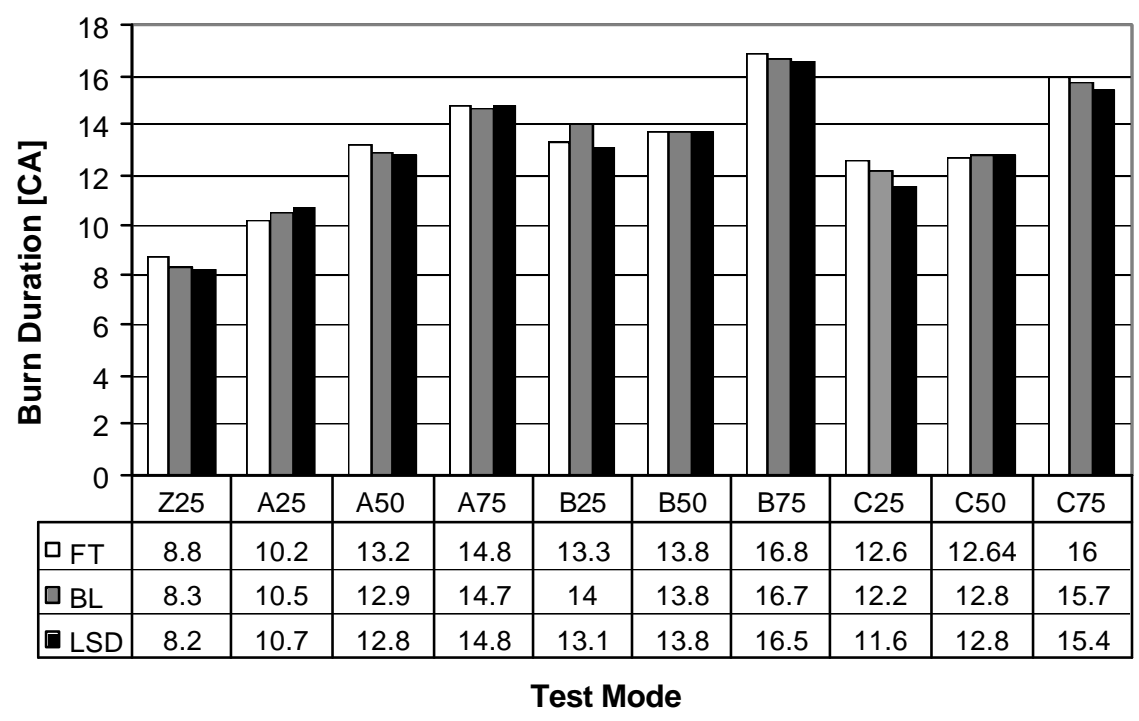


On the other hand, the FT and blend tended to have a slightly longer tail-end burn, demonstrated in Figure 8.15. The tail-end burn for the FT fuel was approximately 5.3\% longer on average, with values ranging from a maximum increase of $10.7 \%$ to a minimum of $2.5 \%$. These values should only be taken as approximate, due to the difficulty associated with determining the location of $99 \%$ heat release. In nearly all the cases, the blend exhibited combustion characteristics somewhere in between the two fuels.

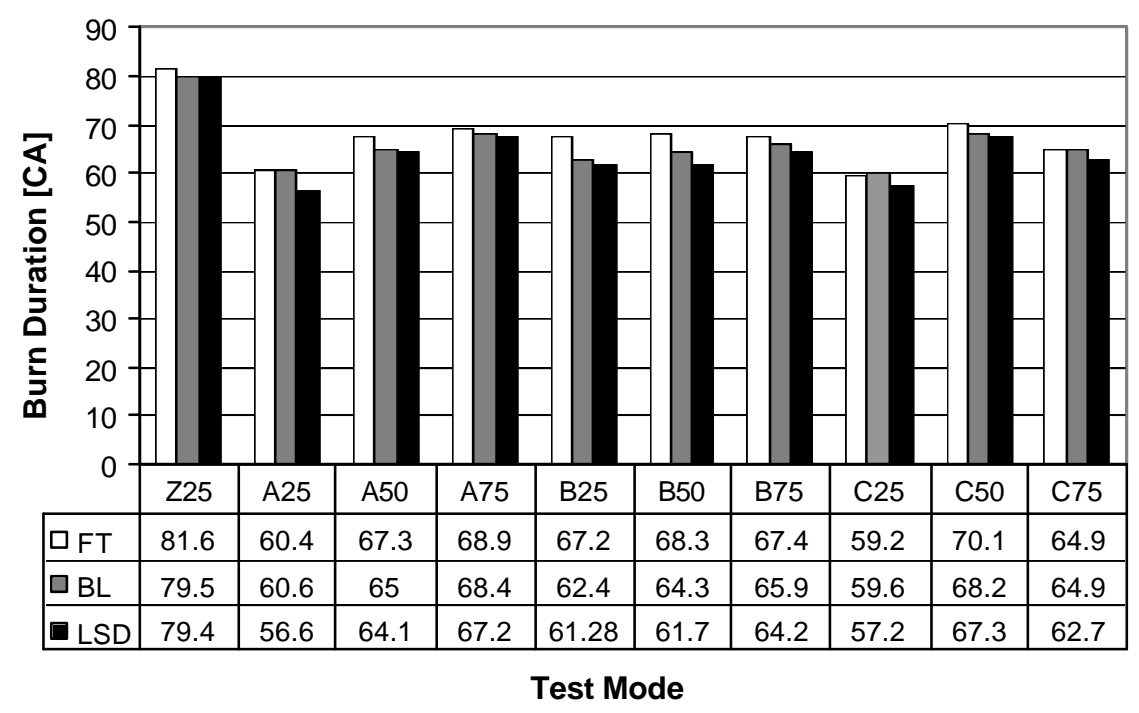

Figure 8.1 Tail-end burn duration

\subsubsection{Maximum In-Cylinder Pressure and Location}

Figures 8.16 and 8.17 compare the maximum in-cylinder pressure for each fuel and its associated location. Since torque was held constant at each test condition for each fuel, maximum cylinder pressure and its location remained fairly constant as well. Slight variations between the two fuels can be attributed to small differences in injection timing, which would affect the location and magnitude of the maximum pressure. 


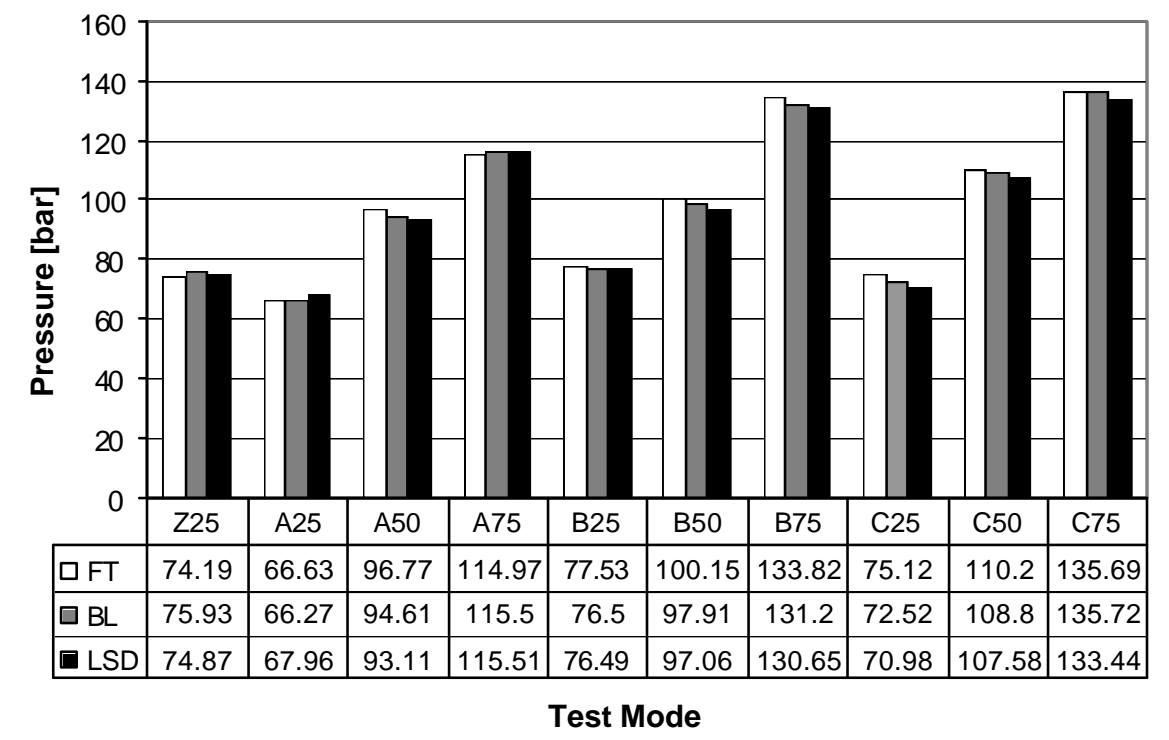

Figure 8.16 Maximum in-cylinder pressure after start of injection

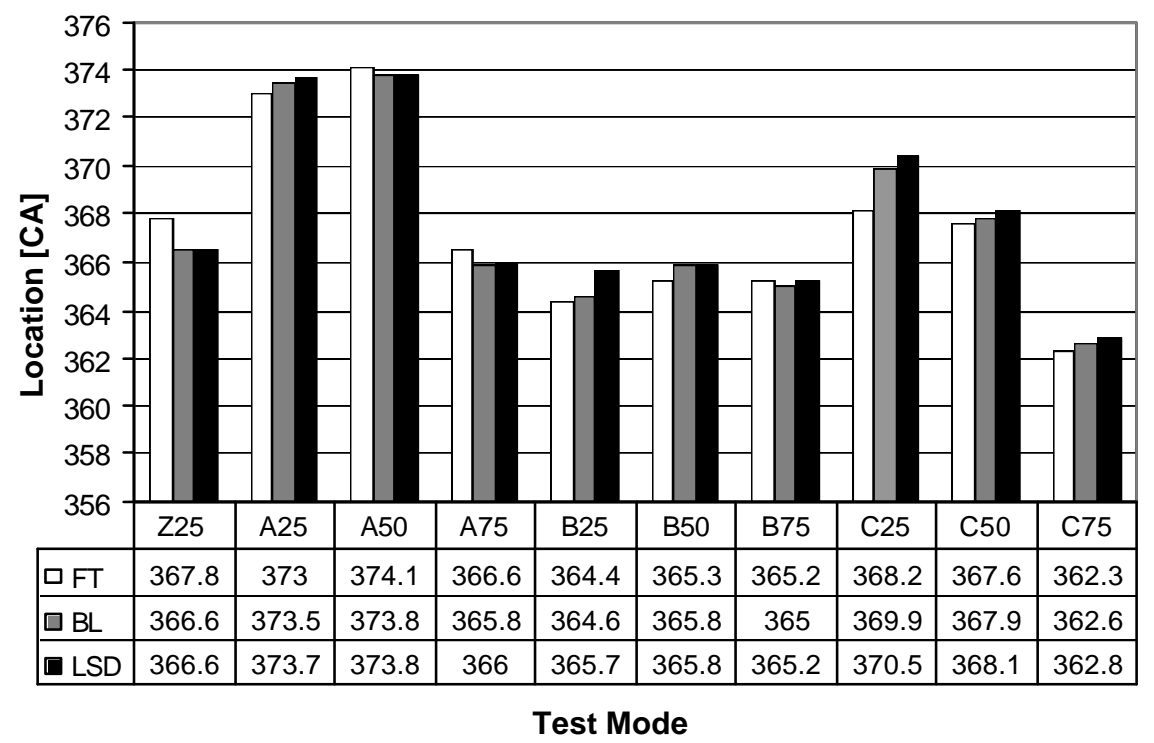

Figure 8.17 Location of maximum in-cylinder pressure after start of injection 


\subsubsection{Pressure Trace and Heat Release Curves}

Since the stock calibration employs a strategy of severely retarding injection timing to decrease in-cylinder temperatures and reduce NOx emissions, the maximum cylinder pressure for a number of test conditions occurred before TDC and significant combustion had taken place. For these cases, the maximum cylinder pressure was taken at the $10 \%$ heat release location to provide a more representative value of the pressure actually experienced by the fuel. An example of a typical pressure trace for a severely retarded injection timing condition is given in Figure 8.18.

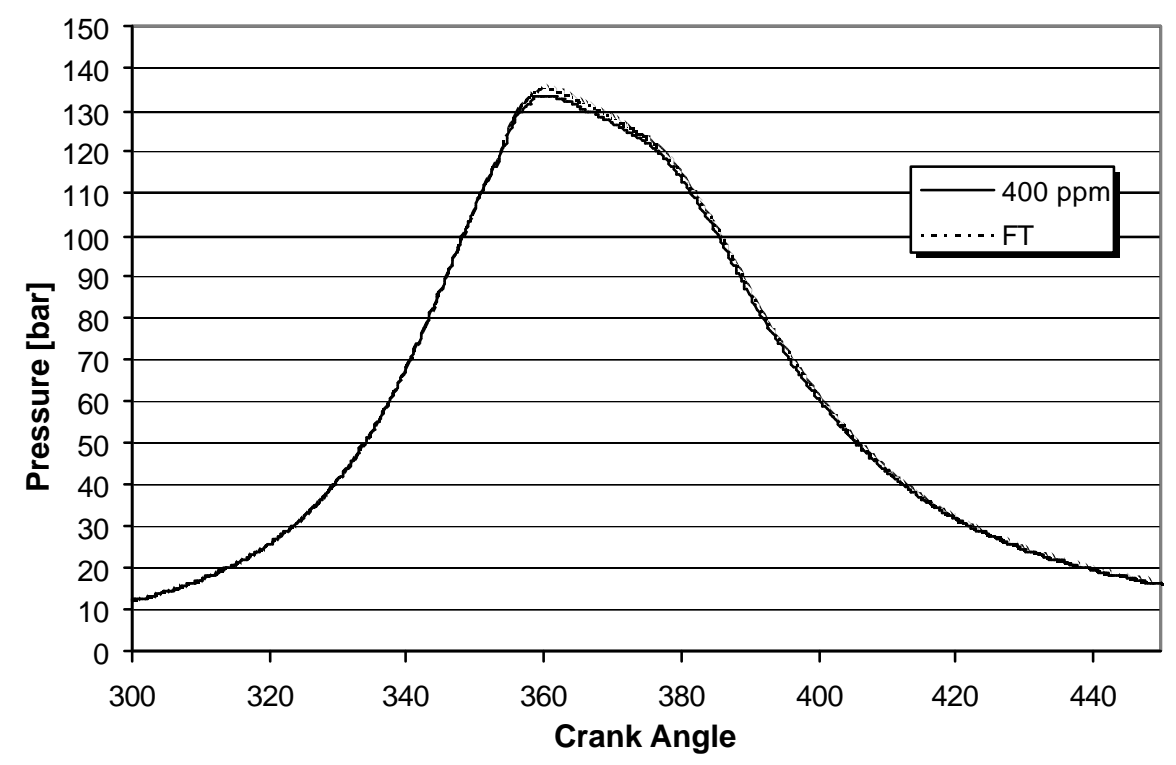

Figure 8.18 Pressure trace for severely retarded timing, 2013 rpm, $1611 \mathrm{kPa}$ IMEP

The figure below corresponds to the heat release curve for the pressure trace presented in figure 8.18 above. The three distinct peaks correspond to the pre-, main-, and postinjection events and their associated heat release profiles.

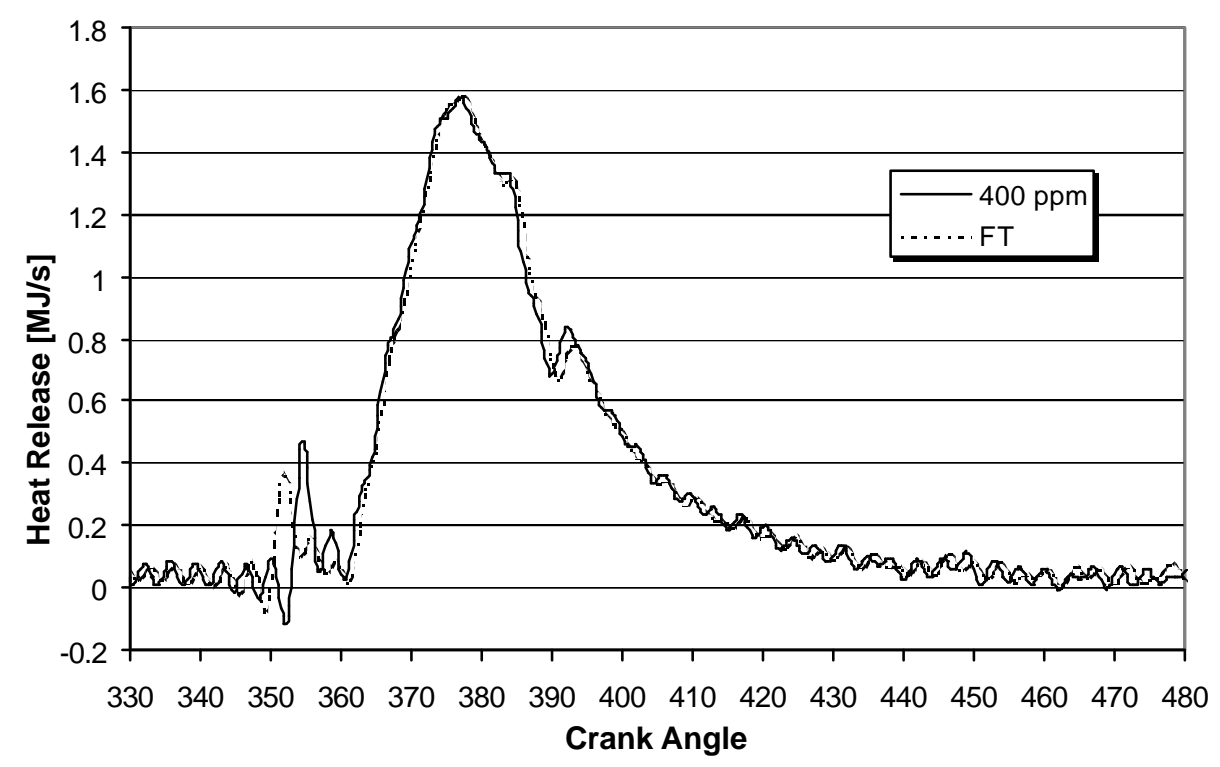


Figure 8.19 Heat release curves, severely retarded timing, 2013 rpm, $1611 \mathrm{kPa}$ IMEP

\subsubsection{Pilot-Injection Maximum Heat Release Rates and Location}

Figures 8.19 and 8.20 depict the maximum heat release rates and locations for each pilot injection event. In nearly all of the cases, the FT and blend exhibited a lower maximum heat release rate occurring slightly earlier than that of the low-sulfur diesel. The most significant difference between the heat release rates occurred for the pilot injection with the FT reducing the maximum heat released by $24 \%$ on average, once again indicating a reduction in the amount of fuel burned during the pre- mixed combustion phase. The C50 and C75 test conditions were omitted in Figure 8.19 and Figure 8.20, due to the absence of a readily discernible heat release profile for the pilot injection event.

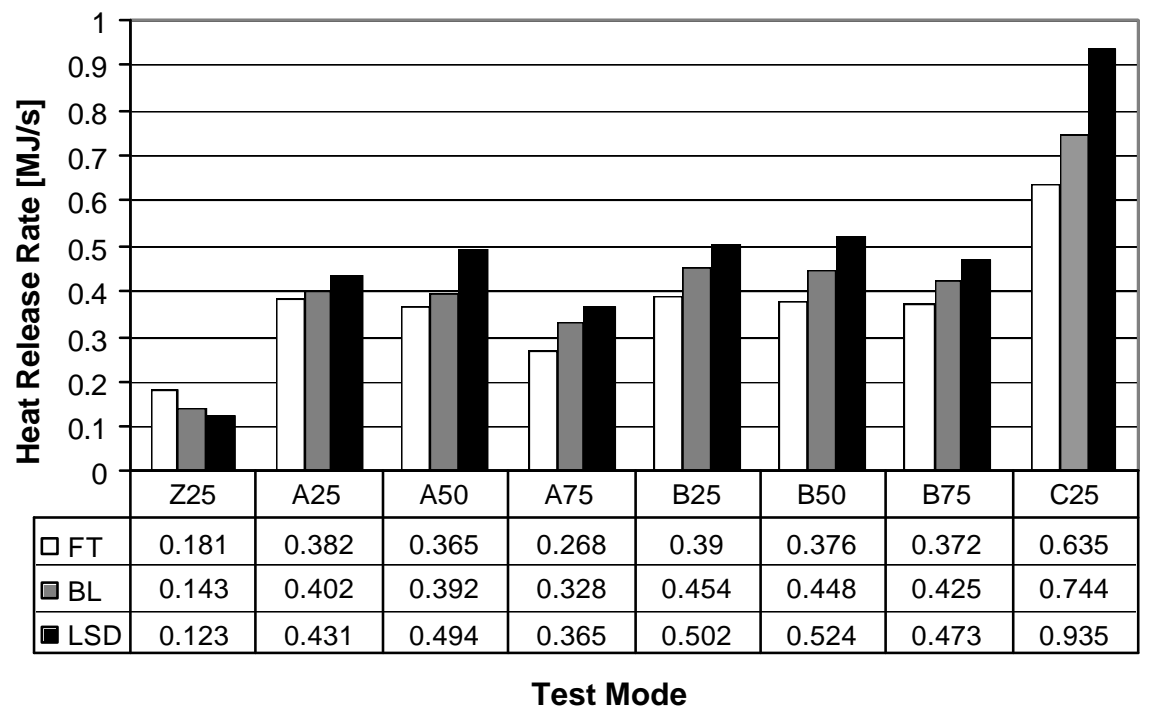

Figure 8.20 Pilot injection maximum heat release rate

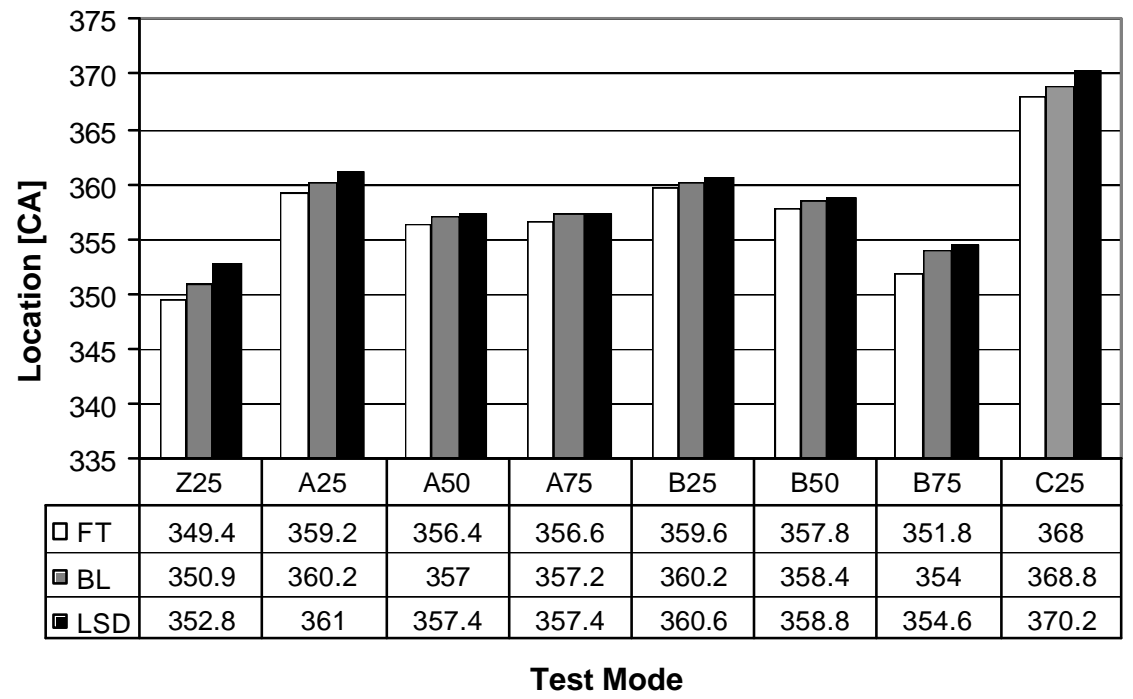

Figure 8.21 Location of pilot injection maximum heat release 


\subsubsection{Main-Injection Maximum Heat Release Rates and Location}

The differences in the maximum heat released for the main injection are quite small, on the order of 1 to $2 \%$. Typically the location of the maximum heat release rate for the main injection event occurred 1 to 2 crank angle degrees earlier for the FT fuel. Once again, the blend exhibited heat release characteristics somewhere between that of the FT und low-sulfur diesel.

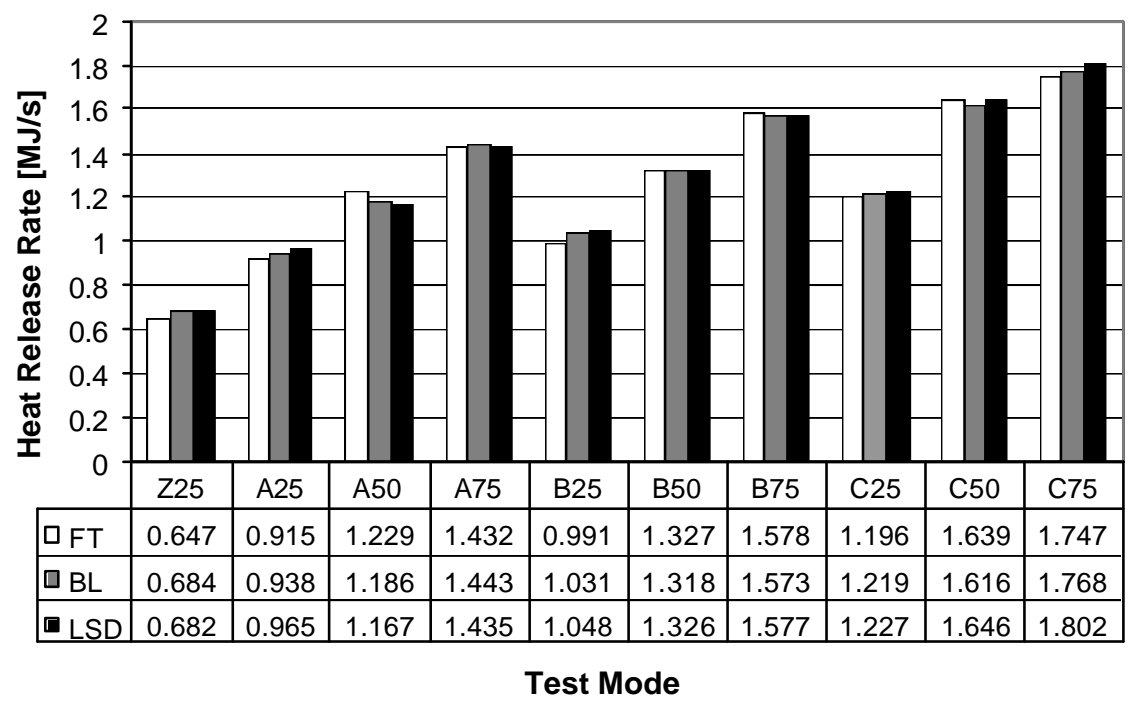

Figure 8.22 Main injection maximum heat release

The fact that the main injection heat release profiles for the various fuels did not differ significantly as reported in previous studies, is primarily attributed to the multiple injection strategy employed by the Cummins ISB. Furthermore, the location of the maximum heat release rates varied less for the higher load conditions.

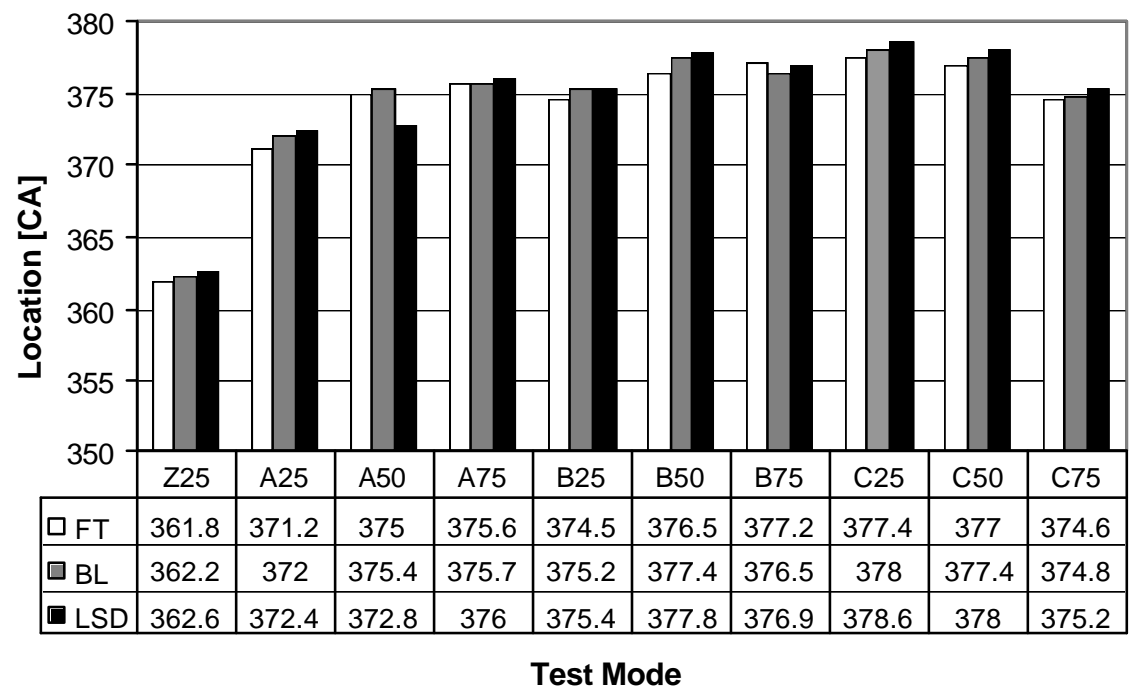

Figure 8.23 Location of main injection maximum heat release 


\subsubsection{Post-Injection Maximum Heat Release Rates and Location}

The differences in the maximum heat released for the post injection event were slightly greater than those observed in the main injection with the FT exhibiting a lower average heat release rate for the post injection of approximately $5 \%$. As before, the blend exhibited combustion characteristics somewhere between that of the FT and low sulfur diesel.

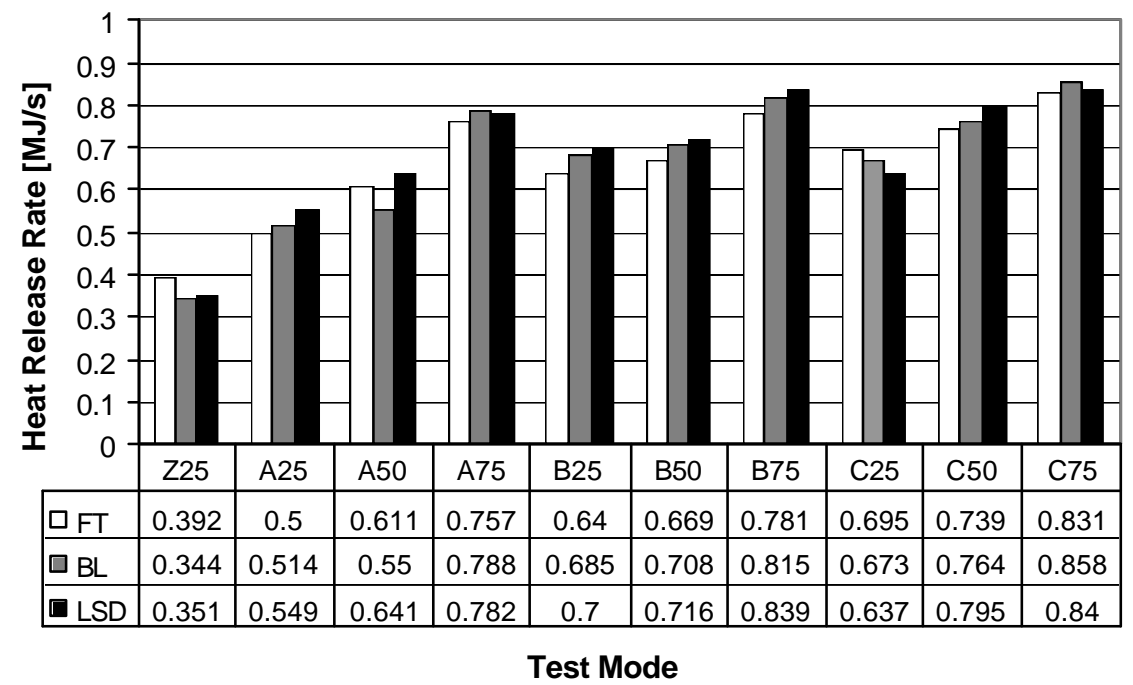

Figure 8.24 Post injection maximum heat release rate

Unlike the location of the maximum heat release rate for the main injection event, the location of the maximum heat release rate for the post injection event occurred only slightly earlier for the FT fuel. This is attributed to the FT fuel's longer tale-end burn duration, and subsequently slower tale-end burn rate. In addition, the location of the post-injection heat release rate was nearly identical for the high load conditions.

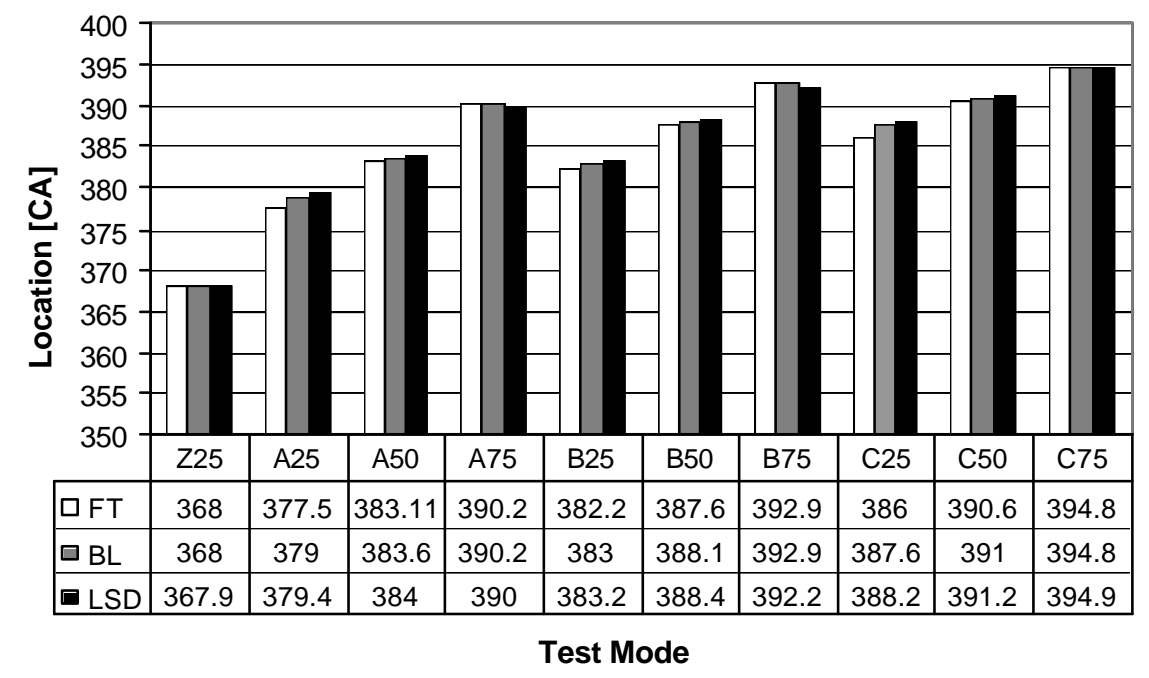

Figure 8.25 Location of post injection maximum heat release 


\subsection{DISCUSSION}

The observed emissions behavior of the fuels can be explained by the differences in the fuel properties, combustion characteristics, and impact of the engine technology.

\subsection{Fuel effects}

The lower density and near zero sulfur and aromatic content of the FT fuel contribute to the reduction in particulate emissions to a certain extent. Furthermore, Lee et al. showed that lower density diesel fuels increase the spray dispersion angle and achieve greater spray penetration in the cylinder, promoting better mixing of the charge and more complete combustion [11]. In addition, the lower $\mathrm{C} / \mathrm{H}$ ratio of the $\mathrm{FT}$ fuel due to its reduced aromatic content reduces the amount of carbon in the cylinder and, thus, the amount of solid carbon in the particulates as well.

While the reduction in fuel sulfur from $400 \mathrm{ppm}$ in the low-sulfur diesel to $0 \mathrm{ppm}$ in the FT diesel does have some effect in terms of overall PM reduction, the effect is believed to be small. Previous results, most notably reported by Kwon et al. and Lee at al., demonstrate that a reduction in fuel sulfur content below $0.05 \%$ yields little incremental benefit in terms of $\mathrm{PM}$ emissions reduction $[11,16]$. Therefore, a significant non-sulfur effect must be accounted for to explain the observed PM emissions trends.

Interestingly, the blend exhibited the same reduction in $\mathrm{HC}$ emissions as the neat FT fuel (figure 8.4). A number of investigators have attempted to relate total hydrocarbon emissions to fuel properties and combustion characteristics with varying degrees of success. It is widely accepted that cetane number and density are the two fuel properties with perhaps the greatest influence on total hydrocarbon emissions [19]. However, a number of other factors such as mixing, flame quenching, fuel atomization, and combustion rate all play an important role in determining total hydrocarbon emissions as well. The fact that the ultra- low sulfur diesel has the lowest cetane number of all the fuels tested, may partially explain its higher HC emissions. Furthermore, the reduction in T90 and T95 from the LSD to the ULSD by $68{ }^{\circ} \mathrm{C}$ and $72{ }^{\circ} \mathrm{C}$ respectively, may also contribute to the large observed increase in HC emissions. A more detailed analysis taking into consideration all of the factors involved is warranted to determine the exact causes of the observed trends in HC emissions.

The detailed particulate analysis carried out by the emissions-chemistry laboratory of a major engine manufacturer confirmed the initial observations of the more than proportional benefit of using the FT diesel blend in terms of overall PM reduction described in the previous reporting period. However, since a more than proportional reduction in all of the PM constituents was observed, little insight is gained into this trend based on fuel properties alone. Of interest is the extremely small, almost negligible contribution of fuel sulfur to the TPM, and while the absolute magnitudes of the numbers are suspect, the observed trend does support the findings presented in [24]. Furthermore, lube oil derived sulfur was seen to contribute significantly to PM emissions of fuels containing less than 15 ppm sulfur, with the lube oil derived sulfur contributing to between $63 \%$ to $74 \%$ of the SO4 emissions observed from the ULSD, and $100 \%$ of the SO4 emissions for the FT fuel. 


\subsection{Combustion characteristics}

The combustion analysis demonstrated that the significantly higher cetane number of the FT fuel reduced the ignition delay, reducing the amount of fuel vaporized during the premixed phase of combustion. This observation was further supported by the significantly reduced maximum heat release observed in the pilot injection. Furthermore, the lower density of the FT fuel reduces the amount of fuel injected for a given time interval, and thus necessitates a slightly longer injection duration in order to achieve the same power output as the baseline fuel. The reduced amount of FT fuel injected during the rich pre-mixed combustion phase may contribute significantly to the reduction in PM formation during this portion of the combustion process. The slightly reduced maximum heat release rates for the main- and post- injections are also indicative of a slightly more uniform combustion in the case of the FT fuel. However, it should be noted that the extreme differences in the heat release profiles for the FT and baseline fuel observed in previous studies [18, 19] were not seen in this investigation. The multiple injection strategy is the most likely cause for this discrepancy.

Since the burn duration is a qualitative indicator of the chemical reaction rates during fuel oxidation, the shorter $50 \%$ to $90 \%$ burn duration for the FT fuel and blend implies a faster burn rate for these fuels as compared to the low-sulfur diesel. This effect is most likely due to the higher cetane number of the FT coupled with the engine's retarded injection timing. As the fuel is injected later in the expansion stroke, the unburned gas temperature in the cylinder decreases. This decrease in cylinder temperature may affect the auto-ignition chemistry of the fuel. Therefore, a high cetane number fuel injected under these conditions, with auto-ignition characteristics that are less sensitive to cylinder temperature, will ignite more readily and maintain a faster rate of combustion than a lower cetane number fuel [27]. The effect of the faster 50\% to $90 \%$ burn rate coupled with the slightly longer tail-end burn of the FT fuel and blend on PM emissions is difficult to determine from the present study, although it is possible that the longer tail-end burn may contribute to additional soot oxidation in the cylinder.

The effect of the FT fuel on reducing NOx emissions is somewhat lower than other results reported in the literature. This may due to the influence of the EGR system, multiple injection strategy, and heavily retarded injection timing on reducing the sensitivity of NOx formation in this engine to the fuel properties. Nonetheless, the reduced exhaust and corresponding cylinder temperatures are most likely the main factors contributing to the observed reduction in NOx emissions for the FT fuel.

The explanations presented above apply equally well to the observed emissions and combustion behavior of the blend. Based on the combustion analysis alone, no specific conclusions can be drawn for the more than proportional reduction in PM emissions of the blend. In most cases the blend exhibited combustion behavior closer to that of the baseline diesel, which is to be expected as the blend contained 75\% LSD by volume.

\subsection{Engine technology}

In addition to the combustion characteristics, a number of engine control parameters 
such as injection timing, EGR fraction, boost pressure, and the time intervals between the pilot-, main-, and post-injection events were monitored throughout the study as well. No significant differences were observed between any of the engine control parameters and the fuels used. It is, therefore, unlikely that any significant interactions between the fuels and the various engine sub-systems should influence the observed results.

\subsection{EXHAUST AFTERTREATMENT SYSTEM}

In order to comply with the increasingly more stringent emission standards in place by 2007, heavy-duty diesel engines will need to employ some form of exhaust aftertreatment systems. Currently diesel particulate traps represent the only technically feasible and economically viable means for reducing particulate emissions to the levels mandated by the new standards. Particulate traps have been the subject of much investigation over the past twenty years; however many of the technical issues such as control and initiation of trap regeneration, sulfur poisoning in catalytic traps, ash accumulation, in addition to durability issues still remain. The absence of sulfur in FT fuels permits the use of more aggressively catalyzed traps, as sulfur poisoning is not an issue. Furthermore, the reduced particulate emissions of FT fuels may potentially lead to increased time between trap regenerations, which in conjunction with advanced catalysts formulations reducing the temperatures required to initiate regeneration, may provide substantial improvements in trap durability and performance. However, the deposition of particulates from FT fuels on the trap substrates and regeneration of the trap with FT particulates and FT fuel have not been adequately addressed. These issues remain the topic of the current phase of the program.

The goals of this task are:

\section{- To evaluate exhaust aftertreatment systems performance and design tradeoffs available using gas-to-liquid fuels. Optimize the fuel/engine/emission-control system.}

Active regeneration strategies such as burners, heaters, throttling, bypasses/waste-gates, microwave devices, late fuel injection, exhaust fuel injection, valve timing, etc. all interfere with engine operation and incur fuel penalties. Passive systems do not necessarily guarantee on-demand regeneration but offer high probabilities that, under most user routes and operating cycles, regeneration occurs continuously or with sufficient frequency that no active ignition of the particulates is required. These passive systems often require either fuel-borne catalysts or catalytic washcoats on the trap substrates. In order to minimize the complexity of the combined engine/aftertreatment system, trap regeneration in this study will be initiated by throttling the intake air. Intake air throttling leads to an enriched air-fuel mixture, thus elevating cylinder and exhaust temperatures.

Bench and engine experiments have shown that particulate regeneration is a function of particulate loading density, oxygen partial pressure, temperature in the trap, as well as trace species in the exhaust such as nitrogen dioxide. Control of the regeneration process requires a thorough understanding of the regeneration map. Some bench tests have developed these maps while maintaining steady inlet conditions (steady-state maps). However, changes in the operating conditions during regeneration, for example the oxygen concentration, as occurring when the engine switches to idle during regeneration, can have catastrophic effects. Runaway, uncontrolled temperatures can occur that could result in the melting or cracking of the 
trap substrate. This project area will address these transient regeneration characteristics both in the control and in the initiation of trap regeneration.

Advances in fuel technology offer potential to optimize the engine/fuel/emission-control system. One area is in catalysis or catalytic regeneration of particulate traps. It has been shown that the catalytic particulate regeneration process involves the oxidation of hydrocarbons, either in the ambient or in the adsorbed organic matter. Unfortunately, fuel sulfur conversion rates to sulfates, even at the low fuel sulfur levels, are concomitantly high. The presence of synthetic zero-sulfur fuel, namely the Fischer-Tropsch gas-to-liquid fuel, removes the sulfur and sulfate constraint. The synthetic fuel can be tailored to provide the optimum combination of $\mathrm{HC}$, particulate composition, and catalysts for low-temperature particulate oxidation and trap regeneration, in the absence of fuel sulfur.

Hence, to study the impact of FT gas-to-liquid fuel and particulate characteristics on trap regeneration, the following are the major initial subtasks:

a) Design, fabricate and install a full-flow un-catalyzed and a catalytic particulate trap system for the Cummins ISB 300 engine for use with both standard no. 2 diesel and Syntroleum fuels.

b) Fully instrument the filter to measure pressure and temperatures throughout the trap.

c) Measure and evaluate the characteristics of particulates from using synthetic zerosulfur fuel versus regular low-sulfur diesel fuel

d) Design and implement means of regeneration that fully investigate the emissions and regeneration characteristics of each fuel. Optimize engine/trap system as appropriate.

To date, all of the above-listed tasks, excluding task (d) which is currently underway, have been completed. The following sections cover the work already completed in this project area, as well as the remaining subtasks.

\subsection{Major Accomplishments to Date}

Initial trap design, sizing calculations, and fabrication and testing of a small prototype trap have already been completed. The prototype trap utilized a Corning Cordierite substrate, $14.37 \mathrm{~cm}$ (5.66") in diameter and $15.24 \mathrm{~cm}$ (6.00") in length, with a cell density of 100 cells per square inch. The substrate was un-catalyzed and canned in a stainless steel housing using an Interam 1100 HT mat mount supplied by 3M. While a trap of this size is much too small for the ISB operating at full-flow conditions, the prototype trap was only tested at low speed and load conditions for a short period of time before allowable backpressure limits were exceeded and testing was terminated. Pressure drop across the trap, as well as exhaust backpressure and trap temperature were monitored. The data collected from the prototype trap was used along with data provided by Cummins and Corning to carry out the sizing calculations for the full-flow unit. The prototype trap mounted on the test bed is depicted in figure 10.1. The mini-dilution tunnel is visible in the far left of the photograph. 


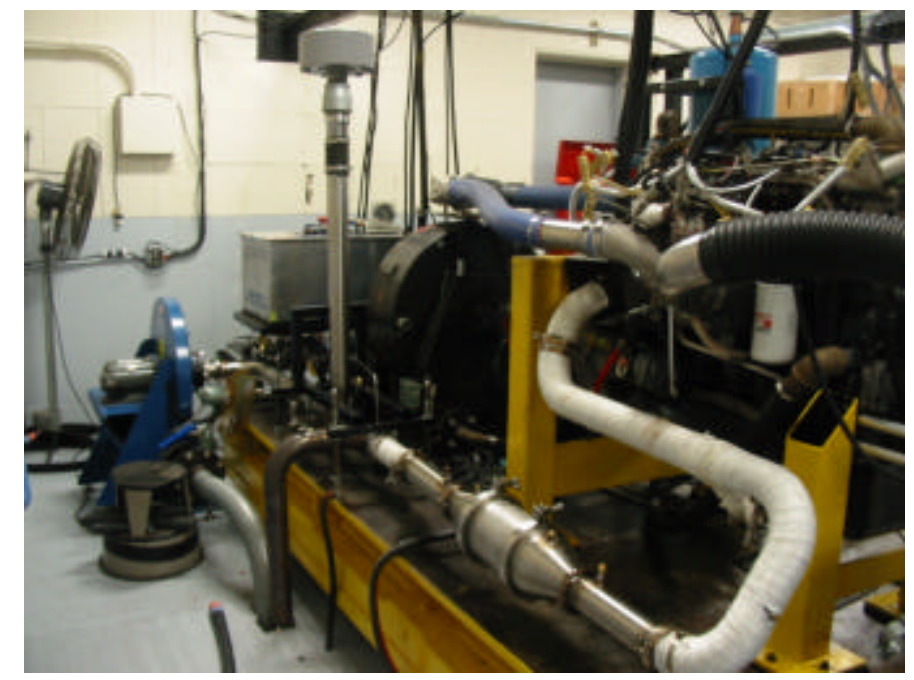

\section{Figure 10.1 Prototype trap installed in ISB exhaust system}

Based on the partial flow data collected from the prototype trap tests, revisions were made to the original full flow pistol cartridge design presented in last year's report. The revisions were made partly based upon the data collected and experience gained testing the prototype unit, and partly to minimize the overall system complexity.

\subsubsection{Subtask (a): Design, Fabricate, and Install Particulate Trap}

A parallel trap configuration was selected as the final design for the following reasons: first to retain some of the flexibility of the pistol cartridge design while minimizing complexity, and second to accommodate larger substrates more representative of the type used on an engine of this size. The primary design criteria are listed below:

- Maximum allowable backpressure for 1998 EPA certification 3 in-hg

- According to Cummins 6 to 10 in-hg allowable without significant adverse effects

- 2 in-hg target clean trap pressure drop

- Minimize interference/interactions with stock engine calibration and ECM.

The original sizing calculations were verified by Corning and Corning's Cordierite substrate, $19.05 \mathrm{~cm}$ (7.5") in diameter and $30.48 \mathrm{~cm}$ (12.00") in length, with a cell density 200 cells per square inch was selected for the full flow design. Although Corning originally recommended their 8.0" diameter by 12.0" substrates for this application (D11.25"x14.00" for single flow), the slightly smaller 7.5" diameter substrate was selected due to its lower loading time and more widespread availability.

Once again, 3M supplied the custom Interam $1100 \mathrm{HT}$ mat mounts to accommodate the larger substrate sizes. To avoid the difficulties encountered canning the prototype unit, a clamshell design was selected for the full-flow parallel trap. The clamshells allow for easy installation of the substrate and mounting system, as well as simplified removal of the substrate for additional laboratory/bench testing or replacement. The final trap design is shown in figure 10.2. 

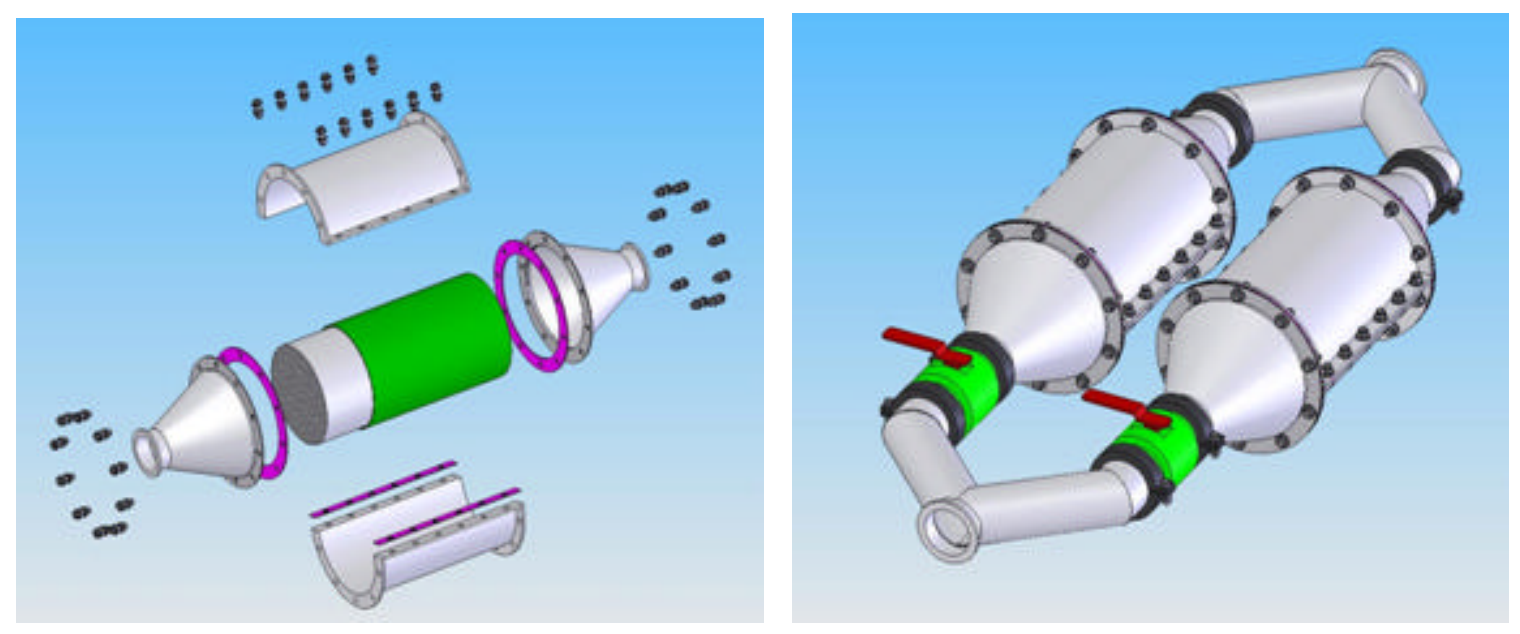

Figure 10.2 Schematic of full flow parallel particulate trap system

The graphic on the left depicts the substrate wrapped in the mat mount (green liner) as well as the associated hardware. Two circular gaskets between the can and end cones as well as gaskets between the two clamshells form a positive seal preventing any exhaust leakage. The parallel unit is also equipped with valves at the trap inlet to allow for greater flexibility in exhaust flow control as depicted in the schematic of the complete system on the right.

Furthermore, individual trap units can also be easily removed for offline regeneration or bench testing by replacing the unit with either another trap or a blank (straight pipe).

\subsubsection{Subtask (b): Fully Instrument the Filter}

Both substrates were heavily instrumented with thermocouples and pressure transducers to record the temperature and pressure profiles during trap loading and regeneration. Omega type $\mathrm{K}$, model KMQXL thermocouples capable of withstanding temperatures as high as $1335^{\circ} \mathrm{C}\left(2440^{\circ} \mathrm{F}\right)$ were selected to monitor the temperatures within the substrate. Thermocouple diameters range from 0.020 " to 0.040 " to minimize any disruptions to the exhaust flow within the substrate. The smaller diameter thermocouples were installed in the inlet channels of the trap, whereas the larger diameter thermocouples were placed in the outlet channels. Details of the thermocouple locations and orientations within the substrate are provided in figure 10.3. The thermocouples were arranged to provide temperature data in both the axial and radial directions within the substrate.

In addition to the thermocouples, Omega PX 212 pressure transducers were mounted at the inlets and exits of both traps to monitor the pressure drop across the trap as well as exhaust back pressure. Additional emissions taps were supplied at the trap inlets and exits as well, and the current gaseous emissions analyzer setup modified to allow for simultaneous sampling of $\mathrm{HC}, \mathrm{NO} / \mathrm{NOx}, \mathrm{CO}, \mathrm{CO}_{2}$, and $\mathrm{O}_{2}$ both before and after the trap. All measurements were monitored and recorded using NI LabView data acquisition systems as described in section 5.4. 

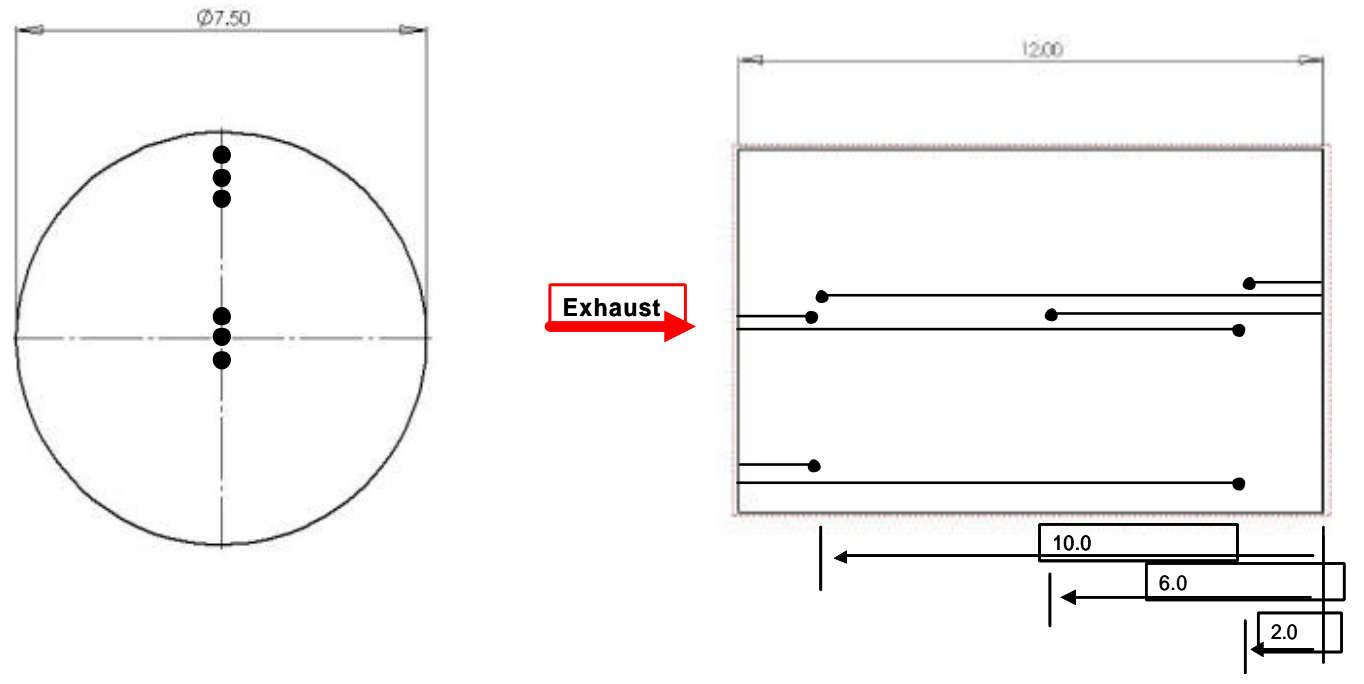

Figure 10.3 Thermocouple locations and orientation within trap substrate

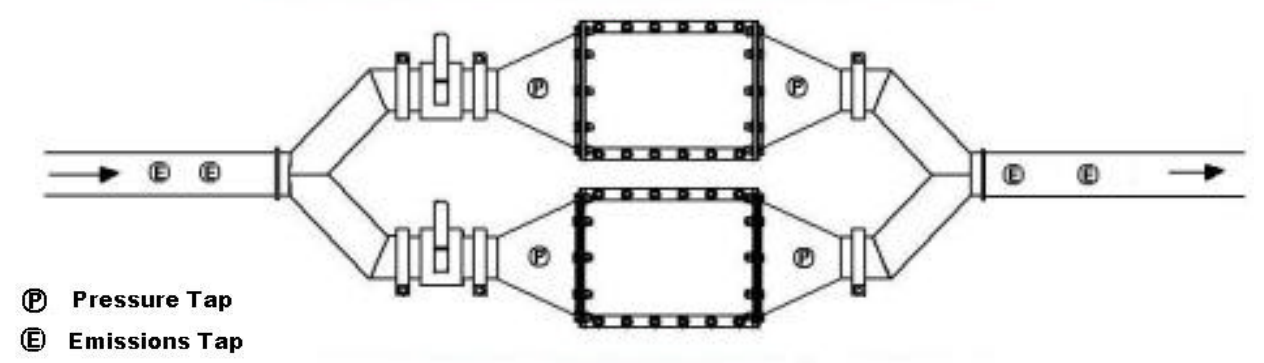

Figure 10.4 Pressure and emissions tap locations

Additional provisions were also made to enable simultaneous particulate sampling from both the pre- and post-trap exhaust stream to determine actual trapping efficiencies. In order to accomplish this, an additional tap and sample line were installed upstream of the trap and routed to the PM emissions sampling cart. A larger model Gast 1423 rotary vane vacuum pump capable of moving $13.2 \mathrm{cfm}$ replaced the smaller model 823 pump to further reduce PM collection times and provide sufficient flow for the additional sample point.

In order to prevent the frequent pump failures experience in the past due to the high temperature and water content of the exhaust sample stream, a number of auxiliary devices were used to condition the sample stream after the sample filter holders and before the pump. The auxiliary equipment was installed in pairs, one for each sample stream, and consisted of a secondary 10 micron inline filter, larger capacity counter flow heat exchanger to cool the exhaust below $30^{\circ} \mathrm{C}$, and an SMC water separator to thoroughly dry the exhaust prior to the pump inlet. In addition a vacuum relief valve and associated gauges were also installed to monitor and control vacuum pressure.

Additional thermocouples and an Omega FVL-1611 volumetric flow meter were installed to monitor the flow and temperature through the second particulate sample filter as well. A detailed schematic of the emissions sampling system and layout of the test bed and particulate trap is presented in figure 10.5. The lines in red depict the secondary PM sample system installed to facilitate the determination of the trap collection efficiency. 


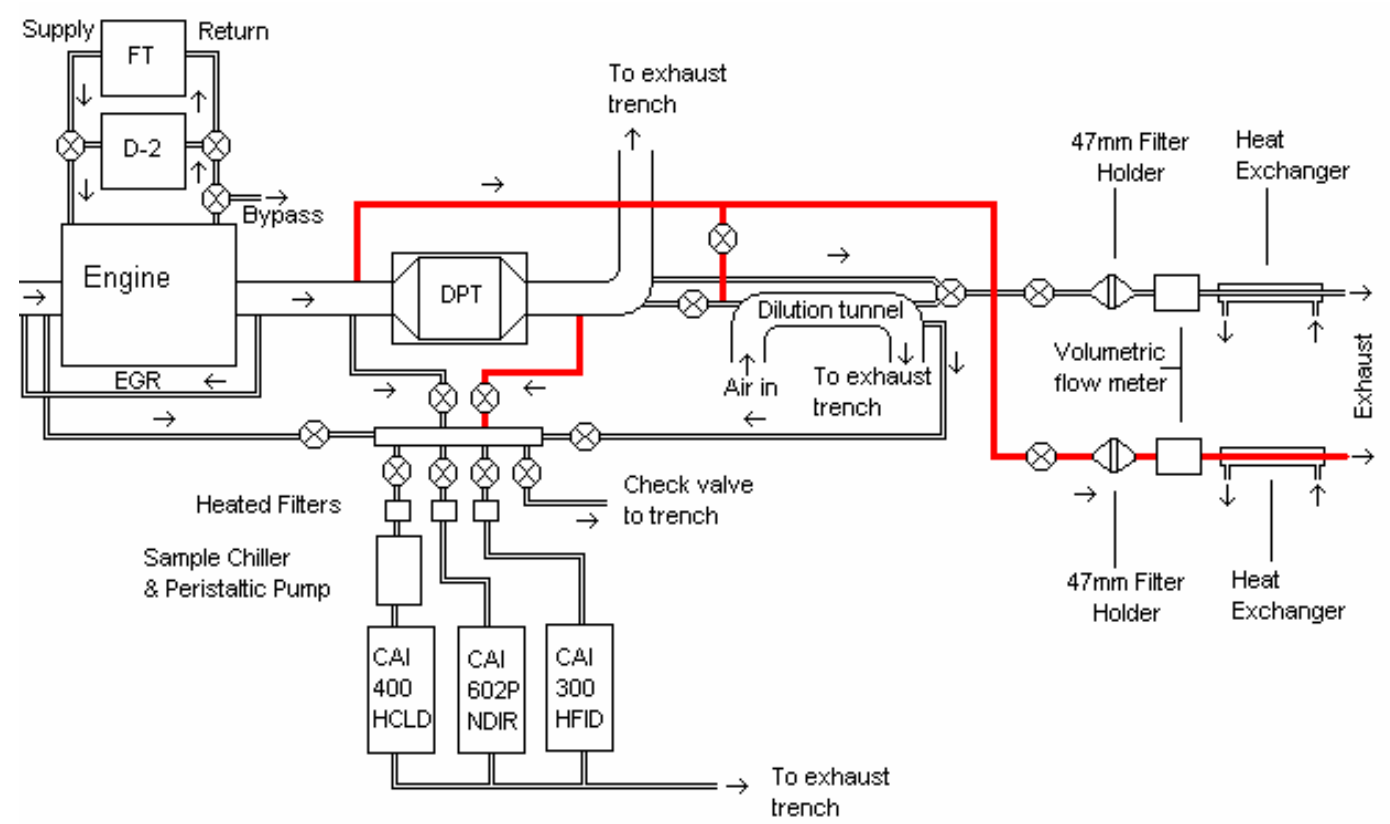

Figure 10.5 Schematic of test bed and exhaust sampling systems

The schematic shown above also depicts the updated gaseous emissions sampling system with four sample points for the measurement of pre-trap, post-trap, dilute, and EGR exhaust constituents. Furthermore, the new system is capable of sampling all emissions of interest from a single sample point simultaneously.

\subsubsection{Subtask (c): Evaluate Characteristics of PM from Synthetic and Standard Diesel}

Subtask (c) was completed during the current reporting period and the major results have already been presented in sections 8.1 through 8.3. Furthermore, results of the work completed during the current reporting period related to the emissions and combustion characteristics of FT diesel and conventional diesel fuels were accepted for publication and will be presented at the ASME Internal Combustion Engine Division 2005 Fall Technical Conference in Ottawa, Canada [38].

In addition to evaluating the fuel effects on particulate and gaseous emissions, a number of PM samples were also sent to the emissions-chemistry laboratory of a major engine manufacturer for detailed analysis and characterization. While this task has essentially been completed, future work may focus on expanding the detailed mapping of gaseous engine-out emissions to better understand the gaseous exhaust constituents entering the trap along with the effect of the various exhaust species on trap performance.

\subsection{Current Work}

The current work in this project area is focused on evaluating the effects of synthetic and regular diesel fuels on particulate trap performance and regeneration. A full-flow parallel trap system has been designed, fabricated, fully instrumented and installed on the test bed. 
Furthermore, a detailed characterization of the fuel effects on the diesel particulate characteristics and emissions has already been carried out.

\subsubsection{Subtask (d): Trap Testing and Evaluation of Fuel Effects}

At this time, testing of the full-flow un-catalyzed cordierite substrates is underway. The full-flow unit is mounted on the test bed as shown in figure 10.6. Following the un-catalyzed tests, a small number of catalyzed filters will be tested as well. The catalyzed filters are supplied by Sud-Chemie, and the catalyst is tailored to exploit the zero sulfur nature of the FT fuel.
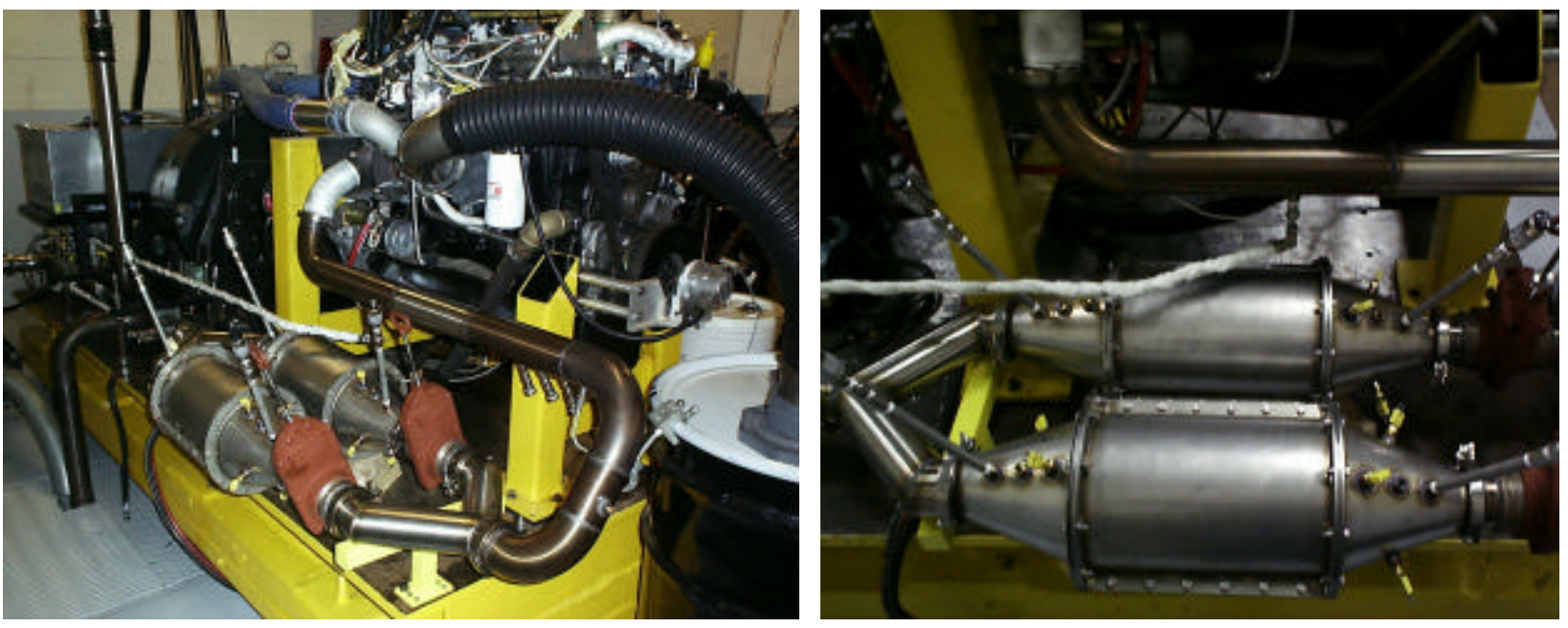

Figure 10.6 Schematic of full-flow trap on test bed

The key components of the test plan for evaluating the fuel effects on trap performance and regeneration are as follows:

- Monitor and characterize exhaust gas composition before and after the trap for the FT fuel and baseline reference diesel

- Evaluate trap loading and regeneration with FT fuel and the standard baseline reference diesel

- Exploit the zero sulfur nature of the FT fuel to explore the limits of employing catalyzed particulate traps to further optimize the fuel/engine/aftertreatment system

- Evaluate the effect of engine transients, namely elevated $\mathrm{O}_{2}$ concentration and reduced exhaust flow conditions, on trap regeneration with FT and standard diesel

Every effort will be made to correlate the fuel effects on engine-out emissions (gaseous and particulate) to the observed loading and regeneration behavior of the catalyzed and uncatalyzed traps, and the results presented in the final project report. 


\subsection{CONCLUSIONS}

An investigation into the relationship between fuel properties, combustion characteristics, and exhaust emissions was carried out using a pre-production 2002 Cummins ISB 300 direct injection turbo-diesel engine. Current results confirm the results presented in previous reporting periods that the Fischer-Tropsch (FT) gas-to-liquid diesel fuel from the Syntroleum small footprint plant performs better and with lower emissions than regular diesel fuel on a modern (MY 2002) direct injection diesel engine. Further improvements in performance and emissions can be realized by configuring the engine to take advantage of FT diesel fuel's properties, and the addition of exhaust aftertreatment systems. A small fraction of FT fuel blended with regular No. 2 diesel can offer significant PM emission reductions more than shown by its proportion in the blended fuel. A full flow parallel diesel particulate trap system has been designed, fabricated, instrumented, and installed on the test bed. Initial tests with a prototype trap have already been completed and investigations on the effects of FT fuel on a particulate aftertreatment system, DPT, are continuing.

The modern engine technology and related subsystems employed by the Cummins ISB has a profound effect on the manner in which the fuel properties affect engine out emissions. The cetane number $(\mathrm{CN})$ of a fuel is commonly believed to control $\mathrm{NO}_{\mathrm{x}}$ output by dictating the amount of fuel that auto-ignites in the initial premixed burn fraction. However, the modern engine tested is designed to have small premixed burn fractions, such as those with high injection pressures to promote good mixing along with late injection in hot cylinder conditions around TDC. Thus, NOx emissions are less sensitive to the value of a fuel's CN. On the other hand, combustion data show that the FT fuel burns faster during the latter part of combustion, in back-to-back comparisons with No. 2 diesel. This helps to oxidize particulates, and when combined with retarded injection timing past TDC provides an optimal combination of both NOx and particulate reduction. Furthermore the multiple injection strategy employed in the Cummins ISB, also has a significant effect on the in-cylinder combustion process and plays a significant role in reducing NOx and PM emissions.

The additional tests performed since the last report includes comparisons of the combustion and emissions characteristics of FT fuel with ultra- low sulfur fuel (15 ppm), with low sulfur regular diesel fuel (400 ppm), as well as blends of FT fuel with regular diesel. The test conditions have also been significantly expanded to include nearly the entire Euro-III 13 mode test cycle. The data collected over the course of the current reporting period leads to the following updated conclusions:

- $\quad$ For a modern MY '02 heavy-duty diesel engine, FT fuel reduces particulate emissions substantially, mostly in the range of $25-50 \%$ for a variety of steady-state conditions tested. Under light load, low speed conditions typical of urban driving, particulate reductions can reach up to $75 \%$.

- $\quad$ A blend of $25 \%$ (by volume) FT fuel with $75 \% 400 \mathrm{ppm}$ sulfur fuel showed that the $25 \%$ FT fuel in the blend produced about half of the particulate reduction of using neat FT fuel alone.

- $\quad$ Significant non-sulfur effects are responsible for the large reductions in PM emissions observed for the FT fuel and blends. The results of the PM analysis carried 
out at the emissions-chemistry laboratory of a major engine manufacturer confirms these findings, and demonstrated reductions in the range of $40 \%$ to $60 \%$ in SOL and SOF for the blend when compared to the reductions observed for the neat FT fuel alone.

- $\quad$ For the same modern engine, FT diesel fuel reduces NOx emissions consistently from 6-20\% versus No. 2 diesel fuel. The more recent results are consistent with previous results of 6-13\% reduction and with overall results reported in the literature. FT fuel's higher cetane number and a shorter ignition delay allow fuel injection to be further retarded for NOx control.

- $\quad$ The reduction in NOx emissions for the FT fuel and blend was directly correlated to the measured reduction in exhaust temperatures and shorter diffusion burn. This data confirms that a temperature sensitive extended Zeldovich type mechanism is primarily responsible for NOx formation in the power cylinder [38].

- While emissions of hydrocarbons were low, and typically within acceptable limits, the significantly higher rate of $\mathrm{HC}$ emissions from the ultra-low sulfur diesel fuel is most likely due to the fuel's higher volatility and significantly different distillation curve. These two factors may also be responsible for the relatively higher sulfur to sulfate conversion rate observed for the ULSD [38].

- $\quad$ The increased cetane number of the FT and blend decreased the ignition delay compared to the baseline fuel. The shorter ignition delay and lower density of the FT fuel and blend contributed to a significant reduction in the maximum heat release of the pilot injection, thus reducing initial particulate formation [38].

- $\quad$ FT fuel burns faster during the latter part of combustion, especially when combustion occurs predominantly during the expansion stroke. The faster $50 \%$ to 90\% burn duration of the FT fuel may lead to additional particulate oxidation [38]. Therefore, late injection timing retard at or after TDC can be employed for large NOx reduction in modern engines.

- $\quad$ Conventional diesel fuel normally produces more particulate matter as EGR increases. FT fuel removes the sensitive dependence of PM production on EGR rate, allowing significant NOx reductions through the use of higher EGR rates before PM levels become unacceptably large.

- Increases in PM output from increased EGR rates can be controlled by aftertreatment systems without concern of system performance deterioration from fuel sulfur, as FT diesel fuel is virtually sulfur free. A particulate trap system has been designed and is currently undergoing testing to investigate the fuel impact on the relative ease to both initiate and control regeneration. This is being addressed in the current work and will be documented in the next report. In addition, as established elsewhere but not presently on the test plan, sulfur-free fuel does not poison catalysts in NOx aftertreatment systems with sulfur originating from the fuel. Sulfur in the lubricant presents a different problem. 
In summary, FT fuel gives greater freedom to engine designers when trying to optimize the engine/emission-control/fuel system in modern engines, by providing the fuel properties as another flexible set of variables that affect the combustion and emission processes.

Furthermore, the zero sulfur nature of the FT fuel allows for the use of additional and more aggressive exhaust aftertreatment devices, previously impossible due to the deleterious effects of fuel sulfur on the catalyst.

\subsection{ACKNOWLEDGEMENT}

This work is supported by the Integrated Concepts and Research Corporation (ICRC) funded under the prime contract from DOE under Cooperative Agreement No. DE-FC26-01NT41099, cost-shared by industrial partners, including Syntroleum and Marathon. The authors would like to thank the sponsors, and in particulate Steve Bergin, Jim Lexo and others at ICRC for their support and encouragement. We also thank Syntroleum for providing the GTL fuel and fuel analysis, and especially Dr. Robert Freerks for his technical comments. We also appreciate the tremendous help of Michael Blanz and the staff at Cummins Technical Center for their technical support, and thanks to Jeff Jocsak of MIT for his help with the heat release programs, and to our other colleagues at MIT for their support. 


\subsection{REFERENCES}

1. Alleman, T. L. and McCormick, R. L., "Fischer-Tropsch Diesel Fuels - Properties and Exhaust Emissions: A Literature Review," SAE Paper 2003-01-0763, 2003

2. Schaberg, P. W., Myburgh, I. S., Botha, J. J., Roets, P. N., Viljoen, C. L., Dancuart, L. P., and Starr M.E., "Diesel Exhaust Emissions Using Sasol Slurry Phase Distillate Process Fuels," SAE Paper 972898, 1997

3. Norton, P., Vertin, K., Bailey, B., Clark, N. N., Lyons, D. W., Goguen, S., and Eberhardt, J., "Emissions from Trucks using Fischer-Tropsch Diesel Fuel," SAE Paper 982526, 1998

4. Clark, N. N., Atkinson, C. M., Thompson, G. J. and Nine, R. D., "Transient Emissions Comparisons of Alternative Compression Ignition Fuels," SAE Paper 1999-01-1117, 1999

5. Atkinson, C. M., Thompson, G. J., Traver, M. L., and Clark, N. N., "In-Cylinder Combustion Pressure Characteristics of Fischer-Tropsch and Conventional Diesel Fuels in a Heavy-duty CI Engine," SAE Paper 1999-01-1472, 1999Fischer-Tropsch Website, http://www.fischertropsch.org/

4. Springer, P. S., Hugman, R. H., Costiness, M. J., Vidas, E. H., "Chemical Composition of Discovered and Undiscovered Natural Gas in the Continental United States - 1998 Update. Project Summary," Gas Research Institute, 1998

5. McMillian, M. H. and Gautam, M., "Consideration for Fischer-Tropsch Derived Liquid Fuels as a Fuel Injection Emission Control Parameter," SAE Paper 982489, 1998

6. Cheng, A. S. and Dibble, R. W., "Emissions Performance of Oxygenate-in-Diesel Blends and Fischer-Tropsch Diesel in a Compression Ignition Engine," SAE Paper 1999-01-3606, 1999

7. Schaberg, P. W., Myburgh, I. S., Botha, J. J. and Khalek, I. A., "Comparitive Emissions Performance of Sasol Fischer-Tropsch Diesel Fuel in Current and Older Technology HeavyDuty Engines," SAE Paper 2000-01-1912, 2000

8. May, M. P., Vertin, K., Ren, S., Gui, X., Myburgh, I. And Schaberg, P., "Development of Truck Engine Technologies for Use with Fischer-Tropsch Fuels," SAE Paper 2001-01-3520, 2000

9. Suppes, G.J., Burkhart, M.L., Cordova, J.C., Sorem, R.M., Russell, B., "Performance of Fischer-Tropsch Liquids with Oxygenates in a VW 1.9L TDI" SAE Paper 2001-01-3521

10. Fanick, E.R., Schubert, P.F., Russell, B.J., Freerks, R.L., "Comparison of Emission Characteristics of Conventional, Hydrotreated, and Fischer-Tropsch Diesel Fuels in a HeavyDuty Diesel Engine," SAE Paper 2001-01-3519

11. Lee, R., Pedley, J., and Hobbs, C., 1998, "Fuel Quality Impact on Heavy-duty Diesel Emissions: - A Literature Review," SAE paper 982649.

12. Thomas, R.W., Buckingham, J., Dodge, L.G., and Olikara, C., 1998, "The Effects of Fuel Properties on Emissions from a 2.5gm NOx Heavy-duty Diesel Engine," SAE paper 982491.

13. Cowley, L.T., Stradling, R.J., and Doyon, J., 1993, "The Influence of Composition and Properties of Diesel Fuel on Particulates Emissions from Heavy-duty Engines," SAE paper 932732.

14. McKinley, T., 1997, "Modeling Sulfuric Acid Condensation in Diesel Engine EGR Coolers", SAE paper 970636.

15. Alleman, T.L., and McCormick, R.L., 2003, "Fischer-Tropsch Diesel Fuels - Properties and Exhaust Emissions: A Literature Review," SAE paper 2003-01-0763.

16. Kwon, Y., Mann, N., Rickeard, D.J., Haugland, R., Ulvund, K.A., Kvinge, F., and Wilson, G., 2001, "Fuel Effect on Emissions- A New Understanding", SAE paper 2001-01-3522.

17. Rickeard, D.J., Bonetto, R., and Signer, M., 1996, "European Programme on Emissions, Fuels and Engine Technologies (EPEFE) - Comparison of Light and Heavy-duty Diesel Studies", SAE paper 961075. 
18. Atkinson, C.M., Thompson, G.J., Traver, M.L., and Clark, N.N., 1999, "In-Cylinder Combustion and Pressure Characteristics of Fischer-Tropsch and Conventional Diesel Fuels in a Heavy-duty CI Engine," SAE paper 1999-01-1472.

19. McMillian, M.H., and Gautam, M., 2001, "Combustion and Emission Characteristics of Fischer-Tropsch and Standard Diesel Fuel in a Single-Cylinder Diesel Engine," SAE paper 2001-01-3517.

20. Mann, N., Kvinge, F., and Wilson, G., 1998, "Diesel Fuel Effects on Emissions - Towards a Better Understanding," SAE paper 982486.

21. Liu, Y., and Reitz, R.D., 2005, "Optimizing HSDI Diesel Combustion and Emissions Using Multiple Injection Strategies", SAE paper 2005-01-0212.

22. Gill, K., Marriner, C., Sison, K., and Zhao, H., 2005, "In-Cylinder Studies of Multiple Diesel Fuel Injection in a Single Cylinder Optical Engine", SAE paper 2005-01-0915.

23. Swiss Agency for the Environment, Forests and Landscape, 2005, "Vert-Filterliste: Gepruefte und Erprobte Partikelfilter-Systeme fuer die Nachruestung von Dieselmotoren", Bern, Switzerland.

24. Frank, B., Tang, S., Lanni, T., Rideout, G., Beregszaszy, C., Meyer, N., Chatterjee, S., Conmway, R., Lowell, D., Bush, C., Evans, J., "A Study of the Effects of Fuel Type and Emission Control Systems on Regulated Gaseous Emissions from Heavy-Duty Diesel Engines," SAE paper 2004-01-1085, 2004.

25. Thompson, N., Stradling, R., Zemroch, P., Craecker, R., Sams, T., and Neunteufel, A., "Fuel Effects on Regulated Emissions from Advanced Diesel Engines and Vehicles," SAE Paper 2004-01-1880, 2004.

26. Lev-On, M., Le Tavec, C., Uihlein, J., Alleman, T., Lawson, D., Vertin, K., Thompson, G., Gautam, M., Wayne, S., Zielinska, B., and Sagebiel, J., "Chemical Speciation of Exhaust Emissions from Trucks and Buses Fueled on Ultra-Low Sulfur Diesel and CNG," SAE Paper 2002-01-0432, 2002.

27. Llaniguez, J.T., “A Fundamental Study of Relationships Among Fuel Properties, Combustion Characteristics, and Emissions with Normal and Synthetic Diesel Fuel", Master's thesis, Massachusetts Institute of Technology, Cambridge, MA, 2003.

28. EPA Test Procedure TP 713D, "Sample Collection, Continuous Hydrocarbon Analysis and Particulate Collection of the Light Duty Diesel Test Procedure"

29. EPA Test Procedure TP 714C, "Diesel Particulate Filter Handling and Weighing Procedure"

30. "Syntroleum S-2 Synthetic Diesel: Driving Clean-Fuel Innovation," http://www.syntroleum.com/media/syntroleum_s2.pdf, Syntroleum Corporation, 2002

31. Heywood, J. B., Internal Combustion Engine Fundamentals, McGraw-Hill, Inc., New York, 1988

32. Acar, J., 2003, "Effect of Engine Operating Parameters and Fuel Characteristics on Diesel Engine Emissions", Master's thesis, Massachusetts Institute of Technology, Cambridge, MA, 2005.

33. DieselNet Website, http://www.dieselnet.com/

34. Johnson, J.H., Bagley, S.T., Gratz, L.D., and Leddy, D.G., 1994, “A review of Diesel Particulate Control Technology and Emissions Effects," SAE paper 940233.

35. Kweon, C.B., Foster, D.E., Schauer, J.J., and Okada, S., 2002, "Detailed Chemical Composition and Particle Size Assessment of Diesel Engine Exhaust", SAE paper 2002-012670.

36. Assanis, D. N., "A Computer Simulation of the Turbocharged Turbocompounded Diesel Engine System for Studies of Low Heat Rejection Engine Performance," Ph.D. Thesis, MIT, 1985

37. Warner, J., Johnson, J., Bagley, S., and Huynh, C., "Effects of a Catalyzed Particulate Filter on Emissions from a Diesel Engine: Chemical Characterization Data and particulate 
Emissions Measured with Thermal Optical and Gravimetric Methods," SAE Paper 2003-010049, 2003.Dec, J. E., Espey, C., "Ignition and Early Soot Formation in a DI Diesel Engine Using Multiple 2-D Imaging Diagnostics," SAE Paper 950456, 1999

38. Sappok, A., Llaniguez, J., Acar, J., Wong, V., "Emissions and In-Cylinder Combustion Characteristics of Fischer-Tropsch and Conventional Diesel Fuels in a Modern CI Engine," ASME Paper ICEF2005-1326, 2005.Dec, J. E., Coy, E. B., "OH Radical Imaging in a DI Diesel Engine and the Structure of the Early Diffusion Flame," SAE Paper 960831, 1996

\subsection{ADDITIONAL REFERENCES NOT CITED}

1. Dec, J. E., "A Conceptual Model of DI Diesel Combustion Based on Laser-Sheet Imaging," SAE Paper 970873, 1997

2. Dec, J. E., Canaan, R. E., "PLIF Imaging of NO Formation in a DI Diesel Engine," SAE Paper 980147, 1998

3. Dec, J. E., Espey, C., "Chemiluminescence Imaging of Autoignition in a DI Diesel Engine," SAE Paper 982685, 1998

4. Flynn, P. F., Durrett, R. P., Hunter, G. L., zur Loye, A. O., Akinyemi, O. C., Dec, J. E., and Westbrook, C. K., "Diesel Combustion: An Integrated View Combining Laser Diagnostics, Chemical Kinetics, And Empirical Validation,” SAE Paper 1999-01-0509, 1999

5. Siebers, D. and Higgins, B., "Flame Lift-Off on Direct-Injection Diesel Sprays Under Quiescent Conditions," SAE Paper 2001-01-0530, 2001

6. Naber, J. D. and Siebers, D., "Effects of Gas Density and Vaporization on Penetration and Dispersion of Diesel Sprays," SAE Paper 960034, 1996

7. Lee, R., Pedley, J., Hobbs, C., "Fuel Quality Impact on Heavy-duty Diesel Emissions: - A Literature Review," SAE Paper 982649, 1998

8. Kennedy, I. M., "Models of Soot Formation and Oxidation," Progress in Energy and Combustion Science, Vol. 23, Elsevier Science, 1997

9. Frenklach, M. and Wang, .H, "Detailed Modeling of Soot Particle Nucleation and Growth," Twenty-Third Symposium (International) on Combustion, The Combustion Institute, Pittsburgh, 1990

10. Richter, H., Grieco, W., and Howard, J., "Formation Mechanisms of Polycyclic Aromatic Hydrocarbons and Fullerenes in Premixed Benzene Flames," Combustion and Flame, The Combustion Institute, 1999

11. Kittelson, D. B., Arnold, M. and Watts, and W. F. Jr., "Review of Diesel Particulate Matter Sampling Methods: Final Report," University Of Minnesota, 1999 


\title{
APPENDIX E
}

\section{Supporting Economic Analysis for US DOE-Sponsored ICRC Clean Fuels Program.}

\author{
Principal author: Robert S. Weber \\ DOE Award Number: DE-FC26-99NT12345, Tasks 6 and 8 \\ Submitting Organization: TIAX LLC, 15 Acorn Park, Cambridge, MA 02140, (617)- \\ 498-6137
}




\section{ABSTRACT}

TIAX assisted the ICRC team to assess the impact of the introduction of ultraclean fuels produced by small footprint Gas-to-Liquid (GTL) facilities on fuel costs, air emissions and energy efficiency. The Gas-to-Liquid process converts synthesis gas (carbon monoxide and hydrogen) to liquid fuels through Fischer-Tropsch catalysis that produces a range of liquid hydrocarbons plus water, heat and, optionally, electricity (turbine-driven generator). Here, the term "small footprint" means a facility that produces less than 10,000 barrels per day of liquid fuels. The goal of this study was to determine the feasibility of employing such plants for fueling the local needs of, for example, remote villages or mining operations, using locally available feedstocks.

We identified stranded natural gas and biomass as potentially viable feedstocks for the production of GTL fuels from small footprint plants. Both exist in sufficient quantities but in small enough streams to warrant the construction of small footprint plants. For natural gas, when the plants produce power as well as fuel, we found conditions under which the internal rate of return for plants with a 20 year lifetime ranged as high as 9 to $146 \%$, depending on plant size and the cost of feedstock. For biomass, which requires a significantly larger capital investment than does natural gas, we could not identify conditions that led to positive returns, implying that this type of plant would need subsidies to make it viable. Other resources, coal, shale oil and coal bed methane, either were available in reservoirs large enough to support large facilities that are more cost effective when run at scale or they were too far from markets to offer the benefits of local supply.

To compare the emissions and fuel economy for vehicles fueled with Fischer-Tropsch dieseland conventional diesel we constructed well-to-wheels analyses that included the effects of fuel generation, transportation and use. The benefit of GTL fuels with respect to criteria pollutants, NOx, CO and PM, is complicated by the mandated introduction of very clean dieselengines nearly simultaneously with the earliest practical introduction of small footprint plants. Thus, in our analysis the benefits of GTL fuels were attenuated since they can only be guaranteed to apply the older fraction of the vehicle fleet and will therefore diminish as those vehicle s are taken out of service. Even so, significant savings in NOx and PM-15\% and 35\%, respectively-were projected for two heavier vehicle classes, buses and utility trucks, if fueled with GTL fuels since almost $80 \%$ of those fleets will consist of vehicles purchased prior to 2010. The cost of attenuating these pollutants ranged from Because there are so few light duty diesel vehicles in the current fleet, the benefits of using GTL-derived fuels are projected to be very small in this category $(<5 \%$ decreases in criteria pollutants) since the future fleet will consist primarily of modern, low emission vehicles. Since the GTL process consumes a much larger portion of the feedstock for just the operation of the plant than does a conventional refinery (60\% in our model versus about $20 \%$ for a refinery), there is a significantly larger $\mathrm{CO}_{2}$ burden for using GTL compared to that of using petroleum-derived diesel fuel. However, biomass-derived GTL fuels can, in principle, exhibit net zero $\mathrm{CO}_{2}$ emissions, leading to as much as $75 \%$ reductions in $\mathrm{CO}_{2}$ from the projected fleet.

In a second task of this study we applied these same methods to the feedstocks, conditions and opportunities that pertain in Alaska. Three sizes of plants were investigated: 600 and 6000 barrels per day, corresponding to feedstock availability for small and medium sized plants, and a 19,000 barrel per day facility, such as might be constructed to use coastal reservoirs of natural gas known to exist in the Kenai Peninsula. Because we assumed that the small footprint plants to be constructed in remote areas would be mostly prefabricated and would be operated by a small staff our estimates were only modestly higher for both the capital costs of the plants (2$10 \%)$ and the operating costs (1-7\%), depending on plant size. The higher price of conventional fuel in Alaska therefore contributed significantly to the economic performance of GTL plants at all size ranges: the economic value, estimated as internal rate of return, could be greater than $100 \%$ for natural gas-fueled plants, providing that markets could be found at the higher prices for all of the products (naphtha, GTL fuel and electricity). We note, however, that even the smallest sized plant would be supply fleets as large as 10,000 light duty vehicles or 800-900 heavy duty vehicles, which are more than would likely be found in remote communities. Therefore, to realize the full emissions and economic benefits of a small footprint plant will require export of fuel. Our analysis indicated that biomass-fueled plants would be much more expensive to construct than natural gasfueled plants, implying that, even in Alaska, the products from a small footprint GTL plant would require significant subsidies (\$3-5/gal) to compete with conventional fuel and power. 


\section{TABLE OF CONTENTS}

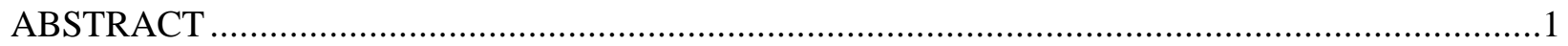

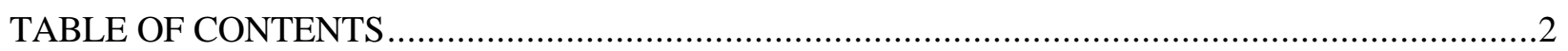

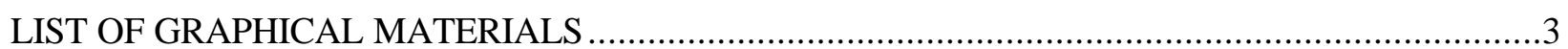

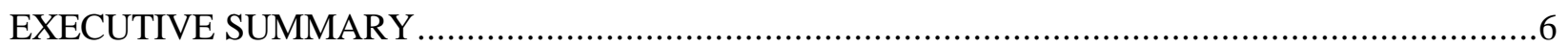

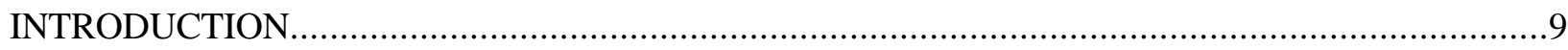

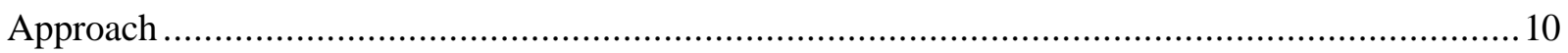

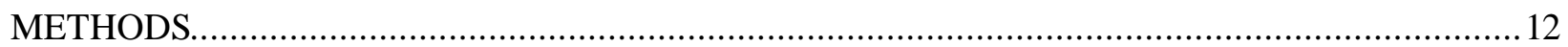

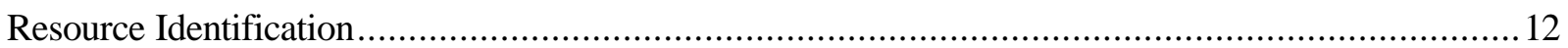

Techno-economic analysis of a Small Footprint Plant................................................................. 13

Well-to-Wheel Analysis of fuels produced by a small footprint plant........................................... 16

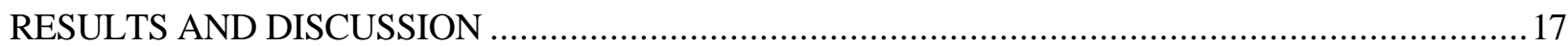

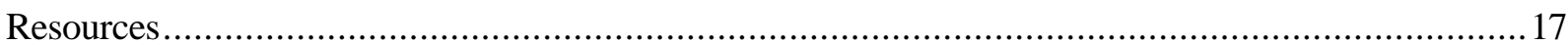

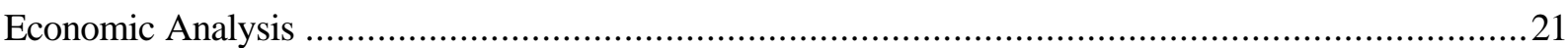

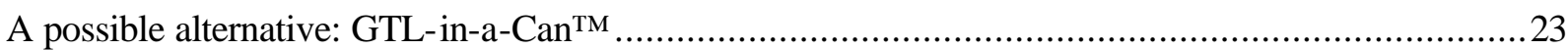

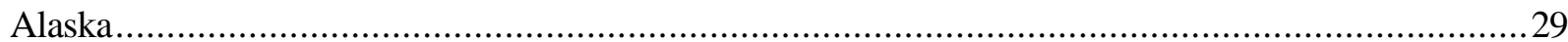

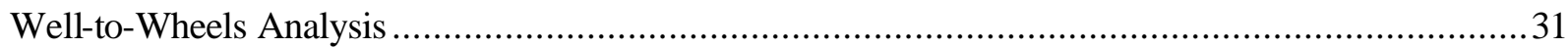

CONCLUSION

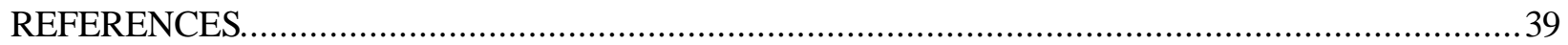

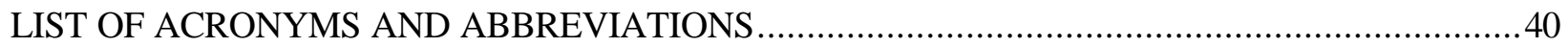




\section{LIST OF GRAPHICAL MATERIALS}

Figure 1. Transformation of $\mathrm{CO}$ and $\mathrm{H}_{2}$ into hydrocarbons by the Fischer Tropsch Process ...................9

Figure 2. Typical distribution of hydrocarbons produced by the Fischer Tropsch process [1]. The weight of products of chain length, $\mathrm{w}_{\mathrm{i}}$, is monotonically dependent on the chain length, $\mathrm{i}$, (constant probability of

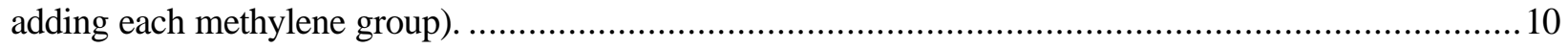

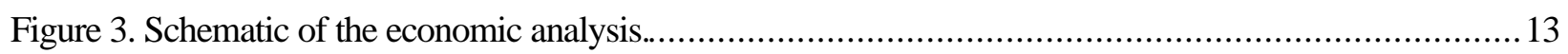

Figure 4. Top level of the Simulink® model that incorporates the revised economics for the small footprint plants.

Figure 5. Results of the screening exercise. Left: Median recoverable ultimate reserves reported in GASIS for the screened resources. Right: .Median higher heating value of reserves of each type......................... 18

Figure 6. Resource distribution by size for the wells screened according to the criteria specified in Appendix 1. Note that the number of resources of each size for the tight wells and shale gas wells have been multiplied by 10 and 100, respectively, to make them visible on this scale. The curve is an exponential fit to the distribution of small, conventional resources in this size range.

Figure 7. Fractal extrapolation of wells in the GASIS database to an EUR of at least 1 billion standard cubic

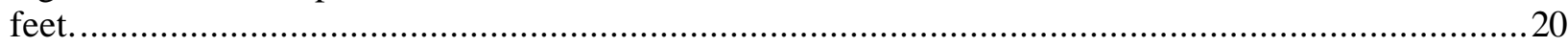

Figure 8. Comparison of capital costs for small footprint plants based on a conventional, "stick-built" architecture across a range of plant sizes. The costs of the individual components are not directly comparable because TIAX has used a different method of allocating process equipment, i.e. heat-exchangers.................2 21

Figure 9. Sensitivity analysis on the capital cost factors for constructing a small footprint plant............22

Figure 10. TIAX estimates of operating costs for stick-built small footprint plants. ..........................22

Figure 11. Sensitivity analysis on the operating expenses of a stick-built small footprint plant. ............23

Figure 12. Schematic of a GTL-in-a-Can ${ }^{\mathrm{TM}}$ process showing the components included in the can..........24

Figure 13. Schematic of the Integrated Modular GTL Technology (Fischer-Tropsch application). The

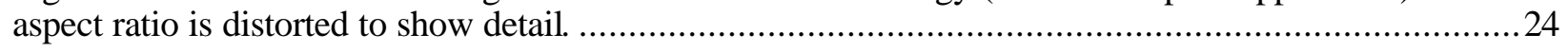

Figure 14. Effect of plant size on profitability for a stick built plant. ................................................25

Figure 15. Effect of plant size on the profitability of a GTL-in-a-can plant ....................................25

Figure 16. Comparison between GTL-in-a-can ${ }^{\mathrm{TM}}$ and stick built plants on the cost of producing 1 gallon of FT

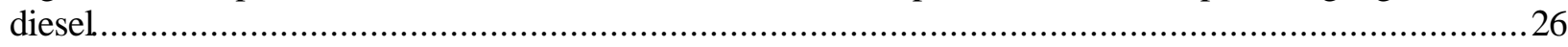

Figure 17. Estimated economics of GTL-in-a-Can ${ }^{\mathrm{TM}}$ at a size of 10 million scf/day (750 bpd products).........26

Figure 18. A Monte Carlo analysis of the NPV20 of the two $100 \mathrm{bbl} /$ day GTL technologies shows the statistical

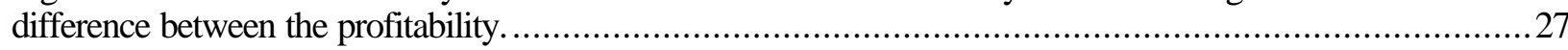

Figure 19. Effect of selling GTL-generated electricity at \$30/MWh...............................................28

Figure 20. Location effects on the net present value of 20-year GTL-in-a-can operation ............................28

Figure 21. Age distribution of compression ignition-powered vehicles projected to 2015 (the three graphs are for

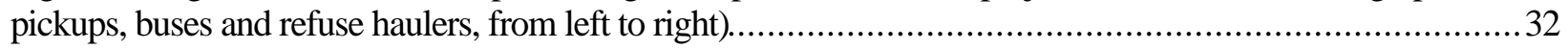

Figure 22. Effect on NOx emissions of fueling various fleets in 2015 with DF2 or FTD .......................... 33

Figure 23. Effect on PM emissions of fueling various fleets in 2015 with DF2 or FTD ............................33 
Figure 24. Effect on $\mathrm{CO}_{2}$ emissions of fueling various fleets with DF2 and FTD derived from two different feedstocks, natural gas and biomass.

Figure 25. Estimates of well-to-wheels emissions of $\mathrm{CO}_{2}$ associated with the use of conventional diesel fuel. Well-to-Tank emissions have been derived from EIA estimates.

Figure 26. Estimate of well-to-wheels emissions of $\mathrm{CO}_{2}$ associated with the use of conventional diesel fuel. Well-to-Tank emissions have been derived from our assumptions regarding the energy conversion efficiency of

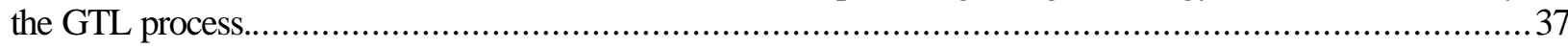

Figure 27. Comparison of our estimates of well-to-wheels emissions of $\mathrm{CO}_{2}$ associated with the use of conventional diesel and GTL fuel. Consistent with our assumptions on the source of the natural gas (small reservoirs) we have assumed that the GTL fuel comprises $1 \%$ of the total fuel used in the US. .38 
Table 1. Nominal conversion of carbon-based feedstocks into distillate fuels.

Table 2. Gas resources considered as possible feedstocks .............................................................. 12

Table 3. Base case parameters used to estimate the economics of an SFP. ........................................... 13

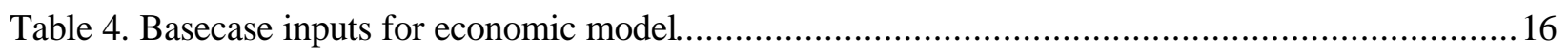

Table 5. Estimates of abatement in criteria pollutants from using FT fuels compared to conventional

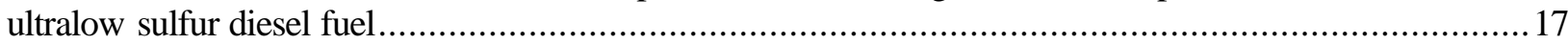

Table 6. Number of SFPs of the specified size that can be supported for the specified lifetime using the screened, small conventional resources of natural gas identified in the GASIS database.

Table 7. Number of SFPs of the specified size that can be supported for the specified lifetime using the screened, small resources of "tight" natural gas identified in the GASIS database.

Table 8. Number of SFPs of the specified size that can be supported for the specified lifetime using the screened, small resources of shale gas identified in the GASIS database......

Table 9. Estimates of investments and returns from modular GTL plants located in the Lower 48 States as a function of feedstock (natural gas) price

Table 10. Estimates of investments and returns from modular GTL plants located in Alaska as a function of feedstock (natural gas) price .

Table 11. Estimates of the investments and returns from modular GTL plants located in the Lower 48 States as a function of feedstock (biomass) price.

Table 12. Estimates of the investments and returns from modular GTL plants located in the Alaska as a function of feedstock (biomass) price

Table 13. Emissions benefits of using FTD in vehicle fleets projected to 2015. Emissions that can be attributed to a fleet of each vehicle type whose size could be fueled the capacity of the indicated small footprint plant.

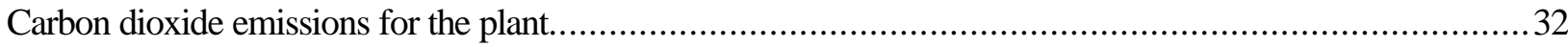

Table 14. Estimated cost per ton for abating NOx using FTD in a 2015 population of light vehicles.............. 34

Table 15. Estimated cost per ton for abating NOx using FTD in a 2015 population of urban buses................34

Table 16. Estimated cost per ton for abating NOx using FTD in a 2015 population of utility vehicles.............35

Table 17. Estimated cost per ton for abating PM using FTD in a 2015 population of light vehicles.................35

Table 18. Estimated cost per ton for abating PM using FTD in a 2015 population of urban buses...................35

Table 19. Estimated cost per ton for abating PM using biomass-derived FTD in a 2015 population of utility vehicles

Table 20. Estimated cost per ton for abating $\mathrm{CO}_{2}$ using biomass-derived FTD in a 2015 population of light vehicles

Table 21. Estimated cost per ton for abating $\mathrm{CO}_{2}$ using biomass-derived FTD in a 2015 population of urban buses

Table 22. Estimated cost per ton for abating $\mathrm{CO}_{2}$ using biomass-derived FTD in a 2015 population of utility vehicles 36

Table 23. Comparison of the cost effectiveness of various approaches to emission abatement. .36 


\section{EXECUTIVE SUMMARY}

Distillate fuels and feedstocks - diesel fuel, kerosene and naphtha-can be produced from carbon-based fuels like natural gas, coal and biomass through a process called Fischer-Tropsch Synthesis or Gas-toLiquids (GTL). The chemical reactions consist of, first, converting the carbon-based fuel to the gases carbon monoxide and hydrogen; second, combining the $\mathrm{CO}$ and $\mathrm{H}_{2}$ to form long chain, liquid hydrocarbon molecules (the Fischer-Tropsch reaction) and, finally, distilling and upgrading the hydrocarbon liquids into the desired products through standard processes borrowed from the petroleum refining industry. Thus, the overall process can start with either gaseous or solid fuels and ends with liquid fuels that are more convenient to distribute and use. The processes can be combined into a dedicated facility that, in principle, can make use of carbon-based resources that are remote or too small to be employed in more conventional ways. The product fuels are necessarily "ultraclean" in the sense that they contain vanishingly small quantities of sulfur-containing or aromatic molecules. Moreover, the structure of the GTL fuel that has the right boiling point and ignition characteristics to be used in diesel engines is inherently less soot-forming than conventional dieselFuel.

For all of these reasons, GTL processes are being actively considered for use in accessing both large sources of stranded gas, e.g., in the Middle East, and for accessing very small, domestic sources of gas that are too small to be economically connected to a pipeline but which might serve the needs of a remote community or industrial site.

As part of this ICRC-led project, TIAX was asked to estimate the economics, emissions and energy requirements associated with using small footprint plants to produce ultraclean fuels from small scale resources. We have completed an assay of the amount of gas in the continental US that might be suitable for processing in this manner and we have refined our estimates of the cost of the facilities and operations required to carry out the conversion. We have also completed a well-to-wheels analysis of the generation and use of the liquid fuels in specific applications. Finally, we have extended the analyses to consider the special case of Alaska, where fuel is less easily distributed and has a higher cost.

In our first task, using available literature, we bounded the potential gas reserves that might be suitable for this process in the Lower 48 States. On the low side, the US DOE GASIS database contains records for about 3000 wells of sufficient size (greater 1 billion but less than 10 billion standard cubic feet of gas in recoverable reserves), that are listed as not currently producing, and that have gas of suitable quality for processing by a small footprint plant (low sulfur). On the high side, through a logarithmic extrapolation of all the wells in the GASIS database, we estimate that the lower 48 states may contain as many as 150,000 gas wells with reserves between 1 billion and 10 billion standard cubic feet, for a total of the equivalent of 65 billion barrels of oil, if processed by a small footprint plant. This large range of estimates could be narrowed through additional research that details the dependencies on resource size, efficiency and cost of discovery and cost of extraction, considerations that lie beyond the scope of the current study. Moreover, given the recent rise in the price of gas, it is likely that many of the wells in GASIS may have come into play since 1996 when that survey was compiled.

Biomass is readily available in quantities consistent with supplying a small footprint plant but the type and costs are location dependent. Conversion of biomass requires a gasification step that is less burdensome than the gasification of coal. Evidently, coal and petroleum coke are available in quite large quantities but each was ruled out early on as being unsuitable for a small footprint plant because each requires an oxygen-blown gasifier, and thus an air-separation facility, which does not appear to be economically feasible for such small facilities.

We found limited opportunities to use the other feedstocks (coalbed methane, tight gas, shale gas and coal gas) — either they were available in reservoirs large enough to support large facilities that are more cost effective when run at scale or they were too far from markets to offer the benefits of local supply. The limited supply and higher production costs of using these feedstocks screened them out of detailed analysis. 
By extending a techno-economic analysis developed for much larger scale plants, we estimated the conditions that would permit a small footprint GTL plant to realize a profit. The model we have constructed, which permits facile variation in the size and location of the plant, agrees very well with both the overall capital and operating expenses of small footprint plants that have been estimated by much more detailed calculations by Syntroleum and others. The relevant conditions for profitability, notably, access to cheap feedstock and high prices for distillate product, imply that the lower 48 states offer few opportunities if the small footprint plant were constructed using standard, "stick-built" technology borrowed from the refining industry. However, a different approach, one that employs a plant constructed from modular units that contain the principal unit operations of syn-gas generation, steam reforming and Fischer-Tropsch synthesis in one pressure vessel appears to offer a much more profitable route to converting stranded or underutilized gas resources.

Finally, by combining published studies we have constructed a well-to-wheels comparison of the emissions and fuel economy for vehicles fueled with Fischer-Tropsch diesel and conventional diesel The tank-to-wheels fuel economies of the two fuels are similar (differing primarily because of the slightly different specific and volumetric heating values). Evidently, the lower well-to-tank energy efficiency of producing Fischer-Tropsch diesel compared with that of refining petroleum must be balanced against the energy security associated with employing a wholly domestic resource.

In addition to convenience and energy security, GTL fuels can offer environmental benefits with respect to $\mathrm{CO}_{2}$ and criteria pollutants. Biomass-derived fuels can, in principle, exhibit net zero $\mathrm{CO}_{2}$ emissions; GTL-fuels based on natural gas have well-to-wheels $\mathrm{CO}_{2}$ emissions that are necessarily larger than would accompany the direct use of natural gas because the GTL conversion process has an overall energy efficiency of between 40-60\%, depending on the use of waste heat for generating electricity or for space heating.

The benefit of GTL fuels with respect to criteria pollutants, NOx, CO and PM, is complicated by the mandated introduction of very clean diesel engines nearly simultaneously with the earliest practical introduction of small footprint plants. The powertrains that will be used to meet upcoming EPA regulations will need substantial emission control even if the engines were fueled with GTL fuels (mandated decreases in NOx and particulates exceeding $90 \%$ compared to $10-50 \%$ decreases that can be obtained through the use of GTL fuels only). Moreover, there is preliminary evidence that the use of GTL fuels in some modern engines without retuning actually leads to increases in NOx emissions. Thus, in our analysis the benefits of GTL fuels are attenuated since they can only be guaranteed to apply the older fraction of the vehicle fleet and will therefore diminish as those vehicles are taken out of service. Even so, significant savings in NOx and PM-15\% and 35\%, respectively - were projected for the two heavier vehice classes, buses and utility trucks, if fueled with GTL fuels since almost $80 \%$ of those fleets will consist of vehicles purchased prior to 2010 . Because there are so few light duty diesel vehicles in the current fleet, the benefits of using GTL-derived fuels are projected to be very small in this category ( $<5 \%$ decreases in criteria pollutants) since the future fleet will consist primarily of modern, low emission vehicles. The "cost" of achieving NOx and PM abatement via FTD from small footprint plants is negative: since plants as small as 100 barrels per day can be operated profitably, the NOx and PM generate a real credit if the plant uses cheap, stranded natural gas. If the plant is, instead, fueled with biomass, then we estimate that the costs of NOx and PM abatements are in line with those that can be achieved through exhaust gas treatment and fleet modifications.

Since the GTL process consumes a much larger portion of the feedstock for just the operation of the plant than does a conventional refinery ( $60 \%$ in our model versus about $20 \%$ for a refinery), there is a significantly larger energy penalty and $\mathrm{CO}_{2}$ burden for using GTL compared to that of using petroleum-derived diesel fuel. However, biomass-derived GTL fuels can, in principle, exhibit net zero $\mathrm{CO}_{2}$ emissions, leading to as much as $75 \%$ reductions in $\mathrm{CO}_{2}$ from the projected fleet.

In a second part of this study we applied these same methods to the feedstocks, conditions and opportunities that pertain in Alaska. Three sizes of plants were investigated: 600 and 6000 barrels per day, corresponding to feedstock availability for small and medium sized plants, and a 19,000 barrel per day facility, such as might be constructed to use coastal reservoirs of natural gas known to exist in the Kenai Peninsula. Because we assumed 
that the small footprint plants to be constructed in remote areas would be mostly prefabricated and would be operated by a small staff our estimates were only modestly higher for both the capital costs of the plants (2$10 \%)$ and the operating costs (1-7\%), depending on plant size. The higher price of conventional fuel in Alaska therefore contributed significantly to the economic performance of GTL plants at all size ranges since the products can be sold for more money. The economic value, estimated as internal rate of return, could be greater than $100 \%$ for natural gas-fueled plants, providing that markets could be found at the higher prices for all of the products (naphtha, GTL fuel and electricity). We note, however, that even the smallest sized plant would supply fleets as large as 10,000 light duty vehicles or 800-900 heavy duty vehicles, which is larger than what would likely be found in remote communities, and that naphtha is valuable as a product only if it can be used as a chemical feedstock, e.g., to make ethylene. Therefore, to realize the full emissions and economic benefits of a small footprint plant will require export of fuel. Our analysis indicated that biomass-fueled plants would be much more expensive to construct than natural gas-fueled plants, implying that, even in Alaska, the products from a small footprint GTL plant would require significant subsidies (\$3-5/gal) to compete with conventional fuel and power. 


\section{INTRODUCTION}

This study is part of a larger effort directed by the Integrated Concepts Research Corporation, on behalf of the US Department of Energy to assess the impact of the introduction of ultraclean fuels produced by small footprint Gas-to-Liquid (GTL) processes on air emissions, cost and energy use. The particular processes and scale of production were selected as a way to exploit under-utilized domestic resources of hydrocarbons, including stranded petro-resources and biomass, as transportation fuels, with the ultimate goals of increased energy security and decreases in criteria pollutants. It was recognized that the potential benefits of small scale production would be magnified if the resources could be tapped close to the point of use since the costs, emissions and risks associated with transportation of the fuel itself would therefore be minimized. However, it was also recognized that, to be economic, the distributed production of fuels would require technology that could be operated reliably with a very small staff and, in instances where the resource could be exhausted, a physical plant that could be relocated conveniently.

We focused on the GTL process because it can be used to produce very clean-burning transportation fuels from a wide variety of feedstocks. In the GTL process, synthesis gas (carbon monoxide plus and hydrogen) is converted to liquid fuels through Fischer-Tropsch catalysis (Figure 1). The product stream contains a distribution of liquid hydrocarbons plus water, heat and, optionally, electricity (turbine-driven generator). The hydrocarbon products consist largely of straight-chain alkanes (Figure 2) that can be concentrated in the range of medium to heavy distillate fuels (e.g., dieselfuel) by appropriate choice of reaction conditions and posttreatment. Lighter molecules, those boiling in the maphtha range, have value as very clean feedstocks to refinery processes. By themselves, however, they are not useful as transportation fuel because they have very low octane numbers. The lightest molecules can be used as a heating fuel in situations where there is a need for liquefied petroleum gas (LPG). Such synthetic fuels have long been known to burn very cleanly in conventional diesel engines - producing significantly lower concentrations of particulates, carbon monoxide and nitrogen oxides compared to conventional, petroleum-derived fuels that contain sulfur compounds and aromatic molecules. Moreover, in the event that they can be used locally, the heat and electricity that come as side-products of the GTL process can increase the overall energy efficiency of the process, thereby helping to offset the cost of the process equipment, which is large compared to that of mere combustion systems.

Figure 1. Transformation of $\mathrm{CO}$ and $\mathrm{H}_{2}$ into hydrocarbons by the Fischer Tropsch Process

$$
\mathrm{nCO}+(2 \mathrm{n}+1) \mathrm{H}_{2} \rightarrow \mathrm{C}_{\mathrm{n}} \mathrm{H}_{2 \mathrm{n}}+2+\mathrm{nH}_{2} \mathrm{O}
$$


Figure 2. Typical distribution of hydrocarbons produced by the Fischer Tropsch process [1]. The weight of products of chain length, $\mathrm{w}_{\mathrm{i}}$, is monotonically dependent on the chain length, $\mathrm{i}$, (constant probability of adding each methylene group).

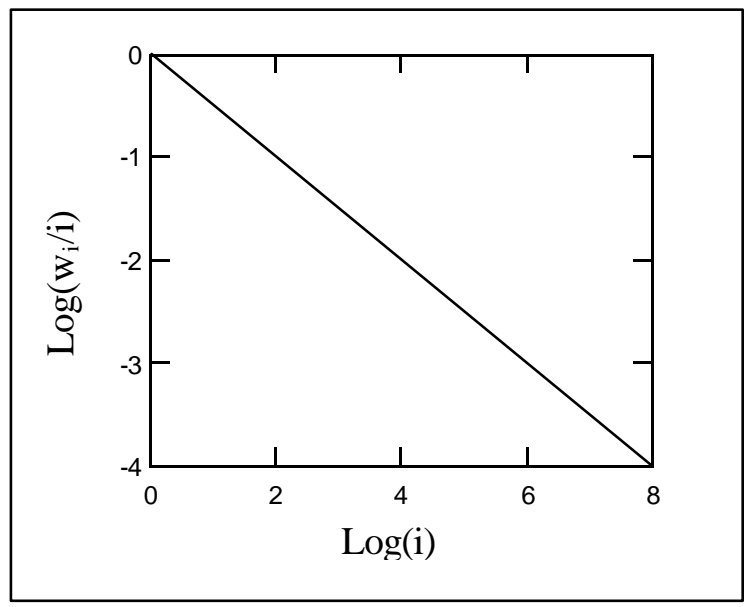

The GTL process has great generality because synthesis gas (syngas) can be generated from a wide range of carbon-based feedstocks, including coal, coke, producer gas, natural gas and biomass, although each feedstock requires its own conversion process (varying in temperature, pressure and concentrations of water and oxygen) to achieve an acceptable process efficiency and effluent composition. GTL processes that use natural gas as the feedstock are now being commercialized at large scales (>100,000 barrels/day) in parts of the world were natural gas is abundant. The goal of this study was to determine the feasibility of using similar, down-scaled and repackaged technologies for fueling the local needs using locally available feedstocks.

We limited our study to "small footprint" plants, meaning facilities that produce less than 10,000 barrels per day of product, so that we could focus on resources that would fail to satisfy the economic criteria of large energy companies but that could have a strong appeal to small, remote communities and industrial operations like mining and to situations that could exploit non-conventional feedstocks like biomass.

\section{Approach}

Market potential of a particular fuel chain involves four closely linked considerations: fuel availability, economics of production and delivery, overall energy efficiency and overall environmental footprint. Because we envisaged small footprint plants generating only small quantities of fuel, we estimated market demand based on existing distillate usage by transportation, residential customers, industrial customers, commercial customers and in electricity generation. We estimated the economics of production of GTL fuels based on a multifactor, scaling method rather than a detailed costing exercise. While the results must therefore be viewed circumspectly, our experience suggests that they are useful for discriminating among technologies and fuel chains. More refined analyses and sensitivity analyses (to identify significant parameters and assumptions) could be the focus of future work. The overall energy efficiency of the GTL processes were estimated by multiplying the energy efficiencies of the individual unit operations while taking into account plausible heat integration. The well-to-wheels comparisons were based on a combination of our own analyses and publicly available estimates for the emissions and energy efficiencies of the well-to-tank and tank-to-wheels conversions for both conventional and GTL diesel and for a representative range of vehicles.

We have, in addition, attempted to localize the results to conditions relevant to Alaska by taking into consideration market size, costs of fuel and electricity along with estimates of the costs and quality of available feedstocks. 
As a first pass, to classify the availability of various feedstocks we assumed that there was an equivalence between the heating value of the inlet and outlet fuel streams, with a conversion efficiency of 40-50\% (i.e., to create an outlet stream whose heating value is $\mathrm{X} \mathrm{kJ}$ requires an inlet fuel equivalent to about $2 \mathrm{X}$ $\mathrm{kJ})$, which is a conservative estimate of the efficiency of a small scale plant. The upper end of the efficiency range applies when electricity is exported. Table 2 shows the amount of feedstock required to generate a given amount of distillate fuel.

Table 1. Nominal conversion of carbon-based feedstocks into distillate fuels

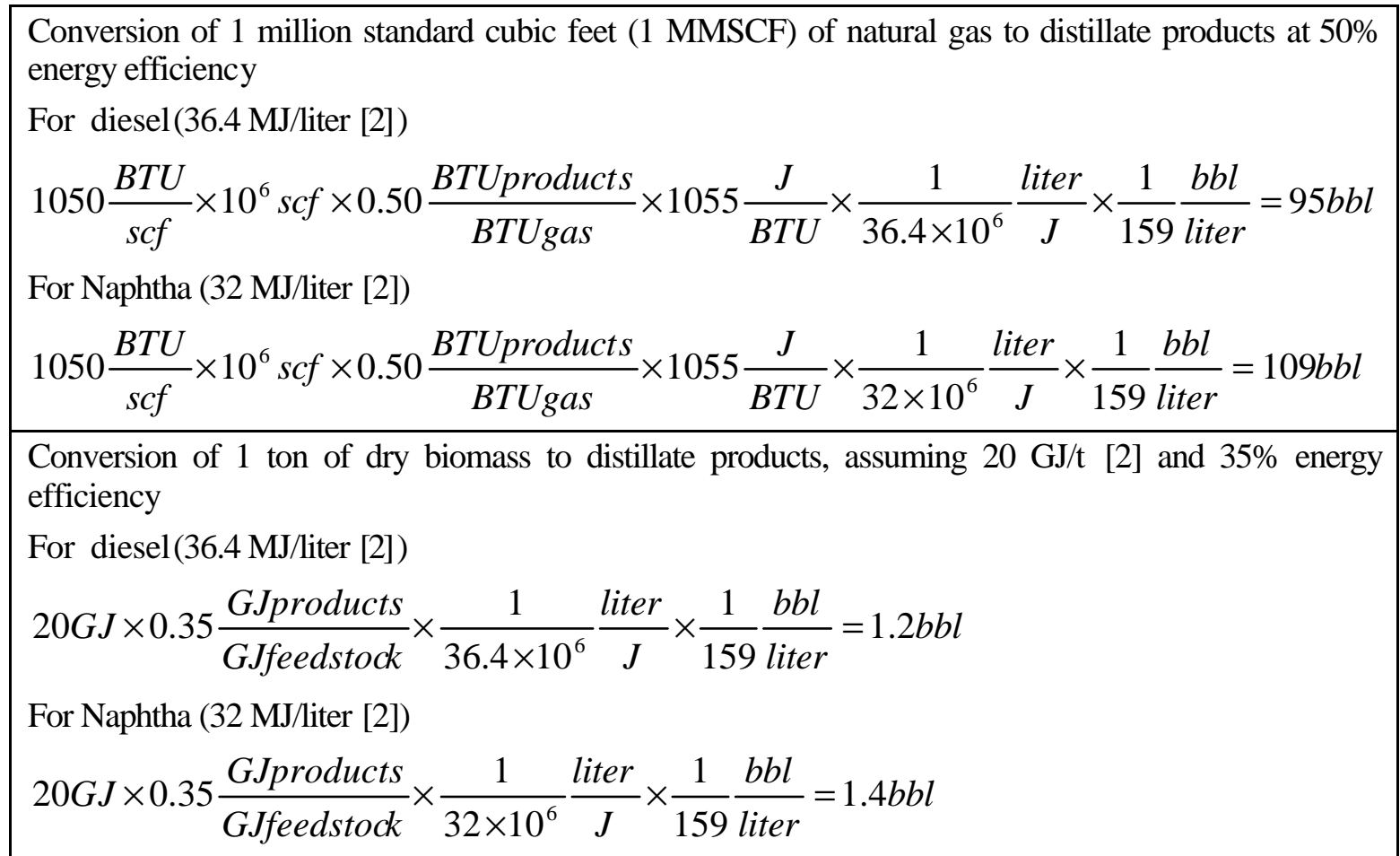

We have considered plants as small as $100 \mathrm{bpd}$ and runs as short as 2 years between plant relocations, to account for the possibility of a non-traditional plant architecture. With these criteria, we identified 2997 gas resources in the lower 48 states of a suitable size and location for relocatable, small footprint GTL plants sized for $100 \mathrm{bpd}$ of production. All of these proven reserves are located within 150 miles of a wholesale diesel outlet, suggesting that conventional fuel suppliers could serve the potential markets for GTL products so the GTL products would have to compete on the basis of price, possibly subsidized to reflect the clean nature of the fuel and its purely domestic provenance.

To estimate the economics of a small footprint GTL plant we extrapolated the results of a technoeconomic analysis carried for a much large scale plant (>50,000 bpd), using standard allometric relations (power-law scaling). Our method produced economic estimates for both capital and operating costs that compared very well to those provided by Syntroleum for a much more detailed analysis of two sizes of plants (100 and 1700 barrels per day). The analysis estimated the capital cost each of the important components required in the GTL process (heat exchangers, reactors, separation units, compressors), each sized according to the desired scale of the plant. Operating expenses combined the costs of the feedstock, expendables and labor. We assumed that the plants were built with $100 \%$ equity.

With the assumptions we used, the preliminary results suggest that a small GTL plant (1000 bpd) would be able to generate profit (10\% internal rate of return) under circumstances of sufficiently cheap feedstock (\$0.00 to \$0.40 per million BTU) if conventional fuel maintained its historical pricing levels (wholesale price of $\$ 0.74 / \mathrm{gal})$. While the results depend sensitively on scale of operation, cost of gas, location and 
market price of the fuel it is fair to infer that remote locations, for example in Alaska, may benefit the most from this technology. Indeed, in Alaska, where fuel and electricity prices can be high, we estimate that the IRR for small footprint plants can exceed $100 \%$.

\section{METHODS}

\section{Resource Identification}

To identify suitable starting resources we employed the GASIS database [3], which includes data on small and unconventional resources in the lower 48 states. Release 2 of the GASIS Reservoir Data System is a national database of geological, engineering, production, and ultimate recovery data for U.S. oil and gas reservoirs. The reservoir data system contains 19,220 reservoir records with 185 data fields per record. These reservoirs represent most of the historical gas production in the areas covered. Included reservoirs are those either meeting minimum cumulative gas production levels (through 1996) or those that were included in the Department of Energy/Gas Research Institute Gas Atlas projects.

Data sources for the Reservoir Data System include the regional DOE/GRI Gas Atlas data sets, new information from Dwights TOTL (field and reservoir) database, Dwights DOGR (well completion) database, GRI tight gas identification data and gas composition data, and other public domain data. Some data elements included in GASIS are calculated values, such as gas well productive area, recovery per well statistics, and estimated ultimate recovery.

We used the query functions in GASIS to characterize and count gas resources of four types (Table 2). On the upper end, the search was limited to fields that contained less than 10 billion standard cubic feet (bcf) of recoverable gas and that was not currently "in play", since gas that is being delivered to the grid was deemed to have a value higher than could be attained by converting it to liquid fuel. On the lower end, the search was bounded at $1 \mathrm{bcf}$, the minimum amount of gas required to keep a 100 BPD SFP in production for 2 years before it would be relocated to another site. For reference, consider that with the assumptions in Table 2 about energy content and energy conversion efficiency, a SFP sized to make 500 BPD of a product stream, consisting of $25 \%$ naphtha and $75 \%$ diesel fuel, for 10 years would require a gas field containing about 20 bcf of gas:

$$
\begin{aligned}
& 0.25 \times \frac{109}{10^{6}} \frac{b b l_{\text {gasoline }}}{s c f}+0.75 \times \frac{95}{10^{6}} \frac{b b l_{\text {Diesel }}}{s c f}=99 \frac{b b l_{\text {product }}}{10^{6} s c f} \\
& 500 b p d \times 365 d \times 10=1,800,000 b b l \\
& 1,800,000 b b l \times \frac{10^{6}}{99} \frac{s c f}{b b l_{\text {product }}}=18 b c f
\end{aligned}
$$

Table 2. Gas resources considered as possible feedstocks

\begin{tabular}{|l|l|}
\hline Resource & Description \\
\hline Conventional & $\begin{array}{l}\text { Reservoirs of associated natural gas (dissolved in or } \\
\text { lying above oil reservoirs) or non-associated gas }\end{array}$ \\
\hline Coal bed methane & Natural gas associated with coal beds \\
\hline Tight gas & $\begin{array}{l}\text { Natural gas from low-permeability (tight) reservoirs, } \\
\text { having permeabilities less than } 0.1 \text { millidarcies [4] }\end{array}$ \\
\hline Shale gas & Natural gas derived from shale deposits \\
\hline
\end{tabular}


We initially considered but did not pursue the use of coal or biomass as starting materials because the oxygen-fed gasifier required to ensure conversion of those feedstocks would have added inordinately to the price of the overall plant. We will revisit that sort of resource and process in another task of this project when we focus on the special needs of Alaska, where there are both abundant supplies of carbonbased feedstocks and very expensive fuels.

\section{Techno-economic analysis of a Small Footprint Plant.}

Initially, we based on our analysis of the technical and economic performance of an SFP by extrapolating our previous work on Gas-to-Liquid technology [5]. We constructed a spreadsheet model that included the costs of the unit operations, the nature of the gas and project financing (Figure 3). In that work, we scaled the sizes and costs of the equipment using standard allometric techniques [6] (power law relations between scale and cost).

Figure 3. Schematic of the economic analysis.

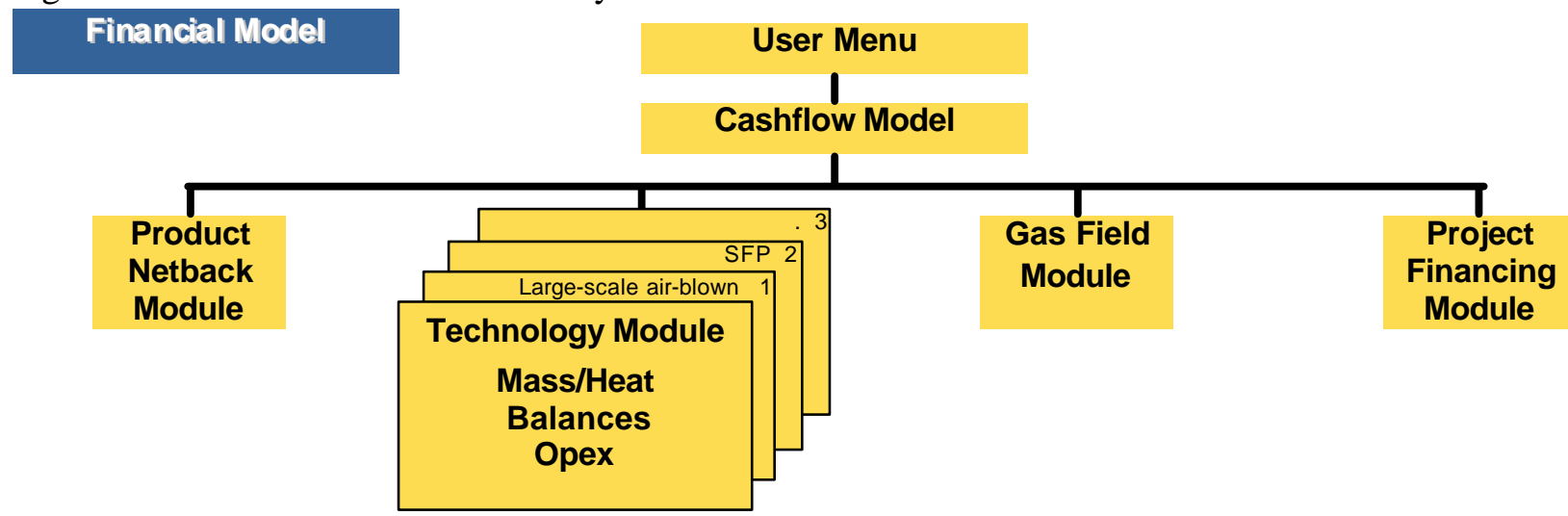

The model was then exercised to determine the sensitivity of the results (capital costs, operating costs, internal rate of return, etc) to the values of the input parameters (e.g, plant scale, cost and quality of gas, price of products). The base case (Table 3) was an air-blown GTL plant designed to resemble the technology employed by Syntroleum.

Table 3. Base case parameters used to estimate the economics of an SFP.

\begin{tabular}{|l|l|}
\hline Parameter & Value \\
\hline Feedstock & Gaseous with a heating value of 1050 BTU/scf \\
\hline Plant capacity & $6000 \mathrm{BPD}$, air-blown generation of synthesis gas \\
\hline Location factor & 1 \\
\hline Energy conversion efficiency & $\begin{array}{l}40 \% \text { (low for well integrated plant, but correct for GTL-in-a- } \\
\text { Can }{ }^{\mathrm{T}}, \text { vide infra). }\end{array}$ \\
\hline Crude oil price & $\$ 24 / \mathrm{bbl}$, our long term projected price for crude oil [7] \\
\hline Products & $80 \%$ diesel, 20\% maphtha, self sufficient in electricity and steam \\
\hline
\end{tabular}

To estimate the effect of geographic remoteness on the perceived value of SFP products we attempted to determine the added cost of delivering fuel from a central depot to outlying locations where one might site an SFP (whose products were assumed to be delivered without cost). Our simple model took into account the costs of storage and transportation: 


$$
\begin{aligned}
& \text { Cost }_{\text {overall }}=\text { Cost }_{\text {transport }}+\text { Cost }_{\text {storage }} \\
& \text { Cost }_{\text {transport }}=\text { Cost }_{\text {fixed }}+\text { Cost }_{\text {variable }}
\end{aligned}
$$

The storage costs were assumed to be 2 cents/gal; the fixed cost for transportation (driver, vehicle) was assumed to be $\$ 700$ per day, prorated by the number of deliveries; and the variable cost was assumed to be 38 cents/mile.

We have not attempted to price the fuel as a function of location or time but rather have used that parameter as an input to a sensitivity analysis.

In the latter half of this project, we updated our previous GTL model with costing and scaling factors to estimate the capital costs of the major components of the SFP. We also rewrote the model in a form that permits much easier maintenance and revision. The previous model was an Excel spreadsheet. The current model (Figure 4) is based on Simulink®, a general purpose modeling tool in which the functionality of each unit operation in the small footprint plant can be encapsulated in an independent module. We believe that this is the first such use of Simulink ${ }^{\circledR}$ for techno-economic modeling. An important benefit of this new approach is that the models can be packaged in a way that permits them to be distributed without revealing confidential information.

Our approach uses a multifactor method that has proved successful in work we have done for much larger GTL plants. The cost of a system is constructed from the costs of the individual components, which are divided into equipment costs, construction costs and installation costs. The latter two are estimated by multiplying the equipment costs by factors (hence the name, "multifactor") derived from field experience for the different types of equipment (synthesis gas generator, Fischer-Tropsch reactor, balance of plant) and for the ancillary services that lie outside the "battery limits" of the core process (e.g., roads, housing, safety services).

We have constructed models for plants sized between 100 and 10,000 barrels per day capacity, operating with an air-blown synthesis gas generator and an operating pressure of $170 \mathrm{psi}$. A major assumption is the overall energy efficiency of the plant, defined to be the heating value of the products divided by the heating value of the input feed gas. We used a value of $50 \%$ for the energy efficiency, a number that has been validated by Syntroleum as being appropriate for this size range of plants. The conventional small footprint plant technology, as employed by Syntroleum, produces 75/25 diesel/naphtha split, whereas with GTL-in-a-can ${ }^{\odot}$, discussed below, the split was assumed to be 80/20.

In order to measure the overall cost and emissions of GTL technology and fuel we elected for the analysis to reflect a scenario wherein Fischer-Tropsch diesel accounts for $1 \%$ of the annual U.S. diesel consumption, (14.4 million barrels per year of diesel fuel). This level of diesel consumption (and, likewise, production) was chosen because it is small enough to be supported for 20 years by stranded gas in the lower 48 and large enough to show reasonable cost and emission effects. As the analysis will show, this level of production can be accomplished by a very reasonably sized fleet of GTL plants.

The result that was used to compare the effect of varying plant size and differing technologies on the total cost per gallon of diesel produced. The method of assembling the total cost of this level of production was done by first assuming a plant size (100-10,000 BPD), then calculating how many of that size plant would be required to produce $14.4 \mathrm{M} \mathrm{bbl/yr}$. Once the number of plants was known, our cost model was exercised to find the CAPEX, OPEX, feedstock cost and relocation cost for a single plant. The feedstock, since it varies by location, was assumed constant at $\$ 1.00$ per MMSCF-a most-likely conservative estimate. The numerator of the following formula is the total cost of production, which is then normalized by the production to get the per gallon cost: 


$$
\$ / \text { gal }=\frac{\text { \#ofplants } \times(C A P E X+20 y r s \times(O P E X+\text { feedstock }))+(\text { \# ofrelocations }) \times \text { relocation_cos } t}{14.4 M \frac{b b l}{y r} \times 20 y r s \times 42 \frac{g a l}{b b l}}
$$

The cost of relocating was calculated as a sum of disassembly/reassembly costs and moving costs, which were $70 \%$ of the initial installed cost and $2 \%$ of the CAPEX, respectively. The relocation cost is only an estimate based on best-guess values. The number of times a plant was required to relocate (which appears as \#of relocations in the equation above) depended on the size of the gas field from which it was drawing its feedstock. Whenever a plant was required to relocate because it depleted its field's gas a relocation cost would be incurred along with three months of zero production from that plant.

The plants were given a credit for their production of naphtha. Per gallon of naphtha produced the overall cost (numerator of above equation) would be decreased by $\$ 0.65$. This price of naphtha reflects the low end (conservative) of the naphtha market. The average naphtha price from May04-Aug04 was closer to $\$ 1.00$. If the price of naphtha increases, the resulting trend would be a lower net production cost of diesel. The lower net cost is more pronounced in the technologies that have a higher naphtha product split, whereas the effect is parallel for different plant sizes within the same technology.

The analysis shows that with increasing plant size, the cost to produce a gallon of diesel decreases. For conventional stick built plant there is dramatic benefit in increasing the plant size from 100 BPD to 1000 BPD, with diminishing benefit as plant size increases from 1,000 to 10,000 BPD. We also note that as plant sizes increase, the cost of relocating probably will not scale directly with CAPEX, but rather would increase greater than linearly because of the costly demands outside the battery limits, which we have shown to be very significant.

More important than the trend of decreasing cost with increasing plant size is the actual cost of producing a gallon of Fischer-Tropsch diesel. For a $\$ 1.00$ per MMSCF feedstock cost and a 10,000 BPD plant, the cost to produce a gallon of diesel fuel is $\$ 0.66$. This number has the potential to be lower in most actual applications because conservative estimates have been made in both the feedstock cost and the price of naphtha. 
Figure 4. Top level of the Simulink ${ }^{\circledR}$ model that incorporates the revised economics for the small footprint plants.

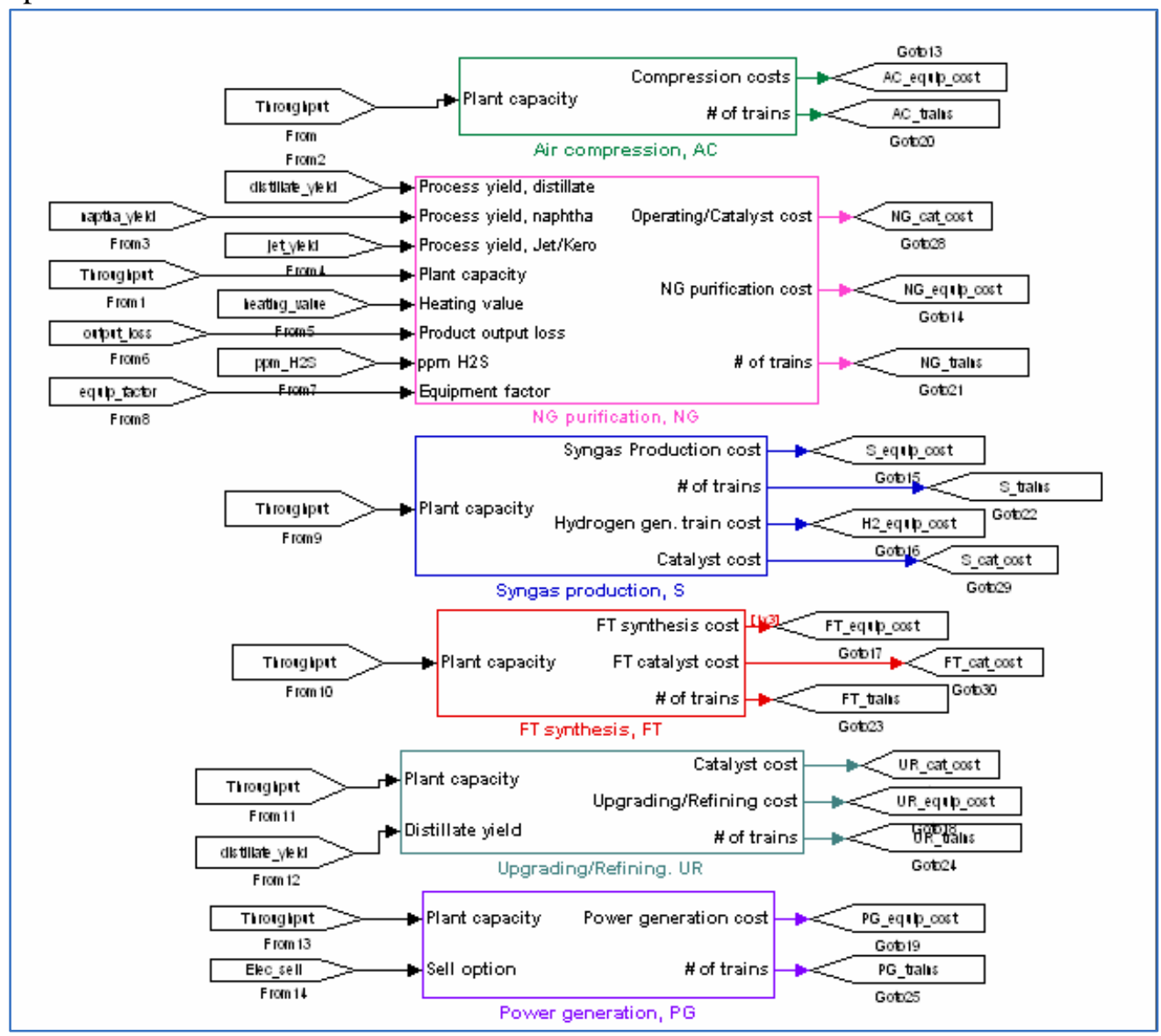

Table 4. Base case inputs for economic model

\begin{tabular}{|lcc|}
\hline Price of oil & 24 & $\$ / \mathrm{bbl}$ \\
\hline Price of electricity & 30 & $\$ / \mathrm{MW}-\mathrm{h}$ \\
\hline Cost of natural gas & 1 & $\$ / \mathrm{MMBTU}$ \\
\hline Diesel markup & 1.3 & - \\
\hline Diesel output - GTL-in-a-can ${ }^{\mathrm{TM}}$ & 80 & $\%$ of product \\
\hline Diesel output - stick-built & 75 & $\%$ of product \\
\hline Thermal Efficiency - GTL-in-a-can $^{\mathrm{TM}}$ & 42 & $\%$ \\
\hline Thermal Efficiency - stick-built $^{\mathrm{s}}$ & 50 & $\%$ \\
\hline Interest Rate & 6 & $\%$ \\
\hline
\end{tabular}

\section{Well-to-Wheel Analysis of fuels produced by a small footprint plant.}

The well-to-wheels analysis consists of two parts, well-to-tank and tank-to-wheels. The former includes the costs of producing and transporting the fuel. The latter includes the efficiency and emissions associated with using the fuel. Data for the former come from our understanding of the thermodynamics and kinetics involved in transforming natural gas into liquid fuels, in particular the effective conversion efficiency. Data for the latter estimates come from recent series of tests of GTL fuels in vehicles (Table 5), where the reductions range from $8-15 \%$ for NOx and $20-50 \%$ for particulate matter. 
Table 5. Estimates of abatement in criteria pollutants from using FT fuels compared to conventional ultralow sulfur diesel fuel

\begin{tabular}{|l|c|c|}
\hline Pollutant & Abatement & Reference \\
\hline NOx & $6.2 \%$ & {$[8]$} \\
& $4-9 \%$ & {$[9]$} \\
& $9 \%$ & {$[10]$} \\
\hline PM & 29 to $45 \%$ & {$[8]$} \\
& $12-45 \%$ & {$[9]$} \\
& $32 \%$ & {$[10]$} \\
\hline
\end{tabular}

The emission reductions indicated in Table 5 are not indicative of the use of GTL fuels in future vehicles because the combustion technologies that are being employed to meet upcoming emissions standards are highly dependent on the nature of the fuel, both its physical and combustion characteristics.

\section{RESULTS AND DISCUSSION}

\section{Resources}

The data in the GASIS database suggest that the resources for feeding an SFP will come most readily from small reservoirs of conventional gas (associated and non-associated), tight gas and coal bed methane (Figure 5). The database contained no coal bed methane resources, when screened according to the criteria described in the Methods section and described more fully in the Appendix. Altogether there were 2997 resources that fit the screening criteria .

Whether a particular resource is, in fact, usable will depend on its location proximity to infrastructure and markets, its quality (energy content of the gas, presence of impurities that require extensive cleanup or removal) and whether the resource can be used in other, more profitable ways. The increasing price of natural gas has a direct bearing on the latter criterion. 
Figure 5. Results of the screening exercise. Left: Median recoverable ultimate reserves reported in GASIS for the screened resources. Right: .Median higher heating value of reserves of each type.
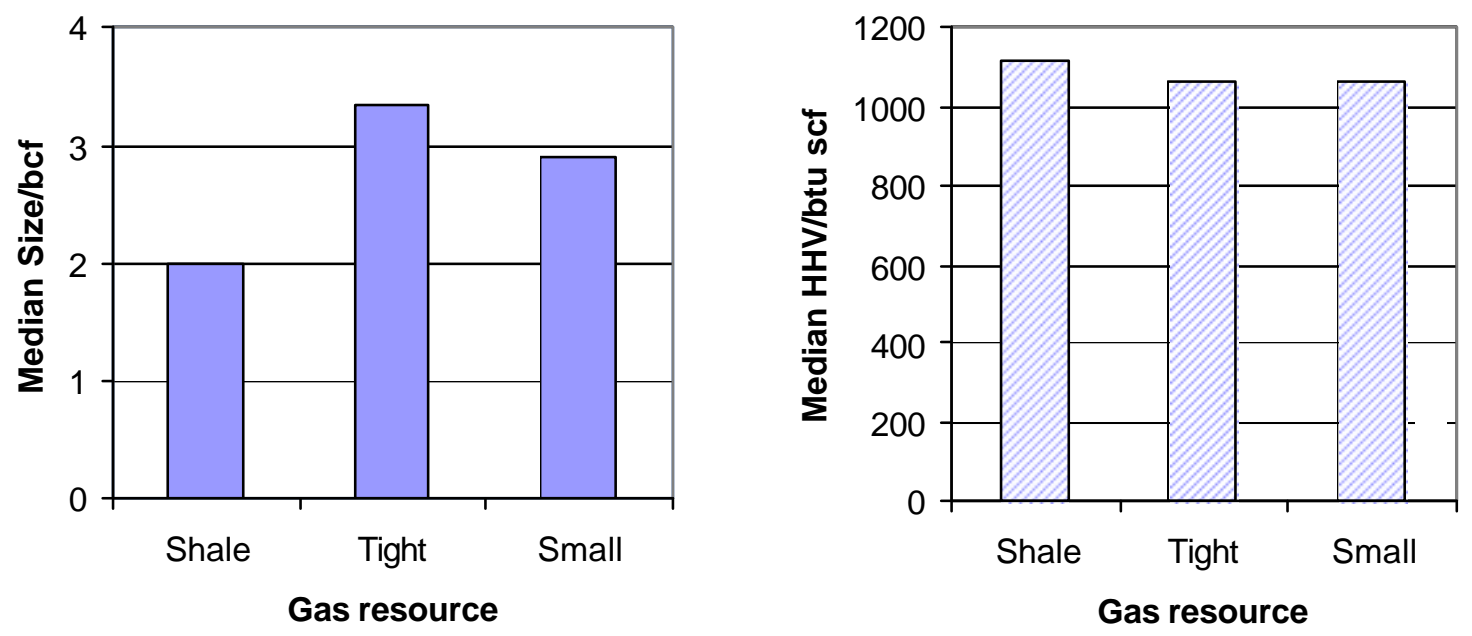

ap0.xls

The selected resources are distributed almost exponentially by size (Figure 6). Small, conventional resources are by far the most numerous (2947 wells), followed by tight gas (43 wells) and shale gas (7 wells). The total amount of gas contained in these wells is equivalent to 800 million barrels of oil at an energy conversion efficiency of $40 \%$. For reference, the US now uses roughly 1.4 billion barrels of diesel fuel per year (US Energy Information Agency).

The number of small footprint plants required to exploit these resources depends on the size and desired lifetime of the SFP (Table 6 - Table 8). The lifetimes were calculated using the conversion factors presented above. Thus, if the resources were to be exploited by means of $100 \mathrm{bpd}$ plants then hundreds could be in service at once. On the contrary, 1000 bpd plants could only be used for short periods of time ( 2 years) on even the largest of these resources. Evidently, an economic optimization between plant construction and plant relocation is required to exploit the resources in as profitable way as possible. We will present that sort of analysis after discussing the two forms of plant architectures. 
Figure 6. Resource distribution by size for the wells screened according to the criteria specified in Appendix 1. Note that the number of resources of each size for the tight wells and shale gas wells have been multiplied by 10 and 100, respectively, to make them visible on this scale. The curve is an exponential fit to the distribution of small, conventional resources in this size range.

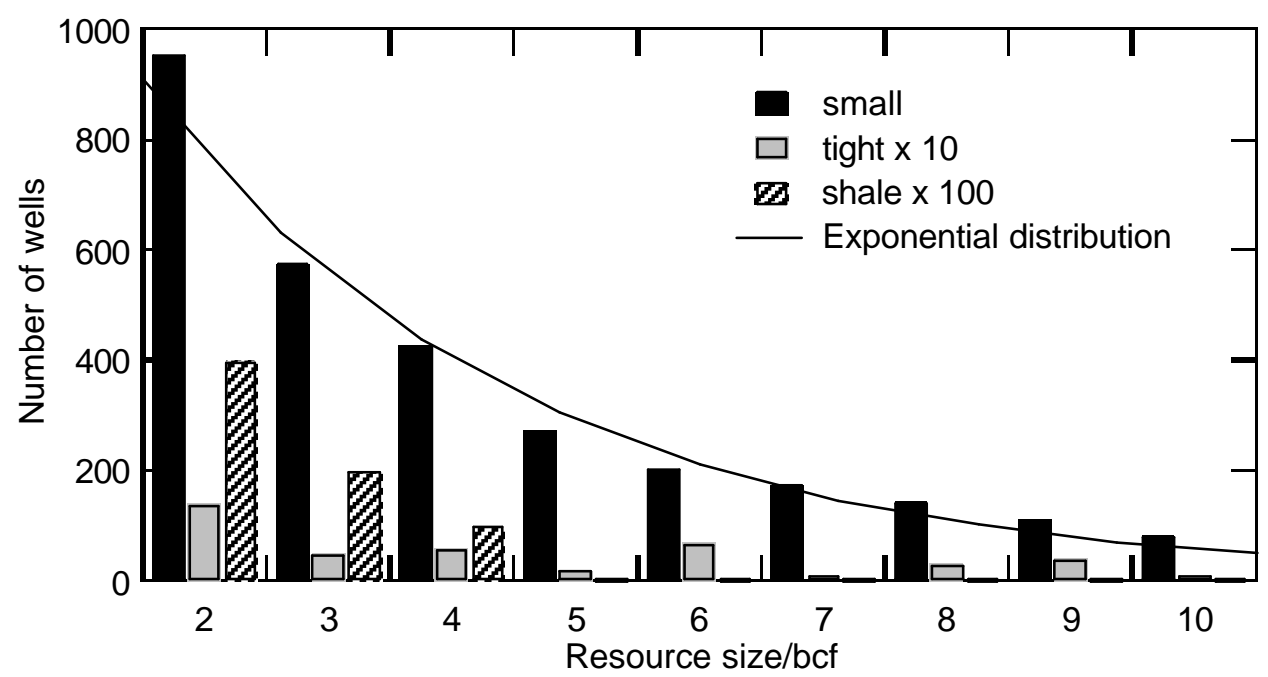

Table 6. Number of SFPs of the specified size that can be supported for the specified lifetime using the screened, small conventional resources of natural gas identified in the GASIS database

\begin{tabular}{|c|c|r|r|r|}
\cline { 2 - 5 } \multicolumn{1}{c|}{} & \multicolumn{4}{c|}{ Lifetime/y } \\
\hline Plant Capacity/bpd & 2 & 5 & 10 & 20 \\
\hline 100 & 308 & 1107 & 882 & 650 \\
\hline 200 & 717 & 1064 & 595 & 0 \\
\hline 500 & 606 & 458 & 0 & 0 \\
\hline 1000 & 255 & 0 & 0 & 0 \\
\hline
\end{tabular}

Table 7. Number of SFPs of the specified size that can be supported for the specified lifetime using the screened, small resources of "tight" natural gas identified in the GASIS database

\begin{tabular}{|c|c|c|c|c|}
\cline { 2 - 5 } \multicolumn{1}{c|}{} & \multicolumn{4}{c|}{ Lifetime/y } \\
\hline Plant Capacity/bpd & 2 & 5 & 10 & 20 \\
\hline 100 & 5 & 12 & 13 & 13 \\
\hline 200 & 5 & 18 & 11 & 0 \\
\hline 500 & 11 & 8 & 0 & 0 \\
\hline 1000 & 5 & 0 & 0 & 0 \\
\hline
\end{tabular}

Table 8. Number of SFPs of the specified size that can be supported for the specified lifetime using the screened, small resources of shale gas identified in the GASIS database

\begin{tabular}{|c|c|c|c|c|}
\cline { 2 - 5 } \multicolumn{1}{c|}{} & \multicolumn{4}{c|}{ Lifetime/y } \\
\hline Plant Capacity/bpd & 2 & 5 & 10 & 20 \\
\hline 100 & 1 & 5 & 1 & 0 \\
\hline 200 & 2 & 1 & 1 & 0 \\
\hline 500 & 1 & 0 & 0 & 0 \\
\hline 1000 & 0 & 0 & 0 & \\
\hline
\end{tabular}


In fact, there is reason to believe that the GASIS database significantly under-represents the amount of gas available in reservoirs containing less than about 10 billion standard cubic feet (Figure 7). The solid curve in Figure 7 shows the amount of gas presumed to be extractable from each reservoir (EUR $=$ estimated ultimate recovery) as a function of the ranking of that reservoir in the database (Well number). The dashed curve corresponds to an extrapolation of the distribution of gas wells to small sizes, assuming that the distribution is fractal, i.e.,

$$
R=\frac{C}{N^{D}}
$$

Equation 1

where $R$ is the size of a feature, $N$ is the number of features having that size and $C$ is an empirical constant. The quantity $1 / D$ is called the fractal dimension of the system. Fractals have been shown to be applicable to a number of geological features, including the distribution of minerals and petroleum [11]. For the data in GASIS, the relationship between well size and well number, determined from the largest well to wells containing 10 billion standard cubic feet of gas is:

$$
E U R=\frac{2.45358 \times 10^{7}}{\text { Well }^{0.84323}}
$$

Equation 2

Integrating this equation over a range of well sizes provides an estimate the gas that appears to have been undercounted in GASIS (shaded region in Figure 7):

$$
\sum E U R_{k} \approx 2.45358 \times 10^{7} \int k^{-0.84323} d k=1.3 \times\left(k_{h}^{1.84323}-k_{l}^{1.84323}\right)
$$

Equation 3

The indices of the wells can be obtained from Equation 1. For wells between 1 and 10 billion standard cubic feet, the shaded region in Figure 7 corresponds 36 trillion cubic feet of gas or the equivalent of 65 billion barrels of distillate fuelat a conversion efficiency of 50\%. While this amount of fuel is significant (it is approximately 6 times the economically recoverable petroleum estimated to lie in the Arctic National Wildlife Reserve [12]), we hasten to point out that it assumes all of the "missing gas" is accessible.

Figure 7. Fractal extrapolation of wells in the GASIS database to an EUR of at least 1 billion standard cubic feet.

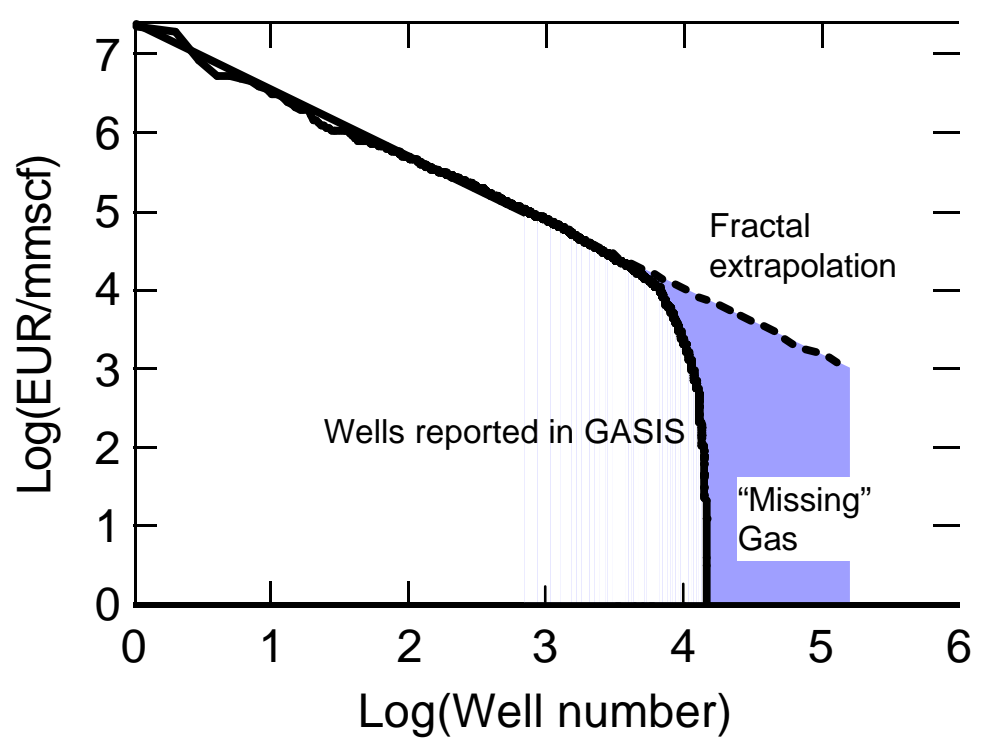


Very likely, we will likely need advances in seismic imaging to find the "missing gas", drilling costs may be disproportionately large for small reserves, the geologic formations in which the gas lies may not be conducive to complete recovery and the overall relationship may be based on a rather optimistic view of the universe of accessible gas [13]. Still, it is probably safe to say that the amount of gas in the Lower 48 States that might be processed by small footprint plants is larger than the 1.3 billion BOE suggested by GASIS and smaller than the 6.5 billion BOE indicated by this analysis.

\section{Economic Analysis}

To validate the new model we compared its output to information provided by Syntroleum for two plant sizes (Figure 8). The overall agreement between our cost estimates is very good. We hasten to point out, however, that the costs of the individual components were not estimated on the same basis since we have allocated utilities like heat exchangers and compressors in a manner different from that used by Syntroleum.

A sensitivity analysis on the model (Figure 9) indicates that the most expensive aspects of constructing a small footprint plant are associated with the infrastructure (services and equipment outside the battery limits), the natural gas purification step and the Fischer-Tropsch reactor. Consideration of those factors has led us to consider ways to significantly decrease the cost of the plant by combining unit operations into a single module. We call that approach GTL-in-a-Can ${ }^{\mathrm{TM}}$ and will discuss it briefly in the later section of this report.

Even in the relatively narrow range of plant sizes in Figure 8 the capital expenditure demonstrates economies of scale, although slight. The same trend is true for the operating costs (Figure 10) with labor costs providing the best economy of scale because of the finite number of personnel required to run a set of unit operations no matter the operation size. Since our model does not account for the small efficiency effects at different sizes, the amount of feedstock increases linearly with the plant size, and so as plant size increases the feedstock becomes a more dominant cost.

Figure 8. Comparison of capital costs for small footprint plants based on a conventional, "stick-built" architecture across a range of plant sizes. The costs of the individual components are not directly comparable because TIAX has used a different method of allocating process equipment, i.e. heat-exchangers.

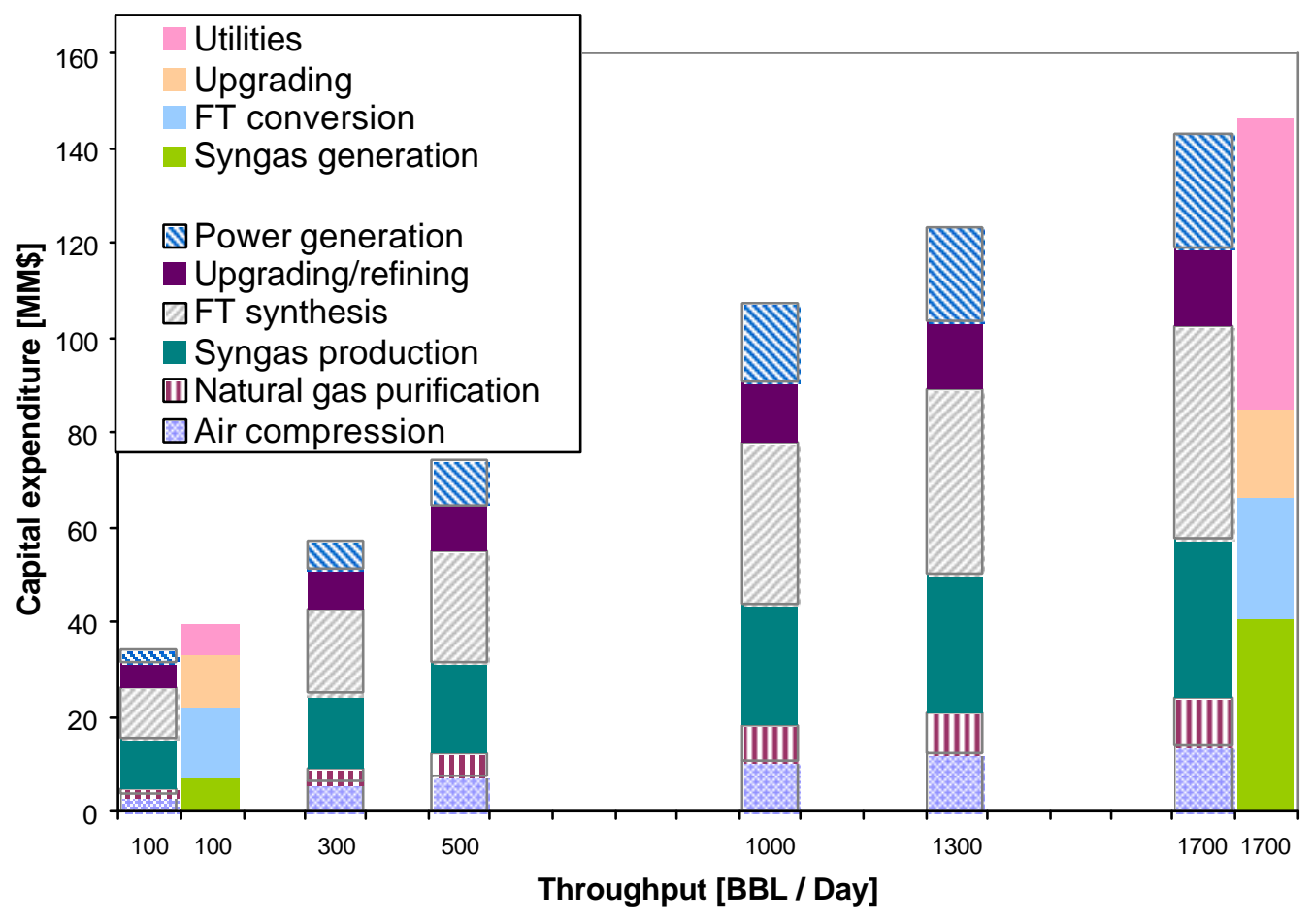


Figure 9. Sensitivity analysis on the capital cost factors for constructing a small footprint plant.

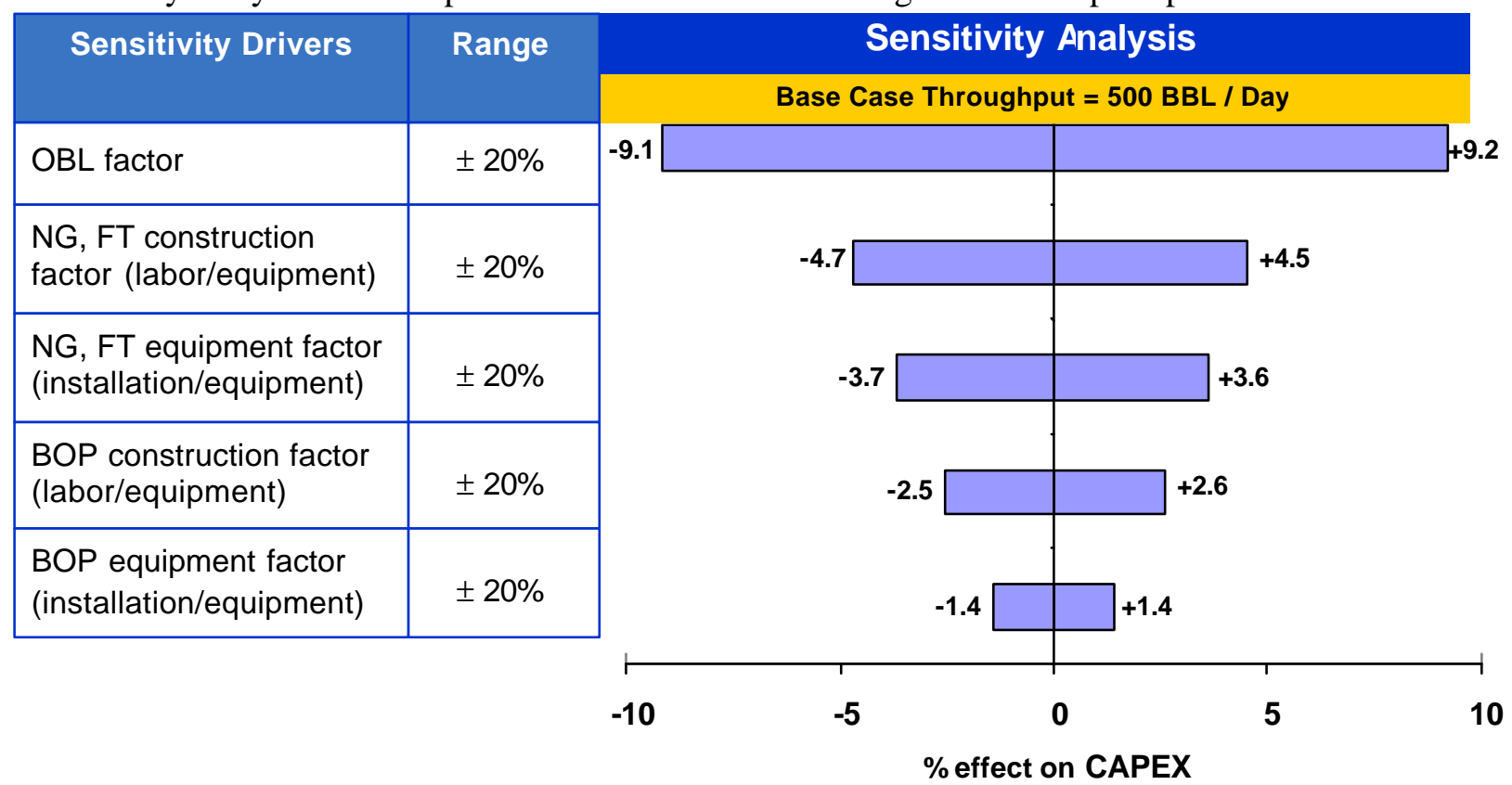

Figure 10. TIAX estimates of operating costs for stick-built small footprint plants.

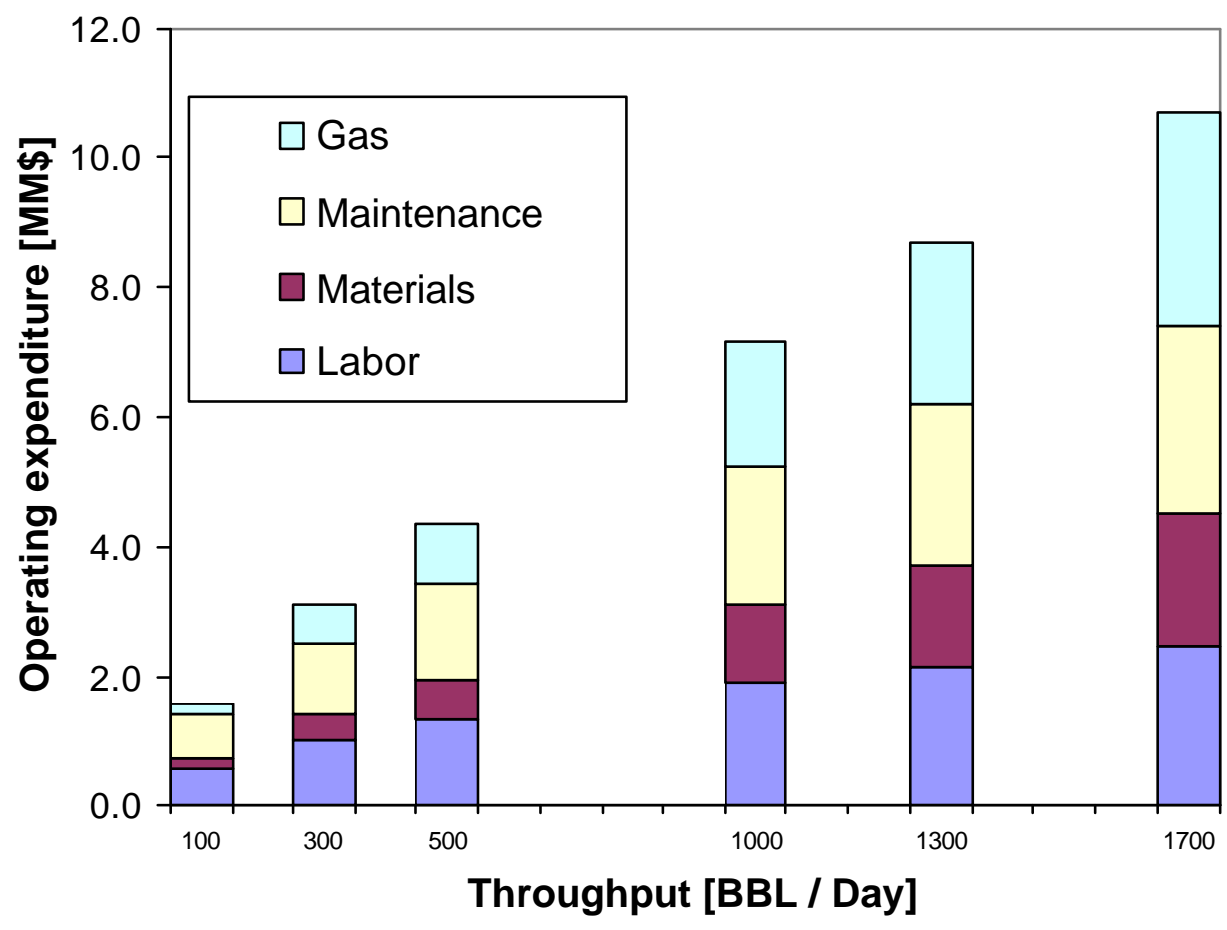


Figure 11. Sensitivity analysis on the operating expenses of a stick-built small footprint plant.

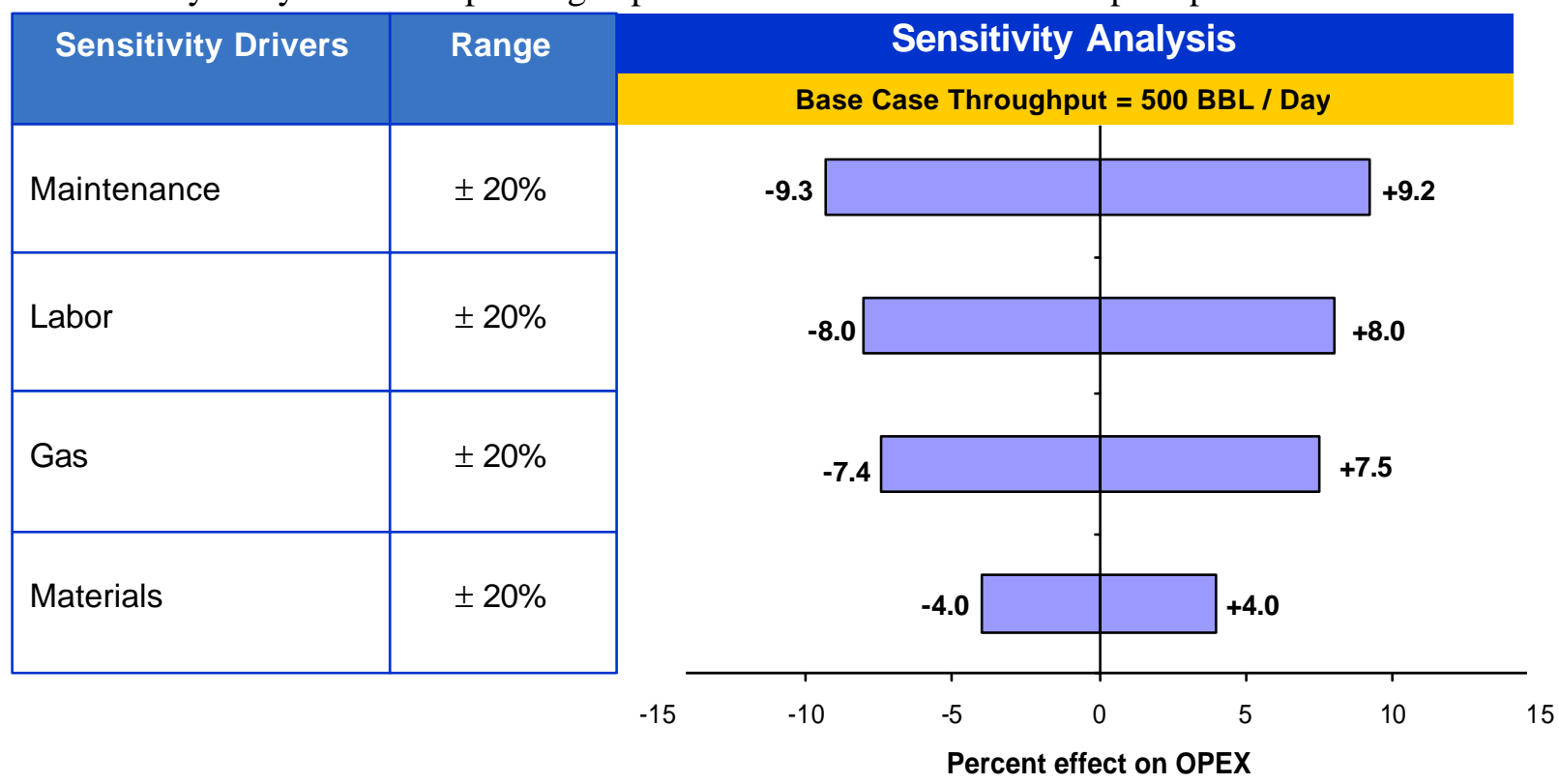

According to our sensitivity analysis (Figure 11), maintenance, labor and feedstock cost all have roughly the same effect on the operating expenses. Reducing the amount of natural gas (at a set cost for the feedstock) would yield smaller OPEX, but at the penalty of lower throughput and hence less revenue. Only decreases in the maintenance and labor costs could decrease costs while sustaining operation levels. Maintenance and labor are two costs that are also reduced in an approach like the GTL-in-a-Can ${ }^{\mathrm{TM}}$ small footprint plant.

\section{A possible alternative: GTL-in-a-Can ${ }^{T M}$}

The revised economic analysis presented above suggests that a small footprint plant would become significantly more profitable and possibly more robust if a way could be found to decrease capital costs and operating costs in the smaller size range $(<1000 \mathrm{bpd})$. To address those issues, in prior work at the predecessor to TIAX, our staff had investigated ways to integrate the synthesis gas generation reactor and the Fischer-Tropsch reactor in one pressure vessel. The combined unit, which we call GTL-in-a-Can ${ }^{\mathrm{TM}}$ appears to be well positioned to become part of a fieldable, modular plant that promises better decreased capital and operating costs as well as increased transportability and reliability than a "stick-built" plant. Our preliminary costing suggests that fuel products could be synthesized for less than $\$ 1 / \mathrm{gal}$ with a capital cost of \$25 million for a 500-1000 bpd plant, about half the costs associated with a stick-built plant. The savings arise from the decreased need for personnel, since we envisage the modular plant being highly automated, and the decreased construction costs, since we envisage the modular plant being produced at high enough volume that it benefits from economies of scale. Such a plant might be used in a number of ways, for example:

- Monetization/utilization of small, remote resources - the topic of this project

- Upgrading/interconversion of fuels - of possible interest to the military

- Alternative to flaring - to enable the drilling of exploration wells or monetization of associated gas

- Conversion of gaseous or liquid fuels to hydrogen or methanol, or other alternative transportation fuels-again, of possible interest to the military or remote communities. 
We present the concept below as an adjunct to our analysis of the conventional plant and will include it in the final analyses to be completed in the next reporting period.

The modular plant incorporates the heart of the GTL plant (Figure 12) in one reactor unit (Figure 13). The reactor unit must be designed to ensure heat integration and the proper flow of species. By arranging the operations concentrically the hottest zone can be located deep inside the can, obviating the need for materials of construction that must withstand both high temperature and high pressure.

Figure 12. Schematic of a GTL-in-a-Can ${ }^{\mathrm{TM}}$ process showing the components included in the can.

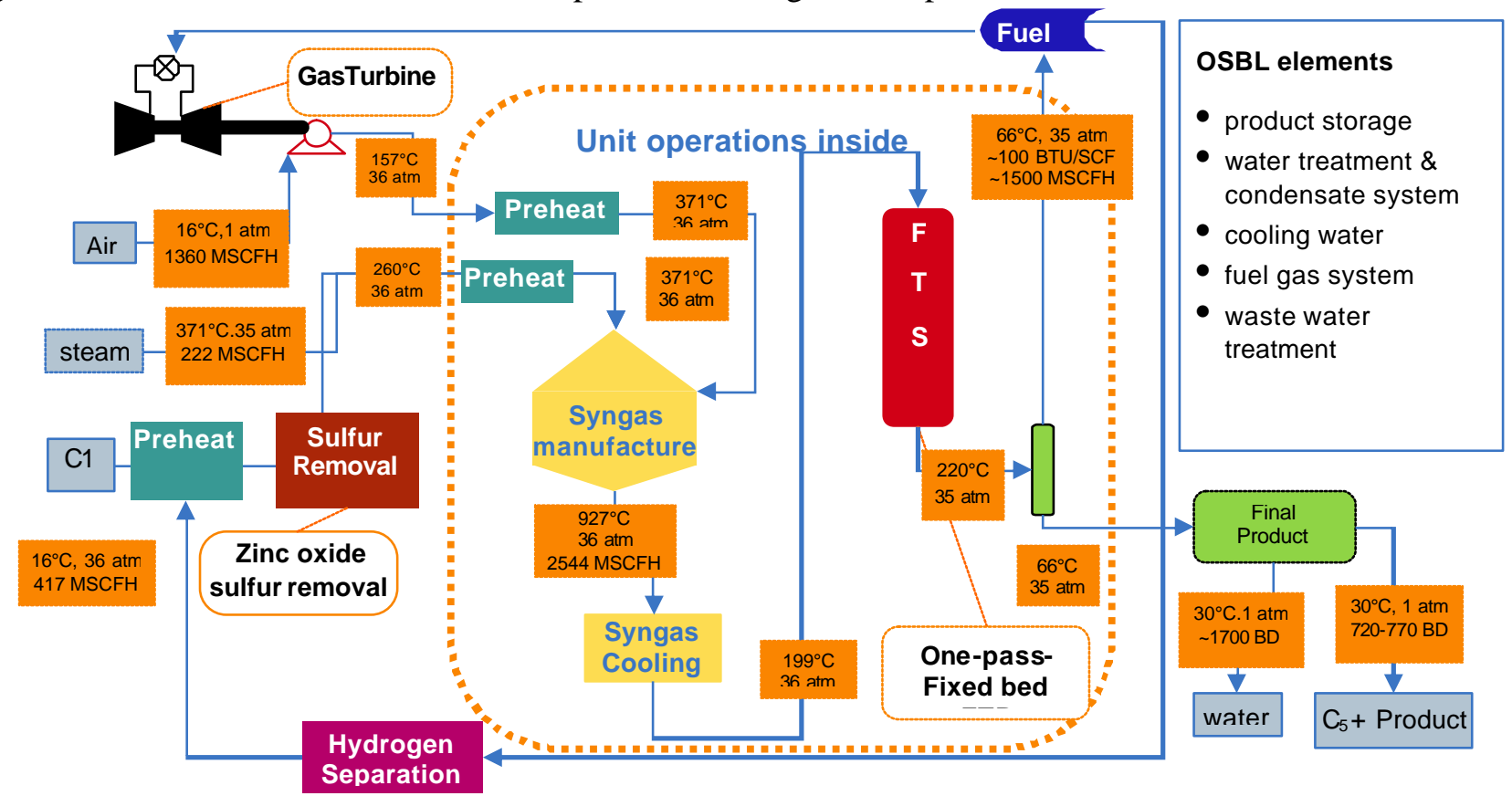

Figure 13. Schematic of the Integrated Modular GTL Technology (Fischer-Tropsch application). The aspect ratio is distorted to show detail.

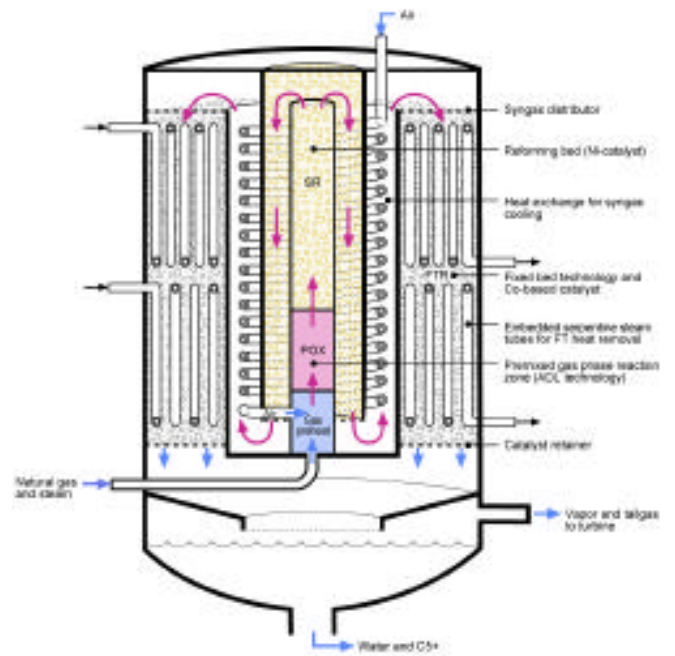

In our economic analysis we estimate that a plant that consumes 10 million scf/day of gas (equivalent to about 750 bpd of liquid products) can be built for about $\$ 25$ million and operated at a cost of about $\$ 2.5$ million/year. Automating the operation of the plant both decreases the number of operators required to 
run it and, potentially, makes the plant safer and more robust. The inherently simpler design also allows for more economical relocating the plant, which becomes a viable option if the plant is able to consume the locally available feedstock in only a fraction of the plant's useful life.

\section{A comparison of}

Figure 14 and Figure 15 show that even at the smallest plant size, an integrated GTL-in-a-can process is far more profitable than a stick built plant owing to the much smaller contributions of CAPEX and OPEX to the cost of producing a gallon of diesel fuel.

Figure 14. Effect of plant size on profitability for a stick built plant.

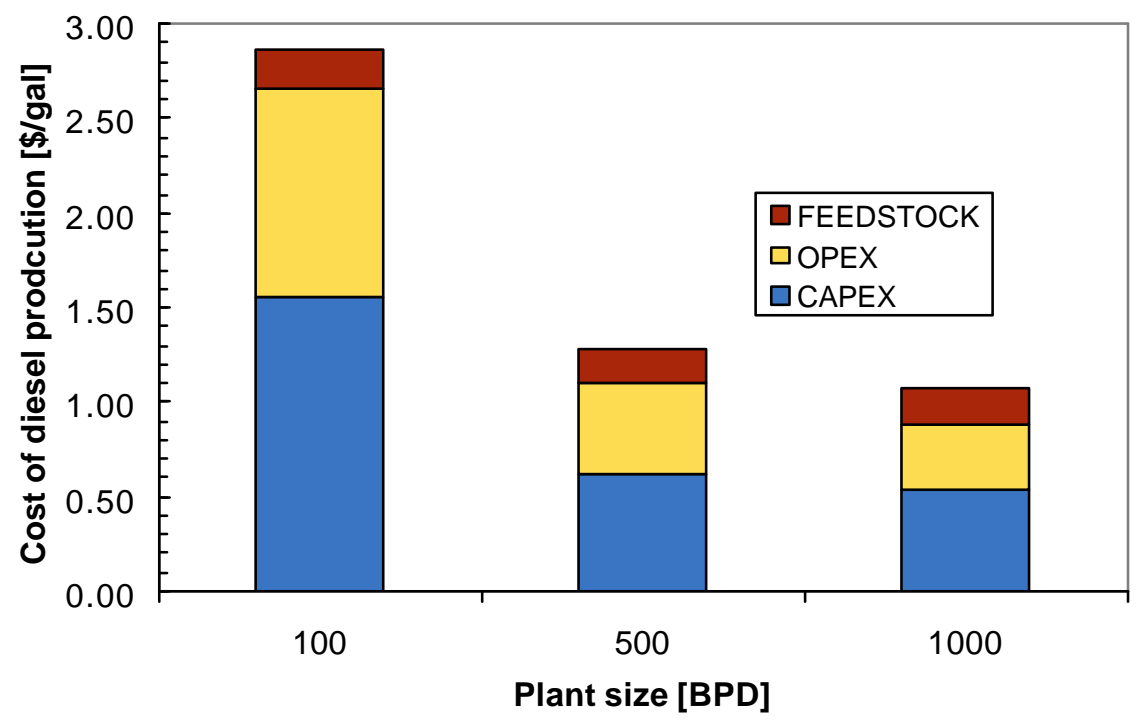

Figure 15. Effect of plant size on the profitability of a GTL-in-a-can plant

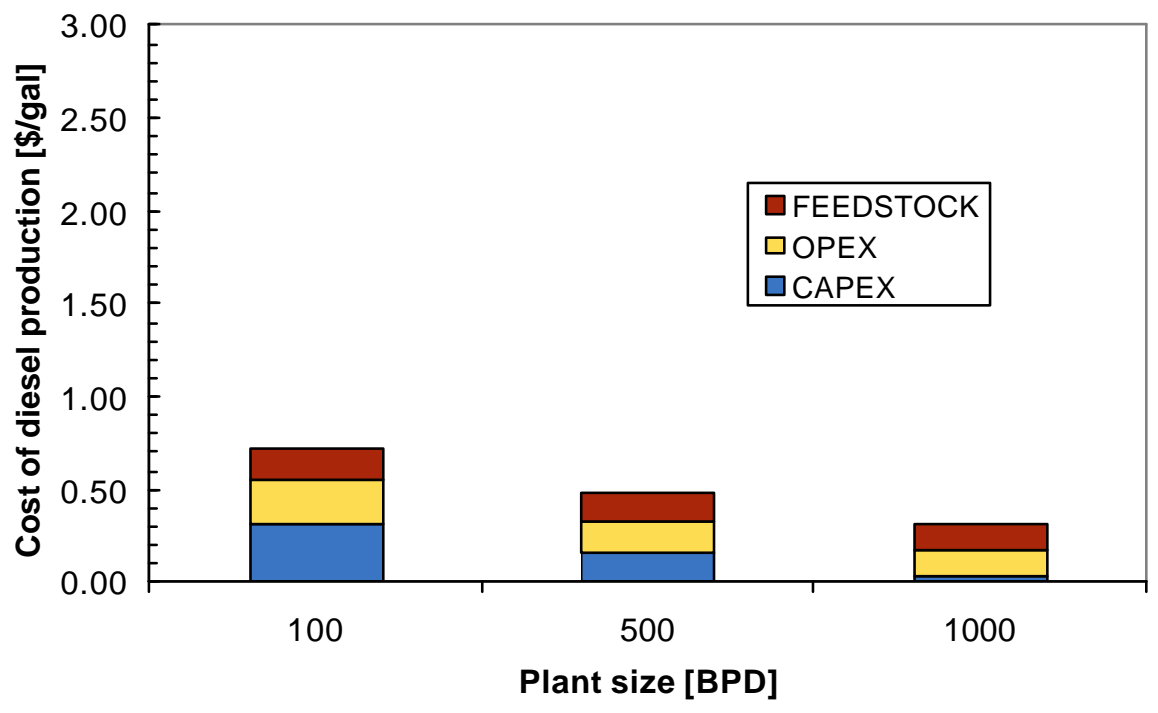

The economies of scale for the GTL-in-a-can ${ }^{\mathrm{TM}}$ approach happen at much smaller throughputs than they do for stick built plants, but there is relatively little to be gained by increasing capacity (Figure 16). Stick-built plants, on the other hand, show significant improvement in their economic performance as the capacity is increased from 100 to $1000 \mathrm{bbl} /$ day. Owing to the lower efficiency (Table 4) of GTL-in-a- 
can ${ }^{\mathrm{TM}}$, at high throughputs, when feedstock costs start to dominate over capital costs, the stick built plant becomes a more profitable. This transition occurs at roughly $9,000 \mathrm{bbl} / \mathrm{day}$.

Figure 16. Comparison between GTL-in-a-can ${ }^{\mathrm{TM}}$ and stick built plants on the cost of producing 1 gallon of FT diesel

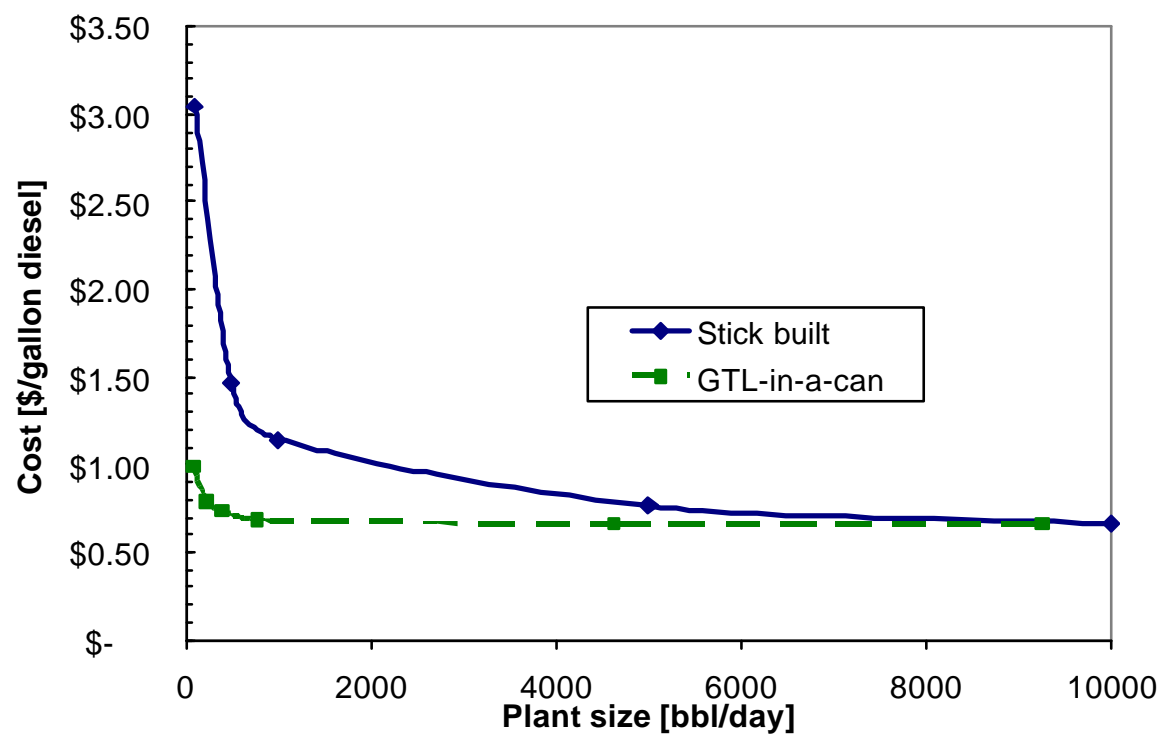

Syngas conversion (the Fischer-Tropsch process) is the most expensive contribution to the capital expense, as it was for the stick-built plant; however, we stress that direct cost comparisons of unit operations can not be made because of the differences in where certain costs were allocated.

Figure 17. Estimated economics of GTL-in-a-Can ${ }^{\mathrm{TM}}$ at a size of 10 million scf/day (750 bpd products).

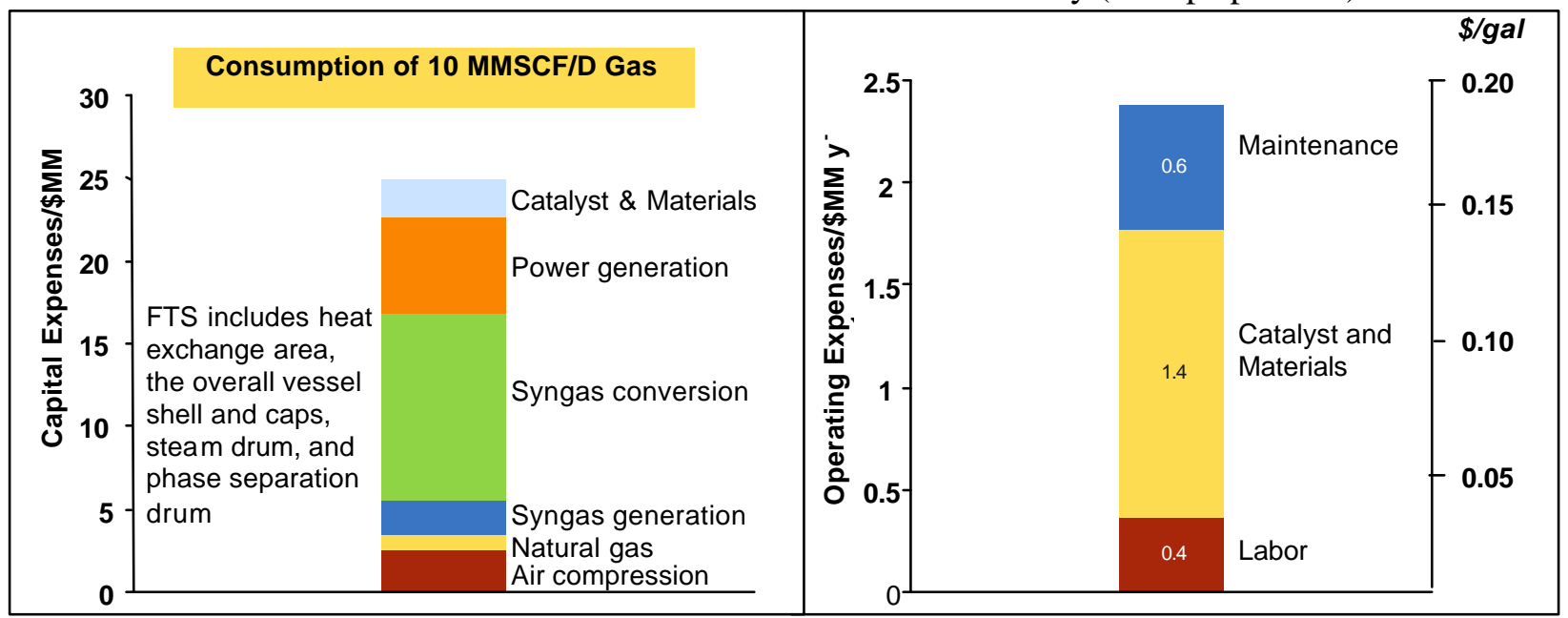

Because we are judging profitability of these plants for a 20-year lifetime where costs are not only inherently uncertain, but expected to change we ran a Monte Carlo simulation to asses the probability of net present values. This statistical analysis (Figure 18) shows that for a stick-built plant negative net present values are the most likely, whereas positive net present values have the greatest probability for GTL-in-a-can. The shape of the probability curve is most influenced by the expansive range of possible values for the price of a barrel of oil over the next 20 years. 
Figure 18. A Monte Carlo analysis of the NPV20 of the two $100 \mathrm{bbl} /$ day GTL technologies shows the statistical difference between the profitability.

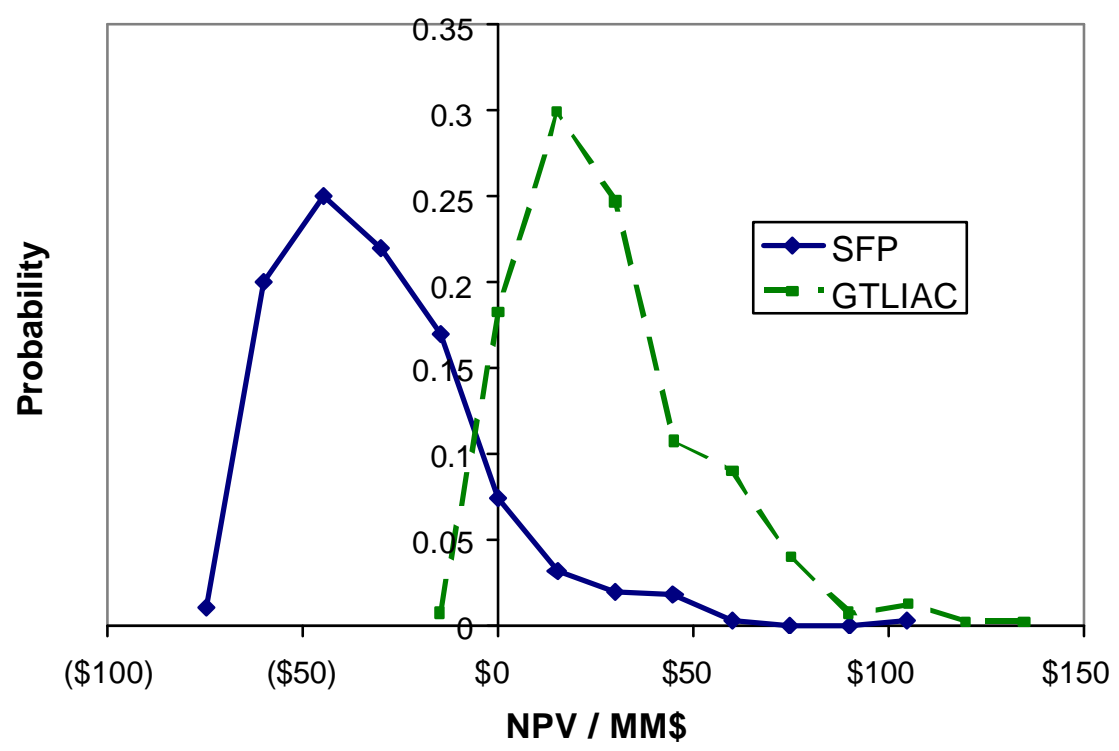

Looking at the CAPEX breakdown of the GTL-in-a-can plant (Figure 17) one of the biggest costs is power generation. However, this investment yields great returns (Figure 19). The incremental value of selling electricity is almost equal to the NPV of the plant without it. The additional cost of buying a larger turbine to not just supply the plant with electricity, but also to export it is easily recovered. There is, however, a discrepancy in the amount of fuel and electricity produced in light of demand. When generating enough electricity to meet a certain market demand, more fuel is produced (by several orders of magnitude) than is consumable by the same market.

This mismatch between fuel and electricity production can not be solved by exporting the fuel because of the costs associated with transportation. As is shown in Figure 20 the further a plant is sited from the rack, the more profitable it will be. The opposite is also true for the case of exporting fuel from a GTL process, where the further it must be exported the smaller the margin on the sale. And if it were economical to import the fuel, it would be done preferentially and thus obviate the need for GTL production. 
Figure 19. Effect of selling GTL-generated electricity at \$30/MWh

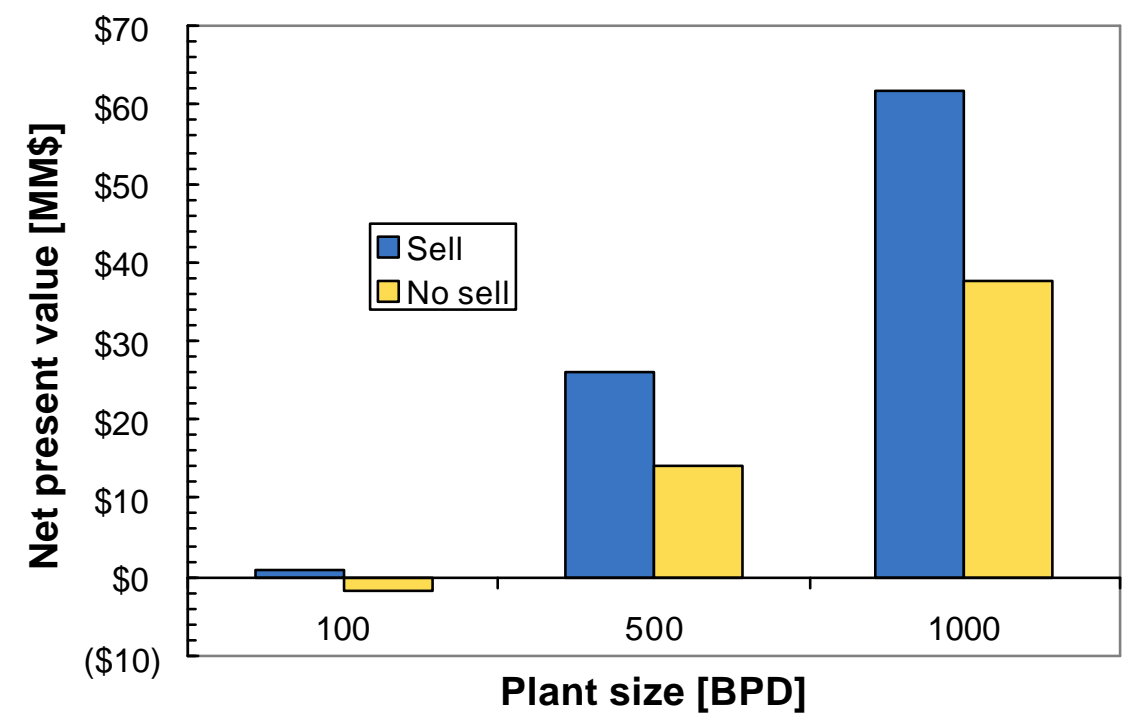

Figure 20. Location effects on the net present value of 20-year GTL-in-a-can operation

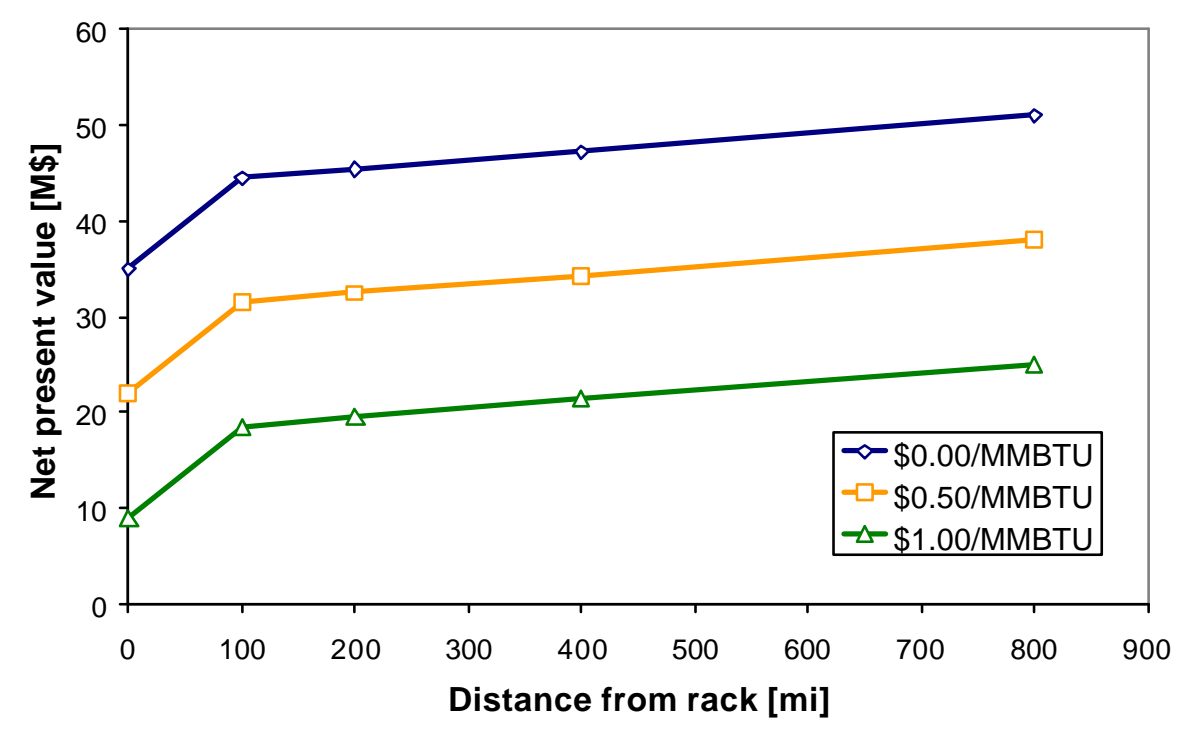




\section{Alaska}

There are substantial economic benefits to be gained by siting a plant in Alaska. A high number of small natural gas fields and available biomass facilitate the acquisition of raw materials. More importantly, Alaska's remote communities are forced to pay high prices for their fuel and electricity. The high prices are a direct result of distance. Transmission and transportation costs require the fuel and electricity prices to be sold at double the prices seen in the Lower 48 States. Small footprint GTL plants are thus an economic solution because they can be cited near communities and sell their products with much higher margins.

The following tables show the profitability metrics for GTL-in-a-can ${ }^{\mathrm{TM}}$ plants in two locations (Lower 48 States and Alaska) with two feedstocks (biomass and natural gas) and two feedstock costs (baseline and free). The option without electricity is always cheaper (CAPEX) than the option with electricity because it involves purchase of a larger turbine. This extra cost of the turbine adds to the cost of producing a gallon of diesel. The revenue from electricity is not included in this metric, but is included in the IRR and NPV.

The returns shown in the tables assume that naphtha, the other major product from the GTL process, can be sold at a price comparable to its historical mean. For remote plants, monetizing the naphtha will require shipping unless it can be burned locally as a fuel. Evidently, having to transport the naphtha would obviate one of the primary benefits envisaged for a small footprint plant, namely autonomy.

Table 9. Estimates of investments and returns from modular GTL plants located in the Lower 48 States as a function of feedstock (natural gas) price

\begin{tabular}{|r|cc|cc|cc|c|c|}
\hline \multirow{2}{*}{ \$1 / MMBTU } & \multicolumn{2}{|c|}{$\mathbf{1 0 0}$} & \multicolumn{2}{c|}{$\mathbf{6 0 0}$} & \multicolumn{2}{c|}{$\mathbf{6 0 0 0}$} & \multicolumn{1}{c|}{$\mathbf{1 9 0 0 0}$} \\
\cline { 2 - 10 } & w/ elec & w/o elec & w/ elec & w/o elec & w/ elec & w/o elec & w/ elec & w/o elec \\
\hline CAPEX [MM\$] & 9.2 & 8.5 & 29 & 26 & 158 & 136 & 385 & 327 \\
OPEX [MM\$] & 0.8 & 0.8 & 4.4 & 4.3 & 42 & 41 & 130 & 129 \\
Diesel [\$/gal] & 0.95 & 0.91 & 0.70 & 0.67 & 0.56 & 0.54 & 0.53 & 0.51 \\
IRR & $9 \%$ & $-6 \%$ & $24 \%$ & $5 \%$ & $54 \%$ & $16 \%$ & $81 \%$ & $23 \%$ \\
NPV20 [MM\$] & 2.1 & -5.7 & 38 & -2.3 & 505 & 93 & $\mathbf{1 7 0 2}$ & 386 \\
\hline
\end{tabular}

\begin{tabular}{|c|c|c|c|c|c|c|c|c|}
\hline \multirow{3}{*}{ \$O / MMBTU } & \multicolumn{8}{|c|}{ Plant size, bpd } \\
\hline & \multicolumn{2}{|c|}{100} & \multicolumn{2}{|c|}{600} & \multicolumn{2}{|c|}{6000} & \multicolumn{2}{|c|}{19000} \\
\hline & $\mathrm{w} /$ elec & w/o elec & w/ elec & w/o elec & $\mathrm{w} /$ elec & w/o elec & $\mathrm{w} / \mathrm{elec}$ & w/o elec \\
\hline CAPEX $[M M \$]$ & 9.2 & 8.5 & 29 & 26 & 158 & 136 & 385 & 327 \\
\hline OPEX $[M M \$]$ & 0.3 & 0.3 & 1.4 & 1.4 & 12 & 12 & 36 & 35 \\
\hline Diesel [\$/gal] & 0.52 & 0.48 & 0.26 & 0.23 & 0.13 & 0.11 & 0.09 & 0.08 \\
\hline IRR & 0.15 & 0.05 & $35 \%$ & $17 \%$ & $88 \%$ & $41 \%$ & $146 \%$ & $61 \%$ \\
\hline NPV20 [MM\$] & 6.0 & -0.7 & 62 & 21 & 738 & 326 & 2439 & 1123 \\
\hline Power gen. [MW] & 1.1 & & 6.6 & & 66 & & 208 & \\
\hline
\end{tabular}


Table 10. Estimates of investments and returns from modular GTL plants located in Alaska as a function of feedstock (natural gas) price

\begin{tabular}{|c|c|c|c|c|c|c|c|c|}
\hline & & & & & \multirow{2}{*}{\multicolumn{2}{|c|}{6000}} & & \\
\hline \multirow{2}{*}{$\$ 1 /$ MMBTU } & \multicolumn{2}{|c|}{100} & \multicolumn{2}{|c|}{600} & & & \multicolumn{2}{|c|}{19000} \\
\hline & $\mathrm{w} /$ elec & w/o elec & w/ elec & w/o elec & $\mathrm{w} /$ elec & $\mathrm{w} / \mathrm{o}$ elec & w/ elec & w/o elec \\
\hline CAPEX [MM\$] & 10.1 & 9.4 & 32 & 28 & 166 & 144 & 400 & 342 \\
\hline OPEX $[M M \$]$ & 0.8 & 0.8 & 4.4 & 4.4 & 42 & 41 & 130 & 129 \\
\hline Diesel [\$/gal] & 1.00 & 0.96 & 0.72 & 0.69 & 0.57 & 0.55 & 0.53 & 0.51 \\
\hline IRR & $13 \%$ & $3 \%$ & $32 \%$ & $15 \%$ & $80 \%$ & $37 \%$ & $132 \%$ & $56 \%$ \\
\hline NPV20 [MM\$] & 5.2 & -1.5 & 59 & 19 & 729 & 316 & 2418 & 1102 \\
\hline
\end{tabular}

\begin{tabular}{|c|c|c|c|c|c|c|c|c|}
\hline \multirow{3}{*}{ \$0 / MMBTU } & \multicolumn{8}{|c|}{ Plant size, bpd } \\
\hline & \multicolumn{2}{|c|}{100} & \multicolumn{2}{|c|}{600} & \multicolumn{2}{|c|}{6000} & \multicolumn{2}{|c|}{19000} \\
\hline & $\mathrm{w} /$ elec & w/o elec & w/ elec & $\mathrm{w} / \mathrm{o}$ elec & $\mathrm{w} / \mathrm{elec}$ & w/o elec & $\mathrm{w} / \mathrm{elec}$ & $\mathrm{w} / \mathrm{o}$ elec \\
\hline CAPEX [MM\$] & 10.1 & 9.4 & 32 & 28 & 166 & 144 & 400 & 342 \\
\hline OPEX $[M M \$]$ & 0.3 & 0.3 & 1.5 & 1.4 & 12 & 12 & 36 & 35 \\
\hline Diesel [\$/gal] & 0.57 & 0.53 & 0.28 & 0.25 & 0.14 & 0.12 & 0.10 & 0.08 \\
\hline IRR & $18 \%$ & $10 \%$ & $43 \%$ & $26 \%$ & $122 \%$ & $68 \%$ & $237 \%$ & $112 \%$ \\
\hline NPV20 [MM\$] & 9.1 & 2.5 & 83 & 42 & 961 & 549 & 3155 & 1839 \\
\hline Power gen [MW] & 11 & & 6.6 & & 66 & & 208 & \\
\hline
\end{tabular}

Table 11. Estimates of the investments and returns from modular GTL plants located in the Lower 48 States as a function of feedstock (biomass) price

\begin{tabular}{|r|cc|cc|cc|cc|}
\hline \multirow{2}{*}{ \$20/ton } & \multicolumn{2}{|c|}{$\mathbf{1 0 0}$} & \multicolumn{2}{c|}{$\mathbf{6 0 0}$} & \multicolumn{2}{c|}{$\mathbf{6 0 0 0}$} & \multicolumn{2}{c|}{$\mathbf{1 9 0 0 0}$} \\
\cline { 2 - 11 } & w/ elec & w/o elec & w/ elec & w/o elec & w/ elec & w/o elec & w/ elec & w/o elec \\
\hline CAPEX [MM\$] & 74 & 74 & 292 & 289 & 1731 & 1709 & 4259 & 4201 \\
OPEX [MM\$] & 2.2 & 2.1 & 10.2 & 10.2 & 81.6 & 81.2 & 238 & 237 \\
Diesel [\$/gal] & 4.99 & 4.98 & 3.47 & 3.44 & 2.30 & 2.28 & 1.92 & 1.90 \\
IRR & - & - & - & - & $-12 \%$ & - & $-\mathbf{8} \%$ & - \\
NPV20 [MM\$] & -79 & -85 & -283 & -323 & -1413 & -1818 & $-\mathbf{3 0 2 4}$ & $-\mathbf{4 3 2 1}$ \\
\hline
\end{tabular}

\begin{tabular}{|c|c|c|c|c|c|c|c|c|}
\hline \multirow{3}{*}{$\$ 0 /$ ton } & \multicolumn{8}{|c|}{ Plant size, bpd } \\
\hline & \multicolumn{2}{|c|}{100} & \multicolumn{2}{|c|}{600} & \multicolumn{2}{|c|}{6000} & \multicolumn{2}{|c|}{19000} \\
\hline & w/ elec & w/o elec & $\mathrm{w} / \mathrm{elec}$ & w/o elec & $\mathrm{w} /$ elec & $\mathrm{w} / \mathrm{o}$ elec & w/ elec & w/o elec \\
\hline CAPEX [MM\$] & 74.3 & 74.2 & 292 & 289 & 1731 & 1709 & 4259 & 4201 \\
\hline OPEX $[M M \$]$ & 1.4 & 1.4 & $\begin{array}{l}5.9 \\
2.85\end{array}$ & 5.9 & 39 & $\begin{array}{c}39 \\
165\end{array}$ & 102 & 101 \\
\hline 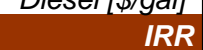 & 4.07 & 4.05 & 2.05 & C.oc & $-3 \%$ & 1.00 & $0 \%$ & 1.टO \\
\hline NPV20 [MM\$1 & -71 & -78 & -237 & -277 & -954 & -1359 & -1570 & -2867 \\
\hline
\end{tabular}

$\begin{array}{lllll}\text { Power gen. }[M W] & 0.7 & 4.2 & 42 & 133\end{array}$ 
Table 12. Estimates of the investments and returns from modular GTL plants located in the Alaska as a function of feedstock (biomass) price

\begin{tabular}{|r|cc|cc|cc|cc|}
\hline \multirow{2}{*}{ \$20/ton } & \multicolumn{2}{|c|}{$\mathbf{1 0 0}$} & \multicolumn{2}{c|}{$\mathbf{6 0 0}$} & \multicolumn{2}{c|}{$\mathbf{6 0 0 0}$} & \multicolumn{1}{c|}{$\mathbf{1 9 0 0 0}$} \\
\cline { 2 - 11 } & w/ elec & w/o elec & w/ elec & w/o elec & w/ elec & w/o elec & w/ elec & w/o elec \\
\hline CAPEX [MM\$] & 75.8 & 75.2 & 295 & 292 & 1739 & 1717 & 4274 & 4215 \\
OPEX [MM\$] & 2.2 & 2.2 & 10.3 & 10.2 & 82 & 81 & 238 & 237 \\
Diesel [\$/gal] & 5.07 & 5.03 & 3.50 & 3.47 & 2.31 & 2.29 & 1.93 & 1.91 \\
\hline IRR & $-7 \%$ & - & $-1 \%$ & - & $6 \%$ & $-14 \%$ & $\mathbf{1 0} \%$ & $-10 \%$ \\
NPV20 [MM\$] & -53 & -81 & -122 & -291 & $\mathbf{4}$ & $-\mathbf{- 1 4 8 2}$ & $\mathbf{1 1 0 9}$ & $-\mathbf{3 2 4 5}$ \\
\hline
\end{tabular}

\begin{tabular}{|c|c|c|c|c|c|c|c|c|}
\hline \multirow{3}{*}{ \$0/ton } & \multicolumn{8}{|c|}{ Plant size, bpd } \\
\hline & \multicolumn{2}{|c|}{100} & \multicolumn{2}{|c|}{600} & \multicolumn{2}{|c|}{6000} & \multicolumn{2}{|c|}{19000} \\
\hline & $\mathrm{w} /$ elec & w/o elec & $\mathrm{w} /$ elec & w/o elec & $\mathrm{w} /$ elec & $\mathrm{w} / \mathrm{o}$ elec & $\mathrm{w} /$ elec & $\mathrm{w} / \mathrm{o}$ elec \\
\hline CAPEX [MM\$] & 75.8 & 75.2 & 295 & 292 & 1739 & 1717 & 4274 & 4215 \\
\hline OPEX $[M M \$]$ & 1.5 & 1.4 & 6.0 & 5.9 & 39.1 & 38.7 & 103 & 102 \\
\hline Diesel [\$/gal] & 4.45 & 4.41 & 2.87 & 2.84 & 1.68 & 1.66 & 1.30 & 1.28 \\
\hline $\begin{array}{r}\text { IRR } \\
\text { NPVOR }\end{array}$ & $-4 \%$ & -73 & $\begin{array}{l}2 \% \\
-8 ?\end{array}$ & $-12 \%$ & $\begin{array}{l}9 \% \\
308\end{array}$ & $\begin{array}{l}-4 \% \\
-102 ?\end{array}$ & $13 \%$ & $\begin{array}{l}-1 \% \\
-1701\end{array}$ \\
\hline NPV20 [MM\$] & -45 & -73 & -82 & -245 & 308 & -1023 & 2056 & -1791 \\
\hline Power gen. $[M W]$ & 0.7 & & 4.2 & & 42 & & 133 & \\
\hline
\end{tabular}

The biomass option in these tables is based on a published estimates for the costs of constructing stickbuilt biomass gasifiers [14-16]. If gasification proved to be a popular option then the front end equipment would be designed for manufacture, much as we envisage for GTL-in-a-Can ${ }^{\mathrm{TM}}$. In that case, the cost of the gasifier might fall as much as $50 \%$, leading to very significant improvements in the overall economics. For example, we estimate that the net present value of a 600 bpd plant with a $50 \%$ cheaper gasifier increases from a loss of $\$ 82$ million to a profit of about $\$ 40$ million. Evidently, this option should be explored in more detail.

\section{Well-to-Wheels Analysis}

By combining published studies on the emissions benefits from using ultraclean GTL-derived fuels and our previous work on future powertrains, we haveconstructed well-to-wheels comparisons of the emissions and fuel economy for vehicles fueled with Fischer-Tropsch diesel and conventional diesel. The tank-to-wheels fuel economies of the two fuels are similar (differing primarily because of the slightly different specific and volumetric heating values) and we ignored the difference. There is a consensus that older style engines (pre2004) fueled with Fischer-Tropsch desel emit significantly less particulate matter and nitrogen oxides (we assumed 9\% less NOx and 32\% less PM). On the contrary, the compression-ignition powertrains that will be produced starting in 2007 will derive much less benefit from special fuels. Indeed, there are preliminary indications that the use of high cetane fuels in engines whose duty cycle includes homogeneous charge compression ignition may increase NOx emissions. Therefore, to make our analysis conservatively realistic we assumed that the benefits of FTD accrued only to the fraction of the 2015 fleets containing pre-2007 model year vehicles. The vehicles we chose, a light duty pickup truck, an urban bus and a utility vehicle (refuse truck) were consistent with the idea that GTL-derived fuels from small footprint plants would be used in the immediate vicinity of the plant. For that reason, we did not include any long haul trucks. 
Figure 21. Age distribution of compression ignition-powered vehicles projected to 2015 (the three graphs are for pickups, buses and refuse haulers, from left to right)
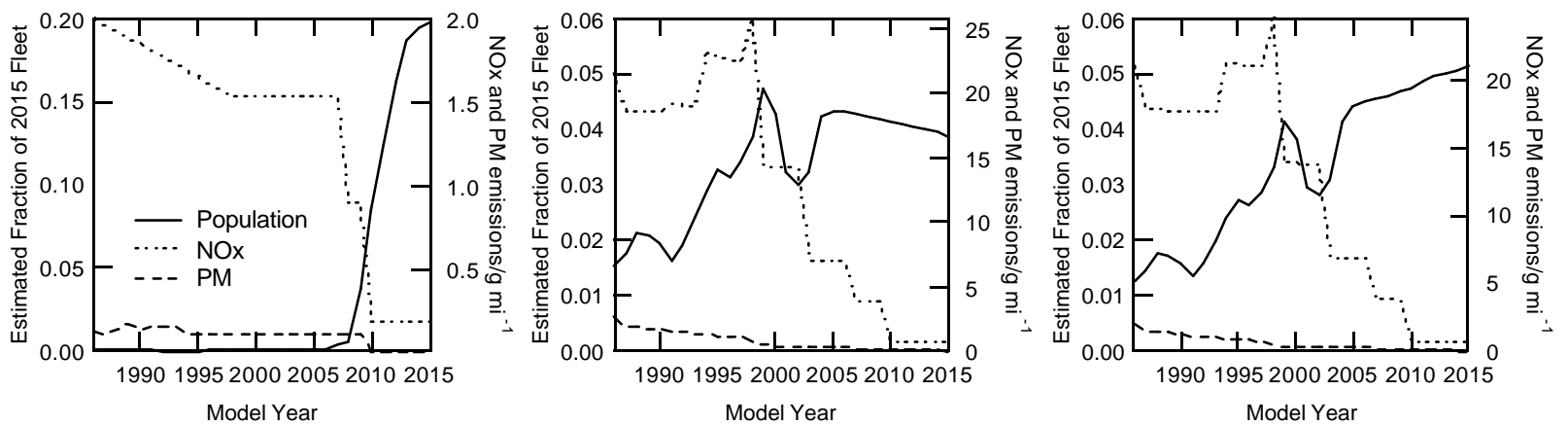

Three types of emissions were estimated: nitrogen oxides (NOx), particulate matter (PM) and carbon dioxide (Table 13). Because of the very long life and slow turnover of heavy duty vehicles, the older vehicles comprised almost $80 \%$ of those fleets (Figure 21). Because there are so few light duty diesel vehicles in the current fleet, the benefits of using GTL-derived fuels are projected to be very small in this category. Significant savings in NOx and PM were projected for the two heavier vehicles. Since the GTL process consumes a much larger portion of the feedstock for just the operation of the plant than does a conventional refinery $(60 \%$ in our model versus about $20 \%$ for a refinery), there is a significantly larger $\mathrm{CO}_{2}$ burden for using GTL compared to that of using petroleum-derived diesel fuel. However, biomass-derived GTL fuels can, in principle, exhibit net zero $\mathrm{CO}_{2}$ emissions.

Table 13. Emissions benefits of using FTD in vehicle fleets projected to 2015. Emissions that can be attributed to a fleet of each vehicle type whose size could be fueled the capacity of the indicated small footprint plant. Carbon dioxide emissions for the plant

\begin{tabular}{|l|c|r|r|r|r|r|}
\cline { 3 - 7 } \multicolumn{1}{c|}{} & \multicolumn{1}{c|}{$\Delta$ NOx (kg) } & \multicolumn{1}{c|}{$\Delta$ PM (kg) } & \multicolumn{2}{|c|}{$\Delta$ CO2 (kg) } \\
\cline { 2 - 7 } \multicolumn{1}{c|}{} & Vehicle Type & Fleet Size & (DF2 - FTD) & (DF2 - FTD) & (DF2 - FTD(NG)) & (DF2 - FTD(Biomass) \\
\hline & Pick-up & 1.698 & 87 & 41 & $(608,550)$ & 605,764 \\
\cline { 2 - 7 } & Bus & 136 & 10,608 & 1,426 & $(7,763,592)$ & $12,596,586$ \\
\cline { 2 - 7 } & Refuse & 157 & 7,512 & 717 & $(7,193,835)$ & $10,215,889$ \\
\hline \multirow{3}{*}{600 BPD FTD } & Pick-up & 10,189 & 525 & 246 & $(3,651,301)$ & $3,634,584$ \\
\cline { 2 - 7 } & Bus & 818 & 63,647 & 8,553 & $(46,581,551)$ & $75,579,514$ \\
\cline { 2 - 7 } & Refuse & 942 & 45,074 & 4,301 & $(43,163,008)$ & $61,295,337$ \\
\hline \multirow{3}{*}{6000 BPD FTD } & Pick-up & 101,886 & 5,245 & 2,460 & $(36,513,011)$ & $36,345,836$ \\
\cline { 2 - 7 } & Bus & 8,176 & 636,474 & 85,534 & $(465,815,510)$ & $755,795,140$ \\
\cline { 2 - 7 } & Refuse & 9,419 & 450,738 & 43,008 & $(431,630,076)$ & $612,953,369$ \\
\hline
\end{tabular}


Figure 22. Effect on NOx emissions of fueling various fleets in 2015 with DF2 ar FTD

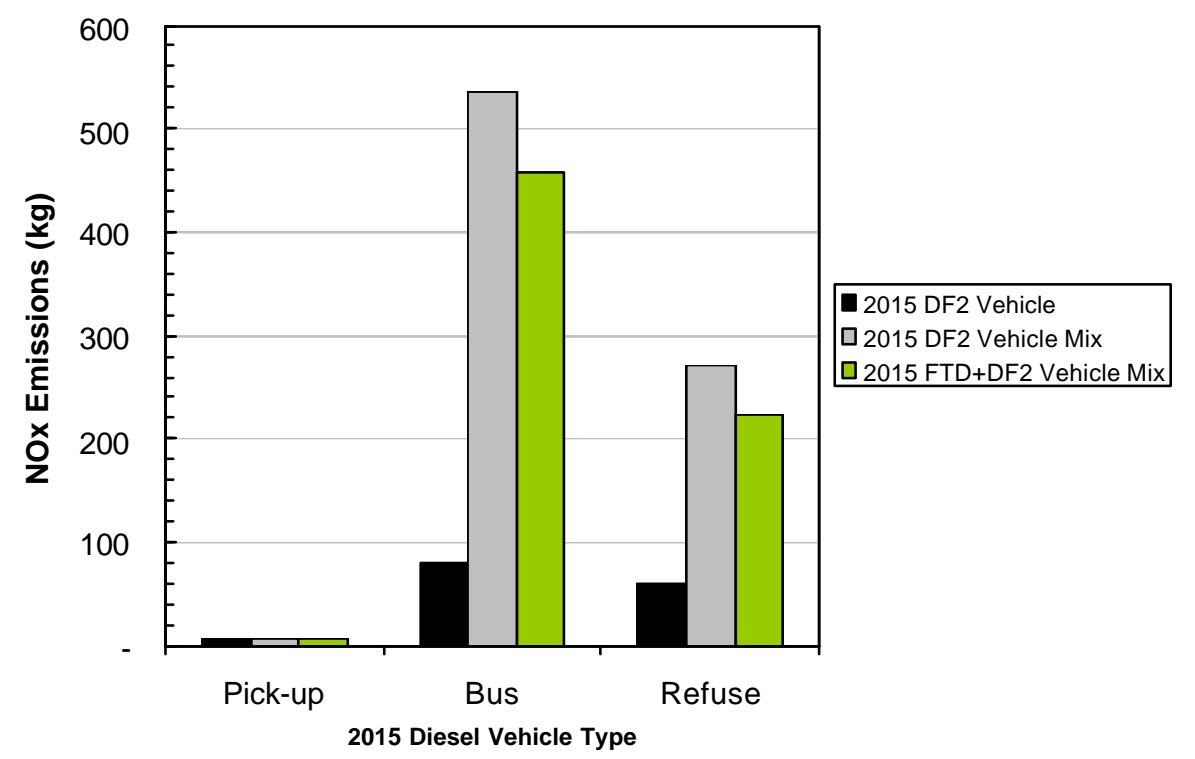

Figure 23. Effect on PM emissions of fueling various fleets in 2015 with DF2 or FTD

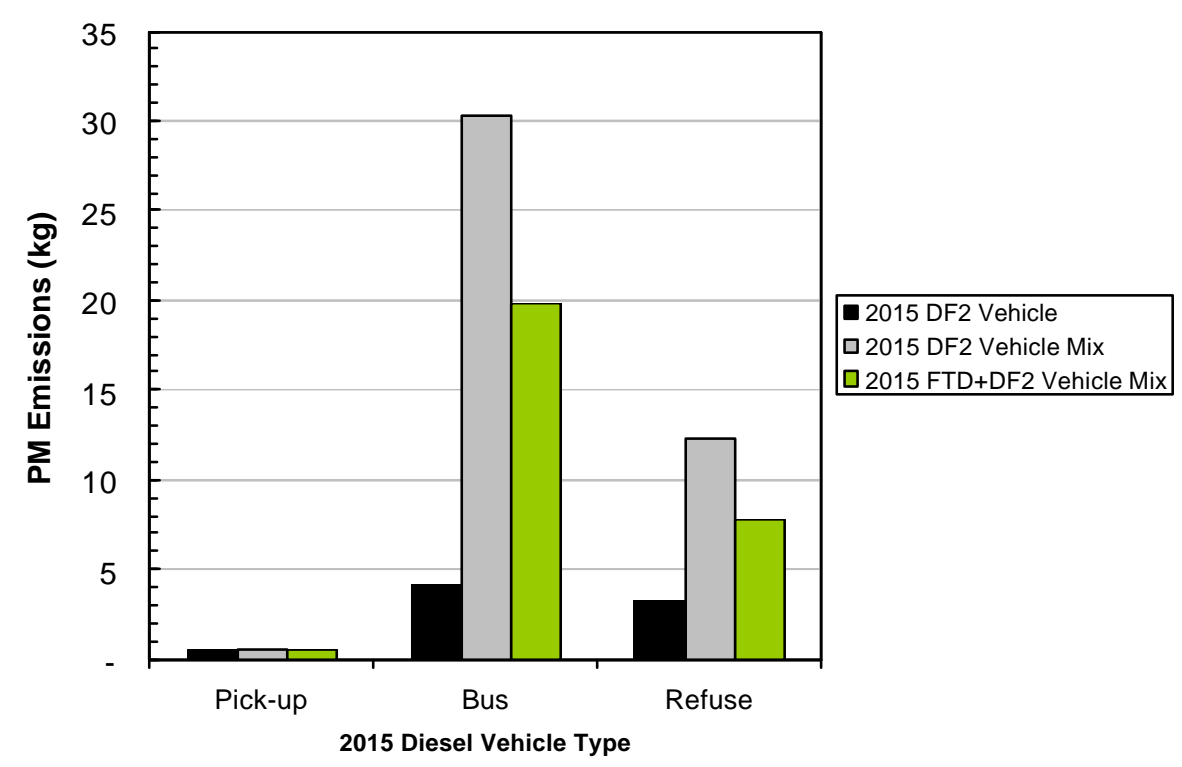


Figure 24. Effect on $\mathrm{CO}_{2}$ emissions of fueling various fleets with DF2 and FTD derived from two different feedstocks, natural gas and biomass

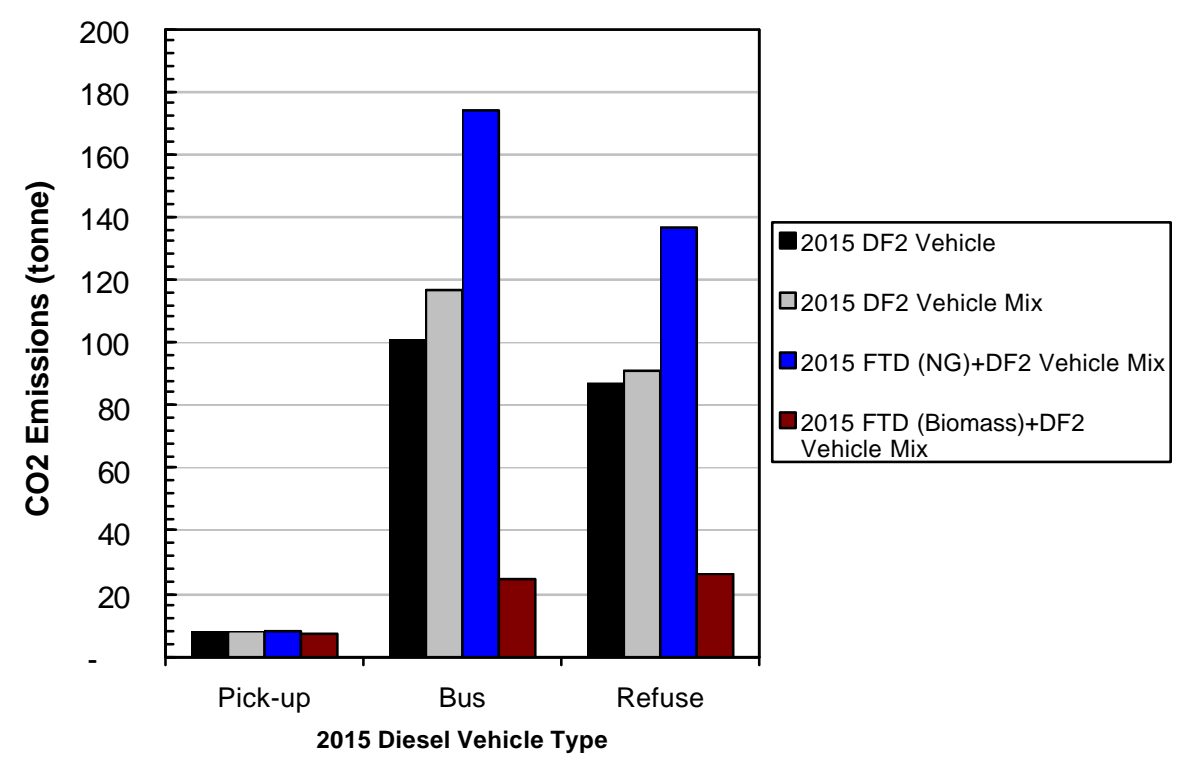

Finally, by combining the net present value (20-year) of the modular GTL plants with the emission benefits, we estimated the cost of emissions abatement from the projected use of these cleaner fuels (Tables 46). Since many scenarios of the GTL plants provide positive net present values, negative costs in the tables below signify that the plant is "getting paid" for the emission reduction. That pleasant circumstance only pertains to the fueling of the heavier vehicles. For reference we include a table that shows the present-day estimates of the costs of abating NOx and PM (Table 23).

Thus, the total package of benefits—energy security, energy supply for remote locations and cost-effective (or, profitable) emissions reductions - support the continued development of small footprint GTL plants and the extension of the technology towards biomass feedstocks.

Table 14. Estimated cost per ton for abating NOx using FTD in a 2015 population of light vehicles

\begin{tabular}{|l|cc|cc|cc|cc|}
\hline \multicolumn{10}{|c|}{ Pickup NOx, M\$/t } & \multicolumn{2}{|c|}{100} & \multicolumn{3}{c|}{600} & \multicolumn{2}{c|}{6000} & \multicolumn{2}{c|}{19000} \\
\hline Electricity option & w/ elec & w/o elec & w/ elec & w/o elec & w/ elec & w/o elec & w/ elec & w/o elec \\
\hline 48 NG & -1 & 3 & -4 & 0 & -5 & -1 & -5 & -1 \\
Alaska NG & -3 & 1 & -6 & -2 & -7 & -3 & -7 & -3 \\
48 Biomass & 45 & 49 & 27 & 31 & 13 & 17 & 9 & 13 \\
Alaska biomass & 30 & 46 & 12 & 28 & 0 & 14 & -3 & 10 \\
\hline
\end{tabular}

Table 15. Estimated cost per ton for abating NOx using FTD in a 2015 population of urban buses

\begin{tabular}{|l|cc|cc|cc|cc|}
\hline Bus NOx k\$/t & \multicolumn{2}{|c|}{100} & \multicolumn{2}{c|}{600} & \multicolumn{2}{c|}{6000} & \multicolumn{2}{c|}{19000} \\
\hline Electricity option & w/ elec & w/o elec & w/ elec & w/o elec & w/ elec & w/o elec & w/ elec & w/o elec \\
\hline 48 NG & -10 & 27 & -30 & 2 & -40 & -7 & -42 & -10 \\
Alaska NG & -24 & 7 & -47 & -15 & -57 & -25 & -60 & -27 \\
48 Biomass & 372 & 402 & 222 & 253 & 111 & 143 & 75 & 107 \\
Alaska biomass & 248 & 380 & 95 & 228 & 0 & 116 & -28 & 81 \\
\hline
\end{tabular}


Table 16. Estimated cost per ton for abating NOx using FTD in a 2015 population of utility vehicles

\begin{tabular}{|l|cc|cc|cc|cc|}
\hline Utility NOx, $\mathrm{k} \$ / \mathrm{t}$ & \multicolumn{2}{|c|}{100} & \multicolumn{2}{c|}{600} & \multicolumn{2}{c|}{6000} & \multicolumn{2}{c|}{19000} \\
\hline Electricity option & w/ elec & w/o elec & w/ elec & w/o elec & w/ elec & w/o elec & w/ elec & w/o elec \\
\hline 48 NG & -14 & 38 & -43 & 3 & -56 & -10 & -60 & -14 \\
Alaska NG & -34 & 10 & -66 & -21 & -81 & -35 & -85 & -39 \\
48 Biomass & 526 & 568 & 314 & 358 & 157 & 202 & 106 & 151 \\
Alaska Biomass & 350 & 537 & 135 & 322 & 0 & 164 & -39 & 114 \\
\hline
\end{tabular}

Table 17. Estimated cost per ton for abating PM using FTD in a 2015 population of light vehicles

\begin{tabular}{|l|cc|ccc|cc|cc|}
\hline Pickup PM, M\$/t & \multicolumn{2}{|c|}{100} & \multicolumn{3}{c|}{600} & \multicolumn{2}{c|}{6000} & \multicolumn{2}{c|}{19000} \\
\hline Electricity option & w/ elec & w/o elec & w/ elec & w/o elec & w/ elec & w/o elec & w/ elec & w/o elec \\
\hline 48 NG & -3 & 7 & -8 & 0 & -10 & -2 & -11 & -2 \\
Alaska NG & -6 & 2 & -12 & -4 & -15 & -6 & -16 & -7 \\
48 Biomass & 96 & 104 & 58 & 66 & 29 & 37 & 19 & 28 \\
Alaska biomass & 64 & 98 & 25 & 59 & 0 & 30 & -7 & 21 \\
\hline
\end{tabular}

Table 18. Estimated cost per ton for abating PM using FTD in a 2015 population of urban buses

\begin{tabular}{|l|cc|cc|ccc|cc|}
\hline Bus PM, $\mathrm{k}$ /t & \multicolumn{2}{|c|}{100} & \multicolumn{3}{c|}{600} & \multicolumn{2}{c|}{6000} & \multicolumn{2}{c|}{19000} \\
\hline Electricity option & w/ elec & w/o elec & w/ elec & w/o elec & w/ elec & w/o elec & w/ elec & w/o elec \\
\hline 48 NG & -75 & 201 & -224 & 14 & -295 & -54 & -314 & -71 \\
Alaska NG & -182 & 54 & -347 & -110 & -426 & -185 & -446 & -203 \\
48 Biomass & 2770 & 2994 & 1654 & 1885 & 826 & 1063 & 558 & 798 \\
Alaska biomass & 1847 & 2830 & 710 & 1699 & -2 & 866 & -205 & 599 \\
\hline
\end{tabular}

Table 19. Estimated cost per ton for abating PM using biomass-derived FTD in a 2015 population of utility vehicles

\begin{tabular}{|l|cc|cc|cc|cc|}
\hline \multicolumn{10}{|c|}{ Utility PM, k\$/t } & \multicolumn{2}{|c|}{100} & \multicolumn{3}{c|}{600} & \multicolumn{2}{c|}{6000} & \multicolumn{2}{c|}{19000} \\
\hline Electricity option & w/ elec & w/o elec & w/ elec & w/o elec & w/ elec & w/o elec & w/ elec & w/o elec \\
\hline 48 NG & -149 & 400 & -446 & 27 & -588 & -108 & -625 & -142 \\
Alaska NG & -361 & 108 & -691 & -219 & -847 & -368 & -888 & -405 \\
48 Biomass & 5509 & 5955 & 3290 & 3749 & 1643 & 2114 & 1110 & 1586 \\
Alaska Biomass & 3673 & 5628 & 1413 & 3380 & -5 & 1723 & -407 & 1191 \\
\hline
\end{tabular}

Table 20. Estimated cost per ton for abating $\mathrm{CO}_{2}$ using biomass-derived FTD in a 2015 population of light vehicles

\begin{tabular}{|l|cc|cc|cc|cc|}
\hline Pickup $\mathrm{CO}_{2}, \$ / t$ & \multicolumn{2}{|c|}{100} & \multicolumn{2}{c|}{600} & \multicolumn{2}{c|}{6000} & \multicolumn{2}{c|}{19000} \\
\hline Electricity option & w/ elec & w/o elec & w/ elec & w/o elec & w/ elec & w/o elec & w/ elec & w/o elec \\
\hline 48 NG & & & & & & & & \\
Alaska NG & & & & & & & & \\
48 Biomass & 6518 & 7046 & 3893 & 4437 & 1944 & 2501 & 1314 & 1877 \\
Alaska biomass & 4347 & 6659 & 1671 & 3999 & -6 & 2039 & -482 & 1410 \\
\hline
\end{tabular}


Table 21. Estimated cost per ton for abating $\mathrm{CO}_{2}$ using biomass-derived FTD in a 2015 population of urban buses

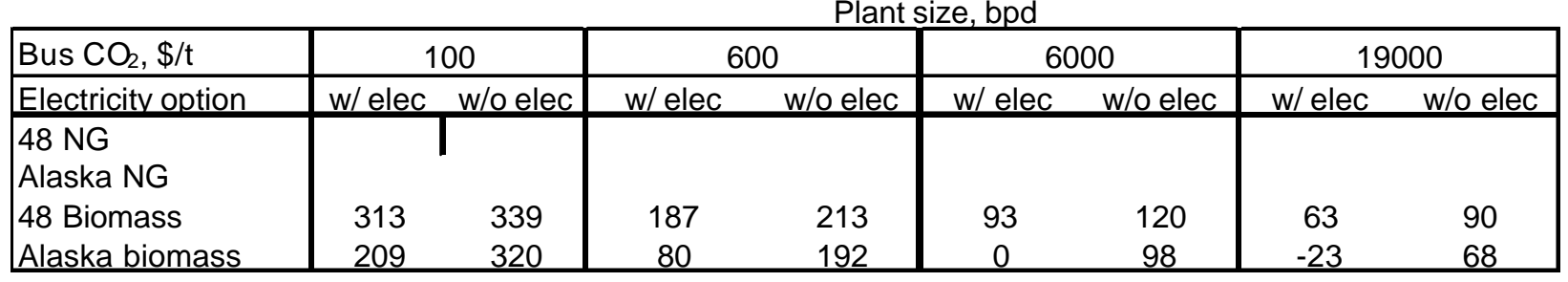

Table 22. Estimated cost per ton for abating $\mathrm{CO}_{2}$ using biomass-derived FTD in a 2015 population of utility vehicles

\begin{tabular}{|c|c|c|c|c|c|c|c|c|}
\hline & \multicolumn{8}{|c|}{ Plant size, bpd } \\
\hline Utility $\mathrm{CO}_{2}, \$ / \mathrm{t}$ & \multicolumn{2}{|c|}{100} & \multicolumn{2}{|c|}{600} & \multicolumn{2}{|c|}{6000} & \multicolumn{2}{|c|}{19000} \\
\hline Electricity option & $\mathrm{w} / \mathrm{ele}$ & w/o elec & $\mathrm{w} / \mathrm{elec}$ & w/o elec & $\mathrm{w} / \mathrm{ele}$ & N/o elec & $\mathrm{w} /$ elec & $\mathrm{w} / \mathrm{o}$ elec \\
\hline $\begin{array}{l}48 \mathrm{NG} \\
\text { Alaska NG } \\
48 \text { Biomass } \\
\text { Alaska Biomass }\end{array}$ & $\begin{array}{l}387 \\
258\end{array}$ & $\begin{array}{l}418 \\
395\end{array}$ & $\begin{array}{r}231 \\
99\end{array}$ & $\begin{array}{l}263 \\
237\end{array}$ & $\begin{array}{c}115 \\
0\end{array}$ & $\begin{array}{l}148 \\
121\end{array}$ & $\begin{array}{r}78 \\
-29\end{array}$ & $\begin{array}{c}111 \\
84\end{array}$ \\
\hline
\end{tabular}

Table 23. Comparison of the cost effectiveness of various approaches to emission abatement

\begin{tabular}{|l|c|l|}
\hline Species & $\begin{array}{c}\text { Abatement } \\
\text { Credit or Cost } \\
\$ / \mathrm{t}\end{array}$ & Comment \\
\hline NOx & 14000 & $\begin{array}{l}\text { Typical value for California's Moyers Program, TIAX estimate } \\
\text { 2007 SIP trading credit, www.evomarkets.com } \\
\text { Lifecycle cost of a 2007 particulate filter divided by total } \\
\text { vehicle pm production, TIAX estimate } \\
\text { EM }\end{array}$ \\
2550 & 5400 & $\begin{array}{l}\text { Estimated costs of } \mathrm{CO}_{2} \text { sequestration, } \\
\text { sequestration.mit.edu/pdf/David_and_Herzog.pdf }\end{array}$ \\
$\mathrm{CO}_{2}$ & $18-41$ &
\end{tabular}

We present below two graphs (Figure 25, Figure 26) that indicate our best estimates of the $\mathrm{CO}_{2}$ emissions from producing and consuming conventional and Fischer-Tropsch dieselfuel. In both cases the tank-to-wheels bars are approximately the same heights since both fuels contain nearly the same energy content. The energy employed, and hence $\mathrm{CO}_{2}$ emissions, from transporting the fuels and from abating emissions are very small (1$2 \%$ of the total) and depend strongly on the actual duty cycle. The largest difference between the two panels is the $\mathrm{CO}_{2}$ emissions associated with producing the two fuels. 
Figure 25. Estimates of well-to-wheels emissions of $\mathrm{CO}_{2}$ associated with the use of conventional diesel fuel. Well-to-Tank emissions have been derived from EIA estimates.

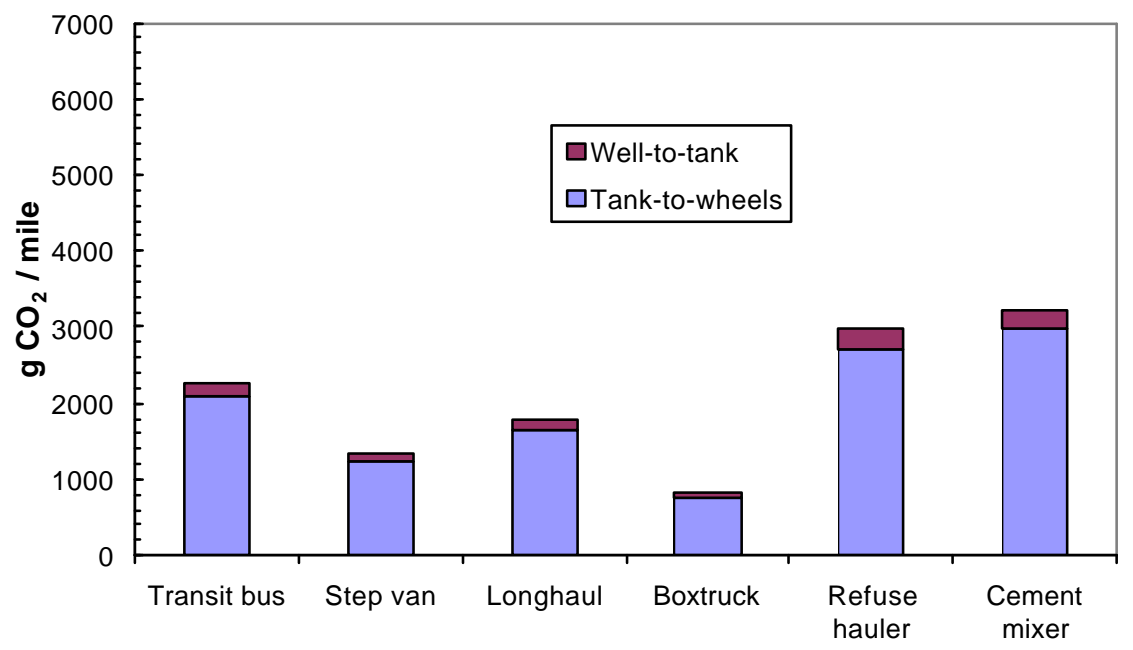

Figure 26. Estimate of well-to-wheels emissions of $\mathrm{CO}_{2}$ associated with the use of conventional diesel fuel. Well-to-Tank emissions have been derived from our assumptions regarding the energy conversion efficiency of the GTL process.

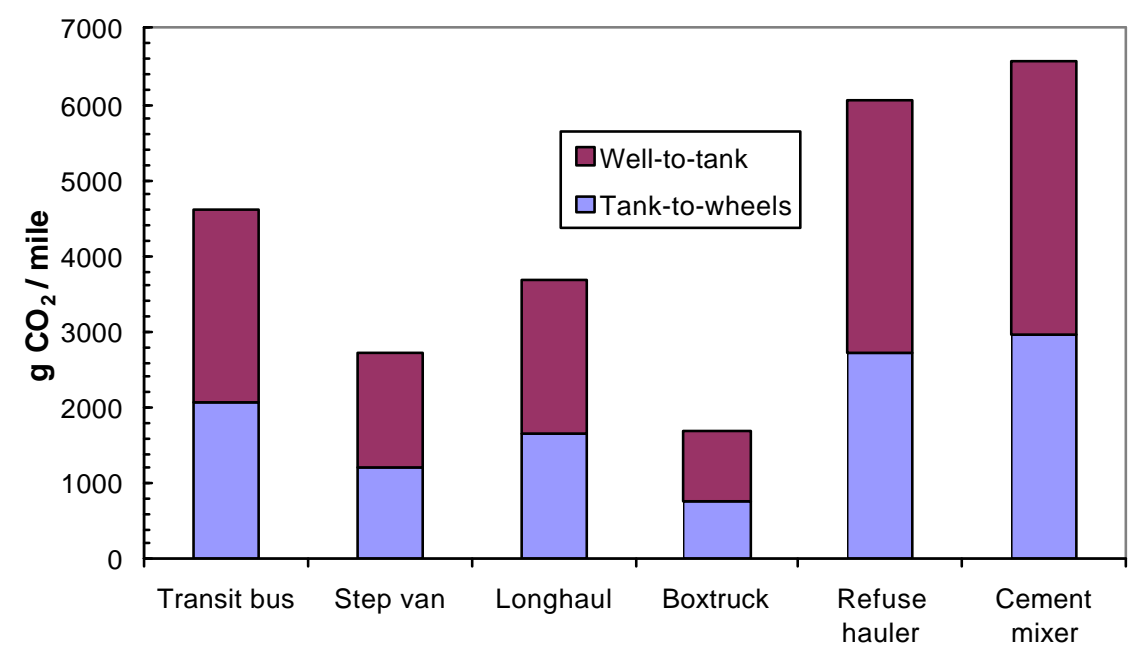


Figure 27. Comparison of our estimates of well-to-wheels emissions of $\mathrm{CO}_{2}$ associated with the use of conventional diesel and GTL fuel. Consistent with our assumptions on the source of the natural gas (small reservoirs) we have assumed that the GTL fuel comprises $1 \%$ of the total fuel used in the US.

The $\mathrm{CO}_{2}$ emissions effect of fueling $1 \%$ of the U.S. heavy duty fleet with FTD

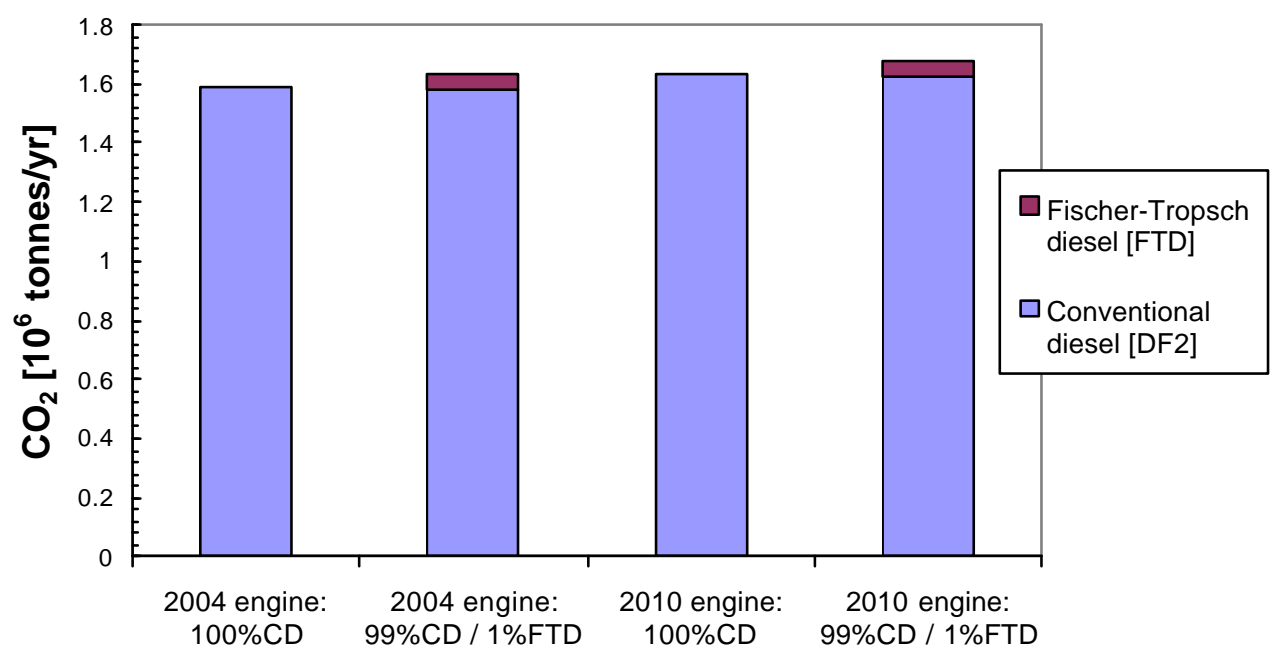

We have estimated the consequences for the fleet of using GTL fuel at a rate of $1 \%$ of the annual US consumption, which is consistent with both the amount of fuel that might be produced by a battery of small footprint plants and with amount of gas contained in the accessible and economically viable resources in the lower 48 states. The additional $\mathrm{CO}_{2}$ burden would then be quite small, roughly $0.5 \%$ of the national emissions associated with heavy duty transportation and roughly equal to the fuel economy penalties mandated by regulations that commence in full force in 2010.

\section{CONCLUSION}

The picture that emerges is that there are resources and conditions under which a SFP can be operated profitably. In particular, high cost of oil, long distances from conventional sources and underutilized resources all contribute to the economic viability of the plant. The addition of credits for electricity, steam, water and, in some instances, criteria pollutants, only serve to improve the economic outlook. However, achieving autonomy and profitability require matching the scale of the SFP to local needs and dealing with all of the side products, including naphtha.

We have identified particular resources to reflect the more accurate economics for constructing and operating small footprint plants. Evidently, the conditions favorable to the economic viability of SFPs prevail in Alaska and it will be interesting to refine the parameters for specific resources and markets there.

A well-to-wheels analysis to estimate the overall economic and environmental impact of the production and use of SFP-produced fuels suggests that the primary benefits of employing GTL fuels derive from both the energy security they confer and the emissions reductions from older vehicles. Emissions benefits from newer vehicles (post 2010) will require tuning of the engines to extract maximum effect and therefore this benefit of GTL fuels from small footprint plants has about a 10-15 year window of opportunity (commissioning of the first plants, assumed to be in 2015, until the pre-2010 vehicles have been retired).

We note that modularization of a small footprint plant increases its appeal for both civilian and military applications. 


\section{REFERENCES}

1. Thomas, J.M. and W.J. Thomas, Principles and Practice of Heterogeneous Catalysis. 1996, New York: VCH. $524 \mathrm{ff}$.

2. Laboratory, O.R.N., Bioenergy Conversion Factors.

3. Analysis, E.a.E., GASIS Gas Information System. 1999, US Department of Energy.

4. Law, B.E. and J.B. J.B. Curtis, Introduction to unconventional petroleum systems. American Association of Petroleum Geologists Bulletin, 2002. 86(11): p. 1851-1852.

5. $\quad$ Arthur D. Little, I., Gas to Liquids Technology: Gauging its Competitive Potential. 1998.

6. Peters, M.S. and K.D. Timmerhaus, Plant design and economics for chemical engineers. 1980, New York: McGraw-Hill.

7. $\quad$ LLC, G.I.a.T., The future of heavy duty powertrains. 2004.

8. Knottenbelt, C., Mossgas "gas to liquid" diesel fuels--an environmentally friendly option. Catal. Today, 2002. 71: p. 437-445.

9. Alleman, T.L. and R.L. McCormick, Fischer-Tropsch diesel Fuels - Properties and Exhaust Emissions: a Literature Review. SAE 2003-01-0763, 2003.

10. Ryan, T.W. and D.A. Montalvo. Emissions Performance of Fischer-Tropsch diesel Fuels. in AIChE Spring Meeting. 1997. Houston, TX.

11. Turcotte, D.L., Fractals and chaos in geology and geophyscis. 1997, Cambridge: University of Cambridge Press.

12. USGS, Arctic National Wildlife Refuge, 1002 Area, Petroleum Assessment, 1998, Including Economic Analysis. 2001.

13. Ross, C. 2004.

14. Simbeck, D. and E. Chang, NREL Report SR-540-32525, Hydrogen Supply: Cost Estimate for Hydrogen Pathways - Scoping Analysis. 2002, SFA Pacific.

15. Tiangco, V., Feedstock- Economic Evaluation for Energy Crops, Urban Wood Waste, Forest Slash, Rice Straw, Orchard Prunings, Pits, and Shells. 1995, California Energy Commission.

16. Perez, P., Costs and Benefits of a Biomass-to-Ethanol Production Industry in California. 2001, California Energy Commission P500-01-002A. 


\section{LIST OF ACRONYMS AND ABBREVIATIONS}

\begin{tabular}{|l|l|}
\hline BPD & Barrels per day (roughly 160 1/day of liquid fuel) \\
\hline BCF & Billion cubic feet \\
\hline BTU & British Thermal Unit, 1055 kJ \\
\hline RUR & $\begin{array}{l}\text { Gas to liquids; alternate name for Fischer-Tropsch } \\
\text { synthesis }\end{array}$ \\
\hline EUR & $\begin{array}{l}\text { Recoverable ultimate reserve; an estimate of the } \\
\text { amount of gas remaining in a well }\end{array}$ \\
\hline SFP & $\begin{array}{l}\text { Estimated ultimate reserves, an estimate of the total } \\
\text { amount of gas that a well contains or contained }\end{array}$ \\
\hline scf & $\begin{array}{l}\text { Small Footprint Plant; a facility dedicated to the } \\
\text { production of liquid fuels starting with natural gas } \\
\text { or other feedstocks, with a production rate less than } \\
\text { in the range of 500-10,000 BPD }\end{array}$ \\
\hline
\end{tabular}




\title{
Appendix F
}

\section{Fischer-Tropsch Small Footprint Plant Economic Feasibility for Rural Alaska}

\author{
Task 8 Report
}

Fischer-Tropsch Fuel Production and Demonstration Project

DE-FC26-01NT41099

Submitted by:
Timothy Bradner
Consultant to Integrated Concepts and Research Corporation 


\section{Table of Contents}

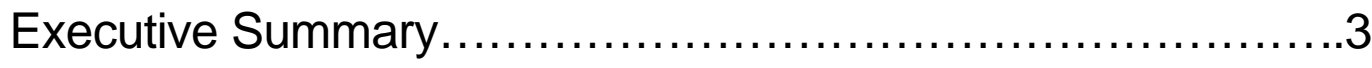

Part 1, Introduction. .......................................

Part 2, Regional F-T Plant Scenarios.......................22

Part 3, Resources Assessment.................................52

Part 4, Rural Alaska Fuel Supply............................69

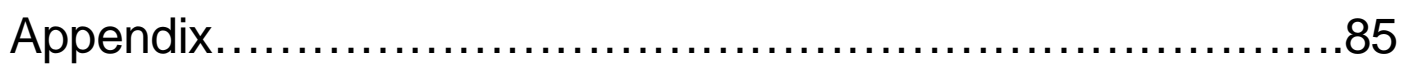




\section{Executive Summary:}

\section{Small Footprint Plant (SFP) Feasibility in Rural Alaska}

We have been asked to investigate the feasibility of supplying ultra-clean Fischer Tropsch (F-T) fuels in rural Alaska with possible smaller-scale F-T plants ("Small Footprint Plants") in selected rural locations near natural resource deposits, or in regional locations near resource deposits from where rural communities could be served.

Task 8.1 reads:

"Using readily available sources from government and private industry, gather information on various Alaska resources, such as oil, gas and coal, that could be used as feedstocks for local or regional SFP fuel processing plants. Consider the location, quantities, accessibility and other factors of these resources affecting how much clean fuel can be produced and distributed to rural communities in the area. Examine the feasibility of placing SFPs in the most promising areas to serve rural communities around the state, including the general and economic benefits to be derived. The economic analysis should include the cost of building and transporting the SFPs to Alaska, the cost of assessing and producing the fuels, the cost of transporting the fuels to the surrounding communities and the cost of storing and using the fuels for power, heat and other purposes. Set out findings and draw conclusions about the feasibility of locating SFPs in areas of Alaska to serve the fuel needs of rural Alaska."

\section{Contractor:}

Timothy A. Bradner

950 Coral Lane

Anchorage, Alaska 99515

\section{The approach:}

Task 8.1 asked us to assess Alaska natural resource deposits and potential deposits that could provide feedstock for F-T plants. In approaching the core mission, an assessment of small footprint F-T plants, we decided to first present a discussion of the state of FischerTropsch development and the challenges, in general, facing the development of smallerscale F-T plants. This is in our "Introduction" in Part 1. Our assumptions in the analyses are also spelled out in the introduction. 
In Part 2, we provide an assessment of possible F-T plants in different Alaska locations. In Part 3 of this report we provide a general overview of Alaska's oil and gas, coal, coalbed methane and biomass (timber) endowment.

In Task 8.1 we were also asked to prepare an assessment of rural Alaska fuel distribution patterns and costs, along with the discussion of issues facing rural fuel distribution, conventional as well as non-conventional (i.e. F-T fuels). It is important to understand how fuel is moved to and around rural Alaska in any assessment of regional F-T plants. This assessment is in Part 4, the final part of this report.

The annual fuel demands of the regions in which we considered sites, and the possibility of exporting fuels surplus to the regions, dictated the size of the F-T plants we considered. Where the regional demand was low, in two small rural communities, we assumed small F-T plants of 300 bbls/day, or 4.5 million gallons per year. Where access to economical water transport was available, such as in coastal locations, we considered larger plants to capture economies of scale.

\section{The sites we considered:}

After considerable research we decided to focus on six potential locations as representative of plausible sites for a plant:

- Nikiski, Alaska ("Case 1") as a kind of "base case." Nikiski was selected because it is now the point from which much of the fuel bound for western Alaska is distributed. Fuel distribution patterns, and costs, are therefore well understood. Nikiski also has established infrastructure, an experienced local workforce and the presence of other industrial facilities to share infrastructure and utility support.

- Beluga, Alaska ("Case 2") as a larger plant site. Beluga was selected as a possible site because there is a large coal deposit very near tidewater.

- Healy, Alaska, (“Case 3”) with its proximity to a coal mine and the Alaska Railroad.

- Bristol Bay, Alaska ("Case 4") because of the potential for large deposits of "stranded" natural gas.

- Galena, Alaska (“Case 5") because of the proximity to a small coal deposit and potential for regional bio-mass resources.

- Fort Yukon, Alaska ("Case 6") because of proximity to potential coal-bed methane and regional bio-mass resources. 


\section{Some initial conclusions:}

- F-T plants in Alaska will require government support. In almost every scenario we studied, a temporary government support mechanism was crucial in reducing the "tail-gate" cost of F-T fuels to levels that might approach economic viability even if crude oil prices remain high. There are several ways the government could support such plants: (1) An energy credit on F-T fuels for an amount similar to tax credits granted to biodiesel, ethanol and compressed natural gas; (2) A government grant to pay the capital costs of a plant; (3) A government fixed-price purchase contract for F-T fuels to make the plant economic.

In this report we assume a federal energy credit similar to existing energy credits for biodiesel, ethanol and compressed natural gas as a plausible form of federal support. We also do one analysis (Case 5-B) of how a government grant covering capital costs would affect the economics of a small rural plant. We discuss the different methods of possible government support in our Appendix, but a more complete analysis of this is outside the scope of this report.

- Higher oil prices could make F-T plants more feasible. While we do not have enough confidence in our estimates to declare that F-T plants in Alaska may or may not be feasible, certainly the continuing rise in crude oil prices and the price of conventional diesel make the possible economics of such plants look better. What must also be taken into consideration are the extra costs required after 2006 and 2010 to supply ultra lowsulfur (ULS) diesel, or conventional diesel with sulfur reduced to 15 parts-per-million (ppm) on top of the cost of conventional diesel. Since F-T fuels will meet the EPA requirements in the 2006 and 2010 regulations, the true comparison will be to weigh possible costs of F-T diesel against conventional diesel with the ultra-low sulfur cost added. We attempt to do this in our report.

- F-T fuels would meet the requirements of new EPA ultra-low sulfur diesel. New U.S. Environmental Protection Agency rules requiring the use of $15 \mathrm{ppm}$ ultra-low sulfur (ULS) diesel are effective in 2006 regarding transportation fuels and 2010 regarding diesel used in off-road (construction, mining, etc.) and stationary diesel engines. These rules will have considerable impacts in rural Alaska, mainly because of the cost of making winter-grade ULS diesel and transportation and storage problems that arise if the fuels are segregated from conventional diesel. We believe, as do many in the industry, that by 2010 all diesel used in rural Alaska will be ULS because of the costs of shipping and storing separate fuels. There will still be a premium charged for this fuel in rural Alaska above the cost of conventional ULS diesel and there are various estimates, ranging from 15 cents per gallon to 70 cents per gallon depending on the location. Since F-T diesel meets the requirements of the EPA rules we believe the cost of F-T diesel delivered to rural locations should be weighed against the cost of the ULS diesel. 
- Low-toxicity and biodegradability of some F-T fuels is an advantage. The low-toxicity and biodegradable nature of F-T fuels is an advantage: Many F-T fuels have low-toxicity and are biodegradable and have been certified as so by the U.S. EPA (see our Introduction section). If these fuels were spilled during handling or because of a rupture of a tank, the environmental impact would be less than that of conventional diesel. We have not attempted to quantify this advantage, but there is a real cost imposed on small rural storage and distribution facilities by spill containment, training and other requirements that arise from the toxic nature of conventional crude oil-based diesel. Use of F-T fuels may not eliminate these requirements, but the nature of the fuel would be weighed by the state and federal government agencies in considering a spill plan and other requirements for a bulk fuel storage facility.

- The uncertainties in our estimates are considerable. There are four major risk factors in the estimates we have made. They are:

1.) Technology risks. We know F-T technology works at large scale, such as at 50,000 barrels/day, but there is insufficient industry experience with smallerscale F-T plants, such as at the 200 bbls/day range. This is a major area of uncertainty, we believe.

2.) Location risks. There are no guidelines for estimating project construction costs in rural Alaska, or even the state as a whole. Project cost estimation is based on past experience and familiarity with site conditions by the project team. We have discussed each location with knowledgeable people and, within the means at our disposal, have attempted to make reasonable assumptions as to local construction costs. However, a realistic assessment of a particular site would take a greater and more focused effort.

3.) Resource risks. We have included a range of estimates for the cost of supplying given resources (coal, biomass, gas) to our locations, but the actual cost will remain unknown until a project is developed. We do have more certainty around the probable cost of biomass and coal at Nikiski and coal at Beluga and Healy, but our estimates for natural gas, coal, biomass and coalbed methane at the Bristol Bay, Galena and Fort Yukon sites are very speculative.

4.) Operations risks. This is an unquantifiable risk, but a serious one in remote or rural settings. An F-T plant is really a kind of chemical plant. As explained in Part 1, our introduction, its operations are complex and require skilled personnel and substantial off-site support. Given this, we can see that it could be a real challenge to staff and operate such a plant in a remote or rural setting. An illustration of the difficulties involved in actually building and operating an F-T plant is that BP was delayed over a year in startup of the company's small $300 \mathrm{bbl} /$ day demonstration plant in Nikiski by problems that had little to do with the new technologies being tested and more to do with just the sheer complexity of building and starting up what amounts to a small chemical plant. 
- The four best locations for a possible F-T plant. A very preliminary analysis indicates that medium-sized (6,000 to $12,000 \mathrm{bbls} / \mathrm{day})$ plants at regional locations, from which F-T products can be distributed to locations in and outside Alaska, offer the best possibilities.

\section{The four locations are:}

(1) Healy: There is a producing coal mine at Healy, industrial facilities have been build there, and a F-T plant would have access to the Alaska Railroad for product transportation and the regional power grid for sales of electricity generated with wasteheat.

(2) Beluga: There is a large coal resource and a tidewater location. The opportunity to ship products efficiently in bulk, and near-proximity to the regional power grid makes this location of interest. The major drawback is that a coal mine has not been developed.

(3) Nikiski: There is a functioning gas-to-liquids (GTL) demonstration plant that could be converted, and because local biomass resources are available. The existing GTL plant is too small for commercial use, and using natural gas as a raw material is too expensive in Cook Inlet. There are possible limits to the size of a bio-mass F-T plant.

(4) Bristol Bay: The Bristol Bay basin is very gas-prone and the possibilities of a gas discovery are good. A medium-sized gas-to-liquids plant is a possible option to commercialize a gas discovery that is too small to support a conventional gas pipeline or a liquefied natural gas project.

Of the four sites listed above, the plants that could be developed on the fastest schedules are at Nikiski and at Healy because a source of resource feedstock is available as well as utility support facilities, transportation infrastructure to move products to market and the existence of a local or regional construction workforce.

Rural community locations: We analyzed two rural community locations in Interior Alaska, assuming small-scale $300 \mathrm{bbl} / \mathrm{day}$ F-T plants because larger plants would require an extensive transportation system to move the fuel products out of the region. Galena and Fort Yukon were selected because these communities are on the Yukon River, which offers a good, if seasonal, transportation option. Also, we had recent information on resource deposits near the communities that could supply feed for small F-T plants. There is coal and biomass near Galena and bio-mass and coal bed methane near Fort Yukon.

Galena and Fort Yukon are analyzed more or less as proxies for other rural communities where there are resource deposits close by. The information we have on very small-sized F-T plants is very limited, to the point that the analyses done for Galena and Fort Yukon 
would be similar if the location were at another village near a coal deposit, coalbed methane or bio-mass resource.

One conclusion we came to is that the state of research and development in smaller-scale F-T plant technology is not advanced enough to adequately assess the potential for such plants in rural community settings. Other, emerging technologies have promise for SFP F-T plants, however, and should be encouraged (see more discussion in our Appendix.)

Capital grant improved economics: We were initially skeptical that a small plant (300 bbl/day) would be even remotely feasible at any rural community locations, and in general our analysis supported this view. However, we were interested when one case we did for Galena (Table 5-B) assumed a government grant to pay the $\$ 65$ million capital cost of the F-T plant and equipment for wood harvesting. This had a dramatic effect in lowering the required price of diesel products from the plant to at or below diesel prices in late 2004 and early 2005. We did not consider a case like this for the larger projects because the prospects for a government grant for the larger projects - involving several hundred million dollars - seem remote. Our conclusion from this is that alternate ways of financing small F-T projects in rural areas may be worthy of further study.

Bio-mass harvest could stimulate rural industry: One other consideration, we believe, is that in the case of a small rural plant supported by bio-mass from regional timber harvesting, the operation of the plant and the harvesting could provide a considerable economic stimulus to the region, particularly if the harvesting is integrated with a sawmill or some other way to use higher-value wood. This is beyond the scope of this report, but we would observe that small-scale wood harvesting is a very old industry in rural villages along the Yukon River and its tributaries. Harvesting wood to fuel steamboats operating on the river was a major source of cash for the communities, and lasted until diesel-fueled boats began operating on the Yukon system in 1948.

\section{More support is needed for SFP research and development: An overall}

conclusion is that more support should be given to research and development of SFP F-T technologies, and that if there are potential military applications for SFPs the federal government should take the lead in providing support. As we discuss in our introduction to this report, the direction of private industry's F-T research and development is toward larger plants which enjoy economies of scale. Little effort is being made, within the private sector, on smaller plants, and very little in the micro-plant category (200-600 bbl/day) that we consider in some of our scenarios on this report.

Sources of our information: The bulk of the analyses in this report is from information made public or provided by firms engaged in F-T development, including Choren Industries of Hamburg, Germany; Sasol, of Johannesburg, South Africa; and Syntroleum Corp. of Tulsa, Okla. There is a substantial amount of other information held confidential by companies engaged in F-T development and unavailable to us. 


\section{PART ONE: Introduction}

\section{The Fischer-Tropsch Process}

Different companies have been developing the Fischer-Tropsch (F-T) process throughout the world since the 1930s. While most people associate the F-T process with the gas-toliquid process (GTL), F-T got its start using coal in Germany and later in South Africa, referred to as coal to liquid (CTL). More recently, bio-mass (BTL) has been used to generate the synthesis gas for the F-T process - creating "green" or bio-renewable energy. All three programs, GTL, CTL and BTL share the same three steps; first, syn-gas generation; second, the F-T conversion; and third, products upgrading. Regardless of the resource input, the second and third steps are identical. Natural gas is reformed (Alaska's Agrium Corp. ammonia and urea fertilizer plant and the BP GTL test plant are examples) while solids; coal and bio-mass are gasified to produce a syn-gas (hydrogen $\boldsymbol{H}_{2}$ and carbon monoxide $\boldsymbol{C O}$ ). A synthesis gas (or syn-gas) is the common supply for the F-T process, as well as methanol and ammonia processes, and for electrical generation and sulfur reduction in refineries

Figure 1 shown here illustrates the F-T process and how different natural resources can be used to make the syn-gas needed in the F-T conversion. The Fischer-Tropsch Process (F-T) has three main processing steps shown here, all of which are commercially proven.

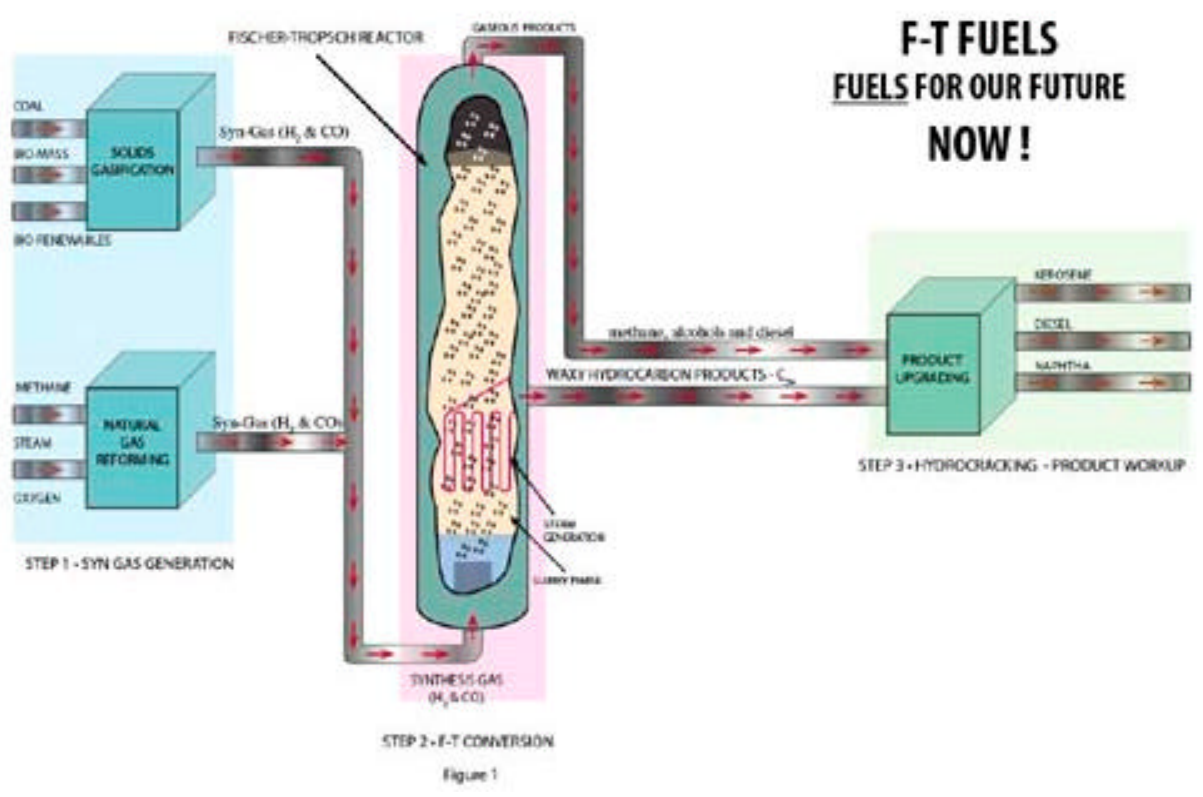




\section{STEP 1:}

Syn-gas generation typically represents 50-plus percent of the total cost of an F-T plant.

\section{STEP 2:}

F-T Conversion is typically 25 percent of the total cost.

\section{STEP 3:}

Product Upgrading is usually 15 percent to 25 percent of the cost.

The type of Syn-Gas Generation, gas reformation or gasification of solids, depends upon the raw material or feed stock available. Around the world stranded natural gas is the choice; however, in the US with the exception of North Slope natural gas, coal, and bio-mass (municipal, timber and agricultural waste) represent the majority of available feedstock for a U.S. based F-T program.

\section{Comparing F-T diesel costs with conventional diesel prices}

The estimated cost and resulting wholesale price of producing Fischer-Tropsch (F-T) diesel in a small-footprint F-T plant must be weighed against the wholesale price of conventional diesel fuel available in a given region. To compare Fischer-Tropsch fuel costs with conventional, we consider the plant "tailgate" costs, shown in tables for the respective scenarios, as wholesale prices for the F-T fuel available at the plant.

To compare this with conventional fuel, in each section we report a 2004 average wholesale price of conventional diesel reported from fuel distributors or wholesale purchasers for the region. We also consider an additional cost to conventional fuel for the ultra-low sulfur diesel (ULSD) that will be required by U.S.

Environmental Protection Agency regulations effective in 2006 for road diesel and 2010 for all diesel.

Since FT fuels already meet the EPA 2006 and 2010 clean-diesel standards, we compare the F-T costs with future estimated prices for ULSD conventional diesel.

\section{How the process works:}

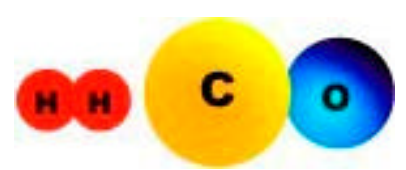

The first step converts natural gas, coal or bio-mass into synthesis gas, a mixture of carbon monoxide $(\mathrm{CO})$ and hydrogen $\left(\mathrm{H}_{2}\right)$ - syn-gas.

This mature process technology has been used in many commercial facilities as the first step for producing ammonia, hydrogen, F-T fuels, petrochemicals and methanol. Sasol, a leader in F-T technology uses both gas reformation and coal gasification to produce syngas for its F-T production.

Step two, the Fischer-Tropsch conversion, was discovered in Germany in the early 1900's, it upgrades the syn-gas into a waxy long chain hydrocarbon. Simplified, this reaction is:

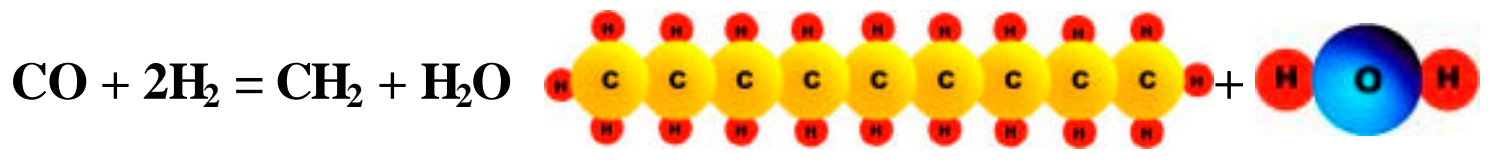


The length of the hydrocarbon chain is determined by the composition (ratio of $\mathrm{H}_{2}$ to $\mathrm{CO}$ ) of the syn-gas, the catalyst selectivity and the reaction conditions (temperature and pressure.)

Sasol has pioneered several types of F-T conversion technologies to produce over 150 different products from the company's plants in South Africa. The hydrocarbon stream $\left(\mathrm{CH}_{2}\right)$ is sent to product workup and the water $\left(\mathrm{H}_{2} \mathrm{O}\right)$ is sent to a water recovery unit. One disadvantage of today's F-T technology is that for every barrel of product produced one barrel of water is also produced. Water disposal is, therefore, a consideration.

\section{The third step: product upgrading:}

Upgrading can produce a wide range of commercial products including gasoline, diesel and specialty products of use for petrochemical manufacturing. For a U.S. based F-T program we would recommend middle distillate fuels: kerosene, diesel and naphtha. If exports are possible, an Alaska-based F-T plant could also make gasoline, which is in short supply in the U.S. west coast, as well as diesel.

The final product workup makes use of standard hydrocracking and hydro-isomerisation processes commonly found in the refinery world. As with the first step, syngas production, suitable technology is widely available from several licensors around the world.

The F-T process produces fuels that contain essentially no sulfur, aromatics or ring chain hydrocarbons that are toxic and harmful to the environme nt. As with a crude oil refinery, the F-T process does produce $\mathrm{CO}_{2}$ but it is in a pure stream and is contained so that it can be sold or sequestered through injection into underground storage reservoirs or used in Enhanced Oil Recovery.

F-T diesel may be one of the cleanest motor fuels available. In the early 1990's UNOCAL Corp. asked the U.S. Environmental Protection Agency to approve F-T diesel from the South African Mossgas GTL plant for use as a drilling fluid in offshore waters. As a result of the tests performed by UNOCAL, the EPA determined that this form of F$\mathrm{T}$ diesel is bio-degradable and non-toxic. Note: The data can be found at EPA Water Docket, EB 57, Reference Docket No. W-98-26, UNOCAL data file 4.A.a, Vol 13.

Choren, a German company has been operating a bio-mass gasifier to produce syn-gas for methanol and electric power production since the 1970's. This plant is considered one of the world's first bio-renewable gasifiers and has the distinction of producing fuels and electricity with a net zero impact on $\mathrm{CO}_{2}$ production. 


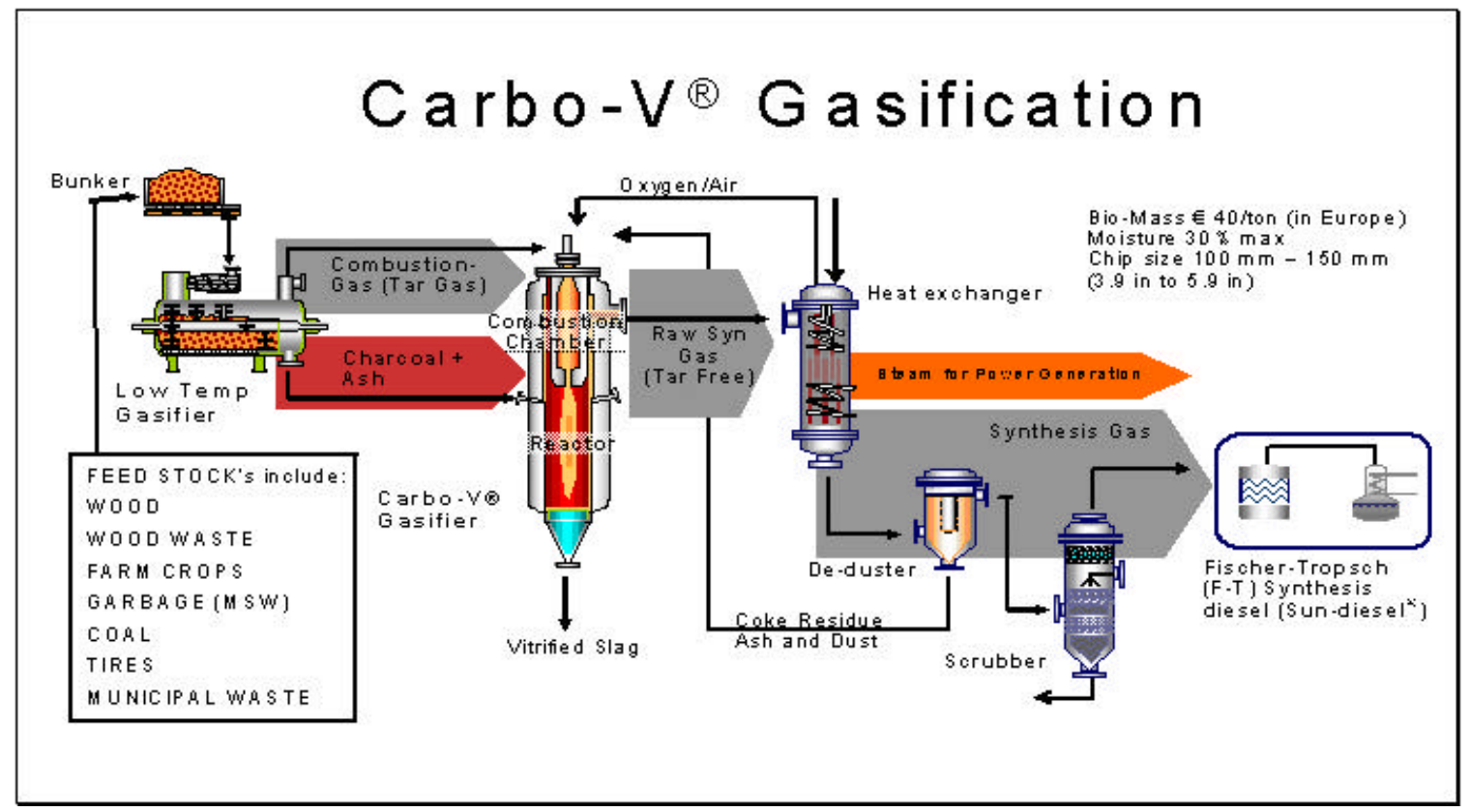

The Choren gasification process illustrated here provides the syn-gas necessary for F-T transport fuels, fertilizer, petrochemicals and electric power generation. It is in essence a bio-renewable generator of higher value energy products. The Choren gasification process has the distinction of being able to gasify coal and bio-mass (such as wood), both abundant in Alaska. One advantage of Choren's gasifier is that it could produce syn-gas from available resources, switching back and forth between coal and biomass on a seasonal basis. The illustration following provides a block flow diagram of the energy conversion process from resource to electricity and or transport fuels. 


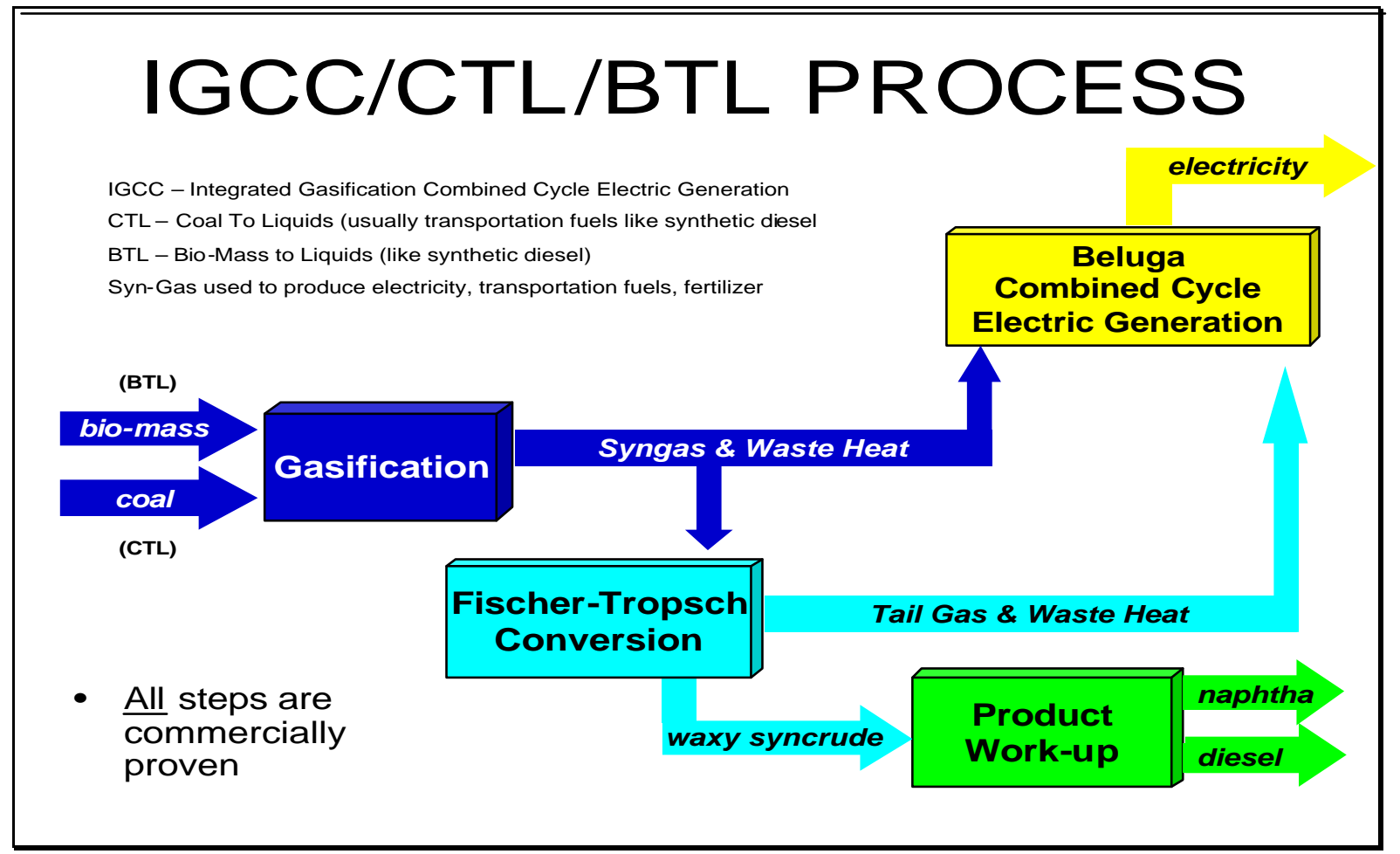

\section{F-T Plant Size}

This report will examine the possibility of small scale F-T plants for several Alaska locations that could provide from 1,000 to 6,000 barrels per day of fuel for transport and electric generation. We note that most F-T technology providers started with pilot plants smaller than this, costing $\$ 200,000$ to $\$ 300,000$ per installed barrel of capacity. Upon proving their technology most developers have embarked on a program of scaling up plant size to reduce to the $\$ 25,000$ to $\$ 65,000$ per installed barrel of capacity. The F-T industry mantra is "bigger is better" because it is more economic. Unfortunately, the F-T industry is moving in opposite direction than the small F-T plants being considered here.

\section{Scale, or size, affects the economics}

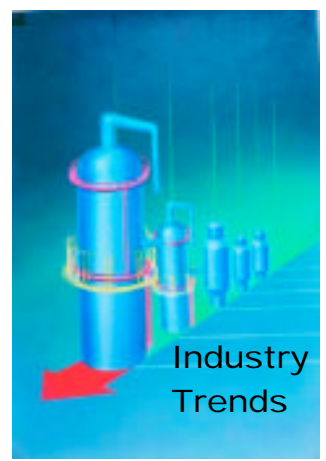

In the manufacture of F-T, size does matter. There are conflicting issues at play in a chemical reaction, especially those that are highly endothermic or exothermic. When we add or take away large amounts of heat; heat controls the rate and direction of the reaction. Heat transfer in large vessels is difficult to model, thus the reason for scale-up development programs. Outside of these issues the rule-of-thumb is that larger is more economic. 
An example with the cost of pipelines illustrates this. The same equipment is used to install a 12-inch pipeline and a 16-inch pipeline. A 16-inch line requires a little more weld time, and a slightly bigger ditch - but we are talking about inches. Typically pipeliners use a rule-of-thumb for calculating the installed cost of a pipeline; " $\mathrm{X}$ " dollars per inch of pipe diameter per mile of length. For example, at $\$ 15,000$ per inch-mile, a 12 -inch pipe costs approximately $\$ 180,000$ per mile. A 16 -inch pipe costs $\$ 240,000$ per mile, a 33 percent increase in cost. The carrying capacity of the two pipelines is considerably different. Under given conditions a 12-inch pipeline can carry 50 million cubic feet of gas, while under these same conditions a 16-inch pipe can carry 106 million cubic feet of gas, more than twice the capacity for a 33 percent increase in costs. The same analogy applies to a flow process in a F-T plant. Small increases in size allow for larger increases in volume, resulting in lower installed costs per unit of volume, or dollars-per-installed-barrel-of-capacity. When we apply the savings across every aspect of a complex plant and the many on and off-site supporting utilities and equipment, we quickly see how "bigger can be better."

\section{The Decentralized-Centralized Concept}

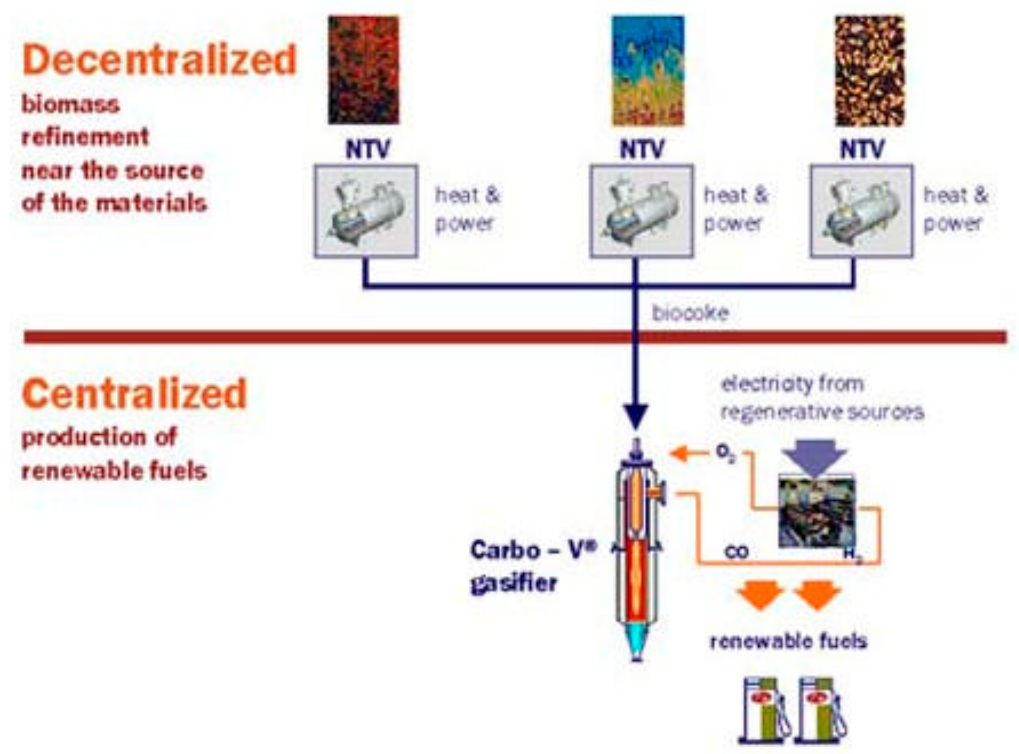

In this analysis we are looking at installed costs per barrel of capacity ranging from $\$ 200,000$ for a $300 \mathrm{bbl} / \mathrm{d}$ BTL plant (bio-mass) located at a remote setting to $\$ 85,000$ for a 6,000 bbl/d facility at Nikiski, an established industrial area. We also consider a case of $\$ 35,000$ for a $300 \mathrm{bbl} / \mathrm{d}$ conversion of an existing BP GTL demonstration to a BTL demonstration plant. We compare these cases to published numbers for a Sasol 33,000 bbl/d GTL plant between $\$ 16,000$ to $\$ 22,000$ per installed barrel for a new "Greenfield" site and we quickly see that small plants are at a disadvantage. Size does, however, bring 
its own challenges. For example, it is one thing to harvest and deliver 250 tons of biomass per day, and quite another to deliver 25,000 tons per day. As plant size increases, feedstock handling costs must be controlled. European studies have found bio-mass transport costs limit a plant size to 3,000 tons per day. Above this number, it is preferable to use systems that concentrate feedstocks at remote locations for semiprocessing and transporting the material to a central plant location. Choren's two-stage biogasifier illustrated above is designed to deal with this larger-volume bio-mass transport issue.

There are some F-T technology providers looking at micro-plant designs with the hopes that military or space applications will support their development costs (see Appendix). As these technologies mature and micro F-T plants are built, costs will come down. They may even become economic for small volume rural applications. At this point, other than in Choren's BTL program, no one has a small-scale, less-than-300 bbl/d commercial F-T program for producing F-T fuels that costs under $\$ 100,000$ per installed barrel to construct. At costs in this range, it would seem that none of these F-T programs are economic for rural Alaska when one compares costs with the delivered costs of crudebased diesel from Cook Inlet or Washington State. In our view the fuels market in Alaska is not of sufficient size to economically support, on its own, an F-T plant with today's technology. However, a larger Alaska plant on or near tidewater, that sells 80 percent to 90 percent of its products in the Lower 48 or Asia, will reduce costs to the point that reasonably-priced F-T diesel might be sold in Alaska.

\section{F-T fuel economics}

There is no question that F-T technology works. There are F-T plants with over 250,000 barrels per day of production operating in the world today, and another 500,000 barrels per day under construction or in the final design phase. There is also no question that F-T transport fuels are compatible with the existing motor fuels market and infrastructure, with over 40 billion gallons of these fuels sold to date throughout the world. Sasol, of South Africa, secured approval to supply FT-based jet fuel to passenger flights of international airlines refueling at Johannesburg.

The question is whether F-T fuels are economic compared with conventional fuels. If the measure of economics is price at the fuel pump, the answer is generally no. However, as the price of crude oil continues to rise, at some point the cost of manufacturing F-T fuels will equal that of crude-based transportation fuels. The problem in the U.S. is that there are many factors at play that affect overall economics. There are hidden costs in our national energy policy and environmental programs that are not apparent at the fuel pump, for example.

There are generally three economic drivers that impact the real cost of U.S. transportation fuels. They are: 
$v$ Strategic, the need to maintain a military presence in the Middle East to insure the free flow of oil to the world. We refer to this as a Security Premium.

$v$ Shortfall in U.S. refining capacity, which affects availability of fuel. We refer to this as a Refining Capacity Penalty.

v Environmental - Lower Emissions and CAFÉ levels (Clean Cities Programs lower GHG emissions and better fuel mileage). We refer to this as the Engine Emission and Efficiency Cost.

National policy issues are at stake here. New alternative fuel refineries (F-T) plants cost tremendous amounts to build because they are more like chemical plants than crude oil refineries. However, if environmental laws require crude oil refineries to make fuels as clean as F-T fuels, then F-T plants could be competitive. Alternatively, if the U.S. charged a tax for importing oil or gave credits for refineries that reduced U.S. dependence on imported crude, F-T plants could be competitive. If the U.S. charged a tax for importing gasoline and diesel, it would encourage new refineries to be built in the U.S., helping make new F-T refineries competitive.

Alaska is different than the Lower 48 in that there is currently excess conventional refining capacity in the state. Building new capacity to meet Alaska demand doesn't make sense on a commercial basis. On a national scale there is a shortage of domestic refining capacity and a need to build new refineries, however. The west coast states in particular are short on gasoline refining capacity, and have stringent air quality regulations for diesel. F-T products imported from the Shell GTL plant in Malaysia now sell at a premium in these markets, and would logically continue to do so.

One way of looking at the economics of F-T manufacture is to compare them with the costs of building or adding other new fuel-making capacity. The table included here illustrates the price products must sell for from a new refinery compared with today's fuel prices to recover the new capital investment. As the price of crude oil continues to rise faster than the price of coal and bio-mass remains stable, BTL and CTL plants might be competitive. Once the capital cost of U.S. built F-T plant is recovered, American BTL and CTL plants can be competitive below today's price of crude oil. 


\section{Estimated Costs of New Refining Capacity}

(plants built in the U.S.)

\begin{tabular}{|c|c|c|c|c|c|}
\hline Refinery Type & $\begin{array}{c}\text { Estimate } \\
\text { By }\end{array}$ & $\begin{array}{c}\text { Plant } \\
\text { size } \\
\text { bbl/d }\end{array}$ & $\begin{array}{c}\text { Cost } / \\
\text { Installed } \\
\text { Barrel }\end{array}$ & $\begin{array}{c}\text { * Refinery } \\
\text { CAPEX at } \\
100,000 \\
\text { bbl/d }\end{array}$ & $\begin{array}{c}\text { \$/gal to } \\
\text { recover } \\
\text { CAPEX }\end{array}$ \\
\hline Crude oil & Oil Majors & 100,000 & $\$ 18,000$ & $\$ 1.8$ billion & $18 \phi$ \\
\hline Coal to liquids & Sasol & 75,000 & $\$ 45,000$ & $\$ 4.5$ billion & $44 屯$ \\
\hline Bio -Mass to liquids & Choren & 6,500 & $\$ 65,000$ & $\$ 6.5$ billion & $67 \phi$ \\
\hline Bio -Mass to liquids & Choren & 300 & $\$ 183,000$ & - & $182 屯$ \\
\hline
\end{tabular}

* Cost of refinery estimate at capacity shown but adjusted to $100,000 \mathrm{bbl} / \mathrm{d}$ for comparison only 10 loan @ $@ 8.5 \%$

\section{F-T Plant Location}

A rule-of-thumb in real estate is that there are three most important aspects in the value of a commercial property: Location, location and location. This is just as important in the economics of an F-T plant.

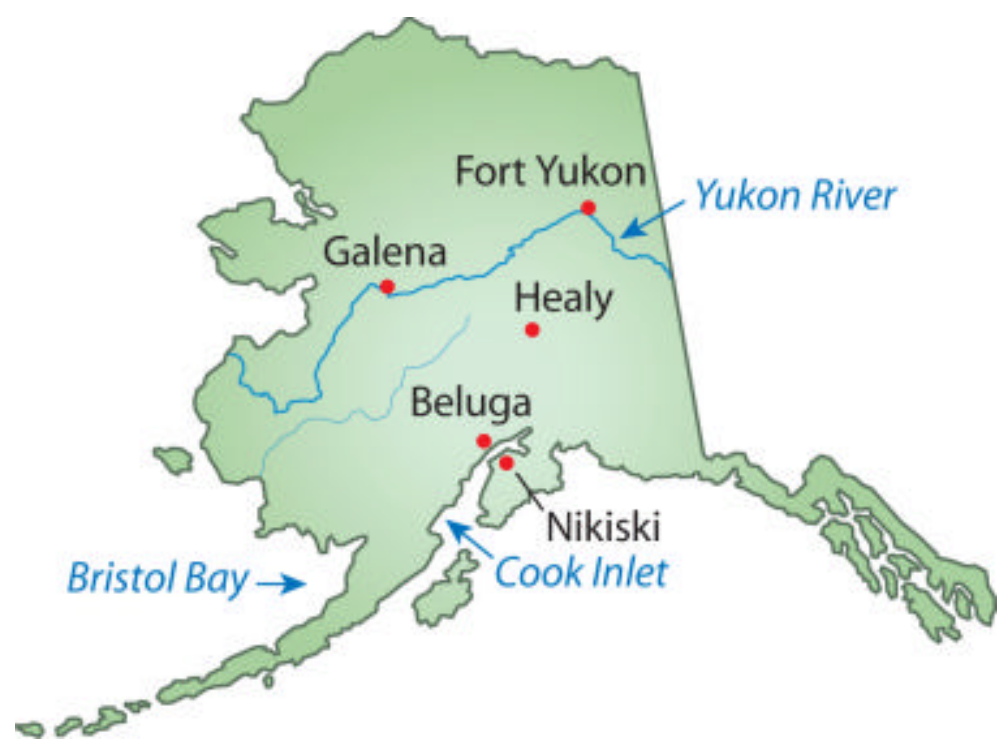

This report looks at the relative economics of BTL and CTL plants at different locations in Alaska, and we include two cases using natural gas, or GTL. Plant construction costs, operating and maintenance costs are estimated very generally, using information made public or provided by firms. We believe these general numbers have a $+/-$ range of 25 percent to 30 percent. Detailed pre-engineering studies that will entail substantial costs will be required to reduce the uncertainty of these estimates. 
We briefly discuss six different potential locations in Alaska and outline the impact of each site on the economics, size and function of the F-T plant. The first two examples we consider in the Cook inlet region are (1) at Nikiski, an established industrial area where there is an existing GTL test facility as well a substantial utility infrastructure; (2) a location at the Beluga coal field on the West side of the Cook Inlet near the village of Tyonek (no mine has yet been developed at Beluga, and there is little support infrastructure); (3) a location near the existing Usibelli coal mine in Healy, between Anchorage and Fairbanks along the Alaska Railroad; (4) a potential large gas field in the Bristol Bay region. This region is gas-prone and there is increased industry interest. If a gas discovery is made that is too small for a conventional pipeline or liquefied natural gas project, it could be is a potential location for an F-T plant. We also consider a remote location near Galena (Case 5) on the Yukon River; and a second remote site at Fort Yukon (Case 6) using a potential coal bed methane reserve.

The F-T plants being considered in this analysis are of an order of magnitude more complex and labor-intensive to operate than the small community power plants that now exist in rural communities. Power generation at remote sites usually occurs with small diesel electric generators. If diesel is not available and bio-mass, or wood, is available, a small steam boiler can be used to power a steam-driven generator. Both are conventional technologies that can be operated and maintained with local support. These power units are typically small skid-mounted units, built offsite in industrialized settings and shipped to the location. Engine emissions are manageable, given the state of new diesel generation technology. There is less concern with effluent streams.

Fischer-Tropsch fuel plants, in contrast, are anything but simple to operate and maintain. They are like chemical plants. They operate at high temperatures and pressures and require heavy pressure vessels that can stand 50 to 100 feet tall. They require enormous amounts of power to start up, but once running can supply large amounts of power through excess waste heat. They need specially treated water for use in the process and they produce large amounts of water that must be treated before it can be discharged.

In addition to producing ultra-clean diesel they also produce a range of other products. In all of the cases we consider naphtha is also produced and is considered a heating fuel.

The additional products have value but must

\section{Cost Breakdown of F-T Process}

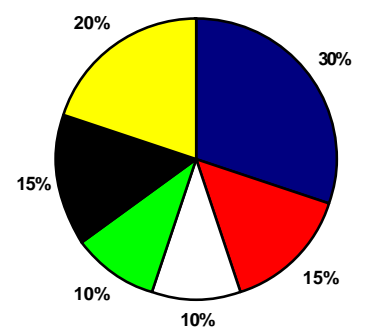

be stored and shipped in separate containers to realize their value. In addition, government agencies closely regulate emissions of plants like these, which necessitates highly trained plant operators and support technicians available 24 hours a day, seven days a week.

Fischer-Tropsch plants also require typically large investments in utility and offsite support systems which can account for 40 percent 50 
percent of the total cost of a plant, as indicated in the illustration below. In our analyses, these support costs are included in the estimates for the three basic F-T steps, syn-gas generation; F-T conversion and finished product manufacture. However, when developing an F-T project in areas where some or all of the utility and support systems are available (such as in Nikiski) there may be significant cost savings available in each of these three steps.

Virtually all the technologies in an F-T plant have a common utility support requirement. Large quantities of energy are needed to drive the air separation processes or the oxygen plant; for the preheat needs of the syngas generation step; for waste heat recovery from syn-gas and its effective utilization; medium/low grade heat generation by the FT process; hydrogen provision for the hydrocracker; and optimum product recovery to maximize yield.

And finally, F-T projects have about 60 percent thermal efficiency, resulting in around 40 percent heat rejection, or waste-heat. There are ways to economically capture this. In addition to heat recovery, offsite support system requirements can be significant, particularly with Greenfield remote locations in Alaska. The offsite systems may include water treatment to support large steam systems and effluent treatment of hydrocarbon contaminated water and system blow downs. Flare systems to deal with high heat flows from the hydrocarbon units as well as high volume flows from the gas processing units, plus firefighting systems to deal with the large volumes of hydrocarbons at their vapor points and process streams containing hydrogen, are very important. Synthetic product tankage and F-T product loading facilities are a significant factor

F-T plants are similar to chemical plants where upsets due to contamination, from small amounts of sulfur for example, can occur. Large-scale, reliable electrical systems are required to supply power during startup. The usual support infrastructure of administration buildings, workshops, warehouses, canteens and medical facilities are required, plus temporary construction facilities will be needed for remote locations. While the ultra-clean F-T diesel fuels have generated considerable interest, we must not forget there are equal challenges in the support systems that are needed when considering engineering needs, construction and overall cost.

An F-T facility can be visualized as a chemical plant. There is a major syn-gas generation facility at the front-end, together with a air-separation plant (oxygen plant), the F-T chemical conversion process in the middle and a refinery on the back end, all supported by a power supply system, steam and electrical systems, a wastewater and air treatment facility plus associated supporting infrastructure. Because F-T plants produce so much excess heat, the economics of a plant are severely degraded if offsite use of waste heat cannot be found. Industrial locations where heat, and water, as well as nitrogen and hydrogen can be obtained, will dramatically improve the economics of an F-T project.

As with crude oil refining, the manufacture of F-T fuels produces $\mathrm{CO}_{2}$ and this gas is becoming increasingly problematic. The advantage of the F-T process is that the $\mathrm{CO}_{2}$ is in a fairly concentrated stream and is easily sequestered so long as there is a place to dispose or utilize the $\mathrm{CO}_{2}$. Depleted gas fields and enhanced oil recovery projects offer 
the best disposal methods, followed by large scale "dry" ice plants, such as those required by the food and fish processing industries. Alaska's Cook Inlet, with its depleted gas and oil fields, may be an ideal location for an Enhanced Oil Recovery and $\mathrm{CO}_{2}$ sequestering program.

All of these issues are more problematic in remote locations. The less industrialized the area or region, the fewer the opportunities to share in utility costs, which will hamper the economics of a remote F-T project.

In Alaska, Nikiski represents the best location in terms of supporting infrastructure. The area has a 70,000 barrel-per-day crude oil refinery, a 1.6 million ton-per-year ammonia plant, a LNG export facility, a GTL test facility, three export docks, a tank farm, a products pipeline to Alaska's largest market and local access to the electric grid, all within a few miles. There is also a large technically-trained and experienced local work force at Nikiski. As for feedstock, the Kenai Peninsula has an abundant amount of biomass with road access to support a mid-size bio-mass to liquids plant. There are, however, no large coal resources on the Kenai. Coal would have to be barged across the

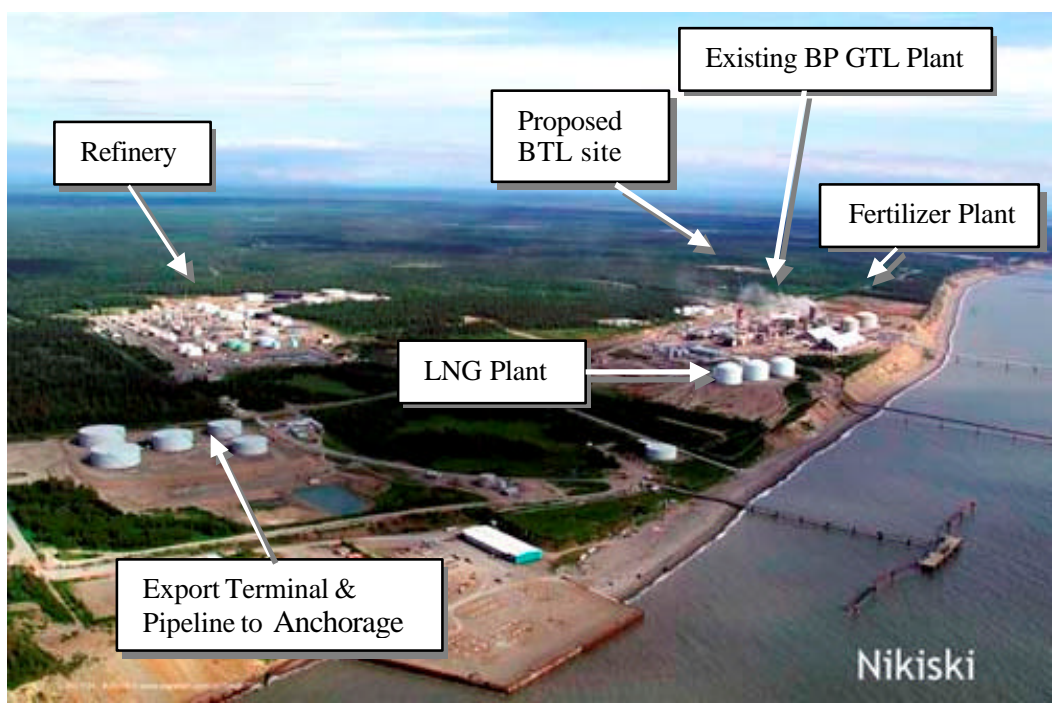
Cook Inlet and stored locally, adding $\$ 3$ per ton to $\$ 5$ per ton to the cost of coal supplied to a CTL F-T plant.

Another potential site location in the area would be on the west side of Cook Inlet near the Beluga coal field. There is, as yet, no mine in this location but the coal resource is identified and proven, and is very large. The location does have a $380 \mathrm{MW}$ electric generating station within 12 miles, and potential access to the electric grid as well as the Drift River oil export terminal for the loading of F-T fuels. Development of a Beluga coal mine would also include a coal export operation, resulting in the sharing of terminal costs. If the F-T plant was capable of using bio-mass and well as coal as resource inputs, wastewood from the region and from Southeast Alaska could be used.

One advantage of a plant at Beluga, as well as Healy, over a Nikiski location is that both would be located adjacent to or near producing coal mines, potentially reducing the feedstock costs by some 20 percent compared with Nikiski.

Both the Nikiski and Beluga locations have access to three large gas fields, each in the 2 to 4 trillion cubic foot (tcf) range, that are being depleted. These could be possible 
locations to sequester $\mathrm{CO}_{2}$ produced during the gasification process. The $\mathrm{CO} 2$ could also possibly be used in Enhanced Oil Recovery to produce more crude oil from Cook Inlet oil fields. The potential for sequestration will require much more study, but if it is possible $\mathrm{CO}_{2}$ credit sales might be possible under the Kyoto Protocol. This can add several hundred thousand dollars to tens of millions of dollars per year in revenue, depending upon the size of the F-T plant. None of the other potential sites considered in our analysis - Healy, Bristol Bay, Galena or Fort Yukon - would have this advantage. 


\section{PART TWO: Regional F-T plant scenarios}

\section{CASE 1: Nikiski, Alaska}

\section{$300 \mathrm{bbl} / \mathrm{d}$ to $6,000 \mathrm{bbl} / \mathrm{d}$ bio-mass to $\mathrm{F}-\mathrm{T}$ (BTL) and coal to F-T (CTL)}

Of all of the potential sites evaluated in Alaska for an F-T fuels project, Nikiski is by far the best suited from a plant site point of view in that infrastructure and contractor and labor support is available. Nikiski is also a major shipping point for fuel deliveries to western Alaska, which means F-T products can be shipped via a wellestablished fuel transportation system. Nikiski's limitations are possible shortages of natural gas for a gas-based F-T project and the costs of supplying coal to a plant if a coalbased project is chosen. If bio-mass is the feedstock of choice, this location is attractive for a number of reasons. However, bio-mass unfortunately limits the size of the F-T plant which adversely affects plant economics.

\section{How the financial analysis was done:}

All analyses in the regional scenarios assume a private investor providing between 20 percent to 25 percent equity and earning either 20 percent or 30 percent internal rate of return (IRR) before federal tax. A 30 percent rate of return results in approximately a 19 percent rate of return after federal tax depending on the tax status of the investor. Until several F-T plants, especially small footprint FT plants, are successfully built and operated, we judge these rates of return to be at the levels required to attract a private investor. Debt is assumed to have a 15-year payback at a 7.5 percent interest rate. The analyses have also reserved 18 percent of net cash flow for local and state taxes. In all cases design and construction is estimated at three and a half years except in the case of the BP gas-to-liquids plant conversion to biomass, in which we assume one year. Capital costs in the case of coal and bio-mass were derived from data made available from Choren Industries of Germany and from Sasol, of South Africa, for a larger coal-to-liquids plant at Beluga. For the Bristol Bay gas-to-liquids plant we use data from Sasol and Syntroleum Corp. of Tulsa, Oklahoma. In the Fort Yukon small gas-to-liquids plant we use published costs associated with the BP gas-to-liquids plant at Nikiski.

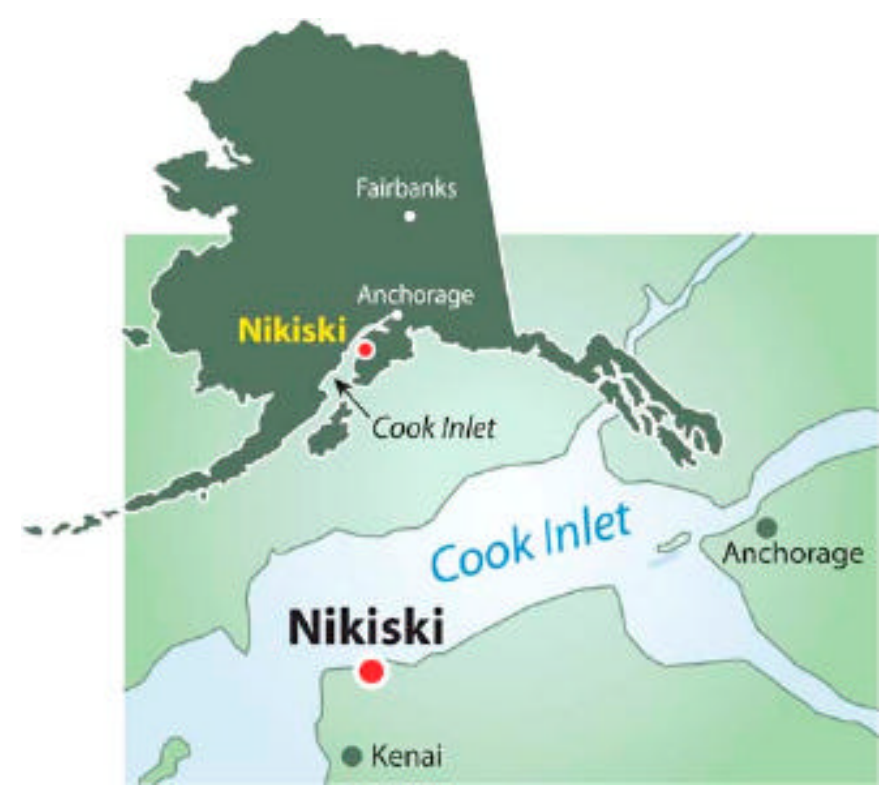

We have evaluated three different potential F-T projects at Nikiski. The first is a $300 \mathrm{bbl} / \mathrm{d}$ (barrel per day) bio-mass to F-T fuels, the second is a 6,000 bbl/d bio-mass to synthetic gas and F-T fuels, and the third is a $6,000 \mathrm{bbl} / \mathrm{d}$ combination coal and bio-mass to F-T fuels.

A prime option we considered is conversion of the $300 \mathrm{bbl} /$ day BP Nikiski GTL test facility to a 300 barrels-per-day (bbl/d) BTL demonstration plant capable of utilizing 250 tons per day of Kenai area bio-mass, from beetlekilled spruce trees, as the feed stock. 


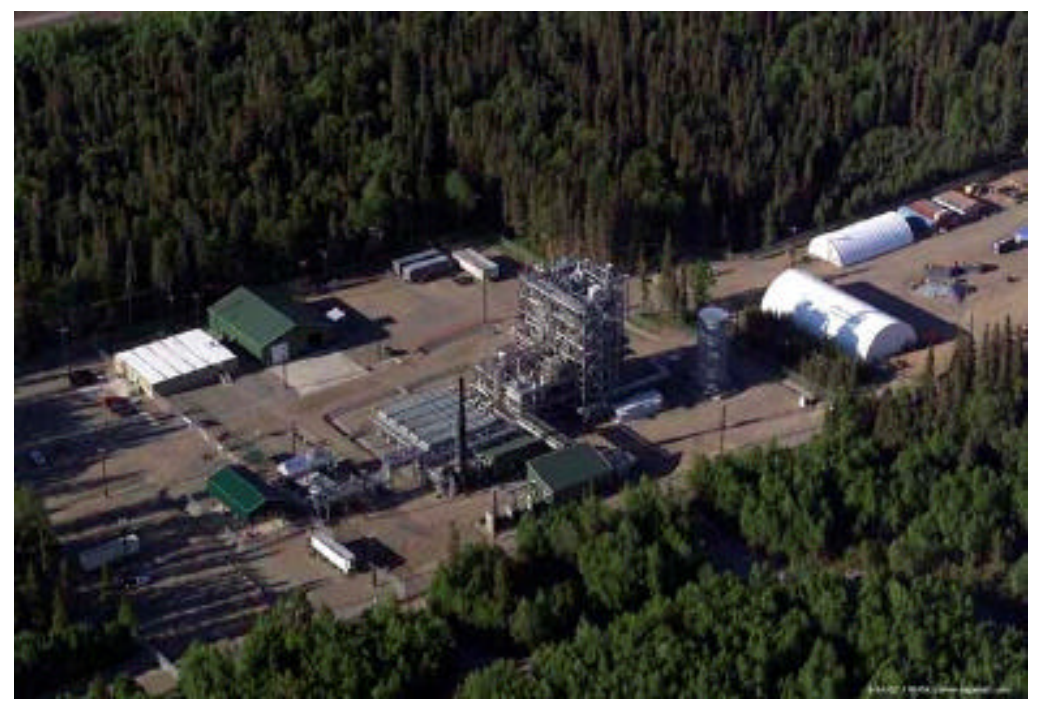

The photograph included here is an aerial view of the $\mathrm{BP}$ GTL plant site. This is in the heart of the Nikiski industrial area, with ample water, electric power, water treatment facilities, access to an export terminal, pipeline to Anchorage, a refinery, oxygen supply and an experienced work force.

The $300 \mathrm{bbl} / \mathrm{d}$ BP test facility, built in 2002, is world class facility containing 80 percent of the F-T and support equipment needed for a BTL program. By using the test facility, if it is available, 50 percent or more of the cost of a new BTL program can be saved, improving the BTL plant economics. If this advantage is combined with the federal forest programs to subsidize the removal of dead spruce trees on the Kenai, a BTL

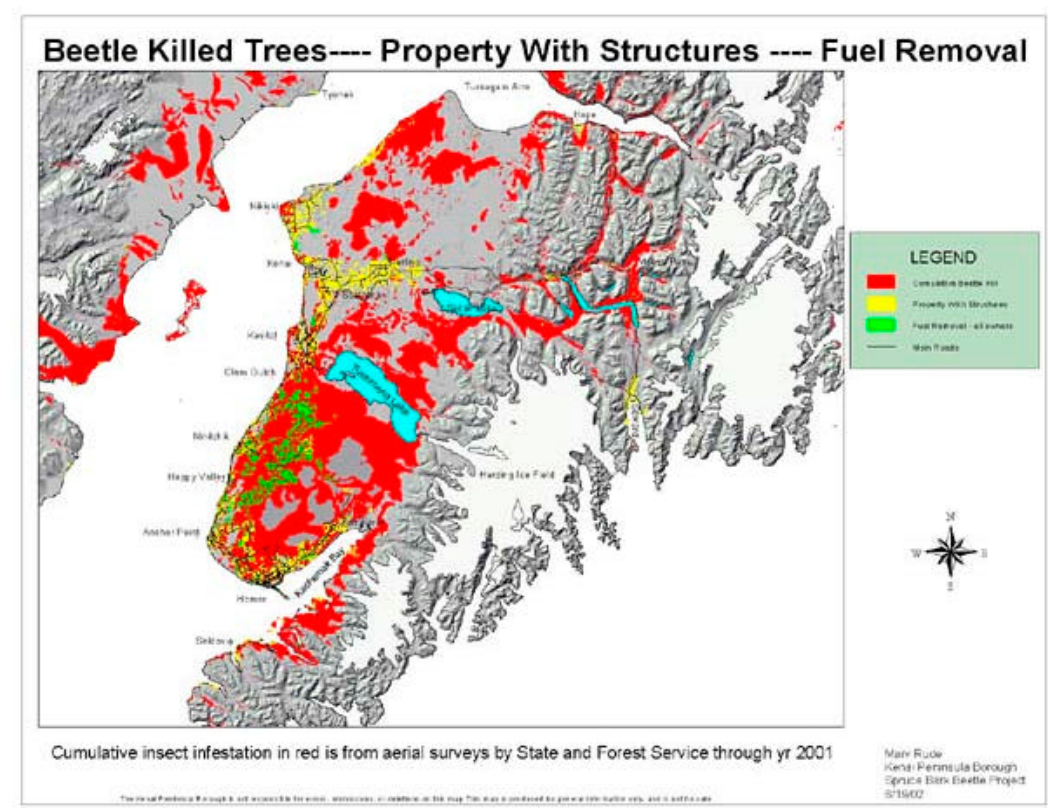
demonstration plant could provide F-T diesel for local and rural Alaska markets. The question is whether it can provide these fuels competitively priced with conventional diesel made at the adjacent Tesoro refinery. The answer to this is generally "no" unless the price of crude oil is above \$40/barrel, and unless there is some form of energy credit on a federal level.

The feedstock for this small-scale BTL plant would come from area beetle-killed spruce forests. Estimates from the Kenai Joint Task Force on beetle kill show there is approximately 1.5 million acres of dead or dying spruce trees in the region with between 30 to 50 tons of bio-mass (from waste timber) per acre recoverable (shown in red in the illustration). As with any bio-mass, as years go by the ability to use this resource decreases as the structural strength of the tree decreases. By the time the tree decays to a 
point where it can longer stand it has lost its value to be gasified and turned into a liquid fuel. One other advantage of a BTL project using a bio-gasifier is that trees damaged in a forest fire that will eventually die can be used in the process. Cost estimates to deliver the Kenai beetle-killed spruce in a chipped form to a Nikiski BTL plant site range from $\$ 4 /$ ton if removal is federally subsidized to $\$ 36 /$ ton if not. If other, green trees of higher value can be harvested at the same time the dead spruce is removed, private logging contractors indicate that costs could be in the $\$ 26 /$ ton range. The $300 \mathrm{bbl} / \mathrm{d}$ BTL demonstration plant would require approximately 250 tons per day of wood/wood waste or approximately 10 truck loads a day seven days a week.

\section{0 bbl BTL plant at the BP GTL site}

A $300 \mathrm{bbl} / \mathrm{d}$ BTL plant at the BP plant site using the Choren bio-gasifier is estimated to cost between $\$ 23$ million to $\$ 55$ million. Small plants of this size are more like demonstration plants than commercial plants because the initial cost makes them noncompetitive. The Nikiski location, however, does improve the plant economics because of the need to remove the dead spruce trees to reduce area fire hazards and by using the existing BP GTL test facility more than half the costs of the BTL demonstration plant could be saved. Even so, a GTL to BTL conversion plant will require a federal fuel subsidy in some form. We consider the case of an energy credit equal to that of biodiesel, which could keep the plant's "tail gate" price for diesel below \$1.60/gal.

\section{Diesel price (wholesale) (\$/gal) required for a $20 \%$ IRR project $300 \mathrm{bbl} / \mathrm{d}$ bio-mass-to-liquids F-T plant at Nikiski}

No Economic Support

\begin{tabular}{|c|c|c|c|}
\hline Wood Cost & $\$ 4 /$ ton & $\$ 26 /$ ton & $\$ 36 /$ ton \\
\hline $\begin{array}{c}\text { Plant Cost } \\
\text { (millions) }\end{array}$ & & & \\
\hline$\$ 23$ & $\$ 1.62 / \mathrm{gal}$ & $\$ 2.19 / \mathrm{gal}$ & $\$ 2.45 / \mathrm{gal}$ \\
\hline$\$ 30$ & $\$ 1.99 / \mathrm{gal}$ & $\$ 2.56 / \mathrm{gal}$ & $\$ 2.82 / \mathrm{gal}$ \\
\hline$\$ 55$ & $\$ 3.23 / \mathrm{gal}$ & $\$ 3.89 / \mathrm{gal}$ & $\$ 4.15 / \mathrm{gal}$ \\
\hline
\end{tabular}

Economic Support \$1/gallon for 10 years

\begin{tabular}{|c|c|c|c|}
\hline Wood Cost & $\$ 4 /$ ton & $\$ 26 /$ ton & $\$ 36 /$ ton \\
\hline $\begin{array}{c}\text { Plant Cost } \\
\text { (millions) }\end{array}$ & & & \\
\hline$\$ 23$ & $\$ 0.66 /$ gal & $\$ 1.23 /$ gal & $\$ 1.48 /$ gal \\
\hline$\$ 30$ & $\$ 1.05 /$ gal & $\$ 1.61 /$ gal & $\$ 1.77 /$ gal \\
\hline$\$ 55$ & $\$ 2.39 /$ gal & $\$ 2.96 /$ gal & $\$ 3.22 /$ gal \\
\hline
\end{tabular}

TABLE 1 
Table 1 illustrates the affect of plant cost, feedstock cost and economic support on the wholesale price of F-T diesel at the plant tailgate to achieve a 20 percent Internal Rate of Return (IRR) for a 20 percent equity investor. (Note: Other scenarios we study assume both a 20 percent and a 30 percent IRR if the project is larger and with more risk). The $\$ 23$ million capital cost represents the expected cost for a BTL conversion using 100 percent of the existing GTL plant facility; \$30 million represents this same facility but adding a different product makeup module to make a wider range of products, while $\$ 55$ million shown represents the cost of a new BTL plant at the same location, without using the BP facility. Wood costs of $\$ 4 /$ ton assume a federal program to remove the beetle-killed spruce trees. $\$ 26 /$ ton represents a private logging contractor's estimate for logging both green wood and the beetle kill, while the $\$ 36 /$ ton shown represents U.S. Forest Service costs estimates to only remove the beetle kill, and to chip and deliver the chips to the Nikiski BTL site. Table 1 shows that without a federal Energy Credit (one option for federal support), the $300 \mathrm{bbl} / \mathrm{d}$ Nikiski BTL plant cannot produce F-T diesel competitive with today's Cook Inlet crude based diesel prices. Even with a significant energy credit or some other direct subsidy, the BTL plant will require a subsidized feedstock to sell F-T diesel below \$1/gallon.

\section{6,000 bbl/day BTL/ CTL plant at Nikiski:}

Kenai Peninsula bio-mass resources are estimated to be in the 40 million to 70 million ton range looking only at the beetle-killed spruce. A 6,000 bbl/d Choren style BTL plant would require approximately 3,200 tons per day of bio-mass or approximately 1.2 million tons per year. The area beetle kill spruce resource could in theory support this plant for decades. However, dead trees decay, and long before the trees can be removed even at 1 million tons per year the wood waste would be unusable. One possibility is that the BTL plant could transition from distressed wood to commercial grade green wood, but this would require paying commercial wood prices. We estimate that for a long term operation, a BTL plant on the Kenai Peninsula would have to pay close to $\$ 26 /$ ton. 


\section{Diesel price (wholesale) (\$/gal) required for a $30 \%$ IRR project $6,000 \mathrm{bbl} / \mathrm{d}$ bio-mass-to-liquids F-T plant at Nikiski}

No Economic Support

\begin{tabular}{|c|c|c|c|}
\hline Wood Cost & $\$ 4 /$ ton & $\$ 26 /$ ton & $\$ 36 /$ ton \\
\hline $\begin{array}{c}\text { Plant Cost } \\
\text { (millions) }\end{array}$ & $\$ 1.70^{\star}$ & $\$ 1.95^{\star}$ & $\$ 2.08^{\star}$ \\
\hline$\$ 550$ & $\$ 2.10 / \mathrm{gal}$ & $\$ 2.32 / \mathrm{gal}$ & $\$ 2.46 / \mathrm{gal}$ \\
\hline
\end{tabular}

Economic Support $\$ 1 /$ gallon for 10 years

\begin{tabular}{|c|c|c|c|}
\hline Wood Cost & $\$ 4 /$ ton & $\$ 26 /$ ton & $\$ 36 /$ ton \\
\hline $\begin{array}{c}\text { Plant Cost } \\
\text { (millions) }\end{array}$ & $\$ 0.74^{\star}$ & $\$ 1.01^{\star}$ & $\$ 1.15^{\star}$ \\
\hline$\$ 550$ & $\$ 1.12 / \mathrm{gal}$ & $\$ 1.38 / \mathrm{gal}$ & $\$ 1.52 / \mathrm{gal}$ \\
\hline
\end{tabular}

${ }^{\star}$ F-T Diesel Price \$/gal required for a $20 \%$ IRR

TABLE 2

Table 2 illustrates how a larger size helps the 6,000 bbl/d BTL plant economics significantly, lowering the required plant tailgate wholesale price from $\$ 3.89 /$ gallon to $\$ 2.32$ /gallon with no federal support. With an energy credit equal to biodiesel, the larger BTL plant could sell FT diesel at $\$ 1.01 /$ gallon if the investor accepts a 20 percent internal rate of return (IRR) where the wood-gathering cost is $\$ 26 /$ ton, and $\$ 1$.38.gallon for a 30 percent IRR. This F-T diesel price is below recent crude oil-based diesel wholesale prices. Once the capital costs of the BTL plant are paid, the plant could compete at today's diesel prices with no additional support, we believe.

As availability of wood and wood waste decreases, the BTL plant feedstock could be supplemented with coal. While coal costs per ton are considerably lower, $\$ 11$ per ton for coal compared with $\$ 36$ per ton for biomass (we assume the energy value per ton is approximately the same for both), the federal energy credit for coal would be half that of the bio-renewable bio-mass, so the economics in the case of coal are not improved until the F-T plant capital has been recovered. As an example, at $\$ 36 /$ ton for bio-mass feedstock and a $\$ 1 /$ gal energy credit, the required F-T diesel price is $\$ 1.52 /$ gallon. The same plant operating with coal priced at $\$ 13 /$ ton, but only receiving a $\$ 0.50 /$ gallon energy credit, requires $\$ 1.69 /$ gallon for F-T diesel to achieve the same IRR. 


\section{Diesel price (wholesale) (\$/gal) required for a $30 \%$ IRR project 6,000 bbl/d coal-to-liquids F-T plant at Nikiski}

No economic support

\begin{tabular}{|c|c|c|c|}
\hline Coal Cost & & $\$ 13 /$ ton & $\$ 16 /$ ton \\
\hline $\begin{array}{c}\text { Plant Cost } \\
\text { (millions) }\end{array}$ & & $\$ 1.84^{\star}$ & $1.88^{\star}$ \\
\hline$\$ 550$ & & $\$ 2.16 / \mathrm{gal}$ & $\$ 2.21 / \mathrm{gal}$ \\
\hline
\end{tabular}

Economic support 50 cents/gallon for 10 years

\begin{tabular}{|c|c|c|c|}
\hline Coal Cost & $\$ 13 /$ ton & $\$ 16 /$ ton \\
\hline $\begin{array}{c}\text { Plant Cost } \\
\text { (millions) }\end{array}$ & & $\$ 1.39^{\star}$ & $\$ 1.44^{\star}$ \\
\hline$\$ 550$ & & $\$ 1.69 / \mathrm{gal}$ & $\$ 1.74 / \mathrm{gal}$ \\
\hline
\end{tabular}

${ }^{*}$ F-T Diesel Price \$/gal required for a 20\% IRR

TABLE 2A

At $6,000 \mathrm{bbl} / \mathrm{d}(250,000 \mathrm{gal})$ of F-T diesel production, such a plant will exceed the local market need and require markets outside the region, such as the U.S. West Coast. However, we believe that by 2010 , all diesels fuel, on-road, off-road and marine, will be required to meet the new EPA ultra-low sulfur (15 PPM) standards. At zero sulfur, BTL F-T diesel could be in demand.

One other advantage of a Nikiski location is that it also provides opportunities for the syn-gas produced by the gasifier. It could, for example, provide syn-gas to a fertilizer plant. The Agrium Corp. plant at Nikiski has announced it may close because of an inability to acquire low cost natural gas to make syn-gas for its process. A BTL-based gasifier could help supply this need. 


\section{CASE 2: Beluga, Alaska}

\section{6,000 bbl/d Coal based F-T plant (CTL) with expansion capabilities beyond $80,000 \mathrm{bbl} / \mathrm{d}$}

Located across the Cook Inlet from the Nikiski industrial site is the identified but undeveloped Beluga coal field. The Beluga area contains one of the world's largest surfacemineable reserves of low-sulfur coal close to tidewater and ocean shipping. There are an estimated 2 billion tons of proven and probable subbituminous coal but economically recoverable reserves are estimated at 500 million to 750 million tons. The coal's principal attraction is its lowsulfur content. It is a significant natural resource that could supply a coal-to-liquids (CTL) F-T plant. The F-T plant location we assume is at a

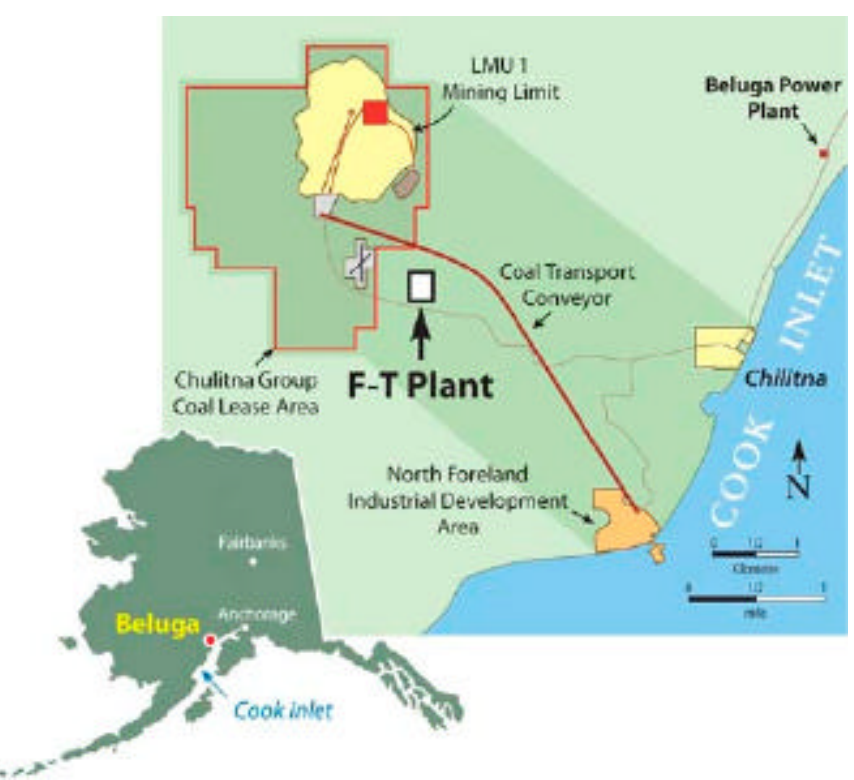
coal mine proposed by its owners, the Chulitna Group, located 12 miles from the Cook Inlet shoreline. Another company, Placer Dome U.S., owns additional coal resources nearby. The Chulitna Group's leases are approximately 12 miles from existing electrical infrastructure at the 380 Megawatt Chugach Beluga power plant, which is owned and operated by Chugach Electric Association, the regional electric utility. Most of the gas turbines at the plant are simple cycle turbines 25 to 35 years in age.

Little infrastructure: Outside of the Beluga power plant and its connection to the regional electric grid, there is little infrastructure to support the development of the coal mine or an F-T plant. There are few roads in the area, and those that are present are gravel. Chugach's power plant operates as a remote site, with workers housed at the location. There is a dock in the nearby community of Tyonek for use during construction, and there is also an oil export terminal, Drift River, located to the south of the proposed Beluga mine and F-T plant that could be expanded.

Because of this lack of infrastructure, in our analysis we have added an additional $\$ 100$ million to the capital cost of the $6,000 \mathrm{bbl} / \mathrm{d}$ Nikiski BTL project, bringing the estimate cost to $\$ 650$ million for an F-T plant at this location. A 6,000 bbl/d CTL F-T plant will require approximately 3,000 tons per day of coal, or approximately 1.1 million tons per year. If the existing Beluga power station were converted to a modern integrated gasification combined cycle (IGCC) power station, it could add an additional 1 million 
tons per year of coal requirement. The owners of the coal leases have said that $750,000 \mathrm{o}$ 1 million tons a year of coal demand might be enough to justify the mine development.

For the purpose of this analysis we will assume that an adequate export market will be found and the coal costs at the mine mouth will be in the $\$ 9$ to $\$ 13 /$ ton range. The assumed coal prices are for illustration only and do not represent prices that a coal mine developer would actually charge. While the F-T process will also produce large quantities of waste heat for the generation of low cost electric power, we do not consider any benefit from this in the analysis. In addition to the extra costs associated with building the supporting infrastructure, we have also added one additional year to the three-year time estimate for the Nikiski BTL plant to construct the similar sized Beluga CTL project.

\section{Frame of reference}

\section{Cook Inlet region:}

2004 conventional diesel OPIS Pacific Northwest wholesale during summer season Alaska shipping period $\$ 1.40 /$ gal.

Estimated premium ULS diesel, post 2006-2010

$\$ 0.10 /$ gal. $^{*}$

Total:

$\$ 1.50 /$ gal.

*ULS diesel premium estimates vary 10 cents/gal. to 75 cents/gal.

\section{Diesel price (wholesale) (\$/gal) required for a $30 \%$ IRR project $6,000 \mathrm{bbl} / \mathrm{d}$ coal-to-liquids F-T plant at Beluga}

No Economic Support

\begin{tabular}{|c|c|c|c|}
\hline Coal Cost & $\$ 9 /$ ton & $\$ 11 /$ ton & $\$ 13 /$ ton \\
\hline $\begin{array}{c}\text { Plant Cost } \\
\text { (millions) }\end{array}$ & $\$ 2.02^{\star}$ & $\$ 2.04^{\star}$ & $\$ 2.07^{\star}$ \\
\hline$\$ 650$ & $\$ 2.49 / \mathrm{gal}$ & $\$ 2.52 / \mathrm{gal}$ & $\$ 2.55 / \mathrm{gal}$ \\
\hline
\end{tabular}

Economic Support $.50 \% / g a l l o n$ for 10 years

\begin{tabular}{|c|c|c|c|}
\hline Coal Cost & $\$ 9 /$ ton & $\$ 11 /$ ton & $\$ 13 /$ ton \\
\hline $\begin{array}{c}\text { Plant Cost } \\
\text { (millions) }\end{array}$ & $\$ 1.55^{\star}$ & $\$ 1.58^{\star}$ & $\$ 1.61^{\star}$ \\
\hline$\$ 650$ & $\$ 2.00$ & $\$ 2.03 / \mathrm{gal}$ & $\$ 2.06 / \mathrm{gal}$ \\
\hline
\end{tabular}

${ }^{\text {* }}$ F-T Diesel Price \$/gal required for a $20 \%$ IRR

TABLE 3 
Table 3 illustrates the effect of plant cost, feedstock cost and economic support on the wholesale price of F-T diesel at the plant tailgate to achieve a 30 percent IRR for a plant investor. $\$ 650$ million represents the cost of a new CTL plant at a mine mouth location. We consider coal costs of $\$ 9 /$ ton, $\$ 11 /$ ton and $\$ 13 /$ ton as representative of a range of expected coal costs provided by the Beluga coal field owners. Table 3 shows that without federal support like an energy credit, the 6,000 bbl/d Beluga CTL plant cannot produce F-T diesel competitive with today's Cook Inlet crude based diesel prices. Even with a significant energy credit, the CTL plant will struggle to sell its F-T diesel unless the price of crude oil stays above $\$ 45 / \mathrm{bbl}$, our analysis indicates. Lower feedstock costs at Beluga compared with Nikiski, coupled with a lower energy credit, do not offset the higher costs associated with the Beluga "Greenfield" site.

\section{A larger plant would achieve economies of scale}

Expansion of the CTL plant at Beluga provides an example of how bigger might be better. The Beluga mine mouth site represents a good location to expand the size of the CTL F-T plant to take advantage of scale-up economics. While it is outside the scope of this analysis, which is focused on smaller F-T plants, we believe an 80,000 bbl/d CTL plant at this location could support development of the Beluga coal mine by itself while reducing the unit cost of the installed facility, especially the necessary support infrastructure. We estimate that the Beluga 6,000 bbl/d CTL facility will cost over $\$ 100,000$ per installed barrel while an $80,000 \mathrm{bbl} / \mathrm{d}$ facility could cost under $\$ 65,000$ per installed barrel. In addition, the 10 million tons per year of coal supply needed for an $80,000 \mathrm{bbl} / \mathrm{d}$ plant could enjoy a coal price of $\$ 9 /$ ton or less because of the larger quantities purchased. Expansion of the supporting pipeline, tank storage and export terminal capacity at the Drift River terminal will further improve the CTL economics.

Additional facilities built in the area, as development of the mine proceeds, could also support a bio-mass collection point for wood and wood waste produced throughout South-central and Southeast Alaska. With many interior Alaska communities on rivers or currently receiving their annual load of diesel fuel via water, a Beluga F-T site could serve these communities with ultra-clean diesel fuel made from Alaska coal while exporting the majority of the F-T diesel to markets on the U.S. west coast, primarily California where low aromatic diesel fuels are prized

How the financial analysis was done: All analyses in the regional scenarios assume a private investor providing between 20 percent to 25 percent equity and earning either 20 percent or 30 percent internal rate of return (IRR) before federal tax. A 30 percent rate of return res ults in approximately a 19 percent rate of return after federal tax depending on the tax status of the investor. Until several F-T plants, especially small footprint F-T plants, are successfully built and operated, we judge these rates of return to be at he levels required to attract a private investor. Debt is assumed to have a 15-year payback at a 7.5 percent interest rate. The analyses have also reserved 18 percent of net cash flow for local and state taxes. In all cases design and construction is estimated at three and a half years except in the case of the BP gas-to-liquids plant conversion to biomass, in which we assume one year. Capital costs in the case of coal and bio-mass were derived from data made available from Choren Industries of Germany and from Sasol, of South Africa, for a larger coal-to-liquids plant at Beluga. 


\section{CASE 3: Healy, Alaska}

\section{6,000 coal-to-liquids (CTL) F-T site}

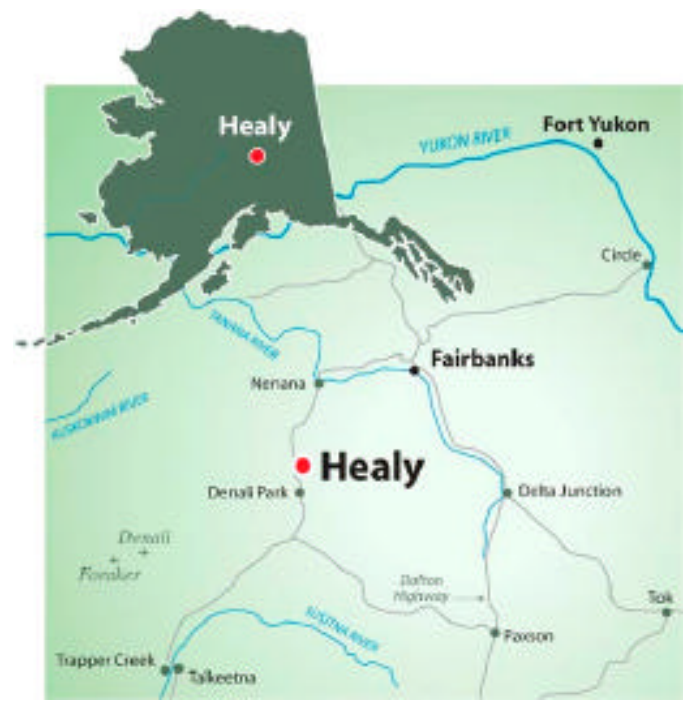

We examined Healy, Alaska as a potential site for a $6,000 \mathrm{bbl} / \mathrm{d}$ coal based Fischer-Tropsch plant. Healy was selected for study because it is has a producing coal mine and because the location has ready access to the Alaska Railroad for bulk transport of liquids along the railbelt. Access to the Anchorage-Fairbanks electric Intertie, a long-distance electric transmission line, is also an advantage. There are two coalfired power plants at Healy, and the potential for sharing of waste heat, infrastructure and support services, although opportunities for this may be limited.

The principal advantage of Healy is the presence of a producing coal mine with the potential to expand production without major additional capital expense. Usibelli Mine Inc., the owner of the mine, has been producing coal at Healy for over 60 years. The reliability of the operator and its efficiency in supplying coal are well established. The mine currently produces 1.2 million to 1.5 million tons per year of sub-bituminous coal, employs approximately 95, and supplies coal to six coal-fired power plants in Interior Alaska plus exports coal to South Korea via the Alaska Railroad and a coal export terminal at Seward, on the southeast coast of the Alaska Kenai Peninsula. Test shipments to plants in Latin America have also been made.

Existing industrial facilities: Healy has existing industrial facilities, including two coal fired power plants (one currently closed down) as well as bulk coal-handling facilities that support the coal mine and the loading of coal on rail cars. Industry support services established for the mine and power stations (fire protection, medical, etc.) could also support an F-T plant construction and operation. Power is available from coal-fired power plant at Healy, and any additional power generated from sales of waste heat from the F-T plant can be readily marketed over the existing electric Intertie.

The Alaska Railroad currently operates bulk liquids trains through Healy, carrying fuel products from the Flint Hills refinery from North Pole, near Fairbanks, to Anchorage. The railroad has a long history of reliable service in this regard, lending confidence to our assumption that rail would be an efficient way to transport 91 million gallons a year of liquids products made in a $6,000 \mathrm{bbl} /$ day F-T plant. 
Usibelli Mine Inc.'s 1300 W Bucyrus-Erie Walking Dragline being moved to the company's Two-Bull Ridge mining area. Usibelli has been mining coal at Healy since 1943.

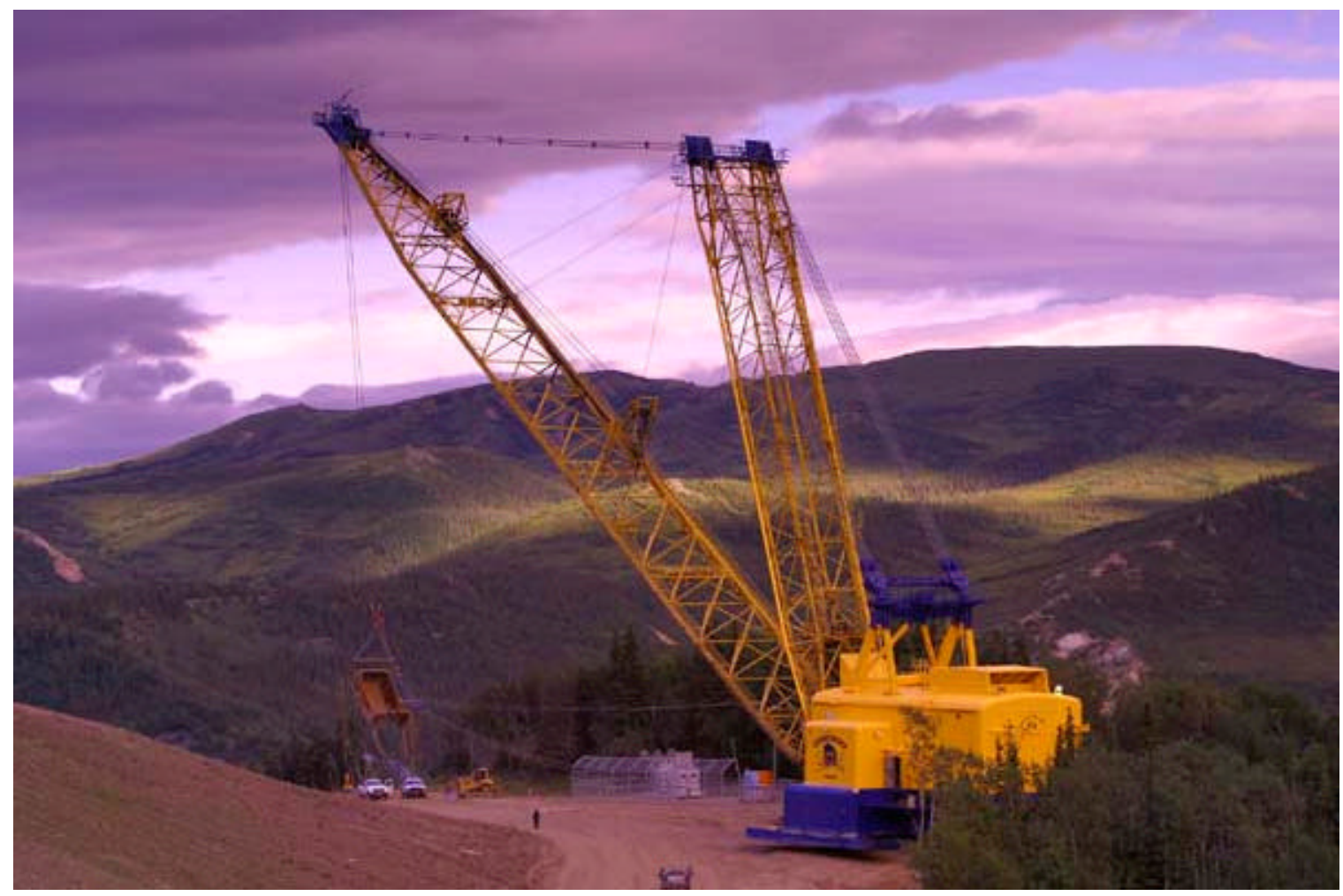

There is experience in construction of complex industrial facilities at Healy. The 50Megawatt advanced-technology Healy Clean Coal Project was built in 1996 and 1997 at a cost of over $\$ 300$ million, so there is a degree of confidence in construction experience in the Interior region. There would be more uncertainty, in contrast, with construction in new "Greenfield" sites such as Galena, Fort Yukon and Bristol Bay. While Healy does not enjoy the same level of infrastructure that an F-T plant in Nikiski would have it is close to a long-term source of feedstock, coal. The regional coal resource may be nearly as large as at Beluga, but with 100 million tons-plus of current proven reserves and an annual need of 1 million tons, the coal reserve life is more than adequate to support the FT plant. Construction costs at Healy should be lower than at Beluga because of existing road access from the surrounding communities. However, the economics of a plant at Healy would be adversely affected by the need to transport the liquid products by rail to the Anchorage/Fairbanks area, which is where most products would be marketed. For Interior Alaska rural communities Healy is relatively close to Nenana, the major shipping point for seasonal fuel delivery by barge to villages on the Yukon River and its tributaries. From the standpoint of supplying F-T products to Alaska military installations, the plant's location would allow it to supply Elmendorf Air Force Base and Fort Richardson near Anchorage, to the south, and Eielson Air Force Base and Fort Wainwright near Fairbanks, to the north.

Unlike a Nikiski or Beluga F-T plant site, a Healy plant does not have depleted gas reservoirs in the area for storage or utilization of $\mathrm{CO}_{2}$. Thus, the plant would not be eligible for $\mathrm{CO}_{2}$ credits, a possible source of revenue. On the other hand, the waste heat 
from an F-T plant would be considerable and the plant could produce very inexpensive electricity for the regional power grid over the Anchorage-Fairbanks electric Intertie, which comes through Healy. We do not quantify benefits of sales of waste heat.

We estimate that a $6,000 \mathrm{bbl} /$ day F-T plant at Healy would cost approximately $\$ 600$ million and take 3.5 years to construct. A plant of this size would require a supply of about 1 million tons of sub-bituminous coal per year, which is possible from the present mine with an expansion. We estimate costs of 5 cents to 6 cents/gallon to transport F-T products to Anchorage or Fairbanks by rail, or by rail or truck to Nenana for seasonal shipment to the Yukon River system via the Tanana River. Although beyond the scope of this report, at 5 cents/gallon (\$2 per barrel,) shipping costs of liquids to Anchorage, we believe an economic analysis should be made for bringing Healy coal to the Cook Inlet area to take advantage of the depleted reservoirs for $\mathrm{CO}_{2}$ sequestration, available natural gas for startup, the presence of export terminals and possibly the combining of Beluga and Healy mining capacity for a larger F-T plant.

\section{Diesel price (wholesale) (\$/gal) required for a $30 \%$ IRR project $6000 \mathrm{bbl} / \mathrm{d}$ coal-to-liquids F-T plant at Healy}

No Economic Support

\begin{tabular}{|c|c|c|c|}
\hline Coal Cost & $\$ 9 /$ ton & $\$ 11 /$ ton & $\$ 13 /$ ton \\
\hline $\begin{array}{c}\text { Plant Cost } \\
\text { (millions) }\end{array}$ & $\$ 1.89^{\star}$ & $\$ 1.92^{\star}$ & $\$ 1.95^{\star}$ \\
\hline$\$ 600$ & $\$ 2.25 / \mathrm{gal}$ & $\$ 2.28 / \mathrm{gal}$ & $\$ 2.31 / \mathrm{gal}$ \\
\hline
\end{tabular}

Economic Support 50\%/gallon for 10 years

\begin{tabular}{|c|c|c|c|}
\hline Coal Cost & $\$ 9 /$ ton & $\$ 11 /$ ton & $\$ 13 /$ ton \\
\hline $\begin{array}{c}\text { Plant Cost } \\
\text { (millions) }\end{array}$ & $\$ 1.43^{\star}$ & $\$ 1.45^{\star}$ & $\$ 1.48^{\star}$ \\
\hline$\$ 600$ & $\$ 1.78 / \mathrm{gal}$ & $\$ 1.81 / \mathrm{gal}$ & $\$ 1.83 / \mathrm{gal}$ \\
\hline
\end{tabular}

${ }^{\star}$ F-T Diesel Price \$/gal required for a 20\% IRR

TABLE 4

Table 4 included here illustrates the effect of plant cost, feedstock cost and possible federal economic support on the wholesale price of F-T diesel required at the plant "tailgate" to achieve a 30 percent and 20 percent IRR for a 20 percent equity plant investor. The assumed coal prices are for illustration only and do not represent prices that a coal producer would actually charge. Six hundred million dollars represents the cost of 
a new CTL plant at the location. Estimated coal costs of $\$ 9 /$ ton, $\$ 11 /$ ton and $\$ 13 /$ ton represent a range of expected delivered coal prices. The table shows that without an energy credit or some other form of support, the 6,000 bbl/d Healy CTL plant cannot produce F-T diesel products competitive with conventional diesel prices. With federal support and a 20 percent investor IRR, the Healy CTL plant could not sell F-T diesel competitively unless the price of crude oil is $\$ 45 / \mathrm{bbl}$ or above.

How the financial analysis was done: All analyses in the regional scenarios assume a private investor providing between 20 percent to 25 percent equity and earning either 20 percent or 30 percent internal rate of return (IRR) before federal tax. A 30 percent rate of return results in approximately a 19 percent rate of return after federal tax depending on the tax status of the investor. Until several F-T plants, especially small footprint F-T plants, are successfully built and operated, we judge these rates of return to be at the levels required to attract a private investor. Debt is assumed to have a 15-year payback at a 7.5 percent interest rate. The analyses have also reserved 18 percent of net cash flow for local and state taxes. In all cases design and construction is estimated at three and a half years except in the case of the BP gas-to-liquids plant conversion to biomass, in which we assume one year. Capital costs in the case of coal and bio-mass were derived from data made available from Choren Industries of Germany . 


\section{CASE 4: Bristol Bay, Alaska}

\section{2,000 bbl/d barge mounted natural gas supplied F-T Plant}

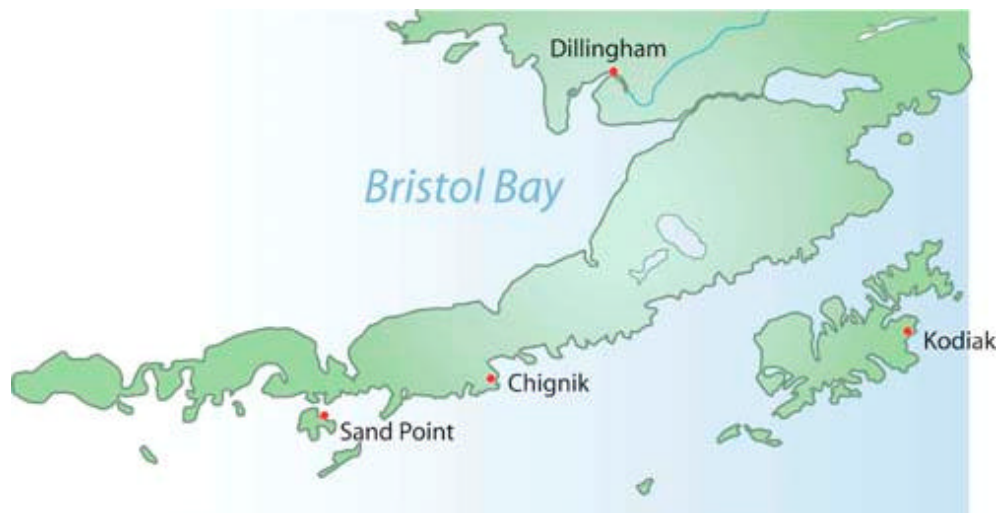

to the region's rich fisheries. No federal or state lease sales have been held in recent years, and there has therefore been no attention from industry.

That is now changing, at the initiative of the local communities. The local fisheries have declined and there is now support in the region for onshore exploration or offshore exploration where wells could be drilled from onshore. The state of Alaska plans leasing of state lands in the middle to southern part of the Bristol Bay basin.

We considered a case for a 12,000 barrels/day gas-to-liquids (GTL) bargemounted plant as an option for Bristol Bay gas commercialization. The GTL barge would require 120 million cubic feet $(\mathrm{mmcf} / \mathrm{d})$ of gas or 1 trillion cubic feet (tcf) over 25 years. In the event that gas discoveries are too small to support a conventional gas pipeline or a liquefied natural gas (LNG) export program (a rule-of-thumb is that 5 tcf to $6 \mathrm{tcf}$ are needed for LNG) we believe GTL could be a viable option (only 1 tcf to 2 tcf would be needed.) While

\section{Frame of reference}

\section{Bristol Bay region:}

2004 conventional diesel Oil Price Information Service (OPIS) Pacific Northwest wholesale during summer season Alaska shipping period $\$ 1.40 /$ gal.

Estimated premium ULS diesel, post 2006-2010 $\$ 0.10 /$ gal. $^{*}$

Total: $\$ 1.50 /$ gal.

*ULS diesel premium estimates vary from 10 cents/gal. to 75 cents/gal for Arctic-grade ULS diesel. export sales would be needed to justify such a plant, its development would also make ultra-clean F-T fuels available in the western Alaska region. 
In the 1990s, Sasol and Norwegian State owned Statoil considered barge-mounted GTL plants as a way to exploit remote small gas fields. More recently Syntroleum, a U.S. company, has worked on a similar program for the military. This analysis uses data from both the Syntroleum and Sasol programs to evaluate a 12,000 bbl/d barge-mounted F-T plant positioned in a sheltered shallow-water location in a port along the north side of the Alaska Peninsula. This location would be near offshore or onshore natural gas discoveries that we assume could be made on nearby state lands or private lands owned by Bristol Bay Native Corporation.

Our analysis considers a hypothetical $\$ 750$ million barge-mounted F-T plant capable of producing 12,000 barrels per day of F-T diesel and naphtha; along with a floating products storage system (FPSS) capable of holding up to one month's production of products, or 360,000 barrels. As stated previously, the plant would require 120 million cubic feet per day of gas supply and a gas reserve of at least 1.1 trillion cubic feet. Gas is the assumed feedstock for the plant because of the gas-prone nature of the regional geology, although there are also coal resources in the region.

Coal deposits are known to exist near Chignik and Port Heiden. While it is conceivable that an onshore coal- to-liquids F-T plant could be built near those communities to use coal as a feedstock, in that case the economics of the project would also have to include the cost of developing a coalmine. The mine would have to be large enough to supply approximately 2 million tons per year of coal so the plant could operate at sufficient volumes to achieve economies of scale. It could be possible that a combination of coal and natural gas might be possible.

If a barge-mounted gas-to-liquids F-T plant were built, its liquid products could be directly loaded into a floating petroleum storage facility and then into barges for delivery to communities in the region. An alternative plan could involve transport of products across the Alaska Peninsula to a deep-water port on the south side through a smalldiameter liquids pipeline. There are positives and negatives with both alternatives. However, our analysis focuses on the direct loading of barges at a plant on the north side of the peninsula. The cross-peninsula pipeline option requires evaluation beyond the scope of this report.

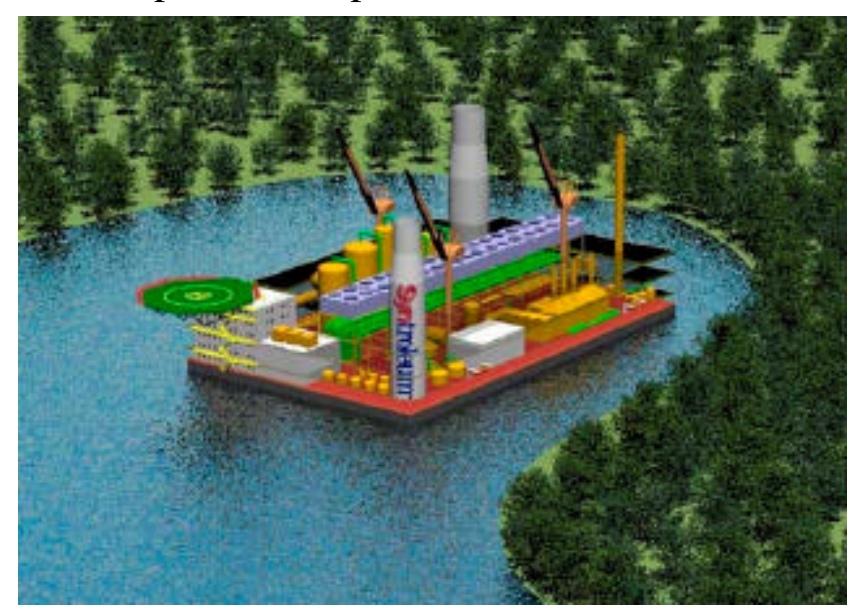

A shore-based F-T plant is also a possibility, but in our view the additional cost of building a complex plant at a remote location with no onshore support infrastructure would far exceed the costs projected by Sasol and Syntroleum for a similar sized barge-mounted facility.

Artist's rendering of a barge-mounted GTL plant of a type being developed by Syntroleum Corp. 
Our analysis assumes a barge-mounted F-T plant installed at a near shore location in one of three locations on the northern, Bristol Bay side of the Alaska Peninsula; in or near Herendeen Bay, Port Heiden or Pilot Point would be situated in areas where oil and gas could possibly be discovered nearby. All three locations could support direct-loading operations of barges for fuel deliveries within the region and other western Alaska communities.

FPSS loading operations for larger tankers needed for the export of products outside Alaska will require extensive studies to determine water depth, wind, wave, and ice impacts for specific sites. It may be possible to also locate the FPSS barge in a deeperwater area of Bristol Bay with a products line from the F-T plant to a storage/loading facility.

All three F-T barge locations we consider, Herendeen Bay, Port Heiden or Pilot Point, could also serve a products pipeline built to deep-water port locations on the southern side of the peninsula. Possible routes for a cross-peninsula pipeline from those communities, along with other pipeline routes, were considered in studies by the U.S. Minerals Management Service in the 1980s. The FPSS barge concept could also be employed in one of the deep-water port locations on the southern side of the peninsula where level land is not available to avoid having to build onshore tankage and products export dock.

No one has built a small scale (pilot size) barge-mounted F-T plant upon which to base a good economic model for a $12,000 \mathrm{bbl} / \mathrm{d}$ or larger facility. Further, one of the few detailed studies reported uses large volumes of conventional gas processing modules on the F-T barge to extract natural gas liquids, such as propane, butane, natural gasoline and naphtha, from a different gas stream (i.e. "wet" gas as would be produced as solution gas with oil) than we would expect from lean, or dry, gas that may be discovered in Bristol Bay. 


\section{Diesel price (wholesale) (\$/gal) required for a $30 \%$ IRR project $12,000 \mathrm{bbl} / \mathrm{d}$ natural gas-to-liquids (GTL) F-T plant at Bristol Bay}

No Economic Support

\begin{tabular}{|c|c|c|c|c|c|c|c|}
\hline Gas Cost & $\$ 1 / \mathrm{mmbtu}$ & $\$ 1.5 / \mathrm{mmbtu}$ & $\$ 2 / \mathrm{mmbtu}$ & Gas Cost & $\$ 1 / \mathrm{mmbtu}^{\prime}$ & $\$ 1.5 / \mathrm{mmbtu}$ & $\$ 2 / \mathrm{mmbtu}$ \\
\hline $\begin{array}{c}\text { Plant Cost } \\
\text { (millions) }\end{array}$ & $\$ 1.23 / \mathrm{gal}^{*}$ & $\$ 1.38 / \mathrm{gal}^{*}$ & $\$ 1.52 / \mathrm{gal}^{*}$ & $\begin{array}{c}\text { Plant Cost } \\
\text { (millions) }\end{array}$ & $\$ 0.95 / \mathrm{gal}^{*}$ & $\$ 1.09 / \mathrm{gal}^{*}$ & $\$ 1.24 / \mathrm{gal}^{*}$ \\
\hline$\$ 750$ & $\$ 1.43 / \mathrm{gal}$ & $\$ 1.58 / \mathrm{gal}$ & $\$ 1.72 / \mathrm{gal}$ & $\$ 750$ & $\$ 1.14$ & $\$ 1.28 / \mathrm{gal}$ & $\$ 1.42 / \mathrm{gal}$ \\
\hline
\end{tabular}

${ }^{\star}$ F-T Diesel Price \$/gal required for a $20 \%$ IRR

TABLE 4

The table above illustrates the effect of plant cost, feedstock cost and economic support on the wholesale price of F-T diesel at the barge plant tailgate to achieve a 30 percent IRR for a 20 percent equity plant investor in the GTL plant. We assume $\$ 750$ million as the cost of a new 12,000 bbl/d GTL barge-mounted plant at a protected Bristol Bay location. This cost also includes a 400,000-barrel floating petroleum storage system (FPSS) to serve as a storage and export terminal. Essentially, a FPSS is a converted older tanker with the engine removed so that it serves as a floating storage and loading facility.

We assumed a natural gas cost of $\$ 1 / \mathrm{mmbtu}, \$ 1.5 / \mathrm{mmbtu}$ and $\$ 2 / \mathrm{mmbtu}$ as a representative range of expected gas costs needed to economically support stand-alone exploration, drilling and production costs. The table above shows that without a federal support such as an energy credit, the 12,000 bbl/d Bristol Bay barge-mounted natural gas based GTL plant can not produce F-T diesel competitive with today's crude-based diesel prices for export outside of the region but may be competitive with local delivered costs of conventional diesel. With a $\$ 0.31 /$ gal energy credit (the same tax credit compressed natural gas (CNG) enjoys in Lower 48 markets) a Bristol Bay barge-mounted GTL plant could be competitive with conventional diesel at today's crude prices. 
Assuming that natural gas in the Bristol Bay area could be found, developed, produced and delivered to a barge mounted F-T at the costs shown and with the type of federal tax credit envisioned (what CNG now receives) such a project could help develop the region's resources, stimulate the local economy with jobs and supply the region with clean fuels for electric power generation and transport.

\section{Potential plant sites in the Bristol Bay region:}

Regional climate: The climate of the region is northern maritime, with extensive precipitation between July and October. Offshore winter ice is not considered a problem off either the Pacific or Bering Sea coasts. Winter ice is not present off the southern coast, and on the northern Bering Sea coast winter ice coverage seldom exceeds 10 percent.

F-T plant site near Herendeen Bay: From Herendeen Bay (or Port Moller, nearby) on Bristol Bay a 43-mile pipeline could be built across to the southern part of the peninsula to a deepwater port site at Albatross Anchorage on Balboa Bay, which is considered one of the best deepwater harbors on the peninsula. Coastal waters are relatively shallow at both Herendeen Bay and Port Moller, with extensive mudflats and water depths that average less than 12 feet in the bays. There are channels of 60 feet depth in approaches to Port Moller and at low tides vessels of 40-foot drafts can be accommodated. Herendeen Bay's entrances can accommodate vessels of 90-foot draft. While there are challenges, it is possible that a barge with an F-T plant could be positioned in one of these areas.

F-T plant site near Port Heiden: There are two other alternatives for plant sites on the north side of the peninsula near pipeline corridors to the south side. From Port Heiden, a 45-mile pipeline could be built across the peninsula to Chignik Bay. While this is a natural pipeline corridor for terrain reasons, Chignik Bay is shallow. The local area also supports a substantial salmon fishery, which would lead to objections for other reasons to a pipeline terminus at Chignik Bay.

F-T plant site near Pilot Point: In the northern part of the peninsula a natural 50-mile pipeline corridor exists from Pilot Point, on the north side, to Wide Bay, on the south side. Wide Bay is considered to be an excellent port site, although shoals exist at its entrance.

\section{Oil and gas potential of the region:}

Geologists consider the Bristol Bay region to be more gas-prone although there is always the potential for oil discoveries. The southern part of the basin, along the western side of the Alaska Peninsula and adjacent offshore lands, is considered to have more potential for oil than the northern parts of the basin, around Bristol Bay itself.

The oil and gas potential of the Bristol Bay Basin has long been known. Oil seeps on the eastern Gulf of Alaska side of the Alaska Peninsula have been known since the early part 
of the $20^{\text {th }}$ century. There are two oil and gas provinces within the area, one in the northern part of the basin around Bristol Bay itself and the other along the Alaska Peninsula. Twenty-six wells have been drilled in the region between 1903 and 1981. Many of these wells had oil or gas shows but none were considered commercial. The gas shows in many of the wells were quite prominent, however.

How the financial analysis was done: All analyses in the regional scenarios assume a private investor providing between 20 percent to 25 percent equity and earning either 20 percent or 30 percent internal rate of return (IRR) before federal tax. A 30 percent rate of return results in approximately a 19 percent rate of return after federal tax depending on the tax status of the investor. Until several F-T plants, especially small footprint $\mathrm{F}$-T plants, are successfully built and operated, we judge these rates of return to be at the levels required to attract a private investor. Debt is assumed to have a 15-year payback at a 7.5 percent interest rate. The analyses have also reserved 18 percent of net cash flow for local and state taxes. In all cases design and construction is estimated at three and a half years except in the case of the BP gas-to-liquids plant conversion to biomass, in which we assume one year. Capital costs in the case of coal and bio-mass were derived from data made available from Choren Industries of Germany and from Sasol, of South Africa, for a larger coal-to-liquids plant at Beluga. For the Bristol Bay gas-to-liquids plant we use data from Sasol and Syntroleum Corp. of Tulsa, Oklahoma. 


\section{CASE 5: Galena, Alaska}

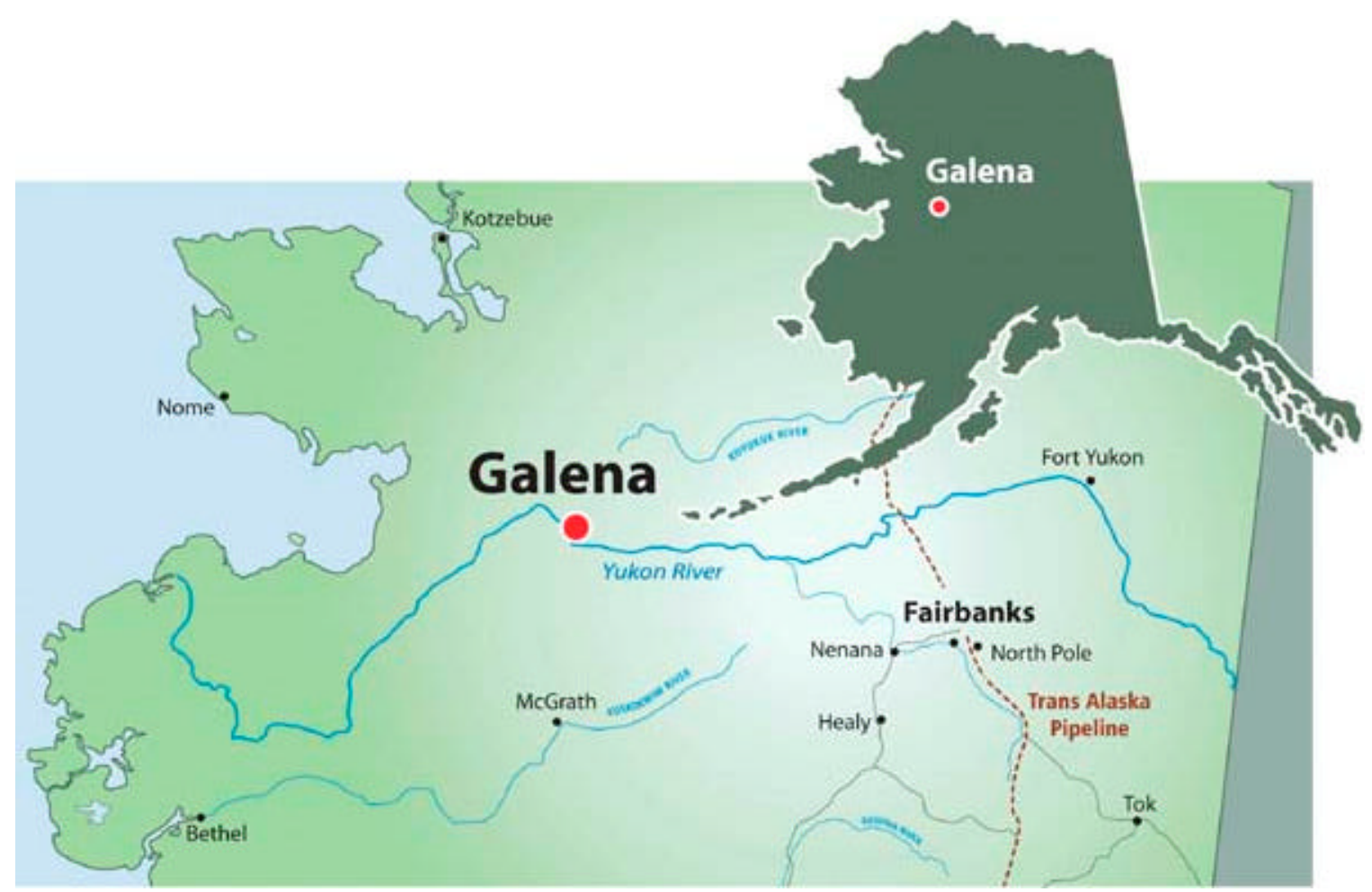

\section{$300 \mathrm{bbl} / \mathrm{d}$ coal-based (CTL) and biomass-based (BTL) F-T plants}

Galena is located on the Yukon River west of Fairbanks and northwest of Anchorage. It is a small community of approximately 750 (2000 census) but acts as a regional bulk fuel distribution center. Galena has a small U.S. Air Force forward interceptor base that is used periodically as well as other government facilities. We selected Galena as a site for evaluation of a small F-T plant in a rural location because of its remote location but also its well-established fuel transportation and storage infrastructure. Galena also has an identified coal deposit on the Yukon River 8 miles from the community that we consider in our analysis of a small (300 bbl/day) coal-to-liquids (CTL) F-T plant, as well as extensive timber resources in the region that could possibly supply wood to a small (300 bbl/day) bio-mass-to-liquids (BTL) F-T plant. 


\section{Diesel price (wholesale) (\$/gal) required for a $30 \%$ IRR project $300 \mathrm{bbl} / \mathrm{d}$ coal-to-liquids F-T plant at Galena}

No Economic Support

\begin{tabular}{|c|c|c|c|}
\hline Coal Cost & $\$ 25 /$ ton & $\$ 35 /$ ton & $\$ 45 /$ ton \\
\hline $\begin{array}{c}\text { Plant Cost } \\
\text { (millions) }\end{array}$ & $\$ 4.31^{\star}$ & $\$ 4.57^{\star}$ & $\$ 4.82^{\star}$ \\
\hline$\$ 65$ & $\$ 5.30 / \mathrm{gal}$ & $\$ 5.55 / \mathrm{gal}$ & $\$ 5.79 / \mathrm{gal}$ \\
\hline
\end{tabular}

Economic Support 50ф/gallon for 10 years

\begin{tabular}{|c|c|c|c|}
\hline Coal Cost & $\$ 25 /$ ton & $\$ 35 /$ ton & $\$ 45 /$ ton \\
\hline $\begin{array}{c}\text { Plant Cost } \\
\text { (millions) }\end{array}$ & $\$ 3.86^{\star}$ & $\$ 4.11^{\star}$ & $\$ 4.37^{\star}$ \\
\hline$\$ 65$ & $\$ 4.82 / \mathrm{gal}$ & $\$ 5.07 / \mathrm{gal}$ & $\$ 5.32 / \mathrm{gal}$ \\
\hline
\end{tabular}

${ }^{\star}$ F-T Diesel Price \$/gal required for a $20 \%$ IRR

TABLE 5

Table 5 illustrates the effect of plant and feedstock cost and the level of required economic support on the wholesale price F-T diesel at the plant tailgate to achieve a 30 percent IRR for an equity investor, assuming the plant is privately-owned. We assume $\$ 65$ million as the cost of a new $300 \mathrm{bbl} / \mathrm{d}$ CTL plant built in modular form and transported to a location near Galena, at a high ground site near the Yukon River (preferably at the coal deposit.) Coal costs of $\$ 25 /$ ton, $\$ 35 /$ ton and $\$ 45 /$ ton represent a range of costs used in our analysis. These coal costs are very speculative, and assume that the F-T plant would be the only customer in the area. Table 5 shows that without federal support like an energy credit, the $300 \mathrm{bbl} /$ day Galena CTL plant cannot produce F-T diesel at costs competitive with today's crude-based diesel prices delivered to the region. Even doubling the energy credit, a private Galena GTL plant would struggle to sell its F-T diesel unless the price of crude oil is well above $\$ 60$ per barrel.

As with other Interior Alaska locations, bio-mass, in the form of timber in the region, presents a potential feedstock for an F-T plant. To this end, we have evaluated a potential $300 \mathrm{bbl} /$ day bio-mass (BTL) plant for a Galena location. 


\section{Diesel price (wholesale) ( $\$ /$ gal) required for a $30 \%$ IRR project $300 \mathrm{bbl} / \mathrm{d}$ wood-to-liquids F-T plant at Galena}

No Economic Support

\begin{tabular}{|c|c|c|c|}
\hline Wood Cost & $\$ 25 /$ ton & $\$ 50 /$ ton & $\$ 109 /$ ton \\
\hline $\begin{array}{c}\text { Plant Cost } \\
\text { (millions) }\end{array}$ & $\$ 4.52^{\star}$ & $\$ 5.21^{\star}$ & $\$ 6.77^{\star}$ \\
\hline$\$ 65$ & $\$ 5.56 / \mathrm{gal}$ & $\$ 6.23 / \mathrm{gal}$ & $\$ 7.84 / \mathrm{gal}$ \\
\hline
\end{tabular}

Economic Support \$1/gallon for 10 years

\begin{tabular}{|c|c|c|c|}
\hline Wood Cost & $\$ 25 /$ ton & $\$ 50 /$ ton & $\$ 109 /$ ton \\
\hline $\begin{array}{c}\text { Plant Cost } \\
\text { (millions) }\end{array}$ & $\$ 3.62^{\star}$ & $\$ 4.29^{\star}$ & $\$ 5.87^{\star}$ \\
\hline$\$ 65$ & $\$ 4.60 / \mathrm{gal}$ & $\$ 5.28 / \mathrm{gal}$ & $\$ 6.86 / \mathrm{gal}$ \\
\hline
\end{tabular}

${ }^{*}$ F-T Diesel Price \$/gal required for a $20 \%$ IRR

TABLE 5A

An alternative to coal as feedstock is bio-mass from timber harvesting in the region, however, but having to deliver 250 tons per day of bio-mass (trees or wood-waste) at $\$ 25$ per ton could be a challenge even using the Yukon River as a method of transportation. In a very simplified analysis of the bio-mass option we relied on a 1981 study of a regional timber harvesting operation, with the further assistance of one of the study authors. The study was the Yukon Basin Timber Survey by Alaska Information and Research Services and Northern Forests, Ltd.

The 1981 study showed green wood chips being delivered from harvesting areas in the middle-Yukon region to the mouth of the Yukon, a 1,000 mile round trip. The costs are over 3 times higher than costs of delivering wood to the Nikiski BTL site discussed in the Nikiski section of this report. Delivering the green wood chips to an F-T plant near Galena would reduce transportation costs, but the extent of the cost-savings would require further study as well as an update of the 1981 estimate of timber harvesting costs. Authors of the 1981 study also note that there have been changes in regional land ownership as well as increased barge construction and fuel costs, which mean that relying on the 1981 study of timber harvesting and delivery can only give very general indications for the BTL option. 
Table 5A illustrates the effect of plant and feedstock cost and the level of required economic support on the wholesale price F-T diesel at the plant tailgate to achieve a 30 percent IRR for an equity investor, assuming the plant is privately-owned. We assume $\$ 65$ million as the cost of a new $300 \mathrm{bbl} / \mathrm{d}$ BTL plant built in modular form and transported to a location near Galena, at a high ground site near the Yukon River. Wood costs of \$25/ton, \$50/ton and \$109/ton represent a range of costs used in our analysis.

Table 5A shows that without federal support like an energy credit, the $300 \mathrm{bbl} / \mathrm{d} \mathrm{Galena}$ BTL plant cannot produce F-T diesel competitive with today's crude-based diesel prices delivered to the region. Even doubling the energy credit, a private Galena BTL plant would struggle to sell its F-T diesel unless the price of crude oil is above $\$ 60 / \mathrm{bbl}$.

In any event, the cost of BTL F-T diesel from a plant at this location would appear greater than \$6/gallon because the initial cost of the BTL plant as well as the high wood costs. The economics would be improved by approximately $10 \notin /$ gallon with a CO2 emission credits at $\$ 15 /$ ton using bio-mass instead of coal as the feedstock. Even so, the cost appears well above current fuel costs in the region. One other possibility is that of delivering dry wood rather than green wood, which could reduce transportation costs. Green wood contains up to 40 percent moisture, which is remo ved when the wood dries. Harvesting trees and stacking them in a wood yard near the river for a period, possibly several years, could accomplish this. However, even if the cost for the delivered wood is $\$ 50 /$ ton and the plant owner has a 20 percent IRR, the $\$ 4.29 /$ gallon required price will not be attractive.

Yet another possibility is to integrate the wood harvesting with a regional sawmill to use higher-value timber to manufacture building materials, with the waste used for the F-T plant. This would reduce the feedstock cost even further, but even at $\$ 25 /$ ton for biomass, the price of F-T diesel is $\$ 3.62 /$ gallon with an energy credit.

However, the bio-mass BTL plant's economic stimulus to the region is a factor that should be considered. Assuming a wood cost of $\$ 25 /$ ton, a Galena BTL project adds $\$ 2.2$ million to the local economy in wood purchases and $\$ 4.3$ million at $\$ 50 /$ ton. Our analysis also indicates such a plant could pay $\$ 600,000$ in local and state tax revenue and provide employment at the plant for about 25 people with an annual plant operations and maintenance cost of approximately $\$ 2$ million. We do not assume any credit for local electric power generation from waste heat, but it is safe to say that with ample waste heat available, electricity could be made available locally at very attractive rates compared with what Galena now pays for power generated with conventional diesel.

\section{Another way to look at a Galena project:}

The analysis above assumes a privately owned project that pays a return on investment to the owner. There are other ways a small rural F-T project could be done, however. 
Historically the federal government, in recent years through the U.S. Dept. of Agriculture rural economic development programs and the Denali Commission, has helped support projects for rural Alaska that would not be economic on their own due to their small size.

If there was government support for a rural plant in the form of capital grants it might be possible for a $300 \mathrm{bbl} / \mathrm{d}$ BTL plant at Galena to supply the diesel requirements for the Interior river and Bering Sea communities for under $\$ 1.25 /$ gallon, on average, FOB Galena and remain under $\$ 1.40 /$ gallon, on average, through 2025 . We assume, in the analysis in Table 5-B, that the capital costs of the F-T plant (\$55 million) and the wood gathering/transport costs for a tug, barge and chipper ( $\$ 10$ million) would be paid for in grants. If this were possible, the revenue stream from the sale of F-T diesel and naphtha produced would pay $\$ 2.2$ million annually for wood supply, provide jobs for several hundred people and would have sufficient cash flow to pay operating costs on a sustained basis.

\section{Diesel price (wholesale) (\$/gal) required for a $300 \mathrm{bbl} / \mathrm{d}$ bio-mass-to-liquids F-T plant at Galena}

No Economic Support

\begin{tabular}{|c|c|}
\hline Wood Cost & $\$ 24 /$ ton \\
\hline $\begin{array}{c}\text { Plant Cost } \\
\text { (millions) }\end{array}$ & $\$ 4.31^{\star}$ \\
\hline$\$ 65$ & $\$ 5.27 / \mathrm{gal}$ \\
\hline
\end{tabular}

Economic Support $\$ 1 /$ gallon for 10 years

\begin{tabular}{|c|c|}
\hline Wood Cost & $\$ 24 /$ ton \\
\hline $\begin{array}{c}\text { Plant Cost } \\
\text { (millions) }\end{array}$ & $\$ 3.38^{\star}$ \\
\hline$\$ 65$ & $\$ 4.32 /$ gal \\
\hline
\end{tabular}

97\% CAPEX Grant

\begin{tabular}{|c|c|}
\hline Wood Cost & $\$ 24 /$ ton \\
\hline $\begin{array}{c}\text { Plant Cost } \\
\text { (millions) }\end{array}$ & $\$ 1.08^{\star}$ \\
\hline$\$ 65$ & $\$ 1.15 /$ gal \\
\hline
\end{tabular}

${ }^{\star}$ F-T Diesel Price \$/gal required for a $20 \%$ IRR

TABLE 5B

Table 5B looks at a $\$ 65$ million total Galena BTL project (not including the saw mill costs) with a $\$ 63$ million government grant, a $\$ 1$ million equity owner investment and a $\$ 1$ million bank loan repaid in 15 years at $7.5 \%$ interest. The table shows that with the grant to pay the capital cost, the initial tailgate sales price could be as low as $\$ 1.08 /$ gallon, an attractive price for the region. At an average tailgate price of 
\$1.25/gallon, the F-T plant could generate enough revenue to sustain operations, covering operations and maintenance, and contingency costs, for 30 years. With the exception of a government grant to pay off the capital costs of a small F-T plant operation, small F-T plants located in remote locations would produce F-T diesel with costs over \$4/gallon, and could not economically compete with the delivered cost of conventional diesel today.

How the financial analysis was done: All analyses in the regional scenarios assume a private investor providing between 20 percent to 25 percent equity and earning either 20 percent or 30 percent internal rate of return (IRR) before federal tax. A 30 percent rate of return results in approximately a 19 percent rate of return after federal tax depending on the tax status of the investor. Until several F-T plants, especially small footprint F-T plants, are successfully built and operated, we judge these rates of return to be at the levels required to attract a private investor. Debt is assumed to have a 15-year payback at a 7.5 percent interest rate. The analyses have also reserved 18 percent of net cash flow for local and state taxes. In all cases design and construction is estimated at three and a half years except in the case of the BP gas-to-liquids plant conversion to biomass, in which we assume one year. Capital costs in the case of coal and bio-mass were derived from data made available from Choren Industries of Germany and from Sasol, of South Africa. 


\section{CASE 6: Fort Yukon}

\section{$300 \mathrm{bbl} / \mathrm{d}$ coal /bio-mass based F-T plant (CTL/BTL)}

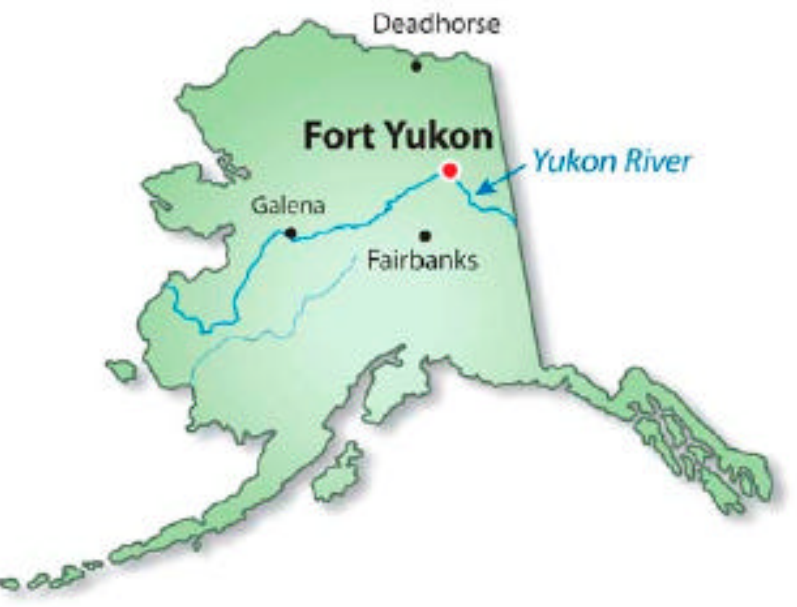

Fort Yukon, Alaska, sits at the confluence of the Yukon and Porcupine rivers about 145 air miles northeast of Fairbanks. It is just north of the Arctic Circle in the Yukon Flats National Wildlife Refuge.

The winters in Fort Yukon, population about 600, are long and harsh and the summers are short but warm. Daily minimum temperatures between November and March are usually below zero degrees Fahrenheit. Extended periods of minus 50 to minus 60 degrees are

common. Summer high temperatures run 65 to 72 degrees. The Yukon River is ice-free from the end of May through mid-September.

Table 6 illustrates the effect of coalto-liquids plant and feedstock cost and the level of required economic support on the wholesale price F-T diesel at the plant tailgate to achieve a 30 percent IRR for a plant investor, assuming the plant is privately-owned. We assume $\$ 65$ million as the cost of a new $300 \mathrm{bbl} / \mathrm{d}$ CTL plant built in modular form and transported to a location near Fort Yukon, at a high-ground site near the Yukon River. Coal costs of $\$ 25 /$ ton, $\$ 35 /$ ton and $\$ 45 /$ ton represent a range of costs used in our analysis. These coal costs are very speculative, and assume that the F-T plant would be the only customer in the area.

The table shows that with even with federal support like an energy credit, the $300 \mathrm{bbl} / \mathrm{d}$ Fort Yukon CTL plant cannot produce F-T diesel competitive with today's crude-based diesel prices delivered to the region. Even doubling the energy aredit, a private Fort Yukon CTL plant would struggle to sell its F-T diesel unless the price of crude oil is above $\$ 60 / \mathrm{bbl}$.

Diagram illustrates coal seams that underlie Fort Yukon at approximately 1,200 feet. Gas was detected in a 1994 test well drilled by the U.S. Geological Survey. The coal could be a source of coal-bed methane, or gas.

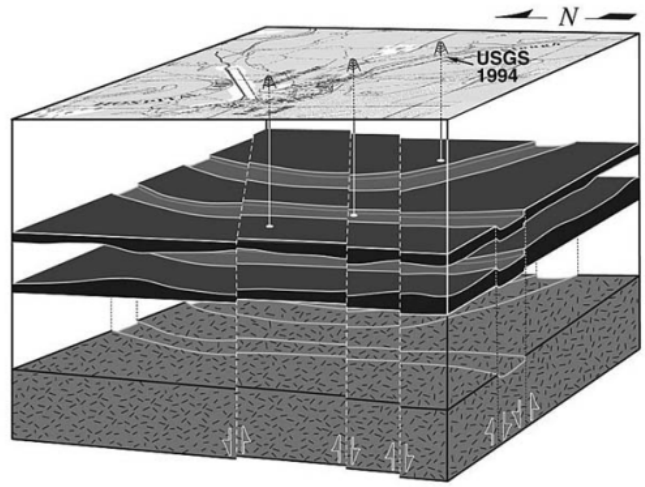




\section{Diesel price (wholesale) (\$/gal) required for a $30 \%$ IRR project $300 \mathrm{bbl} / \mathrm{d}$ coal-to-liquids F-T plant at Fort Yukon}

No Economic Support

\begin{tabular}{|c|c|c|c|}
\hline Coal Cost & $\$ 25 /$ ton & $\$ 35 /$ ton & $\$ 45 /$ ton \\
\hline $\begin{array}{c}\text { Plant Cost } \\
\text { (millions) }\end{array}$ & $\$ 4.31^{\star}$ & $\$ 4.57^{\star}$ & $\$ 4.82^{\star}$ \\
\hline$\$ 65$ & $\$ 5.30 / \mathrm{gal}$ & $\$ 5.55 / \mathrm{gal}$ & $\$ 5.79 / \mathrm{gal}$ \\
\hline
\end{tabular}

Economic Support $50 \% /$ gallon for 10 years

\begin{tabular}{|c|c|c|c|}
\hline Coal Cost & $\$ 25 /$ ton & $\$ 35 /$ ton & $\$ 45 /$ ton \\
\hline $\begin{array}{c}\text { Plant Cost } \\
\text { (millions) }\end{array}$ & $\$ 3.86^{\star}$ & $\$ 4.11^{\star}$ & $\$ 4.37^{\star}$ \\
\hline$\$ 65$ & $\$ 4.82 / \mathrm{gal}$ & $\$ 5.07 / \mathrm{gal}$ & $\$ 5.32 / \mathrm{gal}$ \\
\hline
\end{tabular}

${ }^{*}$ F-T Diesel Price \$/gal required for a 20\% IRR

TABLE 6

An alternative to coal as feedstock is bio-mass from timber harvesting in the region, but as in our Galena case having to deliver 250 tons per day of bio-mass (trees/wood-waste) at $\$ 25 /$ ton would be a challenge even using the Yukon River as a source of transportation.

In a very simplified analysis of the bio-mass option we relied on a 1981 study of a regional timber harvesting operation (cited in our analysis of Galena) with the further assistance of one of the study authors.

The 1981 study showed green wood chips being delivered from harvesting areas in the middle-Yukon region to the mouth of the Yukon, a 1,000 mile round-trip. These costs are over 3 times higher than costs of delivering wood to the Nikiski BTL site discussed in the Nikiski section of this report. Delivering the green wood chips to an F-T plant near Fort Yukon would reduce transportation costs, but the extent of the cost-savings would require further study as well as an update of the 1981 estimate of timber harvesting costs. Authors of the 1981 study also note that there have been changes in regional land ownership as well as increased barge construction and fuel costs, which mean that relying on the 1981 study of timber harvesting and delivery can only give very general indications for the BTL option. 
In any event, the cost of BTL F-T diesel from a plant at this location would appear greater than $\$ 6 /$ gallon because the initial cost of the BTL plant as well as the high wood costs. The economics would be improved by approximately $10 \propto /$ gallon with a $\mathrm{CO}_{2}$ emission credits at \$15/ton for using bio-mass instead of coal as the feedstock. Even so, the cost appears well above current fuel costs in the region. One other possibility is that of delivering dry wood rather than green wood, which could reduce transportation costs. Green wood contains up to 40 percent moisture, which is removed when the wood dries.

Harvesting trees and stacking them in a wood yard near the river for a period, possibly several years, could accomplish this. However, even if costs for the delivered wood are $\$ 50 /$ ton and the plant has a 20 percent IRR, the $\$ 4.29$ /gallon required price will not be attractive.

Yet another possibility is to integrate the wood harvesting with a regional sawmill to use higher-value timber to manufacture building materials, with the waste used for the F-T plant. This would reduce the feedstocks even further, but even at $\$ 25 /$ ton for bio-mass, the price of F-T diesel is $\$ 3.62 /$ gallon.

However, the bio-mass BTL plant's economic stimulus to the region is a factor that should be considered. Assuming a wood cost of \$25/ton, a Fort Yukon BTL project adds $\$ 2.2$ million to the local economy in wood purchases and $\$ 4.3$ million at $\$ 50 /$ ton. Our analysis also indicates such a plant could pay $\$ 600,000$ in local and state tax revenue, and provide employment at the plant for about 25 people with an annual plant operations and maintenance cost of approximately $\$ 2$ million. We do not assume any credit for local electric power generation from waste heat, but it is safe to say that the ample waste heat available could make electricity available locally at very attractive rates compared with what Fort Yukon now pays for power generated with conventional diesel.

\section{Another way to look at a Fort Yukon project:}

The analysis above assumes a privately owned project that pays a return on investment to the owner using either coal, coal-bed methane and/or bio-mass. The Fort Yukon area has coal and coalbed methane (gas from coal seams) potential, according to the Alaska Division of Geological and Geophysical Surveys. Assuming the coal-bed methane resource could be developed for a small gas-to-liquids (GTL) plant we modeled a 300 bbl/d GTL after the $300 \mathrm{bbl} / \mathrm{d}$ BP GTL plant at Nikiski, on the Kenai Peninsula in southern Alaska. While this facility was built as a demonstration/test facility, much of the same equipment and infrastructure would be required at a remote village site such as 
Fort Yukon. The concept would be to build the GTL plant in modules in Anchorage and transport the GTL plant on a barge up the Yukon to Fort Yukon. The modules would be moved inland outside the flood plain similar to the way oil modules are moved on the North Slope.

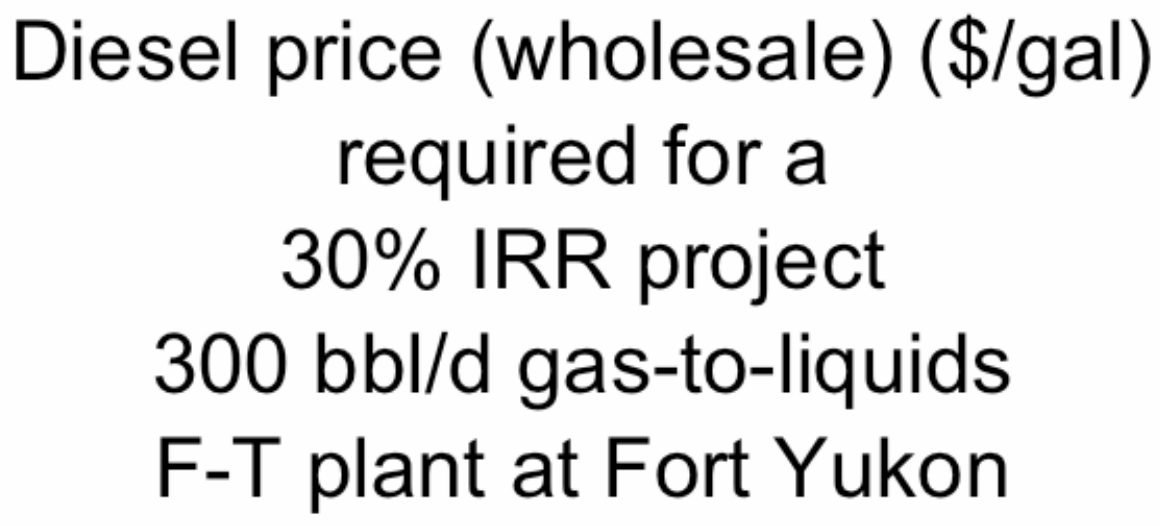

No Economic Support

\begin{tabular}{|c|c|c|c|}
\hline Gas Cost & $\$ 1 / \mathrm{mmbtu}$ & $\$ 2 / \mathrm{mmbtu}$ & $\$ 3 / \mathrm{mmbtu}$ \\
\hline $\begin{array}{c}\text { Plant Cost } \\
\text { (millions) }\end{array}$ & $\$ 5.02^{\star}$ & $\$ 5.34^{\star}$ & $\$ 5.67^{\star}$ \\
\hline$\$ 80$ & $\$ 6.13 / \mathrm{gal}$ & $\$ 6.63 / \mathrm{gal}$ & $\$ 6.95 / \mathrm{gal}$ \\
\hline
\end{tabular}

Economic Support 50\%/gallon for 10 years

\begin{tabular}{|c|c|c|c|}
\hline Gas Cost & $\$ 1 / \mathrm{mmbtu}$ & $\$ 2 / \mathrm{mmbtu}$ & $\$ 3 / \mathrm{mmbtu}$ \\
\hline $\begin{array}{c}\text { Plant Cost } \\
\text { (millions) }\end{array}$ & $\$ 4.74^{\star}$ & $\$ 5.06^{\star}$ & $\$ 5.39^{\star}$ \\
\hline$\$ 80$ & $\$ 6.01 / \mathrm{gal}$ & $\$ 6.34 / \mathrm{gal}$ & $\$ 6.66 / \mathrm{gal}$ \\
\hline
\end{tabular}

${ }^{\star}$ F-T Diesel Price \$/gal required for a $20 \%$ IRR

TABLE 6A

We estimate the cost of such a $300 \mathrm{bbl} / \mathrm{d}$ GTL plant to be $\$ 80$ million delivered to Fort Yukon. The GTL plant would require 3 million cubic feet per day of gas or about 35 $\mathrm{BCF}$ of natural gas over 30 years. The GTL plant would produce $300 \mathrm{bbl} / \mathrm{d}$ of F-T fuels, 75 percent arctic-grade diesel and 25 percent naphtha. With so few people living in the area, waste heat would provide all the needed electric power generation. This still requires that the naphtha be transported and sold in other areas, possibly in Fairbanks as a petrochemical feedstock.

Table 6A illustrates the effect of plant and feedstock cost and the level of required economic support on the wholesale price F-T diesel at the plant tailgate to achieve a 30 percent IRR for an equity plant investor, assuming the plant is privately-owned. We assume $\$ 80$ million as the cost of a new $300 \mathrm{bbl} / \mathrm{d}$ GTL plant built in modular form and transported to a location near Fort Yukon and a range of gas (coal bed methane) costs of $\$ 1 /$ million btus (mmbtu), $\$ 2 / \mathrm{mmbtu}$ and $\$ 3 / \mathrm{mmbtu}$ in a range of costs used in our analysis. These natural gas costs are very speculative, and we assume that the F-T plant would be the only natural gas customer in the area. 
Table 6A shows that even with federal support like an energy credit, the $300 \mathrm{bbl} / \mathrm{d}$ Fort Yukon GTL plant cannot produce F-T diesel competitive with today's crude-based diesel prices delivered to the region. Even tripling the energy credit, a private Fort Yukon GTL plant would struggle to sell its F-T diesel unless the price of crude oil is above $\$ 60 / \mathrm{bbl}$.

While not part of this study, we are aware of some promising new GTL technology that could possibly dramatically lower the capital cost of a small gas-based GTL plant. One company, TIAX, in Boston, Mass., is working to place all three GTL steps in a single vessel - called "GTL in a Can". TIAX believes that it can achieve capital costs per unit of installed capacity in line with the costs quoted for the 12,000 bbl/day Bristol Bay bargemounted GTL plant. If so, the cost per installed barrel for a Fort Yukon small GTL plant could drop from $\$ 266,000 /$ installed barrel to $\$ 60,000 /$ installed barrel. With a capital cost of \$20 million compared to the current estimate of $\$ 80$ million, a Fort Yukon GTL project would look promising. However, technologies like TIAX are still on the drawing boards and years away from being proven.

With the exception of a government grant to pay the capital costs of a small F-T plant operation, small F-T plants located in remote locations would produce F-T diesel with costs over \$5/gallon, and could not economically compete with the delivered cost of conventional diesel today.

How the financial analysis was done: All analyses in the regional scenarios assume a private investor providing between 20 percent to 25 percent equity and earning either 20 percent or 30 percent internal rate of return (IRR) before federal tax. A 30 percent rate of return results in approximately a 19 percent rate of return after federal tax depending on the tax status of the investor. Until several F-T plants, especially small footprint F-T plants, are successfully built and operated, we judge these rates of return to be at the levels required to attract a private investor. Debt is assumed to have a 15-year payback at a 7.5 percent interest rate. The analyses have also reserved 18 percent of net cash flow for local and state taxes. In all cases design and construction is estimated at three and a half years except in the case of the BP gas-to-liquids plant conversion to biomass, in which we assume one year. Capital costs in the case of coal and bio-mass were derived from data made available from Choren Industries of Germany and from Sasol, of South Africa. In the Fort Yukon small gas-to-liquids plant we use published costs associated with the BP gas-to-liquids plant at Nikiski. 


\section{PART THREE: Resources assessment}

Introduction: We assess Alaska's potential for natural resources that could support FischerTropsch plants in different regions of the state. Alaska has potential for more oil and gas discoveries and development, as well as potential for coal development and use of bio-mass to support the manufacture of alternative fuels.

Alaska is important to the nation as a supplier of crude oil and, in the future, natural gas. Although production from the large oil and gas fields on the North Slope and smaller oil fields in Cook Inlet is declining, the state still produces about one-fifth of the nation's domestic oil supply.

Alaska has about one-fifth of the proven natural gas reserves in the nation, and if a natural gas pipeline is built from the North Slope of Alaska it will be an important source of domestic gas supply as well as crude oil.

Alaska is considered to have potential for additional oil and gas discoveries and potential for very large unconventional resources, such as gas hydrates. But while reasoned estimates of resource potential have been made, very little exploration has been done across the state. Even the developed basins of the North Slope and Cook Inlet are considered underexplored, and millions of acres of lands in sedimentary basins in the Interior and southwestern parts of Alaska, as well as the Outer Continental Shelf, have seen very few exploration wells.

Geologists generally believe that many of the onshore sedimentary basins of Alaska have potential for natural gas because the extensive coal fields known to exist in many parts of the state could be a source of natural gas.

\section{OIL RESERVES}

$\begin{array}{ll}\text { Discovered to date: } & 22 \text { billion barrels } \\ \text { Produced to date: } & 15 \text { billion barrels } \\ \text { Discovered reserves } & \\ \text { remaining to be produced: } & 7 \text { billion barrels } \\ & \\ \text { Undiscovered resources, } \\ \text { Technically and economically } \\ \text { Capable of being produced } & 35 \text { billion barrels }\end{array}$

NATURAL GAS (conventional)

Discovered:

North Slope:

Cook Inlet:

35 trillion cubic feet

Produced to date:

* From Cook Inlet
9 trillion cubic feet

7 trillion cubic feet* 
There are unconventional resources as well, such as coal-bed methane (natural gas) which could be produced from coal seams. Coal-bed methane is now produced on a commercial basis in other states, but despite the potential there is not yet commercial production of coalbed methane in Alaska. Also, vast quantities of natural gas are trapped in gas hydrates in the permafrost that underlies much of northern Alaska. It is not known, however, whether gas can be technically or commercially produced from hydrates.

\section{Oil discoveries to date:}

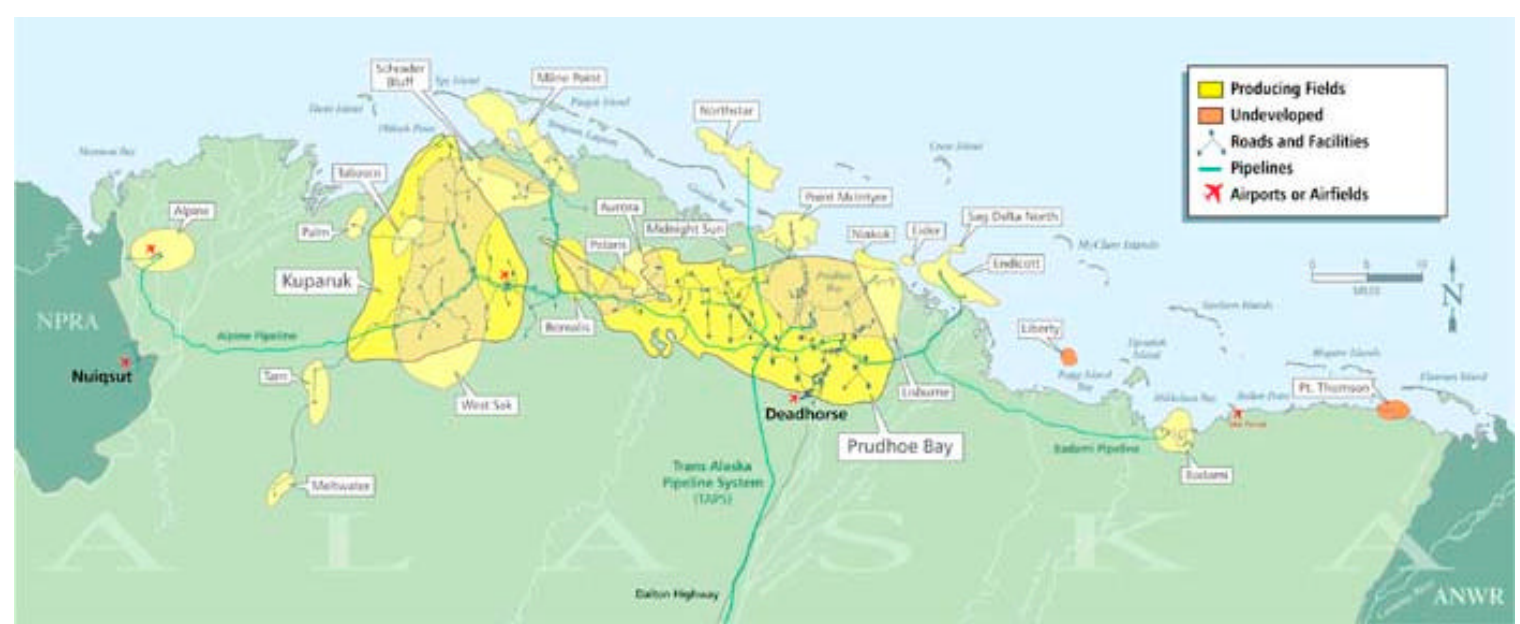

To date approximately 22 billion barrels of oil have been discovered in Alaska in fields that are considered economical to produce. About 15 billion barrels have been produced from these Alaska oil fields to date, and it is estimated that about 7 billion barrels of the confirmed resource are yet to be produced, or about 22 percent of remaining confirmed U.S. oil reserves. Some of the oil remaining to be produced is in fields that are currently producing, and some is in known deposits that are considered economic or marginally economic but not yet producing.

In terms of undiscovered resources, it is estimated that there are about 35 billion barrels of oil that remain to be discovered in Alaska, which can be produced economically with known technology. Most of this is on the North Slope. This estimate relates to oil that can be developed from the undiscovered resource at crude oil price ranges between $\$ 18$ per barrel and $\$ 30$ per barrel.

The amount of oil that can be technically produced from this resource base is far greater. As technology improves costs are reduced and the amount of oil that can be economically recovered will increase. 


\section{The North Slope}

\section{Geologic overview:}

Because of its geologic history, many geologists believe the North Slope of Alaska is one of the world's great sources of oil generation. The region is defined by its principle formation, the Barrow Arch, a broad geologic formation that generally parallels the northern coast of Alaska. It extends from the Arctic National Wildlife Refuge in northeastern Alaska through the central North Slope and the coastal region of the National Petroleum Reserve-Alaska to Point Barrow and beyond, into the Chukchi Sea.

This broad uplift has provided the trapping mechanisms for numerous oil fields that have been discovered in the central North Slope, including the two largest fields in North America, the Prudhoe Bay and Kuparuk River fields. It is believed that new oil fields will eventually be discovered at other points along the Barrow Arch, including the northern parts of the NPR-A, the coastal plain of the Arctic National Wildlife Refuge, and the offshore Outer Continental Shelf through the entire region.

Most of the existing oil fields have been discovered in the coastal region of the central North Slope where lands owned by the state of Alaska were leased in the 1960s and exploration by industry has long been underway. Oil has also been discovered offshore. In the relatively shallow waters of state-owned submerged lands just offshore the central North Slope, the medium-sized Northstar oil field has been producing since 2001 while several other medium-sized and smaller fields, such as Liberty and Tern, have been discovered but not developed.

Oil is also known to exist further offshore, in federal OCS submerged hands. Discoveries have been made at two locations, "Hammerhead" and "Kuvlum." While both discoveries are believed to contain considerable amounts of oil (Kuvlum's recoverable resources have been estimated at approximately 800 million barrels) they are considered too far from the shore to be economic under current circumstances. Prospective geology continues west from the North Slope and National Petroleum Reserve-Alaska into the Chukchi Sea. The presence of oil and gas-bearing formations in the Chukchi Sea was confirmed by 1989 drilling by Shell Western E\&P, although commercial discoveries were not made. The U.S. Minerals Management Service recently reevaluated one of Shell's wells and estimated that it had discovered a large gas and gas condensate accumulation, with an estimate of 14 trillion cubic feet of technically recoverable gas and 700 million barrels of technically recoverable liquid gas condensates.

Lands on the North Slope that are south of the Barrow Arch, extending into the Brooks Range foothills region of the southern slope are generally considered by most geologists to be more favorable for natural gas discoveries than oil. This region has seen relatively little exploration and will remain largely unexplored until a natural gas pipeline project is underway. 


\section{Central North Slope}

The major commercial oil and gas deposits of the North Slope have been discovered in the Central North Slope, or the area of state-owned lands between the Colville River (the eastern boundary of the National Petroleum Reserve-Alaska) and the Canning River (the western boundary of the Arctic National Wildlife Refuge).

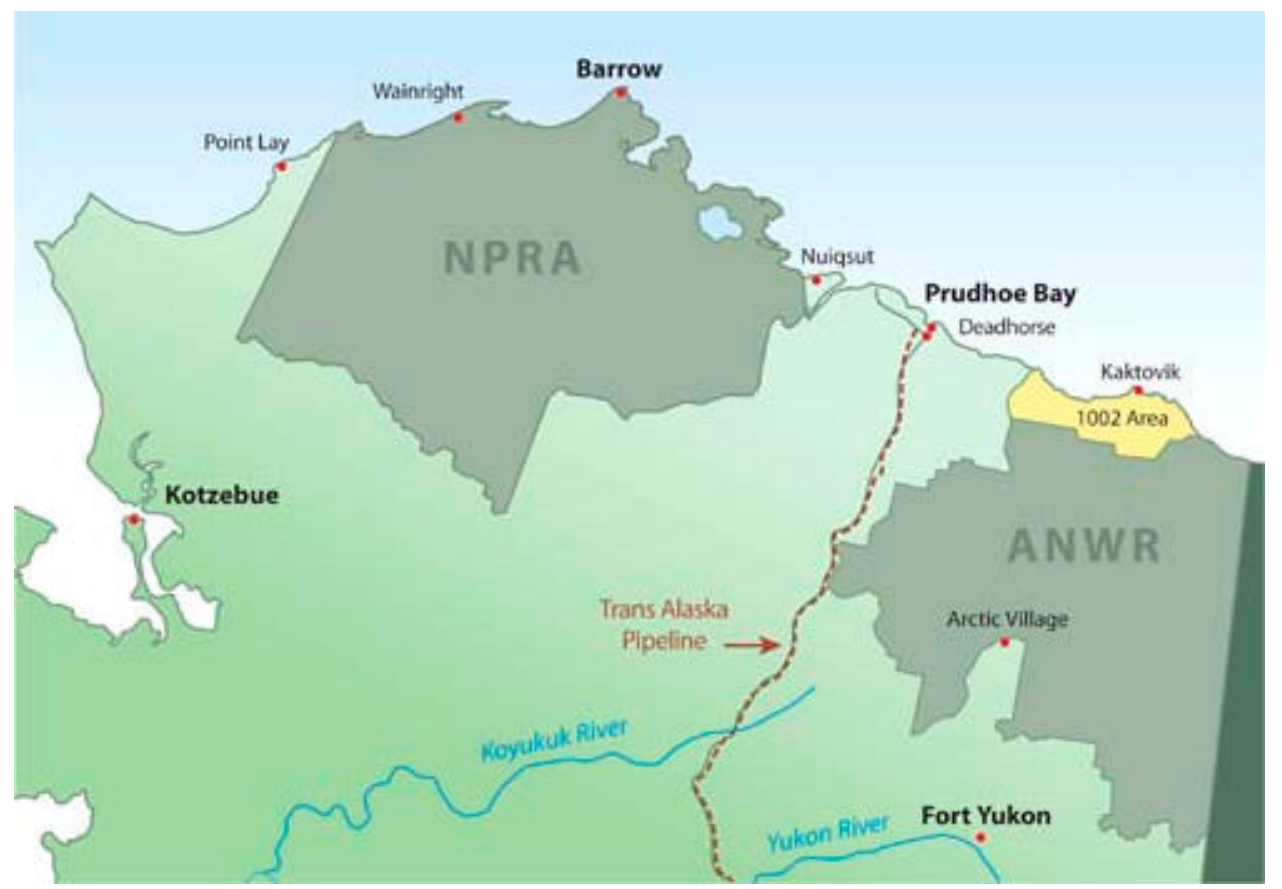

Exploration has been underway in this area since the early 1960s. Discoveries have included the super-giant Prudhoe Bay field with 23 billion barrels of oil in place (13 billion estimated recoverable) and the Kuparuk River field with 6 billion barrels of oil in place and 2 billion barrels estimated to be recoverable.

\section{ANWR}

In its 1995 slope-wide evaluation of hydrocarbon resources, the U.S.G.S. estimated there were 2.3 billion barrels of technically recoverable, undiscovered oil resources in the Central North Slope area. There have been discoveries since 1995, and the Alaska Division of Oil and Gas has estimated that, adjusted for the post-1995 discoveries, there are 1.9 billion barrels of technically recoverable oil left to be discovered in the Central North Slope. Of this, about 46 percent, or 916 million barrels, is estimated to be economically recoverable at oil prices between $\$ 18$ per barrel and \$30 per barrel.

Area:

1.5 million acres

Technically recoverable oil reserves:

10.3 billion barrels

Economically recoverable reserves: 4 billion barrels*

*Assumes \$22/barrel oil price 
Most of the new discoveries have been small discoveries, including Tarn, Meltwater, Tabasco, Midnight Sun and Aurora, although one medium-sized field has been discovered, the Alpine field.

Although these discoveries are smaller than the large Prudhoe Bay and Kuparuk fields, they contain substantial reserves. The Alpine field contains an estimated 429 million barrels of recoverable reserves. Tarn contains an estimated 70 million barrels.

\section{Arctic National Wildlife Refuge}

Many geologists believe the coastal plain of the Arctic National Wildlife Refuge has the greatest potential for new major oil and gas discoveries of any onshore region of the U.S. Because of its oil and gas potential a 1.5-million-acre section in the northwestern corner of ANWR was set aside (the "1002 study area") for further evaluation when Congress enacted the Alaska National Interest Lands and Conservation Act in 1980. Congress must approve any exploration, leasing or development of production in the 1002 area, however.

There has been little exploration in 1002 area. One exploration well was drilled in the early 1980s in a privately-owned enclave in the northern part of this area, and limited seismic surveys were done during the winter of 1983 and 1984. The data from the single exploration well is privately-held but the seismic information is held by the government as well as several oil and gas companies which contributed to the surveys.

The western part of the coastal plain has an extreme high probability that discoveries will be made. Its geology is similar to that under state lands just across ANWR's border on the Canning River, where oil and gas have been found. Point Thomson, a very large gas discovery with considerable volumes of gas condensates and two sizeable oil accumulations have been discovered in the area, demonstrating the potential.

Limited seismic exploration done in ANWR in the mid-1980s show numerous large geologic structures in the coastal plain. If one or more of these hold oil, ANWR has the potential become a major source of new production, state oil and gas geologists believe. The U.S. Geologic Survey estimates about 4.4 billion barrels of oil will likely be economic to produce in ANWR at oil prices of $\$ 22$ per barrel. However, Congress must approve any exploration in the ANWR. The U.S. Energy Information Administration estimates that nine years would pass between any congressional approval for ANWR exploration and first production of oil.

\section{National Petroleum Reserve - Alaska}

The National Petroleum Reserve-Alaska covers 23 million acres in northern Alaska. It was created as Naval Petroleum Reserve No. 4 by President Warren Harding in 1923, 
based on the recommendations of government geologists who had surveyed the region. Numerous oil seeps were noted in the reserve.

The reserve was transferred to the U.S. Bureau of Land Management in 1976 and renamed as the National Petroleum Reserve-Alaska.

There were several phases of exploration, including extensive drilling sponsored by the U.S. Navy following World War II and an exploration program managed by the U.S. Geological Survey in the 1970s. In the 1980s private industry was invited to explore the reserve, and four lease sales were held. Although several oil and gas deposits were discovered through the years, none of them are large enough to support commercial development.

An updated assessment by the U.S. Geological Survey published in 2002 indicates that of 10.6 billion barrels of technically recoverable oil, the NPR-A may hold between 1.3 billion to 5.6 billion barrels that could be economically produced at prices between $\$ 22$ and $\$ 30$ per barrel. The discoveries are likely to be spread out over a wide area. The U.S.G.S. estimates that oil reservoirs in the NPR-A will be medium-sized to small, with possible recoverable reserves of 256 million barrels to 32 million barrels. The NPR-A also has potential for the discovery of considerable volumes of natural gas, but its development will depend on the availability of a natural gas pipeline.

The discovery of the Alpine oil field on state lands in the Colville River delta, on the northeast boundary of the NPR-A, has greatly increased interest in the reserve. The

NPRA

\section{Area:}

23 million acres

Technically recoverable oil reserves:

10.6 billion barrels

Economically recoverable reserves:

1.3 billion barrels* federal government resumed its lease sale program, and several small oil and gas discoveries have been made in the northeastern part of the reserve. In general, many geologists believe the northern areas of the NPR-A along the Barrow Arch are more prospective for oil and gas discoveries.

\section{Alaska Beaufort Sea}

The U.S. Minerals Management Service is responsible for the Outer Continental Shelf submerged lands beyond the state of Alaska's three-mile territorial limit. MMS estimates that there are 8.82 billion barrels of technically recoverable reserves, within which 2.3 billion barrels would be economic to produce at $\$ 18$ per barrel oil prices and 2.5 billion barrels would be economic to produce at $\$ 22$ per barrel oil prices.

\section{North Slope Foothills}

The North Slope foothills, a region encompassing the southern part of the North Slope north of the Brooks Range, is a little-explored region which geologists believe has 
potential for major gas discoveries as possibly oil as well. Companies have leases in this region but little exploration has been done in recent years because of the lack of a way to market any gas that is discovered. As progress is made on a gas pipeline to the North Slope, industry will begin exploring the region.

\section{Cook Inlet}

Cook Inlet was where modern commercial oil and gas fields were first discovered in Alaska. The discovery of the Swanson River oil field on the Kenai Peninsula in 1957 helped convince Congress that Alaska had potential for natural resource development sufficient to pay the costs of state government, and led to the approval of statehood for Alaska in 1959. The leasing of state-owned submerged lands in Cook Inlet in the early 1960s led to commercial oil discoveries in the mid-1960s, which contributed substantially to state government revenues and helped develop an industrial tax base and employment for communities in the region.

Geologists believe most of the Cook Inlet sedimentary basin is prone to natural gas because of the widespread coals found throughout the basin. Coals are a primary source for the formation of natural gas, and most of the large gas fields that have been discovered in the region had their origin in coal.

Most of the oil that has been discovered in the inlet, and where the industry's existing fields are concentrated, is in an area of upper Cook Inlet where oil source rocks are present. It is possible that oil source rocks, and commercial oil deposits, may be found elsewhere in the Cook Inlet Basin. It is virtually certain that additional natural gas will be discovered, given the success of recent exploration programs on Kenai Peninsula lands east of the inlet and lands on the west side of the inlet. For many years local natural gas prices were depressed, discouraging exploration for gas. Prices are now increasing, resulting in exploration programs aimed at finding gas. Despite the industry's long presence in Cook Inlet, however, the area is still considered to be underexplored.

\section{Bristol Bay region, southwest Alaska}

Geologists believe the ingredients for an oil and gas producing region are present in the Bristol Bay basin. The geology of the region is very similar to Cook Inlet, where commercial oil and gas fields have been found. There are numerous oil seeps along the southern half of the Alaska Peninsula, along the Pacific coast side, which indicate that oil has formed in the rocks. Sedimentary source rocks appear to be rich in organic content, which is important to the formation of hydrocarbons. 


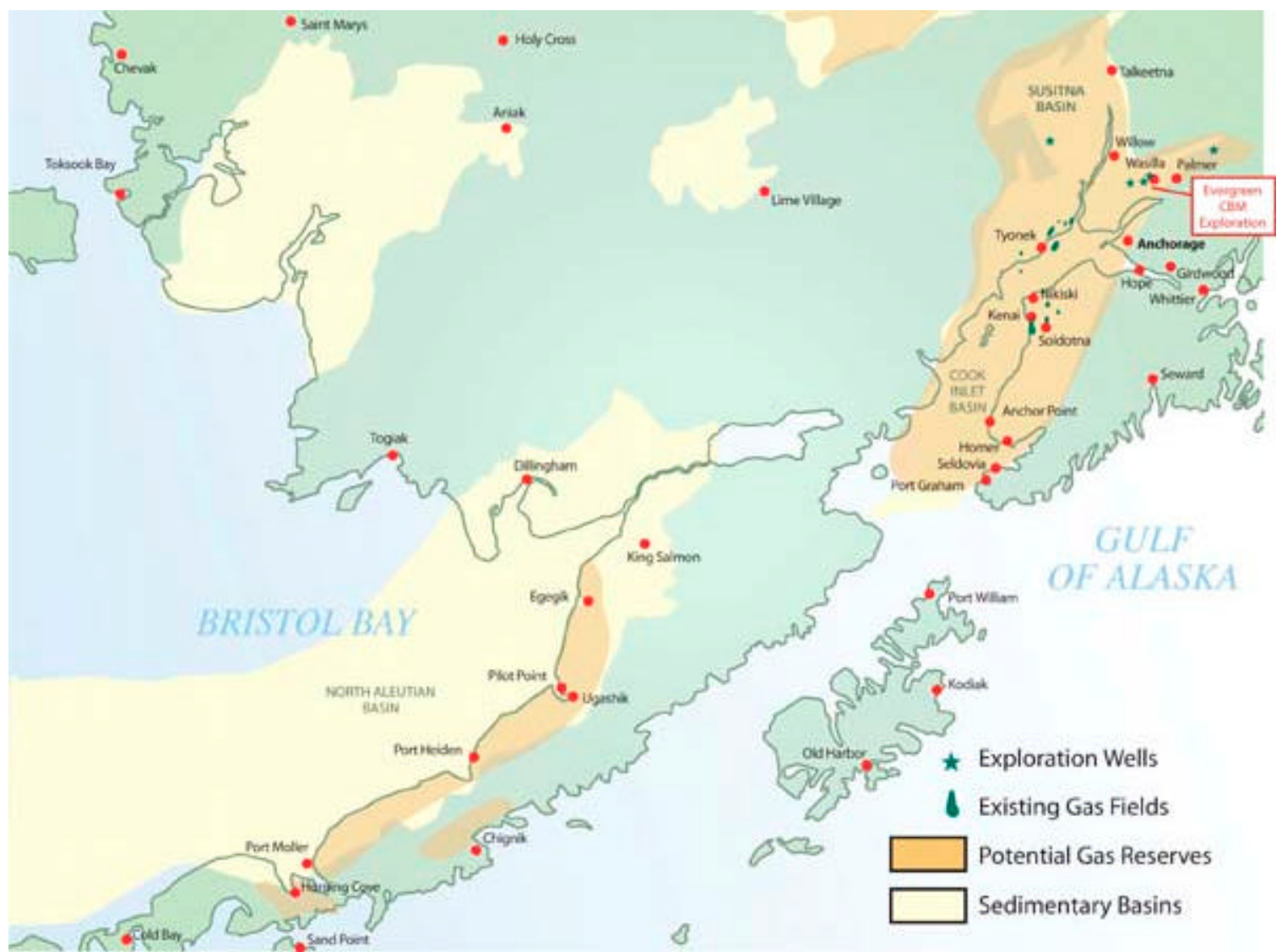

Twenty six wells have been drilled onshore in the Bristol Bay region, the latest being the Amoco Becharof No. 1 well in 1985. One offshore stratigraphic test was drilled in 1983, the ARCO North Aleutian COST Well No. 1. Oil and gas shows are evident in many of the wells that have been drilled, but no commercial flow of oil has been proven to date.

Alaska state Division of Oil and Gas geologists believe that the geologic setting of Bristol Bay is very good for both structural and stratigraphic traps as well as the likelihood of encountering good to locally excellent reservoir quality rocks. State geologists caution that there is some uncertainty over the quality of reservoir rocks, however.

All of the Bristol Bay basin is considered favorable for natural gas discoveries, but the southern part may also have oil potential, according to the state Division of Oil and Gas. Geologists also believe that Cook Inlet and Bristol Bay were once part of one large sedimentary basin that was split when the North Pacific plate shifted, causing a terrestrial uplifting and the formation of the Alaska Peninsula. In a sense, the Bristol Bay basin could be considered a kind of twin of the Cook Inlet basin. 


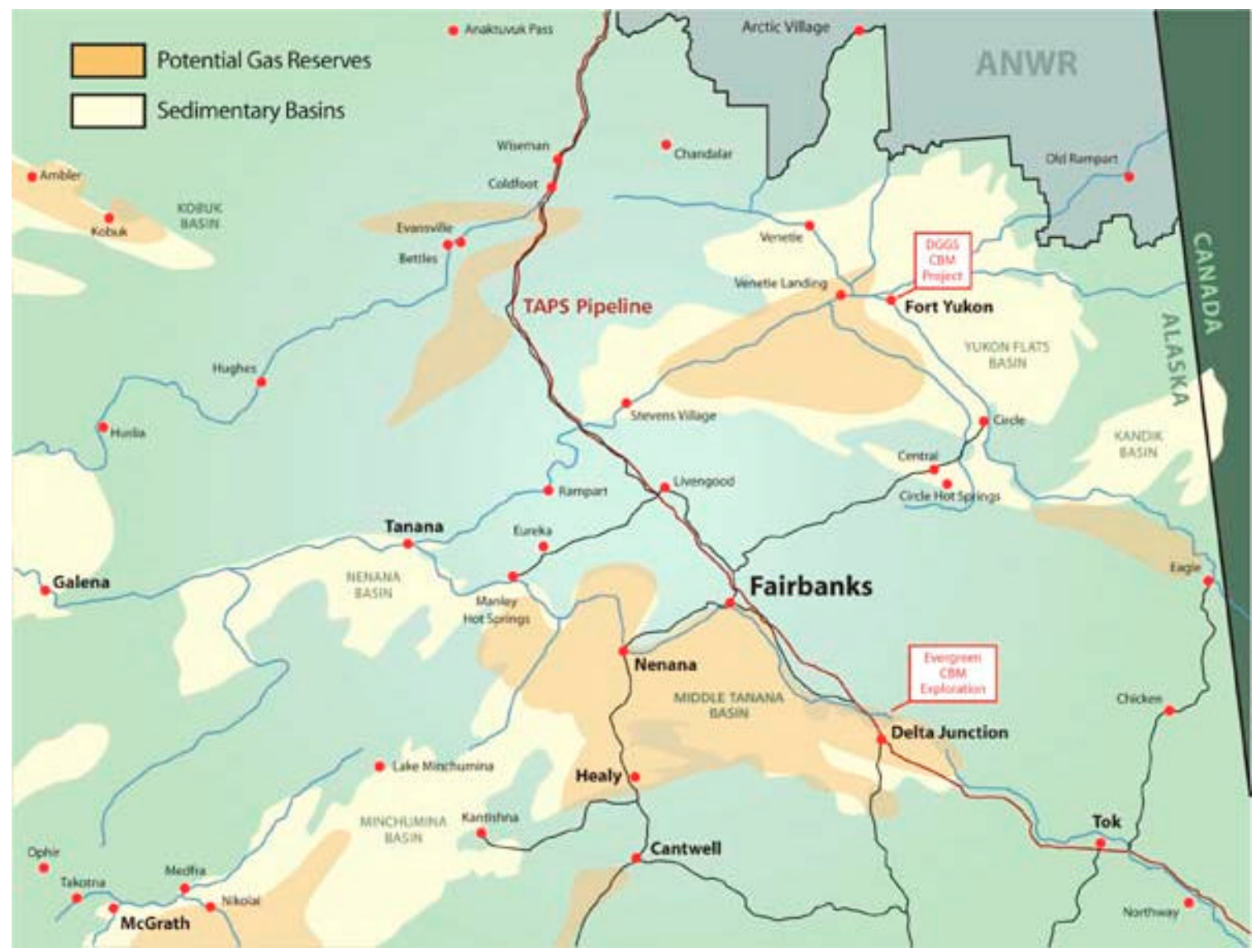

The state of Alaska and Alaska Native regional corporations in the area are now supporting exploration of state and private (Native) lands in the region, which is a change from their previous positions. Oil and gas leasing in the federal Outer Continental Shelf areas have been under a moratorium since a federal OCS lease sale in the 1980s. The federal lease sale then raised concerns among local residents because of the potential adverse effects an oil spill could have on the region's commercial fisheries, and eventually the leases were cancelled with the lease bonuses repaid to the bidders. There are no plans to resume OCS leasing in the region at this point. A current plan by the state of Alaska to offer leases includes onshore and offshore tracts that can be reached from shore by directional drilling.

\section{Other basins}

\section{Yukon Flats Basin:}

Nearly all of the Yukon Flats sedimentary basin is within the Yukon Flats National Wildlife Refuge, which at 12 million acres is the third largest refuge in the national refuge system. There are 2 million acres of Native-owned inholdings within the refuge, and 403,000 acres of state-owned lands in the southeastern part of the basin near Circle. 
The basin is considered to be prospective because coals capable of generating natural gas are present as well as sandstone and other rocks capable of being reservoir-quality. One estimate of the potential of the basin is for recoverable oil reserves between 350 million and 1 billion barrels. There is no estimate for natural gas. Two wells, LLE Doyon \#2 and \#3) were drilled in the eastern part of the basin in the early 1970s. The U.S. Geological Survey recently updated its assessment of the basin's potential for natural gas and found the region to be more prospective for gas than in the earlier U.S.G.S. assessments.

\section{Kandik Basin:}

The Kandik Basin encompasses about 2 million acres and straddles the Alaska-Yukon Territory border, with about 70 percent in Alaska. The southern margin of the basin is within the Yukon-Charley Rivers National Preserve. Doyon Ltd. of Fairbanks owns 750,000 acres in the center of the basin. In 1976 one well, LLE Doyon \#1, was drilled in the basin, with shows of gas and oil-stained strata but no commercial discovery. The basin is considered to have moderate oil and gas potential. Potential source rocks are known to be present, including rocks similar to those of the North Slope, and oil-stained rock outcrops demonstrate that oil has been generated in the region.

\section{Nenana/Tanana Basin:}

The Nenana/Tanana Basin covers a large area extending from the Minto Flats area west of Fairbanks to Delta, in the east. It covers approximately 8,500 square miles. There is interest in commercial exploration for natural gas in the western areas of the basin, the Nenana Basin proper, and it is possible that oil may be found as well.

Gravity and magnetic surveys indicate that the sediments are deeper and are more favorable for oil and gas accumulations in the Nenana Basin than in the Tanana Basin to the east. Two shallow exploration wells have been drilled but neither tested the deeper, more prospective areas of the Nenana Basin.

Potential source rocks for gas and oil appear to be present in the basin, and its potential is considered to be moderate to good. State geologists consider the basin to have the potential for discovering "multiple" trillions of cubic feet of gas. The Nenana Basin is thought of have some potential for oil but the large amounts of coal and the presence of shales deem it more likely that natural gas will be discovered.

The state of Alaska has issued an Exploration License for the Nenana Basin and exploration activity is currently underway by a consortium led by a Denver, Colorado independent company and including three Alaska-based firms. 


\section{Copper River Basin:}

The Copper River Basin covers approximately 3,500 square miles, bordered on the north by the Alaska Range, by the Wrangell Mountains on the east, the Chugach Range on the south and the Talkeetna Mountains on the west. Numerous coal seams extend through the basin and there are sequences of sediments of marine origin, which indicate possible oil potential.

Eleven exploration wells were drilled in the basin between 1957 and 1983, two of which encountered small gas shows. The potential for oil and gas in the basin is considered to be low to moderate, but industry has expressed interest in the region. An exploration well is being drilled in the region

In general, very little is known about the large inland sedimentary basins of Alaska. There has been little drilling or seismic exploration, and only limited gravity surveys. In general these basins are considered to be more prone to natural gas than oil because of the terrestrial origin of the organic material laid down in the sedimentary rocks and the widespread presence of coal in the state, which is a source of natural gas. Gravity surveys have indicated that basins in southwest Alaska may be too shallow for the formation of oil even if marine sediments are present. However, they may have potential for gas.

\section{Coal bed methane}

Exploration in Alaska is underway for possible commercial coatbed methane deposits, where natural gas could be produced from coal seams. Gas is produced commercially from coal in several western states.

Coal is a source of natural gas. In the coalification process, where plant material is converted to coal, large amounts of methane, or natural gas, are generated. Conventional natural gas seeps out of coal and is trapped in reservoirs of porous and permeable rock by an impermeable rock layer, or seal. However, some gas also remains in the coal.

The coal serves not only as the reservoir rock for the gas but is the source of the gas as well. Because of its large internal surface area (porosity), a given volume of coal can contain six to seven times the amount of gas as the same volume of conventional reservoir rock.

Coal-bed methane is composed primarily of methane and unlike conventional natural gas contains no other hydrocarbons, such as ethane and propane. It also contains no carbon dioxide or hydrogen sulfide, which can be found in conventional gas.

Interest in possible coalbed methane production in Alaska began in the early 1990s. In 1994 the state of Alaska funded and operated an exploratory test well drilled to shallow 
depths near Wasilla, in the Matanauska-Susitna Borough. The well demonstrated that significant quantities of gas exist in coal seams at shallow depths in the area.

The Alaska Division of Geological and Geophysical Survey has identified 35 Alaska rural communities with local coal deposits and where coal-bed methane could be a source of local energy. Evergreen Resources Inc., a Colorado coalbed methane producer (now Pioneer Natural Resources), explored in the Matanuska-Susitna Borough, in Southcentral Alaska. Evergreen drilled test wells but did not establish commercial production.

\section{Gas hydrates}

Gas hydrates are crystalline substances composed of large quantities of methane trapped in a crystalline, cage-like structure of water. Potentially, hydrates could be a source of unconventional natural gas because of the large amounts of methane that could be trapped. Hydrates typically occur in permafrost regions and have been found in Siberia, the North Slope and the Mackenzie delta of Canada. Hydrates are found on the North Slope because there is both a source of gas and permafrost at shallow depths.

There are questions as to whether gas can be technically or economically produced from hydrates. An effort by Anadarko Petroleum Corp., assisted by the U.S. Department of Energy, to test the production potential of hydrates on the North Slope was inconclusive. The hydrate turned out not to be present in the interval being tested. However, the presence of hydrates has been confirmed in other areas on the North Slope. In another research effort by BP Exploration Alaska Inc., with the assistance of the U.S. Department of Energy, BP did reservoir simulations of gas hydrate production from hydrates known to exist in the Prudhoe Bay, Milne Point and Tarn field areas of the North Slope. Based on this work, state geologists believe that gas might be produced with conventional well technology where the hydrate occurs over a conventional trap of free gas. Drilling into the gas trap and depressuring the conventional gas might allow gas to come out of the hydrate and into the production well, state geologists believe. The work by BP and DOE has led to a conclusion that there may be as much as 100 tcf of gas in hydrates in the immediate Prudhoe Bay oil field area, according to the state Division of Oil and Gas. It is possible that as much as 60 percent of this might be recoverable, which could add 60 tcf in new gas resources to the known 35 tcf gas reserve base on the North Slope.

If technical problems associated with finding hydrates and producing gas could be overcome, substantial quantities of gas might be produced. The U.S. Geological Survey has estimated that there could be 519 trillion cubic feet of gas trapped in hydrates on the North Slope, and much more in offshore regions of the Beaufort Sea, according to DOE. 


\section{Coal}

Coal deposits are widespread in Alaska. The state is estimated to have between one third and one half of U.S. coal resources, possibly 5 trillion to 5.5 trillion tons, with approximately 4 trillion tons estimated on the Arctic Slope region of the state. These estimates, however, are based on hypothetical coal resources in Alaska. The hypothetical resource was estimated by extrapolation from a known coal occurrence, such as an outcrop or coal seam identified by drilling.

An analysis of the many known coal occurrences has resulted in an estimate of over 160 billion tons of identified coal resources. There is little doubt that if more exploration were done, more of the hypothetical resources would be identified and the identified resources would be better defined.

No matter what the basis of comparison, however, Alaska has huge undeveloped coal resources. If the average energy content of coal is 10,000 btus per pound, a ton of coal has the same energy content at three barrels of oil. Looked at that way, Alaska's estimated 160 billion tons of identified coal resources represents the energy equivalent, in btus, of 240 billion barrels of oil. The coal is also attractive because of its very low sulfur (generally less than 0.5 percent) and nitrogen content, which reduces sulfur dioxide and nitrogen oxide in emissions when the coal is burned.

Many of Alaska's widespread coal deposits have been mined over the years. One of Alaska's early economic activities involved coal mining. In 1855, before the U.S. purchase of Alaska, the Russian American Company developed a small mine at a coal deposit that had been discovered in 1786 by an English sea captain at Port Graham, on the lower Kenai Peninsula. The Russian American Company made an attempt to export coal to California, but the Alaska coal could not compete with less expensive coal from British Columbia. Coal was mined to support a local sawmill and a foundry, and 5,000 tons were mined until the mine closed in 1865.

Coal deposits were an important source of fuel for whaling and government ships before the turn of the century, for gold mining camps and communities during the Gold Rush and for riverboats on the Yukon River and its tributaries. Coal deposits were known along the Northwest Alaska coast on the Chukchi Sea, and these were mined on a small scale for whaling ships and shipped south to Nome, on the Seward Peninsula, then a flourishing gold mining community. A commercial coal mine was operated at Unga Island, in the Aleutians, from 1896 to 1904, to supply fuel to naval and other vessels.

In 1905 the federal government supported development of a small coal mine at Chickaloon, in the Matanuska River valley north of Anchorage, and production continued until 1922. Small coal mines were developed in the Wishbone Hill district near Palmer, in 
the same region, beginning in 1914 to support construction of the Alaska Railroad. Two of these, the Eska mine and the Evan Jones mine, began production in 1917. Coal production continued to 1971 .

Coal was the major source of fuel for power generation at military bases in Interior and South-central Alaska during and after World War II. Natural gas is now used at Elemendorf Air Force Base and Fort Richardson near Anchorage but coal from the Usibelli coal mine near Healy still fuels military and civilian power plants in Fairbanks, and at Healy itself.

Usibelli Mine Inc. coal mine at Healy, Alaska, with 1300W Bucyrus-Erie Walking Dragline in background. Usibelli has been mining coal at Healy since 1943.

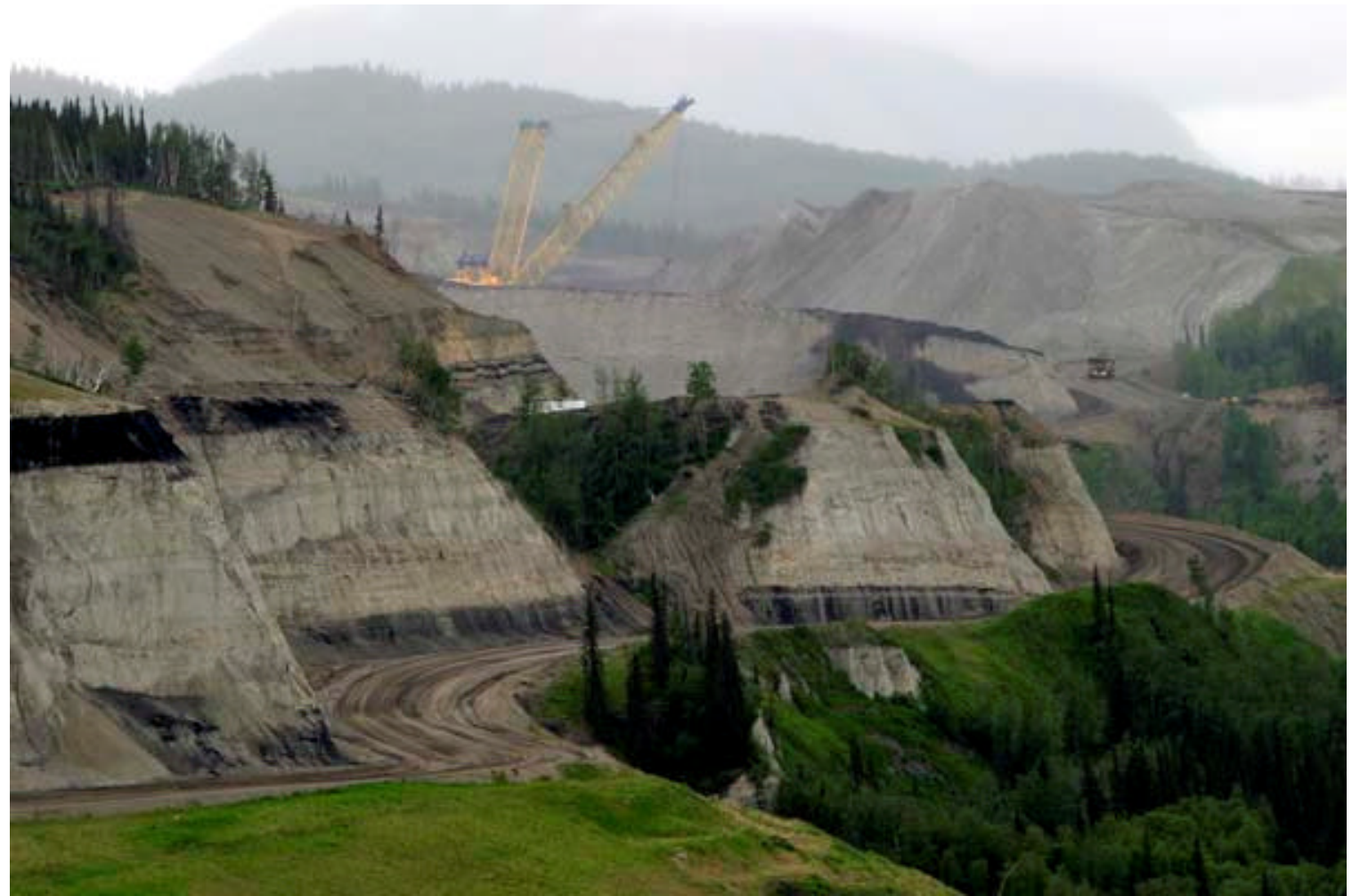

Several attempts have been made to develop coal mines in Alaska in recent years. Alaska's only producing coal mine is the Usibelli Mine at Healy, which produces coal for Fairbanks-area power plants and for export to South Korea. Usibelli has also sent shipments of coal to power plants in Latin America. There is considerable potential for expansion of coal production at the Usibelli Mine.

Considerable work has also been done by the Bass-Hunt-Wilson group and Placer Dome U.S. in developing a coal mine at the Beluga coal deposits west of Anchorage, where there is potential for 2 billion tons or more of mineable resources. High costs and low 
coal prices have stymied this development to date. However, international coal prices are now higher and possible new technologies to reduce the 25 percent moisture of the subbituminous coal at Beluga could raise its value, making the project possibly economic.

Idemitsu Kosan, a Japanese company, attempted to develop a mine at Wishbone Hill, a small deposit of higher-grade bituminous coal 10 miles from Palmer, north of Anchorage. Idemitsu's project was delayed by litigation over land ownership disputes and then shelved when coal prices dropped. The property has since been sold.

Arctic Slope Regional Corporation, the Alaska Native corporation for the Arctic Slope area of northern Alaska, has done considerable work in identifying coal resources in the large Deadfall Syncline area of northwest Alaska, where crews from early-day whaling fleets mined coal. The resources in this region are some of the largest in North America. The coal is also of good quality, with substantial resources of bituminous coal as well as subbituminous, and some high-grade anthracite as well. ASRC has tested Arctic mining methods and continues to work with the state of Alaska on solving transportation access problems to these large reserves.

Other, smaller coal deposits have been investigated as energy sources for local communities. The state Division of Geological and Geophysical Survey has investigated the Chicago Creek coal deposit on the Seward Peninsula. In the early $20^{\text {th }}$ century Chicago Creek produced 100,000 tons for use in regional gold mining operations. The state DGGS has also carried out investigations of coal near Unalakleet on Norton Sound and Kobuk and Koyuk in northwest Alaska, deposits near Nulato on the Yukon River in Interior Alaska, on St. Lawrence Island in the Bering Sea, the Chignik and Herendeen Bay fields on the Alaska Peninsula, and on Unga Island in the Aleutians.

The City of Galena has investigated a coal deposit that outcrops on the river a few miles from the community. The Jarvis Creek deposit near Delta, in the eastern Interior, has been investigated as a possible fuel source for local power generation, to support missile defense facilities at Fort Greely and the new Pogo gold mine, also near Delta. In years past Korean companies have investigated extensive deposits in the Bering River coal field, near Cordova.

The widespread coal resources of Alaska are important in a number of respects. Coal itself can be mined and used locally or regionally for power generation or space heating. The coal is, potentially, also a source of coal-bed methane, or gas trapped in the coal seams. Gas production from coal is done on a commercial basis in the continental U.S. and it may also be possible to produce gas from coal in Alaska. The widespread coals also point to substantial undeveloped resources of conventional natural gas also, since coal is a major source of gas. 
The Fischer-Tropsch process of converting coal into transportation fuels and petrochemical feedstocks is well established in South Africa and Southeast Asia. With the potential of crude oil prices remaining in the $\$ 40$ per barrel range, this process could convert 1 ton of coal into 1.5 to 2 barrels of liquid synthetic fuel. As an example, the Beluga coal field near Cook Inlet has coal resources that could be converted to 6 billion barrels of synthetic fuels.

\section{Bio-mass}

Alaska has a substantial forest bio-mass resource. About 129 million acres of Alaska's 356 million acres are covered with forest. Approximately 22 million to 25 million acres of the total forest area contains forests of potential commercial value.

In Alaska, there are two distinct forest types, the coastal rain forest and the boreal forest. The coastal rainforest begins in southern Southeast Alaska, and extends through Prince William Sound, and down the Kenai Peninsula to Afognak and Kodiak Islands In Southcentral Alaska. The two largest national forests in the United States, the Tongass National Forest in Southeast and the Chugach National Forest in South-central, are in these coastal regions. The boreal forest covers much of interior and much of southcentral Alaska.

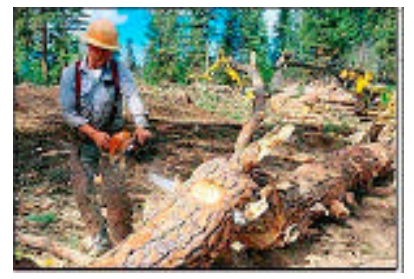

The Tongass National Forest covers 16.8 million acres, of which 9.5 million acres are forested. About 400,000 acres of the forest lands of the Tongass have been harvested, and some of these lands are now in their second-growth stage although no secondgrowth harvest will be possible for some time.

The Chugach National Forest covers 5.9 million acres, but most of it consists of mountainous and glacial terrain with relatively little forest of commercial value.

Sitka spruce, hemlock and cedar are the dominant species in Southeast and South-central, while white spruce, black cottonwood, aspen, and paper birch are found in the Interior forests.

As with oil and gas and coal, the timbered lands are managed by four landholders - the federal government, 51 percent; state, university and local governments, 25 percent; Native corporations, 24 percent; and other private landowners, 0.4 percent. Most of the commercial timber harvest is in the coastal rain forest, primarily on federal and Native corporation land.

Alaska's forest products industry is very small, and the lack of a method to dispose of low-grade timber and wood waste bio-mass is a serious problem for the small sawmills which mostly operate in Southeast Alaska. 
From the late 1950s until the early 1970s there were two pulp mills in Southeast which used low-value wood that was harvested along with high-value logs that were sawn or exported in the round to export markets. These pulp mills were closed, however, and at present there is no market for low-value logs. This hampers the efficiency of commercial forest harvesting.

Aside from this, a substantial volume of wood waste, mostly sawdust, has accumulated at the remaining sawmills in Southeast Alaska. The mill operators are looking for ways to economically remove or use these accumulated wastes.

Much of Southeast Alaska's coastal regions are covered with old-growth forest consisting of spruce, hemlock and some yellow cedar. The spruce and hemlock coastal forest continues northward into South-central Alaska. Most of the inland South-central and Interior regions of Alaska are covered with boreal forest consisting of certain species of spruce and birch. There is no substantial commercial forest industry in the Interior or South-central regions other than small local sawmills.

However, the resource is substantial, and one issue attracting considerable attention now is the South-central spruce forests which have been damaged or killed by a major infestation of spruce bark beetle. Spruce bark beetle infestations have killed many of the trees on the Kenai Peninsula in recent years.

The entire Chugach forest, and much of the Kenai Peninsula region, has been affected by this pest. An estimated 1.5 million acres of spruce forests in the Cook Inlet region alone are beetle-killed and constitute a considerable fire danger. The U.S. Forest Service and the Alaska State Division of Forestry are interested in ways of removing beetle-damaged timber, reducing the fire hazard and salvaging what commercial value remains in the wood.

There has also been substantial damage to spruce forests along the western shores of Cook Inlet as well as widespread areas of the Copper River valley north of Valdez.

To some extent these damaged trees retain value. If they are harvested in time they can be chipped and sold for use in paper manufacturing. But even after they have deteriorated further they can be used as feedstock in a Fischer-Tropsch process to make liquid products.

The large boreal forest of the interior creates a potential resource for bio-mass use. While much of the interior forests do not support species as valuable as the coastal forests in the Southeast part of the state, the interior birch forests have value for certain types of uses, including bio-mass to F-T fuels. 


\section{PART FOUR: Rural Alaska fuel supply}

\section{Refineries}

Introduction: We assess Alaska rural fuel distribution patterns and the capabilities of the state's refineries as well as challenges posed by new U.S. Environmental Protection Agency regulations that will take effect in 2006 and 2010. Basically, the high costs of fuels delivered to rural Alaska communities result from the inefficiencies imposed by small volumes, seasonal deliveries, lack of infrastructure and impediments to navigation in certain locations.

Alaska has four crude oil refineries that produce a variety of products, principally jet fuel, gasoline, diesel and heating oil and other products. The major refineries include two at North Pole, east of Fairbanks; one at Nikiski, near Kenai; and one near Valdez, the terminus of the Trans-Alaska Pipeline System.

\section{Flint Hills Resources refinery at North Pole, Alaska}

Flint Hills Resources purchased the plant from Williams Alaska Petroleum Co. in March 2004. The refinery was originally built in 1977 by Earth Resources, a Dallas, Texasbased firm and subsequently sold to Mapco, which was later merged with Williams Energy.

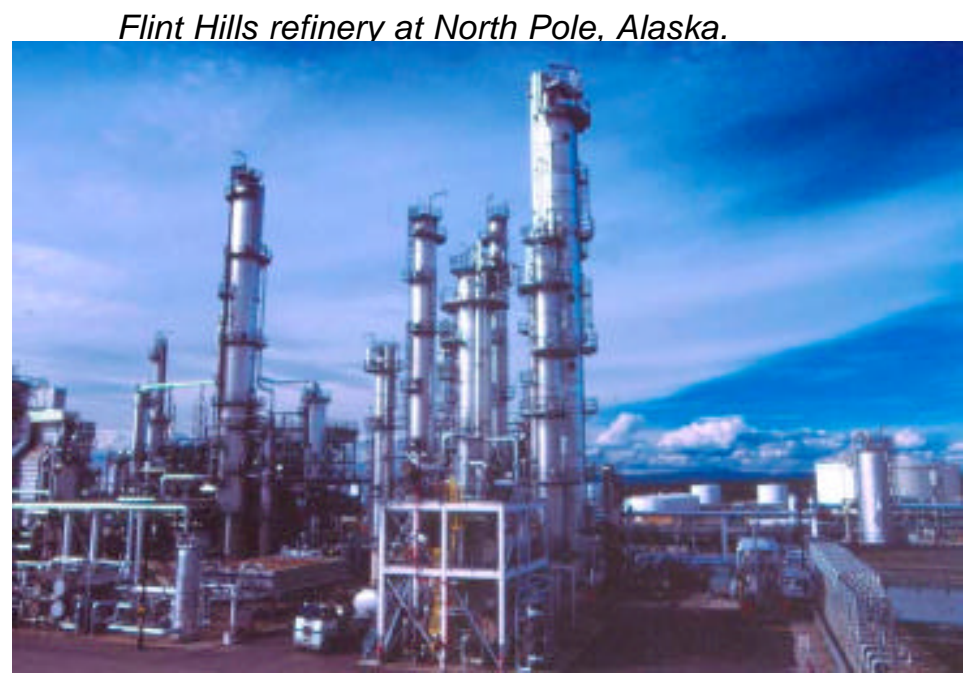

The refinery has traditionally relied on purchases of stateowned North Slope royalty oil for most of its crude oil supply, but from time to time has purchased oil from North Slope producing companies. The crude oil is taken from the Trans-Alaska Pipeline System and refined, with residuals returned to the TAPS pipeline. The refinery pays a fee to the TAPS owner companies to compensate for the degradation of the crude oil stream from North Pole south to Valdez, the terminus of the pipeline.

The North Pole refinery processes about 220,000 barrels per day of crude oil and produces about 70,000 barrels per day of products, which include gasoline, naphtha, and jet fuel, heating oil, diesel fuel and asphalt. About 60 percent of the refinery's production 
is jet fuel. Approximately 30 percent of the refinery's remaining output is gasoline, naphtha and diesel, averaging about 7,000 barrels per day of each product. Other products make up the remaining 10 percent of the product slate. Jet fuel, the most important product, is sold to commercial airlines and the U.S. military.

\section{North Pole refinery is the principal supplier for Interior river communities}

Industrial complex at Nikiski, Alaska. Tesoro Alaska

Petroleum Co. refinery is at left, in rear, of photo.

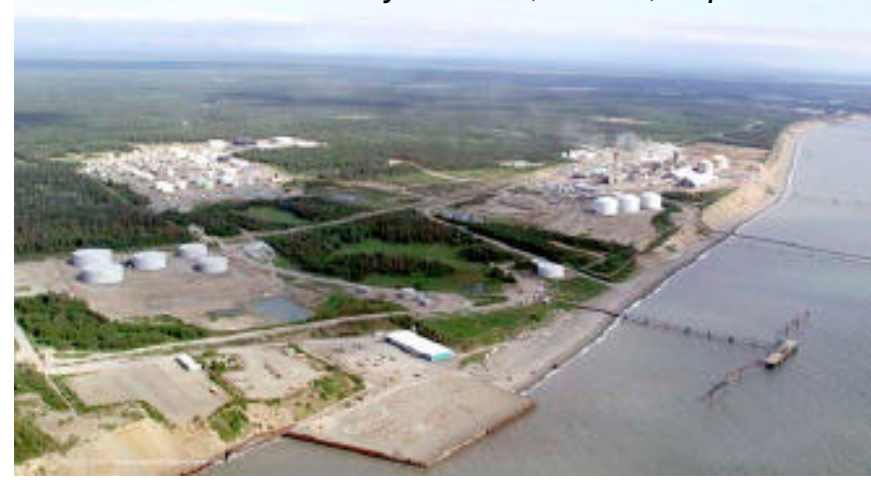

Flint Hills markets its products in Interior Alaska and is the principal supplier of diesel and heating oil for small villages along the Interior river system. The company also transports considerable volumes by rail to Anchorage in Alaska Railroad tank cars. Approximately 35,000 tanks cars per year of product, mainly jet fuel, gasoline and naphtha, are moved by railroad to Anchorage. The company operates bulk storage facilities in Anchorage and Fairbanks. Flint Hills sells its products wholesale to retail gasoline outlets and to commercial air carriers at international airports in Fairbanks and Anchorage.

Flint Hills has announced that it will install desulphurization facilities at the North Pole refinery to produce ultra-low sulfur diesel as well as low-sulfur gasoline to meet new U.S. Environmental Protection Agency specifications. The company is investing approximately $\$ 200$ million in plant modifications to produce the new products, and expects to have the products available in 2006 and 2007.

\section{Tesoro Alaska Petroleum Corp. refinery at Nikiski, on the Kenai Peninsula}

Tesoro Alaska Petroleum Corp. operates a 70,000 bbl/day refinery at Nikiski, near Kenai on the Kenai Peninsula south of Anchorage. The refinery was built in 1969 and purchased during its construction by Tesoro from the company that had initially developed the project. In the 1980s Tesoro upgraded its plant with a catalytic cracker to produce a wider range of fuels.

In its early years the refinery relied on state of Alaska royalty crude oil from Cook Inlet as a source of crude oil supply. Cook Inlet production has declined over the years, however, and the refinery has had to diversify its crude oil supply sources. In recent years the refinery has purchased Alaska North Slope (ANS) crude oil, both state royalty oil from the slope and oil purchased from the producers there. Because ANS crude oil has a 
lower API gravity and higher sulfur content than Cook Inlet crude oil the refinery continues to purchase oil from Cook Inlet oil producers as well as oil imported from foreign sources, including Sakhalin, in the Russian Far East.

Tesoro's refinery is capable of processing approximately 70,000 barrels per day but, based on product demand, now typically produces about 50,000 barrels per day of products. The company produces jet fuel, diesel and heating oil, gasoline, liquefied petroleum gas, heavy oil and bunker fuel and asphalt. About 30 percent of its production is jet fuel, about 30 percent gasoline, 10 percent diesel and the remainder is other products. During the winter months Tesoro has gasoline supplies that are surplus to local market needs, and exports the gasoline to other regions. The refinery has hydrocracking and vacuum distillation processes.

Tesoro's products are distributed locally on the Kenai Peninsula and are shipped to Anchorage through a 70-mile pipeline that carries 37,000 barrels per day to the company's bulk storage and distribution terminals in Anchorage. Tesoro is a major supplier of jet fuel to airlines at Ted Stevens International Airport in Anchorage and sells gasoline through branded retail locations across the state and to other gasoline retailers.

Tesoro supplies the majority of fuel products transported by barge from Cook Inlet to communities in southwest and northwest Alaska.

\section{Petro Star, Inc. refineries at North Pole and near Valdez, Alaska}

Petro Star Inc. operates two refineries in Alaska, one at North Pole, near Fairbanks, and the other near Valdez, at the terminus of the Trans-Alaska Pipeline System.

Petro Star's North Pole refinery processes 17,000 barrels per day of crude oil, and makes a variety of products mainly for the Interior Alaska markets. Products from the North Pole refinery are mainly trucked to market, but some diesel fuel is transported by air to rural communities. The company's Valdez refinery processes about 50,000 barrels per day of crude oil, to make a variety of products. Products are moved to market by truck and by barge from Valdez. 


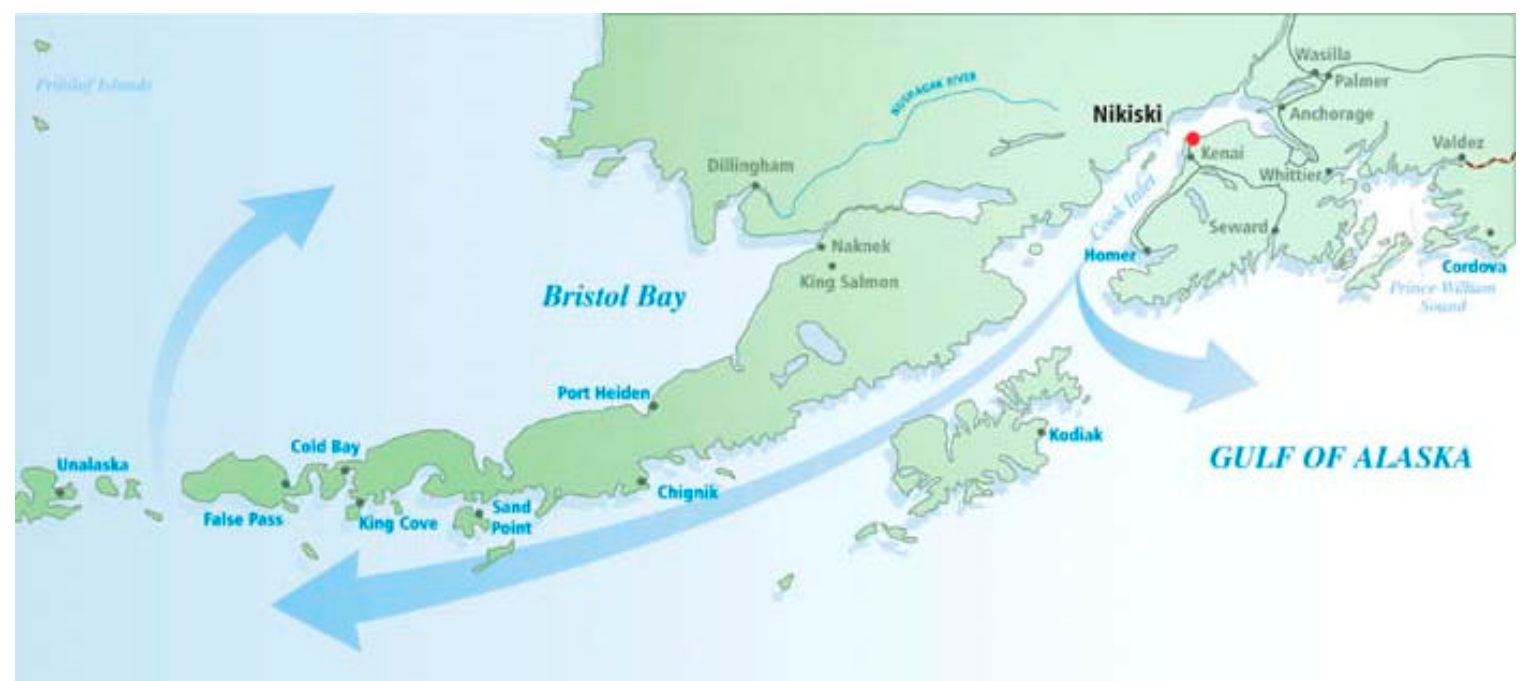

As is the case of the Flint Hill refinery, unused portions of the crude stream are returned to the TAPS pipeline from both Petro Star refineries. Petro Star makes commercial and military jet fuel, marine diesel fuel, home heating oil and a variety of lubricants and other products.

\section{Product distribution}

\section{Western Alaska}

\section{Companies in trade:}

\section{Yukon Fuel Co.}

Sells to rural communities in Interior, southwest and northwest Alaska. Uses contract tug and barge companies. Yutana Barge Lines, an affiliate of Yukon Fuels operates tugs and barges on the Interior river system and the Bristol Bay region, carries fuel for Yukon Fuel and serves other customers. In western Alaska Yutana and Yukon Fuel rely on Seattlebased contract tug and barge operators for "mainline" fuel shipments to regional hubs.

\section{Crowley Maritime Inc.}

Sells to coastal and inland communities in Southwest and Western Alaska. Crowley uses company-owned equipment.

Note: A merger agreement has been negotiated that could combine Yukon Fuel and Crowley operations in Alaska. The agreement is subject to litigation and is not yet in effect. 


\section{Delta Western Inc.}

Owns and operates fuel terminals at Unalaska/Dutch Harbor, St. Paul and St. George, and serves Bristol Bay and Emmonak and, at times, other communities on the Lower Yukon River.

\section{Patterns of seasonal shipments}

The majority of fuel shipped to western and northern Alaska coastal communities is supplied from the Tesoro Alaska Petroleum Co. refinery at Nikiski, near Kenai. Both Yukon Fuel and Crowley Maritime deliver fuel from Cook Inlet to the regional markets. Fuel is loaded at the Tesoro dock, using contracted and, in Crowley's case, companyowned equipment.

At times, Crowley and Yukon Fuel ship fuel from the Port of Anchorage. Fuel loaded in Anchorage is purchased from both the Tesoro refinery near Kenai and the Flint Hills refinery in North Pole, near Fairbanks, which is transported to Anchorage on the Alaska Railroad.

Fuel distributors begin western Alaska seasonal service in late May with shipments to Dillingham and Naknek, which are in Bristol Bay. These communities are usually the first regions open for navigation. After delivering fuel to Bristol Bay, the tug and barges continue along the coast to Norton Sound for the first delivery of fuel of the season to Nome. Generally, the first fuel deliveries of the season follow the winter ice as it recedes.

After the first deliveries to Norton Sound, tugs and barges return to Cook Inlet for another load and make usually the next delivery to Bethel, on the Kuskokwim River. The first delivery to Bethel is typically made in the last week of May. Tugs and barges return to Cook Inlet for another load and then sail for Kotzebue north of the Bering Strait. The first fuel of the season is normally delivered to Kotzebue in the first two weeks of July.

\section{Crowley deliveries to western Alaska}

Crowley Marine Services also makes large-scale fuel deliveries to Southwest and Northwest Alaska. The company maintains a bulk fuel storage tank farm in Kotzebue and makes deliveries from Kotzebue to inland communities on the Kobuk River using smaller barges and tugs.

Crowley also makes fuel deliveries to communities on the northwest and northern coasts of Alaska, including Kivalina, Point Hope and Kaktovik, in northeast Alaska near the Canada border.

Crowley maintains a "mainline" barge in Alaska year-around and brings other large barges north for the summer shipping season. In 2004 Crowley had four mainline barges 
operating in the state. Two of these barges have capacities of 5.3 million gallons each; a third has a 3.6 million gallon capacity and a fourth has 1.7 million gallons.

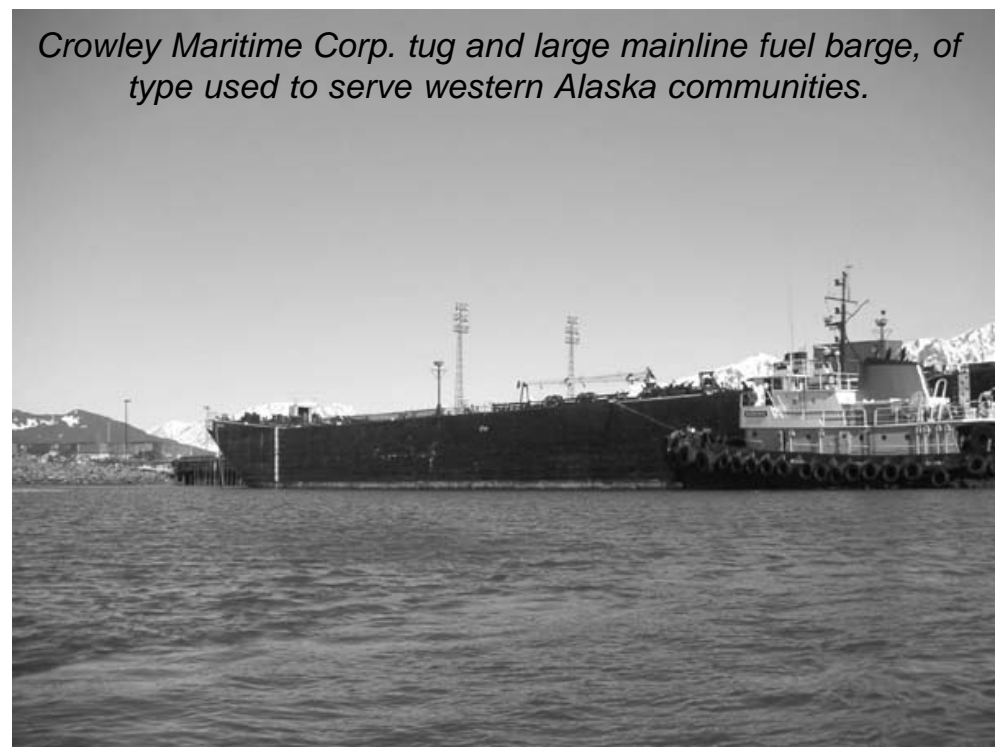

Smaller barges and tugs are maintained by Crowley in Alaska for use in "lightering" fuel and for river transport. A typical lightering barge has a capacity for 120,000 gallons.

At times in the past fuel for the communities along Alaska's northern coast has been delivered by the Northern Transportation Co. Ltd. from Hay River, Northwest Territories, via the Mackenzie River. The shipments are made down the Mackenzie to the Beaufort Sea and then west along the Yukon Territory and Alaska coasts.

Delta Western supplies fuel to western Alaska, and will expand its marketing in the region as a result of a consent decree agreed on between the State of Alaska, Crowley and Yukon Fuel, relating to Crowley's acquisition of Yukon Fuel and Yutana Barge Lines.

\section{Delta Western now has access to terminal facilities in Bethel; and Kotzebue, Alaska}

Through a Consent Decree agreed on by Crowley and Yukon Fuels as a part of their merger, Delta Western would acquire a terminal in Bethel formerly owned and operated by Yukon Fuel, and has been guaranteed access to Crowley's terminal facilities in Kotzebue.

Prior to acquiring new assets through the Consent Decree, Delta Western supplied about 50 million gallons of fuel per year to the western Alaska region. Much of this is to terminals the company operates in Unalaska/Dutch Harbor and St. Paul and St. George in the Pribilof Islands, which support the region's fisheries. The company also supplies fuel to the Bristol Bay region, again to support fisheries. 
Delta Western relies on third party contractors to transport fuel, using barges ranging from 50,000 gallons to 120,000 gallons capacity. The company operates terminals in Unalaska/Dutch Harbor, Dillingham and Naknek, and through a joint venture with local Alaska Native corporations, in St. Paul and St. George.

Delta Western also supplies fuel to Southeast Alaska, along with Petro Marine. Delta Western operates terminals in Juneau, Wrangell and Haines, and typically sells 10 million to 20 million gallons of fuel yearly in Southeast Alaska.

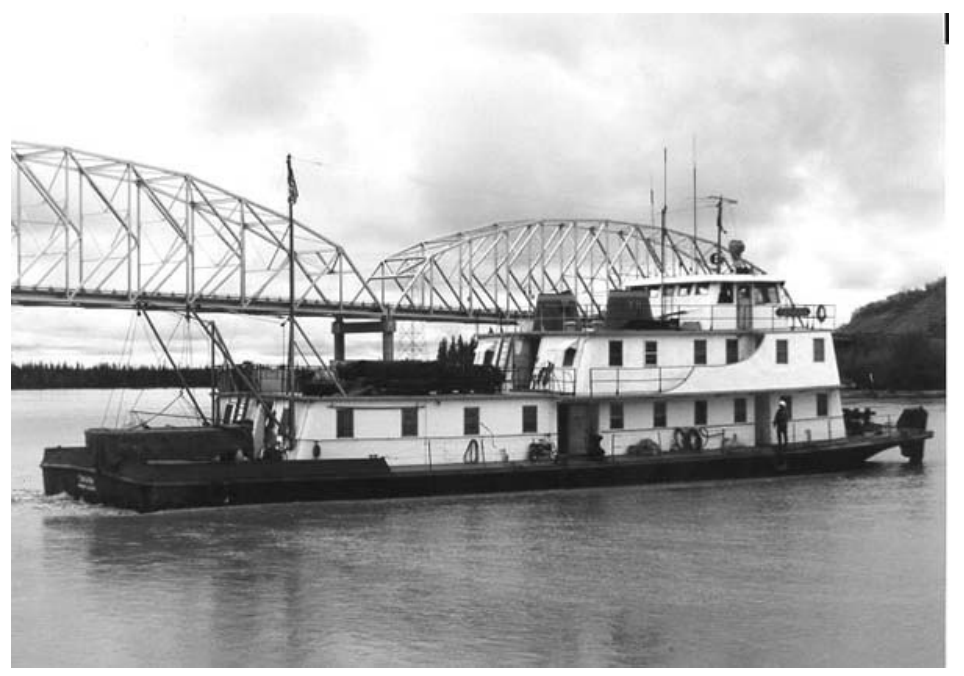

MV Tanana, operated by Yutana Barge Lines, at Nenana, Alaska. Yutana carries out seasonal fuel deliveries on the Yukon River and its tributaries in Interior Alaska.

\section{Interior Alaska river system}

Yukon Fuel Co. serves Interior Alaska river communities along the Tanana and Yukon Rivers from Nenana as far upriver as Fort Yukon and downriver as far as Emmonak. The transportation of the fuel is by Yutana Barge Lines, an affiliate company to Yukon Fuel.

Fuel is trucked from the Flint Hills or Petro Star refineries at North Pole to Nenana, a distance of approximately 60 miles by highway. At times, fuel is trucked to Nenana from Anchorage, a distance by highway of about 350 miles. During the summer navigation season there are typically 3 to 5 trucks a day delivering fuel from North Pole to Nenana and typically 1 truck a day from Anchorage carrying unleaded and aviation gasoline.

The river navigation season is typically late May to September, with the first deliveries of the year made to Galena from Nenana in late May. Through the season, Yukon Fuel and Yutana typically make 3 trips to lower Yukon River communities via the Tanana River from Nenana and 3 trips to upper Yukon communities, as far as Fort Yukon. At times fuel is trucked to the Dalton Highway bridge on the upper Yukon and moved by barge to communities on the upper river.

Using a smaller tug and barge, fuel deliveries are also made from Nenana to Huslia, on the Koyukuk River, a tributary of the Yukon. There are several additional trips made on the Yukon to Galena during the summer to supply fuel to government installations in that community.

In a typical year Yukon Fuels and Yutana deliver about 9 million gallons of liquid fuels along the Yukon River system, including 4 million gallons of diesel, 1.5 million gallons 
of gasoline, and 1.1 million gallons of aviation gasoline to communities along the Interior rivers. Additional volumes of jet fuel are supplied to an Air Force station at Galena.

\section{Navigation issues}

Navigation problems, particularly problems posed by very shallow coastal waters in approaches to coastal communities, are a major contributor to the high cost of delivering fuel to rural communities in western Alaska.

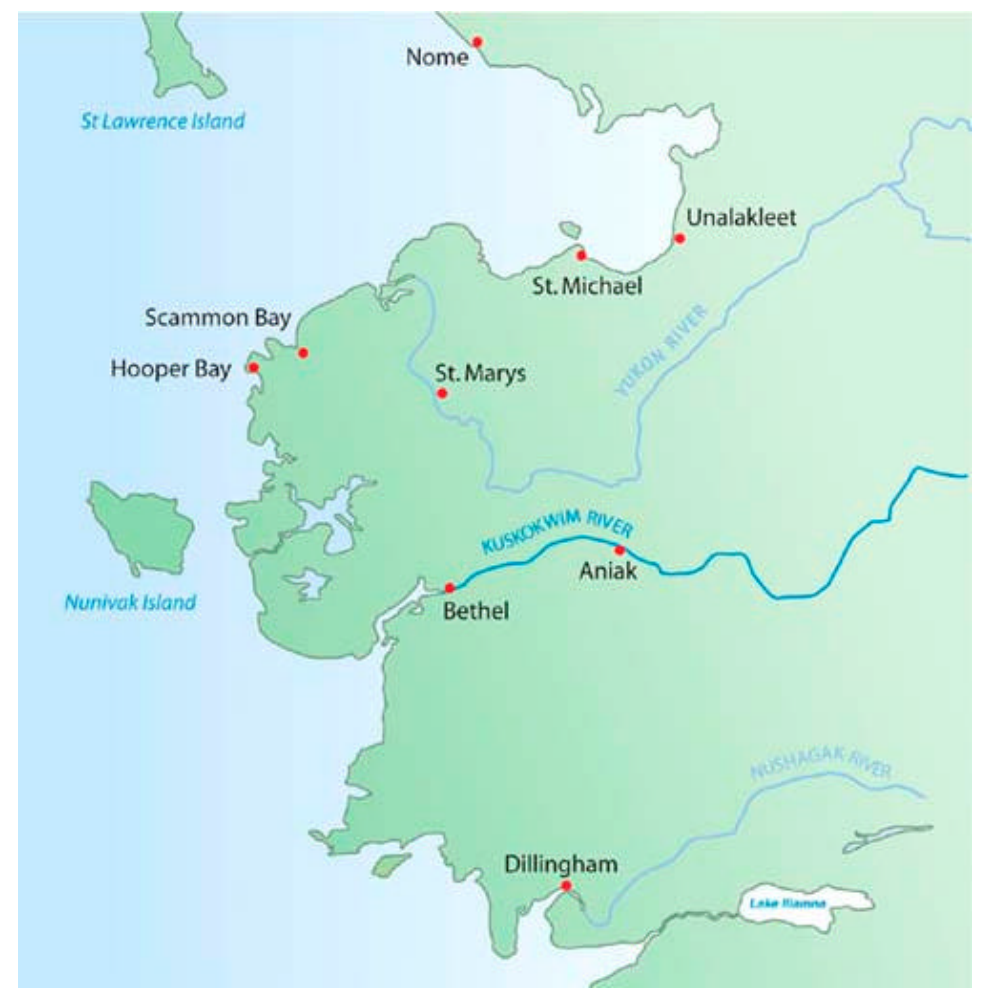

A typical arrangement is to use deeper-draft mainline barges for service to regional hubs with ports. Fuel is then transferred to onshore storage tanks or directly to shallow-draft barges for service to other communities in the region. In many communities the deeper-draft ocean barges anchor offshore in deeper water, and fuel is transferred at sea to smaller shallow-draft "lightering" barges.

In some communities it is possible that the cost of lightering fuel from deeper water a mile or so offshore is equal to the cost of transporting the fuel from its point of origin via a larger ocean-going barge to the transfer point offshore. In addition to the costs of transferring and lightering fuel, transportation companies must bear the costs of mobilizing the shuttle barges and tugs to remote locations.

\section{Kuskokwim River access}

The Kuskokwim River opens into the Bering Sea north of the entrance to Bristol Bay, and is illustrative of the navigation challenges faced in southwest Alaska. It is an area with frequent shoals and channels through the bay that are not always apparent. A 40mile approach to the Kuskokwim has many shifting sandbars, some visible and some submerged. The channels undergo changes from year to year because of sea action, currents and ice.

The deepest draft vessel that can reach Bethel, 65 miles upriver from the Kuskokwim's mouth, is about 12 feet. Barge operators with shallower draft equipment operate further up the Kuskokwim from Bethel. Drafts are limited to 4.5 to 5 feet and sometimes 4 feet 
and shallower during dry summers. McGrath, 400 miles up the Kuskokwim, is the head of navigation for the river. At times barges can serve Nikolai, located above McGrath on the river. Because the Kuskokwim is narrow and has a faster ice "breakup" in the spring the navigation season on the Kuskokwim is typically about three weeks longer than on the Yukon River. Typically, navigation is possible for 120 open-water days on the Kuskokwim compared with about 100 days for the Yukon.

\section{Interior river navigation issues}

One of the major issues affecting fuel deliveries to the Interior river communities are navigation restrictions along the Tanana River from Nenana to its confluence with the Yukon River. Yutana Barge Lines operates barges up to 240,000-gallon capacity. On the Tanana River, however, these can only be loaded to about two-thirds of their capacity due to depth limitations on the river. Typically Yutana would move the barges partly-full to the Yukon, and then transfer fuel to load the barges to capacity. Once on the Yukon River

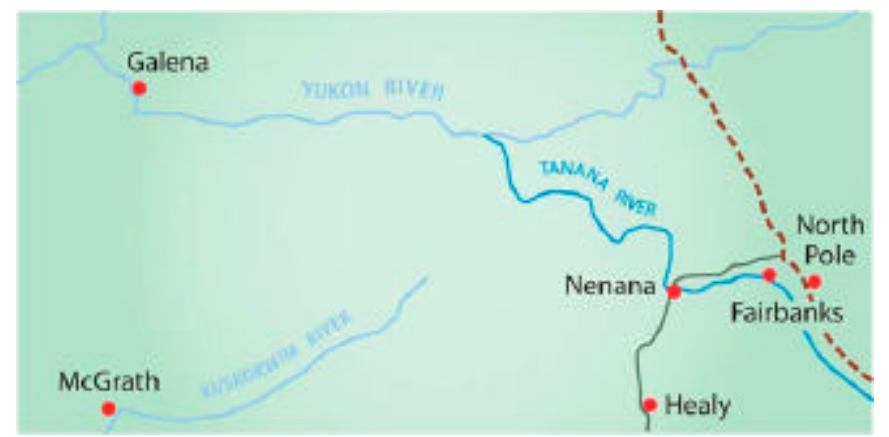
the barges can carry their full load.

\section{Navigation issues on the lower Yukon River and the Yukon Delta}

Distance and navigation, as well as lack of infrastructure, are major impediments to efficient fuel supply on the lower Yukon River. Shallow approaches to the Yukon River at its mouth are major restrictions. The Yukon is typically approached by vessels traveling through the Gulf of Alaska and around the Alaska Peninsula, a journey of 1,250 nautical miles from Anchorage. Because of this, fuel is more efficiently supplied to lower Yukon communities from Nenana rather than via ocean-going barge through the mouth of the Yukon River. Approaches to the Yukon River at its mouth are shallow, and the channels through the shallow approaches are narrow, crooked and bordered by shoals exposed at low water. The shoals are also subject to constant change. Barge operators recommend transshipment of fuel from oceangoing barges to barges with a draft of no more than 11 feet.

If conditions require it, barges are "light-loaded to a depth less than 10 feet for the trip through the Yukon mouth to St. Mary's. Light-loading is a shipping practice where a vessel is loaded to less than its capacity to lessen its depth.

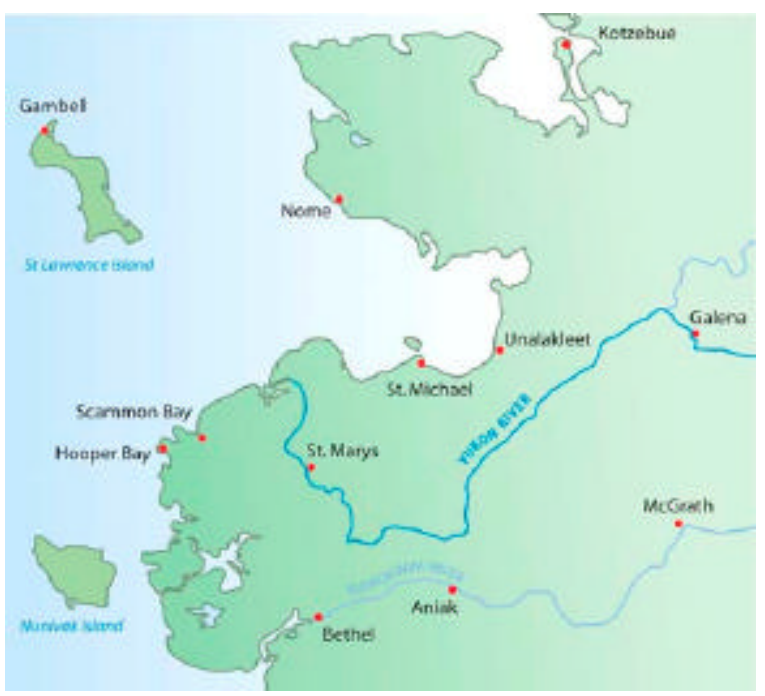


typical 175,000-gallon barge draws about 2 feet when empty and 7 feet when loaded to capacity.

Lightering barges are often used that draw no more than 4 feet. Lightering vessels are more economical than larger ocean-going barges for making deliveries at many lower Yukon River communities due to lack of dock and fuel storage facilities.

Crowley Maritime and Yutana maintain tugs and barges in Alaska designed for shallowwater uses. Some are capable of operating in water between 3 and 4 feet in depth.

\section{Infrastructure issues}

Lack of infrastructure and shallow coastal waters are key factors in the high cost of delivering fuel to rural communities. Where communities have approaches with deeper water and docks or harbors, large fuel barges can be unloaded efficiently.

A fully-loaded sea-going "mainline" barge used by Crowley Maritime to serve Western Alaska is typically 430 feet long by 78 feet wide and carries 5.3 million gallons of fuel. It typically draws 17 feet to 19 feet fully loaded. Unless a dock is available with deep enough water, the transportation cost advantage of the larger barge is lost.

Dillingham, Naknek, Bethel and Nome have docks and water depths sufficient for these barges. Many coastal communities have no docks, however. For service to these communities fuel must be transferred to smaller barges that draw less water, as described earlier.

\section{Landing sites typically unimproved}

Landing sites in many communities are typically unimproved river banks or beaches. Landing sites in many river communities vary from year to year and even within a season depending on the levels of water and movement of sandbars.

Alaska is unusual in that a barge must typically be grounded to unload fuel, a procedure not permitted in other states that have more infrastructure. Typically the barge operator will do a site inspection before the barge is brought to shore, to insure safety. Landing locations in many coastal communities are challenging, and one area has been nicknamed "the mud coast" by barge operators. On Saint Lawrence Island, in the northern Bering Sea, fuel is unloaded via hoses through the surf line and across a gravel beach from a barge anchored offshore.

\section{Location issues}


The location of a community also makes a great deal of differences as to how efficiently it can be served. If a community is on the coast near a route with periodic mainline barge service, fuel supply is easier than with a community that is far from the coastal transportation routes.

Communities that are at the far end of the fuel distribution system include Hooper Bay on the Yukon Delta, which is served from Nenana via the Tanana River (as well as from the Bering Sea); Fort Yukon, on the upper Yukon, which must be served from Nenana via the Tanana River; McGrath, on the upper Kuskokwim River, which must be served from Bethel, on the lower river, which in turn is supplied from Cook Inlet, and White Mountain, a Seward Peninsula community which is inland from the coast.

Some communities, such as Nightmute and Chefornak, are in locations that are tidesensitive; others, like White Mountain, are in locations where winds and low water levels in rivers, as well as tides, influence water depths. Many communities are supplied just once a year when local navigation conditions are optimal. White Mountain is challenging because it is accessible only when tides, winds and river water levels are all favorable. White Mountain is usually served only once a year, in fact. Typically a barge operator would land the barge at high tide, conduct fuel unloading during the low tide cycle, and then refloat the barge on the next high tide.

\section{Costs of lightering, regional distribution}

The cost penalty imposed on rural communities because of their small size, remoteness, navigation challenges and lack of infrastructure is considerable. When fuel destined for outlying communities must be stored and transferred through a regional bulk fuel distribution hub, such as in Bethel, Nome or Kotzebue, the facility, storage and extra handling costs can add 7 cents to 10 cents per gallon to the final price of the fuel.

The cost of "lightering," or transferring fuel to smaller, lighter-draft vessels is in addition to the terminal costs. These incremental costs vary by location and season, and are estimated for different specific locations at 10 cents to 20 cents per gallon.

The range of additional costs is also illustrated by these estimates: Costs for moving fuel to coastal regional hubs with large mainline barges is typically 20 to 30 cents per gallon, although it can be as low as 15 cents per gallon with a large-volume, multi-year customer where the customer assumes the risks. These costs can be 30 cents per gallon if the location is difficult, however. When the costs of lightering to small communities are added, average costs for a rural fuel transportation operator, across the entire distribution system, can average 30 cents per gallon to $\$ 1.20$ /gallon depending on location.

\section{Small scale is a problem}

The principal problem Alaska faces, particularly in supplying small, outlying communities, is the very small scale of regional fuel markets which prevents refineries 
and fuel distributors from achieving large economies of scale with a full range of products. For example, airlines operating through Ted Stevens International Airport in Anchorage are major customers for jet fuel, with annual fuel demand averaging almost a billion gallons a year.

In contrast, total fuel sales to western Alaska communities supplied mostly from Cook Inlet typically do not exceed 150 million gallons a year, and fuel sales to Interior river communities supplied through Nenana are typically about 9 million gallons a year.

The large demand for jet fuel creates issues and seasonal imbalances in the product mix for refiners. For example, refiners often are unable to supply the total jet fuel requirements for airlines at Ted Stevens International Airport in Anchorage, resulting in the need to import some jet fuel. Also, gasoline production exceeds the regional market demand at certain times of the year, resulting in some gasoline being sold out of state.

There are also seasonal issues. There is more demand for jet fuel in the winter, when kerosene is used as Arctic-grade fuel in diesel engines and oil-fired heaters, and more demand for No. 2 diesel fuel during summer.

Naphtha is also produced at the Flint Hills refinery near Fairbanks, and is transported to Anchorage by rail tank-car and sold in export markets as a feedstock for petrochemical industries.

The location of a particular rural community affects local fuel prices. If a community is fortunate in being close to navigation routes of large "mainline" barges, access via lightering barges is easier and less expensive. As previously mentioned, local navigation problems such as shallow coastal waters which require lightering, or shallow rivers and seasonal low water and lack of infrastructure like docks can add substantially to costs.

\section{Economies of scale}

One of the principal reasons for high fuel costs in rural Alaska is the very small size of the market being served, and the resulting high incremental costs. In a regional hub community such as Galena, which supports more local economic activity, costs will be lower because larger quantities of fuel are stored in larger tanks and more fuel is sold. Conversely, costs will be higher in communities that use less fuel, either because of small size or lower levels of economic activity.

\section{Local distribution costs}

The high costs of operating a terminal and distribution system in a small community contribute to the inefficiencies of the rural fuel delivery system. These costs are directly 
proportional to the amount of fuel sales because costs must be spread across the amount of fuel sold.

Two examples illustrate this: Galena, on the middle Yukon River, and Hooper Bay, on the lower Yukon. Galena actually has a smaller population (750) than Hooper Bay $(1,100)$ but more fuel is stored and sold there because there is more local economic activity.

Galena is a regional hub, supporting a certain level of economic activity, with a local Air Force installation, a regional boarding school, a city government active in administering local projects, developed local infrastructure such as roads and water service. The local fuel distributor sells about 1 million gallons a year. The cost of the local distribution system must be added to the cost of delivered fuel.

In Hooper Bay, a community with approximately 1,100 people, there is less local and regional economic activity. About 200,000 gallons of fuel are sold annually, one fifth of the volume typically sold in Galena. Hooper Bay fuel sales must support the operation and maintenance of the local bulk fuel storage facility. Hooper Bay's facility operates 40 hours per week and employs 2.5 full-time equivalent employees. In addition to its operating costs, the facility must pay a return on approximately $\$ 1$ million in capital investment in the terminal.

The operational costs of the terminal, the salaries of the employees, the repayment of capital investment and a profit margin must be part of the per-gallon price of the 200,000 gallons of fuel sold annually.

Operating costs must also include facility maintenance and inspections, insurance, spill prevention and containment capability, and inventory carrying costs. The "fixed" costs are typically about $\$ 1$ per gallon in Hooper Bay. In total, the costs of operating the local distribution system add about $\$ 1.18$ per gallon to the wholesale cost of delivering the fuel to Hooper Bay.

\section{Small fuel purchases are common}

A striking aspect of terminal and fuel distribution systems in communities like Hooper Bay is the small size of the typical fuel purchase. For many reasons, including limited local cash resources, the average sale of fuel in Hooper Bay is 5 gallons. A typical residential customer buys fuel in small increments over several days of the week.

If customers could change their purchasing practices and buy larger quantities in fewer purchases, it would allow operating costs for the local distributor to be reduced, in the opinion of the terminal operator. If fuel sales could be made in larger increments so that the terminal is open for business one day a week rather than five days, the savings in labor alone might lower local costs by as much as 20 cents a gallon. The local fuel 
operator has installed facilities to allow 24-hour purchases, however, such as dispensing equipment where payment is made by credit or debit card, or a fuel purchase card.

There is a local economic tradeoff for this. Since any gain in efficiency would be mostly in lower labor costs, through fewer hours of employment per week, in lower fuel prices come at the cost of lost wages to the terminal employees.

\section{Pricing}

The wholesale price for fuel in Alaska is determined by U.S. west coast fuel prices and influenced directly by crude oil prices, which are determined by international markets. Alaska refineries and fuel distributors base their wholesale product prices mostly on the west coast Oil Price Indexing Service (OPIS), a national price indexing service, with transportation costs added.

Rural Alaska communities served by waterborne transport receive the benefit of a discount on wholesale fuel prices, which can amount to 10 cents to 15 cents per gallon. The discount, which applies to fuel moving by barge from Nikiski to western Alaska and through Nenana to Interior river communities, is given because these fuel volumes are taken out of the main railbelt regional markets so as to not affect competition among refiners and distributors in the larger markets of South-central and Interior Alaska. Also, the additional volume of fuel sales allows refiners to spread fixed costs over more volume, which has the effect of lowering costs for all fuel sales.

\section{Environmental compliance}

Environmental compliance costs are paid by fuel suppliers and must be part of the final price paid by the consumer. The burden is felt particularly in rural Alaska, however, because these costs are spread across the small volumes of fuel that are sold there. Private fuel distributors have estimated that compliance costs, which include installation of spill containment and cleanup equipment, training, insurance and inspections adds an average of 45 cents per gallon to the price of fuel in rural Alaska. These costs range from 20 cents to 60 cents per gallon depending on location.

One of the advantages of having access to Fischer-Tropsch fuels is the non-toxic, biodegradable character of some F-T fuels. This has advantages in small rural communities where storage and transportation of conventional diesel fuels create environmental hazards.

\section{Ultra-low sulfur fuel requirements}


U.S. Environmental Protection Agency rules will require that ultra-low sulfur diesel fuel, with a sulfur content of 15 parts per million or less, be used for on-road vehicles in 2006 and off-road vehicles and construction equipment in 2010. It is assumed that the EPA rule for ultra-low sulfur fuel will eventually be extended to include fuel used in stationary diesel engines, such as in power plants, and in marine engines, such as those typically used in Alaska fishing vessels. These requirements pose significant problems for rural Alaska.

The problems occur mainly because of the transportation and storage problems in the supply of different types of diesel, ultra-low sulfur and standard diesel. Ultra-low sulfur diesel must be moved and stored in dedicated tanks, or tanks must be thoroughly cleaned prior to transporting or storing ultra-low sulfur diesel. Either ways, costs are added. If dedicated tanks are used the costs are paid by the small quantities of ultra-low sulfur diesel moved and stored. If tanks are cleaned, the costs of cleaning must be paid. In the opinion of state officials and many community leaders in rural Alaska, the most practical arrangement for a rural community is to use ultra-low sulfur diesel for all engines used locally, or in the region if the community is a regional hub, which is likely. By doing this, larger tanks for transportation and storage can be used and the extra-handling costs would be eliminated or reduced.

There are only very general estimates for the cost of supplying ultra-low sulfur diesel to rural communities. Estimates by refineries in the Pacific Northwest are that the ultra-low sulfur fuel will cost 5 cents to 10 cents above the price of conventional summer-grade diesel. Arctic grade ultra-low sulfur diesel will be another issue. Alaska Village Electric Cooperative, a rural Alaska electric utility, has estimated costs for the fuel delivered to its rural utilities at 25 cents a gallon above current costs of purchasing conventional diesel. Another estimate is 50 cents a gallon above conventional diesel for Fairbanks delivery by highway from Edmonton, Alberta, where refineries will produce the ultra-low sulfur diesel.

\section{Source for ultra-low sulfur diesel}

There are also questions about where ultra-low sulfur diesel can be purchased. Refineries in the Pacific Northwest will be making ultra-low sulfur diesel but will probably not be making the Arctic grades of diesel needed in much of Alaska during the winter. Flint Hills Resources has announced that it will make ultra-low sulfur Arctic-grade diesel in the company's refinery at North Pole and will have it available in 2007. However, Flint Hills' price of the fuel is unknown at this time. Flint Hills is able to make the investment, it says, because it will also be investing in desulfurization equipment to make low-sulfur gasoline to meet EPA deadlines for this fuel.

Tesoro Alaska Petroleum Co. is considering making the fuel at its Kenai Peninsula refinery, but may also supply Alaska from its refineries in Washington state or Hawaii. 
Other alternatives include a refinery in the Pacific Northwest making a special "batch run" of Arctic-grade ultra-low sulfur diesel. Making the fuel would involve a relatively low volume given the scale at which these refineries typically operate, and the low quantity would add to expense. It could, however, be made at one time of year, stored locally and loaded on barges for transport to western Alaska.

Alternatively, Arctic grade ultra-low sulfur diesel could be purchased from refineries in Alberta which will make the product for use in northern regions of Canada. From Alberta it could be shipped by rail to the Pacific Northwest for transshipment by barge to Alaska, or trucked to Fairbanks and Nenana for transshipment. An Alaska trucking company estimated the costs of moving the fuel from a refinery in Edmonton, Alberta to Fairbanks at 50 cents per gallon.

There are other transportation issues. Ultra-low sulfur diesel will require special handling and perhaps special tankage to keep it from being contaminated with higher-sulfur diesel. It cannot be stored in tanks or shipped in pipelines that previously stored or shipped fuel with higher levels of sulfur without the ultra-low sulfur fuel becoming contaminated. The tanks and pipelines will have to be thoroughly cleaned, or the ultra-low sulfur fuel will have to have dedicated tankage. These special handling requirements will add costs.

The fuel could be shipped to Yukon River communities through the existing truck and barge system that operates through Nenana. If Tesoro makes the fuel at its Kenai refinery, the existing barge distribution system from Cook Inlet can be used. If the new fuel must be supplied from the Lower 48, special shipments will be required to Cook Inlet or directly to Western Alaska communities.

A final alternative is that if a Fischer-Tropsch plant were built in an Alaska location which could serve western Alaska, the "clean" diesel that could be produced would meet the EPA requirement. 


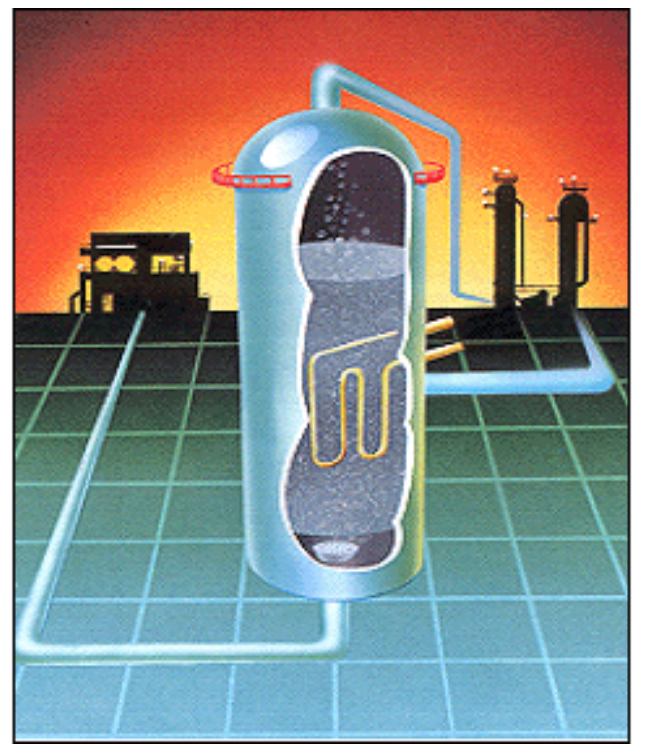

$\underline{\text { Appendix }}$

Fischer-Tropsch Fuels

History

World Drivers

Developments in Technology

Gas-to-Liquids Transportation Fuels

Economic Support for a U.S. F-T Program 


\title{
Fischer-Tropsch Technology Development Gas To Liquids Transportation Fuels
}

\begin{abstract}
Fischer-Tropsch (F-T) is the conversion of natural gas to liquids (GTL), coal to liquids (CTL) or bio-mass to liquids (BTL), all three processes commonly referred to as Gas-toLiquids. (GTL) is the process for the chemical conversion of carbon into liquid products. It has been a developing technology for over 75 years. The first 50 years saw coal as the primary feed stock. In the late 1980s natural gas started a trend that today has over 500,000 barrels per day (bbl/d) of GTL plants announced or under construction in Qatar alone. Chiefly responsible for this trend has been the desire to reduce the annual 3.8 tcf of natural gas flaring and venting and to commercialize the estimated 4,200 tcf of proven gas reserves in FSU, Middle East and Africa. In the late 1990's bio-mass or biorenewable feed stocks such as trees and dedicated crops were added to the picture in Germany.

In general the trend in the industry has been towards larger GTL plants to improve plant economics and reduce operating costs. As plant size increases, gas reserves required to support the GTL plants increase with overall costs of the GTL complex running into the $\$ 2$ million to $\$ 5$ billion dollar range, eliminating all but the largest oil companies and State-run oil companies (Parastatals) from developing new projects. To date almost all technology advances are geared towards the "mega" GTL plant projects. Development of small GTL projects, under 1,000 bbl/d, will have to be driven for specific applications such as military, space or national defense needs.

F-T fuels, an option to LNG for stranded gas development are prized for their ultra clean properties and their ability to fit into the existing transportation motor fuels system with no change to the infrastructure. Many countries around the world are providing incentives for this environmentally friendly but expensive fuel, creating incentives that draw these fuels and technology to their region of the world. If the U.S. is to participate in an F-T revolution, it will have to provide incentives to $\mathrm{F}-\mathrm{T}$ as it does to many other alternative fuel and energy technologies.
\end{abstract}

This paper will briefly outline the historic development of F-T technologies and address the following points:

- F-T Drivers

- F-T Economics

- New F-T Technologies

- Support for F-T fuels In The U.S. 


\section{Gas-to-Liquids Fischer-Tropsch Technology}

\section{Development in the World}

\section{INTRODUCTION - HISTORY OF GAS-TO-LIQUIDS}

In the early 1900's Germany led the world in the development of Fischer-Tropsch (F-T) transport fuels from coal. By the mid 1930's Adolph Hitler backed the development of the early F-T process to provide aviation fuel for his war efforts, resulting in numerous large scale plants built during the 1938 to 1943 era. At the conclusion of the war both the U.S. and Russia took this revolutionary F-T technology back to their respective countries. The U.S. was still an exporter of domestic crude oil and awash with cheap natural gas and while it looked at this new technology the US oil industry was not interested as it was too costly to make F-T transport fuels from coal.

South Africa, blessed with abundant coal resources but no domestic oil and natural gas resources, asked the U.S. for the rights to this technology in 1948. The South African Government formed the South African Coal, Oil and Gas Corporation (SASOL) and began development of a coal-based slurry bed F-T plant in Sasolburg in 1951.

By the late 1970s Sasol had advanced F-T technology that reduced capital costs, increased conversion efficiency and reduced operating costs. As a result of the Arab oil embargo and Sasol's advances, many other oil companies began or renewed their interests in the F-T process. By the early 1980s, the Arab oil embargo ended, a world wide recession developed and oil prices dropped. All but Sasol put their F-T work back on the shelf or relegated it to R\&D.

Following work begun in Germany during the late 1950s, Sasol began looking at a new F-T reactor design called "slurry bubble column" or slurry phase. This new design had the promise of reducing operating costs and increasing both carbon and energy conversion efficiencies. In addition, work with new cobalt catalysts held promise of longer life and higher product selectivity - making more of one product and less of another while reducing the production of $\mathrm{CO}_{2}$, a troublesome by-product when iron catalysts are used.

In the mid 1980s South Africa discovered natural gas off its southern coast. Since the F$\mathrm{T}$ process is all about carbon conversion through a chemical process, Sasol was asked to design a plant to convert this new resource into F-T transport fuels. This first gas-toliquids (GTL) plant located in Mossel Bay, South Africa rekindled the FT efforts of many of the oil majors as a way to monetize the vast stranded natural gas reserves across the world. Total world gas reserves of 6,205 TCF, equivalent to approximately 1,105 billion BOE, are on a par with estimated world oil reserves of 1,147 billion barrels.

As demand for crude oil based transportation fuels continues to increase resulting in higher crude oil prices, more oil companies are looking at natural gas based GTLs to help 
meet these growing demands. However, with over $70 \%$ of these gas reserves located in the Former Soviet Union (FSU) and the Middle East and little undedicated reserves in the U.S., F-T programs in the U.S. will have to focus on coal and bio-mass for their feed stocks.

Throughout the late 1990s there was a resurgence of industry interest in GTL's, driven by the need to reduce gas flaring and the prospect of turning the world's vast reserves of natural gas into clean fuels to meet increasingly stringent air quality regulations.

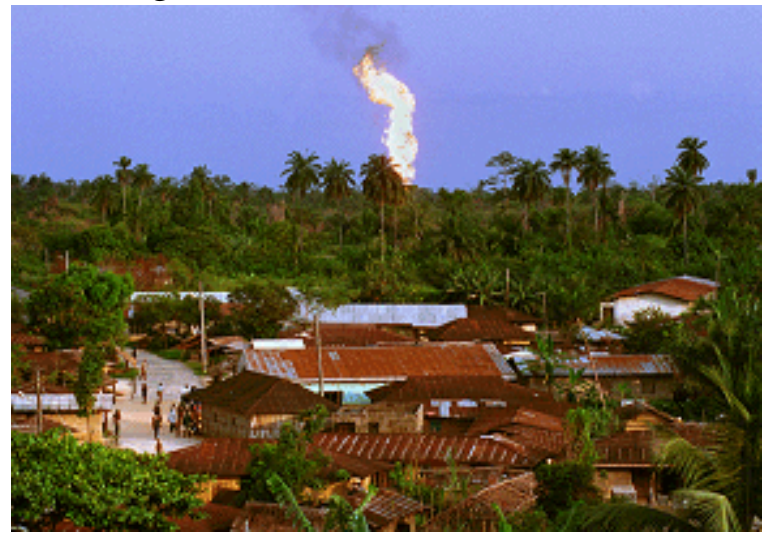

According to a World Bank study, 3.8 trillion cubic feet per year (tcf/yr) of natural gas, equivalent to approximately 700 million barrels of oil equivalent (BOE) is flared or vented as associated gas with oil production. Ten countries account for over $75 \%$ of global flaring and venting. The photo to the right is a gas flare in Nigeria flowing nonstop since 1972 from an Agip oil field. Flaring and venting in Nigeria amounts to $16 \%$ of the world total and if used in electric power generation would represent half of Africa's electric demand. U.S. flaring represents about $3 \%$ or $312 \mathrm{mmcf} / \mathrm{d}$ of the world's total.

\section{WHAT IS THE F-T PROCESS?}

The F-T process has three individual steps. In the first step carbon in natural gas (methane) or carbon in coal and bio-mass is reacted with oxygen and steam to form a mixture of hydrogen and carbon monoxide $\left(\mathrm{H}_{2}+\mathrm{CO}\right)$ called syn-gas. In the Second Step, the syn-gas is reacted under pressure in the presence of a catalyst to form long chain carbon-hydrogen molecules, termed F-T wax or paraffin. The third Step "cracks" these long chain molecules to form individual products like diesel, gasoline and petrochemical feed stocks.

Early F-T programs in Germany in the 1930s and South Africa in the early 1950s used fixed bed or fluidized bed F-T reactors with iron $(\mathrm{Fe})$ catalysts with coal as the feed stock to supply syn-gas. Modern F-T plants, post 1990, are using both fluidized bed and slurry bubble column, almost all with cobalt catalysts and focusing on natural gas as the feed stock to supply the syn-gas. In the mid 1990s, Germany again began experimenting with bio-mass - bio-renewable feed stocks to provide the syn-gas. Bio-renewable feed stocks hold the promise of producing F-T transport fuels that are $\mathrm{CO}_{2}$ neutral when evaluated on a full life cycle basis. This is a very attractive point as reducing green-house-gas (GHG) emissions gains more prominence across the world. 
Figure 1, below, illustrates a typical process flow diagram for the generic F-T reaction.

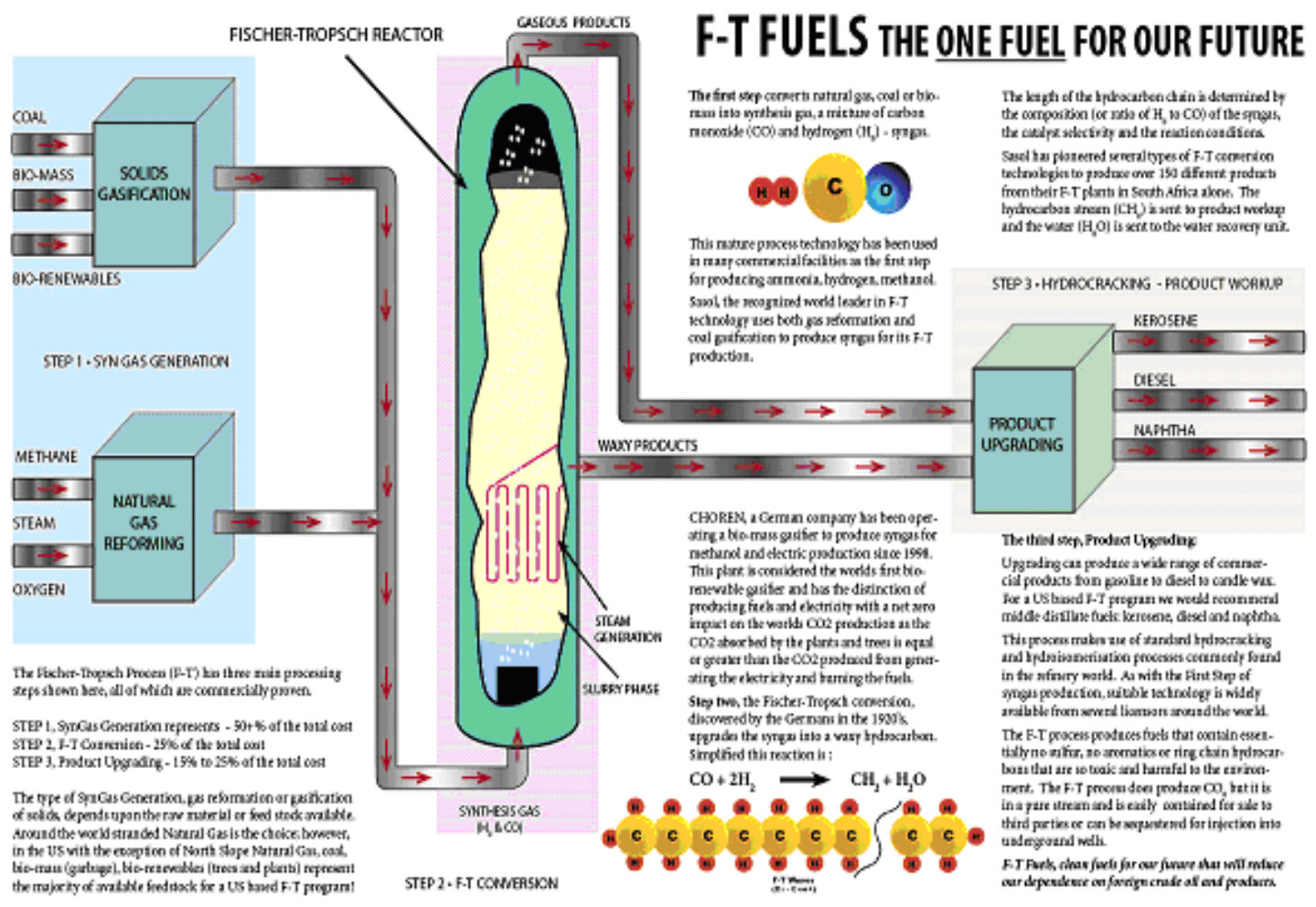

Figure 1

The F-T process offers the potential to produce a range of products: middle distillates (jet, diesel, kerosene) and gasoline, as well as lubricants and specialty waxes. Because F$\mathrm{T}$ products are made from natural gas, coal or bio-mass via a chemical process, they have none of the impurities associated with crude oil derived products such as sulfur, heavy metals and carcinogenic compounds such as benzene. These environmental benefits associated with F-T products add to their value in the market place. Higher product values attract new companies with innovative carbon conversion technologies to the game. In addition, well established F-T companies continue to optimize catalysts, F-T reactor designs and work with engineering contractors to reduce the costs of new F-T plant construction.

There are six factors that control the economics of modern F-T plants. The cost of capital; construction costs; the cost of the inlet feed (natural gas, coal or bio-mass); the conversion/thermal efficiency; plant operating costs; and the value of the finished products. We assume that the cost of capital, cost of feed stock and the value of the finished products are the same for any technology. Sasol, one of the recognized leaders in GTL, has been working hard to reduce the costs of traditional GTL F-T technology. The cost trends are down but the size of F-T plants is increasing; leaving behind smaller 
gas fields that can't support bigger F-T plants. Figure 2 below illustrates the advances Sasol has made by investing over $\$ 100$ million in 5 years on process improvements and EPC optimizations.

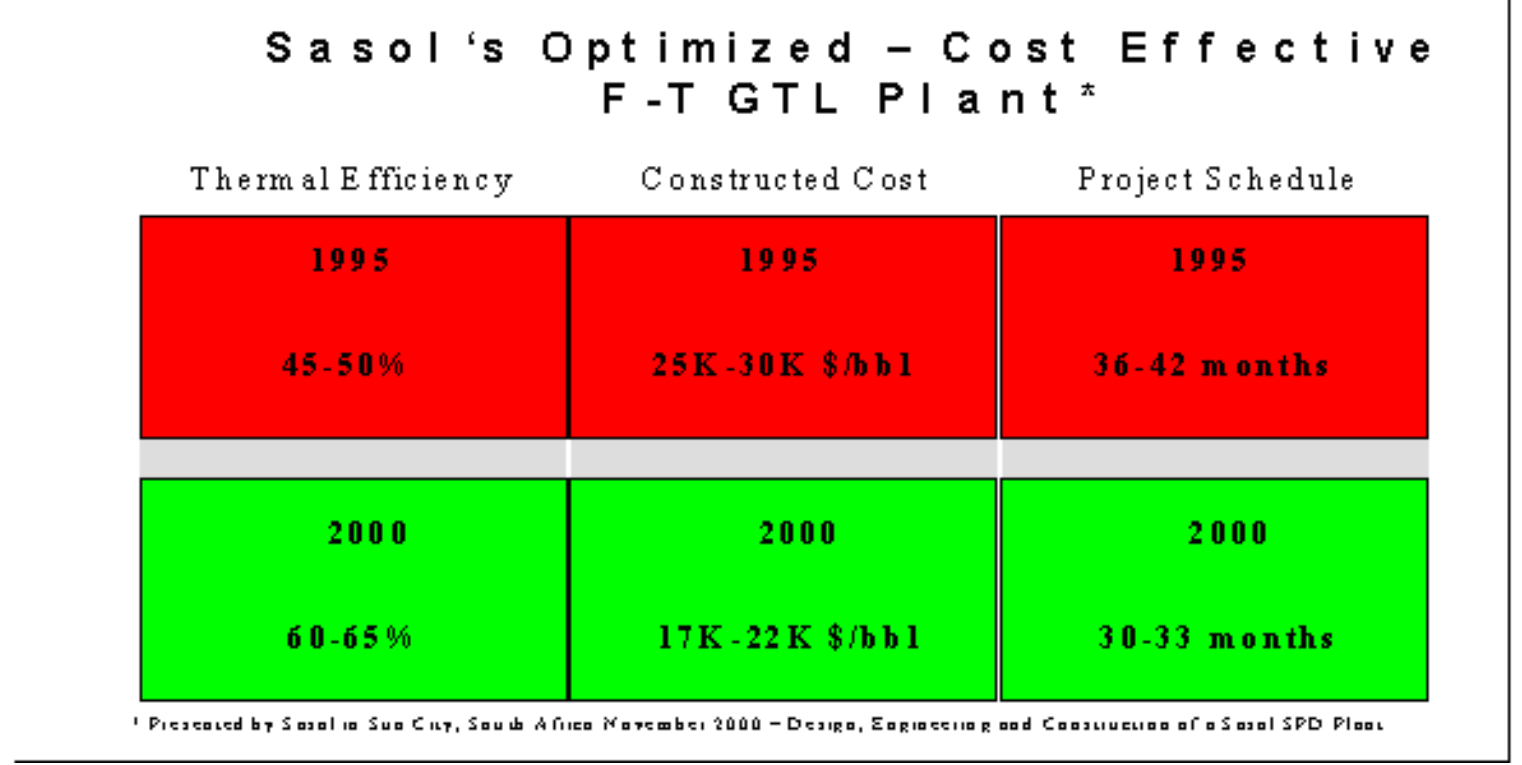

Figure 2

Using numbers quoted by Sasol for its 33,000 bbl/d F-T plant currently under construction in Qatar, the cost per installed barrel of daily capacity is less than $\$ 20,000$ per installed barrel. All the leading F-T technology providers have targets ranging from $\$ 14,000$ to $\$ 18,000$ per installed barrel of daily capacity; but all are working with design capacities in the 30,000 to $75,000 \mathrm{bbl} / \mathrm{d}$ or larger size F-T plants utilizing natural gas as the feed stock.

Cost Breakdown of F-T Process

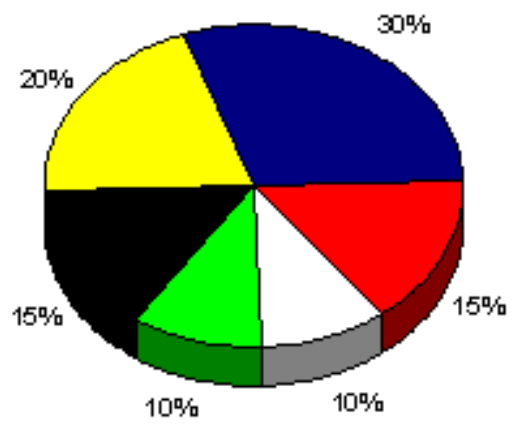

Figure 3
- Syn-Gas Generation DF-T Synthesis u dher Process Units Uutilities
口Product Work-up 口Offites
The target of $\$ 14 \mathrm{~K} /$ installed barrel is to make future GTL plants competitive with crude oil refineries. Since the operating cost of these big GTL plants is approximately the same as a modern crude oil refinery - $\$ 4$ to \$5/bbl future GTL plants can go head to head with new crude oil refineries based on the price of the feed stock compared to the price of crude oil, as process efficiency is improved.

From the Sasol/Foster Wheel Engineering work on GTL plants: 
Typically F-T fuel plants require big investments in utility and offsite support systems which can account for $40 \%-50 \%$ of the total cost of a plant, (Figure 3). These costs are usually included in each of three basic F-T steps, synthetic gas generation; F-T wax conversion and product workup; with the typical cost allocation of $50 \%$ to $55 \%$ of the total cost allocated to syn-gas generation; $25 \%$ to $30 \%$ to the F-T conversion with the remaining $15 \%$ to $25 \%$ to product upgrading. However, when developing an F-T project in areas were some or all of support systems are present, there may be significant cost savings available in each of these three steps. Conversely, building an F-T plant in an area with no support systems available the actual installed cost can almost double.

Virtually all the technologies for a large scale F-T plant have a common infrastructure requirement. This includes: the need for large quantities of energy to drive the air separation processes - oxygen plant; the preheat needs for the syn-gas generation step; waste heat recovery from syn-gas and its effective utilization; medium/low grade heat generation by the FT process; hydrogen provision for the hydrocracker; and optimum product recovery to maximize yield. And finally, as F-T projects are around $60 \%$ thermal efficient, resulting in around $40 \%$ heat rejection to the surroundings, ways to economically capture this $\sim 40 \%$ of the heat contained in the feed stock have to be found. In addition to heat recovery, offsite systems can be significant, especially when dealing with "Greenfield" remote locations in Alaska. Such offsite systems may include water treatment to support large steam systems and effluent treatment of hydrocarboncontaminated water and system blow downs. Gas flare systems to deal with high flows from the hydrocarbon units and high volume flows from the gas processing units; plus firefighting systems to deal with the large volumes of volatile hydrocarbons at their vapor points and process streams containing hydrogen, are very important. Isolated synthetic product tankage and dedicated F-T product loading facilities are significant factors; compared to a crude oil refinery as a F-T plant may require similar volumes in storage, but its utilization will be low until a robust market is established for these ultra clean products. F-T plants are similar to chemical plants where upsets due to contamination from small amounts of sulfur, as well as large-scale reliable electrical systems, that must supply power during startup and market power to the grid during normal operation can adversely affect plant economics. The usual support infrastructure of administration buildings, workshops, warehouses, cafeterias and medical facilities are required, plus temporary construction facilities will be needed for remote locations. While ultra clean F-T diesel fuels have generated the most interest, we must not forget that there are many challenges in the support systems when considering engineering, construction and cost that can be improved.

The element of market risk is particularly significant due to the massive scale at which the plants are planned. With expected cash flows of over $\$ 1$ billion per year from the sale of products, unexpected down time can doom a project. On a smaller scale, installation costs of GTL/CTL/BTL F-T plants rise rapidly, soon exceeding $\$ 80,000$ per daily barrel of capacity. Below 10,000 bbl/d, these plants scale down poorly, not so much in the design of the gas reformer, the F-T reactor or the product workup but in the ancillary equipment such as pumps, coolers, heat exchangers and treating facilities. 
Most major F-T technology companies are seeking large gas fields to support major F-T projects. Unfortunately for the U.S., with the exception of the North Slope, we have no stranded gas fields to attract natural gas based F-T projects. We are fortunate to have large coal reserves and an exceptional growing environment to supply bio-mass. CTL and BTL programs require larger syn-gas generation facilities because the available carbon is typically lower in woods and low rank coals than natural gas. Additionally, tons of waste (ash) and other impurities in coal and bio-mass that must be removed from the syn-gas before it is sent to the F-T reactor. These extra operations drive up the cost of a CTL/BTL program. Low cost mine mouth coal reserves can help offset the larger Capex costs but bio-mass will always struggle to be competitive, especially in the U.S. We will discuss later in this paper ways that the U.S. can support F-T to close this economic gap between crude based diesel and F-T diesel.

\section{DRIVERS FOR GAS TO LIQUIDS}

In the beginning of the 1980s many of the major oil companies began to invest considerable efforts and expenditure in the development of technologies for the conversion of natural gas into F-T liquid transportation fuels. The rapid rise in the price of oil following the mid 1970s Arab oil boycott and the belief that oil supplies had peaked at 50 million barrels per day of production provided strong incentives. There have been many ups and downs in the energy market in the 25 years since that time, stalling the development of GTL technology. Today world production of crude oil is just below 80 million barrels per day but enthusiasm for GTL processes has never been higher, driven by the need to reduce flaring, because of climate change fears and the prospect of turning the world's vast reserves of natural gas into clean fuels that could meet increasingly stringent air quality regulations. Many oil companies again believe the world's oil producing regions have reached their limits of sustainable production and natural gas must now be exploited to produce transportation fuels. Increased demand from China and India will quickly outstrip the world's ability to supply crude oil-based products, raising crude oil prices and creating more uncertainty in the world. China is looking at all sorts of energy production ranging from hydro to coal and bio-mass to liquids to nuclear to meet its growing energy demands.

\section{Environmental Driver - "free gas" with a hidden cost}

Gas flaring, the amount of gas that is flared or lost as associated gas with oil production is estimated at 3.8 trillion cubic feet (tcf) per $\mathrm{yr}(10.4 \mathrm{bcf} / \mathrm{d})$. This is equivalent to approximately 700 million barrels of oil (BOE) per year. Figure 4 breaks out these values by region of the world. (Source: World Bank report) 


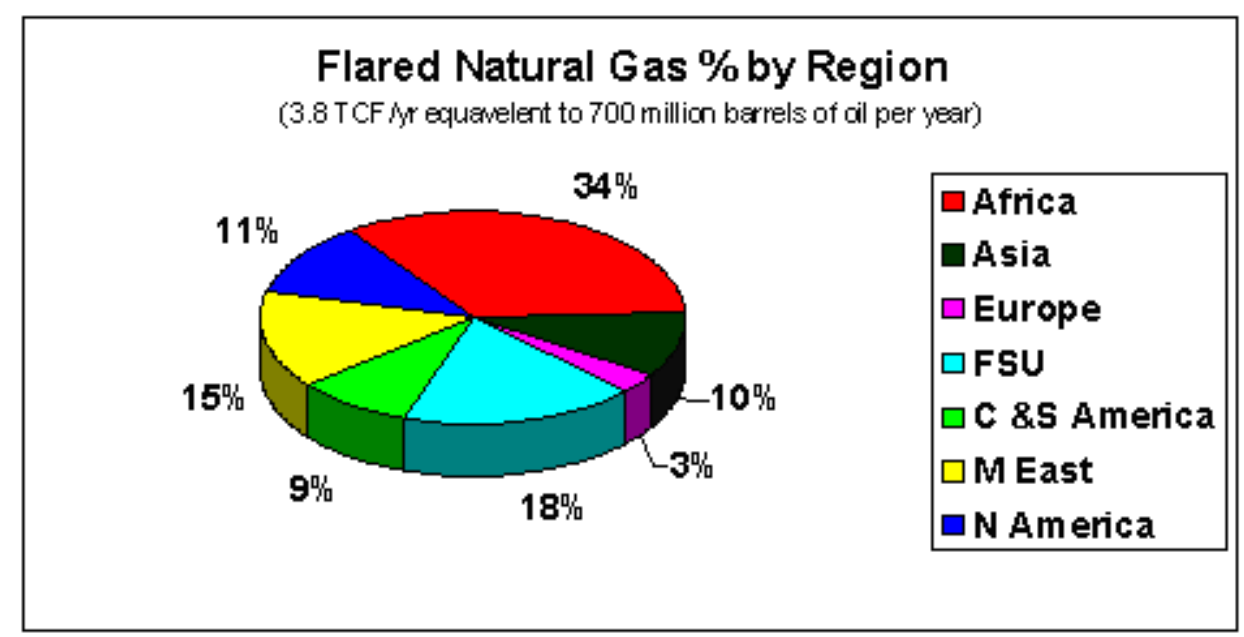

Figure 4

Gas flaring is gaining an increasingly bad name because of the severe impact on green house gas (GHG) emissions. In some countries, particularly Nigeria, flaring past a given date will bring economic penalties such that the natural gas resource will have negative values, dramatically improving the economics of most GTL programs.

\section{Stranded Gas - Net Present Value of Zero}

Total world gas reserves of 6,205 TCF, equivalent to 1,105 billion BOE, (Figure 5) are on a par with estimated world oil reserves of 1,147 billion barrels. However, the Former Soviet Union (FSU) and the Middle East account for over $70 \%$ of world reserves of natural gas (32.1\% - 40.8\%) and crude oil (7.6\% - 63.3\%) respectively. (Source 2004 BP Statistical Review) Once the development and production costs of the reserves can be covered, not producing these gas reserves can have a negative value.

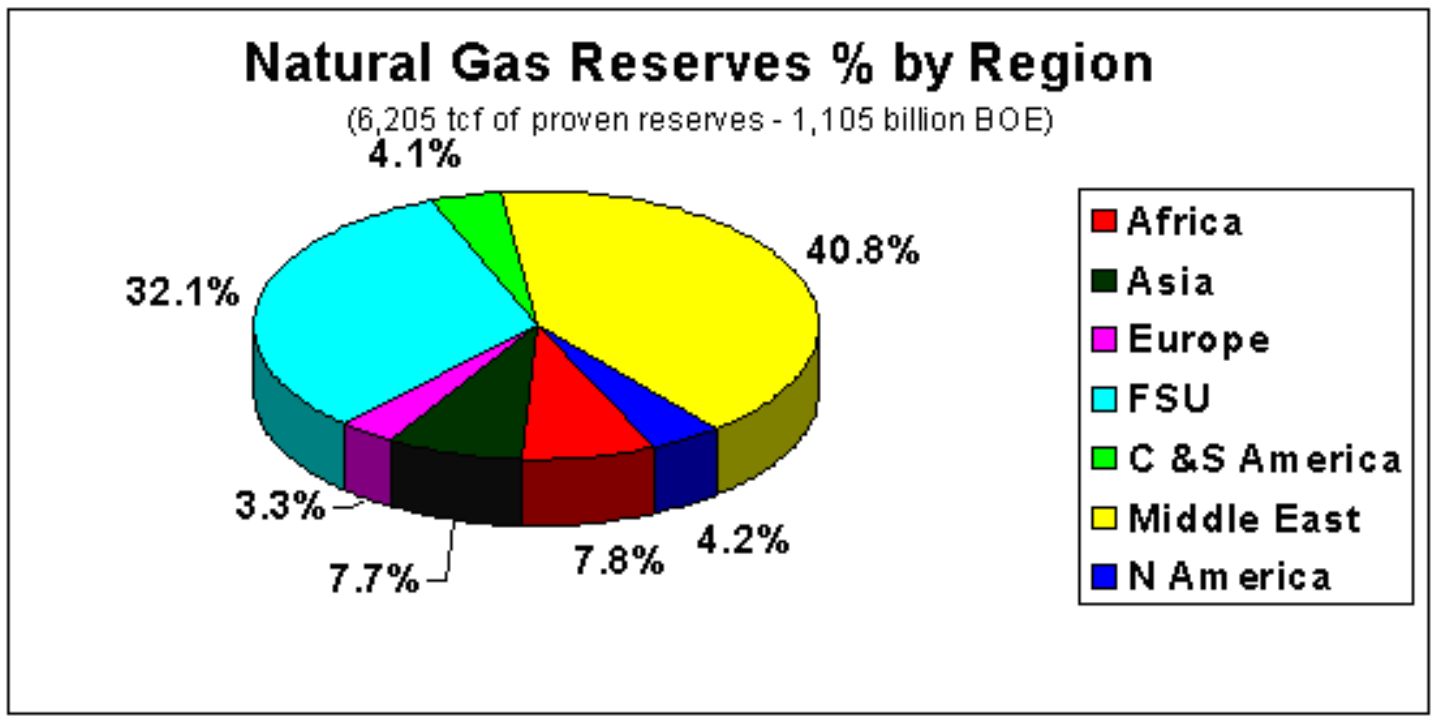

Figure 5 
The GTL majors, Sasol and Shell are swamped with requests to build GTL plants adjacent to big fields in Russia, Qatar, Iran and the FSU. Engineering companies are challenged to find the necessary manpower to design and build both large and small scale projects. As more and more GTL plants come on line the available pool of engineers, process designers, plant operators will grow exponentially so that smaller EPC companies can provide expertise for smaller GTL projects across the world. The same holds true for F-T plants relying on coal and bio-mass for their feed stocks

From a GTL refining point of view, 10.4 bcf/d of flared natural gas would make approximately 1.2 million barrels per day of finished products or 420 million barrels per year. In addition, a GTL plant generates enormous quantities of waste heat and can produce large quantities of steam-derived electricity, so the conversion efficiency is improved, thermally speaking. This was pointed out in the Sasol "Optimized F-T GTL Plant" shown in Figure 2 where Sasol achieved a 20\% increase in thermal efficiency in just 5 years. We need to keep in mind that early crude oil refineries were not very efficient and, with time, advances in technology improved the crude oil refinery conversion efficiency. The same will happen with GTL refineries when more are built.

Keep in mind that the first step of the GTL process, syn-gas generation, is used in many processes ranging from fertilizer, methanol and specialty che mical production to electric generation in IGCC power plants. A good example of improvements in efficiency over time is that of combined cycle electric generation. In the early 1970 s the best plants were around $45 \%$, which in itself was a major improvement over coal/steam electric generation at $30 \%$. By early 2002, efficiencies of CCGT plants were $60 \%$ or better. We would expect similar improvements in the F-T process over the next 30 years.

There are dozens of commercial companies providing syn-gas generation technologies across the world that are looking for an edge to sell their technology. Each company is driving to develop a lower capital cost and more efficient process to market to new projects developed each year. The same goes for the hydrocracking process, as advances in design, catalyst selectivity and life can be applied in hundreds of existing refineries across the world and future GTL plants. Advances in these areas will continue each year. They will be small steps, saving a few million dollars or a percent of operating cost, or improving process efficiency.

For large-scale plants, the savings or improvements are welcome but few developers are looking at small plant designs. Still, the biggest challenge that lies ahead for GTL technology developers is process integration or the combining of all three steps to make an energy efficient process. Here is the one place smaller GTL plant technology providers may have an edge. 


\section{FISCHER- TROPSCH NEW TECHNOLOGY}

From a technology viewpoint, the areas of maximum impact on profitability are Efficiency of Conversion (Energy and Carbon) and Capital Cost, especially as they relate to smaller GTL plant applications.

FT will always be a three-step program where a syn-gas $\left(\mathrm{H}_{2}+\mathrm{CO}\right)$ is generated from a carbon bearing gas or solid; the syn-gas is then reacted with a catalyst in the F-T reactor to make long-chain hydrocarbon molecules (waxes) and then is split into shorter-length hydrocarbon molecules (diesel, naphtha, kerosene to name three) in a hydrocracking or product workup stage that is almost identical to crude oil refining. The capital cost allocation of each step is generally $50 \%$ for the syn-gas generation (step one); $30 \%$ for the F-T reaction, (step two); and 20\% for the product workup (step three.) Like all crude oil refineries, (step three), product workup is the most advanced, the most efficient and likely to have the least chance of major improvements in capital cost reduction, process efficiency improvements or operating cost reductions. The one advantage that F-T hydrocracking has over crude oil is that the long chain FT molecule is very easy to crack, requiring lower temperatures and pressures. In addition, while hydrocracking, the product can be isomerised to improve cold flow properties before sending the hydrocarbon to the refinery distillation tower for fractionation. Thus F-T product workup will be a little more efficient and have a lower operating cost than its crude oil cousin. While process integration, the efficient combining of all three steps, is a major challenge for F-T technology providers, advances in the first two steps will result in step changes in costs, carbon conversion, thermal and process efficiencies.

One thing should be pointed out with respect to the F-T/GTL process; the heat required to initiate a chemical reaction; the pressure at which the reaction occurs; the heat given off by a chemical reaction; the water or steam required for a reaction or that will result from a reaction is no different for a $200 \mathrm{bbl} / \mathrm{d}$ plant or a 75,000 bbl/d plant. The only difference is the amount required, or given off. The type of catalyst required driving the reaction, and the pressure or temperature at which it occurs remains the same. Thus the ancillary equipment required to support the F-T/GTL process has the same operating requirements.

Large pumps, heat exchangers, steam generators and catalyst charges are required for many different processes across the world and are supplied by many competitors at commercial prices. One-of-a-kind or very small specialized equipment is costly. Space, military and airplane parts are examples of limited market, expensive to manufacture equipment (we have all heard of the $\$ 600$ toilet seat). Small GTL plants will be in this category, making it difficult to justify in a commercial economic setting. 


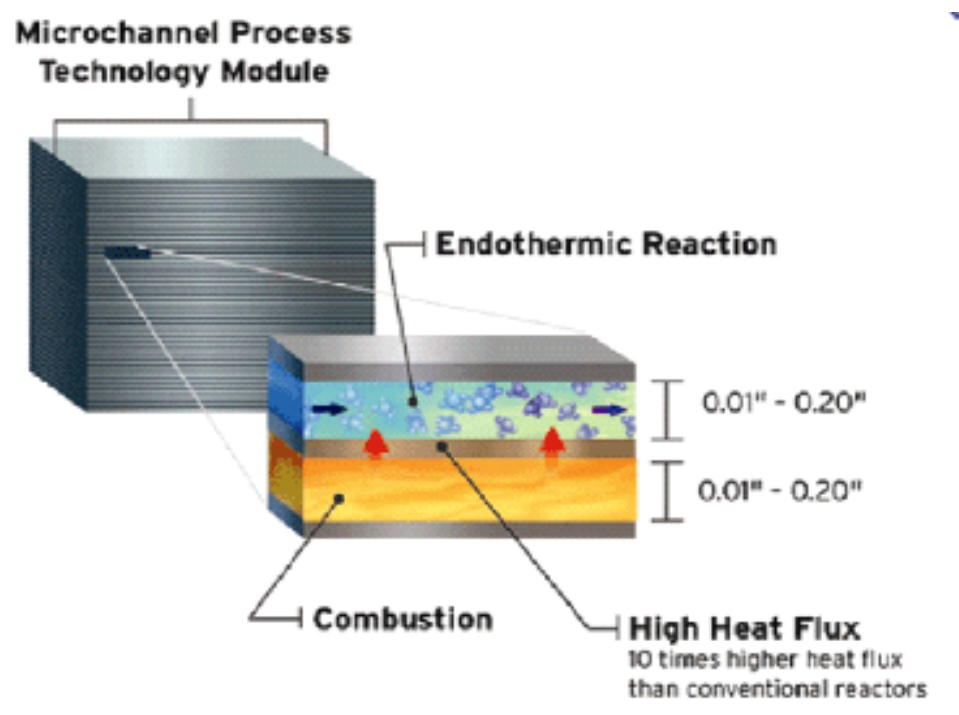

Some new and innovative F-T technologies are looking at major reductions in the capital cost of the syn-gas generation step. One is the Air Products-led consortium looking at ceramic membranes which aim to create syn-gas for one half the current capital costs. Still others, like GTL Microsolutions and Velocys, a commercial arm of Battelle, are combining step one and two using microchannels; a very interesting and promising new technology reminiscent of the 1960s improvements-gain in the semiconductor industry. Here the F-T process is carried out in thousands of identical miniature process channels bolted together to provide a desired output.

To the left is a pictorial of a microchannel process. The more "plates" we bolt together, the more natural gas we reform to syn-gas, and the more F-T hydrocarbons are formed in the second step. This design concept may have the advantage of being able to scale up or down to meet the feed stock and/or market requirements of the area. 


\section{GTL-in-a-Can - a one stop process}

Still yet another company, TIAX, is proposing to combine all three GTL steps in one process, called "GTL-in-a-Can". Some, like the TIAX process are still paper proposals; others like the Velocys program, illustrated here actually have operating pilot plants. Other innovators are working on improvements in catalyst design, catalyst reactivity and life; some are looking at heat transfer issues in the F-T reactor. One thing all have in common is a great deal of secrecy associated with their technology and for the most part, little capital to prove up the technology.

For the remainder of this paper we will look at those technologies designed to reduce the size of the natural gas-based F-T plant while not sacrificing the economics of scale. I would point out that even the so called "small" GTL technology providers are looking at 5,000 to 10,000 barrel-per-day plants (1000 bbl/d modules) with economics in the $\$ 30,000$ per installed barrel range as the target. Plants ranging from 200 to $500 \mathrm{bbl} / \mathrm{d}$ are not the focus. However, developing plants for mission specific projects such as a battlefield F-T fuel module will help reduce the costs of the large-scale targets. Of the technologies looked at, only the microchannel technology lends itself to scalability, to downsize by removing "plates" from the module. However, total unit installed costs will still rise dramatically as size drops.

Abundant supplies of natural gas in remote and off-shore locations cannot be costeffectively brought to market. Conversion of natural gas to liquids (GTL) has been a technology development goal for more than two decades as a means of capitalizing on this resource. Numerous processes have been developed and demonstrated on a relatively small scale, but Sasol's Synthol plants at Secunda, Sasolburg and Mossel Bay, South Africa and Shell's SMDS plant in Indonesia remain the only large commercial CTL and GTL plants. Widespread adoption of the various GTL processes continues to be limited by economic uncertainties, including fluctuating oil and gas prices, the cost of capital and technical risks in a fast-developing field.

Many more gas fields can be open to exploitation with a smaller plant, including gas associated with offshore platforms. Applications that can be exploited by the military for mission specific purposes can help reduce technology development costs and provide markets for smaller ancillary equipment, reducing the overall cost of new technology for civilian (commercial) applications. A GTL technology that achieves the economics of the large-scale $50,000 \mathrm{bbl} / \mathrm{d}$ plants at a $500 \mathrm{bbl} / \mathrm{d}$ scale would permit new companies to enter the GTL market. Military commercialization of small plant technology permits time for leading edge technology to advance and mature, providing operational experience, and a market for critical plant equipment manufacture, all further reducing costs for civilian projects. 


\section{Microchannel Process Technology}

One of the most promising technologies is Microchannel Process Technology (MPT). Due to its modular nature, MPT scales down well and can reduce costs below those of conventional processes at all scales. While there are several ongoing MPT programs, two of the most public are the Velocys and GTL Microsystems programs. Both are pursuing programs that generate syn-gas and the F-T hydrocarbon but are initially relying on third party technology to make a finished F-T diesel fuel. However, Velocys was just awarded a DOE grant to carry the process through its final step and make a finished F-T fuel. A spokesperson for Velocys said the company hopes to validate this new program within five years.

The F-T process, upgrading natural gas to diesel fuel includes three steps: 1. Converting natural gas to synthesis gas (syngas); step 2. Upgrading the syngas to hydrocarbon liquids; and step 3. Hydrocracking the liquids to give the desired product mixture. Options for natural gas upgrading include steam reforming, partial oxidation, or a combination of the two, such as autothermal reforming. While each of the syn-gas generation processes has various advantages, the steam reforming process lends itself to significant process improvements and precludes the construction of a capital and energy intensive oxygen plant. This is similar to the Syntroleum concept of gas reforming except the MPT uses only steam and doesn't suffer the process inefficiencies and extra capital costs associated with using air, which introduces inert gases like nitrogen into the process.

In the MPT process natural gas and steam are converted in a first stage reactor heated by the combustion of fuel gas and waste heat from the F-T process - which is very exothermic. The ratio of $\mathrm{H}_{2}$ and $\mathrm{CO}$ in the resulting syngas is adjusted to the desired ratio by separation in a membrane, providing some of the fuel gas for the reformer and an $\mathrm{H}_{2}$ stream for use in the third step, hydrocracking.

The $\mathrm{H} / \mathrm{CO}$ syngas is fed to an F-T reactor, where it reacts to form hydrocarbons and water while the heat is removed by producing steam for the first stage reformer or electric generation. The wax F-T products are then hydrocracked to produce high quality, clean diesel fuel or other specialty chemical products.

One of the biggest advantages of MPT is that unlike many hydrocarbon process technologies it does not have to be vertical and it is unaffected by motion. The MPT process can be laid out in any format allowing for horizontal modules (multiples of containers arranged end-to-end or side-by-side) and since the process is unaffected by movement it can be used for ship, spar, TLP and FPSO applications in unprotected waters. It also has a tremendous advantage when used in a hostile military environment in that if a portion of the plant is damaged, the unit can be replaced with a new module or blocked off to put the plant back in service in short order.

Both MPT providers that were willing to discuss their technology are hopeful for an installed cost in the $\$ 24 \mathrm{~K}$ to $\$ 30 \mathrm{~K}$ per barrel of capacity plus product workup costs. As far as we can determine, these costs did not include ancillary equipment costs. MPT 
providers will freely tell you that their goals are $10,000 \mathrm{bbl} / \mathrm{d}$ plants to take advantage of the modular design and mass production cost savings of the microchannel design. When you compare them to Sasol's total cost to engineer, design, build and place in-service target of between $\$ 16 \mathrm{k}$ to $\$ 22 \mathrm{k}$ per installed barrel, these mini-GTL plants will be expensive.

\section{GTL-in-a-Can}

TIAX's concept to put all three F-T steps in one vessel is a novel approach and if it works can revolutionize the GTL industry. However, unlike MPT which has a very large chemical industry interested in its process, GTL-in-a-Can is geared towards one industry (gas) and this industry believes "bigger is better." Without a bench scale plant to show a technology can be transferred from paper to plant, this technology appears to be off in the distance. The flow diagram of the process shows air introduced to the process in the reforming step, gas clean up prior to the "CAN" and the cracking of the $\mathrm{C}+5$ hydrocarbons outside of the process "CAN". In effect, this places it along-side the MPT process in that two steps will be combined in the new technology and the product workup will be accomplished via other commercial means. Given the projected costs of $\$ 25,000$ to $\$ 50,000 / \mathrm{bbl}$ per installed barrel costs (does this exclude product workup? - No one is saying) the only advantage may be in size or foot print.

While there are references to industry and university GTL research programs plus other forms of MPT work ongoing, none has sufficient public reporting to provide comments here.

There are however, several programs that are addressing syn-gas generation that show promise of reducing the costs of natural gas based F-T.

\section{Syn-Gas gene ration}

Syn-gas generation represents half of the GTL complex Capex costs. The greatest step changes in the GTL process are anticipated to occur in this critical step because in addition to F-T, syn-gas is the building block for the majority of chemical and petrochemical processes across the world.

Another form of microchannel technology is the Air Products/DOE led consortium looking at ceramic membranes or Ion Transport Membranes (ITM) to reduce the cost of making syn-gas from methane and oxygen. The ITM process consists of methane $\left(\mathrm{CH}_{4}\right)$, steam $\left(\mathrm{H}_{2} \mathrm{O}\right)$ and oxygen $\left(\mathrm{O}_{2}\right)$ chemically combined to form $\mathrm{CO}$ and $\mathrm{H}_{2}$ without the expense of building an air separation $\left(\mathrm{O}_{2}\right)$ plant. Figure 6 below provides a flow diagram of the process and a picture of a ceramic membrane. The ITM process is in the middle of a 10 year development program with commercial demonstration scheduled for the 200809 time period. Once commercialized, the ITM process can save up to $50 \%$ of the cost of reforming or $25 \%$ of the total capital cost of the GTL process. 


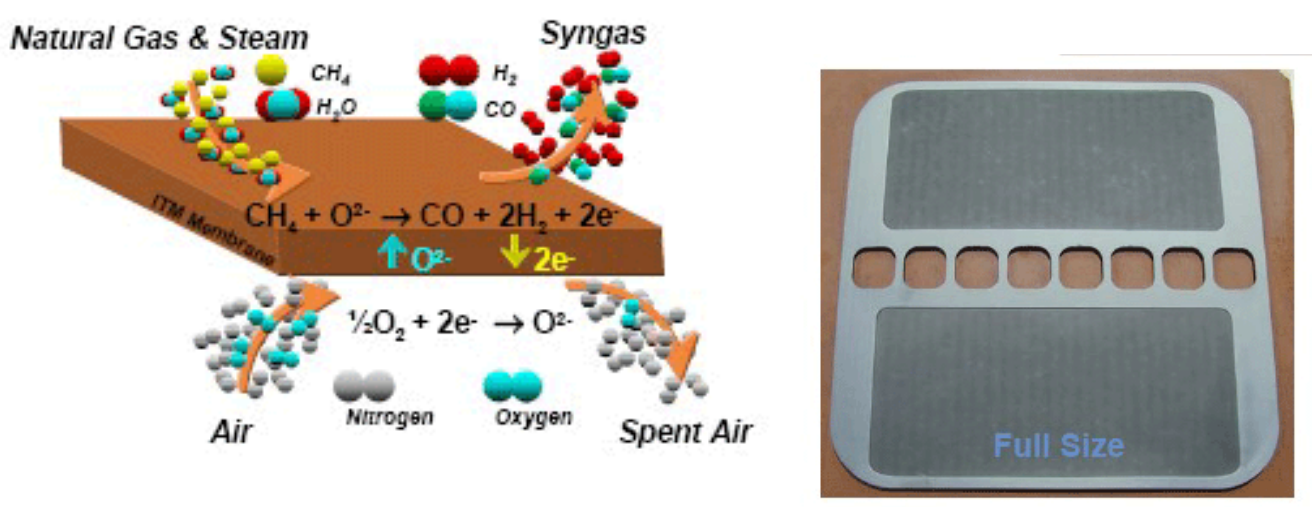

Figure 6

The ITM process will also lend itself well to the modular concept, creating reforming modules that can be mass produced in central manufacturing plants, reducing costs and will provide great flexibility in plant size for field applications.

The technology is well proven; the problem has been the manufacturing of commercial size membranes for plant sizes in the 100 million cubic foot per day range. In discussions with Air Products, the demonstration size ITM currently in the final phase of testing may be ideal for the small natural gas based F-T plants (under 10 million cubic foot per day $-1,000 \mathrm{bbl} / \mathrm{d}$ ) that are the focus of this paper. There is an industry group, consisting of several of the same companies working with Air Products that is also pursuing similar ITM technology. Their findings have not been made public but we know that they are making similar progress.

\section{Compact reformer design}

Several leading companies are investigating technology that would reduce the size (foot print) and cost of traditional natural gas reforming. Each is following paths that will result in step-changes in the reforming area. Of this group, the most public has been a joint venture with BP and Davy/Kvaerner. The BP/Davy compact reformer as it has become know as was first demonstrated at the BP Nikiski, Alaska GTL test site in 2002. The radical design results in a reformer foot print of less than $30 \%$ of a normal steam gas reformer. Statements in the public domain indicate that the purpose of this design was to be used in offshore production areas to reduce or eliminate natural gas flaring/venting. No public release has been made on the reduction in cost for the compact reformer but one obvious cost savings is that it does not require an oxygen (air separation) plant which usually represents $1 / 3$ of the gas reforming costs. Weighing in at over 3,000 tons for the $300 \mathrm{bbl} / \mathrm{d}$ test facility, it is lighter than a similar sized gas reformer by some $75 \%$, can be manufactured in a central plant and delivered to the GTL site unlike typical steam methane reformers that usually have to be constructed on site. But it is not, nor was it ever intended to be field portable. BP/Davy's goal is a $1000 \mathrm{bbl} / \mathrm{d}$ compact reformer module that can be added in parallel to support 30,000 bbl/d + GTL plants. According to Davy, there are no plans to look at smaller applications. 
Plasma Arc technology shows some promise for converting methane into syn-gas. But it requires large amounts of electrical energy making it questionable for any remote location syn-gas generation programs and certainly not suitable for field portable or mobile applications like ships.

There are numerous companies in the syn-gas generation field that are working on improvements in their current designs, catalysts and combinations of technologies that will reduce overall Capex costs and improve efficiencies. However, none of these companies to the best of our knowledge are focusing on small gas reformer technology and are not part of this paper. Advances in large scale reformer technology will find their way to smaller applications but it is our belief that microchannel, whether through the MPT or ITM route will result in the step-change in cost and efficiency that mini-GTL plants will need to compete effectively for smaller packages of stranded gas.

\section{Catalysts}

In the early days of F-T, iron-based catalysts were the most used, primarily because coal was the feed stock of choice. Early experimentation with cobalt showed improved selectivity and reduced $\mathrm{CO}_{2}$ generation. Catalyst life was limited and early designs were expensive to produce. When Sasol first chose to commercialize its slurry phase F-T program for natural gas, catalyst life before regeneration was at most one year. Today with advances in formulation and design, life expectancy is 3 or more years with the goal of 5 years by 2006. Other GTL providers have stated similar expectations for their unique catalyst formulations and designs. This has reduced the operations and maintenance costs of the gas based GTL plants considerably. Coal or bio-mass-based F-T plants for the most part still use iron-based catalysts, but with catalyst life expectancies of 30 to 90 days they still have a long way to go.

Catalysts are involved in all three steps of the F-T process. Advances in the oxygen transfer ceramic membrane reformer (ITM) process will further reduce operating costs by eliminating catalysts in the gas reformer. The MPT program promises catalyst integration with very high selectively and conversion ratios 3 to 5 times greater than in conventional F-T reactor designs. 


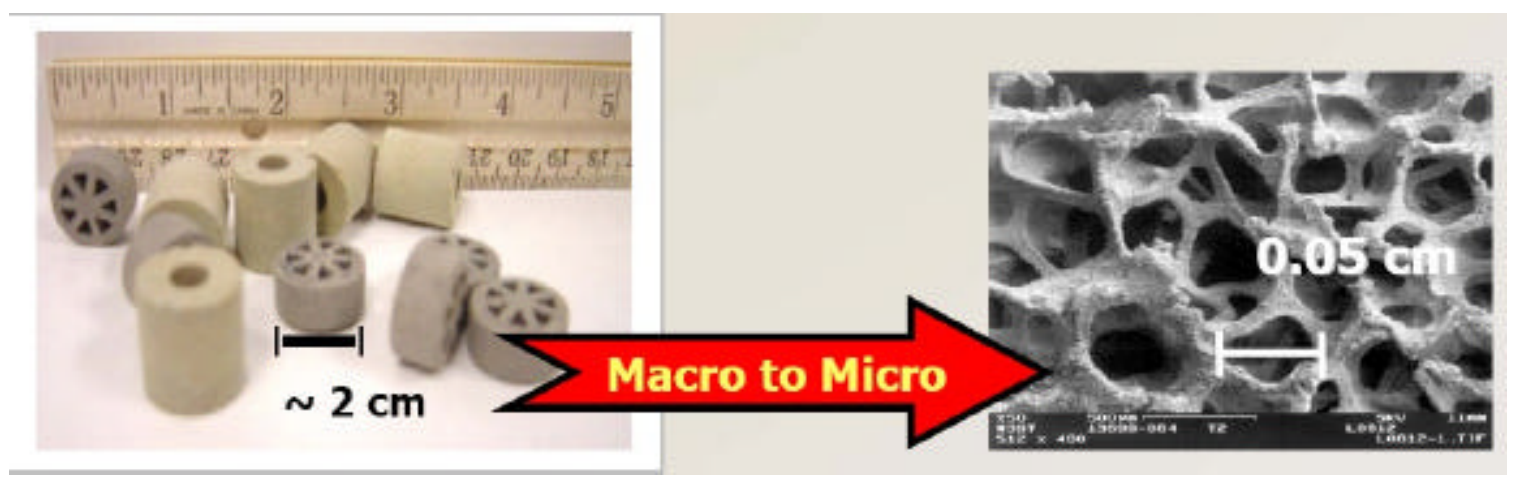

Figure 7

Figure 7 above illustrates the differences in catalysts for conventional reforming and F-T plants, on the left with catalyst size measuring in centimeters and for the microchannel syn-gas and F-T hydrocarbon applications on the right measuring in millimeters. The smaller catalysts associated with the microchannel technology provides much more surface area to drive the reaction of making syn-gas or the F-T hydrocarbon chains.

\section{THE WORLD HAS STRANDED/FLARED GAS FOR F-T DEVELOPMENT WHAT CAN BE DONE TO DEVELOP F-T IN THE U.S.?}

\section{LIQUID RESERVES FROM COAL AND BIO-MASS IN THE U.S.}

Beginning in the late 1990s virtually all F-T developers have focused on flared gas and large gas reservoirs across the world as feed stock for gas based F-T plants, the " $G$ " in GTL's. With the exception of Alaska's stranded North Slope gas reserves, the U.S. has no giant stranded gas field waiting for a GTL program to develop it. Until someone develops a technology to extract the vast reserves of hydrates locked in our frozen north or in deep offshore pools, coal and bio-mass are the only carbon based materials available to supply large scale U.S. based, domestic F-T plants. Having the resources is one thing; being able to convert them into an economic transportation fuel is another.

\section{COAL - THE U.S. SAUDI-SIZED NATURAL RESOURCE}

It is estimated that the U.S. has over 250 billion tons of recoverable coal reserves. Using a typical conversion ratio of two barrels of F-T from one ton of coal, the U.S. has approximately 500 billion barrels of F-T fuels or almost $50 \%$ of known world's oil reserves. CTL in the U.S. can have a significant impact on imported crude oil if we want it to.

Certainly from a military fuel supply point of view, a U.S. CTL program should be attractive. 


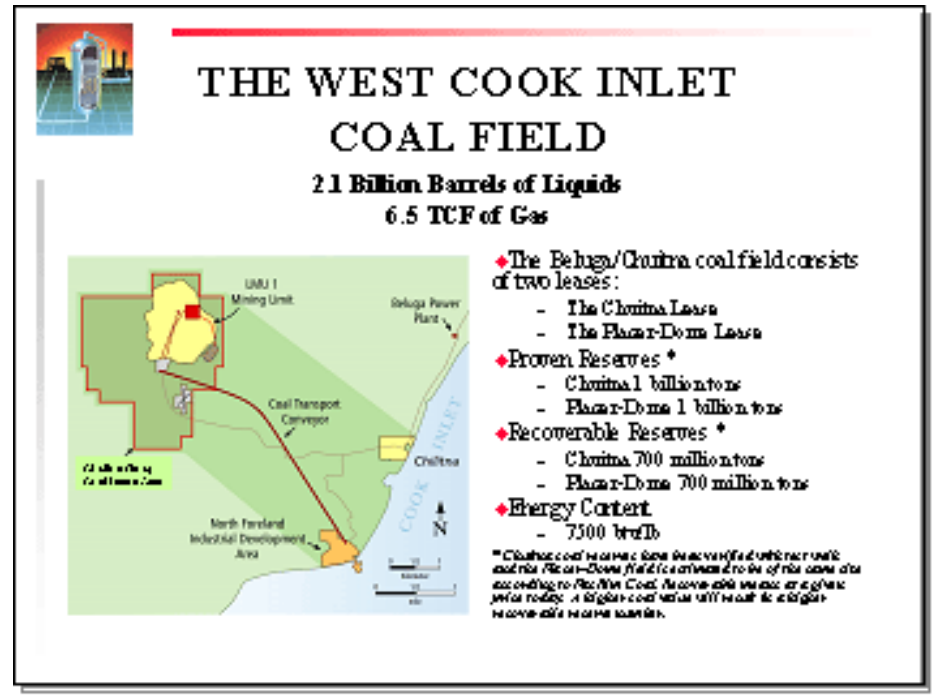

As an example, Alaska has a "small" coal field in the Cook Inlet 40 miles south west of Anchorage called Beluga, see Figure 8. This west Cook Inlet Beluga area coal field has approximately 1.4 billion tons of proven recoverable subbituminous coal or the equivalent of 2.1 billion barrels of liquids. Using the Sasol F-T thermal conversion efficiency of $65 \%$ shown in Figure 2, that means that $35 \%$ of the thermal energy in the coal, if captured, can be converted into the same btu energy content as 6.5 tcf of natural gas. A 2.1 billion barrel oil field is the second largest oil field in the U.S. behind Prudhoe Bay and 6.5 TCF is the largest gas field ever found in the Cook Inlet and 20\% of the proven gas reserves on the North Slope. The Beluga coal field is a significant Alaskan energy resource that should not be over looked. Multiply this across the U.S. and you can quickly see how coal can fill the gap between U.S. oil production and product demand. We will touch on ways the federal government can help make CTL and BTL economically attractive in the U.S. later in this paper.

\section{F-T Fuels Economics for the World and the U.S.}

There is no question that F-T technology works with over 250,000 barrels per day of F-T plants operating in the world today and another 500,000 barrels per day under construction or in the final design phase. It is a PROVEN concept.

There is no question that F-T transport fuels are compatible with the existing motor fuels market and infrastructure with over 40 billion gallons sold to date throughout the world. It's COMMERCIALY proven.

No new refinery (crude oil or alternative fuel) built in the U.S. can recover its capital cost (CAPEX) if it has to sell its "new cleaner fuels" at the same price as "conventional fuels".

NEW REFINERIES, whether or not they are crude oil or GTL based, will need an economic boost or incentive to compete in the U.S. This is not the case in Europe or Asia where F-T diesel sells for a premium over even low sulfur diesel.

The question is then, "CAN F-T FUELS BE ECONOMIC"? If the measure of economics is price at a U.S. fuel pump, the answer is generally no. However, as the price of crude oil continues to rise at some point the cost of manufacture of F-T fuels will equal 
that of crude-based transportation fuels. Environmental issues, reducing a nation's dependence on imported crude oil are two factors that will favorably affect the economics of F-T fuels across the world.

There are generally three economic drivers that impact the real cost of U.S. transportation fuels outside of the basic cost of crude oil feed stock. They are:

$\checkmark$ Strategic, the need to maintain a military presence in the Middle East to insure the free flow of oil to the world. We refer to this as a Security Premium.

$\checkmark$ Shortfall in U.S. Refining Capacity (fuel availability). We refer to this as a Refining Capacity Penalty.

v Environmental - Lower Emissions + CAFÉ Levels (Clean Cities Programs - lower GHG emissions \& better fuel mileage). We refer to this as the Engine Emission and Efficiency Costs.

The problem in the US is that many factors are at play that affect overall economics of fuel at the pump. There are the hidden costs of our national energy policy that are not apparent at the fuel pump but do cost us as tax paying citizens - the Security Premium. There are costs we see at the fuel pump each driving season that as individuals we have no control over - the Refining Capacity Penalty. New alternative fuel refineries (F-T) plants cost tremendous amounts to build as they are more like chemical plants instead of crude oil refineries. If new environmental laws require crude oil refineries to make fuels as clean as F-T, then F-T plants could be competitive. If the U.S. charged a premium for importing oil or gave credits for refineries that reduced U.S. dependence on imported crude, F-T plants could be competitive. If the U.S. charged a tax for importing gasoline and diesel, refineries would be built in the U.S. making new F-T refineries competitive.

As individuals there is little we can do to control our fuel costs except buy more fuel efficient vehicles - Engine Emission and Efficiency Costs. However, there are two areas where the Federal Government can help promote new alternative fuel refineries in the U.S.

\section{Strategic}

The National Defense Council Foundation has performed a very detailed study of the "Cost of Imported Oil" including other factors such as loss of jobs showing that as consumers we pay a Security Premium approaching \$2.00/gallon. Years ago the government estimated this number to be $50 \phi /$ gallon. We currently use approximately 12 million barrels per day of gasoline and diesel in the U.S., using the lower figure of 50\&/gallon this Security Premium cost is approaching $\$ 92$ billion per year - $\$ 368$ billion at $\$ 2 /$ gallon.

\section{Shortfall in US Refining Capacity}

The U.S. currently has a 3 million barrel per day refining capacity shortfall. This means that each driving season U.S. refineries cannot make enough gasoline and diesel to supply motor fuels demand. They raise the price at the fuel pump to cause "economic 
conservation." It is estimated that the lack of U.S. refining capacity, costs the US consumer $\sim 25 \notin /$ gallon for 3 months or about $\$ 11$ billion per year - Refining Capacity Penalty.

Crude oil refiners have no incentive to eliminate this refining capacity short fall as they would lose this annual windfall, plus they will claim there is no way to recover the capital cost of the new refinery if they are selling motor fuels at the same price as other refiners. Most refiners will say it is cheaper to import gasoline than to build new refineries in the U.S. In addition because Europe has a higher CAFÉ standard and cleaner diesel, most European refiners are struggling to meet diesel demands but are awash in gasoline, which they export to the U.S. A refining shortfall in the U.S. provides a home for their excess gasoline supplies in Europe.

It is estimated that if the U.S. was to institute CAFÉ standards similar to Europe, the American consumer through better mileage would save over 1.4 million barrels per day of gasoline; resulting in a fuel savings of over $\$ 35$ billion dollars each year. Like in Europe, diesel would become the preferred transport fuel because diesel engines are more efficient and generally diesel vehicles get $25 \%$ to $30 \%$ better mileage than similar gasoline powered vehicles.

By instituting a tax credit or energy credit to build new refineries the federal government can reduce the refining capacity shortfall, eventually reducing the annual price fly-up seen at the pump each driving season. Who benefits? The American consumer, with lower fuel pump prices and more efficient, higher-mileage vehicles. Who loses? The traditional crude oil refiner.

Table 1 below illustrates the price needed for products from a new refinery above today's fuel prices to recover the capital cost of the refinery. As we can see even a crude oil refinery will need a higher price for its gasoline and diesel if it is to recover its capital investment. Smaller-size coal and bio-mass F-T plants will need an even higher price. However, their gasoline and diesel F-T fuel is of much better quality. Environmental rules affecting crude-based fuels can add more costs to a crude oil refinery closing the gap. As the price of crude oil continues to rise and the price of coal and bio-mass (F-T plant feed stocks) remains stable, BTL and CTL plants will become more competitive. 
Conversely, crude oil prices can drop, making BTL and CTL less competitive. This has been the traditional way oil producing nations have stopped alternative fuel programs in the past. Whether world demand for crude has outstripped the ability of oil producers to produce excess crude is the big question today.

\section{Estimated Costs of New Refining Capacity (plants built in the U.S.)}

\begin{tabular}{|c|c|c|c|c|c|}
\hline Refinery Type & $\begin{array}{c}\text { Estimate } \\
\text { By }\end{array}$ & $\begin{array}{c}\text { Plant } \\
\text { size } \\
\text { bbl/d }\end{array}$ & $\begin{array}{c}\text { Cost / } \\
\text { Installed } \\
\text { Barrel }\end{array}$ & $\begin{array}{c}\text { * Refinery } \\
\text { CAPEXat } \\
100,000 \\
\text { bbl/d }\end{array}$ & $\begin{array}{c}\text { 申/gal to } \\
\text { recover } \\
\text { CAPEX }\end{array}$ \\
\hline Crude oil & Oil Majors & 100,000 & $\$ 18,000$ & $\$ 1.8$ billion & $18 \phi$ \\
\hline Coal to liquids & Sasol & 75,000 & $\$ 45,000$ & $\$ 4.5$ billion & $44 \phi$ \\
\hline Bio-Mass to liquids & Choren & 6,500 & $\$ 65,000$ & $\$ 6.5$ billion & $67 \phi$ \\
\hline Bio-Mass to liquids & Choren & 300 & $\$ 183,000$ & - & $182 \phi$ \\
\hline
\end{tabular}

* Cost of refineryestimate at capacity shown but adjusted to 100,000 bbl/d for comparison only 10 loan @ $8.5 \%$

A recent quote regarding the Sasol CTL plants built in South Africa said "Sasol's Secunda CTL Plant: Costly To Build, But Now It's A Cash Cow". Once the capital costs of U.S. built F-T plant are recovered, American BTL and CTL plants can be competitive well below today's price of crude oil.

\section{DIFFERENT WAYS FOR THE U.S. TO SUPPORT ALTERNATIVE FUELS}

Support for alternative fuels in the U.S. is really about reducing the cost of the "new" fuel to be competitive with existing fuels. It's not about the echnology even though we expect improvements in process and conversion efficiency. Unlike European consumers, the typical American consumer will not pay a higher price for a cleaner fuel unless he is legislated to do so. As a result programs that reduce the cost of new fuels or tax the new fuel at a much lower rate so the pump price appears the same will create the largest demand for the new fuel and the greatest interest from the industry.

Europe is years ahead of America when it comes to support for cleaner fuels, alternative energy and non-petroleum fuels. As a consequence, many alternative fuel developers are focusing on non-U.S. projects. With a limited amount of qualified engineering, construction and manufacturing facilities capable of developing new alternative fuel programs across the world, the U.S. needs to develop programs to attract them to projects in America. 
There are several options available to the federal government that can cause an alternative fuel program to grow in the U.S. It makes sense to provide these incentives on a federal level as each "new" refinery built in the U.S. reduces the amount of crude oil imported to the U.S. - a Security Benefit - and reduces the refining capacity short fall and corresponding annual price fly-up at the fuel pump - Refining Capacity Penalty. These benefits will be seen across the country. Even if an alternative fuel plant is built in Wyoming, Kansas Iowa, Alaska or Mississippi, it is best dealt with on a federal level. Examples of support are:

$v$ Legislation

v Government Grants

v Government Loan Guarantees

v Low Interest Loans

v Fuels Purchase Agreement

v Tax Credits

v Motor Fuels Excise Tax Reductions

v Energy Credits

\section{Legislation}

Historically, Congress has passed legislation to reduce engine emissions creating an economic pathway for alternative fuels. As an example, the 1992, EPACT established emission reduction levels for certain size fleets and cities. Individual companies and municipalities were forced to invest in new technologies or special fuels on a case by case basis. While creating a demand for alternative fuel programs the volumes were generally too small and the cost too high to cause major changes in demand. In general, legislation that focuses on a small segment of the motor fuels market doesn't serve the entire country. In contrast, legislation that requires changes across the industry can stimulate the alternative fuel programs and have a positive impact in reducing emissions, increasing fuel economy and reducing U.S. dependence on imported crude oil.

\section{Government Grants}

A second generally accepted form of government support is a grant, generally small in size, applied to a specific company or for a unique process. Typically the grant is upfront but in general it advances the alternative fuels market one small step at a time because the industry at large does not benefit. If it takes approval of the DOE/DOE or Congress, those not in the lead for the grant will lobby against it. Also there is no guarantee that a successful process will result from the grant. One advantage of grants is that in general they are small, one-time and easier to get approved than a multi-year, multi-billion dollars subsidy. Another advantage is that once given a grant can't be taken away or reduced by future government action. 


\section{Government Loan Guarantees}

Government loan guarantees are not that common as they usually involve large sums of money which means Congressional approval is required. Loan guarantees also means the government is taking the risk that the technology will work and that the project developer can actually build a successful project. Like a grant, a loan guarantee applies to one project, one developer, one technology and in general does not advance the industry at large. In addition to technology risk, the government also takes a risk that the market projections of the developer are correct. A classic example of this is the Great Plains Coal Gasification plant built in the late 1970's in North Dakota. While the technology worked and the project was successfully built and operated, the economics of the project depended upon natural gas prices being $\$ 6 / \mathrm{mmbtu}$ or higher. The developers were wrong, the market price collapsed shortly after the plant was built and the government was forced to take over the project. Today, some 25 years later the plant is a successful venture for its new owners but the government lost more than a billion dollars. One advantage, like a grant, is that once given a government loan guarantee can't be taken away or reduced by future government action.

\section{Low Interest Loans}

Low interest loans are attractive when the cost of money is $12 \%, 15 \%$ or greater, as in the 1980s. But with today's commercial rates in the $7 \%$ range, a lower rate in the $4 \%$ range isn't going to save a project much money. An advantage is that once given it can't be taken away or reduced by future government action. Like a grant or loan guarantee, a low interest loan generally applies to one project, one technology, one developer and will in general not advance alternative fuels programs across-the-board.

\section{Fuels Purchase Agreement}

When developing a project the lender will always assign risk to the market price and the market's willingness to purchase the full plant output at the market price. Having a longterm fuels purchase agreement from a qualified buyer will reduce this risk. It also puts the risk of project development and technology on the developer. If the plant can 't deliver the finished product to specifications, the fuels purchaser has to find a new supplier but is not out millions of dollars guaranteeing a project. A fuels purchase agreement is, however, similar to a grant, low interest loan and government loan guarantee in that it applies to one project, one technology and one developer. Again it will not advance the industry in general. One advantage again is that once given a fuels purchase agreement can't be taken away or reduced by future government action during the contract term.

\section{Tax Credits}

Tax credits are not that common or sought after by ind ustry because it requires one to be very profitable, earn large amounts of pre-tax income to take advantage of a tax credit. In general the larger the plant the greater potential for income and the lower the unit cost of the "alternative" fuel. The smaller the project the higher the unit cost, the more support 
needed and generally the lower pre-tax income available to offset a credit. Smaller plants bring greater industry participation in terms of numbers of firms; larger plants limit development to all but the largest developers. A disadvantage is that once given, a tax credit can be taken away or reduced by future government action.

\section{Motor Fuels Excise Tax Reductions}

Probably the most common form of economic support for alternative fuels is the motor fuels excise tax reduction. Virtually all motor fuels are taxed at the fuel pump by federal, state and local governments. This tax can be as high as $50 \notin /$ gallon at the point of sale. By reducing the tax on a particular fuel the fuel manufacturer gets to sell the new fuel at the pump at the same price so the consumer is indifferent; and the fuel manufacturer keeps the difference. This works especially well when the new fuel is actually a blend. As an example:

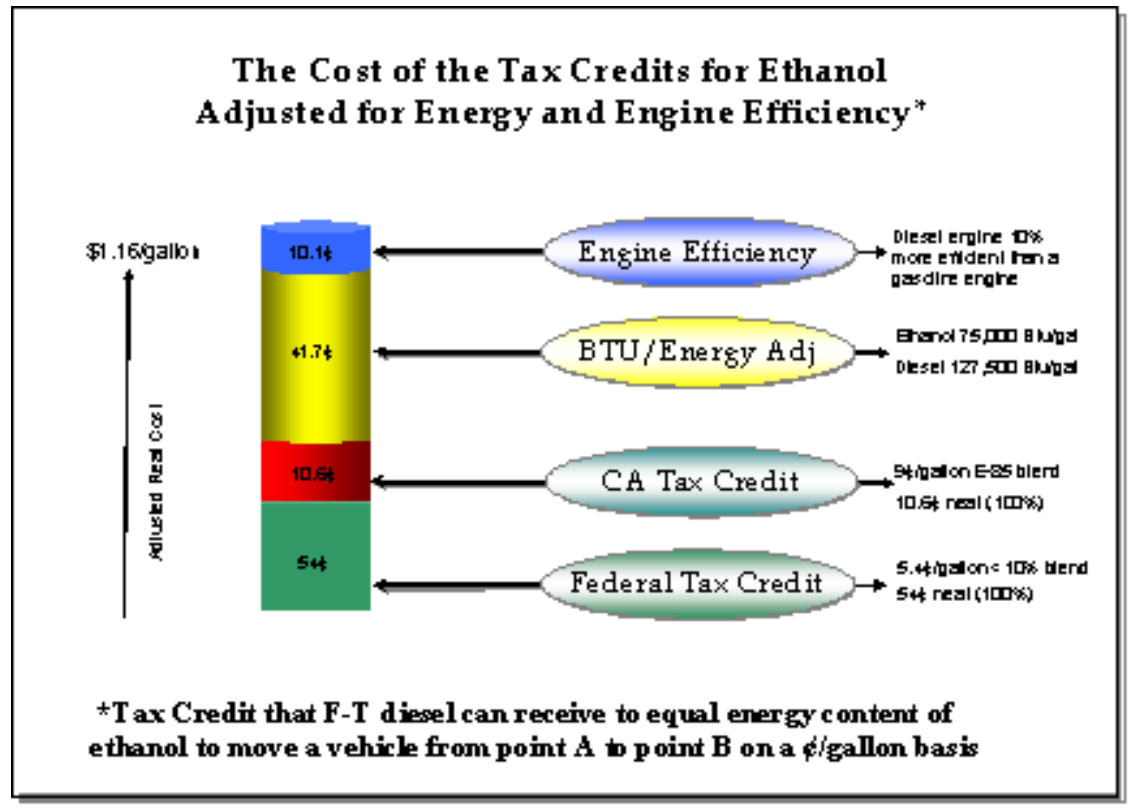

Gasohol is actually a blend of 1 gallon of ethanol and 9 gallons of gasoline. The excise tax reduction for gasohol is 5.4ø/gallon. While the apparent $5.4 \varnothing /$ gallon is insufficient to offset the higher manufacturing, transport, storage and delivery costs of this new fuel, the real value of the tax reduction is $54 \phi / g a l l o n$ for the ethanol, which is sufficient. The American consumer sees the same price at the pump and is happy. Congress sees a 5.4ф/gallon tax reduction and believes it is small while the industry receives a refund of $54 \phi /$ gallon of ethanol and is happy.

Figure 9 to the left provides a good illustration of this apparent and true cost of an alternative fuel.

Another example is the reduced motor fuels tax for compressed natural gas (CNG) when used in a diesel engine. Currently the federal and state tax on crude oil based diesel in California is $43 \phi / g a l l o n$. The motor fuels tax for $\mathrm{CNG}$ is $11 \phi / g a l l o n$ equivalent or $32 \varnothing /$ gallon - $\$ 13.40 / \mathrm{bbl}$ less. If this same tax rate were applied to natural gas based F-T diesel, this clean burning, zero sulfur F-T diesel would be attracted to this market. It is not, so the F-T diesel goes to Thailand where it enjoys a $7.5 \% / g a l l o n$ support. 
One big advantage of the motor fuels excise tax program for the U.S. is that the government takes no risk in the technology or the development and operation of the fuels plant. If the manufacturer doesn't deliver the fuels to the consumer, he doesn't receive the credit. It places the development and technology risk where it should be, with the industry.

One disadvantage is that a motor fuel excise tax reduction applies only to markets that pay the tax. If you are trying to market your "new" fuel to a municipality or federal agency that does not pay the tax or only a portion of it, the tax reduction may not apply. Another disadvantage is that once given an excise tax reduction can be taken away or reduced by future government action. It is difficult to invest hundreds of millions or billions of dollars in an alternative fuels project if you are unsure the tax credit will be available three years down the road. Still another disadvantage is that each individual fuel group lobbies for support, placing the government in the position of trying to determine which fuel is best or which segment of the voting public has the strongest lobbying group.

\section{Energy Credits}

Energy credits are similar to a motor fuels excise tax reduction, have similar benefits and disadvantages except one. An energy credit provided to the fuel manufacturer doesn't care whether the market is a tax payer or not. Thus the fuel can be sold to any consumer and the government refunds the value of the energy credit to the manufacturer. Again a big advantage of the energy credit program like a motor fuels excise tax reduction is that the government takes no risk in the technology, the development and operation of the fuels plant. If the manufacturer doesn't deliver the fuels to the consumer, he doesn't receive the credit. It places the risk where it should be, with the industry. The big advantage is that an energy credit applies to all markets regardless if they pay tax on their fuels or not.

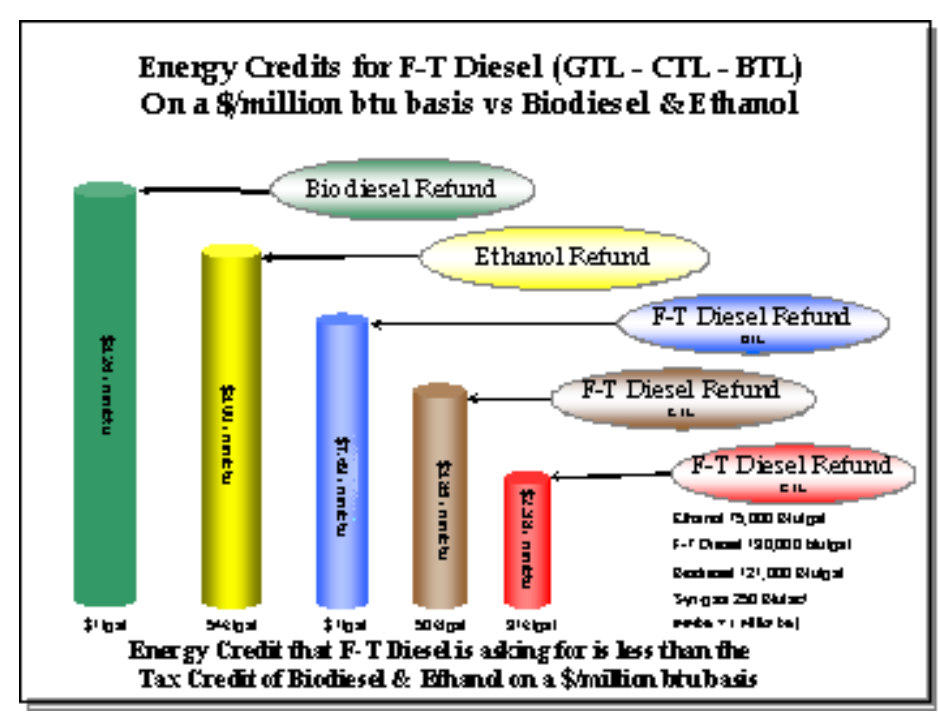

Figure 10
A disadvantage again is that once given an energy credit can be taken away or reduced by future government action. It is difficult to invest hundreds of millions or billions of dollars in an alternative fuels project if you are unsure the energy credit will be available years down the road. Still again, another disadvantage is that each individual fuel group lobbies for support with the government.

There are numerous forms of legislation that support alternative fuel programs in the U.S. They all compete for funding and many are hidden in special legislation by special interest groups. 
We believe there is a better way for the government to deal with all of these different and competing fuels programs.

\section{F-T Fuels}

By establishing an energy credit for F-T diesel produced in the U.S. from domestic resources the Federal Government could improve the economics of F-T plants throughout the Western U.S. F-T is one of the better alternative fuels for the U.S. because it can be integrated into the existing motor fuels infrastructure with minimal to no change required. F-T fuels can be used in blends from $1 \%$ to $100 \%$ with no adverse impact on the existing motor fuels infrastructure. F-T fuels appear to be the fuel of choice for the U.S. Military. Energy credits for F-T will attract the biggest and best F-T technology providers to the U.S., creating a big pool of domestic F-T for the military. Each gallon of F-T diesel produced and sold in America would reduce a gallon of imported fuel.

(See Figure 10) Virtually all alternative transport fuels in the U.S. except for F-T receive some form of federal / state economic support. F-T diesel is the one "alternative" fuel that will work in Alaska's harsh winter environment, the desert southwest or New England and still meet EPA fuel specifications. By giving F-T fuels a similar level of economic support that biodiesel and ethanol based gasohol receive; F-T plants can be economic throughout the U.S.

A Syn-Fuels Energy Credit for F-T diesel similar to ethanol, CNG, LPG, LNG \& recently approved Biodiesel Tax Credit Program:

v BTL (bio-renewable to F-T diesel) "trees/crops"

- $1 \notin /$ gal per $\%$ of blending - maximum of $\$ 1 /$ gallon for $100 \%$

v CTL (bio-mass to F-T diesel) "coal"

- $1 / 2 \phi /$ gal per $\%$ of blending - maximum of $50 \phi /$ gallon for $100 \%$

v GTL (natural gas to F-T diesel) "gas"

- $32 \phi / g a l l o n$ the same tax rate as $\mathrm{CNG}$

v SYN-GAS (bio-renewable) "trees/crops"

- $\$ 1 / \mathrm{mscf}$ (thousand standard cubic feet)

\section{An Energy Credit Allows Anyone To Build New F-T Refining Capacity.}

An energy credit established for F-T that provides a clear time-frame to develop and build an F-T plant but, more importantly a clear time period under which the fuel manufacturer can collect the energy credit will go a long way in attracting the most interest from both big and small F-T technology providers to the U.S.

An energy credit established for all alternative fuels, regardless of the type of process used to manufacture the fuel, will result in the greatest amount of interest from the 
industry to build new alternative fuels plants in the U.S. The market will decide which fuel is the best for the particular application, weeding out the worst technology from the best and attracting more efficient technology from F-T and other alternative fuel entrepreneurs.

\section{Domestic Security Tax}

Today alternative fuels are funded through a variety of tax (credit) measures, historically from the Federal Highway Trust Fund, but now from the General Fund. We believe the best way to fund an energy credit is to place a $5 \phi / g a l l o n$ tax (Domestic Security Tax) on all motor fuels, on-road, off-road, marine and rail and place this money in an "alternative fuel pool" from which ALL alternative transportation fuels draw from. Based upon today's diesel and gasoline sales, this account would receive approximately $\$ 15$ billion dollars each year, considerably more money that the current credits provided for ethanol, methanol, biodiesel, CNG, LNG, LPG, propane and butane to name several now receive. Government can limit the size of the alternative fuel programs by limiting the amount of money that can be drawn out of the pool each year or dropping different alternative fuels from the support pool.

We do not believe alternative energy programs should be funded forever. Once the capital costs of the "refinery" are paid off the level of support should drop or be eliminated all together. For all of you readers who rolled your eyes in the back of your head and said" read my lips - no new taxes" it is important to note that you are not creating a "new" tax when you place a "Domestic Security" tax on gasoline and diesel. All you are doing is consolidating all the different alternative fuel funding mechanisms into one place and placing all alternative fuels under one program. In addition the $20 \phi$ to 30 /gallon price fly-up of spring 2005 has not reduced consumption so one could conclude that a $5 \phi /$ gallon tax that reduced the importation of crude and crude oil products would be acceptable to the American consumer.

Let government establish the level and duration of support each particular fuel should receive based upon its benefit for the economy, the environment and national security. Once determined, let the fuels industry decide the best way to produce these alternative fuels. When the alternative fuels are delivered to a consumer, then and only then, the alternative fuel manufacturer is paid from the "alternative fuel pool".

As more and more alternative fuel plants are built in the U.S., the Refining Capacity Penalty will decrease and could actually create intense competition for market share in non peak driving times, further driving down the price at the fuel pump. As more alternative fuel refining capacity is added to the U.S., oil producing nations will see that the U.S. has the resolve to reduce its dependence on imported crude opening the door for negotiations and possible reductions in the U.S. military presence in the Middle East reducing the U.S. Security Premium. Each dollar saved is a dollar that offsets the Domestic Security Tax.

We believe an energy credit program such as this will provide a clear path forward for the industry. It is important that we begin as soon as possible as there is not an unlimited 
supply of qualified companies in the world today that can design, build and operate large sophisticated alternative fuel plants. Countries that provide economic support first will attract the best and most talented leaving countries who delay to choose from second and third tier companies.

\section{MILITARY NEEDS}

The military has a dual role in the future of fuels in the U.S. Foremost, it has to be concerned that the fuel to power its vast array of machines and aircraft is available in time of national need. Almost as important is the need to insure that the military's fuel of the future is environmentally friendly and can power the advanced high performance engines of the future.

As the refining capacity of the U.S. continues to decline, the amount and quality of the world's crude supply falls short of meeting world demand the U.S. military needs to attract domestic alternative fuel programs to the U.S. You can park your car in time of national crisis; you can't park your tank or ground your aircraft. In addition to supporting an energy credit, the military may want to create a program similar to its sea lift and air transport programs for U.S. built alternative fuel plants - a U.S. Military Refining Assistance Program (MRAP).

By investing in alternative fuel plants that will produce fuels specific for the needs of the military, the military could reserve the right to call on the output of an alternative fuel refinery in time of national need. The co-funding (grant) or annual subsidy paid to the alternative fuel plant may be just the economic boost the new plant needs to be able to compete with existing refineries at a market price, while producing ultra clean fuels the military needs for its advanced fighting machines.

We believe combining both the energy credit and the U.S. Military Refining Assistance program will address the needs of both the military and the U.S. transport fuels consumer. 


\section{SUMMARY}

Fischer-Tropsch fuels, many believe the "fuels of the future", have been around for over 75 years but are just now beginning to gain prominence world wide. As the world deals with increased demand for crude oil, dwindling crude oil and natural gas reserves, almost equivalent to proven world oil reserves are being exploited to fill the gap. F-T technology, long the purview of major oil companies and Parastatals is attracting new companies in hopes of developing more efficient processes to convert the world's stranded gas reserves into valuable transportation fuels and petrochemical feed stocks. Some of these new technologies are the result of hundreds of millions spent on R\&D, others are innovative ways to modify existing processes and still others are the result of advances in other industries, applied to one or more of the F-T processes.

The general trend in the industry is for the conversion of natural gas into valuable liquids, (GTL) while a select few companies are looking into bio-mass feed stocks in an effort to produce bio-renewable fuels (BTL) and electric power. Both industries have the attitude that bigger is better, taking advantage of scale up lowering the cost of the large ancillary requirement for process water and gas treating, electric generation and power supply, products storage and loading facilities. Second generation GTL plants are under construction in Qatar with next-generation GTL facilities expected to show marked improvement in economies of scale and syn-gas generation beyond the general creep of improvements in machinery and catalyst design.

Syn-gas generation, the first step of the F-T process holds the biggest promise of cost reduction. Programs like the Air Products led consortium are a few years away from commercializing an exciting new technology called ceramic membranes that will reduce the CAPEX costs of an F-T plant by as much as $25 \%$. Other companies are pursuing micro-channel technologies where the F-T process is carried out in thousands of identical process blocks. Similar to the advances in the semi conductor industry in the 1960s, micro-channel holds the promise of both large and small scale F-T plants based upon how many "blocks" you bolt together. While these new technologies will improve the economics of future F-T applications, they still suffer from the same issues as today's GTL plant, the high capital cost of the supporting equipment and utilities. As a result the drive is towards "bigger is better" even for these new technologies.

Many under funded F-T technology entrepreneurs are trying to attract investment capital to prove up their "new" concept. We believe that once many GTL or F-T plants are built around the world and the public recognizes the value of F-T fuels, funding for different technologies will become common. We do not think spending limited resources on 20 different F-T technology or process improvements makes sense at this time. Spending dollars on proven F-T technology and building commercial scale F-T plants today will generate more interest from the public and create economic support for future F-T technologies.

Unfortunately for the U.S., it is not blessed with large volumes of stranded natural gas reserves. F-T programs based in the U.S. will have to use coal and bio-mass for its feed stock. Coal to liquids, CTL, the grand daddy of F-T, began the process in Germany in 
the 1930s and today helps South Africa supply 50\% of its gasoline and diesel needs from domestic resources. The U.S. can do the same with its extensive coal reserves and its world leading farm producing regions.

The economics of producing new ultra clean environmentally sensitive fuels and selling them at the same price as crude based fuels will have to be addressed before F-T plants can be economically built in the U.S. The American consumer pays a hidden cost from $50 \phi /$ gallon to $\$ 2.00 /$ gallon ( $\$ 90$ billion to $\$ 360$ billion dollars per year) to maintain a military presence in the Middle East and each driving season an additional $\$ 10$ billion to $\$ 12$ billion dollars at the pump because we lack enough domestic refining capacity to meet U.S. demand.

Establishing a U.S. alternative fuels F-T program could go a long way in reducing these costs, both hidden and at the pump. Adding F-T fuels to existing economic support programs established for other alternative transportation fuels can reduce U.S. dependence on imported crude oil. F-T fuels can provide the U.S. military with a domestic source of fuel while meeting the mission specific fuel requirements of the next generation military combat vehicles, vessels and aircraft.

We believe F-T fuels are the future of a U.S. transport fuel system. They represent the cleanest transport fuels man has made and are totally compatible with the existing motor fuels transportation infrastructure. Once introduced to the American public, demand for F-T fuels will outstrip production creating, economic incentives for new F-T technologies and process improvements. 


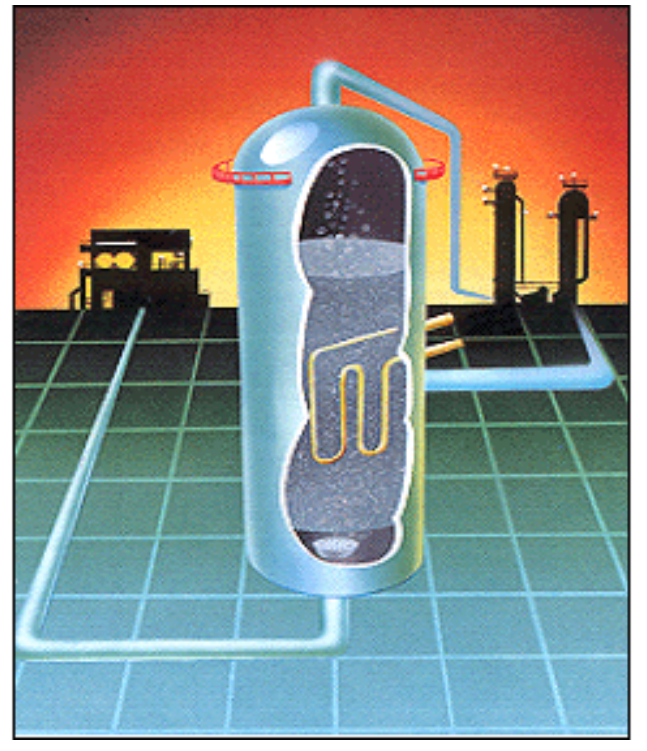

Addendum to Appendix F

Fischer-Tropsch Fuels

History

\author{
World Drivers
}

Developments in Technology

Gas-to-Liquids Transportation Fuels 
Economic Support for a U.S. F-T Program 


\title{
Fischer-Tropsch Technology Development Gas To Liquids Transportation Fuels
}

\begin{abstract}
Fischer-Tropsch (F-T) is the conversion of natural gas to liquids (GTL), coal to liquids (CTL) or bio-mass to liquids (BTL), all three processes commonly referred to as Gas-to-Liquids. (GTL) is the process for the chemical conversion of carbon into liquid products. It has been a developing technology for over 75 years. The first 50 years saw coal as the primary feed stock. In the late 1980s natural gas started a trend that today has over 500,000 barrels per day (bbl/d) of GTL plants announced or under construction in Qatar alone. Chiefly responsible for this trend has been the desire to reduce the annual 3.8 tcf of natural gas flaring and venting and to commercialize the estimated 4,200 tcf of proven gas reserves in FSU, Middle East and Africa. In the late 1990's bio-mass or bio-renewable feed stocks such as trees and dedicated crops were added to the picture in Germany.

In general the trend in the industry has been towards larger GTL plants to improve plant economics and reduce operating costs. As plant size increases, gas reserves required to support the GTL plants increase with overall costs of the GTL complex running into the $\$ 2$ million to $\$ 5$ billion dollar range, eliminating all but the largest oil companies and State-run oil companies (Parastatals) from developing new projects. To date almost all technology advances are geared towards the "mega" GTL plant projects. Development of small GTL projects, under $1,000 \mathrm{bbl} / \mathrm{d}$, will have to be driven for specific applications such as military, space or national defense needs.
\end{abstract}

F-T fuels, an option to LNG for stranded gas development are prized for their ultra clean properties and their ability to fit into the existing transportation motor fuels system with no change to the infrastructure. Many countries around the world are providing incentives for this environmentally friendly but expensive fuel, creating incentives that draw these fuels and technology to their region of the world. If the U.S. is to participate in an F-T revolution, it will have to provide incentives to F-T as it does to many other alternative fuel and energy technologies.

This paper will briefly outline the historic development of F-T technologies and address the following points:

- F-T Drivers

- F-T Economics

- New F-T Technologies

- Support for F-T fuels In The U.S. 


\section{Gas-to-Liquids Fischer-Tropsch Technology}

\section{Development in the World}

\section{INTRODUCTION - HISTORY OF GAS-TO-LIQUIDS}

In the early 1900's Germany led the world in the development of Fischer-Tropsch (F-T) transport fuels from coal. By the mid 1930's Adolph Hitler backed the development of the early F-T process to provide aviation fuel for his war efforts, resulting in numerous large scale plants built during the 1938 to 1943 era. At the conclusion of the war both the U.S. and Russia took this revolutionary F-T technology back to their respective countries. The U.S. was still an exporter of domestic crude oil and awash with cheap natural gas and while it looked at this new technology the US oil industry was not interested as it was too costly to make $\mathrm{F}-\mathrm{T}$ transport fuels from coal.

South Africa, blessed with abundant coal resources but no domestic oil and natural gas resources, asked the U.S. for the rights to this technology in 1948. The South African Government formed the South African Coal, Oil and Gas Corporation (SASOL) and began development of a coal-based slurry bed F-T plant in Sasolburg in 1951.

By the late 1970s Sasol had advanced F-T technology that reduced capital costs, increased conversion efficiency and reduced operating costs. As a result of the Arab oil embargo and Sasol's advances, many other oil companies began or renewed their interests in the F-T process. By the early 1980s, the Arab oil embargo ended, a world wide recession developed and oil prices dropped. All but Sasol put their F-T work back on the shelf or relegated it to R\&D.

Following work begun in Germany during the late 1950s, Sasol began looking at a new F-T reactor design called "slurry bubble column" or slurry phase. This new design had the promise of reducing operating costs and increasing both carbon and energy conversion efficiencies. In addition, work with new cobalt catalysts held promise of longer life and higher product selectivity - making more of one product and less of another while reducing the production of $\mathrm{CO}_{2}$, a troublesome by-product when iron catalysts are used.

In the mid 1980s South Africa discovered natural gas off its southern coast. Since the F-T process is all about carbon conversion through a chemical process, Sasol was asked to design a plant to convert this new resource into F-T transport fuels. This first gas-to-liquids (GTL) plant located in Mossel Bay, South Africa rekindled the F-T efforts of many of the oil majors as a way to monetize the vast stranded natural gas reserves across the world. Total world gas reserves of 6,205 TCF, equivalent to approximately 1,105 billion BOE, are on a par with estimated world oil reserves of 1,147 billion barrels. 
As demand for crude oil based transportation fuels continues to increase resulting in higher crude oil prices, more oil companies are looking at natural gas based GTLs to help meet these growing demands. However, with over $70 \%$ of these gas reserves located in the Former Soviet Union (FSU) and the Middle East and little undedicated reserves in the U.S., F-T programs in the U.S. will have to focus on coal and bio-mass for their feed stocks.

Throug hout the late 1990s there was a resurgence of industry interest in GTL's, driven by the need to reduce gas flaring and the prospect of turning the world's vast reserves of natural gas into clean fuels to meet increasingly stringent air

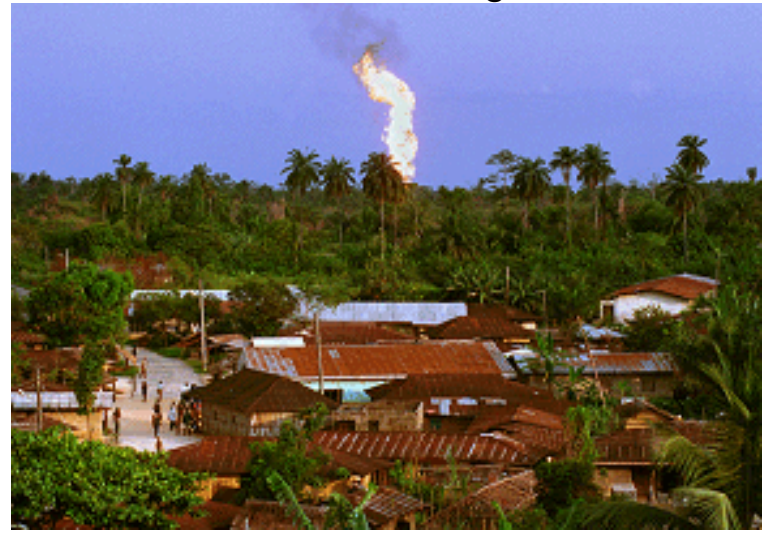

quality regulations. According to a World Bank study, 3.8 trillion cubic feet per year (tcf/yr) of natural gas, equivalent to approximately 700 million barrels of oil equivalent (BOE) is flared or vented as associated gas with oil production. Ten countries account for over $75 \%$ of global flaring and venting. The photo to the right is a gas flare in Nigeria flowing nonstop since 1972 from an Agip oil field. Flaring and venting in Nigeria amounts to $16 \%$ of the world total and if used in electric power generation would represent half of Africa's electric demand. U.S. flaring represents about $3 \%$ or $312 \mathrm{mmct} / \mathrm{d}$ of the world's total.

\section{WHAT IS THE F-T PROCESS?}

The F-T process has three individual steps. In the first step carbon in natural gas (methane) or carbon in coal and bio-mass is reacted with oxygen and steam to form a mixture of hydrogen and carbon monoxide $\left(\mathrm{H}_{2}+\mathrm{CO}\right)$ called syn-gas. In the Second Step, the syn-gas is reacted under pressure in the presence of a catalyst to form long chain carbon-hydrogen molecules, termed F-T wax or paraffin. The third Step "cracks" these long chain molecules to form individual products like diesel, gasoline and petrochemical feed stocks.

Early F-T programs in Germany in the 1930s and South Africa in the early 1950s used fixed bed or fluidized bed F-T reactors with iron $(\mathrm{Fe})$ catalysts with coal as the feed stock to supply syn-gas. Modern F-T plants, post 1990, are using both fluidized bed and slurry bubble column, almost all with cobalt catalysts and focusing on natural gas as the feed stock to supply the syn-gas. In the mid 1990s, Germany again began experimenting with bio-mass - bio-renewable feed stocks to provide the syn-gas. Bio-renewable feed stocks hold the promise of producing F-T transport fuels that are $\mathrm{CO}_{2}$ neutral when evaluated on a full life cycle basis. This is a very attractive point as reducing green-house-gas (GHG) emissions gains more prominence across the world. 
Figure 1, below, illustrates a typical process flow diagram for the generic F-T reaction.

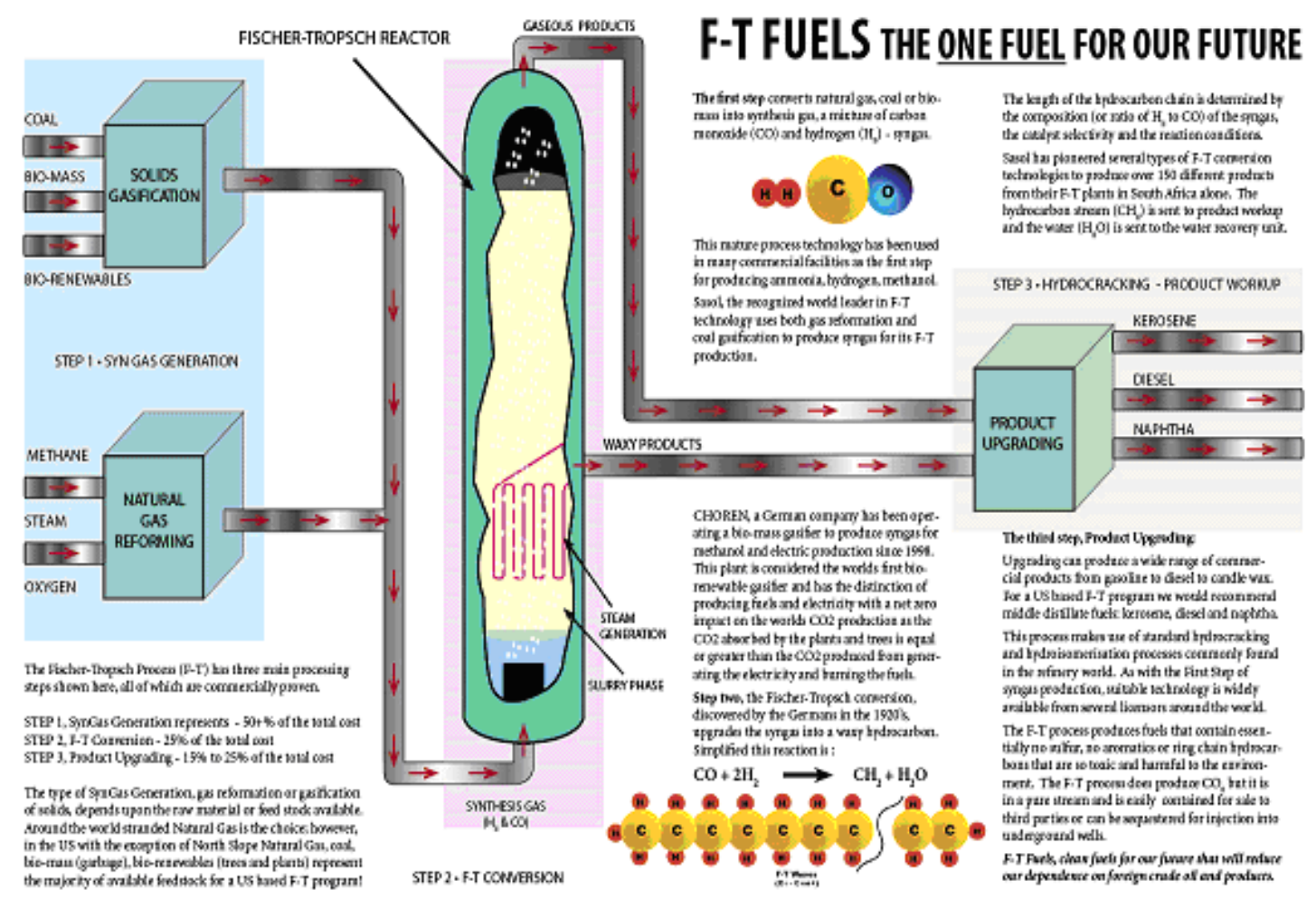

Figure 1

The F-T process offers the potential to produce a range of products: middle distillates (jet, diesel, kerosene) and gasoline, as well as lubricants and specialty waxes. Because F-T products are made from natural gas, coal or bio-mass via a chemical process, they have none of the impurities associated with crude oil derived products such as sulfur, heavy metals and carcinogenic compounds such as benzene. These environmental benefits associated with F-T products add to their value in the market place. Higher product values attract new companies with innovative carbon conversion technologies to the game. In addition, well established F-T companies continue to optimize catalysts, F-T reactor designs and work with engineering contractors to reduce the costs of new F-T plant construction.

There are six factors that control the economics of modern F-T plants. The cost of capital; construction costs; the cost of the inlet feed (natural gas, coal or biomass); the conversion/thermal efficiency; plant operating costs; and the value of the finished products. We assume that the cost of capital, cost of feed stock and the value of the finished products are the same for any technology. Sasol, one of the recognized leaders in GTL, has been working hard to reduce the costs of 
traditional GTL F-T technology. The cost trends are down but the size of F-T plants is increasing; leaving behind smaller gas fields that can't support bigger FT plants. Figure 2 below illustrates the advances Sasol has made by investing over $\$ 100$ million in 5 years on process improvements and EPC optimizations.

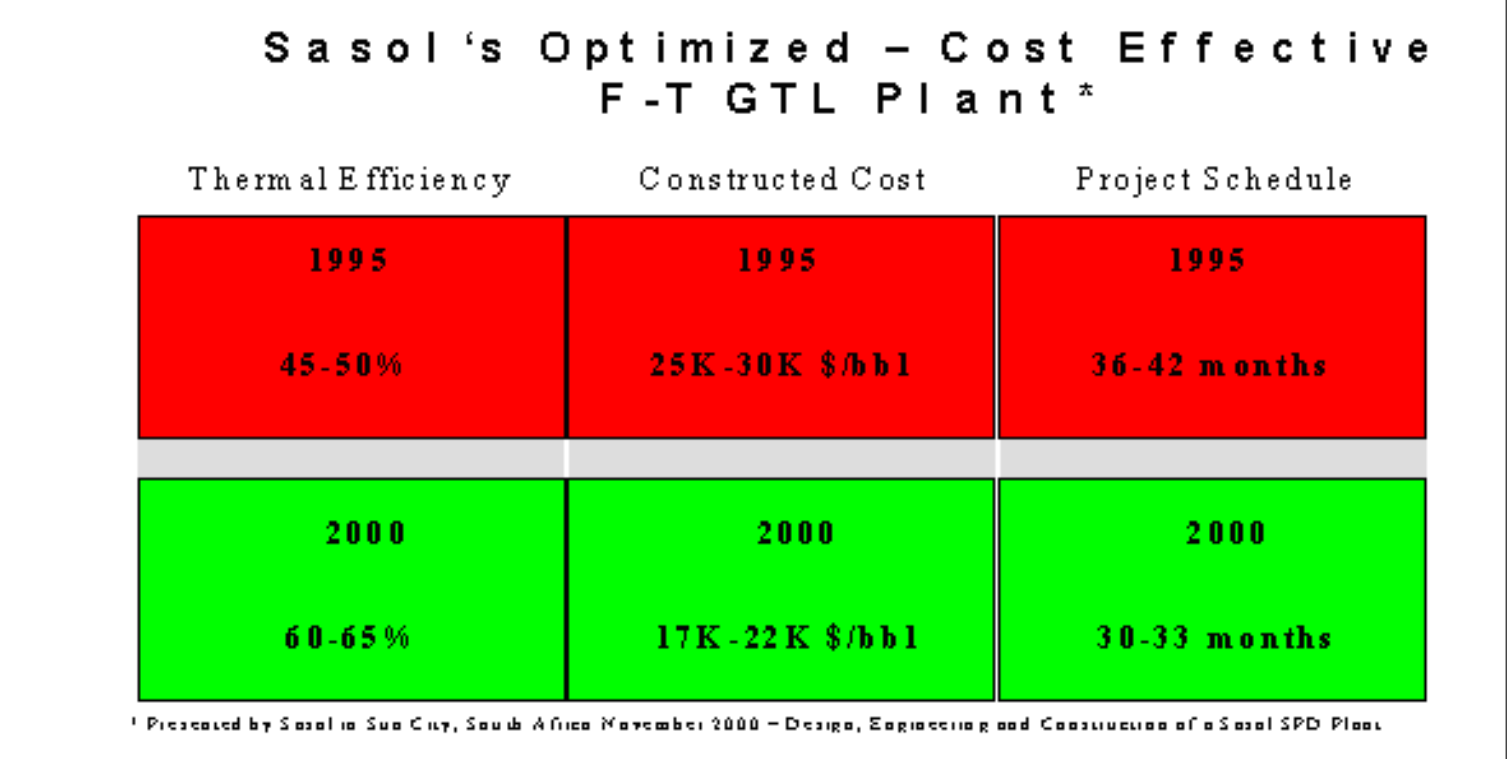

Figure 2

Using numbers quoted by Sasol for its $33,000 \mathrm{bbl} / \mathrm{d}$ F-T plant currently under construction in Qatar, the cost per installed barrel of daily capacity is less than $\$ 20,000$ per installed barrel. All the leading F-T technology providers have targets ranging from $\$ 14,000$ to $\$ 18,000$ per installed barrel of daily capacity; but all are working with design capacities in the 30,000 to $75,000 \mathrm{bbl} / \mathrm{d}$ or larger size F-T plants utilizing natural gas as the feed stock.

The target of $\$ 14 \mathrm{~K}$ / installed barrel is to make future GTL plants competitive with crude oil refineries. Since the operating cost of these big GTL plants is approximately the same as a modern crude oil refinery - $\$ 4$ to $\$ 5 / b b l$ future GTL plants can go head to head with new crude oil refineries based on the price of the feed stock compared to the price of crude oil, as process efficiency is improved. 
Figure 3

Cost Breakdown of F-T Process

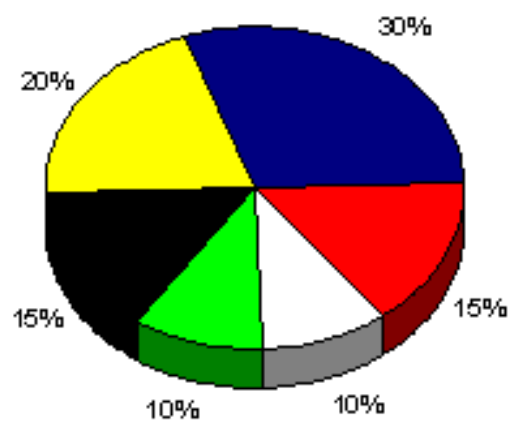

- Syn-Gas Generaion af-T Synthesis

u Cher Process Units Uutilities
From the Sasol/Foster Wheel Engineering work on GTL plants: Typically F-T fuel plants require big investments in utility and offsite support systems which can account for $40 \%-50 \%$ of the total cost of a plant, (Figure 3). These costs are usually included in each of three basic F-T steps, synthetic gas generation; F-T wax conversion and product workup; with the typical cost allocation of $50 \%$ to $55 \%$ of the total cost allocated to syn-gas generation; $25 \%$ to $30 \%$ to

the $\mathrm{F}-\mathrm{T}$ conversion with the remaining $15 \%$ to $25 \%$ to product upgrading. However, when developing an F-T project in areas were some or all of support systems are present, there may be significant cost savings available in each of these three steps. Conversely, building an F-T plant in an area with no support systems available the actual installed cost can almost double.

Virtually all the technologies for a large scale F-T plant have a common infrastructure requirement. This includes: the need for large quantities of energy to drive the air separation processes - oxygen plant; the preheat needs for the syn-gas generation step; waste heat recovery from syn-gas and its effective utilization; medium/low grade heat generation by the FT process; hydrogen provision for the hydrocracker; and optimum product recovery to maximize yield. And finally, as F-T projects are around 60\% thermal efficient, resulting in around $40 \%$ heat rejection to the surroundings, ways to economically capture this $\sim 40 \%$ of the heat contained in the feed stock have to be found. In addition to heat recovery, offsite systems can be significant, especially when dealing with "Greenfield" remote locations in Alaska. Such offsite systems may include water treatment to support large steam systems and effluent treatment of hydrocarboncontaminated water and system blow downs. Gas flare systems to deal with high flows from the hydrocarbon units and high volume flows from the gas processing units; plus firefighting systems to deal with the large volumes of volatile hydrocarbons at their vapor points and process streams containing hydrogen, are very important. Isolated synthetic product tankage and dedicated F-T product loading facilities are significant factors; compared to a crude oil refinery as a F-T plant may require similar volumes in storage, but its utilization will be low until a 
robust market is established for these ultra clean products. F-T plants are similar to chemical plants where upsets due to contamination from small amounts of sulfur, as well as large-scale reliable electrical systems, that must supply power during startup and market power to the grid during normal operation can adversely affect plant economics. The usual support infrastructure of administration buildings, workshops, warehouses, cafeterias and medical facilities are required, plus temporary construction facilities will be needed for remote locations. While ultra clean F-T diesel fuels have generated the most interest, we must not forget that there are many challenges in the support systems when considering engineering, construction and cost that can be improved.

The element of market risk is particularly significant due to the massive scale at which the plants are planned. With expected cash flows of over $\$ 1$ billion per year from the sale of products, unexpected down time can doom a project. On a smaller scale, installation costs of GTL/CTL/BTL F-T plants rise rapidly, soon exceeding $\$ 80,000$ per daily barrel of capacity. Below $10,000 \mathrm{bbl} / \mathrm{d}$, these plants scale down poorly, not so much in the design of the gas reformer, the F-T reactor or the product workup but in the ancillary equipment such as pumps, coolers, heat exchangers and treating facilities.

Most major F-T technology companies are seeking large gas fields to support major F-T projects. Unfortunately for the U.S., with the exception of the North Slope, we have no stranded gas fields to attract natural gas based F-T projects. We are fortunate to have large coal reserves and an exceptional growing environment to supply bio-mass. CTL and BTL programs require larger syn-gas generation facilities because the available carbon is typically lower in woods and low rank coals than natural gas. Additionally, tons of waste (ash) and other impurities in coal and bio-mass that must be removed from the syn-gas before it is sent to the F-T reactor. These extra operations drive up the cost of a CTL/BTL program. Low cost mine mouth coal reserves can help offset the larger Capex costs but bio-mass will always struggle to be competitive, especially in the U.S. We will discuss later in this paper ways that the U.S. can support F-T to close this economic gap between crude based diesel and F-T diesel.

\section{DRIVERS FOR GAS TO LIQUIDS}

In the beginning of the 1980s many of the major oil companies began to invest considerable efforts and expenditure in the development of technologies for the conversion of natural gas into F-T liquid transportation fuels. The rapid rise in the price of oil following the mid 1970s Arab oil boycott and the belief that oil supplies had peaked at 50 million barrels per day of production provided strong incentives. There have been many ups and downs in the energy market in the 25 years since that time, stalling the development of GTL technology. Today 
world production of crude oil is just below 80 million barrels per day but enthusiasm for GTL processes has never been higher, driven by the need to reduce flaring, because of climate change fears and the prospect of turning the world's vast reserves of natural gas into clean fuels that could meet increasingly stringent air quality regulations. Many oil companies again believe the world's oil producing regions have reached their limits of sustainable production and natural gas must now be exploited to produce transportation fuels. Increased demand from China and India will quickly outstrip the world's ability to supply crude oilbased products, raising crude oil prices and creating more uncertainty in the world. China is looking at all sorts of energy production ranging from hydro to coal and bio-mass to liquids to nuclear to meet its growing energy demands.

\section{Environmental Driver - "free gas" with a hidden cost}

Gas flaring, the amount of gas that is flared or lost as associated gas with oil production is estimated at 3.8 trillion cubic feet (tcf) per yr (10.4 bcf/d). This is equivalent to approximately 700 million barrels of oil (BOE) per year. Figure 4 breaks out these values by region of the world. (Source: World Bank report)

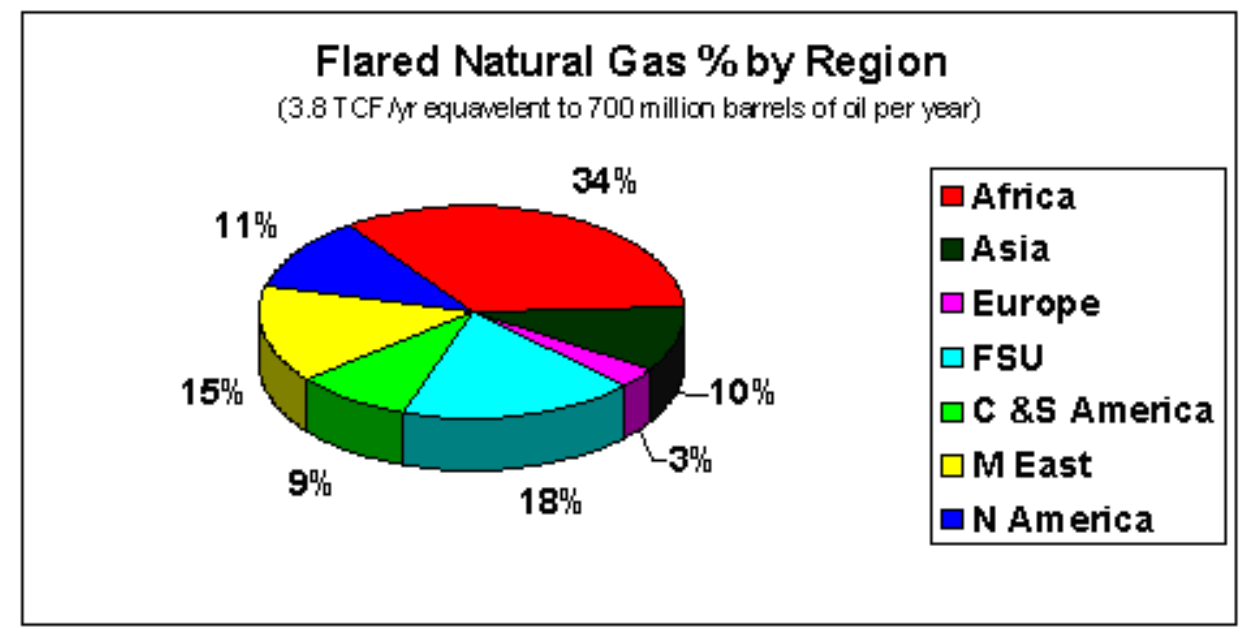

Figure 4

Gas flaring is gaining an increasingly bad name because of the severe impact on green house gas (GHG) emissions. In some countries, particularly Nigeria, flaring past a given date will bring economic penalties such that the natural gas resource will have negative values, dramatically improving the economics of most GTL programs.

\section{Stranded Gas - Net Present Value of Zero}

Total world gas reserves of 6,205 TCF, equivalent to 1,105 billion BOE, (Figure 5) are on a par with estimated world oil reserves of 1,147 billion barrels. However, the Former Soviet Union (FSU) and the Middle East account for over $70 \%$ of world reserves of natural gas $(32.1 \%-40.8 \%)$ and crude oil $(7.6 \%$ $63.3 \%$ ) respectively. (Source 2004 BP Statistical Review) Once the development and 
production costs of the reserves can be covered, not producing these gas reserves can have a negative value.

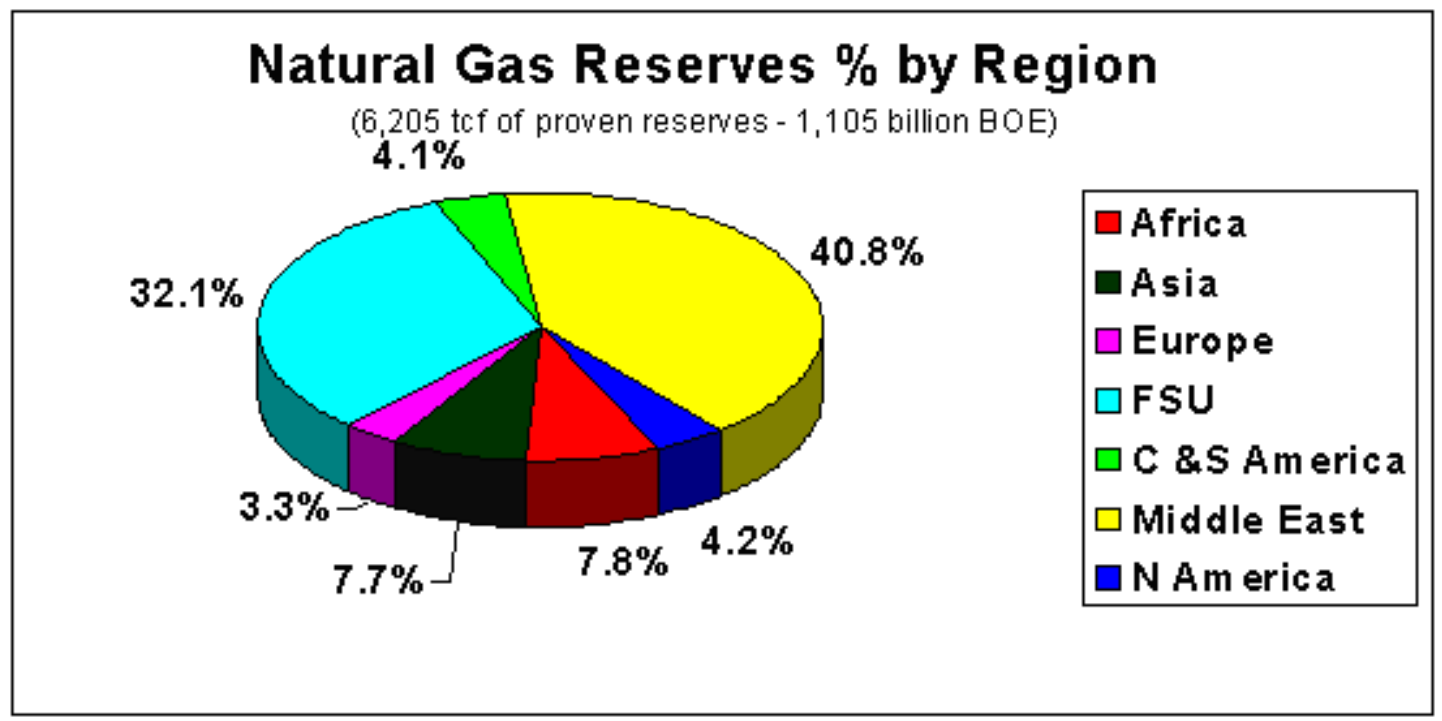

Figure 5

The GTL majors, Sasol and Shell are swamped with requests to build GTL plants adjacent to big fields in Russia, Qatar, Iran and the FSU. Engineering companies are challenged to find the necessary manpower to design and build both large and small scale projects. As more and more GTL plants come on line the available pool of engineers, process designers, plant operators will grow exponentially so that smaller EPC companies can provide expertise for smaller GTL projects across the world. The same holds true for F-T plants relying on coal and bio-mass for their feed stocks

From a GTL refining point of view, $10.4 \mathrm{bcf} / \mathrm{d}$ of flared natural gas would make approximately 1.2 million barrels per day of finished products or 420 million barrels per year. In addition, a GTL plant generates enormous quantities of waste heat and can produce large quantities of steam-derived electricity, so the conversion efficiency is improved, thermally speaking. This was pointed out in the Sasol "Optimized F-T GTL Plant" shown in Figure 2 where Sasol achieved a $20 \%$ increase in thermal efficiency in just 5 years. We need to keep in mind that early crude oil refineries were not very efficient and, with time, advances in technology improved the crude oil refinery conversion efficiency. The same will happen with GTL refineries when more are built.

Keep in mind that the first step of the GTL process, syn-gas generation, is used in many processes ranging from fertilizer, methanol and specialty chemical production to electric generation in IGCC power plants. A good example of improvements in efficiency over time is that of combined cycle electric 
generation. In the early 1970 s the best plants were around $45 \%$, which in itself was a major improvement over coal/steam electric generation at $30 \%$. By early 2002, efficiencies of CCGT plants were $60 \%$ or better. We would expect similar improvements in the F-T process over the next 30 years.

There are dozens of commercial companies providing syn-gas generation technologies across the world that are looking for an edge to sell their technology. Each company is driving to develop a lower capital cost and more efficient process to market to new projects developed each year. The same goes for the hydrocracking process, as advances in design, catalyst selectivity and life can be applied in hundreds of existing refineries across the world and future GTL plants. Advances in these areas will continue each year. They will be small steps, saving a few million dollars or a percent of operating cost, or improving process efficiency.

For large-scale plants, the savings or improvements are welcome but few developers are looking at small plant designs. Still, the biggest challenge that lies ahead for GTL technology developers is process integration or the combining of all three steps to make an energy efficient process. Here is the one place smaller GTL plant technology providers may have an edge.

\section{FISCHER-TROPSCH NEW TECHNOLOGY}

From a technology viewpoint, the areas of maximum impact on profitability are Efficiency of Conversion (Energy and Carbon) and Capital Cost, especially as they relate to smaller GTL plant applications.

FT will always be a three-step program where a syn-gas $\left(\mathrm{H}_{2}+\mathrm{CO}\right)$ is generated from a carbon bearing gas or solid; the syn-gas is then reacted with a catalyst in the F-T reactor to make long-chain hydrocarbon molecules (waxes) and then is split into shorter-length hydrocarbon molecules (diesel, naphtha, kerosene to name three) in a hydrocracking or product workup stage that is almost identical to crude oil refining. The capital cost allocation of each step is generally $50 \%$ for the syn-gas generation (step one); $30 \%$ for the F-T reaction, (step two); and $20 \%$ for the product workup (step three.) Like all crude oil refineries, (step three), product workup is the most advanced, the most efficient and likely to have the least chance of major improvements in capital cost reduction, process efficiency improvements or operating cost reductions. The one advantage that F-T hydrocracking has over crude oil is that the long chain F-T molecule is very easy to crack, requiring lower temperatures and pressures. In addition, while hydrocracking, the product can be isomerised to improve cold flow properties before sending the hydro-carbon to the refinery distillation tower for fractionation. Thus F-T product workup will be a little more efficient and have a lower operating cost than its crude oil cousin. While process integration, the efficient combining of all three steps, is a major challenge for F-T technology providers, advances in 
the first two steps will result in step changes in costs, carbon conversion, thermal and process efficiencies.

One thing should be pointed out with respect to the F-T/GTL process; the heat required to initiate a chemical reaction; the pressure at which the reaction occurs; the heat given off by a chemical reaction; the water or steam required for a reaction or that will result from a reaction is no different for a $200 \mathrm{bbl} / \mathrm{d}$ plant or a $75,000 \mathrm{bbl} / \mathrm{d}$ plant. The only difference is the amount required, or given off. The type of catalyst required driving the reaction, and the pressure or temperature at which it occurs remains the same. Thus the ancillary equipment required to support the F-T/GTL process has the same operating requirements.

Large pumps, heat exchangers, steam generators and catalyst charges are required for many different processes across the world and are supplied by many competitors at commercial prices. One-of-a-kind or very small specialized equipment is costly. Space, military and airplane parts are examples of limited market, expensive to manufacture equipment (we have all heard of the $\$ 600$ toilet seat). Small GTL plants will be in this category, making it difficult to justify in a commercial economic setting.

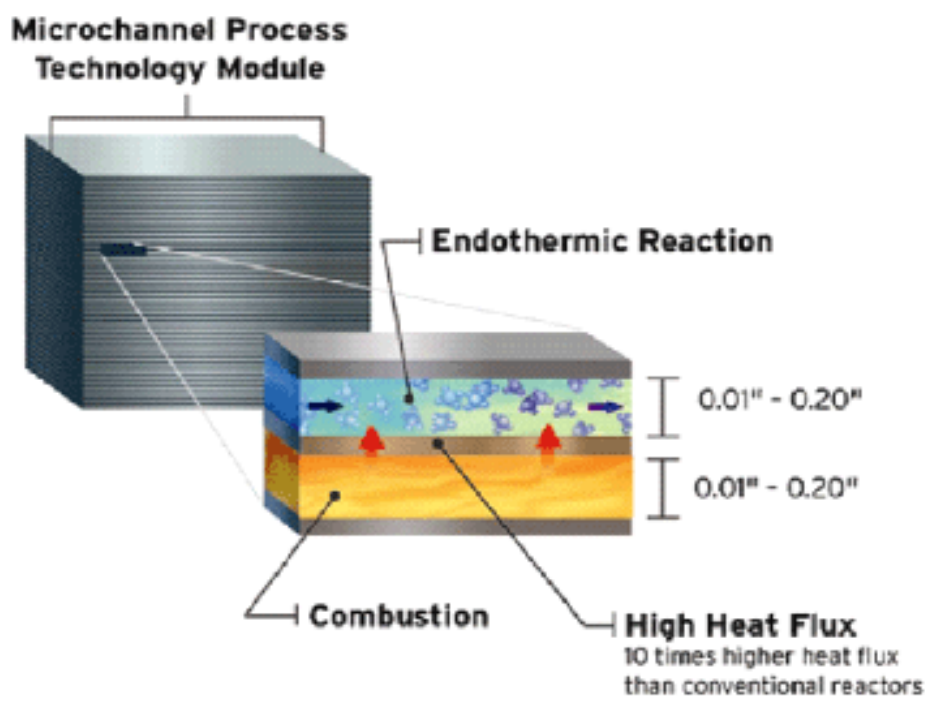

Some new and
innovative F-T
technologies are looking
at major reductions in the
capital cost of the syn-
gas generation step. One
is the Air Products-led
consortium looking at
ceramic membranes
which aim to create syn-
gas for one half the
current capital costs. Still
others, like GTL
Microsolutions and
Velocys, a commercial

arm of Battelle, are combining step one and two using microchannels; a very interesting and promising new technology reminiscent of the 1960s improvements-gain in the semiconductor industry. Here the F-T process is carried out in thousands of identical miniature process channels bolted together to provide a desired output.

To the left is a pictorial of a microchannel process. The more "plates" we bolt together, the more natural gas we reform to syn-gas, and the more F-T hydrocarbons are formed in the second step. This design concept may have the advantage of being able to scale up or down to meet the feed stock and/or market requirements of the area. 


\section{GTL-in-a-Can - a one stop process}

Still yet another company, TIAX, is proposing to combine all three GTL steps in one process, called "GTL-in-a-Can". Some, like the TIAX process are still paper proposals; others like the Velocys program, illustrated here actually have operating pilot plants. Other innovators are working on improvements in catalyst design, catalyst reactivity and life; some are looking at heat transfer issues in the $\mathrm{F}-\mathrm{T}$ reactor. One thing all have in common is a great deal of secrecy associated with their technology and for the most part, little capital to prove up the technology.

For the remainder of this paper we will look at those technologies designed to reduce the size of the natural gas-based F-T plant while not sacrificing the economics of scale. I would point out that even the so called "small" GTL technology providers are looking at 5,000 to 10,000 barrel-per-day plants (1000 $\mathrm{bbl} / \mathrm{d}$ modules) with economics in the $\$ 30,000$ per installed barrel range as the target. Plants ranging from 200 to $500 \mathrm{bbl} / \mathrm{d}$ are not the focus. However, developing plants for mission specific projects such as a battlefield F-T fuel module will help reduce the costs of the large-scale targets. Of the technologies looked at, only the microchannel technology lends itself to scalability, to downsize by removing "plates" from the module. However, total unit installed costs will still rise dramatically as size drops.

Abundant supplies of natural gas in remote and off-shore locations cannot be cost-effectively brought to market. Conversion of natural gas to liquids (GTL) has been a technology development goal for more than two decades as a means of capitalizing on this resource. Numerous processes have been developed and demonstrated on a relatively small scale, but Sasol's Synthol plants at Secunda, Sasolburg and Mossel Bay, South Africa and Shell's SMDS plant in Indonesia remain the only large commercial CTL and GTL plants. Widespread adoption of the various GTL processes continues to be limited by economic uncertainties, including fluctuating oil and gas prices, the cost of capital and technical risks in a fast-developing field.

Many more gas fields can be open to exploitation with a smaller plant, including gas associated with offshore platforms. Applications that can be exploited by the military for mission specific purposes can help reduce technology development costs and provide markets for smaller ancillary equipment, reducing the overall cost of new technology for civilian (commercial) applications. A GTL technology that achieves the economics of the large-scale 50,000 bbl/d plants at a $500 \mathrm{bbl} / \mathrm{d}$ scale would permit new companies to enter the GTL market. Military commercialization of small plant technology permits time for leading edge technology to advance and mature, providing operational experience, and a market for critical plant equipment manufacture, all further reducing costs for civilian projects. 


\section{Microchannel Process Technology}

One of the most promising technologies is Microchannel Process Technology (MPT). Due to its modular nature, MPT scales down well and can reduce costs below those of conventional processes at all scales. While there are several ongoing MPT programs, two of the most public are the Velocys and GTL Microsystems programs. Both are pursuing programs that generate syn-gas and the F-T hydrocarbon but are initially relying on third party technology to make a finished F-T diesel fuel. However, Velocys was just awarded a DOE grant to carry the process through its final step and make a finished F-T fuel. A spokesperson for Velocys said the company hopes to validate this new program within five years.

The F-T process, upgrading natural gas to diesel fuel includes three steps: 1 . Converting natural gas to synthesis gas (syngas); step 2. Upgrading the syngas to hydrocarbon liquids; and step 3. Hydrocracking the liquids to give the desired product mixture. Options for natural gas upgrading include steam reforming, partial oxidation, or a combination of the two, such as autothermal reforming. While each of the syn-gas generation processes has various advantages, the steam reforming process lends itself to significant process improvements and precludes the construction of a capital and energy intensive oxygen plant. This is similar to the Syntroleum concept of gas reforming except the MPT uses only steam and doesn't suffer the process inefficiencies and extra capital costs associated with using air, which introduces inert gases like nitrogen into the process.

In the MPT process natural gas and steam are converted in a first stage reactor heated by the combustion of fuel gas and waste heat from the F-T process which is very exothermic. The ratio of $\mathrm{H}$ and $\mathrm{CO}$ in the resulting syngas is adjusted to the desired ratio by separation in a membrane, providing some of the fuel gas for the reformer and an $\mathrm{H}_{2}$ stream for use in the third step, hydrocracking.

The $\mathrm{H}_{2} / \mathrm{CO}$ syngas is fed to an F-T reactor, where it reacts to form hydrocarbons and water while the heat is removed by producing steam for the first stage reformer or electric generation. The wax F-T products are then hydrocracked to produce high quality, clean diesel fuel or other specialty chemical products.

One of the biggest advantages of MPT is that unlike many hydrocarbon process technologies it does not have to be vertical and it is unaffected by motion. The MPT process can be laid out in any format allowing for horizontal modules (multiples of containers arranged end-to-end or side-by-side) and since the process is unaffected by movement it can be used for ship, spar, TLP and FPSO applications in unprotected waters. It also has a tremendous advantage when used in a hostile military environment in that if a portion of the plant is damaged, the unit can be replaced with a new module or blocked off to put the plant back in service in short order. 
Both MPT providers that were willing to discuss their technology are hopeful for an installed cost in the $\$ 24 \mathrm{~K}$ to $\$ 30 \mathrm{~K}$ per barrel of capacity plus product workup costs. As far as we can determine, these costs did not include ancillary equipment costs. MPT providers will freely tell you that their goals are 10,000 $\mathrm{bbl} / \mathrm{d}$ plants to take advantage of the modular design and mass production cost savings of the microchannel design. When you compare them to Sasol's total cost to engineer, design, build and place in-service target of between $\$ 16 \mathrm{k}$ to \$22k per installed barrel, these mini-GTL plants will be expensive.

\section{GTL-in-a-Can}

TIAX's concept to put all three F-T steps in one vessel is a novel approach and if it works can revolutionize the GTL industry. However, unlike MPT which has a very large chemical industry interested in its process, GTL-in-a-Can is geared towards one industry (gas) and this ind ustry believes "bigger is better." Without a bench scale plant to show a technology can be transferred from paper to plant, this technology appears to be off in the distance. The flow diagram of the process shows air introduced to the process in the reforming step, gas clean up prior to the "CAN" and the cracking of the $\mathrm{C}_{+5}$ hydrocarbons outside of the process "CAN". In effect, this places it along-side the MPT process in that two steps will be combined in the new technology and the product workup will be accomplished via other commercial means. Given the projected costs of $\$ 25,000$ to $\$ 50,000 / \mathrm{bbl}$ per installed barrel costs (does this exclude product workup? - No one is saying) the only advantage may be in size or foot print.

While there are references to industry and university GTL research programs plus other forms of MPT work ongoing, none has sufficient public reporting to provide comments here.

There are however, several programs that are addressing syn-gas generation that show promise of reducing the costs of natural gas based $\mathrm{F}-\mathrm{T}$.

\section{Syn-Gas generation}

Syn-gas generation represents half of the GTL complex Capex costs. The greatest step changes in the GTL process are anticipated to occur in this critical step because in addition to F-T, syn-gas is the building block for the majority of chemical and petrochemical processes across the world.

Another form of microchannel technology is the Air Products/DOE led consortium looking at ceramic membranes or lon Transport Membranes (ITM) to reduce the cost of making syn-gas from methane and oxygen. The ITM process consists of methane $\left(\mathrm{CH}_{4}\right)$, steam $\left(\mathrm{H}_{2} \mathrm{O}\right)$ and oxygen $\left(\mathrm{O}_{2}\right)$ chemically combined to form $\mathrm{CO}$ and $\mathrm{H}_{2}$ without the expense of building an air separation $\left(\mathrm{O}_{2}\right)$ plant. Figure 6 below provides a flow diagram of the process and a picture of a ceramic membrane. The ITM process is in the middle of a 10 year development program 
with commercial demonstration scheduled for the 2008-09 time period. Once commercialized, the ITM process can save up to $50 \%$ of the cost of reforming or $25 \%$ of the total capital cost of the GTL process.

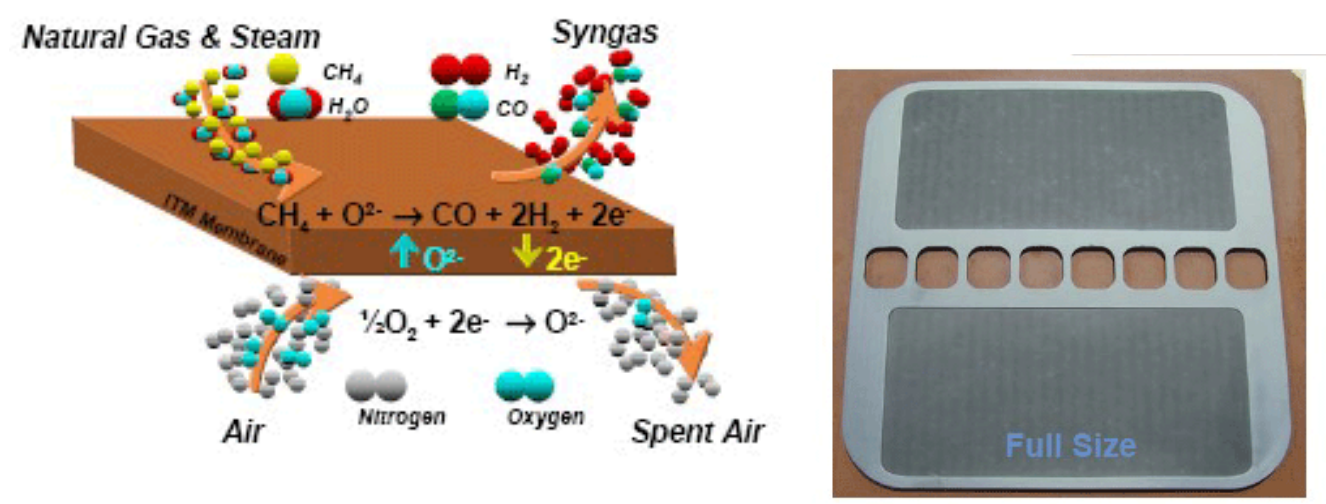

Figure 6

The ITM process will also lend itself well to the modular concept, creating reforming modules that can be mass produced in central manufacturing plants, reducing costs and will provide great flexibility in plant size for field applications.

The technology is well proven; the problem has been the manufacturing of commercial size membranes for plant sizes in the 100 million cubic foot per day range. In discussions with Air Products, the demonstration size ITM currently in the final phase of testing may be ideal for the small natural gas based F-T plants (under 10 million cubic foot per day $-1,000 \mathrm{bbl} / \mathrm{d}$ ) that are the focus of this paper. There is an industry group, consisting of several of the same companies working with Air Products that is also pursuing similar ITM technology. Their findings have not been made public but we know that they are making similar progress.

\section{Compact reformer design}

Several leading companies are investigating technology that would reduce the size (foot print) and cost of traditional natural gas reforming. Each is following paths that will result in step-changes in the reforming area. Of this group, the most public has been a joint venture with BP and Davy/Kvaerner. The BP/Davy compact reformer as it has become know as was first demonstrated at the BP Nikiski, Alaska GTL test site in 2002. The radical design results in a reformer foot print of less than $30 \%$ of a normal steam gas reformer. Statements in the public domain indicate that the purpose of this design was to be used in offshore production areas to reduce or eliminate natural gas flaring/venting. No public release has been made on the reduction in cost for the compact reformer but one obvious cost savings is that it does not require an oxygen (air separation) plant which usually represents $1 / 3$ of the gas reforming costs. Weighing in at over 
3,000 tons for the $300 \mathrm{bbl} / \mathrm{d}$ test facility, it is lighter than a similar sized gas reformer by some $75 \%$, can be manufactured in a central plant and delivered to the GTL site unlike typical steam methane reformers that usually have to be constructed on site. But it is not, nor was it ever intended to be field portable. $\mathrm{BP} /$ Davy's goal is a $1000 \mathrm{bbl} / \mathrm{d}$ compact reformer module that can be added in parallel to support $30,000 \mathrm{bbl} / \mathrm{d}+$ GTL plants. According to Davy, there are no plans to look at smaller applications.

Plasma Arc technology shows some promise for converting methane into syngas. But it requires large amounts of electrical energy making it questionable for any remote location syn-gas generation programs and certainly not suitable for field portable or mobile applications like ships.

There are numerous companies in the syn-gas generation field that are working on improvements in their current designs, catalysts and combinations of technologies that will reduce overall Capex costs and improve efficiencies. However, none of these companies to the best of our knowledge are focusing on small gas reformer technology and are not part of this paper. Advances in large scale reformer technology will find their way to smaller applications but it is our belief that microchannel, whether through the MPT or ITM route will result in the step-change in cost and efficiency that mini-GTL plants will need to compete effectively for smaller packages of stranded gas.

\section{Catalysts}

In the early days of F-T, iron-based catalysts were the most used, primarily because coal was the feed stock of choice. Early experimentation with cobalt showed improved selectivity and reduced $\mathrm{CO}_{2}$ generation. Catalyst life was limited and early designs were expensive to produce. When Sasol first chose to commercialize its slurry phase F-T program for natural gas, catalyst life before regeneration was at most one year. Today with advances in formulation and design, life expectancy is 3 or more years with the goal of 5 years by 2006 . Other GTL providers have stated similar expectations for their unique catalyst formulations and designs. This has reduced the operations and maintenance costs of the gas based GTL plants considerably. Coal or bio-mass-based F-T plants for the most part still use iron-based catalysts, but with catalyst life expectancies of 30 to 90 days they still have a long way to go.

Catalysts are involved in all three steps of the F-T process. Advances in the oxygen transfer ceramic membrane reformer (ITM) process will further reduce operating costs by eliminating catalysts in the gas reformer. The MPT program promises catalyst integration with very high selectively and conversion ratios 3 to 5 times greater than in conventional F-T reactor designs. 


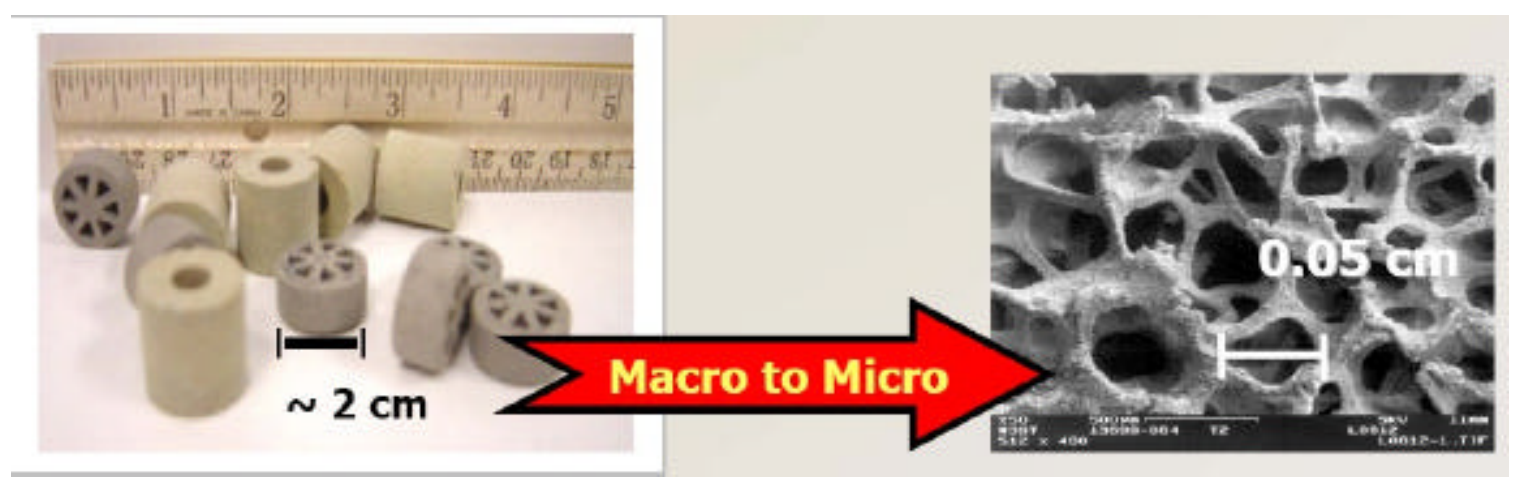

Figure 7

Figure 7 above illustrates the differences in catalysts for conventional reforming and F-T plants, on the left with catalyst size measuring in centimeters and for the microchannel syn-gas and F-T hydrocarbon applications on the right measuring in millimeters. The smaller catalysts associated with the microchannel technology provides much more surface area to drive the reaction of making syngas or the F-T hydrocarbon chains.

\section{THE WORLD HAS STRANDED/FLARED GAS FOR F-T DEVELOPMENT WHAT CAN BE DONE TO DEVELOP F-T IN THE U.S.?}

\section{LIQUID RESERVES FROM COAL AND BIO-MASS IN THE U.S.}

Beginning in the late 1990s virtually all F-T developers have focused on flared gas and large gas reservoirs across the world as feed stock for gas based F-T plants, the "G" in GTL's. With the exception of Alaska's stranded North Slope gas reserves, the U.S. has no giant stranded gas field waiting for a GTL program to develop it. Until someone develops a technology to extract the vast reserves of hydrates locked in our frozen north or in deep offshore pools, coal and biomass are the only carbon based materials available to supply large scale U.S. based, domestic F-T plants. Having the resources is one thing; being able to convert them into an economic transportation fuel is another.

\section{COAL - THE U.S. SAUDI-SIZED NATURAL RESOURCE}

It is estimated that the U.S. has over 250 billion tons of recoverable coal reserves. Using a typical conversion ratio of two barrels of F-T from one ton of coal, the U.S. has approximately $\mathbf{5 0 0}$ billion barrels of F-T fuels or almost $50 \%$ of known world's oil reserves. CTL in the U.S. can have a significant impact on imported crude oil if we want it to.

Certainly from a military fuel supply point of view, a U.S. CTL program should be attractive. 


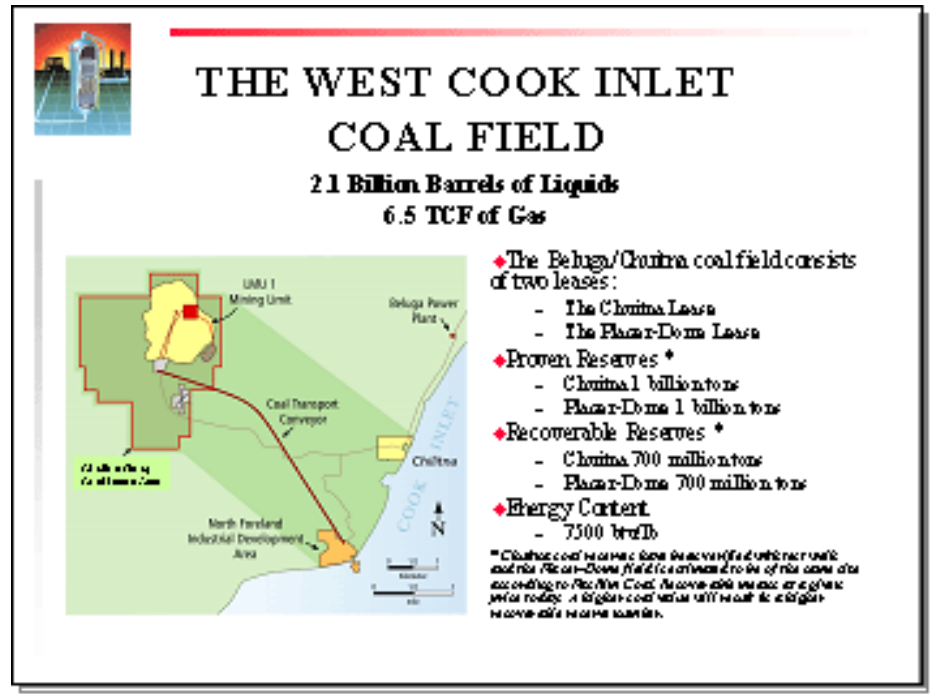

As an example, Alaska has a "small" coal field in the Cook Inlet 40 miles south west of Anchorage called Beluga, see Figure 8. This west Cook Inlet Beluga area coal field has approximately 1.4 billion tons of proven recoverable subbituminous coal or the equivalent of 2.1 billion barrels of liquids. Using the Sasol F-T thermal conversion efficiency of $65 \%$ shown in Figure 2, that means that $35 \%$ of the thermal energy in the coal, if captured, can be converted into the same btu energy content as 6.5 tcf of natural gas. A 2.1 billion barrel oil field is the second largest oil field in the U.S. behind Prudhoe Bay and 6.5 TCF is the largest gas field ever found in the Cook Inlet and $20 \%$ of the proven gas reserves on the North Slope. The Beluga coal field is a significant Alaskan energy resource that should not be over looked. Multiply this across the U.S. and you can quickly see how coal can fill the gap between U.S. oil production and product demand. We will touch on ways the federal government can help make CTL and BTL economically attractive in the U.S. later in this paper.

\section{F-T Fuels Economics for the World and the U.S.}

There is no question that F-T technology works with over 250,000 barrels per day of F-T plants operating in the world today and another 500,000 barrels per day under construction or in the final design phase. It is a PROVEN concept.

There is no question that F-T transport fuels are compatible with the existing motor fuels market and infrastructure with over 40 billion gallons sold to date throughout the world. It's COMMERCIALY proven.

No new refinery (crude oil or alternative fuel) built in the U.S. can recover its capital cost (CAPEX) if it has to sell its "new cleaner fuels" at the same price as "conventional fuels".

NEW REFINERIES, whether or not they are crude oil or GTL based, will need an economic boost or incentive to compete in the U.S. This is not the case in Europe or Asia where F-T diesel sells for a premium over even low sulfur diesel.

The question is then, "CAN F-T FUELS BE ECONOMIC"? If the measure of economics is price at a U.S. fuel pump, the answer is generally no. However, as 
the price of crude oil continues to rise at some point the cost of manufacture of $\mathrm{F}$ $T$ fuels will equal that of crude-based transportation fuels. Environmental issues, reducing a nation's dependence on imported crude oil are two factors that will favorably affect the economics of F-T fuels across the world.

There are generally three economic drivers that impact the real cost of U.S. transportation fuels outside of the basic cost of crude oil feed stock. They are:

$v$ Strategic, the need to maintain a military presence in the Middle East to insure the free flow of oil to the world. We refer to this as a Security Premium.

$v$ Shortfall in U.S. Refining Capacity (fuel availability). We refer to this as a Refining Capacity Penalty.

$v$ Environmental - Lower Emissions + CAFÉ Levels (Clean Cities Programs - lower GHG emissions \& better fuel mileage). We refer to this as the Engine Emission and Efficiency Costs.

The problem in the US is that many factors are at play that affect overall economics of fuel at the pump. There are the hidden costs of our national energy policy that are not apparent at the fuel pump but do cost us as tax paying citizens - the Security Premium. There are costs we see at the fuel pump each driving season that as individuals we have no control over - the Refining Capacity Penalty. New alternative fuel refineries (F-T) plants cost tremendous amounts to build as they are more like chemical plants instead of crude oil refineries. If new environmental laws require crude oil refineries to make fuels as clean as F-T, then F-T plants could be competitive. If the U.S. charged a premium for importing oil or gave credits for refineries that reduced U.S. dependence on imported crude, F-T plants could be competitive. If the U.S. charged a tax for importing gasoline and diesel, refineries would be built in the U.S. making new $\mathrm{F}-\mathrm{T}$ refineries competitive.

As individuals there is little we can do to control our fuel costs except buy more fuel efficient vehicles - Engine Emission and Efficiency Costs. However, there are two areas where the Federal Government can help promote new alternative fuel refineries in the U.S.

\section{Strategic}

The National Defense Council Foundation has performed a very detailed study of the "Cost of Imported Oil" including other factors such as loss of jobs showing that as consumers we pay a Security Premium approaching \$2.00/gallon. Years ago the government estimated this number to be $50 \$ /$ gallon. We currently use approximately 12 million barrels per day of gasoline and diesel in the U.S., using the lower figure of $50 \$ /$ gallon this Security Premium cost is approaching $\$ 92$ billion per year - \$368 billion at \$2/gallon. 


\section{Shortfall in US Refining Capacity}

The U.S. currently has a 3 million barrel per day refining capacity shortfall. This means that each driving season U.S. refineries cannot make enough gasoline and diesel to supply motor fuels demand. They raise the price at the fuel pump to cause "economic conservation." It is estimated that the lack of U.S. refining capacity, costs the US consumer 25 /gallon for 3 months or about $\$ 11$ billion per year - Refining Capacity Penalty.

Crude oil refiners have no incentive to eliminate this refining capacity short fall as they would lose this annual windfall, plus they will claim there is no way to recover the capital cost of the new refinery if they are selling motor fuels at the same price as other refiners. Most refiners will say it is cheaper to import gasoline than to build new refineries in the U.S. In addition because Europe has a higher CAFÉ standard and cleaner diesel, most European refiners are struggling to meet diesel demands but are awash in gasoline, which they export to the U.S. A refining shortfall in the U.S. provides a home for their excess gasoline supplies in Europe.

It is estimated that if the U.S. was to institute CAFÉ standards similar to Europe, the American consumer through better mileage would save over 1.4 million barrels per day of gasoline; resulting in a fuel savings of over $\$ 35$ billion dollars each year. Like in Europe, diesel nould become the preferred transport fuel because diesel engines are more efficient and generally diesel vehicles get $25 \%$ to $30 \%$ better mileage than similar gasoline powered vehicles.

By instituting a tax credit or energy credit to build new refineries the federal government can reduce the refining capacity shortfall, eventually reducing the annual price fly-up seen at the pump each driving season. Who benefits? The American consumer, with lower fuel pump prices and more efficient, highermileage vehicles. Who loses? The traditional crude oil refiner.

Table 1 below illustrates the price needed for products from a new refinery above today's fuel prices to recover the capital cost of the refinery. As we can see even a crude oil refinery will need a higher price for its gasoline and diesel if it is to recover its capital investment. Smaller-size coal and bio-mass F-T plants will need an even higher price. However, their gasoline and diesel F-T fuel is of much better quality. Environmental rules affecting crude-based fuels can add more costs to a crude oil refinery closing the gap. As the price of crude oil continues to rise and the price of coal and bio-mass ( $\mathrm{F}-\mathrm{T}$ plant feed stocks) remains stable, BTL and CTL plants will become more competitive. 
Conversely, crude oil prices can drop, making BTL and CTL less competitive. This has been the traditional way oil producing nations have stopped alternative fuel programs in the past. Whether world demand for crude has outstripped the ability of oil producers to produce excess crude is the big question today.

\section{Estimated Costs of New Refining Capacity (plants built in the U.S.)}

\begin{tabular}{|c|c|c|c|c|c|}
\hline Refinery Type & $\begin{array}{c}\text { Estimate } \\
\text { By }\end{array}$ & $\begin{array}{c}\text { Plant } \\
\text { size } \\
\text { bbl/d }\end{array}$ & $\begin{array}{c}\text { Cost / } \\
\text { Installed } \\
\text { Barrel }\end{array}$ & $\begin{array}{c}\text { * Refinery } \\
\text { CAPEXat } \\
100,000 \\
\text { bbl/d }\end{array}$ & $\begin{array}{c}\text { 申/gal to } \\
\text { recover } \\
\text { CAPEX }\end{array}$ \\
\hline Crude oil & Oil Majors & 100,000 & $\$ 18,000$ & $\$ 1.8$ billion & $18 \phi$ \\
\hline Coal to liquids & Sasol & 75,000 & $\$ 45,000$ & $\$ 4.5$ billion & $44 \phi$ \\
\hline Bio-Mass to liquids & Choren & 6,500 & $\$ 65,000$ & $\$ 6.5$ billion & $67 \phi$ \\
\hline Bio-Mass to liquids & Choren & 300 & $\$ 183,000$ & - & $182 \phi$ \\
\hline
\end{tabular}

* Cost of refinery estimate at capacity shown but adjusted to 100,000 bbl/d for comparison only 10 loan @ $8.5 \%$

A recent quote regarding the Sasol CTL plants built in South Africa said "Sasol's Secunda CTL Plant: Costly To Build, But Now It's A Cash Cow". Once the capital costs of U.S. built F-T plant are recovered, American BTL and CTL plants can be competitive well below today's price of crude oil.

\section{DIFFERENT WAYS FOR THE U.S. TO SUPPORT ALTERNATIVE FUELS}

Support for alternative fuels in the U.S. is really about reducing the cost of the "new" fuel to be competitive with existing fuels. It's not about the technology even though we expect improvements in process and conversion efficiency. Unlike European consumers, the typical American consumer will not pay a higher price for a cleaner fuel unless he is legislated to do so. As a result programs that reduce the cost of new fuels or tax the new fuel at a much lower rate so the pump price appears the same will create the largest demand for the new fuel and the greatest interest from the industry.

Europe is years ahead of America when it comes to support for cleaner fuels, alternative energy and non-petroleum fuels. As a consequence, many alternative fuel developers are focusing on non-U.S. projects. With a limited amount of qualified engineering, construction and manufacturing facilities capable of 
developing new alternative fuel programs across the world, the U.S. needs to develop programs to attract them to projects in America.

There are several options available to the federal government that can cause an alternative fuel program to grow in the U.S. It makes sense to provide these incentives on a federal level as each "new" refinery built in the U.S. reduces the amount of crude oil imported to the U.S. - a Security Benefit - and reduces the refining capacity short fall and corresponding annual price fly-up at the fuel pump - Refining Capacity Penalty. These benefits will be seen across the country. Even if an alternative fuel plant is built in Wyoming, Kansas lowa, Alaska or Mississippi, it is best dealt with on a federal level. Examples of support are:

$v$ Legislation

v Government Grants

v Government Loan Guarantees

$v$ Low Interest Loans

$\checkmark$ Fuels Purchase Agreement

$v$ Tax Credits

$v$ Motor Fuels Excise Tax Reductions

$v$ Energy Credits

\section{Legislation}

Historically, Congress has passed legislation to reduce engine emissions creating an economic pathway for alternative fuels. As an example, the 1992, EPACT established emission reduction levels for certain size fleets and cities. Individual companies and municipalities were forced to invest in new technologies or special fuels on a case by case basis. While creating a demand for alternative fuel programs the volumes were generally too small and the cost too high to cause major changes in demand. In general, legislation that focuses on a small segment of the motor fuels market doesn't serve the entire country. In contrast, legislation that requires changes across the industry can stimulate the alternative fuel programs and have a positive impact in reducing emissions, increasing fuel economy and reducing U.S. dependence on imported crude oil.

\section{Government Grants}

A second generally accepted form of government support is a grant, generally small in size, applied to a specific company or for a unique process. Typically the grant is upfront but in general it advances the alternative fuels market one small step at a time because the industry at large does not benefit. If it takes approval of the DOE/DOE or Congress, those not in the lead for the grant will lobby against it. Also there is no guarantee that a successful process will result from the grant. One 
advantage of grants is that in general they are small, one-time and easier to get approved than a multi-year, multi-billion dollars subsidy. Another advantage is that once given a grant can't be taken away or reduced by future government action.

\section{Government Loan Guarantees}

Government loan guarantees are not that common as they usually involve large sums of money which means Congressional approval is required. Loan guarantees also means the government is taking the risk that the technology will work and that the project developer can actually build a successful project. Like a grant, a loan guarantee applies to one project, one developer, one technology and in general does not advance the industry at large. In addition to technology risk, the government also takes a risk that the market projections of the developer are correct. A classic example of this is the Great Plains Coal Gasification plant built in the late 1970's in North Dakota. While the technology worked and the project was successfully built and operated, the economics of the project depended upon natural gas prices being $\$ 6 / \mathrm{mmbtu}$ or higher. The developers were wrong, the market price collapsed shortly after the plant was built and the government was forced to take over the project. Today, some 25 years later the plant is a successful venture for its new owners but the government lost more than a billion dollars. One advantage, like a grant, is that once given a government loan guarantee can't be taken away or reduced by future government action.

\section{Low Interest Loans}

Low interest loans are attractive when the cost of money is $12 \%, 15 \%$ or greater, as in the 1980s. But with today's commercial rates in the $7 \%$ range, a lower rate in the $4 \%$ range isn't going to save a project much money. An advantage is that once given it can't be taken away or reduced by future government action. Like a grant or loan guarantee, a low interest loan generally applies to one project, one technology, one developer and will in general not advance alternative fuels programs across-the-board.

\section{Fuels Purchase Agreement}

When developing a project the lender will always assign risk to the market price and the market's willingness to purchase the full plant output at the market price. Having a long-term fuels purchase agreement from a qualified buyer will reduce this risk. It also puts the risk of project development and technology on the developer. If the plant can't deliver the finished product to specifications, the fuels purchaser has to find a new supplier but is not out millions of dollars guaranteeing a project. A fuels purchase agreement is, however, similar to a grant, low interest loan and government loan guarantee in that it applies to one project, one technology and one developer. Again it will not advance the industry in general. One advantage again is that once given a fuels purchase agreement can't be taken away or reduced by future government action during the contract term. 


\section{Tax Credits}

Tax credits are not that common or sought after by industry because it requires one to be very profitable, earn large amounts of pre-tax income to take advantage of a tax credit. In general the larger the plant the greater potential for income and the lower the unit cost of the "alternative" fuel. The smaller the project the higher the unit cost, the more support needed and generally the lower pre-tax income available to offset a credit. Smaller plants bring greater industry participation in terms of numbers of firms; larger plants limit development to all but the largest developers. A disadvantage is that once given, a tax credit can be taken away or reduced by future government action.

\section{Motor Fuels Excise Tax Reductions}

Probably the most common form of economic support for alternative fuels is the motor fuels excise tax reduction. Virtually all motor fuels are taxed at the fuel pump by federal, state and local governments. This tax can be as high as $50 \$ / g a l l o n$ at the point of sale. By reducing the tax on a particular fuel the fuel manufacturer gets to sell the new fuel at the pump at the same price so the consumer is indifferent; and the fuel manufacturer keeps the difference. This works especially well when the new fuel is actually a blend. As an example:

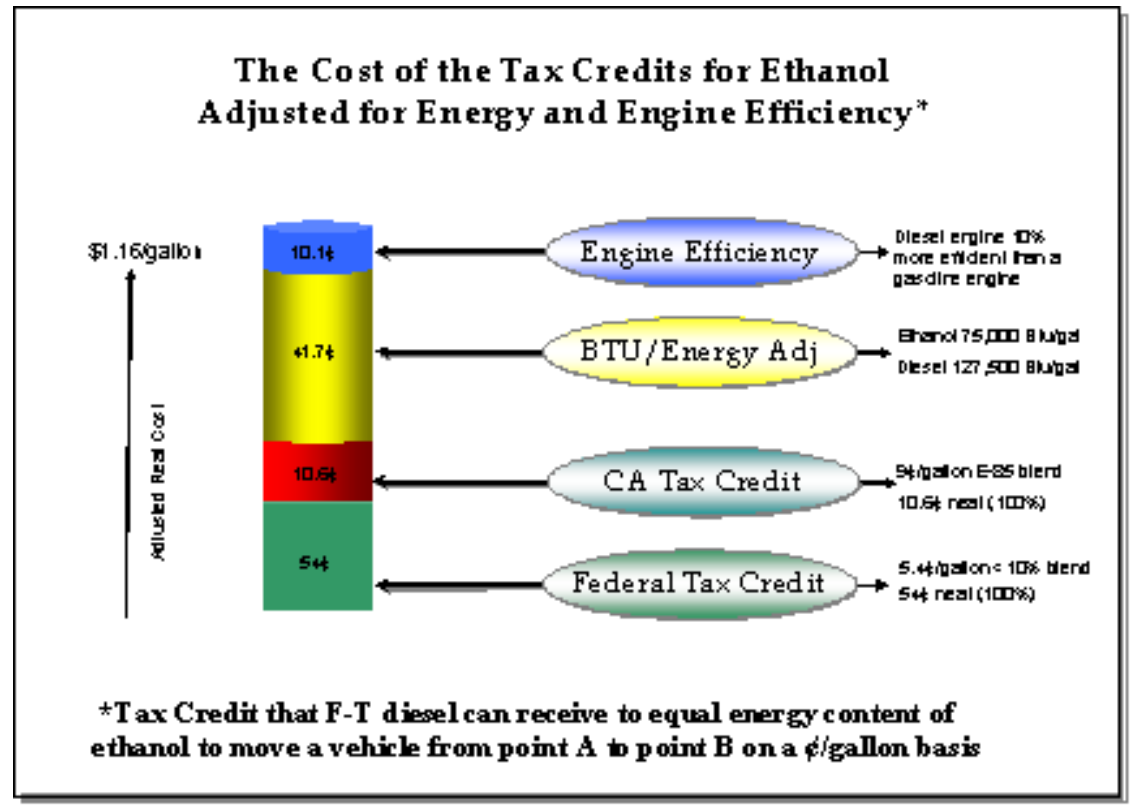

Gasohol is actually a blend of 1 gallon of ethanol and 9 gallons of gasoline. The excise tax reduction for gasohol is 5.4 \$gallon. While the apparent 5.4 \%/gallon is insufficient to offset the higher manufacturing, transport, storage and delivery costs of this new fuel, the real value of the tax reduction is $54 \$ /$ gallon for the ethanol, which is sufficient. The American consumer sees the same price at the pump and is happy. Congress sees a $5.4 \$ /$ gallon tax reduction and believes it is small while the industry receives a refund of $54 \mathrm{q} / \mathrm{gallon}$ of ethanol and is happy.

Figure 9 to the left provides a good illustration of this apparent and true cost of an alternative fuel. 
Another example is the reduced motor fuels tax for compressed natural gas (CNG) when used in a diesel engine. Currently the federal and state tax on crude oil based diesel in California is $43 \% / g a l l o n$. The motor fuels tax for CNG is $11 \$ /$ gallon equivalent or $32 \% /$ gallon $-\$ 13.40 / \mathrm{bbl}$ less. If this same tax rate were applied to natural gas based F-T diesel, this clean burning, zero sulfur F-T diesel would be attracted to this market. It is not, so the F-T diesel goes to Thailand where it enjoys a $7.5 \$ / g a l l o n$ support.

One big advantage of the motor fuels excise tax program for the U.S. is that the government takes no risk in the technology or the development and operation of the fuels plant. If the manufacturer doesn't deliver the fuels to the consumer, he doesn't receive the credit. It places the development and technology risk where it should be, with the industry.

One disadvantage is that a motor fuel excise tax reduction applies only to markets that pay the tax. If you are trying to market your "new" fuel to a municipality or federal agency that does not pay the tax or only a portion of it, the tax reduction may not apply. Another disadvantage is that once given an excise tax reduction can be taken away or reduced by future government action. It is difficult to invest hundreds of millions or billions of dollars in an alternative fuels project if you are unsure the tax credit will be available three years down the road. Still another disadvantage is that each individual fuel group lobbies for support, placing the government in the position of trying to determine which fuel is best or which segment of the voting public has the strongest lobbying group.

\section{Energy Credits}

Energy credits are similar to a motor fuels excise tax reduction, have similar benefits and disadvantages except one. An energy credit provided to the fuel manufacturer doesn't care whether the market is a tax payer or not. Thus the fuel can be sold to any consumer and the government refunds the value of the energy credit to the manufacturer. Again a big advantage of the energy credit program like a motor fuels excise tax reduction is that the government takes no risk in the technology, the development and operation of the fuels plant. If the manufacturer doesn't deliver the fuels to the consumer, he doesn't receive the credit. It places the risk where it should be, with the industry. The big advantage is that an energy credit applies to all markets regardless if they pay tax on their fuels or not.

A disadvantage again is that once given an energy credit can be taken away or reduced by future government action. It is difficult to invest hundreds of millions or billions of dollars in an alternative fuels project if you are unsure the energy credit will be available years down the road. Still again, another disadvantage is that each individual fuel group lobbies for support with the government.

There are numerous forms of legislation that support alternative fuel programs in the U.S. They all compete for funding and many are hidden in special legislation 
by special interest groups. We believe there is a better way for the government to deal with all of these different and competing fuels programs.

\section{F-T Fuels}

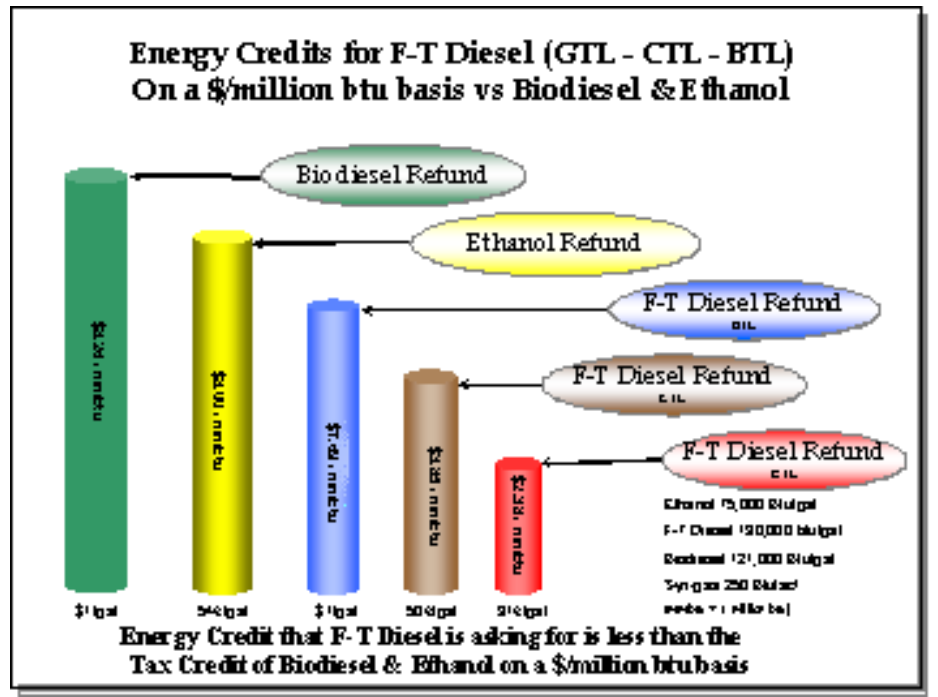

By establishing an energy credit for F-T diesel produced in the U.S. from domestic resources the Federal Government could improve the economics of F-T plants throughout the Western U.S. $\mathrm{F}-\mathrm{T}$ is one of the better alternative fuels for the U.S. because it can be integrated into the existing motor fuels infrastructure with minimal to no change required. F-T fuels can be used in blends from $1 \%$ to $100 \%$ with no adverse impact on the existing motor fuels infrastructure. F-T fuels appear to be the fuel of choice for the U.S. Military. Energy credits for F-T will attract the biggest and best F-T technology providers to the U.S., creating a big pool of domestic F-T for the military. Each gallon of F-T diesel produced and sold in America would reduce a gallon of imported fuel.

(See Figure 10) Virtually all alternative transport fuels in the U.S. except for F-T receive some form of federal / state economic support. F-T diesel is the one "alternative" fuel that will work in Alaska's harsh winter environment, the desert southwest or New England and still meet EPA fuel specifications. By giving F-T fuels a similar level of economic support that biodiesel and ethanol based gasohol receive; F-T plants can be economic throughout the U.S.

A Syn-Fuels Energy Credit for F-T diesel similar to ethanol, CNG, LPG, LNG \& recently approved Biodiesel Tax Credit Program:

v BTL (bio-renewable to F-T diesel) "trees/crops"

- $1 \mathrm{\phi} / \mathrm{gal}$ per $\%$ of blending - maximum of $\$ 1 /$ gallon for $100 \%$

$v$ CTL (bio-mass to F-T diesel) "coal"

- $1 / 2 \phi /$ gal per $\%$ of blending - maximum of $50 \$ /$ gallon for $100 \%$

v GTL (natural gas to F-T diesel) "gas"

- 32 \%/gallon the same tax rate as CNG

$v$ SYN-GAS (bio-renewable) "trees/crops" 
- $\$ 1 /$ mscf (thousand standard cubic feet)

\section{An Energy Credit Allows Anyone To Build New F-T Refining Capacity.}

An energy credit established for F-T that provides a clear time-frame to develop and build an F-T plant but, more importantly a clear time period under which the fuel manufacturer can collect the energy credit will go a long way in attracting the most interest from both big and small F-T technology providers to the U.S.

An energy credit established for all alternative fuels, regardless of the type of process used to manufacture the fuel, will result in the greatest amount of interest from the industry to build new alternative fuels plants in the U.S. The market will decide which fuel is the best for the particular application, weeding out the worst technology from the best and attracting more efficient technology from $\mathrm{F}-\mathrm{T}$ and other alternative fuel entrepreneurs.

\section{Domestic Security Tax}

Today alternative fuels are funded through a variety of tax (credit) measures, historically from the Federal Highway Trust Fund, but now from the General Fund. We believe the best way to fund an energy credit is to place a $5 \mathrm{\Phi} / \mathrm{gallon}$ tax (Domestic Security Tax) on all motor fuels, on-road, off-road, marine and rail and place this money in an "alternative fuel pool" from which ALL alternative transportation fuels draw from. Based upon today's diesel and gasoline sales, this account would receive approximately $\$ 15$ billion dollars each year, considerably more money that the current credits provided for ethanol, methanol, biodiesel, CNG, LNG, LPG, propane and butane to name several now receive. Government can limit the size of the alternative fuel programs by limiting the amount of money that can be drawn out of the pool each year or dropping different alternative fuels from the support pool.

We do not believe alternative energy programs should be funded forever. Once the capital costs of the "refinery" are paid off the level of support should drop or be eliminated all together. For all of you readers who rolled your eyes in the back of your head and said" read my lips - no new taxes" it is important to note that you are not creating a "new" tax when you place a "Domestic Security" tax on gasoline and diesel. All you are doing is consolidating all the different alternative fuel funding mechanisms into one place and placing all alternative fuels under one program. In addition the $20 \phi$ to $30 \$ /$ gallon price fly-up of spring 2005 has not reduced consumption so one could conclude that a $5 \$ / g a l l o n$ tax that reduced the importation of crude and crude oil products would be acceptable to the American consumer.

Let government establish the level and duration of support each particular fuel should receive based upon its benefit for the economy, the environment and national security. Once determined, let the fuels industry decide the best way to 
produce these alternative fuels. When the alternative fuels are delivered to a consumer, then and only then, the alternative fuel manufacturer is paid from the "alternative fuel pool".

As more and more alternative fuel plants are built in the U.S., the Refining Capacity Penalty will decrease and could actually create intense competition for market share in non peak driving times, further driving down the price at the fuel pump. As more alternative fuel refining capacity is added to the U.S., oil producing nations will see that the U.S. has the resolve to reduce its dependence on imported crude opening the door for negotiations and possible reductions in the U.S. military presence in the Middle East reducing the U.S. Security Premium. Each dollar saved is a dollar that offsets the Domestic Security Tax.

We believe an energy credit program such as this will provide a clear path forward for the industry. It is important that we begin as soon as possible as there is not an unlimited supply of qualified companies in the world today that can design, build and operate large sophisticated alternative fuel plants. Countries that provide economic support first will attract the best and most talented leaving countries who delay to choose from second and third tier companies.

\section{MILITARY NEEDS}

The military has a dual role in the future of fuels in the U.S. Foremost, it has to be concerned that the fuel to power its vast array of machines and aircraft is available in time of national need. Almost as important is the need to insure that the military's fuel of the future is environmentally friendly and can power the advanced high performance engines of the future.

As the refining capacity of the U.S. continues to decline, the amount and quality of the world's crude supply falls short of meeting world demand the U.S. military needs to attract domestic alternative fuel programs to the U.S. You can park your car in time of national crisis; you can't park your tank or ground your aircraft. In addition to supporting an energy credit, the military may want to create a program similar to its sea lift and air transport programs for U.S. built alternative fuel plants - a U.S. Military Refining Assistance Program (MRAP).

By investing in alternative fuel plants that will produce fuels specific for the needs of the military, the military could reserve the right to call on the output of an alternative fuel refinery in time of national need. The co-funding (grant) or annual subsidy paid to the alternative fuel plant may be just the economic boost the new plant needs to be able to compete with existing refineries at a market price, while producing ultra clean fuels the military needs for its advanced fighting machines.

We believe combining both the energy credit and the U.S. Military Refining Assistance program will address the needs of both the military and the U.S. transport fuels consumer. 


\section{SUMMARY}

Fischer-Tropsch fuels, many believe the "fuels of the future", have been around for over 75 years but are just now beginning to gain prominence world wide. As the world deals with increased demand for crude oil, dwindling crude oil and natural gas reserves, almost equivalent to proven world oil reserves are being exploited to fill the gap. F-T technology, long the purview of major oil companies and Parastatals is attracting new companies in hopes of developing more efficient processes to convert the world's stranded gas reserves into valuable transportation fuels and petrochemical feed stocks. Some of these new technologies are the result of hundreds of millions spent on R\&D, others are innovative ways to modify existing processes and still others are the result of advances in other industries, applied to one or more of the F-T processes.

The general trend in the industry is for the conversion of natural gas into valuable liquids, (GTL) while a select few companies are looking into bio-mass feed stocks in an effort to produce bio-renewable fuels (BTL) and electric power. Both industries have the attitude that bigger is better, taking advantage of scale up lowering the cost of the large ancillary requirement for process water and gas treating, electric generation and power supply, products storage and loading facilities. Second generation GTL plants are under construction in Qatar with next-generation GTL facilities expected to show marked improvement in economies of scale and syn-gas generation beyond the general creep of improvements in machinery and catalyst design.

Syn-gas generation, the first step of the F-T process holds the biggest promise of cost reduction. Programs like the Air Products led consortium are a few years away from commercializing an exciting new technology called ceramic membranes that will reduce the CAPEX costs of an F-T plant by as much as $25 \%$. Other companies are pursuing micro-channel technologies where the F-T process is carried out in thousands of identical process blocks. Similar to the advances in the semi conductor industry in the 1960s, micro-channel holds the promise of both large and small scale F-T plants based upon how many "blocks" you bolt together. While these new technologies will improve the economics of future F-T applications, they still suffer from the same issues as today's GTL plant, the high capital cost of the supporting equipment and utilities. As a result the drive is towards "bigger is better" even for these new technologies.

Many under funded F-T technology entrepreneurs are trying to attract investment capital to prove up their "new" concept. We believe that once many GTL or F-T plants are built around the world and the public recognizes the value of F-T fuels, funding for different technologies will become common. We do not think spending limited resources on 20 different F-T technology or process improvements makes sense at this time. Spending dollars on proven F-T technology and building commercial scale F-T plants today will generate more interest from the public and create economic support for future F-T technologies. 
Unfortunately for the U.S., it is not blessed with large volumes of stranded natural gas reserves. F-T programs based in the U.S. will have to use coal and biomass for its feed stock. Coal to liquids, CTL, the grand daddy of F-T, began the process in Germany in the 1930 s and today helps South Africa supply $50 \%$ of its gasoline and diesel needs from domestic resources. The U.S. can do the same with its extensive coal reserves and its world leading farm producing regions.

The economics of producing new ultra clean environmentally sensitive fuels and selling them at the same price as crude based fuels will have to be addressed before F-T plants can be economically built in the U.S. The American consumer pays a hidden cost from $50 \$ /$ gallon to $\$ 2.00 /$ gallon ( $\$ 90$ billion to $\$ 360$ billion dollars per year) to maintain a military presence in the Middle East and each driving season an additional $\$ 10$ billion to $\$ 12$ billion dollars at the pump because we lack enough domestic refining capacity to meet U.S. demand.

Establishing a U.S. alternative fuels F-T program could go a long way in reducing these costs, both hidden and at the pump. Adding F-T fuels to existing economic support programs established for other alternative transportation fuels can reduce U.S. dependence on imported crude oil. F-T fuels can provide the U.S. military with a domestic source of fuel while meeting the mission specific fuel requirements of the next generation military combat vehicles, vessels and aircraft.

We believe F-T fuels are the future of a U.S. transport fuel system. They represent the cleanest transport fuels man has made and are totally compatible with the existing motor fuels transportation infrastructure. Once introduced to the American public, demand for $\mathrm{F}-\mathrm{T}$ fuels will outstrip production creating, economic incentives for new F-T technologies and process improvements. 


\title{
APPENDIX G \\ Report on a Cold Weather Performance Study of Syntroleum Fuels at Denali National Park, Winter 2004 - 2005.
}

\author{
Bill Friesen \\ Fleet Manager \\ Denali National Park \& Preserve, Alaska
}

Initial Study Proposal: In the early fall of 2004 a study was proposed by ICRC to conduct a field test of 4,000 gallons of Syntroleum fuel, an alternative to diesel fuel derived from natural gas using the Fisher-Tropsh gas to liquids process. This study proposal was suggested during the closeout of the successful summertime test of this fuel using fleet buses owned and managed by the Denali National Park Concession Doyon Ltd. / ARAMARK Joint Venture. As a follow-up to that successful test, a study was proposed to test the cold weather performance of this fuel. Vehicles designated were a truck and selected heavy equipment owned by the National Park Service and engaged in snow removal work through the winter of 2004 - 2005 at Denali National Park, Alaska. If the study was successful, and fuel remained available, the scope of the study would expand in early spring to include the heavy equipment used during spring road opening along the park road.

\section{Historical Conditions Prior to the Study:}

Roadway and Equipment: The majority of the Denali National Park road system closes due to snowfall, usually within the month of October each year. Only 3 miles of paved road connecting the park headquarters and Alaska Route 3 remain open throughout the winter. The heavy equipment and truck assigned to snow removal duties through the winter are:

- 1 - 1998 Ford L9000 snow plow truck,

○ 1 - 2004 Caterpillar $140 \mathrm{H}$ motor grader and

- 1 - 1990 Case W14 front end loader.

Periodically a Caterpillar 972 and 950 front end loader and a Caterpillar 12G grader provide support during heavy snowfalls or heavy ice buildup. We use bio-based hydraulic oil in all of our heavy equipment after their warranty periods. A temperature cutoff of minus $20 \mathrm{~F}$ is observed with our winter equipment in deference to the limits of these oils and to avoid excessive strain on cold soaked steel components.

Fuels: We switch from summer grade diesel (\#2), to purchasing winter grade (\#1) diesel fuel in early August each year. Our experiences have shown us that there is enough fuel turnover in our bulk tanks between early August and late September (our final fuel purchase for the winter), to provide us with a fuel that resists gelling at temps lower than $-45 \mathrm{~F}$. We add a lubricity enhancer to all winter grade bulk fuel deliveries. Our bulk fuels are supplied from in-state refineries and sold to federal facilities using contracts managed through the Defense Logistics Agency. Typical sulphur content of these fuels is: $<5,000$ PPM for Diesel Fuel \#2 (+10F), and <1,000 PPM for Diesel Fuel \#1. 
Conditions: Typical winter conditions found in our park are snow cover from late September to early May, snow depth averages of 3 - 4 feet and winter temperatures between $+10 \mathrm{~F}$ and $-60 \mathrm{~F}$.

Experiences within the Study Period: Initial bulk delivery of 4,000 gallons of Syntroleum occurred in October 4, 2004. The fuel was delivered to an above ground 8,000 gallon tank located at the JV / ARA bus parking area. The equipment involved in our study would pick up their fuel from that location.

The winter of $2004-2005$ provided snowfall accumulations of 6.37 feet at headquarters, and a temperature range of $+51 \mathrm{~F}$ to $-33 \mathrm{~F}$ at our weather station, with other local spots registering to $-50 \mathrm{~F}$. A total of 51 days registered below zero readings this winter at headquarters. Working conditions required reliable performance at full load and on grades up to a $12 \%$ incline. A total of 290 hours of equipment use was logged, and a total of 1,740 gallons of Syntroleum was consumed during the period from October 7 , 2004 to March 18, 2005.

The Syntroleum fuel performed in a 100\% reliable manner, within all equipment using it. No reduction in power was observed under any conditions encountered. Engine performance at start, idle, partial and full load conditions were all observed with no problems noted at any point during the study.

The fuel experienced temperatures down to at least $-33 \mathrm{~F}$ while in equipment fuel tanks. This equipment was then brought back into operation immediately once ambient temperatures warmed to $-20 \mathrm{~F}$. At no occasion did this fuel offer any indication of problems due to extreme temperatures.

During fuel handing, it was observed that Syntroleum is a much "clearer" fuel, lacking in color. It consistently presented a clear sample during random "clean / clear / bright" tests. Odor was light and non-offensive. Small spills evaporated quickly with no oil residue left afterward.

Exhaust emissions had fewer visible particulates in equipment involved in this study. Comparably, a grey exhaust plume is typical to diesel engines operated in temperatures $0 \mathrm{~F}$ or lower, with the cloud growing in density as the temperature drops. The equipment using Syntroleum showed anywhere from a "zero" to "barely visible" exhaust signature in temperatures down to $-20 \mathrm{~F}$. Employees aware of our study commented on the absence of a visib le exhaust plume. Exhaust odor followed the volume of visible plume, with only trace exhaust odor being detected while following behind equipment operating in temperatures $-10 \mathrm{~F}$ or colder. Above this temperature it was difficult to detect any exhaust odor while following behind equipment using this fuel.

No fuel filter change outs were necessary, though we anticipated some clogging during the change over to this fuel. No fuel related repairs were necessary to any equipment using this fuel during the study.

The success of the winter study led us to expand the test to include all equipment involved in the park's spring road opening efforts. While road opening work is ongoing, we have not experienced any fuel related difficulties in any equipment involved in this expanded portion of the study.

Other observations:

○ Operator comments were numerous, and all consistent. "Very clean exhaust, it's amazing to not be leaving an exhaust trail everywhere I go." 
"I don't notice any lack in power, it feels like this fuel has every bit as much pick up as our usual diesel, maybe abit more." "The 972 typically has a slight lope at idle, but while burning the Syntroleum it went away and idled smoothly for the first time." "I wound up spilling a small amount of Syntroleum onto the side of the fuel tank and by the time I had gotten down to retrieve a rag for cleanup and then returned the fuel had evaporated! Even while trying to clean up where the fuel had been spilled didn't result in picking up much oily residue. This is a really clean fuel."

- At -30F a space heater mistakenly was fueled with a container holding a summer grade diesel, which rapidly gelled and stalled the heater. During the repair, Syntroleum was used as the replacement fuel and the unit restarted. It continued to run outdoors non-stop with no other gelling complaints. This unit ran using Syntroleum through the coldest temperatures recorded at Denali this winter.

Conclusions: Our experiences have been consistently positive with this fuel. We would gladly replace our currently available Diesel Fuels with Syntroleum if the price and availability were comparable to our choices currently offered within the DLA fuel contract regimen. 
Winter Use Records, October 10 through March 18

\begin{tabular}{|c|c|c|c|c|}
\hline Equipment Description & Total Hours of Use & Total Days Used & $\begin{array}{c}\text { Total Gallons } \\
\text { Consumed }\end{array}$ & Average GPH \\
\hline 2004, Caterpillar 140H motor grader & 162 & 19 & 633.1 & 3.908 \\
\hline 1998, Ford L9000 plow truck & 46 & 7 & 835.6 & 3.630 \\
\hline 2001, Caterpillar 972 loader & 59 & 12 & 105.0 & 14.16 \\
\hline 1990, Case W14 loader & 23 & 5 & & 4.565 \\
\hline Totals of equipment use & & & $1,740.7$ & 6.559 \\
\hline
\end{tabular}

Spring Road Opening Records, March 19 though April 12

\begin{tabular}{|c|c|c|}
\hline Equipment Description & Total Days Used & Total Gallons Consumed \\
\hline 2002, Caterpillar D7 XR bulldozer & 18 & 866 \\
\hline 1987, Caterpillar 966 C loader & 5 & 169 \\
\hline 1996, Rolba 280 rotary snowblower & 5 & 392 \\
\hline 1993, Caterpillar 12 G motor grader & 14 & 297 \\
\hline 2001, Ingersol-Rand 30 kW genset & 19 & 366 \\
\hline 2001, Caterpillar 972 loader & 10 & \\
\hline & & 2,230 \\
\hline
\end{tabular}

